

FISCALIZACIÓN Y DEFENSA. LA CIUDAD DE LOS ÁNGELES Y EL TERRITORIO IMPERIAL. 1698-1724 



\title{
FISCALIZACIÓN Y DEFENSA. LA CIUDAD DE LOS ÁNGELES Y EL TERRITORIO IMPERIAL. 1698-1724
}

\author{
JORGE GONZÁLEZ ARAGÓN CASTELLANOS
}

Directores de Tesis

Dr. Juan Luis de las Rivas

Dr. Carlos Luis Arturo González y Lobo

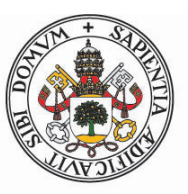

Universidad deValladolid

Programa de Doctorado en Arquitectura 
Jorge González Aragón Castellanos

Programa de Doctorado en Arquitectura

Universidad de Valladolid

Valladolid, España, 2017

Portada y contraportada: Detalle del plano Ciudad de Los Ángeles (México), 1700, Museo Naval de Madrid. Dibujo-copia de Ignacio Paul G. Aragón Medina

Corrección de estilo: Ana Julia Arroyo Urióstegui

Diseño y formación: Amada Pérez con la colaboración de Vania Bartolini

Jorge GAC

Coyoacán, Ciudad de México, 2017 




\section{AGRADECIMIENTOS}

A Juan Luis de las Rivas, director de la tesis por la Universidad de Valladolid por su disposición para revisar los avances y la conclusión de la misma. En especial destaco la importancia de sus comentarios y la propuesta del guión que acordamos en julio de 2011 y que cumplí en toda su extensión; también sus reflexiones en torno a la estructura del lugar (1992) fueron soporte en el método que desarrollé. Fue significativa la ayuda que me brindó para cumplir con los requerimientos de presentación de la investigación en los protocolos académicos de una tesis de doctorado de la Universidad de Valladolid. Decidió, finalmente, culminar como director de la tesis que ahora presento.

A Carlos González Lobo, profesor e investigador de la UNAM, quien ha sido el principal guía en mi trayectoria como investigador universitario. Ha dirigido mi tesis de doctorado con rigor científico y constancia a lo largo de ocho años. Con su recomendación, retomé el método de análisis de mapas y planos que había utilizado en mis tesis anteriores de la UNAM, con la dirección de González Lobo y de Joaquín Galarza, etnólogo que inició la teoría de la escritura azteca-náhuatl. Este método se adecuó y aplicó al estudio de los planos históricos de la antigua Ciudad de Los Ángeles, hoy Puebla de Zaragoza, que fueron complementados con planos temáticos a "mano alzada" que nos permitieron un ejercicio de lectura urbanística sobre las grafías, dibujos, pinturas e iconos del documento. C. González Lobo tuvo a bien leer y criticar certeramente mi trabajo para completarlo y mejorarlo en lo referente al papel de la urbanización regional, los artificios urbanísticos y arquitectónicos locales con el inicio del capitalismo en su fase comercial de los siglos XVII y XVIII, sus ingresos fiscales y la aplicación de los recursos obtenidos para la guerra y la consolidación del poder imperial en el mundo. 
A Luis Ignacio Sáinz, ya que parte de este trabajo lo plasmamos en una colección de seis libros y seis exposiciones en el proyecto de investigación iniciado en el 2000, denominado Corpus Urbanístico de México; y en 2015 compartimos la autoría de una publicación precisamente sobre temas relacionados con esta tesis. A Norma E. Rodrigo Cervantes sus comentarios y apreciaciones a mi trabajo como experta de las diversas escuelas europeas relacionadas con la morfología urbana y el análisis de cada una de ellas, que han sido referentes importantes para confirmar el método que he utilizado. A Mario González Aragón Aguirre los planos temáticos del año 1862 que realizó con mi guía. Durante las diversas estancias en España desde 1995 cuando inicié el trabajo de identificación de planos y mapas de México en los archivos españoles, conocí en el Archivo General de Indias a Federico Garza-Carbajal y Consuelo Diez Ortega , amigos de siempre, quienes me ayudaron en todo momento con sus apreciaciones y comentarios precisos del trabajo sobre los planos históricos de México, el apoyo y la guía para recopilar información sobre los mismos. A Jorge Pérez Pijoan que me guió para explorar la relación entre los fenómenos locales de Puebla con el estado absolutista del momento. A María Castrillo y Oscar Ramírez, por su trato siempre conveniente y amable. A Alfonso Álvarez Mora, con quien establecí siempre un diálogo crítico, también es de mencionar las facilidades para mantener una relación institucional entre la UVa y la UAM Xochimilco, que aún sigue vigente. Finalmente, mi cariño paterno a Maura, Mario, Luis y, posteriormente Ignacio Paul, que siempre me acompañaron y ayudaron en este trabajo.

Un reconocimiento particular a Raúl Hernández Valdest, José Luis Cortés Delgado, Jaime Kravzhov Jinich, Norberto Manjarrez Álvarez, Luis Romero Ragús, Rodolfo Santamaría, Everardo Carballo Cruz, María de Jesús Gómez Cruz y Gabriela Gay; todos ellos funcionarios, en su momento, de la Universidad Autónoma Metropolitana. 


\section{ÍNDICE}

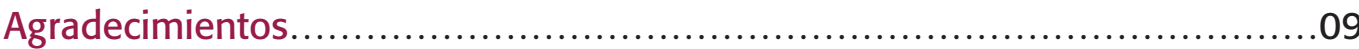

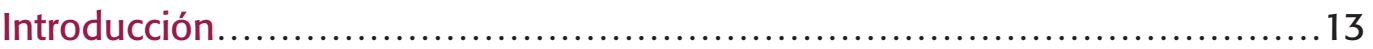

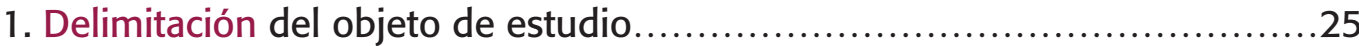

2. Método de investigación para códices-planos aztecas...............................31

2.1. Método para la lectura de planos de casas y ciudad............................32

2.2. Método para la lectura de planos habitacionales...............................32

2.3. Método para la lectura urbana del códice Plano en papel maguey ............47

3. Preexistencias urbanísticas en la región Puebla-Tlaxcala........................61

3.1. La región Puebla- Tlaxcala en el siglo XV......................................64

3.2. La fundación de la ciudad de Puebla en el contexto regional.................66

3.3. Los motivos fundamentales de la fundación de la ciudad y su esplendor...68

3.4. Morfología y trazo urbanístico de la ciudad....................................71

3.5. Resumen del proyecto de LCLA durante el encuentro cultural.................75

4. Método para la lectura de cuatro planos virreinales de la Ciudad de Los

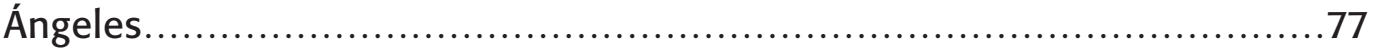

5. Lectura urbana de la Planta de La Ciudad de Los Ángeles, $1698 \ldots \ldots \ldots \ldots \ldots . . .83$

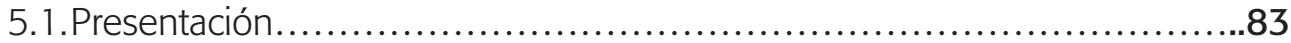

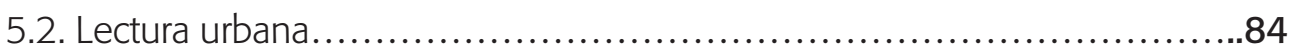

5.3. Los motivos que llevaron a la realización del plano...........................85

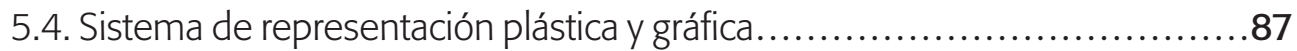

5.5. División de la ciudad por sectores urbanos...................................90

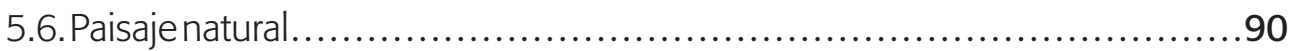

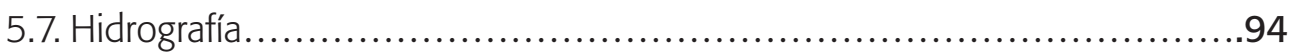

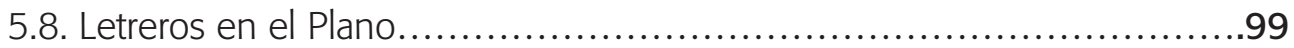

5.9. Morfología urbana: calles, caminos, plazas, manzanas y parcelaciones......102

5.10. Principales ejes de composición de la ciudad...............................108

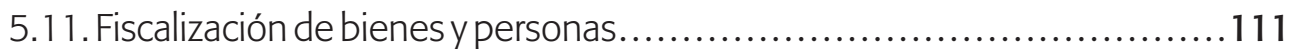

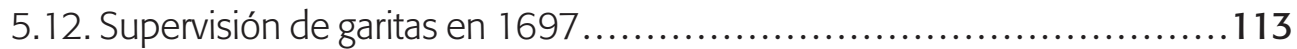

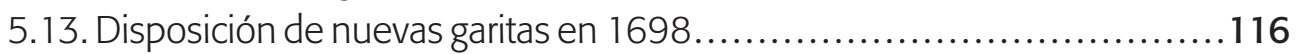

5.14. Administración y función de las reales alcabalas...........................120

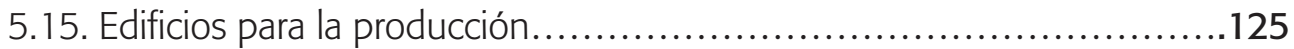

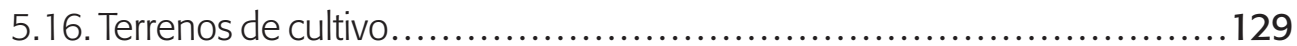

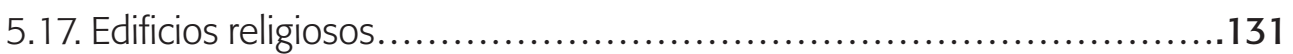

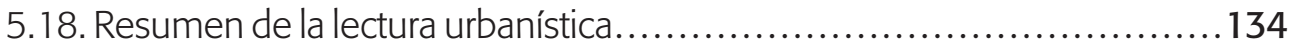


6. Tres cortes en la Ciudad de Los Ángeles 1700-1724 y 1862

6.1. Lectura urbanística del plano Ciudad de Los Ciudad Ángeles (México)......138

6.2. Lectura urbanística del Plano de las Garitas de la Aduana de la Puebla de Los Ángeles.

6.3. Croquis de la Ciudad de Puebla y sus alrededores........................170

6.4. Principales características urbanísticas................................. 178

7. El conjunto de garitas de 1698 a la actualidad.............................. 181

8. La Ciudad de Los Ángeles, sus rutas novohispanas, del Gran Caribe y en ultramar....

Conclusiones

Bibliografía

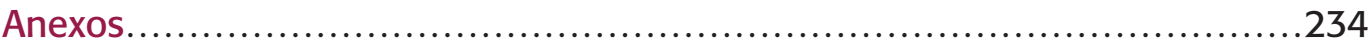

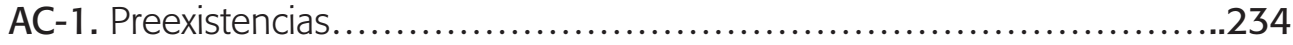

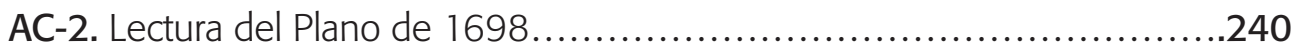

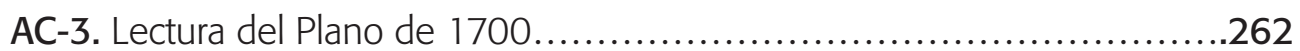

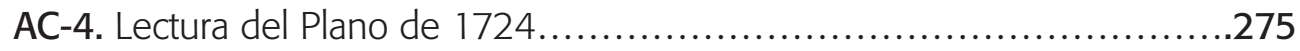

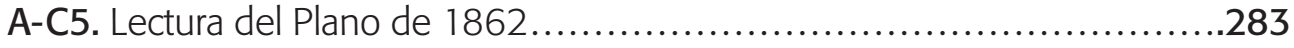

AD-1. Paleografía parcial del testimonio que acompañó al Plano de 1698.....288

AD-2. Paleografía parcial del testimonio que acompañó al Plano de $1724 \ldots . . .300$

AD-3.Glosario............................................................. 308 


\section{Introducción}

\section{EL PROBLEMA}

\section{LA EXPECTATIVA DE UNA TESIS DE DOCTORADO}

La intención original de la tesis fue develar o hacer una nueva lectura urbanística de la Ciudad de Los Ángeles del siglo XVI a inicios del XVIII mediante fuentes primarias: mapas y planos de 1698, 1700, 1724 y 1862 (éste último sólo con referente urbanístico); esta lectura fue representativa de hallazgos nuevos y significativos para percatarnos de: a) los motivos de esa urbanización, b) los elementos relevantes de cada momento seleccionado, c) las cualidades que la propia investigación nos daría como líneas de exploración urbanística en relación con lo que nos ofrecían los planos históricos y, d) las políticas e intervenciones económicas que realizaba la corona imperial y el gobierno virreinal en la ciudad y el amplio territorio regional de contacto, que complementamos con fuentes de información secundarias.

Las preguntas de investigación fueron las siguientes:

- ¿Puede considerarse a los mapas y planos como fuentes primarias confiables para la investigación científica y la lectura en el campo urbanización?

- ¿Qué método de lectura de planos y mapas urbanos sería pertinente?

- ¿Es posible dar certeza de la eficacia del método para cumplir a cabalidad con la lectura urbanística del plano histórico?

- ¿Cuáles serían los elementos o conocimientos que podríamos descubrir de la Ciudad de Los Ángeles en esta lectura urbanística? 
- ¿Qué fuentes de información secundarias serían pertinentes para una tesis o investigación que tiene como base la lectura y la exploración de la ciudad a través de los cuatro planos históricos seleccionados?

Estas preguntas fueron la base de la investigación, su respuesta está en los capítulos siguientes y en las conclusiones mostraremos los alcances, los atributos y las cualidades respecto a estas interrogantes.

\section{EL ANÁLISIS DE LA CIUDAD A TRAVÉS DE LOS CÓDICES, PLANOS Y MAPAS HISTÓRICOS}

Cuando hablamos de la urbanización del territorio o de la implantación de artificios en el espacio físico que nos rodea para satisfacer las necesidades de cobijo, vivienda y dotación de agua potable, descarga de aguas servidas y la gran complejidad de equipamientos y empresas para la producción, distribución y consumo de mercancías, nos referimos a las etapas históricas contemporáneas con pocas citas o alusiones a los documentos dibujados o pintados de nuestro territorio de interés. Los planos históricos imitan o presentan un modelo del espacio físico, es decir, los códices-planos ${ }^{1}$ de los siglos XVI y XVII, los planos y mapas del período virreinal en México y los del siglo XIX son fundamentales para comprender los pueblos y ciudades mexicanas en el tiempo.

Por ello, la primera pregunta destaca si se requiere la utilización de estas fuentes de información histórica y geográfica en nuestros análisis del fenómeno urbano y de los edificios. El caso de México es particular, así como en otras culturas con amplia tradición pictórica, porque existe una cantidad impresionante de documentos que representan los pueblos, las ciudades y las obras civiles de manera exhaustiva. A pesar de la pérdida irreparable de los códices precolombinos que registraban una variedad de relatos históricos de las etnias mesoamericanas, se continuaron realizando planos con las convenciones de dibujo y pintura a la usanza indígena y se incorporó a éstos la europea del siglo XVI. Hay un corpus significativo de este tipo de documentos con mezclas de estilos y códigos de representación que podemos clasificarlos en la categoría de planos mexicanos, pues son únicos en su estilo. Otros de gran calidad y mesura de lugares y espacios se elaboraron con las tradiciones academicistas de los ingenieros

\footnotetext{
1. El término científico de códices-planos fue acuñado por J. Galarza para definir aquel grupo de documentos de tradición pictórica indígena elaborados desde la época prehispánica hasta el siglo XVIII, y que por su contenido específico atienden o se concentran en la descripción del espacio físico: desde representaciones de casas habitación hasta grandes extensiones del territorio. Es importante mencionar el amplio conocimiento que tenía Galarza de los documentos antiguos mexicanos denominados códices. Fue él quien elaboró el Catálogo de códices en la Biblioteca Nacional de Francia y de otros repositorios, que más tarde los publicó como se cita: Códices Mexicanos de la Biblioteca Nacional de París, Índice de Manuscritos Pictográficos Mexicanos: colección de códices delMuseo Nacional de Antropología e Historia, México, 1979, Archivo General de la Nación, Guías y Catálogos \#44, además participó activamente en la clasificación y registro del catálogo de códices del Archivo General de la Nación.
} 
militares durante el XVIII y el XIX (Rodríguez Viqueira, 2010 y Xose Lois Martínez, 2014). Este registro del espacio físico estableció mediante el registro de ciudades, pueblos y regiones durante el período de Porfirio Díaz y Vicente Riva Palacio, producto de ello fue la creación de la Sociedad Geográfica Exploradora.

Los planos de estas ciudades del período virreinal y del siglo decimonónico nos aportan información para el conocimiento profundo de los orígenes de los pueblos, ciudades y organización del territorio mexicano, pues en los ejercicios de lecturas de planos históricos descubrimos nuevos códigos del período virreinal, fundamentales para el conocimiento del espíritu del lugar o genius loci de las regiones culturales.

Cada vez con mayor continuidad son usados estos documentos cartográficos en el análisis de la ciudad, sin embargo y específicamente para la lectura urbanística y arquitectónica son pocas las experiencias de trabajos exhaustivos y sistemáticos que traten la evolución específica de los edificios y las ciudades mexicanas.

\section{INICIO DE LA EXPERIENCIA EN ANALIZAR PLANOS VIRREINALES CON EL MÉTODO APLICADO EN CÓDICES-PLANOS DE TRADICIÓN AZTECA²}

Los primeros trabajos de investigación que realicé fueron con códices-planos de tradición azteca-nanuatl, guiado por Joaquín Galarza, autor del descifre de diversos códices mexicanos y teórico de la escritura azteca a través de glifos; conté también con el apoyo de Carlos González Lobo en la lectura urbana y arquitectónica. El producto de esas primeras investigaciones fueron publicados en artículos científicos en México, Oxford y Santiago de Chile.

La experiencia con mis dos tesis, de licenciatura y maestría, en la UNAM, la publicación de seis libros sobre los Corpus urbanísticos de seis regiones mexicanas y la curaduría de seis exposiciones en lugares emblemáticos de México han sido parte de mi formación para determinar la importancia de estos documentos en el trabajo sobre morfología urbana y su relación con los sistemas hidráulicos y defensivos de algunos de los pueblos México. Durante la década de los años ochenta y noventa del siglo pasado me llamó especialmente la atención, por la relación entre la sociedad agrícola prehispánica y su conexión funcional con muchas de las formas de urbanización mexicanas, los trabajos antropológicos de: Ángel Palerm, Pedro Armillas, Pedro Carrasco, Erick Wolf para Mesoamorica y Karl Witthfogel para Asia, en lo referente a las sociedades agrícolas, los

2. Nos referimos a los trabajos de investigación realizados por el autor de la presente y publicados en varios ensayos y capítulos de libros, así como en las tesis de licenciatura y maestría en la UNAM, citados al final en la bibliografía. 
sistemas hidráulicos comunitarios de gran escala y de experiencias locales y aisladas; la relación que manifiestan entre la evolución de los sistemas hidráulicos con la consolidación de los estados despóticos. Palerm, Armillas y Wolf trabajan desde finales de los años cuarenta del siglo XX algunos conceptos incipientes sobre la relación entre la agricultura productiva, con las características de los sistemas hidráulicos y de fortificación precolombinos de Mesoamérica desde el preclásico, antes del año 200 de nuestra era hasta el posclásico de 900 a 1519 de nuestra era.

En cuanto a los planos históricos de la Ciudad de Los Ángeles de esta tesis, fueron descubiertos en los repositorios del Archivo General de Indias, son de 1698, 1724 y 1862; en el Museo Naval de Madrid, Luisa Martín-Meras me mostró el plano de 1700 en su belleza original.

Al estudiar estos planos y otros dos o tres más Juan Luis de las Rivas me recomendó investigar de dónde provenían y cuál había sido el motivo de su elaboración. A partir de ello confirmé que los planos de 1698, 1700 y 1724 se realizaron para el control, la construcción, la transformación y el mantenimiento de las garitas y las alcabalas de la Ciudad de Los Ángeles, Puebla, México, en el contexto de mayor regulación de las transacciones de mercancías entre la Nueva España, desde Filipinas y América hasta el Gran Caribe y Europa. Son planos que en su representación de la forma y acomodo de los espacios construidos responden a una compleja relación económica, militar y política que representó una de las ciudades centrales del Imperio español desde su fundación, pero con mayor interés comercial y de fiscalización durante la segunda mitad del siglo XVII y la primera del siglo XVIII.

Por la compleja red de relaciones y mis limitaciones para emprender una investigación de carácter económico, centré mi trabajo en el tema urbanístico de la Ciudad de Los Ángeles y pude realizar una nueva lectura a partir de aproximaciones sucesivas, es decir, que, en ocasiones realizamos diversos ejercicios para hacer un plano temático, un intenso trabajo de dibujo a mano alzada; muy importante en el proceso de conexión cerebro-mano y reflexión sobre el espacio físico de la ciudad, que sin duda facilitan la comprensión pausada de los diversos componentes. 


\section{EL MÉTODO Y EL PROCESO DE INVESTIGACIÓN}

Algunos autores citados más adelante han trabajado los planos históricos del territorio o de edificios, quienes aplicando el método de su especialidad o disciplina con sus particulares intenciones de análisis e interpretación tuvieron resultados alentadores. Por mi parte, con la herencia analítica del oficio de la arquitectura, las valiosas enseñanzas y guía de Joaquín Galarza y mi propia trayectoria en el tema de descifrar el espacio urbanizado, he amalgamado ciertos conceptos para aplicar un método de lectura con especial interés por aquellas ubicadas en la amplia franja del eje neo volcánico de México, del Puerto de Veracruz al Puerto de Acapulco sobre la tierra firme, con la Cuenca del Lerma por el norte de esta y la del Balsas por el sur, acompañando al Eje neovolcánico en la misma ruta.

Algunos trabajos analíticos que utilizan planos como fuente primaria provienen de historiadores, geógrafos y arquitectos, quienes los han aplicado como referencia principal de su trabajo y realizado aproximaciones con mayor o menor profundidad de interpretación de los mismos. Destacan en el estudio de la ciudad histórica Manuel Toussaint y Ritter, Justino Fernández García, Federico Gómez de Orozco (1938); Paul Kirchhoff, Luis Reyes García, Lina Odena (1975); Joaquín Galarza (1979); Keiko Yoneda (1991); Luis González Aparicio (1973); Jorge González Angulo Aguirre y Yolanda Terán (1976); Carlos González Lobo (2014); Norma Elisabethe Rodrigo Cervantes (2014); Luis Ignacio Sáinz Chávez (2015); y Manuel Rodriguez Viqueira (2009); del exterior: Fernando de Terán (1989); M. Gunter Conzen y Jeremy Whitehand (1981); José Sala Catalá(1994); Carmen Manzo Porto (2008); Barbara E. Mundy (1996); Xose Lois Martínez Suárez (2014) y Manuel Teixeira (2004).

\section{DEL MÉTODO Y SUS ETAPAS}

La secuencia de actividades fue la siguiente:

i. Se realizaron entre diez y veinte planos temáticos para el análisis urbanístico de los de 1698, 1700, 1724 y 1862.

ii. Se realizó la búsqueda en el Archivo General de Indias de los expedientes que acompañaron a los planos de 1698 y 1724 y se encontraron voluminosos legajos, cuyas fojas se muestran en las fichas de solicitud en el AGı y las paleografías en los anexos A. 1. y A.2. Para el original de 1700 buscamos la documentación referente, sin embargo, o no existe o no aparece en el Museo Naval de Madrid.

iii. Realizamos una redacción de lo que apreciamos el análisis temático.

iv Definimos con mas detalle el método de análisis para la lectura urbanística de La Ciudad de Los Ángeles. 
vi. Complementamos la lectura urbanística con información de contexto para tener una idea más precisa de las condicionantes generales para la producción de la ciudad.

\section{APORTACIONES DE LA INVESTIGACIÓN}

Las aportaciones se dieron en diferentes niveles:

i. Una nueva lectura de la Ciudad de Los Ángeles en términos de su diseño, esto es, se aportan descubrimientos geográficos, de infraestructura de caminos y urbanísticos que definieron la morfología y los límites de su crecimiento durante largos períodos.

ii. La inducción hacia las condicionantes políticas, económicas y militares a la que nos llevó la observación, la consulta de los expedientes de archivo y la estrecha relación que encontramos entre las obras de infraestructura, fiscalización y defensa de la Ciudad de Los Ángeles.

iii. La aplicación del método nos permitió explorar la creación y transformación de la forma urbana a través de la conjunción de experiencias provenientes de las culturas oriundas y mediterráneas en la urbanización mexicana.

\section{CONTENIDO CAPITULAR}

El primer capítulo presenta la argumentación para el estudio de los documentos cartográficos seleccionados.

El segundo expone el método para la lectura de los edificios y de la ciudad azteca, aplicado a un grupo conjunto de códices-planos de tradición azteca-nahuatl elaborados por pintores indígenas -tlacuilos- según sus propios códigos pictóricos, pero también incorporando elementos y modos de la pintura europea. En este capítulo demostramos lo siguiente: por un lado, la eficacia del método usado en esas investigaciones; por el otro, los antecedentes de investigación que nos permiten proponer el método para la lectura de planos históricos con las convenciones más apegadas a los patrones plásticos europeos de los siglos XVII y XVIII. Este capítulo es el estado de la cuestión en la lectura urbanística y arquitectónica realizada por Jorge González Aragón; es una propuesta que ha venido desarrollando desde los años ochenta y que documenta de manera breve y concisa para observar la funcionalidad del método y sus hallazgos sobre la ciudad azteca.

En el capítulo tres se reflexiona acerca del territorio denominado transmontaña o Valle Puebla-Tlaxcala en el que sostenemos que hubo una urbanización amplia, dispersa 
pero de control de un territorio extenso, con grandes movimientos de etnias prehispánicas, con guerras continuas por el dominio militar y el acopio de los tributos otorgados por los pueblos sujetos: especias, mantas, animales domésticos y exóticos, minerales, sal y plumas. Una región, por lo tanto, urbanizada a la manera indígena, especialmente en caminos construidos, canalizaciones para la dotación de agua y selección de sitios con las condiciones propicias para la habitabilidad, así como lo tocante a ubicaciones estratégicas y orientación de sus cultivos y edificios de acuerdo con los ciclos naturales para una mayor productividad agrícola y su veneración a los elementos del cosmos y la naturaleza cercana.

En el capítulo cuatro se presenta el método propuesto para la lectura de la Ciudad de Los Ángeles: es un método laborioso en el dibujo y la interpretación. Si bien es un método sencillo cuenta con un gran potencial para el análisis. Requiere mucho trabajo para identificar los documentos que se van analizar y el porque se seleccionaron, la calidad de la imagen es fundamental, la aplicación del método para describir cada uno de los elementos urbanos o arquitectónicos en los planos temáticos. Sin embargo no es un método universal, se trata de hacer una taxonomía de la ciudad descrita, sin embargo como los planos son diversos y tienen una cantidad de elementos temáticos a estudiar, el investigador selecciona aquellos aspectos o temas que son de su interés primordial. Además descubrimos que la mayoría de los aspectos que definimos, son los que ha usado el geógrafo urbano M. R. Günter Conzen, de la escuela de morfología de la Universidad de Birmingham, para sus investigaciones iniciadas hace 80 años, con temas, conceptos definidos y categorías de las ciudades inglesas.

El método lo aplicamos al estudio de los edificios y artificios militares y fiscales que se fueron planeando e implantando en la ciudad y su entorno inmediato por decisiones políticas; fueron impulsados por la Corona española por enviados o encargados de realizar estas tareas de amplio interés global y local para la manutención de una economía pujante y de alta actividad militar; como sabemos, consumió enormes porcentajes de dinero para la manutención de ejércitos de tierra y navales, así como la construcción de edificios y conjuntos militares en los amplios litorales del Atlántico y Pacífico americano y asiático. La Ciudad de Los Ángeles ocupó un espacio de tránsito de mercancías muy importante en el período analizado; fue también el lugar o uno de los lugares seleccionados para imponer la urbanización y edificios militares-comerciales que requería el nuevo modelo de recaudación fiscal, que identificamos desde la presencia del Obispo Juan de Palafox y Mendoza (1640-1650) responsable de la secularización hasta José Veitia y Linaje, encargado de las alcabalas reales de Puebla entre 1697 y 1722, fue el lugar geoestratégico relevante para la recaudación de alcabalas para la Nueva España con las políticas de los borbones hacia la mitad del XIX y hasta los brotes de rebelión independentista. El método nos permitió identificar que los planos más 
importantes y relevantes de la Ciudad de Los Ángeles de finales del XVII y principios del XVIII están dedicados al tema fiscal y militar, su morfología y la calidad de la planeación y diseño de la ciudad.

En el capítulo cinco se hace la lectura del Plano de 1698; se precisan los motivos de su realización, como la evidente presencia de guardas para la protección de las entradas a la ciudad y garitas para el registro y pago de alcabalas. Es un documento que se ordenó a un antiguo funcionario de la ciudad, don Christobal de Guadalaxara en 1697; fue dibujado con otros ayudantes que conocían ampliamente la región y la ciudad, con las técnicas de medición europeas contemporáneas, es decir, escala en varas y elementos de referencia geográfica. Para esta lectura se elaboraron diecinueve planos, con los que se redactaron las observaciones respectivas: primero se realizó un plano con el tema seleccionado sin ninguna otra referencia del territorio como se aprecia en el documento original; después el plano con el mismo tema pero con los dibujos correspondientes, con el original de fondo y los colores disminuidos. Fue una tarea minuciosa, ya que en la primera etapa, se hicieron ampliaciones del original digitalizado, luego el dibujo a mano aspecto por aspecto. Como mencionamos antes, el dibujo fue a mano porque al copiar y enfatizar el contenido se facilita la identificación de elementos difíciles de percibir con la vista rápida y sin estructura. Estos dibujos a mano se escanearon y en muchos casos se complementaron o corrigieron. De esta manera, se conformó un catálogo de planos temáticos para la lectura urbanística. Es preciso enfatizar que hay una enorme cantidad de información además de las garitas y guardas que aparecen en el plano; uno de los aspectos son los edificios productivos entre los que resaltan los molinos de trigo junto a las riveras de la ciudad, edificios significativos si tomamos en consideración que había campos de cultivo de trigo muy fértiles, se producía la harina en los molinos y había una enorme cantidad de panaderías para satisfacer las necesidades locales, pero también para exportar harina a algunas ciudades del Gran Caribe y también, de relevancia en el campo militar, la producción de panes, biscochos y galletas de larga duración para llevarlas como parte de la alimentación de las tropas navales en su tránsito a ultramar; de allí la cantidad tan asombrosa de molinos de trigo.

En el capítulo seis tratamos la lectura de los planos de 1700, 1724 y 1892. Los planos de 1698, 1700 y 1724 están dedicados a la hacienda de la ciudad, esto es, a la fiscalización y diseño de edificios con localización estratégica y con caminos existentes o nuevos que unieron los edificios de control en el paso de personas y "mercaderías". Para el tránsito de mercancías y víveres desde Tierra firme, Puebla, en específico se requirió de la Armada de Barlovento para acompañar a buen destino los productos, es decir, de las rutas de Puebla-Veracruz-Gran Caribe y Europa. 
En el capítulo siete se hace una descripción amplia acerca de los edificios de las garitas a través de lo observado en los cuatro planos trabajados, imágenes de planos de garitas en el Archivo General de Indias y en el Archivo General de la Nación en México, así como por dibujos de JGAC a partir de fotografías de Hugo Leicht en los años treinta del siglo XX.

En el capítulo 8 hacemos una breve descripción del lugar que ocupó La Ciudad de Los Ángeles durante la segunda mitad del siglo XVII y la primera del XVIII en la economía global y el inicio del capitalismo mundial en su fase comercial con la presencia de América en el cambio de las relaciones políticas, económicas y de urbanización del territorio entre el viejo y el nuevo continente. 


\section{ANTECEDENTES DE INVESTIGACIÓN}

Con la disposición, el apoyo académico tutelar y la asesoría de Carlos González Lobo realicé mi tesis de licenciatura con un tema poco trabajado por los arquitectos: las características y patrones de la ciudad de México en su vertiente indígena a través del desciframiento urbanistico del Códice Plano en Papel Maguey. ${ }^{3}$ Posteriormente el trabajo de maestría de Arquitectura: La casa de tradición azteca en la ciudad de México. Siglos XVI y XVII.

Con Joaquín Galarza†, investigador de códices mexicanos, en el desciframiento de escrituras antiguas, me asistí y participé en el Seminario de escritura indígena tradicional azteca-nahuatl que inicia en México a finales de los setenta en el Centro de Investigaciones Superiores del Instituto Nacional de Antropología e Historia (CISINAH) que posteriormente cambió de nombre al incorporarse directamente a la Secretaría de Educación Pública por Centro de Investigaciones Superiores en Antropología Social (CIESAS).

Allí conocí su análisis y lectura de documentos pictóricos antiguos de tradición azteca-nahuatl y tuve el primer contacto con documentos originales de este tipo en la Biblioteca Nacional de Antropología e Historia y otros acervos destacados del país.

Conocí su trabajo con 20 códices-planos ${ }^{4}$ de casas en la ciudad de México del Archivo General de la Nación realizados en el XVI, usando un método para la lectura de estos

3 El Plano en Papel Maguey es un Códice-Plano que se encuentra depositado en la Cámara de Códices, ubicada en el sótano del Museo Nacional de Antropología e Historia de México y bajo el resguardo de la Biblioteca Nacional de Antropología e Historia.

4. La definición de códice-plano fue elaborada por J. Galarza para identificar aquellos documentos con las convenciones pictóricas de tradición azteca-náhuatl y que temáticamente correspondían a edificios o espacios urbanos. 
documentos creado por él. Mi participación en el Seminario consistió en la elaboración de una lectura de los documentos mencionados, pero desde desde la arquitectura. Comencé a hacer dibujos de los glifos que aparecían en los planos de las casas; leí textos contemporáneos que se relacionaban con el tema sin acercarme siquiera a una propuesta de lectura arquitectónica. Sin embargo en las reuniones de trabajo con Galarza me comentó algo muy importante: "No leas absolutamente nada que consideres relacionado con el tema que estás trabajando, enfréntate al problema que te he pedido y con tus propios recursos da una respuesta; es muy importante que no te predispongas con los trabajos, ideas y conceptos que han hecho otros investigadores". Algunos años después ya contaba con avances; terminé una primera etapa de la investigación y la presenté en julio de 1988 en el 46 Congreso Internacional de Americanistas en Ámsterdam; el trabajo fue publicado en 1989 en Oxford.

En 1989 comencé a estudiar el Códice Plano en papel maguey, un documento que mide 168 × $238 \mathrm{~cm}$, elaborado a principios del siglo XVI, que registra una parte de la ciudad de Tenochtitlan. En 1993 fue publicado ese trabajo por la Universidad Autónoma Metropolitana, Unidad Xochimilco. ${ }^{5}$

En 1995, fui invitado por los arquitectos José Luis Cortés Delgado, 6 Raúl Hernández Valdés ${ }^{7}$ y Carlos Baztán Lacasa ${ }^{8}$ para realizar el catálogo de códices, planos y mapas sobre arquitectura y urbanismo que se encontraban en los acervos españoles durante una estancia de exploración de tres meses en el Ministerio de Cultura de España.

Después de haber tenido amplio contacto en la Ciudad de México con los códices mexicanos; en España, fue una experiencia gratificante conocer los documentos originales, cuando así lo permitían los repositorios visitados, durante el trabajo en los repositorios más importantes de Iberia, con la ayuda de Carlos Baztán: La Biblioteca y el Archivo del Palacio Real, el Archivo Histórico Nacional, la Biblioteca Nacional, la Real Academia de la Historia, el Archivo General de Simancas, el Archivo General de Indias, la Biblioteca de Catalunya y los archivos militares del Centro Geográfico del Ejército, el Instituto de Historia y Cultura Militar y el Museo Naval de Madrid.

\footnotetext{
5. Jorge González Aragón La urbanización indígena de la Ciudad de México. El caso del Plano en Papel Maguey, Universidad Autónoma Metropolitana, Unidad Xochimilco, 1993, 77 páginas "Analyzes the Plano en Papel Maguey, an early colonial Indian map of a section of Tenochtitlán, to better understand the city's 16th-century urban structure. Well-illustrated monograph and valuable document for study of the early development of Mexico City and Spanish colonial influence on pre-existing urban structure", Handbook of Latin American Studies, v. 57.

6. Coordinador de la Carrera de Diseño de los Asentamientos Humanos de la Universidad Autónoma Metropolitana, Unidad Xochimilco.

7. Director de la División de Ciencias y Artes para el Diseño, UAM-X.

8. Responsable de las intervenciones arquitectónicas en los Museos estatales españoles en el Ministerio de Cultura.
} 
Una vez elaborada la base de datos general de los documentos identificados en archivo, pero sin reproducción fotográfica o imagen escaneada, iniciamos en México José Luis Cortés y yo la realización de las primeras tres exposiciones de los documentos inéditos en fotografías impresas de gran formato; se reprodujeron con el material recién recopilado en negativos o en archivos digitalizados proporcionados por los repositorios españoles y que comenzamos a adquirir con la ayuda económica de la Universidad Autónoma Metropolitana con el apoyo del rector general José Luis Gázques Mateos, el coordinador de Difusión Cultural Luis Ignacio Sáinz en la colección que denominó Corpus urbanístico de México. En esta empresa nos apoyaron diversos funcionarios del gobierno español del Ministerio de Cultura y la Embajada de España en México: Carlos Baztán Lacasa, María de Jesús Figa y María Cristina Barrios Almazor ${ }^{9}$ cuyas gestiones en los archivos españoles fueron determinantes para la recopilación de imágenes.

Del conjunto de fuentes primarias que hemos denominado Corpus Urbanístico de México en los Archivos Españoles, un acervo de cerca de 1400 documentos pictóricos de códices, planos y mapas del territorio mexicano y novohispano que iniciamos en 1995, primero en colaboración con José Luis Cortés Delgado y después con Luis Ignacio Sáinz Chávez; me interesaron especialmente cuatro planos de la ciudad de Puebla, ubicados tres ${ }^{10}$ en el AGl y uno en el Museo Naval de Madrid.

9. Como embajadora de España en México propició la mayor colección de imágenes digitalizadas de los archivos estatales y militares de España para México.

10. Fueron los planos de los años de 1698, 1724 y de 1862, este último fue una copia con caracteres latinos en francés de otro que se encuentra en el Archivo del Ayuntamiento Municipal de Puebla y que fue el documento planimétrico que finalmente utilizamos en esta tesis. 


\section{I \\ Delimitación del objeto de estudio}

\section{LA TEMÁTICA}

Tiene como objeto de estudio la ciudad de Puebla para identificar la estructuración y las transformaciones entre 1698 y 1724 en el conjunto de elementos militares y comerciales de los siglos XVII, XVIII y su permanencia hasta 1862.

El análisis del territorio se realiza en tres escalas: la primera, en el contexto regional amplio de la Nueva España; la segunda, la microrregión o territorio inmediato a la ciudad; la tercera, el espacio físico de la ciudad y sus características.

Por territorio regional consideramos el rol que ocupó la ciudad de Puebla en el contexto de la Nueva España y las condiciones políticas, militares y económicas que motivaron la fundación de la ciudad en el sitio seleccionado. Territorio micro-regional se refiere al papel de Puebla en el contexto de los asentamientos preexistentes alrededor de la misma y las condiciones geográficas. Para la ciudad, tomamos en cuenta la mancha urbana y los espacios relacionados directa y cotidianamente con sus funciones de acuerdo con el relato contenido en los planos históricos.

En particular para el Plano de 1698, nos interesó estudiar los objetos urbanos principales que están definiendo y conformando la ocupación del espacio en su relación con los recursos naturales, los edificios de la producción y de fiscalización comercial, de control y seguridad de la ciudad, así como, su relación con la morfología urbana. 


\section{FUENTES PRIMARIAS}

La investigación se basa en el estudio de fuentes primarias: los planos históricos de la ciudad de Puebla; se complementó con fuentes documentales primarias y secundarias.

Cuando nos referimos al estudio exhaustivo de los planos históricos, tenemos como principio descubrir lo que nos presenta ese documento antes de adjetivarlo, a partir de este principio vamos a develar el discurso que nos presenta la imagen del plano a estudiar. Desde nuestro punto de vista y atendiendo a la experiencia personal, estamos convencidos de que antes de otorgarle un calificativo a los documentos desde nuestros parámetros culturales, es necesario realizar una lectura de las imágenes en cada una de sus partes para posteriormente hacer una general del documento que nos permita acceder a nuevos conocimientos de la ciudad.

Hasta ahora son escasos y limitados los estudios exhaustivos de planos realizados con formas de representación y símbolos de raíces renacentistas, por ello es una empresa científica para confirmar o refutar la eficacia y calidad del método propuesto para el estudio de las estructuras urbanas. Por raíces pictóricas renacentistas se consideran cuatro aspectos técnicos principales en la pintura de los siglos XV y XVI: 1. Modelado de bulto pleno o lo que es lo mismo, representación realista de los volúmenes mediante adecuado tratamiento de los efectos de luz y sombra; 2 . Situación de los personajes en interiores o paisajes regidos por las leyes de la perspectiva geométrica más elaborada. Dichos personajes, por otra parte, guardan entre sí y con relación al espacio en que se hallan correctas relaciones de proporción; 3. Durante el Renacimiento el color se concibe situado en la atmósfera e influido por las variaciones que los reflejos, la reverberación, la proximidad o lejanía, etc., producen en su naturaleza; 4. Estructuración compositiva de las pinturas basada en formas geométricas estables, como el triángulo, o en la simetría. En este sentido, consideramos pertinente comenzar a descubrir los elementos de la ciudad, las formas, estilos y simbología que implícitamente utilizan los autores de la obra documental -el plano antiguo- para expresar los diferentes componentes de la ciudad. Las interpretaciones realizadas ofrecen nuevas pautas para el descubrimiento o profundización del conocimiento de la ciudad a través de los mapas y planos históricos.

\section{PLANOS SELECCIONADOS}

A través de la experiencia y familiaridad con el Corpus de los planos de la época virreinal, que existen en los archivos españoles y en los mexicanos, elegimos cuatro de la 
ciudad de Puebla, seleccionados para nuestro trabajo por un motivo fundamental: el registro de garitas y guardas, alhóndigas y aduanas, calles, caminos y plazas, así también, su disposición dentro de la estructura urbana; y son los siguientes:

1. Nombre del Plano: Planta de la Ciudad de Los Ángeles de Nueva España

Autor: Christobal de Guadalaxara

Año de Realización: 1698

Repositorio de Resguardo: Archivo General de Indias

Clasificación: AGI, MP, México, 529

2. Nombre del Plano: Ciudad de Los Ángeles (México)

Autor: Antonio de Santa María Inchauztegui

Año de Realización: 1700

Repositorio de Resguardo: Museo Naval de Madrid

Clasificación: X. MN-p 13-3

3. Nombre del Plano: Plano de Las Garitas de la Aduana de Puebla de Los Ángeles

Autores: Juan José de Veitia y José Joaquín de Uribe y Castrejón

Año de Realización: 1724

Repositorio de Resguardo: Archivo General de Indias

Clasificación: AGl, MP, México, 519

4. Nombre del Plano: Croquis de la Ciudad de Puebla y sus alrededores

Año de Realización: 1862

Repositorio de Resguardo: Archivo Municipal de Puebla

Dos de los cuatro planos son ampliamente conocidos y corresponden a los años 1698 y 1862, los otros dos, de los años 1700 y 1724 que hasta el año de 1995 no habíamos observado en publicación alguna, mantuvieron su condición de inéditos hasta el año 2001 cuando aparecieron publicados en: González Aragón y Cortés Delgado, 2001, pp. 67 y 69, éstos presentan los atributos que a continuación se detallan.

\section{DOS PLANOS IDENTIFICADOS POR EL AUTOR}

- El Plano de 1700 con el nombre: Ciudad de los Ángeles (México). Fundada el 4 de abril de 1531, resguardado por el Museo Naval de Madrid, es muy importante por la fecha de realización, ya que es el segundo más antiguo de esta ciudad de que se tenga conocimiento; su contenido informativo es sin duda alguna fundamental para el estu- 
dio urbano, pues contiene por primera vez el conjunto de garitas previstas o algunas ya construidas o en proceso de edificación y que:

Forma un circuito alrededor de la mancha urbana. Presenta con gran detalle los espacios públicos de la ciudad: las calles y las plazas. Estos atributos fueron los que nos motivaron y estimularon para el análisis del documento debido a que nos indicaba una gran cordura entre la dimensión estética de la ciudad, sus condiciones edilicias y políticas para el ejercicio de un poder adjunto al central y su condición amplia para el auspicio y control del mercado; también la nueva condición que adopta la ciudad para su resguardo y defensa. Adicionalmente, el plano tiene una gran cantidad de edificios, obras civiles y medio natural dibujados en perspectiva con una gran fidelidad en cuanto a la ubicación, descripción espacial y constructiva que manifiesta una calidad plástica muy destacada para su época y también para la actual.

- El segundo se encuentra en el AGI, es del año 1724 con el nombre de Plano de Las Garitas de la Aduana de Puebla de Los Ángeles. Es importante mencionar que hay dos planos con el mismo nombre, fecha, signatarios y en el mismo repositorio; parece que uno es copia del otro, pues contiene la misma información de las garitas aunque hay diferencias en cuanto al esquema de la ciudad, sobre todo en lo que se refiere a la variación en el número de manzanas en la zona central y los barrios periféricos.

En cuanto al contenido de este plano, tiene como tema de énfasis las garitas que existieron en 1724 y los proyectos para construir otro circuito interior de garitas al ya establecido; la descripción de las mismas es exhaustiva pues cuenta con la ubicación de cada una de las garitas edificadas o por construir, la distancia que separa a cada una de ellas de la siguiente próxima y su distancia a la Plaza Mayor de la ciudad. Este registro exhaustivo de las garitas se realiza en un período de transformación muy importante de la ciudad en la recaudación fiscal y su manifestación en el espacio urbano, ya que se modifica la ciudad con edificios dispuestos estratégicamente para el control y fiscalización de las mercancías y de la población. Aunque pudiera considerarse que la descripción de la ciudad en cuanto a trazo, disposición de manzanas, edificios principales y paisaje natural es una pintura caprichosa, contiene una abstracción que señala la composición por partes o barrios de la ciudad de la Puebla de Los Ángeles.

Ambos planos, el de 1700 y el de 1724, fueron un hallazgo fundamental para mi trabajo porque, además de ser poco conocidos, tienen la virtud de proporcionar una gran cantidad de información para comprender las grandes transformaciones que se dieron desde el inicio del XVIII, que condicionaron el proceso de crecimiento y acotación de la ciudad hasta la siguiente modificación profunda a partir de la presencia del ferrocarril a finales del siglo XIX. 


\section{NIVELES TERRITORIALES Y CORTES DE TIEMPO}

La delimitación del objeto de estudio tiene varios niveles territoriales que abarcan desde la parcela urbana y el edificio hasta la región, según sea pertinente referirse a cada uno de ellos; se definieron diversos cortes de tiempo asociados con las fechas de elaboración de los planos seleccionados. Los niveles territoriales, los cortes de tiempo y su importancia urbanística fueron los siguientes:

1. La región y los motivos políticos, militares y económicos de la fundación de la ciudad y sus alrededores.

2. La ciudad en el momento de su fundación y su entorno territorial preexistente, esto es, la disposición de los asentamientos prehispánicos en el entorno inmediato y las cualidades del medio natural para la fundación y desarrollo de la ciudad a partir de las experiencias urbanas de Mesoamérica, la impronta franciscana y los intereses políticos y económicos de la Corona.

3. La ocupación y la mutación de la ciudad en los años 1698, 1700, 1724 y 1862 a partir de la relación con la geografía, los edificios de defensa, fiscalización, comercio y con los espacios públicos.

4. La presencia del ferrocarril y el traspaso de los bordes urbanos, apunta a la transformación extensiva de la ciudad después de 1862.

\section{DELIMITACIÓN DEL OBJETO DE ESTUDIO}

La delimitación física de la ciudad se define a través de las condiciones naturales en las inmediaciones de la misma: los ríos Alseseca, San Francisco y Atoyac; el arroyo de Xonaca; la Barranca de las Trancas; cerros y montañas de Loreto, Belén, San Juan, Tepoxuchitl y Amalucan. Su selección como bordes urbanos se realiza a partir de los espacios de las actividades humanas más estrechamente relacionadas con la ciudad: comercio, defensa, trabajo y recreación.

Para esta investigación, se tomó en cuenta esta demarcación, aunque no se restringió solamente a ella, pues nos interesó analizar los procesos históricos que consideran los proyectos urbanos, la edificación y la transformación de la ciudad de Puebla, por lo que en algunas ocasiones nos referimos a entornos territoriales más amplios que nos permitieron explicar con rigor la condición misma de la ciudad. 


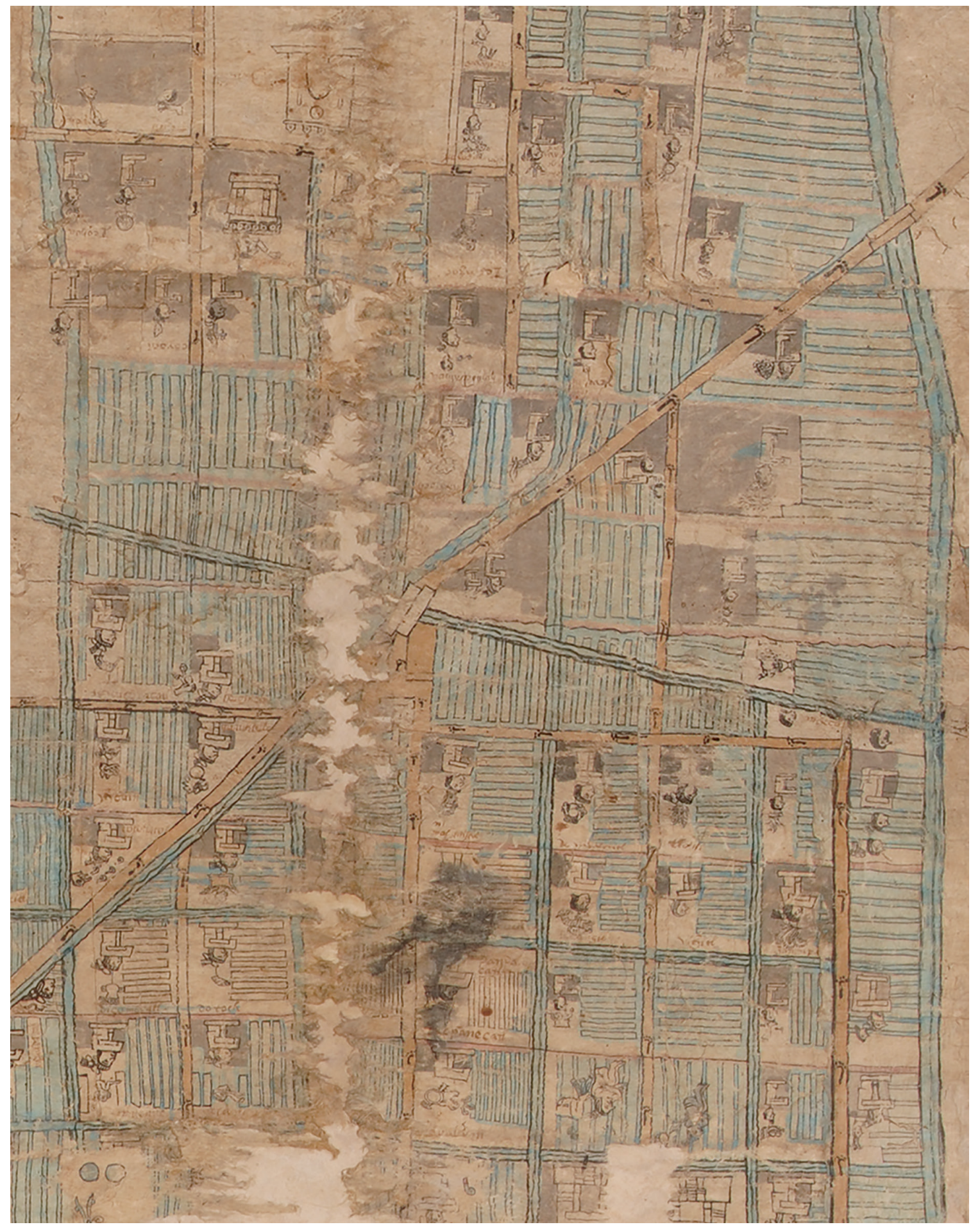




\section{2 \\ Métodos de investigación Códices-planos aztecas}

\section{LOS PLANOS Y EL REGISTRO DEL TERRITORIO POR LA CORONA ESPAÑOLA}

La península Ibérica tuvo una tradición importante en la administración de los bienes; el seguimiento de los grandes proyectos de la Corona, para su conclusión exitosa, lo realizaba a través del registro expedito en documentos escritos, portulanos, atlas, mapas y planos del territorio que aplicaron al Nuevo Mundo para lo siguiente: 1. El seguimiento eficaz y oportuno del gobierno; 2. La explotación y salida de riquezas hacia ultramar; 3. La dotación de armas, pólvora y mercancías europeas hacia el territorio conquistado; 4. Las autorizaciones de la Corona para la realización y control de las grandes obras de infraestructura y equipamiento. La Casa de Contratación de Sevilla y el Archivo de Simancas en Valladolid fueron los registros más importantes a finales del siglo XVl; allí se encuentran algunos de los documentos encargados por Felipe II conocidos como las Relaciones Geográficas de la Nueva España, que consistió en un extenso cuestionario aplicado a una gran cantidad de pueblos y regiones importantes que daba cuenta de las características de la población, el entorno natural, los edificios y los recursos posibles de explotación; además, iba acompañado de un mapa elaborado por una persona que conociera ampliamente ese territorio (generalmente oriundo de la localidad). También se hicieron mapas y planos sobre las jurisdicciones de la Iglesia y del gobierno, de las obras realizadas (ciudades, puertos, fortificaciones, caminos, desagües, dotación de agua, iglesias), de las pugnas internas por delimitación o modificación de las fronteras de un lugar o provincia, por mencionar algunos de los motivos de este impresionante acervo de códices, planos, mapas, croquis y una gran cantidad de expedientes en caracteres latinos ligados a ellos. 


\section{LOS PLANOS SELECCIONADOS DE LA CIUDAD DE PUEBLA}

La identificación, el análisis y la interpretación de elementos urbanos y edilicios en la ciudad se realizaron a través de su representación en los planos:

1. Planta de la Ciudad de Los Ángeles de Nueva España, 1698.

Ciudad de Los Ángeles (México), 1700.

3. Plano de las Garitas de la Aduana de Puebla de Los Ángeles, 1724.

4. Croquis de la Ciudad de Puebla y sus alrededores, 1862.

La relación entre los componentes urbanos, militares y comerciales en los cuatro planos requirió de un método basado en el análisis exhaustivo de cada uno de los elementos gráficos, íconos y símbolos relacionados con los temas mencionados. El método se hizo a partir de lo que se desarrolló y aplicó en las investigaciones anteriores, cuyos resultados han sido publicados en diversos libros y revistas científicos. ${ }^{1}$

\subsection{MÉTODO PARA LA LECTURA DE PLANOS DE CASAS Y CIUDAD}

En esta investigaciión se aplicó un método para la lectura de planos de tradición azteca-nahuatl mediante la incorporación de los aspectos significativos para la lectura espacial, de elementos constructivos y de la ciudad, en dos estudios:

1. 34 códices-planos ${ }^{2}$ de viviendas de tradición azteca resguardados por el Archivo General de la Nación en México y la Biblioteca José María Lafragua de la Universidad Autónoma de Puebla.

2. El Códice denominado Plano en papel maguey custodiado por la Biblioteca Nacional de Antropología e Historia, conservado en la Cámara de Códices en el edificio del Museo Nacional de Antropología e Historia

3. Los resultados de ambos se sintetizan en los siguientes apartados.

\subsection{MÉTODO PARA LA LECTURA DE CÓDICES-PLANOS HABITACIONALES}

El método se realizó como instrumento para poder realizar la lectura de 34 códices-planos de las casas de tradición azteca-nahuatl para identificar la organización del espacio

1. González-Aragón, 1989, 1992, 1993, 2000, 2002, 2004, 2007, 2009, 2010, 2014 y 2015.

2. El término de códice-plano propuesto por J. Galarza es para identificar al corpus de documentos que registraron espacios habitacionales con las convenciones pictóricas tradicionalmente usadas por los aztecas en la representación de las viviendas y los elementos de la ciudad. Se les denomina de tradición azteca-nahuatl porque fueron documentos realizados con la presencia española en México, pero siguieron conservando la tradición pictórica prehispánica en los documentos realizados por los indígenas. 
habitacional y los elementos constructivos en sus aspectos formales, funcionales, ambientales y antropométricos.

Para comprender los elementos generales que le dan cuerpo a este instrumento de análisis y que permite percibir un grupo de conceptos definidos y comprobados en diversas investigaciones, señalamos los pasos del método aplicado por Joaquín Galarza y posteriormente la propuesta de lectura arquitectónica elaborada por el autor de estas líneas:

1. Codificación. El primer paso es el registro o codificación, en el que se enumeran todos los elementos según la localización en el espacio de su superficie dibujada, para situar su distribución individual y asociada. Siguiendo la clara organización de los dibujos en grupos plásticos. De esta manera se obtiene un diagrama en el que todos los elementos codificados pueden localizarse en el conjunto del manuscrito. ${ }^{3}$

2. Desglosamiento. Consiste en la separación de cada uno de los elementos constitutivos de un glifo o conjunto de glifos: una escena, un relato, una parte de un territorio, con el objeto de conocerlos a profundidad.

3. Clasificación. Los glifos son clasificados de acuerdo con diversas características o atributos inherentes a ellos: 1. Técnicas de adquisición; 2. Técnicas de fabricación; 3. Técnicas de consumo; 4. Armas, implementos y utensilios; 5. Materias primas; 6 . Varios. ${ }^{4}$

4. Comparación. En este paso se realizan agrupaciones de aquellos glifos que presentan características similares, con el fin de realizar comparaciones y observar las recurrencias y las diferencias que presentan.

5. Propuesta de lectura. Una vez realizados los pasos anteriores, el investigador tiene la posibilidad de proponer una lectura descriptiva de cada uno de los elementos glíficos en lo individual y en su conjunto.

En la investigación de los 34 códices-planos, que se muestran en la siguiente lámina, se realizó la construcción de una tipología a partir de las recurrencias en la distribución de los espacios y la morfología de los componentes de la casa. Se incorporaron otros elementos que permitieron estudiar la estructuración de los espacios, la movilidad del usuario en la casa y la preferencia por ciertas orientaciones solares de la edificación.

Las etapas del método fueron las siguientes: 1. Ficha de registro por cada plano de casa; 2. Láminas comparativas de todos los planos; 3. Lectura de los temas espacial y constructivo individual y del corpus analizado.

3. Galarza: 1992, p. 85.

4. Galarza: 1980, pp. 13-21 

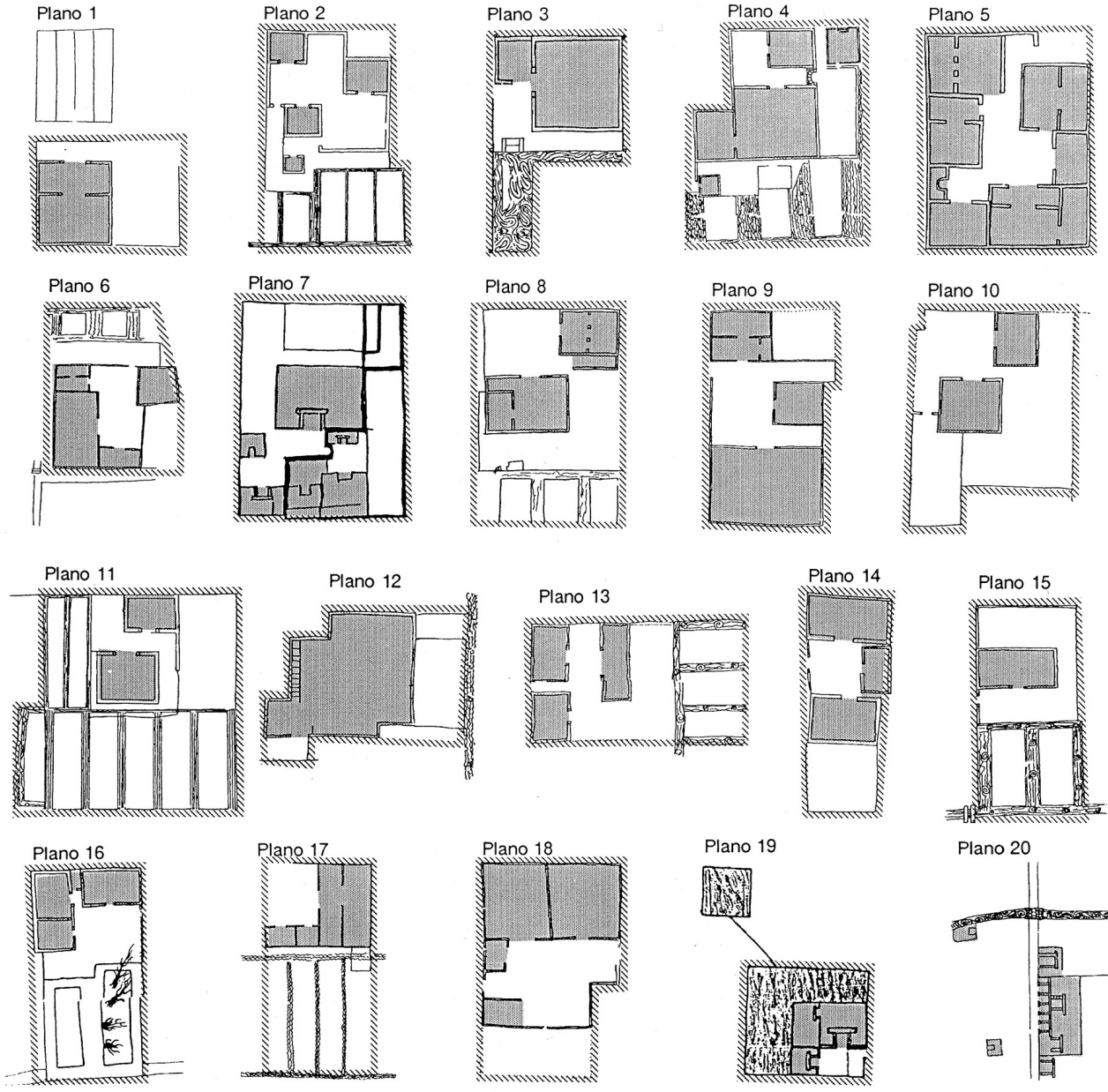

Plano 19

16.
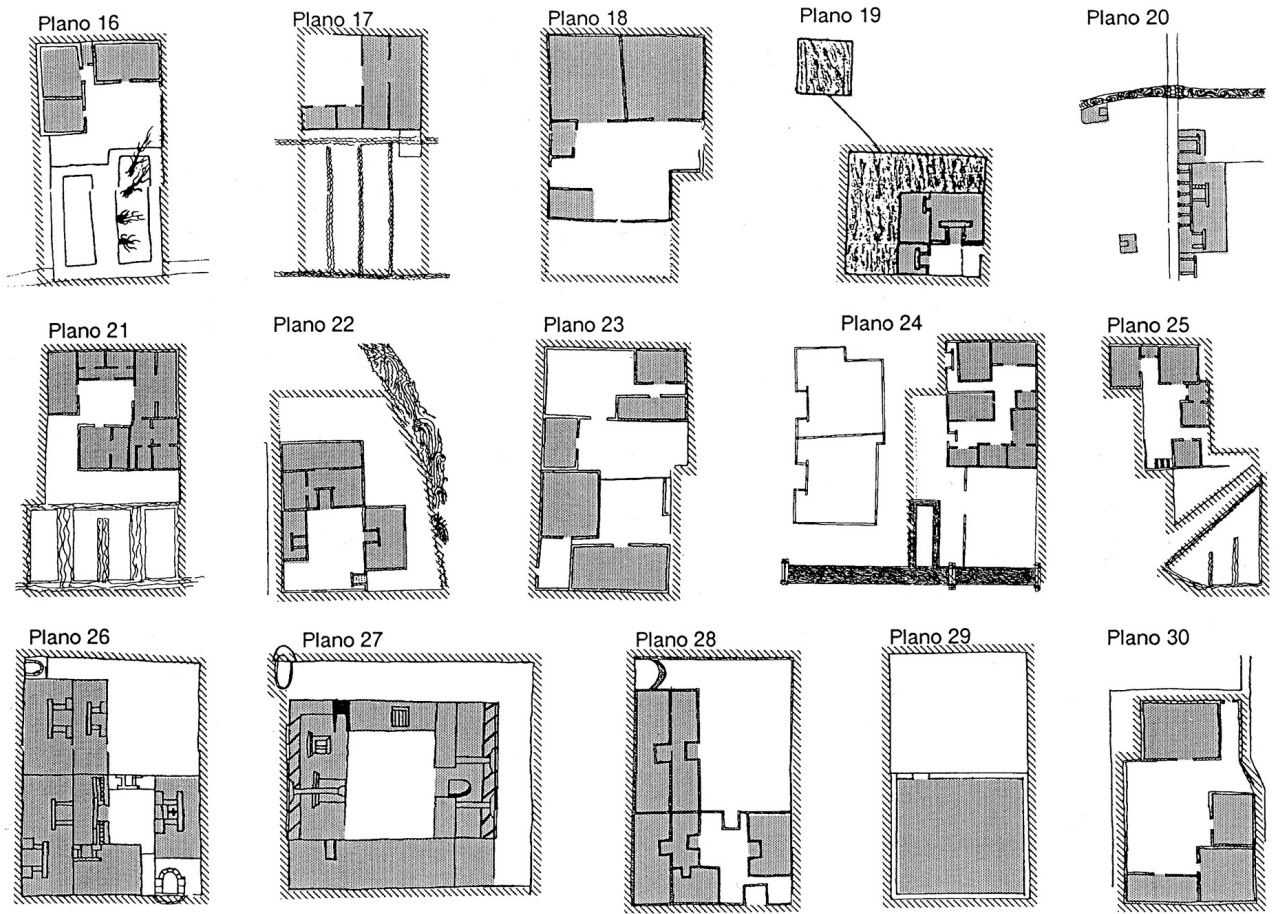

Plano 30

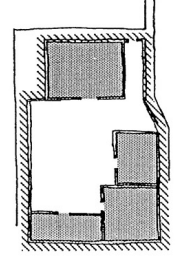

Plano 31
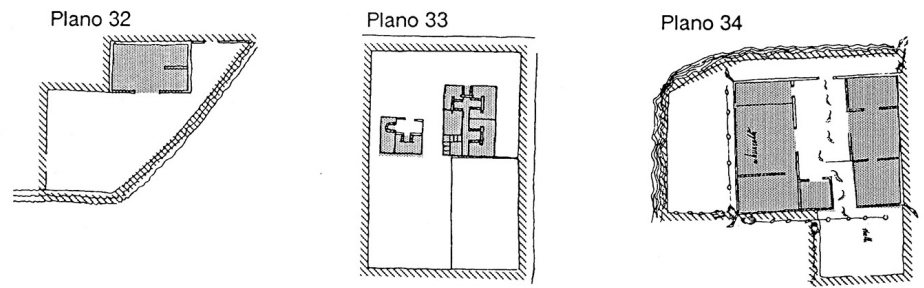

PLANO 3-1. 34 planos de casas de tradición 


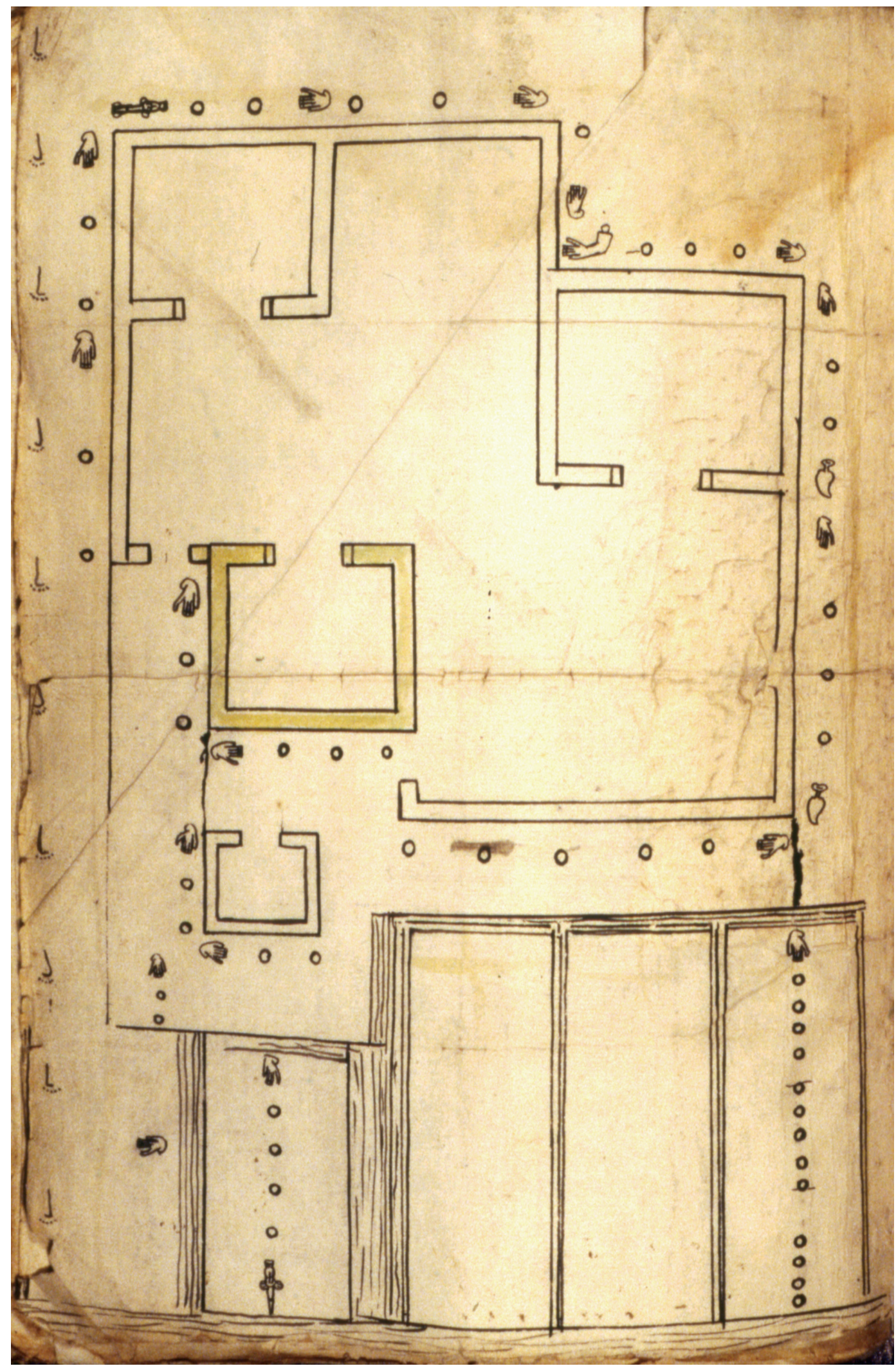

PLANO 3-2. Códice-plano original (Catálogo de llustraciones, 553, AGN) 


\subsubsection{FICHA DE REGISTRO}

Se realizó una ficha en computadora con información proveniente de diversas fuentes:

1. Catálogo de Ilustraciones del Archivo General de la Nación

2. Joaquín Galarza y otros, 1985, ms, inédito, "20 Planos urbanos del siglo XVI en la Ciudad de México".

3. Luis Reyes y otros, 1996, Documentos nahuas de la Ciudad de México del siglo $x v i$.

4. González Aragón, 1989, "Planos aztecas de la Ciudad de México. Aspectos arquitectónicos," en Galarza, J. y otros, editores.

La ficha se compone de ocho partes como se describe a continuación:

a. La parte 1 contiene los siguientes elementos:

- La imagen en blanco y negro del plano de la casa

- No. de ilustración, de acuerdo con el Catálogo de llustraciones del AGN

- Ramo del Archivo en que se encuentra clasificado el Plano en el AGN

- Año de elaboración del plano

- Signatarios del plano

- Localización del inmueble en la ciudad

- Escala en medidas indígenas

- Orientación

b. La parte 2 contiene los siguientes elementos:

- Lectura inicial del plano. Se realizó un texto preliminar que tiene por objeto hacer una descripción de los diversos elementos que contiene.

- La convención plástica de representación "en planta".

- La convención plástica de representación "de frente o de perfil".

- La convención plástica de representación "en volumen o tridimensional".

En cuanto a los elementos espaciales se registraron los siguientes items:

- Número de cuartos

- Número de patios

- Número de corredores

- Número de solares

- Número de corrales

- Número de chinampas

- Acequias para el regadío agricola

- Canales para la circulación de canoas

- Otros espacios 
En cuanto a elementos constructivos se registraron los siguientes elementos:

- Número de embarcaderos

- Número de puentes

- Número de accesos en la casa

- Número de ventanas

- Número de muros

- Otros elementos divisorios

- Otros elementos constructivos

c. La parte 3 contiene la clasificación y codificación de cada uno de los elementos espaciales identificados en el plano.

d. La parte 4 contiene la clasificación y codificación de cada uno de los elementos constructivos identificados en el plano.

e. La parte 5 presenta las posibilidades de circulación del usuario dentro de la casa, representado en un esquema que además identifica la forma en que se encuentra organizado el espacio y el grado de intimidad de cada uno en la casa.

f. La parte 6 registró un resumen del expediente de transferencia de la propiedad que acompaña al plano original. Es una síntesis de los aspectos que se consideraron importantes para el análisis habitacional. Generalmente se registra en esos expedientes el año de litigio o transferencia de la propiedad del inmueble, su localización, los propietarios, la orientación de la casa y sus medidas. ${ }^{5}$

g. La parte 7 registra la orientación de las casas que se observa o bien en el plano o en el expediente que lo acompaña; este dato es muy importante para saber si existieron convenciones y preferencias por un determinado tipo de orientación de los espacios con respecto al sol.

h. La parte 8 es una interpretación axonométrica del plano de la casa con tres puntos de observación con la finalidad de que el lector o el observador poco familiarizado con los códices-planos pueda contar con una referencia interpretativa de la casa con las convenciones plásticas comunes que usamos en la actualidad. 


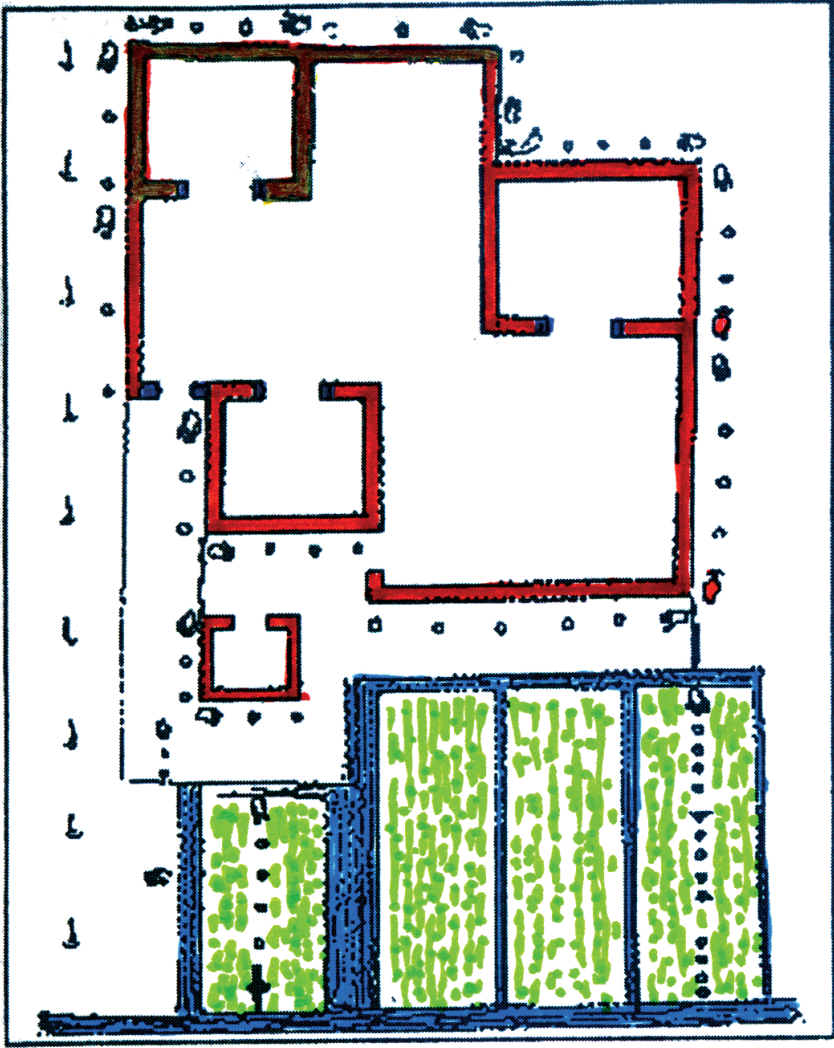

E plano cuenta con tres secciones. La primera con tres cuartos de un solo acceso y dispuestos alrededor de un patio ortogonal con una forma compleja que se asemeja a una " $Z$ " Los accesos de los cuartos se encuentran desfasados, es decir nunca hay un acceso frente a otro, permitiendo una mayor intimidad; uno de los cuartos es de color amarillo ocre. Esta sección cuenta con dos accesos, uno al camino o calle y otro a las chinampas. La segunda sección cuenta con un cuarto un poxo más pequeño y un espacio de circulación alrededor, esta sección es una transición entre la primera scición y la tercera sección un conjunto de cuatro chinampas rectanguiâres rodeadas por acequias: tres son de idéntico tamaño y una más chica

Los glifos.

Se tiene huellas de pies para indicar el camino que corre a to largo de un costado de la unidad habitacional

los glifos de medidas indígenas se encuentran en los perimetros del área edificaday al centro de dos de las chinampas. Las unidades de medida registradas son: flechas, circulos, manos, brazo. y corazón.

Los muros de la casa están vistos en planta y se representan con doble línea; hay otros elementos divisorios en cl corredor. representados con línea sencilla, pudiera tratarse de cercas de menor solidez.

La casa era habitada por más de una familia

\section{Observaciones:}

\section{Plann ?}

Clasificación begún
Catálogo de ilustraciones pel 553 Ilustración: 55 . Color

Ramo: Tierras: vol. 22,1 a. pte. exp. $5, \mathrm{f}$. $122 v$

Medidas del documento: $31 \times 22 \mathrm{~cm}$. Año de elaboración: 1564

Signatarios:

Localización del inmueble:

San Juan Tlachquac; Cd. de México

Escala:(En medidas indígenas) indi goud

Orientación. Las chinampas están hacia el occidente) ind'se

Registro arquitectónico PLANO 2
CONVENCIONES DE REPRESENTACION
En planta: Todos los clcmentos de la unidad
habitacional
De frente
o perfil:
En Yolumen:
ELEMENTOS ESPACIALES Otros espacios:
No. Cuartos: 4
No. Patios: 1
No. Corredores: 1
No. Solares:
No. Corrales: ¿Canales plcircular canoas?
No. Chinampas: 4
ELEMENTOS ARQUITECTONICOS
Embarcaderos:
Puentes: $\quad$ Otros elementos am.
Accesos: 6
Yentanas:
Muros: 17
Otros elementos divisonios:
Una línea sencila en el corredor

\section{Registro arquitectónico PLANO 2} CONYENCIONES DE REPRESENTACION

habitacional

o perfil:

En Yolumen:

ELEMENTOS ESPACIALES

No. Cuartos: 4

No. Patos.

No. Solares:

No. Corrales:

No. Chinampas: 4

as?

ELEMENTOS ARQUITECTONICOS

Puentes:

Accesos: 6

entanas:

Una línea sencila en el corredor 

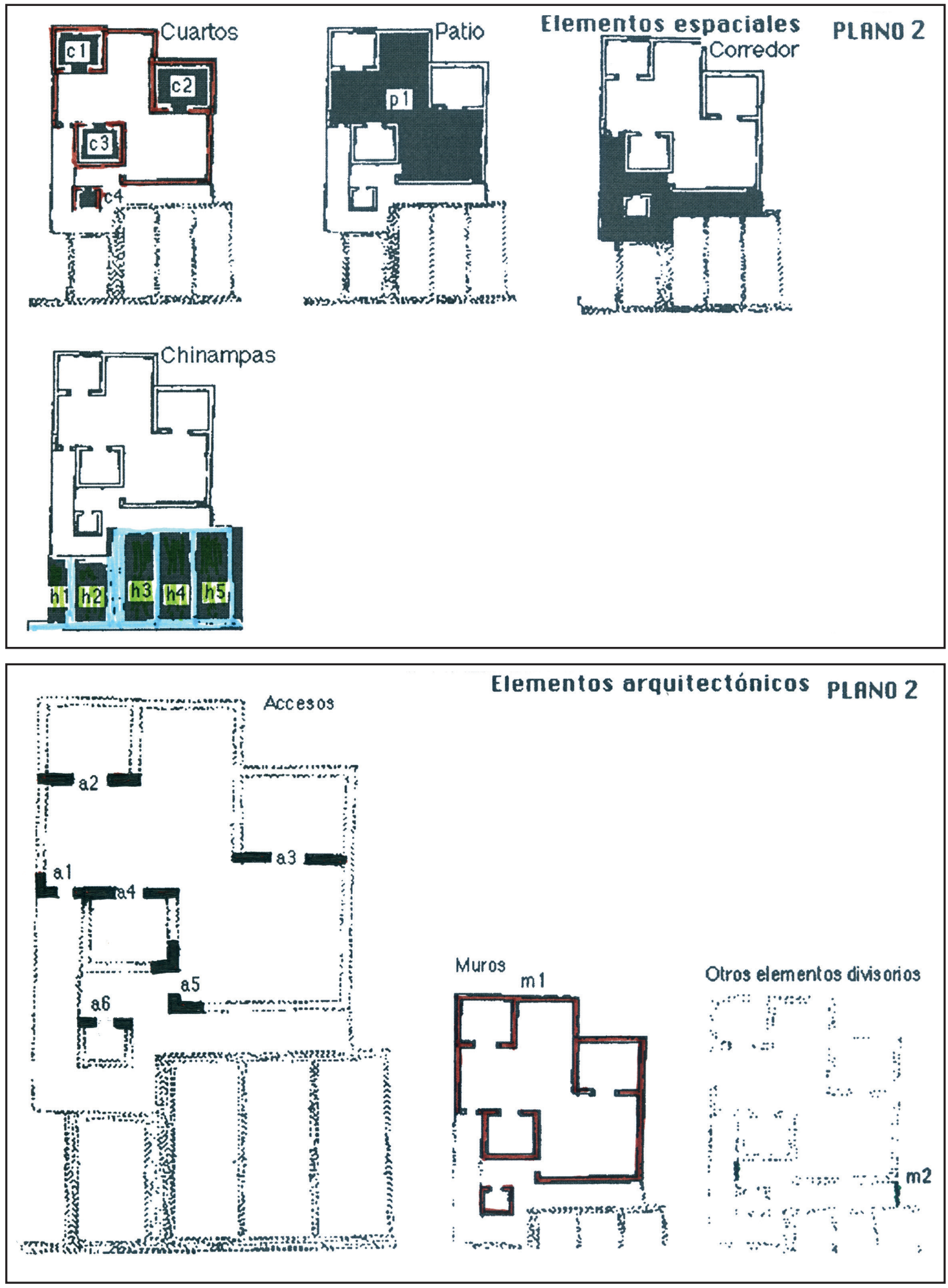

PLANO 3-4. Partes 3 y 4 de la Ficha de Registro del códice-plano. 


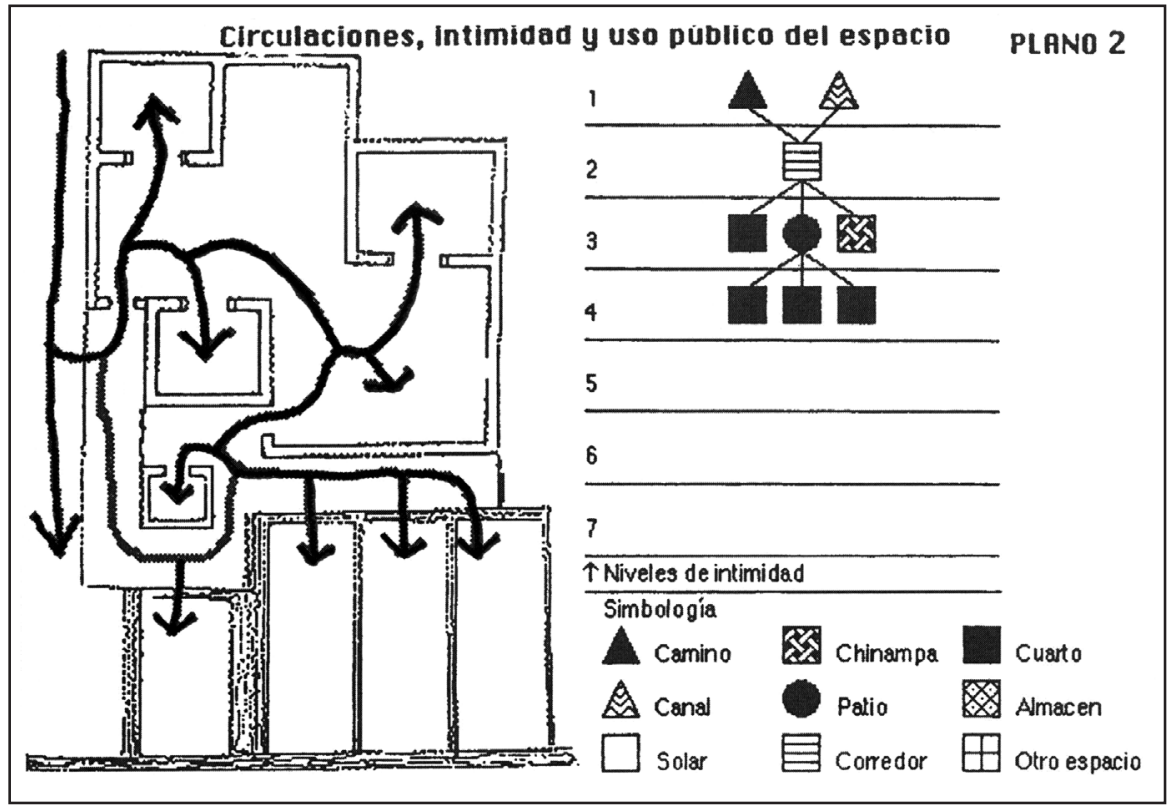

Localización del inmueble: barrio San Juan Tlachquac

Año de venta: 1564

Proceso: Venta de casas, camellines (chinampas) y tierras que doña María de don Diego y don Pedro

Dionisio vendieron a Miguel Popoyotl y su nujer María Tiacapan; y la venta de una casa y un camellón a

las mismas personas por parte de Anton Tlahui.

Doña María de don Diego y don Pedro Dionisio vecinos de San Pablo Teocaltitlan tienen una casa que está hacia donde sale el sol con las siguientes medidas:

por las espaldas: cuatro brazas

por el lado: tres brazas

Tienen tres camellones (chinampas) hacia el occidente de la primera, cada uno tiene de largo catorce brazas por 10 brazas de ancho

La casa de Anton Tlahui tiene su acceso hacia donde sale el sol y mide tres por tres brazas (por las espaldas y el costado) y un camellón a las espalsas que mide cinco y media brazas.

Costo de propiedad: Treinta y un pesos oro. Veinticinco correspondiente a la parte de Doña María y don pedro y seis a la parte de Anton.

Una vez efectuada la venta, los propietarios frente a los testigos, cavaron la tierra con una coa, tomándola y esparciéndola por toda la propiedad en señal de la toma de posesión del predio.

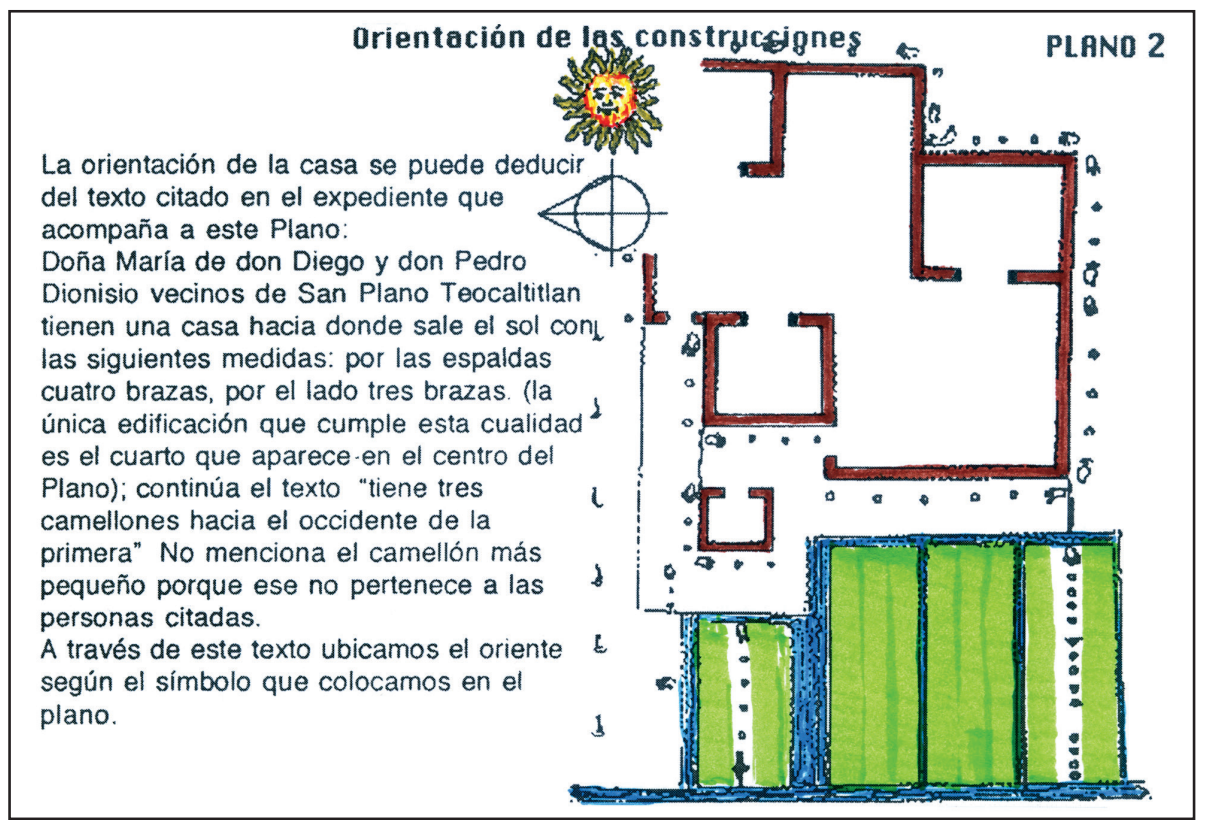

PLANO 3-5. Partes 5 y 6 de la Ficha de Registro del códice-plano.

PLANO 3-6. Parte 7 de la Ficha de Registro del códice-plano. 

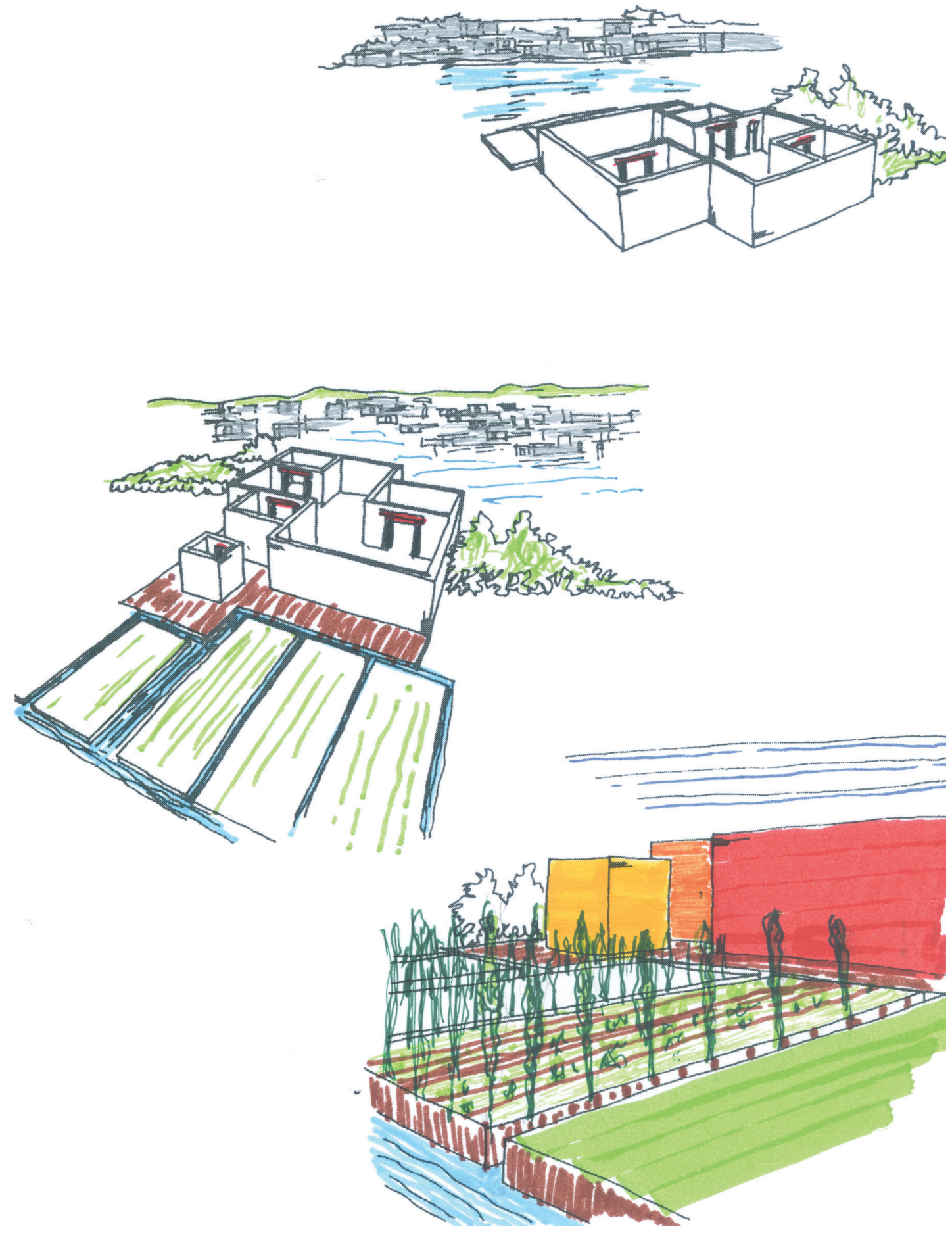

PLANO 3-7. Parte 8 de la Ficha de Registro del códice-plano. 


\subsubsection{LÁMINAS COMPARATIVAS}

Una vez realizada la ficha de registro de cada uno de los códices-planos se hizo la clasificación de los elementos gráficos, para identificar los espacios, su emplazamiento y los elementos constructivos; después la lectura general. De esta manera pudimos identificar los siguientes aspectos:

a. Emplazamiento de la casa con relación al contexto urbano.

b. Elementos espaciales de la casa.

c. Elementos constructivos de la casa.

Con estas definiciones se realizaron un conjunto de láminas comparativas que permitieron también identificar:

a. Las recurrencias de la forma y disposición de los lotes.

b. Las diversidades de cada uno de los espacios.

c. La morfología de los espacios.

d. La variedad de elementos constructivos de la casa.

e. Las representaciones plásticas de cada uno de los elementos.

Con las láminas descritas se pudieron elaborar los siguientes documentos:

a. Catálogo de emplazamiento del lote con relación al contexto urbano inmediato

b. Catálogo de comparación de elementos espaciales

c. Catálogo de comparación de elementos constructivos.

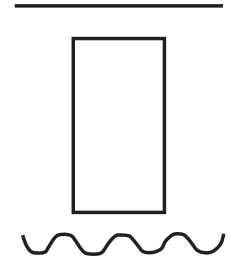

7 casos

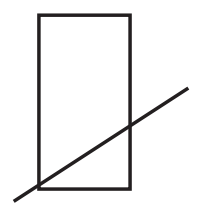

1 caso
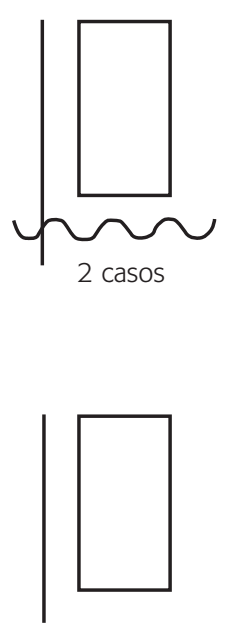

1 caso

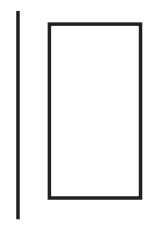

1 caso

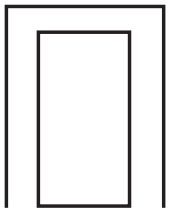

1 caso

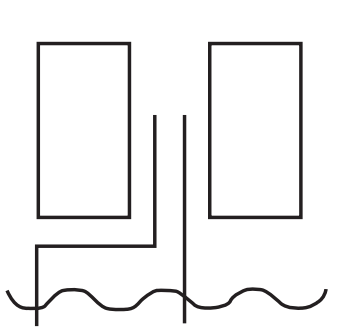

1 caso

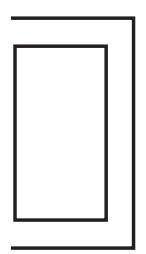

1 caso
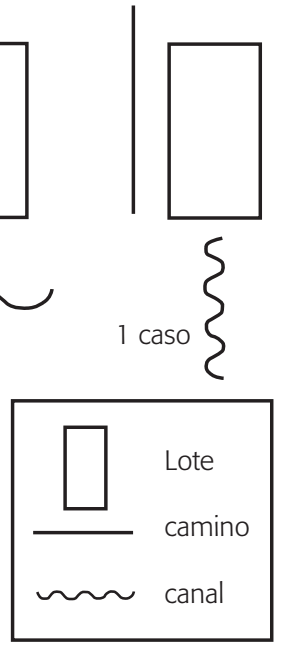

anal

PLANO 3-8. Resumen comparativo de emplazamientos

de las casas con relación a caminos y canales. 


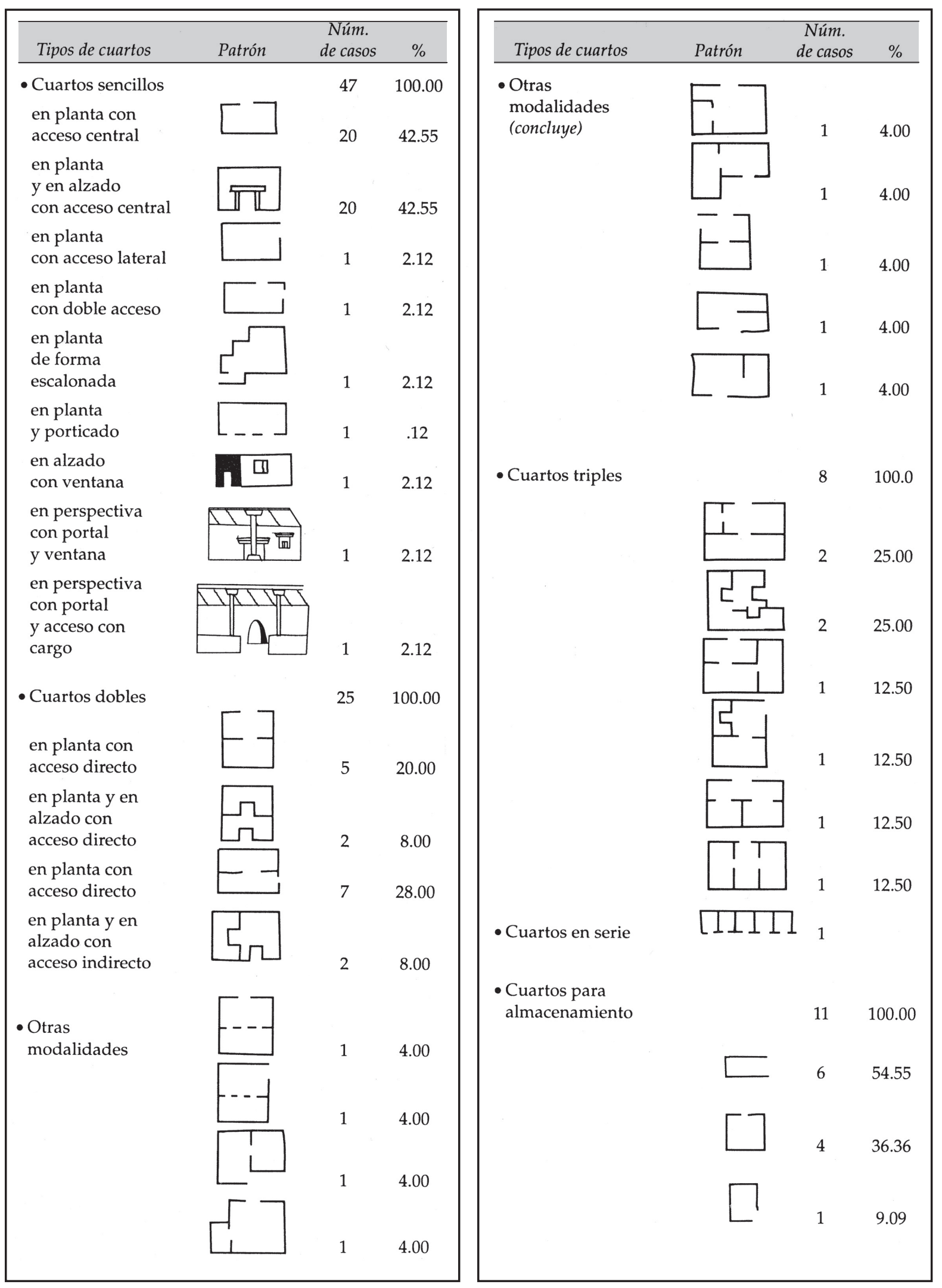

PLANO 3-9. Resumen comparativo de cuartos en 33 casas. 


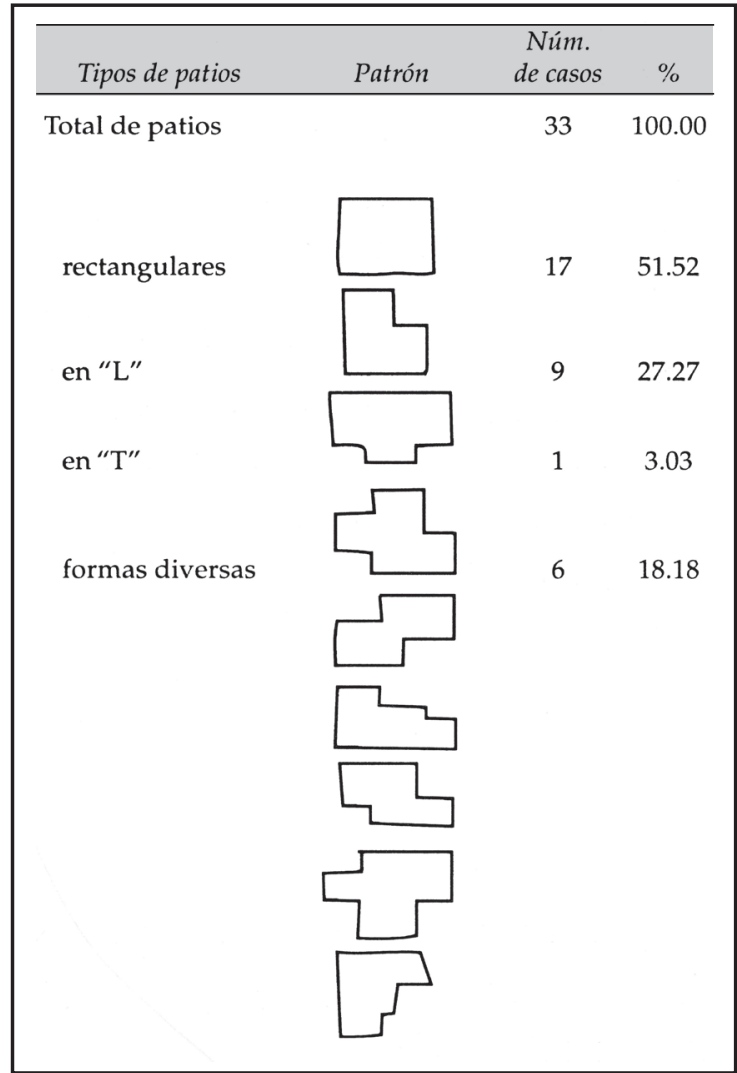

PLANO 3-10. Resumen comparativo de patios en 33 casas.

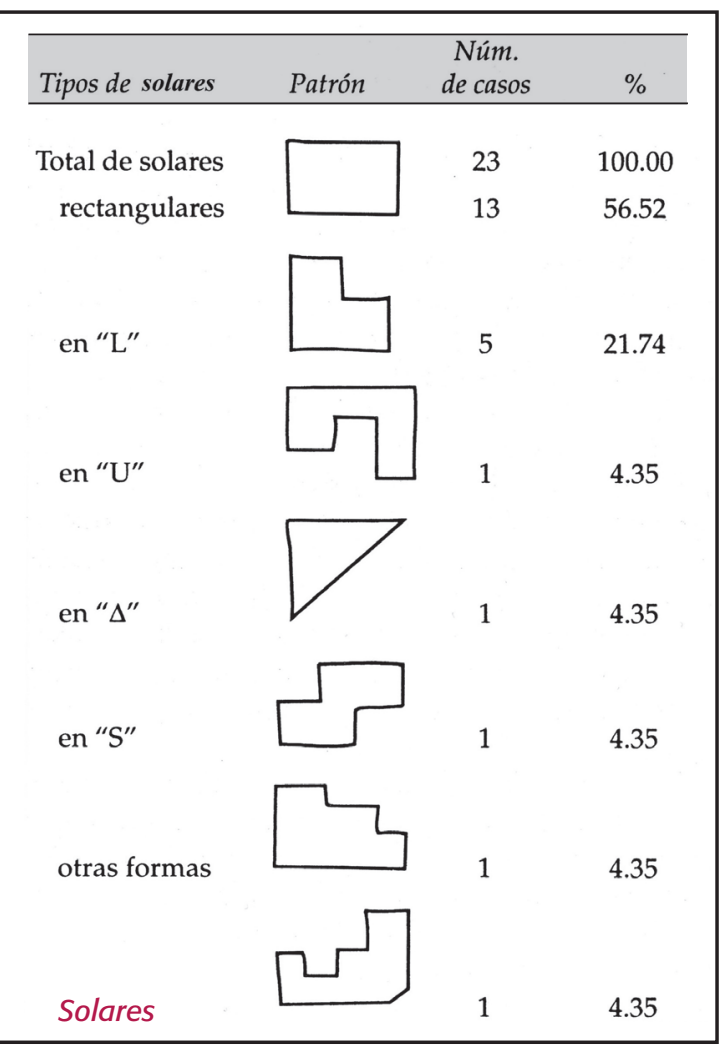

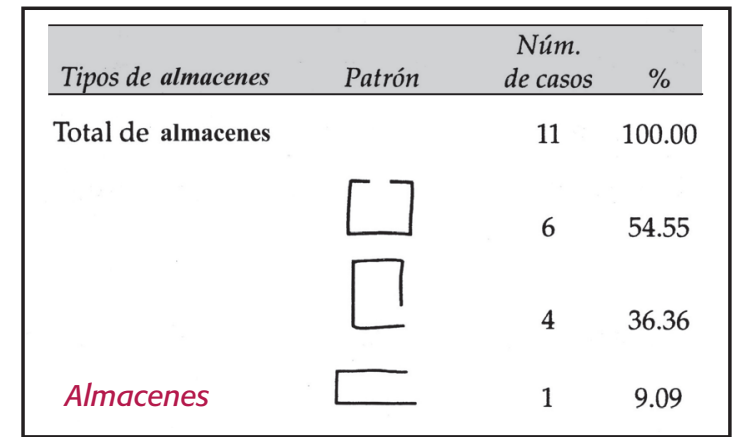

\begin{tabular}{|c|c|c|c|}
\hline Tipos de escaleras & Patrón & $\begin{array}{c}\text { Núm. } \\
\text { de casos }\end{array}$ & $\%$ \\
\hline Total de escaleras & & 4 & 100.00 \\
\hline de un tramo & & 3 & 75.00 \\
\hline de dos tramos & & 1 & 25.00 \\
\hline Escaleras & $\Rightarrow$ & & \\
\hline
\end{tabular}

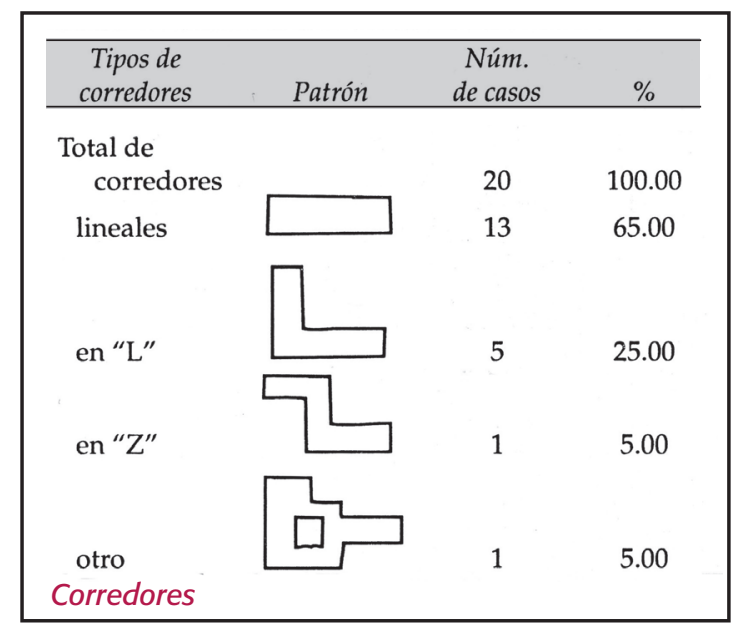

\begin{tabular}{|c|c|c|c|}
\hline $\begin{array}{c}\text { Grupos } \\
\text { de chinampas }\end{array}$ & Patrón & $\begin{array}{l}\text { Núm. } \\
\text { de casos }\end{array}$ & $\%$ \\
\hline Total de grupos & & 13 & 100.0 \\
\hline con 1 chinampa & & 2 & 15.38 \\
\hline con 2 chinampas & & 4 & 30.77 \\
\hline con 3 chinampas & & 4 & 30.77 \\
\hline con 4 chinampas & & 2 & 15.38 \\
\hline $\begin{array}{l}\text { con } 8 \text { chinampas } \\
\text { Chinampas }\end{array}$ & & 1 & 7.96 \\
\hline
\end{tabular}

PLANO 3-11. Resumen comparativo de corredores, solares, chinampas, almacenes y escaleras. 


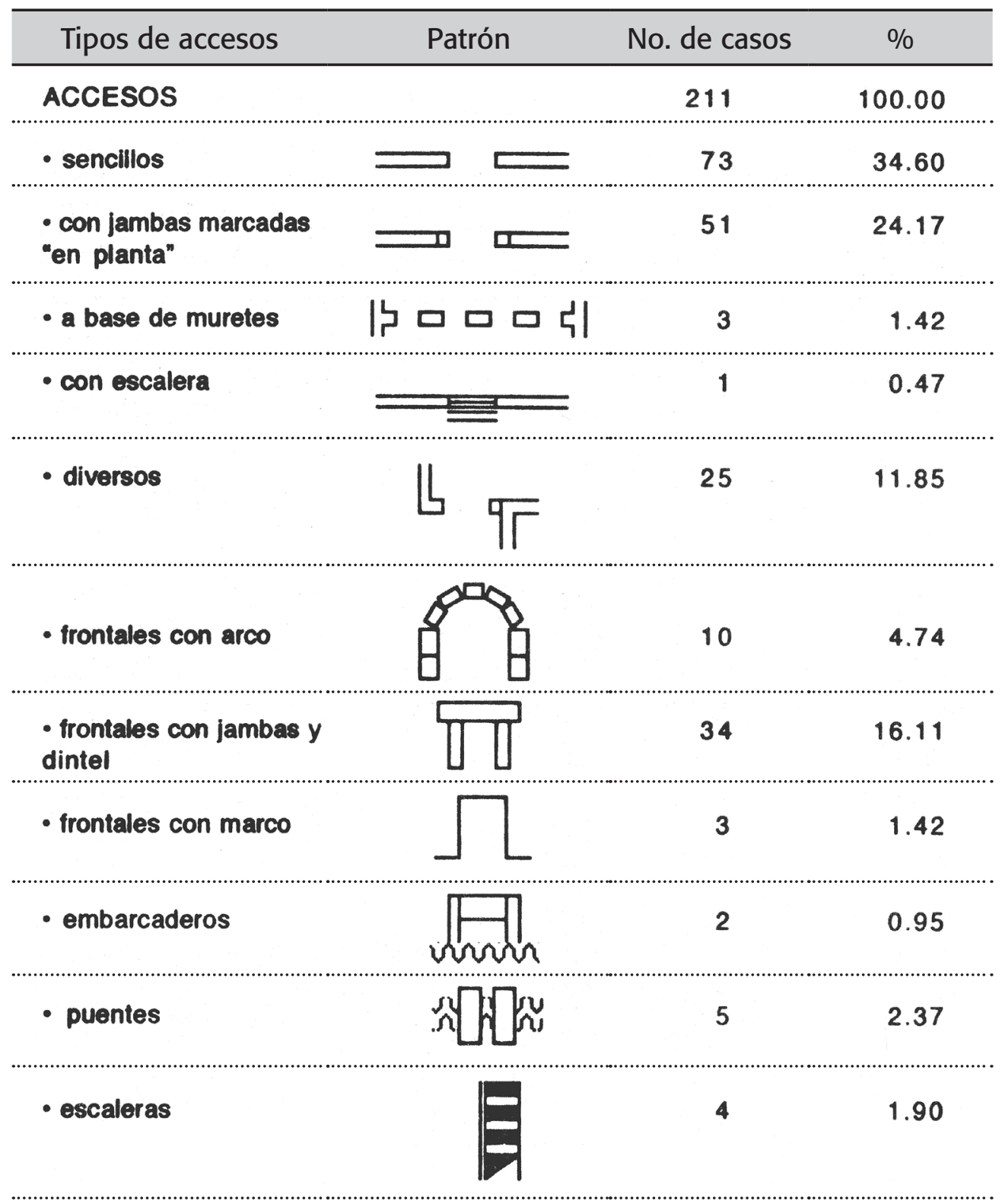

PLANO 3-12. Resumen de elementos constructivos en accesos en 33 casas.

Los catálogos son de gran utilidad para la investigación:

a. Hacen posible la sensibilización, comprensión y sistematización rigurosa del objeto de estudio;

b. Como documento base, para que otros interesados tengan la posibilidad de realizar su propia lectura o bien incorporar nuevos casos para enriquecer los catálogos. 


\subsubsection{LECTURA ARQUITECTÓNICA DEL CORPUS ANALIZADO}

La última etapa en el método que aplicamos consistió en realizar un trabajo relacionado entre las lecturas o interpretaciones individuales y de conjunto acerca del corpus arquitectónico y urbano. Con la lectura aplicada se han generado algunos conocimientos acerca de la ciudad y las casas de tradición azteca en sus características físicas.

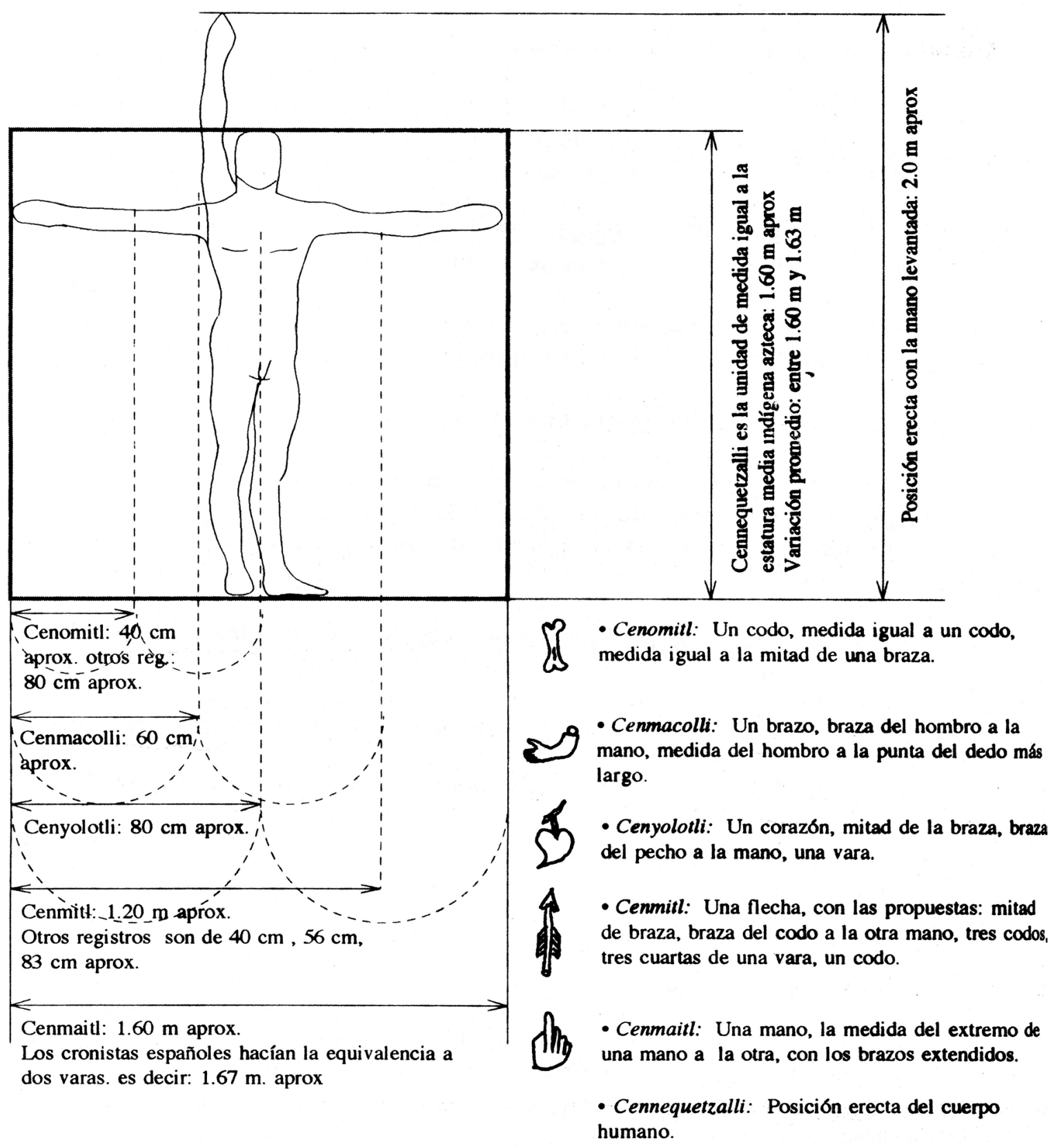

PLANO 3-13. Dibujo con las medidas utilizadas en la casa de tradición azteca; las medidas son antropométricas y por ende son proporcionales entre sí. Se realizó inspirado en el Esquema de proporción humana de Leonardo Da Vinci, el estudio de Marcos Matías de1984 y los análisis y dibujos de JGA. 


\subsection{MÉTOdO PARA LA LECTURA URBANA DEL CÓDICE-PLANO EN PAPEL MAGUEY}

La lectura urbano-arquitectónica de este documento consistió en un conjunto de pasos que permitieron reflexionar y escribir la interpretación del Plano en papel maguey; antes de señalar los pasos del método aplicado, mencionaremos las características del documento que se han publicado.

\subsubsection{ACERCA DEL DOCUMENTO PLANO EN PAPEL MAGUEY}

De acuerdo con el Catálogo de la colección de códices de John B. Glass ${ }^{6}$ se encuentran los siguientes datos acerca del documento:

\section{Plano Parcial de la Ciudad de México}

Plano en papel maguey. Original

Clasificación: Cartográfico. Tenochtitlan-Tlatelolco, D. F., siglo XVI temprano Historia del manuscrito: Colección de Boturini. Núm. 2-30 de los inventarios de 1743 y 1745; núm. VII-15 del catálogo de 1746. Fue exhibido en Londres por Bullock en 1824.

Material y dimensiones: Papel de amate. 238 x 168 cm.

Copias:Existe en la colección la copia hecha a la acuarela sobre cartulina por Adrián Unzueta para la Exposición Histórico-Americana de Madrid (35-3 A).

Una copia con restauraciones de las partes destruidas en el original ha sido reproducida por Marquina (1961). La ubicación de esta copia es incierta, aunque parece haber estado en el Museo Nacional de Antropología e Historia hace algunos años. Podría ser la misma que la que se ha atribuido a Sigüenza y Góngora (Gondra, 1846:10). Una copia sobre lienzo es mencionada por Orozco y Berra (1871: núm. 2159). Se encuentran otras copias mencionadas en las publicaciones que citamos en la bibliografía.

Descripción: El plano muestra una parte de la ciudad indígena de México cruzada por caminos y acequias. Por el margen derecho hay una serie de dibujos de gobernantes indígenas de la ciudad, tanto prehispánicos como coloniales. El más reciente de éstos es Cristóbal de Guzmán, gobernador entre 1557 y 1562. Según el estudio de Robertson, una parte de esta serie de gobernantes es una adición al plano, y por consecuen- 
cia, no se pueden utilizar para determinar la fecha del mismo, probablemente de los años de la época colonial.

El estudio de Toussaint, Fernández y Gómez de Orozco llegó a la conclusión que "el plano corresponde a una fracción de la ciudad indígena, al oriente de Tlatelolco y en el extremo N.E. de lo que fue la antigua isla..."

Bibliografía: Hay una reproducción fotográfica y una litografía a colores de tamaños grandes en Maudsley (1908-1916, tomo III). Estas reproducciones van acompañadas de estudios de Breton y de Seler. Los estudios más detallados sobre el plano son los de Toussaint, Fernández y Gómez de Orozco (1938: 55-84, figs. 5-12) y Robertson (1959: 77-83, láms. 17-19). Ambos contienen reproducciones fotográficas. La primera edición fue la de Bullock (1824 a: 297-300, lám. entre las páginas 532-533). La lámina de Bullock está reproducida por Fernández (1956: fig. 19). Otros estudios menores son los de Barlow (1947 a: 148-155, l-am. E), García Cubas (1909) y Maudslay (1909). Hay una amplia bibliografía de las ediciones del plano en Carrera Stampa (1949: 325-328, lám. III). La copia exhibida en Madrid es descrita por Del Paso y Troncoso (1892-1893).

Por otro lado, de acuerdo con una descripción general de Joaquín Galarzaaํ observa lo siguiente:

"El Plano en papel maguey fue realizado en un estilo prehispánico innegable se representan los detalles topográficos de los terrenos, chinampas y construcciones de una parte de considerables dimensiones de una sección de la Tenochtitlan indígena (conservada tal vez en los primeros años de la época colonial). Por sus características tradicionales se puede observar que en su composición confluyen los elementos y las bases de la convención plástica prehispánica: vista de planta para todos los elementos situados en la superficie de la tierra (canales, terrenos y chinampas): vistas de frente y de perfil las construcciones religiosas y civiles. Grandes y pequeños templos, palacios y residencias de principales, habitaciones de familias de agricultores, elementos que aunados a los canales y campos de cultivo y chinampas, serían suficientes para que el documento cumpla con la definición de plano en el sentido europeo de la palabra. Pero, contiene una riqueza temática mucho mayor que un simple plano en su definición eurocentrista. Este plano indígena contiene la información de los personajes que vivían en cada división de terrenos con chinampas, con sus nombres en glifos antroponímicos. En un gran espacio se escribió la genealogía o relato cronológico del gobierno de los señores indígenas en Tenochtitlan, desde 


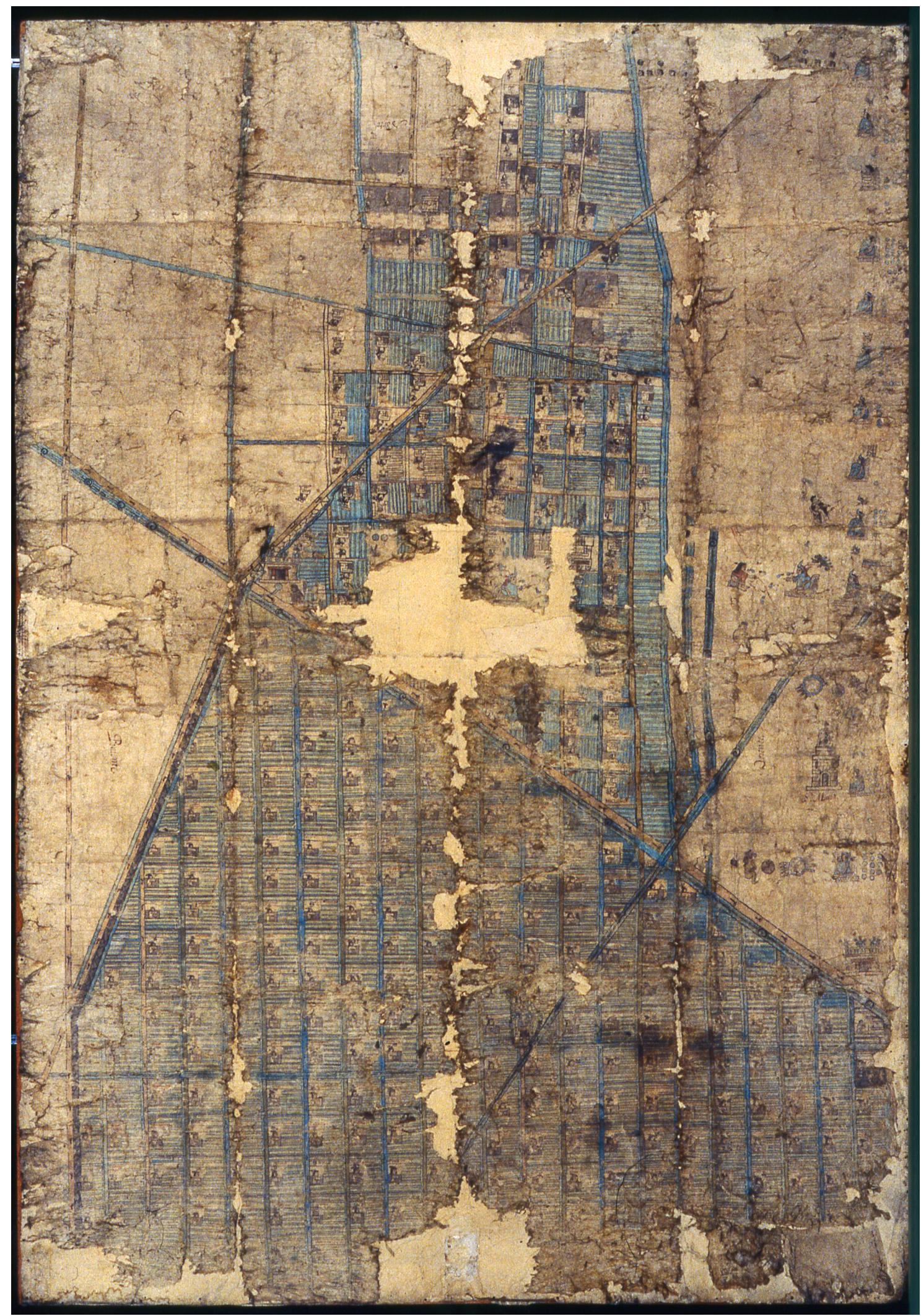

PLANO 3-14. Códice Plano en papel maguey, Biblioteca Nacional de Antropología e Historia, Cámara de Códices. 
la época prehispánica hasta los tiempos de la Colonia. Ya en sus temas principales

este plano indígena es a la vez plano, catastro y censo, además de relato histórico del gobierno indígena de esta gran ciudad."

\subsubsection{MÉTODO DE ANÁLISIS PARA LA LECTURA URBANA Y ARQUITECTÓNICA DEL PLANO EN PAPEL MAGUEY}

Los pasos que realizamos durante esta investigación fueron los siguientes:

1. Se realizó una revisión del método aplicado por J. Galarza en lo referente a mapas y planos indígenas y se tomaron aquellos elementos importantes para la lectura de los componentes urbanos.

2. Se realizaron diversos conjuntos fotográficos en diapositivas, negativos e impresiones profesionales del Plano completo y en 16 partes de éste para la observación de los detalles de la imagen.

3. Se elaboraron varios conjuntos de planos descriptivos y analíticos que permitieron clasificar los elementos urbanos identificados en el original a través de las fotografías señaladas. Para la elaboración de cada conjunto de planos se hizo lo siguiente:

a. Identificación de cada uno de los usos del suelo, edificaciones y obras registradas en esa parte de la ciudad.

b. Agrupación de elementos urbanos o arquitectónicos con características afines y similares.

c. Clasificación de los temas urbanos identificados

d. Codificación de los elementos clasificados

4. Elaboración de láminas o planos finales con los siguientes aspectos:

a. Zonificación

b. División predial

c. Obras hidráulicas en el plano

i. Albarradón o dique

ii. Canales principales

iii. Canales secundarios

iv. Canales terciarios

v. Ojo de agua o manantial

vi. Caminos de agua

d. Sistema vial terrestre

e. Caminos interurbanos primarios 
i. Caminos interurbanos secundarios

ii. Caminos primarios

iii. Caminos secundarios

iv. Caminos vecinales

v. Caminos atípicos

f. Chinampas para la agricultura intensiva

g. Orientación solar de las construcciones

h. Edificios prehispánicos

i. Edificios de tradición europea

j. Elementos constructivos

5. Lectura analítica e interpretativa tomando en consideración la temática urbana y arquitectónica observada en cada uno de los planos finales realizados.

6. Lectura crítica de textos seleccionados por el autor que hicieran referencia al urbanismo y la arquitectura del siglo XVI en la Ciudad de México, para observar y diferenciar las posturas teóricas de la producción edilicia indígena y redactar un capítulo que le diera contexto a la investigación.

A continuación se presentan algunas láminas para la identificación y lectura de los elementos urbanos de esa parte de la ciudad azteca. 


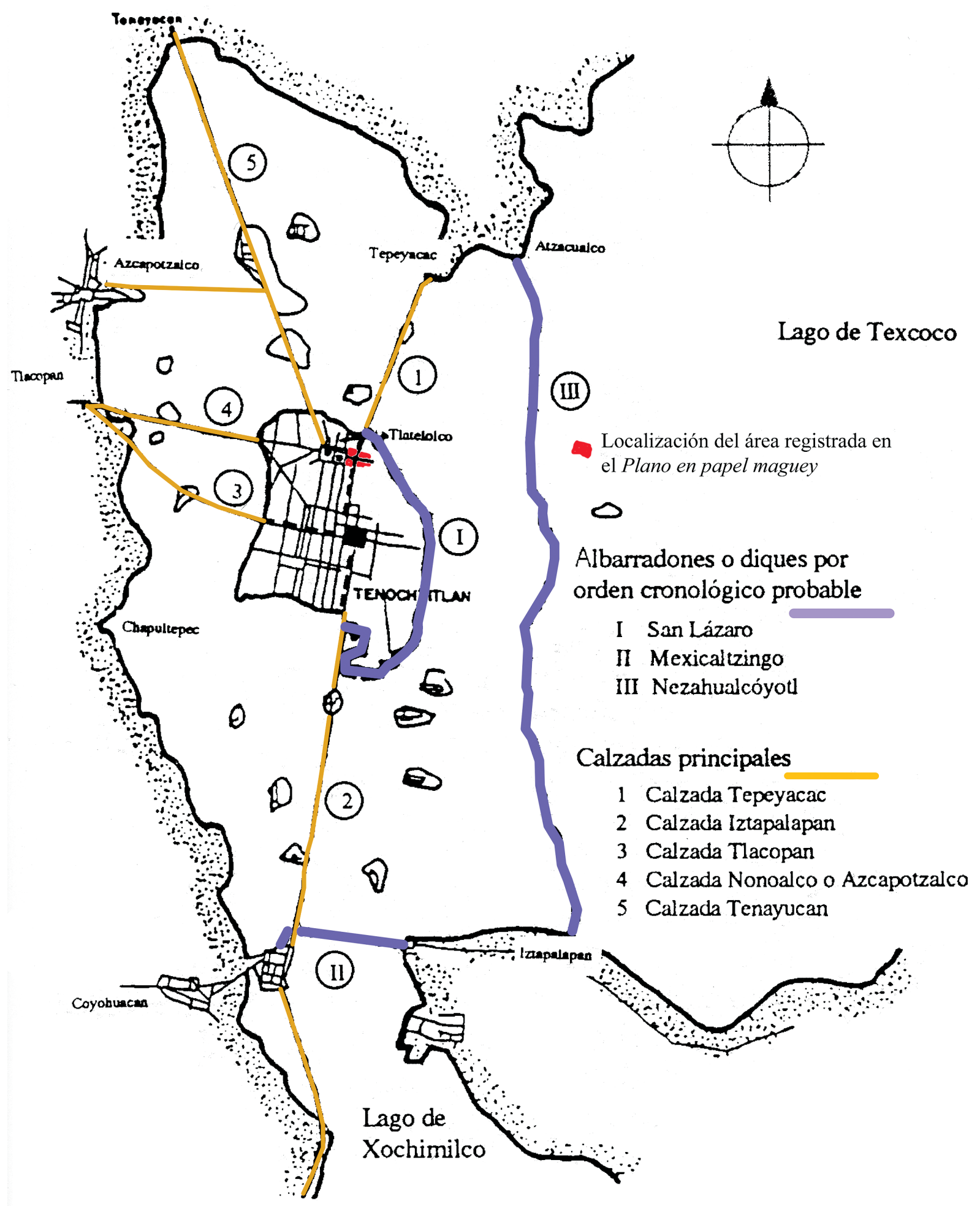

PLANO 3-15. La Isla de Tenochtitlan en la Zona Lacustre y la ubicación

en que se encontraba la parte de la ciudad registrada en el Plano

en Papel Maguey. 


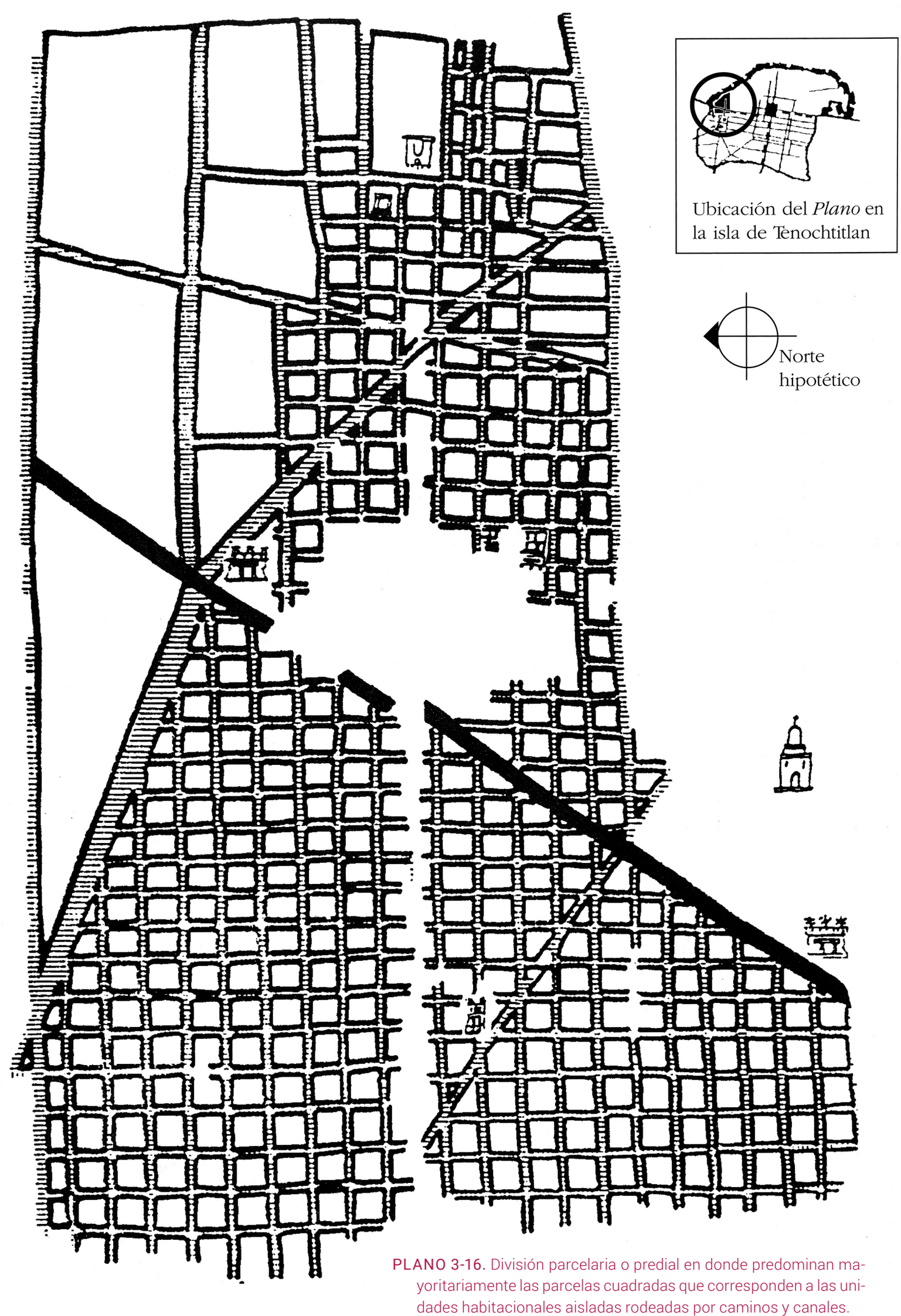




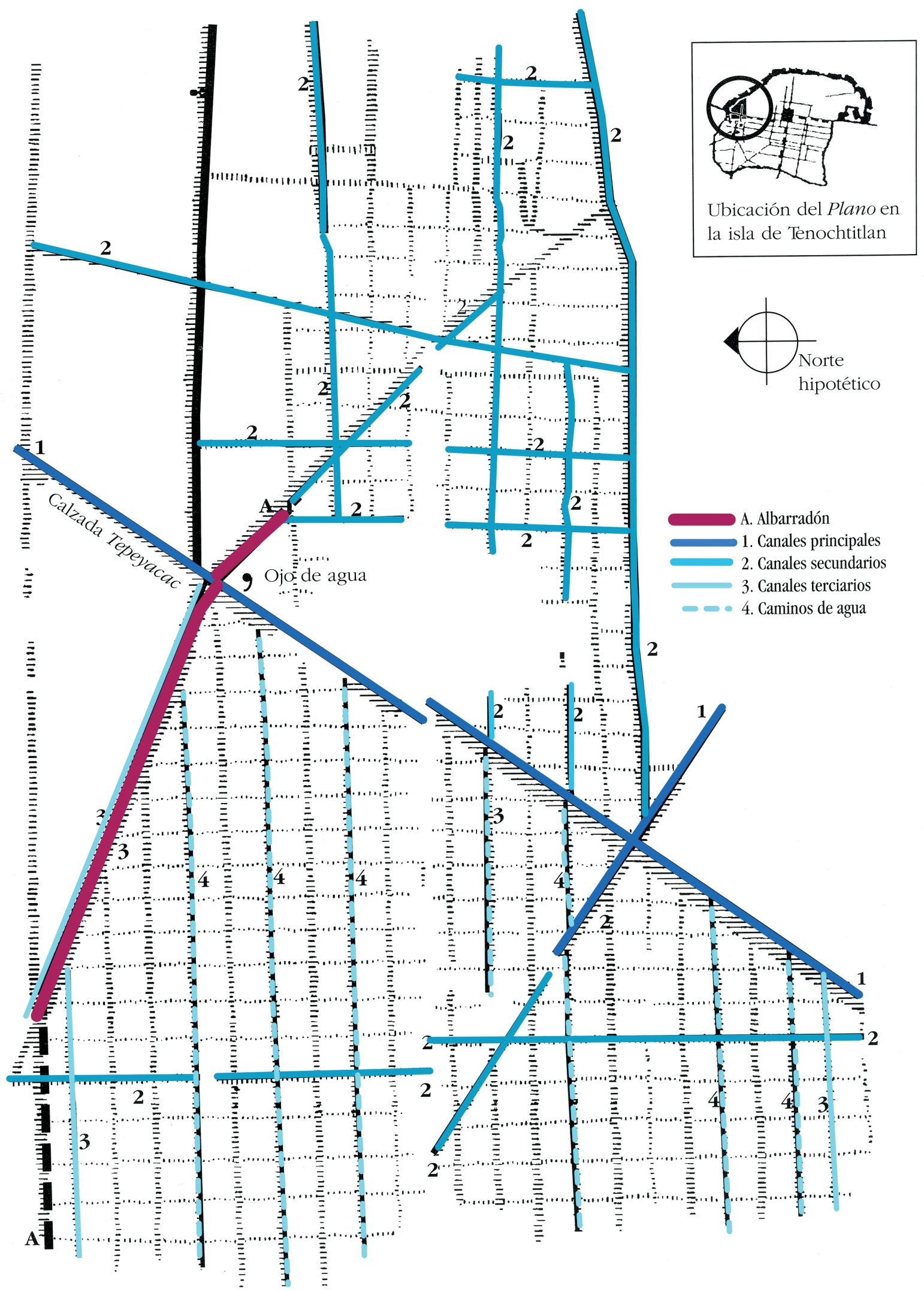

PLANO 3-17. Clasificación y localización de las obras hidráulicas de la ciudad. 


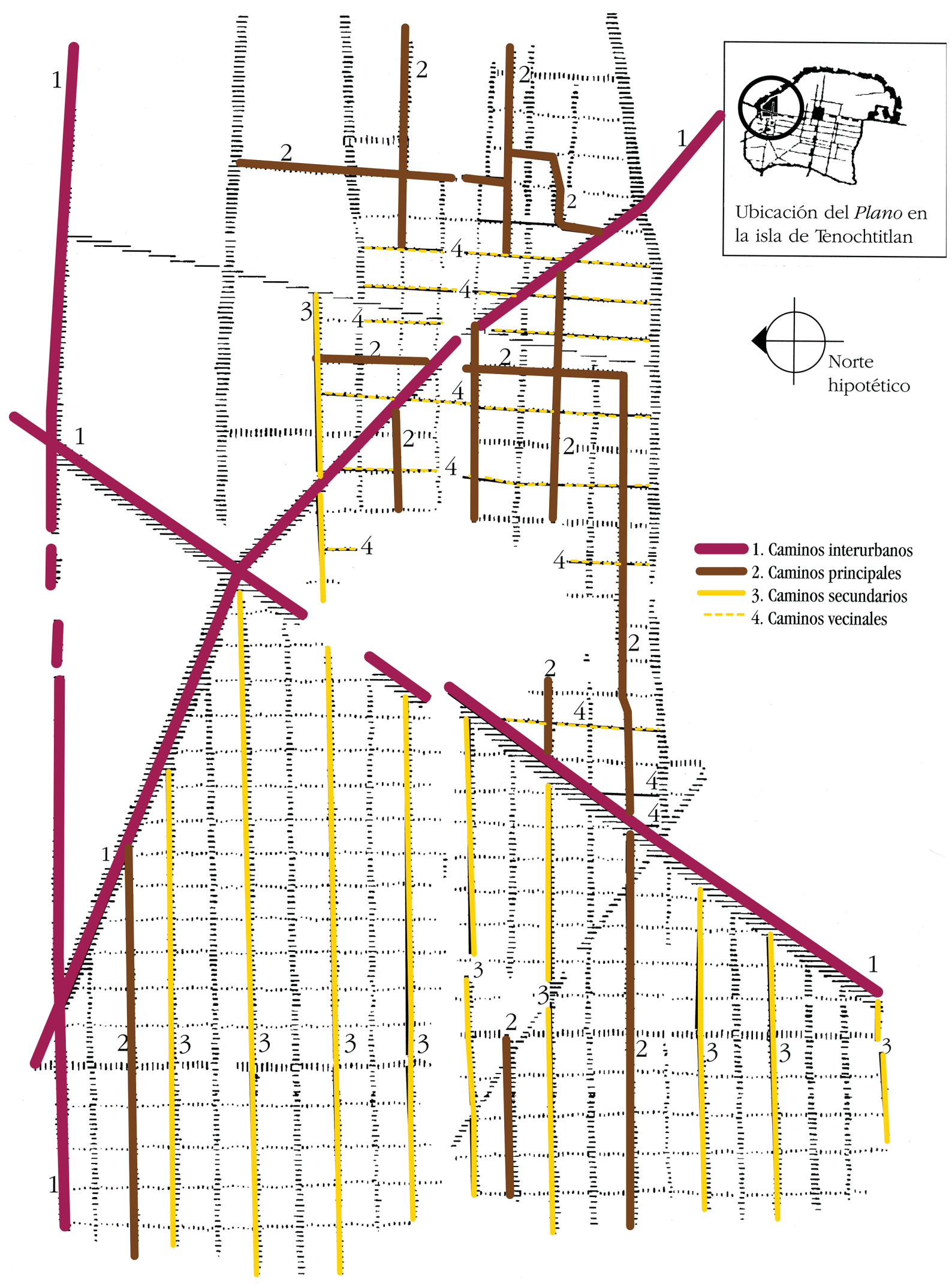

PLANO 3-18. Plano destacando los diferentes tipos de caminos. 


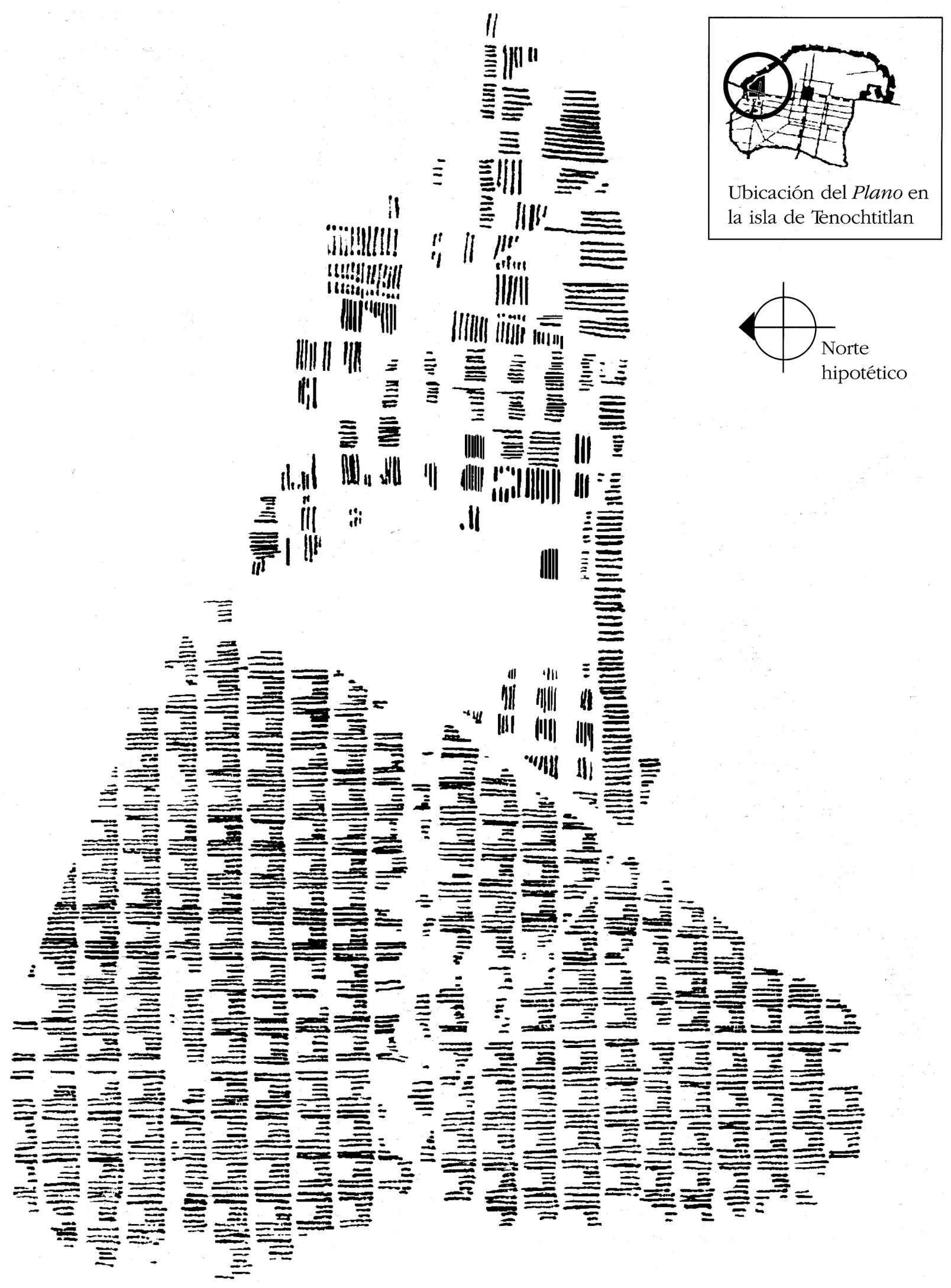

PLANO 3-19. Las chinampas (porciones de terreno

dentro del lago para la agricultura intensiva). 


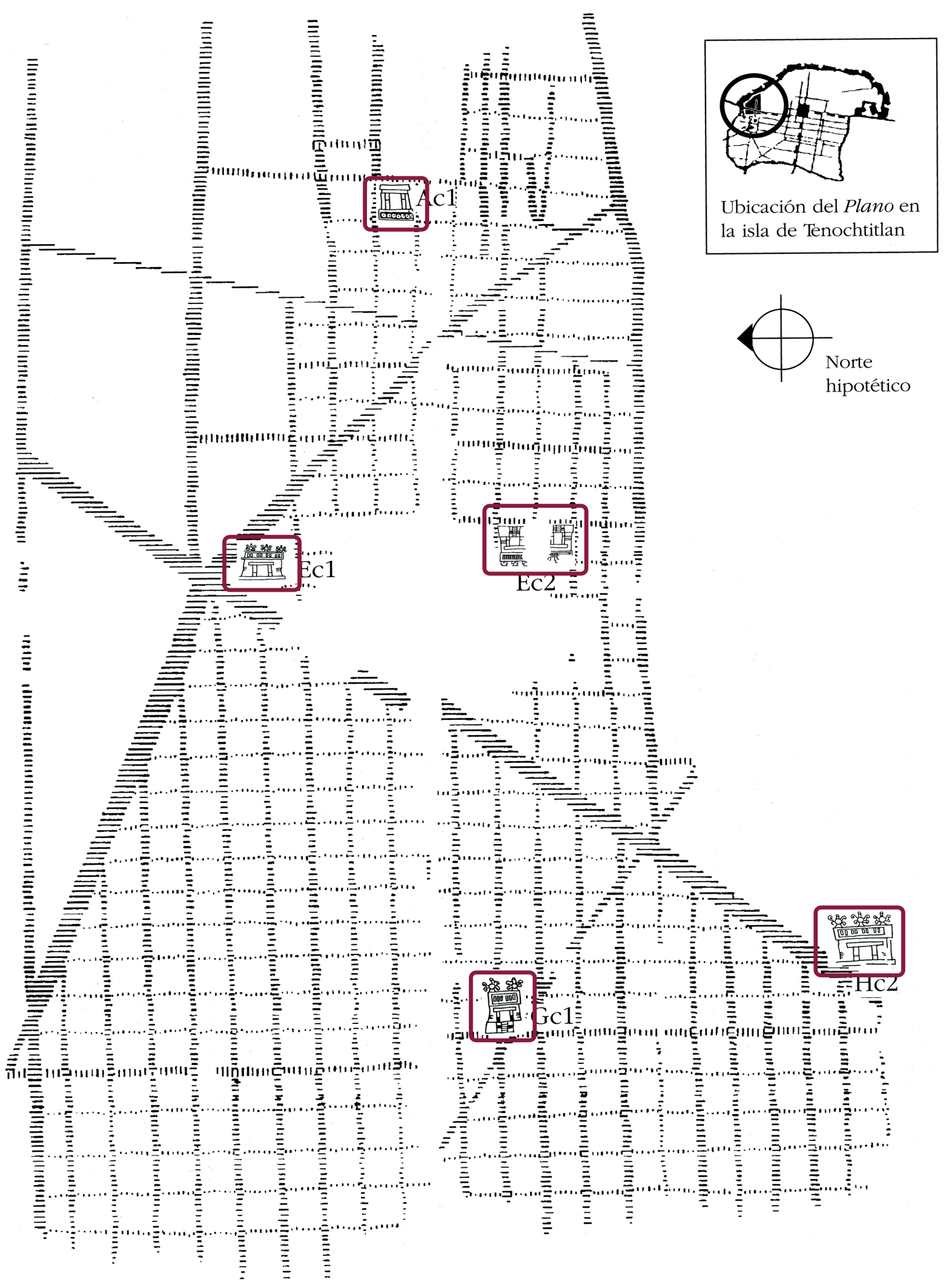

PLANO 3-20. Edificios de culto indígena (Ec1, Ec2, Gc1 y Hc2) y casa de un noble indígena llamada en lengua nahuatl Tecpancalli (Ac1). 


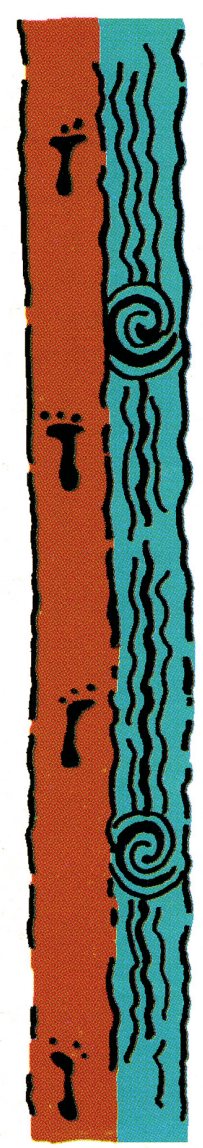

$\mathbf{a}$

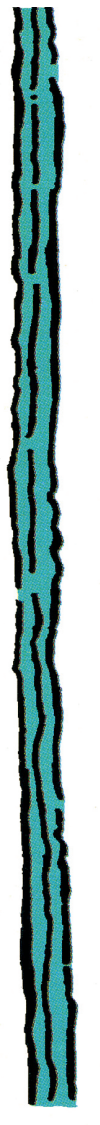

b

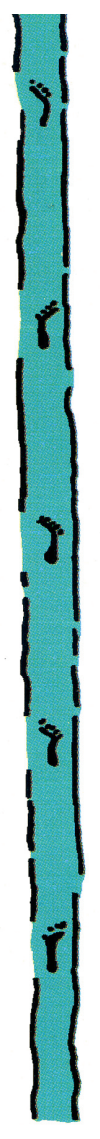

c

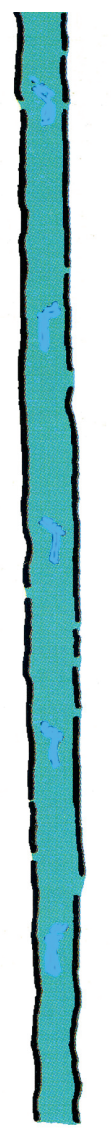

d

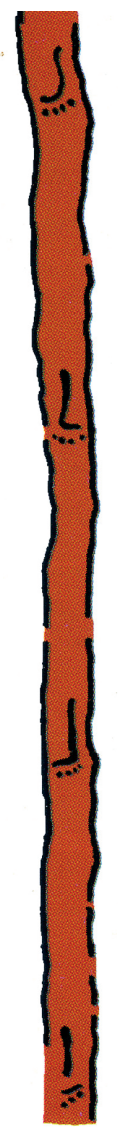

e

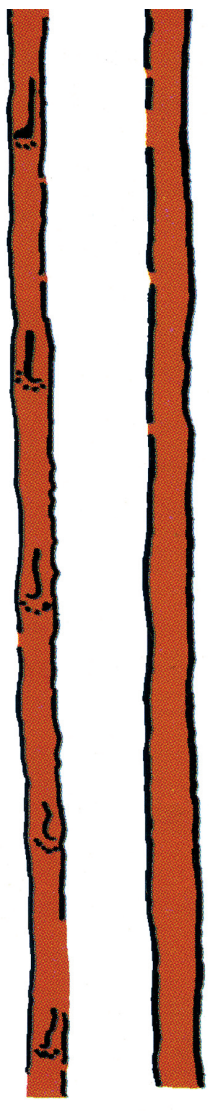

g

a. Camino interurbano-canal principal

b. Canal secundario

c. Camino de agua

d. Canal terciario

e. Camino interurbano

f. Camino primario

g. Camino secundario

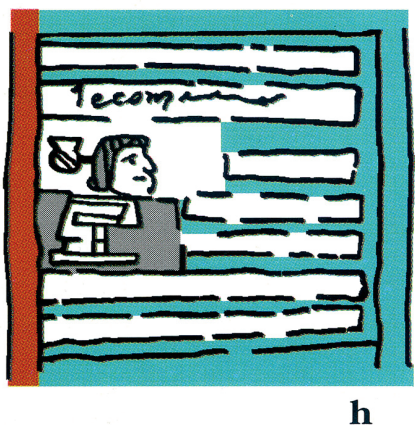

Unidad habitacional típica con canales, camino, chinampas, solar, el glifo de la casa y el glifo del propietario del predio con su antropónimo en la convención indígena y en caracteres latinos
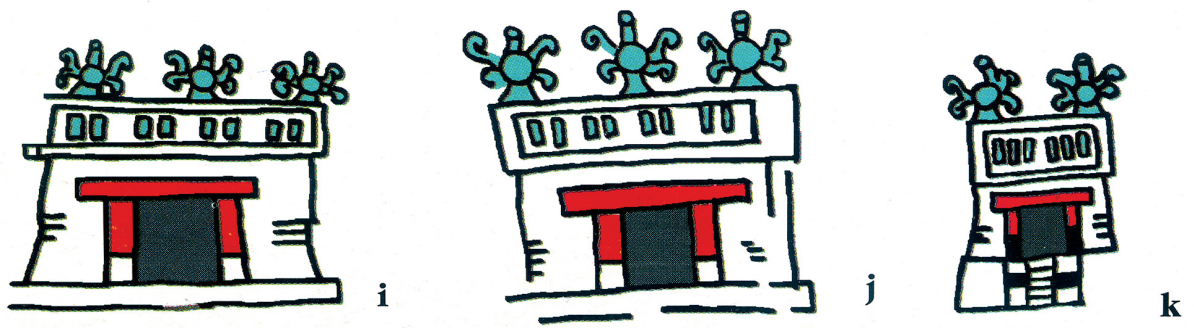

Templos con coronamientos de espejos humeantes de color azul tuquesa (Xiub Tezcatlipoca) 


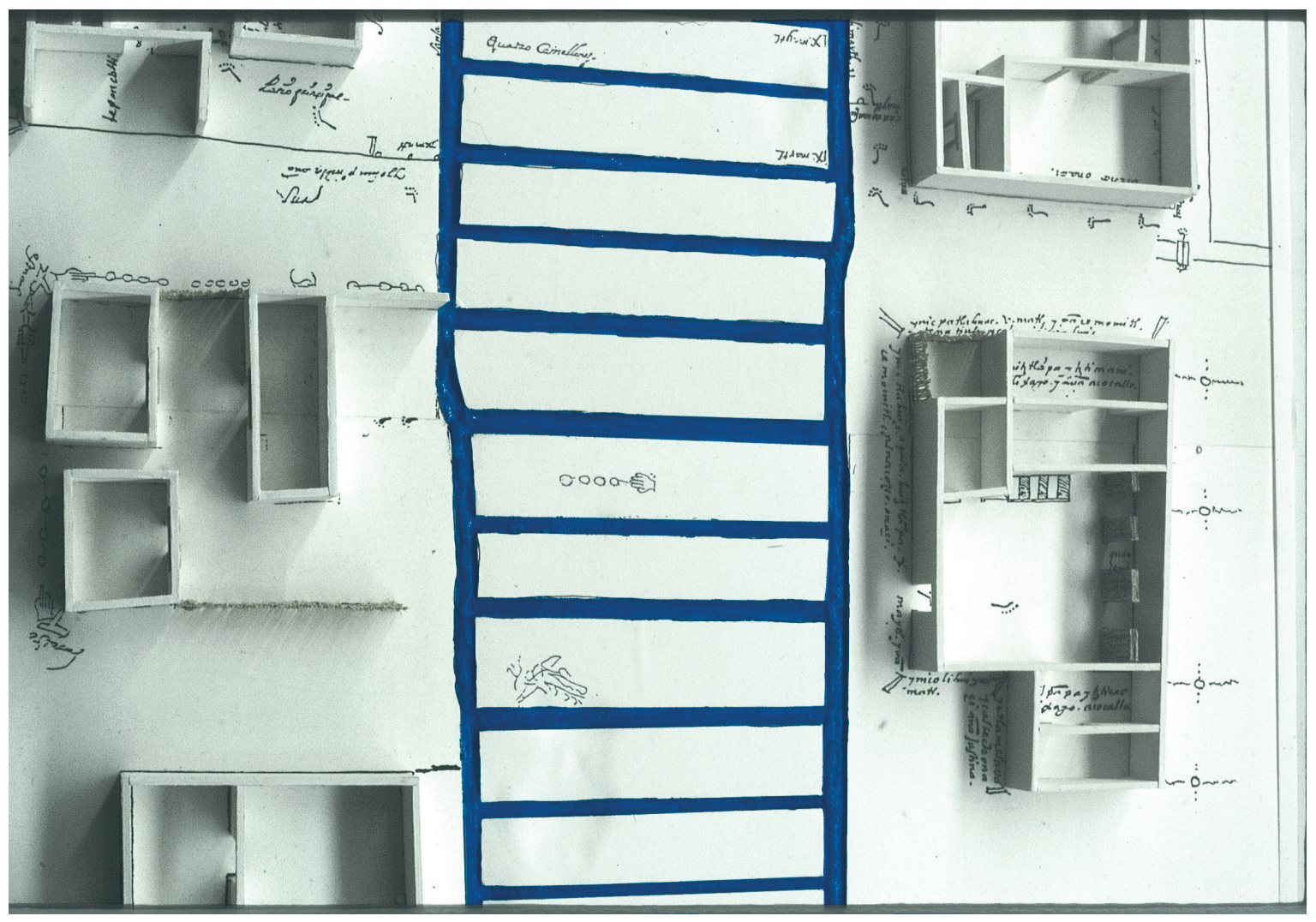

PLANO 3-22. Maqueta Recreación de un barrio azteca, Detalle. Museo Nacional de Arquitectura, INBA, 1995. 


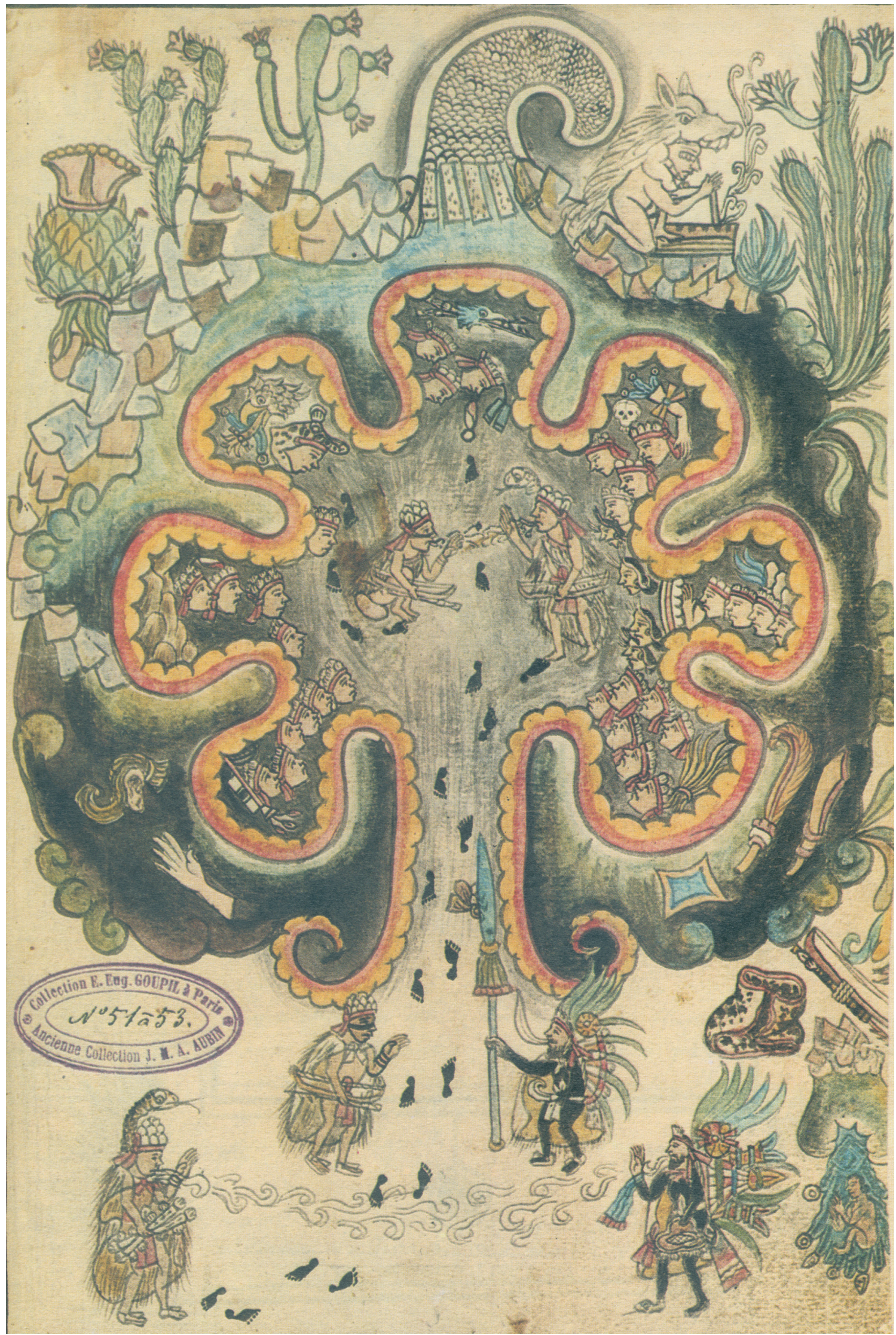




\section{Preexistencias urbanísticas en la región Puebla-Tlaxcala}

La ciudad de Puebla en la Nueva España forma parte del primer corredor regional comercial y socioeconómico entre la Ciudad de México, Puebla y Veracruz; la microrregión cuenta con características significativas que fueron tomadas en consideración por las autoridades en la etapa de su fundación: es decir, las conveniencias de asentarse en un lugar cercano a su principal aliado militar indígena: Tlaxcala. Este era un lugar con pueblos de indios que era fundamental para la protección de la comunidad y la nueva ciudad europea, la edificación, la fuerza de trabajo productiva en el campo y la ciudad, así como el servicio doméstico para la comunidad española. De hecho esta condición se observa también en la delimitación de los barrios alrededor de la traza española donde, en general, cada uno de ellos está asociado con el origen de sus pobladores indígenas.

De gran importancia son estos factores que definen la ciudad histórica de Puebla en su contacto inmediato con otros asentamientos de origen prehispánico en la microrregión, pues son determinantes en la prefiguración del crecimiento futuro de la ciudad.

En el análisis hecho por Manlio Barbosa (1994) del Códice Historia Tolteca-Chichimeca (Biblioteca Nacional de Paris) y otros documentos históricos y recientes de Puebla, éste señala que en torno a la fundación de la ciudad de Puebla hay muchas incongruencias en los datos acerca del año de su fundación; relata que se trató de un proceso de poblamiento español en tierras habitadas por indios que comenzó probablemente en 1523 y se consolidó como asentamiento humano con actividades económicas y políticas autosuficientes hacia 1545. Dice que las antiguas tierras de Cuetlaxcoapan y sus alrededores estaban habitadas por naturales, como se puede comprobar en el Códice 
citado. Por su parte Gonzalo Yanes elaboró una revisión bilbliográfica para ubicar los asentamientos humanos prehispánicos que estaban establecidos en la región en que se fundó esta ciudad. Con base en estos trabajos se presenta la relación de los principales lugares indígenas, poblados antes y durante la fundación oficial de ésta en 1531.

En la siguiente descripción identificamos los principales pueblos agrupados de acuerdo con la importancia económica y poblacional, que se encuentran más cercanos al antiguo Valle de Cuetlaxcoapan (el asiento de la Ciudad de Los Ángeles, posteriormente denominada Puebla de Los Ángeles):

\begin{tabular}{|c|c|}
\hline \multicolumn{2}{|c|}{$\begin{array}{c}\text { Cuadro 3.1 Pueblos prehisánicos asentados alrededor del sitio elegido } \\
\text { para la fundación de la Ciudad de Puebla }\end{array}$} \\
\hline $\begin{array}{c}\text { Pueblos } \\
\text { prehispánicos }\end{array}$ & Ubicación \\
\hline Centepetl & $\begin{array}{l}\text { En el antiguo cerro Centepetl o San Juan, actualmente Cerro de la } \\
\text { Paz, al poniente de la ciudad }\end{array}$ \\
\hline Xilotzingo & Actualmente colonia del mismo nombre, al sur de la ciudad \\
\hline Tepoxocho & En el cerro del Tepoxuchitl, al oriente de la ciudad \\
\hline Xonacatepec & $\begin{array}{l}\text { Barrio de la ciudad colindante con el municipio de Amozoc, al } \\
\text { noreste de la ciudad }\end{array}$ \\
\hline $\begin{array}{l}\text { Totomihuaque o } \\
\text { Totimehuacan }\end{array}$ & Al sur de la ciudad, en el pueblo actual del mismo nombre \\
\hline Cuauhtinchan & En el pueblo actual del mismo nombre, al oriente de la ciudad \\
\hline Tepeaca & En el pueblo actual del mismo nombre, al oriente de la ciudad \\
\hline Cholula & Ciudad prehispánica al poniente de la de Puebla \\
\hline Huejotzingo & Pueblo al poniente de la ciudad \\
\hline Calpan & Pueblo al poniente de la ciudad \\
\hline Cuauhquecholac & $\begin{array}{l}\text { Pueblo al suroeste de la ciudad, actualmente cerca de la ciudad de } \\
\text { Atlixco }\end{array}$ \\
\hline Tlaxcala & Al norte de la ciudad \\
\hline
\end{tabular}

En la lista anterior sólo destacamos los principales poblados de la región.

Desde la perspectiva regional, la ciudad de Puebla posibilita su consolidación económica a través de:

1. Paul Kirchkof en 1943 define a Mesoamérica como una amplia región cultural que va desde los ríos Sinaloa y Pánuco en el centro-norte de México al río Motagua en Guatemala y el Golfo de Nicoya en Nicaragua en la época de contacto de los conquistadores con el territorio americano. 


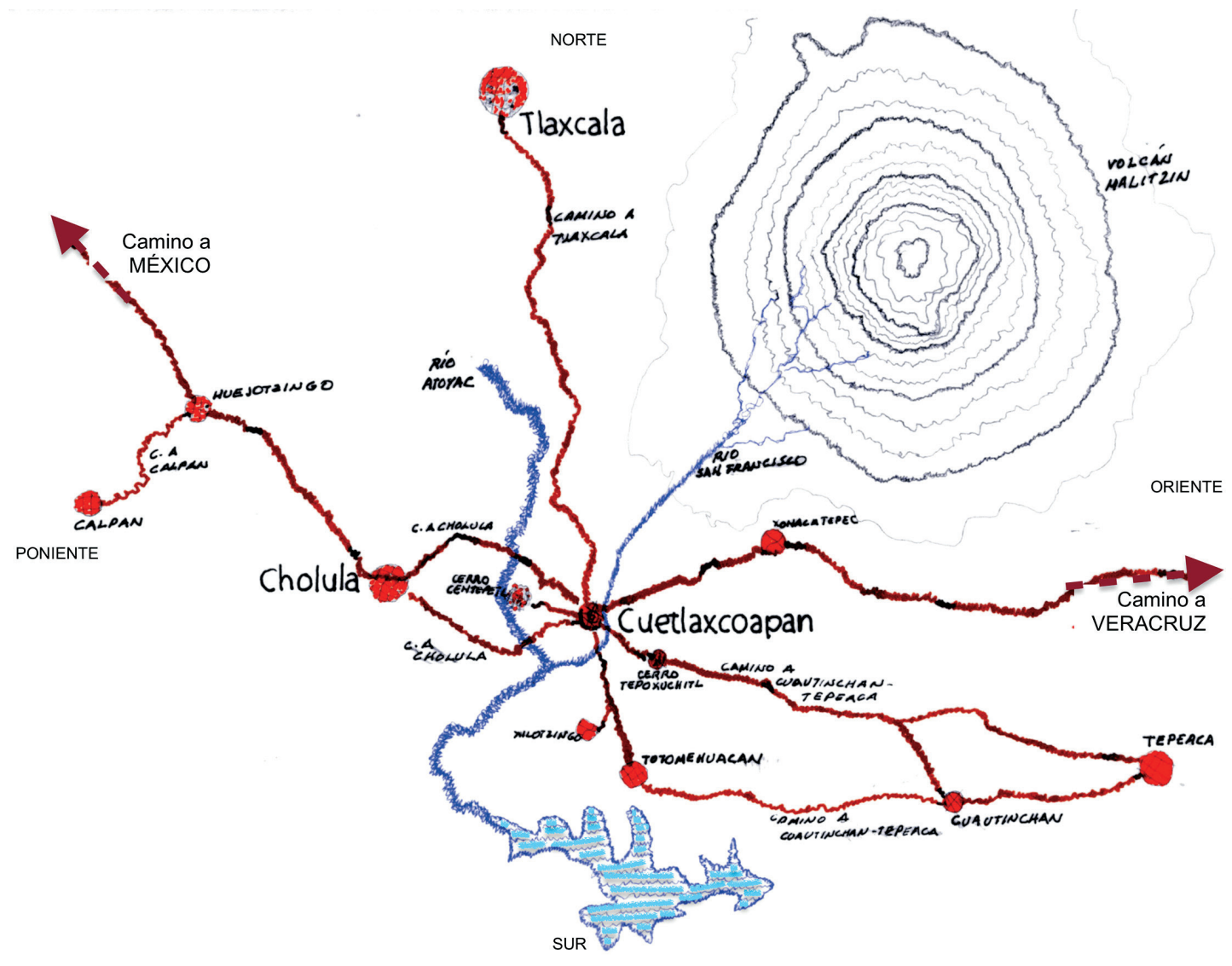

PLANO 3.1. Pueblos prehispánicos y sitios existentes antes de la fundación de la Ciudad Los Ángeles; es importante señalar que se asentó en el lugar conocido como Cuetlaxcoapan, en el intersticio de los principales pueblos indígenas de la región: Tlaxcala, los aliados de los conquistadores; Cholula; Tepeaca, el gran mercado regional de la época; Totomehuacan, los antiguos propietarios de los territorios en que se asentaría la nueva ciudad; Cuautinchan, Huejotzingo y Calpan. Sin duda el asentamiento se realizó con el consenso o la sujeción de las diferentes etnias que habitaron los pueblos citados y en un lugar geográfico excepcional por sus recursos naturales y las características específicas que anotaremos más adelante.

i. Las redes comerciales establecidas previamente, tal es el caso de la cercanía con Tepeaca, uno de los mercados más importantes de la antigua Mesoamérica; ${ }^{1}$

ii. La explotación agrícola en una amplia región culturalmente consolidada en este renglón;

iii. La formación de nuevos pueblos para congregar a los indígenas y control de la explotación de su trabajo y la transición al espiritualismo cristiano;

iv. Las encomiendas, es decir, la asignación de indios para el servicio o el tributo al encomendero, el cual recibió la merced Real de explotación de un territorio y sus habitantes para su beneficio personal;

v. Los acuerdos con los caciques indígenas tlaxcaltecas asociados al nuevo orden español, que permitieron las alianzas para combatir a los pueblos y grupos de indios sublevados y utilizaron las formas de organización precedentes a la novohispana para la producción y el tributo recaudado por el nuevo gobierno. 


\subsection{LA REGIÓN PUEBLA-TLAXCALA EN EL SIGLO XV²}

La investigación de Dyckerhoff nos ofrece un panorama del desarrollo cultural y comercial de la región y las diversas guerras, alianzas y dominio del territorio que los colocó como uno de los grupos guerreros más importantes de Mesoamérica durante los siglos xv y xvi de nuestra era.

A partir de mediados del siglo xv los desenvolvimientos políticos en el Valle de Puebla-Tlaxcala fueron considerablemente determinados por el exterior, por las aspiraciones expansionistas de la Triple Alianza del Valle de México [mexicas, tepanecas y acolhuas]. Estas tendían, bajo el señor mexicano Motecuhzoma Ilhuicamina (1441-1469), a conquistar o dominar las rutas comerciales más importantes que conducían a las tierras bajas tropicales del sur y sudeste de México, y naturalmente debían de llevar a una confrontación con los señoríos de la región Puebla-Tlaxcala, los cuales colindaban directamente con estas zonas y efectuaban por sí mismos un extenso comercio.

Huexotzinco, Cholollan, Tlaxcallan y Totomehuacan fueron aliados guerreros durante la segunda década del siglo xvi, los cuatro pueblos se encontraban y se encuentran situados alrededor del sitio llamado Cuetlaxcoapan; otros pueblos cercanos al Valle de Cuetlaxcoapan por el lado oriente fueron Tepeyacac (hoy Tepeaca), Cuauhtinchan y Tecalco (Tecali), sin embargo, hasta antes de la época de contacto hispano-indígena fueron sometidos y dominados por la Triple Alianza junto con otros pueblos importantes en la parte oriental de la Región Puebla-Tlaxcala: Tecamachalco y Quechollac; y al sur y suroeste de la misma: Teopantlan y Cuauhquechollan.

En ese contexto tuvo lugar la alianza entre indígenas y europeos y la nueva ocupación del territorio del Valle Puebla-Tlaxcala. Como es conocido, el primer obispado de la Nueva España se estableció en Tlaxcala con sede en la ciudad del mismo nombre hacia el año 1527; desde allí el primer obispo Julián Garcés junto con los miembros de la Segunda Audiencia (1531-1535)

2. Basado en parte de las investigaciones de Ursula Dyckerhoff, 1988 [1978]. Estamos considerando como la Región Puebla Tlaxcala al Valle que se forma aproximadamente desde la ciudad de Tlaxcala a la ciudad de Huaquechula (anteriormente Cuauhquecholac, ubicada al sur de Atlixco, la antigua Huehue-Cuauhquecholac) en el intersticio de las grandes montañas de la Sierra Nevada al Poniente y la Malinche y otras pequeñas serranías al oriente del Valle citado. La intención de la presente adenda se realiza porque consideramos muy bien fundamentado el trabajo de investigación realizado por Ursula Dyckerhoff y publicada en su primera edición en el año de 1978, sus fuentes de información son amplias y de diverso carácter, desde las primarias: Historia Tolteca-Chichimeca, Unos Annales, Anales de Quauhtitlan, Códice Cuetlaxcoapan, Lienzo de Tlaxcala, Historia de Tlaxcala de Diego Muñoz Camargo, Chimalpahin, Alva Ixtlixochitl, Juan de Torquemada, Bernardino de Sahagún, Diego de Durán; como las provenientes de fuentes secundarias: Paul Kirchhoff, Hans Prem, Luis Reyes García, Cayetano Reyes García, Mercedes Olivera, Pedro Carrasco, Johanna Broda, todos ellos con una importante y destacada trayectoria en la investigación científica en los campos de la geografía, historia, etnohistoria, antropología y arqueología de los siglos XV y XVI en la Cuenca de México y en el Valle Puebla-Tlaxcala. 


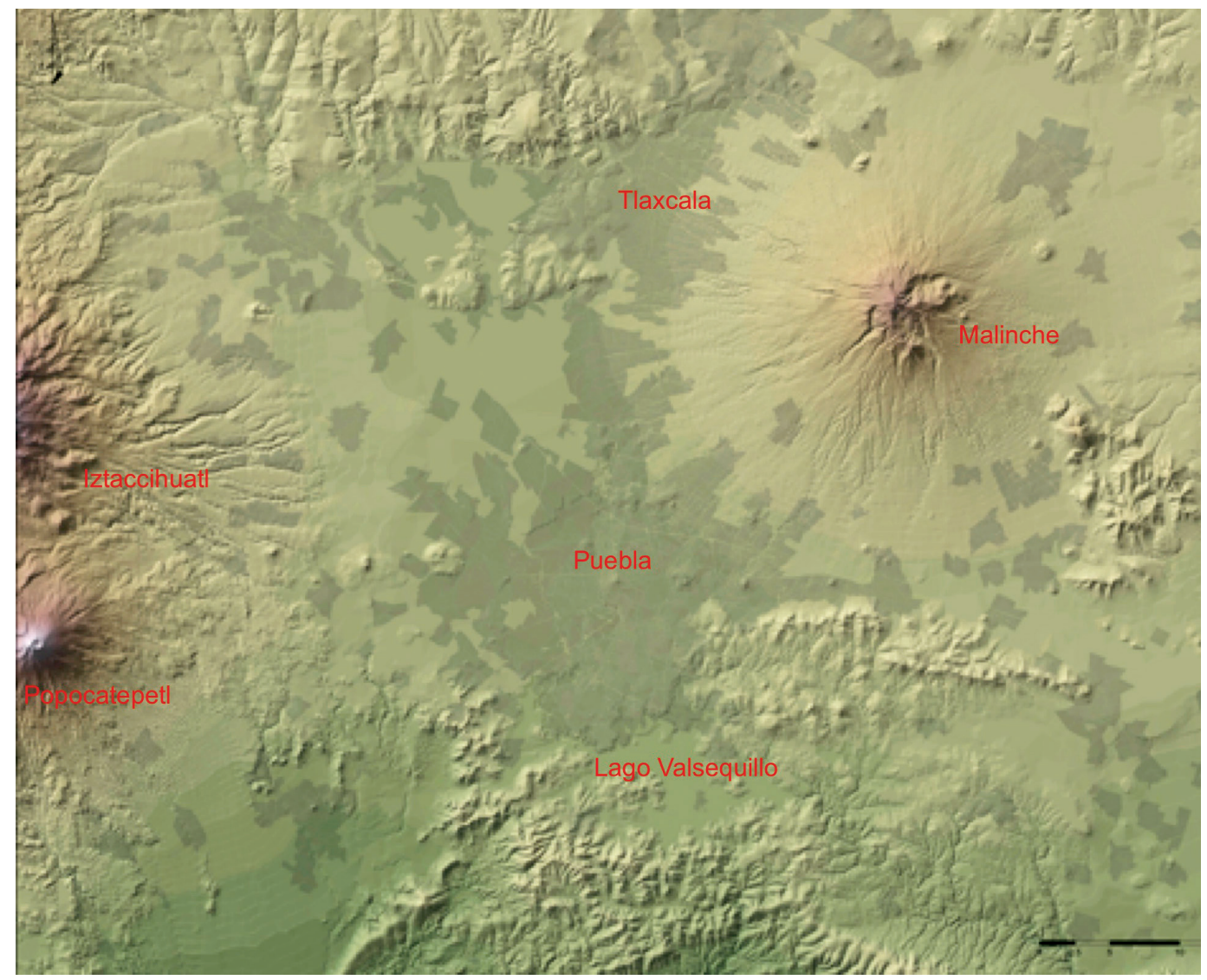

PLANO 3.2. Mapa de la Región de Trans-montaña o Valle Puebla-Tlaxcala. En el lado izquierdo se observa la cúspide del Volcán Popocatepetl y su extensión al norte con el Volcán Ixtaccihuatl; En el lado derecho superior está el Volcán Matlalcueyetl o La Malinche. Esas grandes conformaciones geológicas y geográficas hacen posible la aparición de territorios intervolcánicos con grandes cantidades de cuerpos de agua superficiales y subterráneos y tierras con alta productividad para la actividad agropecuaria. Es una imagen actual en la que se observa con sombras grises la mancha urbana especialmente del corredor Puebla-Tlaxcala.

y los nobles indígenas que resguardaban a todos ellos durante sus estancias en la región y la selección del sitio para la nueva Ciudad de Los Ángeles fueron capaces, estos últimos, de indicar a los recién llegados el mejor sitio geográfico que reunía, desde nuestro punto de vista, las siguientes cualidades y la posibilidad de ser ocupado sin conflicto con los pueblos vecinos:

i. En el centro del conjunto de pueblos aliados y de guerreros más poderosos en la región.

ii. En el lugar geográfico más resguardado en el valle contra posibles intervenciones o ataques de inconformes o rebeldes; su resguardo fue debido a las condiciones de la orografía, ríos de gran caudal y accidentes topográficos (barrancas), que como era costumbre de los indígenas, fueron los sitios elegidos para la defensa y el ataque militar en su condición de pueblos guerreros.

iii. La adopción del sitio por los europeos que también tenían la tradición de seleccionar los espacios geográficos ubicados estratégicamente, además, el lugar 
elegido les permitiría crear la nueva ciudad con las formas y disposición de los elementos urbanos, la producción agrícola, la ganadera y la industrial a la manera del viejo mundo y crear también las condiciones edilicias para la formación del puerto comercial y de tierra adentro más importante que ocupara la ciudad durante casi todo el período del virreinato de la Nueva España.

Consideramos también los enviados por la Corona española para la administración de justicia y de apropiación del territorio en acuerdo con los aliados tlaxcaltecas, esto es los personajes progresistas: el primer obispo de Tlaxcala Julián Garcés y los miembros de la Segunda Audiencia de la Nueva España nominada por la Corona el 30 de julio de 1530: ${ }^{3}$ obispo de Santo Domingo Ramírez de Fuenleal presidente de la Audiencia y los oidores: Alonso Maldonado, Francisco de Ceynos, Juan de Salmerón y Vasco de Quiroga; ellos fueron enviados por sus cualidades para la negociación y el consenso con los aliados indígenas: los tlaxcaltecas y los acuerdos que favorecieran un mejor trato en los beneficios mutuos que recibirían los recién llegados al territorio y los ocupantes centenarios de la región y Mesoamérica lo que sitúa, a diferencia de las versiones que consideran a los indígenas exclusivamente como mano de obra barata o gratuita y bien calificada; esta condición añadida les permitió a los señores importantes de la legión tlaxcalteca y otras unidades regionales sentar las bases de acuerdos para el dominio del amplio territorio mesoamericano y del norte, por lo menos durante el amplio período de los siglos XVI y XVII.

\subsection{LA FUNDACIÓN DE LA CIUDAD DE PUEBLA EN EL CONTEXTO REGIONAL}

Formalmente se tiene definida como fecha de fundación de la ciudad el 16 de abril de 1531 (en el plano de 1700 aparece que fue fundada el 6 de abril); independientemente de la fecha exacta de la fundación se tienen documentados dos: la primera se realizó aparentemente hacia el oriente del río San Francisco (Fernández Echeverría y Veytia, 1931), aunque en esta primera experiencia se enfrentaron problemas relevantes en cuanto a inundaciones ${ }^{5}$ y condiciones no favorables que obligaron al obispo Julián Garcés, al licenciado Juan de Salmerón, a Fray Toribio de Benavente (Motolinia) y los franciscanos a realizar la segunda fundación que tiene como centro urbanístico la actual plaza mayor de la ciudad.

3. Ruiz Medrano: 1991, p. 31

4. Plano de La Ciudad de Los Ángeles fechado en 1700 y custodiado por el Museo Naval de Madrid.

5. En cuanto al riesgo de inundaciones en la zona descrita no es muy confiable esta afirmación pues tiene una pendiente, proveniente del volcán La Malinche, más que suficiente para desagüarla; pareciera más explicable la reubicación de la ciudad en un terreno llano y de suelo de roca travertino más conveniente para uso urbano en el que se ubica la Segunda Fundación, la definitiva; las características planas del suelo eran también más acordes al modelo reticular de trazado que aplicaron a la nueva ciudad. 
El obispo de Tlaxcala fray Julián Garcés fue el primero en plantear la creación de una nueva ciudad para resolver los siguientes problemas:

a. Concentrar en el nuevo asentamiento a un conjunto de españoles de los que había en el territorio novohispano, para formar una comunidad más segura para los comerciantes y viajeros que iban o venían del Puerto de Veracruz a la Ciudad de México y al Pacífico.

b. En los primeros años, Tlaxcala fue la ciudad de paso y descanso de los europeos en la ruta de Veracruz a la de México, con gran mayoría de población indígena. Los tlaxcaltecas en su alianza con los conquistadores para la derrota de los aztecas recibieron el beneficio otorgado y el privilegio de que no se fundaría una ciudad española cerca de su asentamiento. Fue necesario entonces contar con una ciudad más adecuada y funcional para los intereses de los Habsburgo, con población hispana dominante y, al igual que Tlaxcala, como punto intermedio en la principal ruta comercial y de albergue de personas entre Veracruz y la capital de la Nueva España. Algunos autores sostienen que el Obispo Garcés no estaba de acuerdo con la ubicación que actualmente tiene la ciudad y que fueron los franciscanos los que lo decidieron; otros que fue Fray Toribio de Benavente, lo que nos parece preciso señalar es la audacia de los protagonistas recién llegados, junto con la participación activa de los tlaxcaltecas, conocedores de la región, para seleccionar el sitio y recomendar el lugar del nuevo asentamiento. ${ }^{6}$ Es importante mencionar el rechazo de la comunidad de Totomehuacan (población ubicada a unos cuantos kilómetros del sitio elegido) para que allí se realizara el nuevo asentamiento, ya que afectaba las propiedades que hasta ese momento les pertenecían: no fueron tomados en cuenta y no pudieron defenderla debido a que su condición militar en ese momento estaba debilitada por la reciente sujeción que habían sufrido por los guerreros de Tepeaca. Esta adjudicación para la fundación de la nueva ciudad en el antiguo territorio de Totomehuacan hizo relativamente sencilla la ocupación del sitio para la nueva comunidad que la habitaría y con el resguardo militar de la comunidad indígena de Tlaxcala y sus aliados.

La segunda Audiencia, en ese momento con el mayor poder político en la Nueva España, estaba conformada por hombres instruidos y humanistas que habían leído las obras progresistas del renacimiento. ${ }^{7}$ Ellos apoyaron intensamente la fundación de la ciudad.

6. En cuanto a la selección del sitio para la nueva fundación está el mito ampliamente conocido de que el Obispo Julián Garcés en un sueño recibió de los ángeles la comunicación de fundar la nueva ciudad novohispana en el sitio que actualmente ocupa Puebla, aunque es casi evidente que fueron los nobles tlaxcaltecas, los aliados, quienes aconsejaron al obispo en vigilia, la ubicación de la nueva Ciudad de Los Ángeles.

7. François Chevalier en Contreras y Cuenya (2000: p. 34). 
Los frailes franciscanos fueron la primera orden que tuvo presencia en la región y quienes participaron en los trabajos materiales y de evangelización indígena en la fundación de la ciudad. Su representante fray Toribio de Benavente (Motolinia), considerado humanista y protector indígena, tuvo una participación fundamental en este proceso.

\subsection{LOS PRINCIPALES MOTIVOS DE LA FUNDACIÓN DE LA CIUDAD Y SU ESPLENDOR}

La fundación de la Ciudad de Los Ángeles (Puebla) es una experiencia innovadora de la época por sus características renacentistas y progresistas, tanto en lo social como en la morfología y traza de la ciudad. Fue concebida inicialmente como una ciudad para pobladores españoles con la presencia indígena en condiciones menos violentas en términos de explotación y trato que en el resto de la Nueva España. Un referente fundamental para la fundación de ésta fue el hospital de Santa Fe (cerca de Ciudad de México) ideado y definido por Vasco de Quiroga, basado en los planteamientos establecidos en la Utopía de Tomás Moro. De hecho, había relación social y coincidencia política entre Vasco de Quiroga, Juan de Salmerón y Toribio de Benavente; todos ellos participantes en la fundación. El licenciado Salmerón estableció que la ciudad de pobladores españoles no iba a reproducir el sistema de encomiendas, ${ }^{8}$ con lo que establecía una nueva relación entre españoles e indios, es decir, un cambio cualitativo de la condición española de conquistador a colonizador.

Los eventos prácticos de la construcción de la ciudad no permitieron un seguimiento formal de las ideas de Salmerón, pues desde la fundación se requirió de la participación indígena en el trazo de las manzanas y lotes, la edificación de las casas e inmuebles para diversos usos y el servicio doméstico para la clase dominante. De allí que a los primeros colonos se les asignaron, a cada uno, 30 indios por noventa días y 20 más para el desmonte de sus huertas, ${ }^{9}$ aunque, los períodos de tiempo se ampliaron en varias ocasiones.

La ciudad de Puebla se estableció conscientemente en un lugar que no hubiera sido ocupado por población indígena. Esta decisión tomada por Salmerón implicó ventajas y desventajas.

Las ventajas consistieron en lo siguiente:

8. La encomienda consistía en la asignación de un número mayor de 20 indios que estaban al servicio y la explotación del trabajo por el encomendero español, era el Señor de "tributos" y servicios del grupo de indígenas.

9. Ver Contreras Cruz y Cuenya (2000, p. 22). 
a. La relativa ausencia de conflictos por la repartición de la propiedad, esto posibilitó la asignación a los españoles de los solares de la ciudad planificada.

b. Iniciar una experiencia con ausencia de encomiendas para los españoles.

c. La creación de una ciudad planificada de acuerdo con los motivos, parámetros y conceptos de una ciudad innovadora para la época, es decir, de una ciudad abierta, sin murallas.

d. Su estratégica posición productiva, comercial y de seguridad. Productiva en la agricultura en el entorno regional. Desde la transacción comercial, ha ocupado un lugar central de conexión con en el camino entre la gran Ciudad de México y Veracruz (La Antigua, San Juan de Ulúa y el Puerto de Veracruz), así también con el camino al Puerto de Acapulco; ambos puertos de conexión con ultramar. Desde la defensa castrense, la ubicación adecuada de la ciudad para la vigía y defensa del sitio a través de las condiciones del paisaje natural: cerros, ríos y barrancas; en el centro de los principales asentamientos aliados, de origen prehispánico: Tlaxcala, Cholula, Tepeaca y Huejotzingo; con el complemento de obras castrenses y de resguardo fiscal.

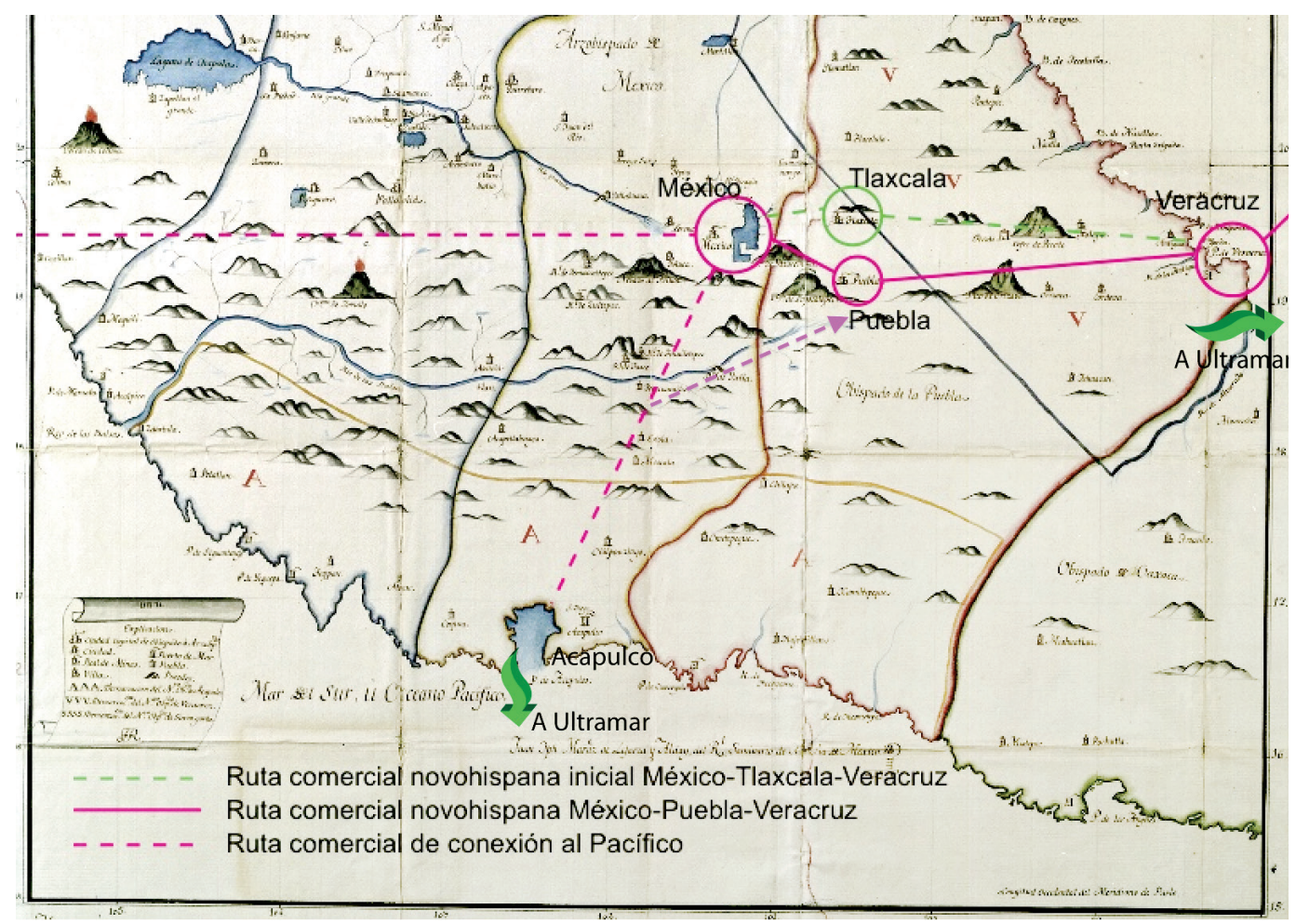

PLANO 3.3. Mapa en el que se observa la localización de Veracruz, Puebla y Ciudad de México en las rutas comerciales tierra adentro y hacia los puertos marítimos; sobre un detalle del Mapa General del Obispado de Michoacán, Arzobispado de México y Obispado de la Puebla. AGI, MP, México, 49. 


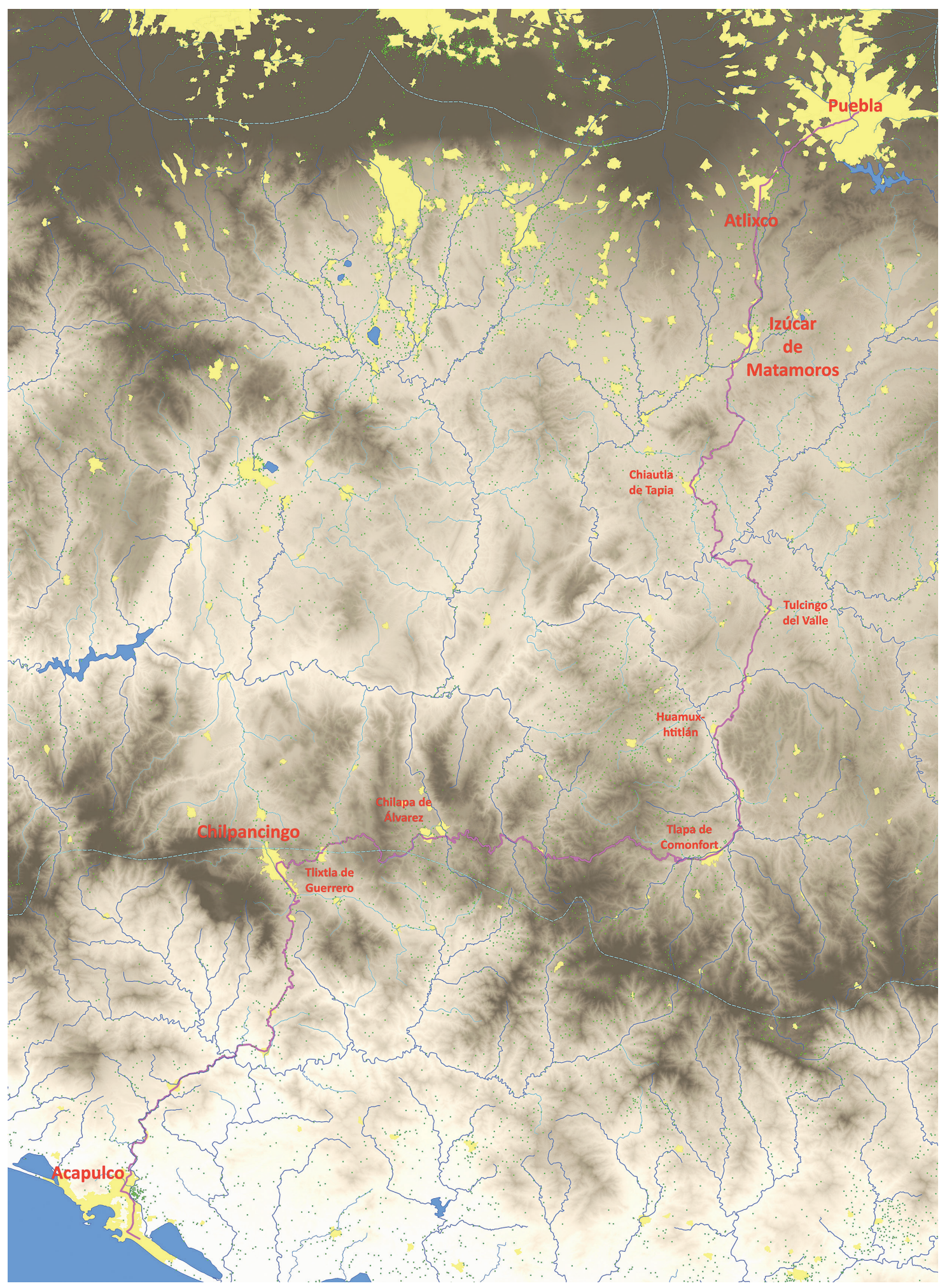

PLANO 3.4. Ruta comercial desde el Puerto de Acapulco al Puerto de Veracruz, siguiendo las vertientes de la Cuenca del Balsas; por allí circulaban las recuas cargadas de mercaderías entre Acapulco y Puebla, un camino menos sinuoso que el paso por la Ciudad de México y de allí a Puebla. La entrada y salida de mercancías por el sur de la ciudad de Puebla fue muy importante en la ruta hacia las islas filipinas con el transbordo por Acapulco. 
Las desventajas consistieron en:

a. Que los primeros pobladores fueron españoles que en su mayoría eran errantes, es decir, vivían en un asentamiento, luego en otro y, en muchos casos no se ajustaban a las normas sociales de sedentarismo, condición civil de casados por la iglesia y trabajadores responsables, pues habían mantenido el estado de soltería y la evasión del trabajo. Debido a estas características se requirió del trabajo indígena para la fundación y edificación de la ciudad y para las tareas y faenas que no consideraban propias de su condición europea privilegiada.

b. La persuasión de indígenas que habitaban los pueblos cercanos con la ayuda fundamental de los tlaxcaltecas: Huejotzingo, Cholula, Calpan, Cuauhtinchan y Tepeaca, para emprender servicios temporales con la asignación de solares en los barrios dispuestos para ellos, así como una cuota de tiempo para dedicarla a la construcción de sus casas, aunque en muchas ocasiones no contaron con esta última condición.

c. La concepción progresista que estableció la Segunda Audiencia en LCLA, es decir, con condiciones menos violentas para los indígenas, generó en gran parte de los españoles allí asentados, desacuerdos y oposición debido a la rebeldía y desobediencia de los primeros hacia los segundos, estos últimos pugnaban por el regreso a la condición de mantenerlos dentro de los preceptos de la encomienda.

\subsection{MORFOLOGÍA Y TRAZO URBANÍSTICO}

La idea de la ciudad reticular y abierta de la segunda fundación fue debida a la conjunción de intereses de personajes ilustrados y de ideas progresistas: el obispo de Tlaxcala Julián Garcés, Juan de Salmerón, Toribio de Benavente, Vasco de Quiroga (el segundo y el cuarto, formaron parte de la Segunda Audiencia); y a las condiciones favorables de la alianza con los grandes señores de Tlaxcala, quienes facilitaron y propiciaron la fundación de LCLA.

La ubicación de la ciudad se fundó en el llamado Valle de Cuetlaxcoapan, ubicado en el camino entre la Ciudad de México y el puerto de Veracruz. El sitio específico elegido fue al margen de los ríos San Francisco y Xonaca, en ese lugar de aguas limpias había también manantiales, suelos adecuados para la edificación (una extensa placa de travertino, propicia para el adecuado desarrollo constructivo) y el desarrollo agrícola y pecuario por las condiciones naturales del entorno territorial.

François Chevalier, ${ }^{10}$ a través del cotejo de fuentes primarias y secundarias, nos relata que hacia 1533, en el establecimiento definitivo de la villa, se cuenta con un plan cui- 
dadosamente estudiado y sometido a la Audiencia, a través de éste se construye una plaza mayor muy espaciosa y siguiendo el modelo de 217 x 128 varas, es decir, unos 182 x 107 metros. En torno a la plaza principal se trazan las manzanas rectangulares de 100 x 200 varas castellanas (83.5 x 167 m.) con subdivisión en ocho predios de 50 x 50 varas. "En el curso de las dos siguientes décadas esta plaza [la Mayor] fue encuadrada por arcadas o portales y edificios públicos. Había una fuente a un costado. Ocho calles de longitud uniforme que partían de sus cuatro ángulos"

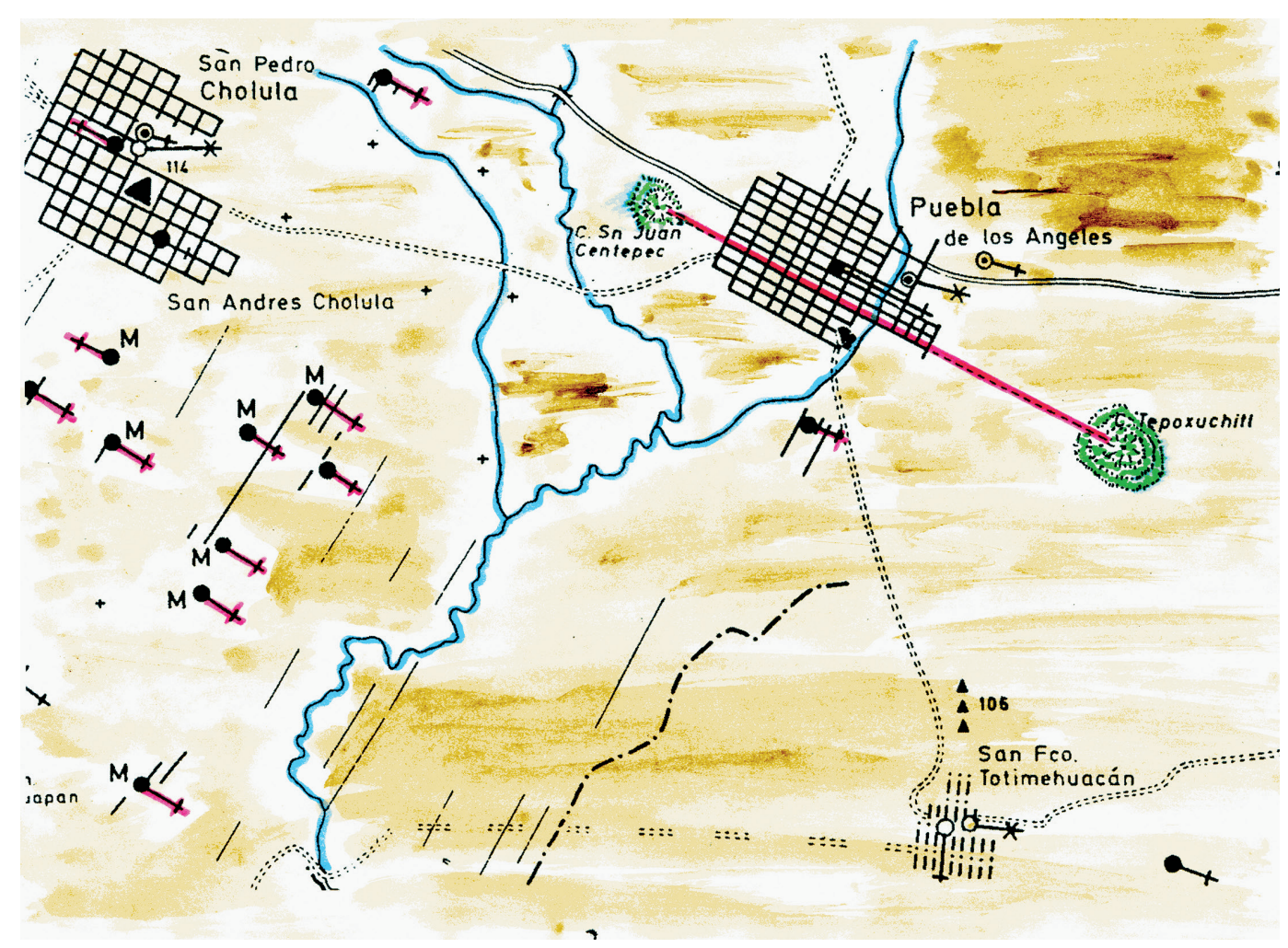

PLANO 3.5. Croquis de la Ciudad de Los Ángeles en el siglo XVI donde se observa la inclinación de la traza de la ciudad del Norte hacia el Este de $17^{\circ}$, así como las iglesias representadas por una cruz que mantienen la misma dirección descrita. De acuerdo con Franz Tichy las desviaciones coinciden con las anteriormente utilizadas por los indígenas en el trazo de sus cultivos agrícolas, centros ceremoniales y ciudades. Plano editado con base en Tichy, F., Rev. Comunicaciones, Puebla, 1974: Figura 6. Asimismo y coincidiendo con lo anteriormente dicho afirma que la traza de la ciudad está definida por el eje que se marca virtualmente desde el Cerro de Tepoxuchitl al de Centepec; añade además que la ciudad de Cholula mantiene también el mismo trazo que Puebla como aquí se muestra.

La ciudad estuvo conformada por la plaza mayor, las manzanas reticulares alrededor de ésta, con su parte más larga con una orientación noroeste-sureste, su parte más corta en la dirección noreste-suroeste, debido a que, en general, todo el trazado se delineó 
con un desfase de $17^{\circ}$ hacia el oriente del eje norte-sur. Las plazas públicas además se realizaron en el conjunto del tejido urbano. Para 1698, había un grupo de 13 plazas: 1. San Luis, San Antonio, San José, San Francisco, Los Carros (hoy Jardín de Aquiles Serdán), San Roque (hoy el Parián), Los Sapos, El Carmen, La Concordia o Santa Inés, San Agustín o San Hipólito, Guadalupe (parte del actual Paseo Bravo), La Compañía de Jesús y la Plaza Mayor (Gonzalo Yanes: 1995, pp. 19-20).

\subsubsection{LOS BARRIOS INDÍGENAS}

Fausto Marín-Tamayo ${ }^{11}$ menciona que la asignación de solares a los indígenas sólo fue de usufructo temporal, es decir, no se les asignó una propiedad a perpetuidad pues el Ayuntamiento la siguió manteniendo. Los primeros grupos indígenas provenientes de Tlaxcala y Cholula, ocuparon un lugar al oriente del río San Francisco que se denominó Tlaxcaltecapan, ubicado en el intersticio de los ríos San Francisco y Xonaca y otro al norte en el barrio llamado de Santa Ana. Hacia el sur de Tlaxcaltecapan se extendió otro barrio con en el nombre de Analco (que en lengua nahuatl significa "al otro lado del río"), también habitado por tlaxcaltecas. En el segundo cuarto del siglo XVII se establecieron al norte de la traza española los barrios de Xanenetla (nombre debido al material usado para la construcción de edificios llamado xalnene (piedra arenosa que se extraía del barrio) y Xonacatepec. Al oriente se estableció el barrio de Santiago habitado por cholultecas y otros grupos. Al norte de Santiago, en el entorno de la iglesia de San Sebastián, se establecieron otros grupos nahuas.

Marín-Tamayo describe que en resumen fueron siete los barrios indígenas principales que rodeaban a la traza española, sin contar el pueblo de San Baltasar ubicado al sur de la misma. Estos son los siguientes: Tlaxcaltecapan o San Juan del Río, Analco, Santiago, San Pablo de los Naturales, San Sebastián, Santa Ana y su arrabal San Antonio de los Coleros, San Miguel ó San Miguelito, indica que no se consideran los barrios de Xanenetla y Xonacatepec por haberse incorporado tardíamente al conjunto urbano. Los sectores de mestizos que se implantaron a finales del XVI y principios del XVII son el barrio del Santo Ángel Custodio (en Analco), El Alto detrás del templo de San Francisco), Oaxaquilla o El Parral, El Carmen (al sureste de la traza) y San José (al norte). ${ }^{12}$

11. Fausto Marín-Tamayo (2000, [1960]).

12. Idem. 


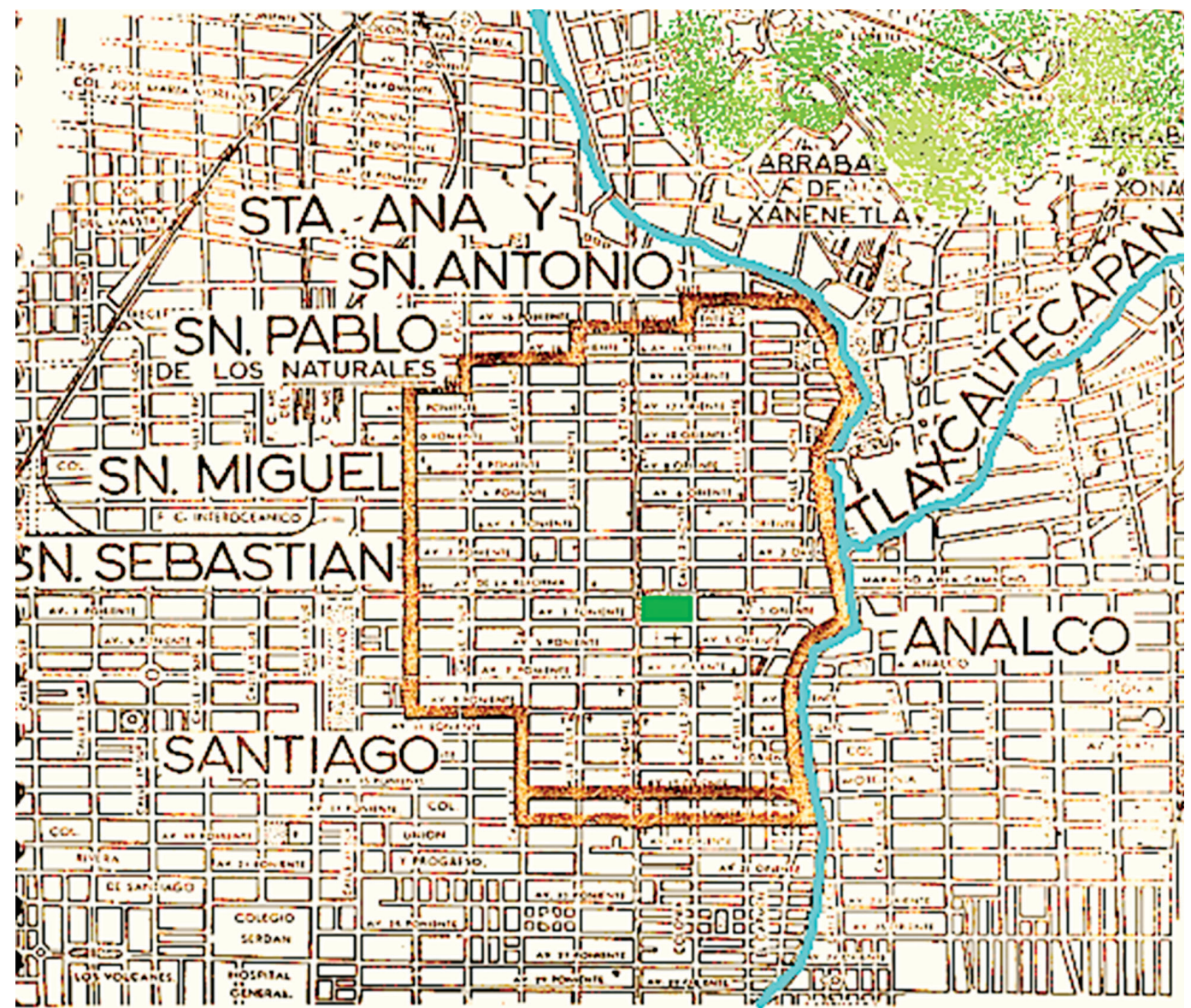

PLANO 3.6. Sector central ocupado por la comunidad española y barrios indígenas en los alrededores. (Marín-Tamayo, 1960).

\subsubsection{LA DIVISIÓN SOCIAL EN CLASES EN EL SIGLO XVII}

Durante el XVII se agudizaron más los conflictos en las relaciones sociales de la ciudad, debido a los problemas que enfrentaba el poder absolutista y el virreinato para enfrentar la contradicción entre encomienda y repartición del servicio de indios a los españoles. La encomienda asignaba a un conquistador o español con hidalguía un grupo de indios a su servicio exclusivo por tiempo indefinido y ellos estaban obligados al pago de tributo. La repartición de indios sólo se asignaba por un tiempo determinado, en actividades específicas y con el pago de un salario. Este proceso del trabajo indígena se dirigió a los principales de la ciudad: en el poder político, en el económico y en el eclesiástico; fue más intenso durante el XVII. Una cuota adicional fue el pago adecuado y oportuno de alcabalas de todos los súbditos de la ciudad y la región a la Corona. 
Gantes Tréllez (2000) clasifica las siguientes clases sociales: República de peninsulares-criollos (los civiles y los cleros secular y regular), República de indios y negros, mulatos y mestizos.

República de peninsulares-criollos. Fueron los dirigentes del gobierno y de lo económico, que se sustentaba en la agricultura y la ganadería, que por su alta producción era considerada el granero de la Nueva España, ${ }^{13}$ proporcionaba además el trigo y la lana para la industria; la industria textil y de la harina de trigo y el comercio, sobre todo con el auge por la dotación de biscochos y paños para la Armada de Barlovento. Había una estrecha relación entre lo político y lo económico, de hecho para ocupar un cargo en el gobierno había condiciones de raza, educación y poder económico, lo que dependía de la jerarquía gubernamental que se tratara. Por su parte, el clero secular era tan importante como el poder económico y político por su trascendencia social en las diversas clases sociales. En un principio, las órdenes religiosas (el clero regular) fueron protagonistas en la ciudad: franciscanos, dominicos, agustinos y jesuitas, pero en el XVII el clero secular tuvo el papel preponderante en la ciudad y en el Obispado; cabe destacar los fuertes conflictos que hubo entre el obispo Juan de Palafox y Mendoza con los franciscanos y la Compañía de Jesús, por no sujetarse al cumplimiento preciso de sus órdenes, esto es, una mejor distribución de los recursos adquiridos por las órdenes mendicantes en beneficio del rey.

República de indios. Como se mencionó anteriormente, los indios vivían en los barrios dispuestos para ellos, alrededor del centro español, se dedicaban al cultivo agrícola y de animales en sus tierras, así como al trabajo que daban a los peninsulares criollos. Durante los siglos XVI y XVII se presentaron abusos en la ocupación de la propiedad indígena por los españoles, por lo que la Corona dicta un conjunto de normas para reparar los daños a los indígenas. Gantes Tréllez (2000, p. 31) señala que:

Junto a sus propiedades, el indígena tenía su propia organización política: sus representantes eran los caciques y gobernadores, que dirigían la vida político-económica de los barrios donde se agrupaban, defendiendo sus intereses.

\subsection{RESUMEN DEL PROYECTO DE LCLA DURANTE EL ENCUENTRO CULTURAL}

A lo largo del capítulo hemos abordado lo más importante respecto a la fundación de la ciudad novohispana de Los Ángeles y resumimos los principales elementos de esta urbanización: 
1. La ubicación de la ciudad en el cruce de caminos hacia Ciudad de México, Tlaxcala, Veracruz y Acapulco, pero con la condición de una ciudad dominada y apropiada por españoles fuera del entorno inmediato de Tlaxcala, la ciudad de los aliados. Un lugar estratégicamente localizado en la región que estuviera alejado de la ciudad de los tlaxcaltecas, la ciudad indígena, pero relativamente cerca para el traslado del poder de justicia del recién creado Obispado de Tlaxcala

2. A través de diversos autores clásicos y contemporáneos de LCLA confirmamos la intensa relación entre españoles y tlaxcaltecas en la fundación de la ciudad, en la disposición de barrios, en la selección más adecuada del sitio para fundación de la nueva ciudad, acorde con las necesidades y aspiraciones de los españoles: disposición de agua potable a través de manantiales y ríos, suelo apto para la urbanización y para la producción agropecuaria, elementos geográficos de la orografía del sitio, ríos y barrancas para el resguardo adecuado de la nueva ciudad.

3. La disposición de caminos y pueblos prehispánicos determinantes en el trazado de la ciudad y en la orientación de sus calles, siguiendo los patrones prehispánicos del Sistema de $17^{\circ}$.

4. Una ciudad resguardada por pueblos de indios aliados con los colonizadores y con una posición estratégica para la concentración y traslado de mercancías dentro de la demarcación del Reino de México y hacia ultramar por el Atlántico y el Pacífico, es decir, la gran plaza comercial de la Nueva España en los finales del XVI y principios del XVII.

5. Disponer de un espacio físico convenido con los pueblos aliados de los tlaxcaltecas y que no generara conflictos en torno a la propiedad de la tierra establecida hasta el momento del contacto europeo-indígena.

6. También estratégicamente por sus antecedentes guerreros. El sitio de Cuetlaxcoapan, de acuerdo con diversos historiadores alemanes y mexicanos fue el sitio donde en un amplio período del siglo XV se realizaron las Guerras Floridas, guerras institucionalizadas como las define Ursula Dickerhoff (1988) y Contreras Martínez (1995) que fueron los referentes para manifestar el poderío de un pueblo sobre los otros, en particular las guerras entre la Triple Alianza y los pueblos del Valle Puebla-Tlaxcala; los vencedores tendrían el privilegio de los tributos de los pueblos conquistados. 


\section{Método para la lectura de cuatro planos virreinales de la Ciudad de Los Ángeles}

Propusimos un método que nos permitiera realizar la lectura desde las temáticas de la arquitectura y la urbanística. Durante este proceso realizamos el siguiente esquema general que se adecuó a cada documento de acuerdo con sus características particulares. En lo que toca a los planos históricos, se consideraron cuatro planos que cubren históricamente las transformaciones de la ciudad en el período virreinal y en el XIX. Los primeros tres planos, de 1698, 1700 y 1724, forman parte de un mismo proceso o cambio de modelo en la fiscalización de la ciudad y la región, es decir, donde se apuntan las características y obras que deben implantarse, en el futuro inmediato, en el espacio físico de La Ciudad de Los Ángeles, para una más adecuada administración de los recursos fiscales de la propia ciudad y de sus referentes regionales a diversos niveles. El Plano de 1862 puede considerarse estrictamente referencial debido a que nos interesó para confirmar plenamente el carácter estratégico-militar de los edificios y obras civiles construidas durante la primera mitad del siglo XVIII, así también, el círculo de garitas que permaneció hasta esta fecha pero que fue definido y delineado en el año de 1697 por la autoridad hacendaria mayor de la ciudad para fines fiscales y de vigía; se transformó en 1700 y con más severidad en 1724. Desde entonces el círculo de garitas fue un elemento de contención del crecimiento y frontera urbana en un espacio físico definido durante poco más de ciento cincuenta años, hasta la aparición del ferrocarril y posteriormente el desborde de la mancha urbana del círculo citado.

A partir de las fuentes primarias de los planos, se realizó un conjunto amplio de planos explicativos, analíticos e interpretativos a través del método científico, desarrollado por Jorge González Aragón, para mostrar la lectura urbana y arquitectónica. 
Los planos considerados fueron los siguientes:

1. Planta de la Ciudad de Los Ángeles de Nueva España, elaborado por Christóbal de Guadalaxara en 1698. Custodiado en el Archivo General de Indias, Sevilla, España.

2. Ciudad de los Ángeles (México), elaborado por Antonio de Santa María Ynchaustegui en el año de 1700. Resguardado en el Museo Naval de Madrid.

3. Plano de las Garitas de Puebla de Los Ángeles, elaborado en 1724. En custodia del Archivo General de Indias, Sevilla, España.

4. Croquis de la ciudad de Puebla y sus alrededores, elaborado en 1862. Resguardado en el Archivo del Ayuntamiento de Puebla. Existe otro plano con la misma información y representación gráfica con título: Plan de la Puebla et de ses environs, copia del realizado en México y que se encuentra en el Servicio Geográfico del Ejército.

El método de análisis es el siguiente:

I. Copia o reproducción de alta resolución del plano histórico seleccionado para comenzar a realizar los diversos planos base y temáticos que se requieran.

II. Identificación de los aspectos físico-espaciales que nos interesa analizar, por ejemplo: geográficos, flora y fauna, elementos urbanos y arquitectónicos.

III. Sectorización de la ciudad en el plano, tomando en cuenta cuerpos de agua, accidentes topográficos, homogeneidad de la traza y asentamientos periféricos. El objeto de la sectorización se hace para identificar las características particulares de cada una de las partes de la ciudad en términos morfológicos, funcionales y de especialización de cada uno de ellos, a fin de elaborar una lectura temática y de sus peculiaridades.

Aun cuando en nuestro análisis particular usamos la sectorización sólo para el plano de 1698, porque fue importante en el estudio morfológico de manzanas y parcelas que viene ampliamente detallado en el plano original. Nuestro interés en esta tesis está enfocado a la relación entre los aspectos comercial y militar con la disposición de los elementos urbanísticos: caminos y calles, plazas públicas, aduanas, alhóndigas y garitas. Tiene utilidad para otros análisis temáticos: la morfología de la parcelación, bloques de manzanas, traza, tejido urbano y usos del suelo, que evidentemente nos permite la comparación entre diversos períodos de tiempo para observar las coincidencias y diferencias que presentan los sectores de la ciudad.

IV. El dibujo de los planos temáticos se realizó sobre el plano primigenio y sólo se dibujarán los elementos plásticos y gráficos relacionados con el tema seleccionado; se respeta la representación original del plano y sólo se hicieron cambios en 
ésta cuando fue necesario para su comprensión. Con la realización de cada uno de los planos temáticos el observador-dibujante fue capaz de ir descubriendo diversos aspectos: los edificios y espacios relacionados con el tema analizado, la morfología que presentan, los símbolos utilizados y la reflexión acerca de la ocupación específica del espacio por los edificios.

Los planos temáticos que definimos fueron los siguientes:

a. Medio natural: cerros y montañas;

b. Hidrografía: ríos, arroyos, manantiales, barrancas, canalizaciones y acueductos;

c. Caminos: interurbanos primigenios o de segundo nivel, a la periferia de la ciudad, internos en lo que se denomina traza urbana;

d. Espacios públicos: calles y plazas;

e. Espacios para la fiscalización: garitas, guardas, alhóndiga, aduanas y caminos o corredores asociados a estos espacios;

f. Usos del suelo: espacios productivos, edificios religiosos, defensa militar, plazas de comercio, de convivencia, recreativas y rituales;

g. Letreros que aparecen en el Plano;

h. Morfología de manzanas y parcelas;

i. Áreas edificadas y no edificadas;

j. Áreas para el cultivo agrícola o ganadero.

V. Clasificación de cada uno de los elementos presentes en cada plano temático. Se estableció a partir de la realización de un plano donde se dibujaron exclusivamente los elementos que correspondían a un tema. Con ello, se puede asignar un código a cada uno de los elementos urbanos o del paisaje geográfico que se van registrando con la finalidad de clasificar y hacer los catálogos por temas: una tarea muy laboriosa que para esta tesis no se cubrió en su totalidad.

VI. Comparación morfológica y agrupación por características comunes de los elementos identificados para cada uno los temas.

VII. Tipología exhaustiva de los elementos temáticos a partir de su recurrencia formal.

VIII. Lectura de cada uno de los planos temáticos. Se realiza a través de la descripción de lo que se observa y de las relaciones que el lector de la imagen pueda establecer, tomando en cuenta el aspecto urbanístico como primordial.

IX. Lectura general del plano, para enfatizar sobre los aspectos centrales en torno a la estructura y elementos urbanos, así como en aquellos que hasta el momento no se han mencionado o se han trabajado poco por otros investigadores; también destacar los que se han estudiado desde una perspectiva diferente a la obtenida a través del análisis de las fuentes primarias: los planos históricos. 
X. Complementar con fuentes documentales secundarias aquellos temas o elementos de la estructura urbana que se considere conveniente profundizar o contextualizar.

XI. Comparar cada uno de los mapas temáticos de un corte de tiempo con los planos correspondientes a otros cortes de tiempo, para observar las transformaciones del espacio urbano y sus edificios.

XII. Lectura de las transformaciones urbanas en cada uno de los temas, con una reflexión en torno a los motivos sustanciales que produjeron esos cambios.

XIII. Lectura general de las principales características de la región y la ciudad en los cortes de tiempo, para enfatizar los descubrimientos y nuevos conocimientos que se aportan en torno al origen y principales claves de transformación urbana de La Ciudad de Los Ángeles.

XIV. Conclusiones finales

\section{NOTAS RESPECTO AL MÉTODO USADO}

Como antecedentes al método propuesto, nos parece importante señalar el método del geógrafo germano-inglés Michael Robert Günter Conzen, 1981, quien en los diversos artículos científicos del libro, The urban landscape: histórical, development and management, editado por J. W. R. Whitehand, hace un análisis que apunta con precisión la identificación de la morfología urbana de las ciudades en sus diferentes períodos históricos. En esos papers identificamos los siguientes temas asociados a la elaboración de uno o más planos como parte del plan de análisis e interpretación del paisaje urbano, la morfología y la conservación de áreas históricas y ciudades:
i. Topografía
ii. Cuerpos de agua
iii. Calles y caminos
iv. Áreas urbanas
v. Morfología de manzanas
vi. Morfología de manzanas y lotes
vii. Áreas edificadas en los lotes
viii. Plazas, parques y jardines
ix. Usos de suelo

Mencionamos brevemente a Conzen por sus aportaciones para estructurar el análisis morfológico de la ciudad y para identificar las acciones para su conservación e intervención urbana con argumentos explícitos. Para nosotros fue importante descubrir las semejanzas que tuvimos, desde el análisis exhaustivo de los planos históricos, con el método estructurado de Conzen, quien identificó los elementos que determinan las 
formas urbanas de muchas de las ciudades inglesas; también, la guía de estructuración que tuvimos a partir de la lectura de esos papers.

Juan Luis de las Rivas, 1992, p. 195, resume lo siguiente, sin duda, fundamental para la comprensión de la ciudad histórica y contemporánea:

Norberg-Schulz propone un análisis como descripción de la estructura del lugar en términos de topología, morfología y tipología, enlazado con la tradición analítica en arquitectura. La tipología trata el orden espacial. Aquí aplica lo desarrollado en el espacio existencial: las ideas básicas de centro y recorrido. La topología ofrece definiciones de los elementos espaciales, sus interrelaciones y el análisis de sus tipos (estructura geométrica, sistemas de agregación, relación dentro fuera ...). La morfología trata el "cómo" de la forma arquitectónica, la obra singular y su articulación formal, los límites, la estructura construida, el carácter y presencia real de la construcción. Tipología, topología y morfología forman el lenguaje de la arquitectura.

Con el método de lectura que proponemos para los Cuatro Planos de La Ciudad de Los Ángeles, realizamos una taxonomía del plano, es decir, la clasificación, catalogación, comparación, tipologías y lectura de éste en su conjunto. Trabajamos cada uno de los planos temáticos de ese documento como si fuera un palimpsesto. Nos interesó comparar el desarrollo y transformación de algunos elementos de la estructura urbana podemos decir que observamos e hicimos la lectura de los diversos estratos de la ciudad a través de los cuatro planos de Puebla seleccionados específicamente por los temas comerciales, fiscales y militares que son sustanciales al origen y transformaciones en el período virreinal y del siglo XIX. 


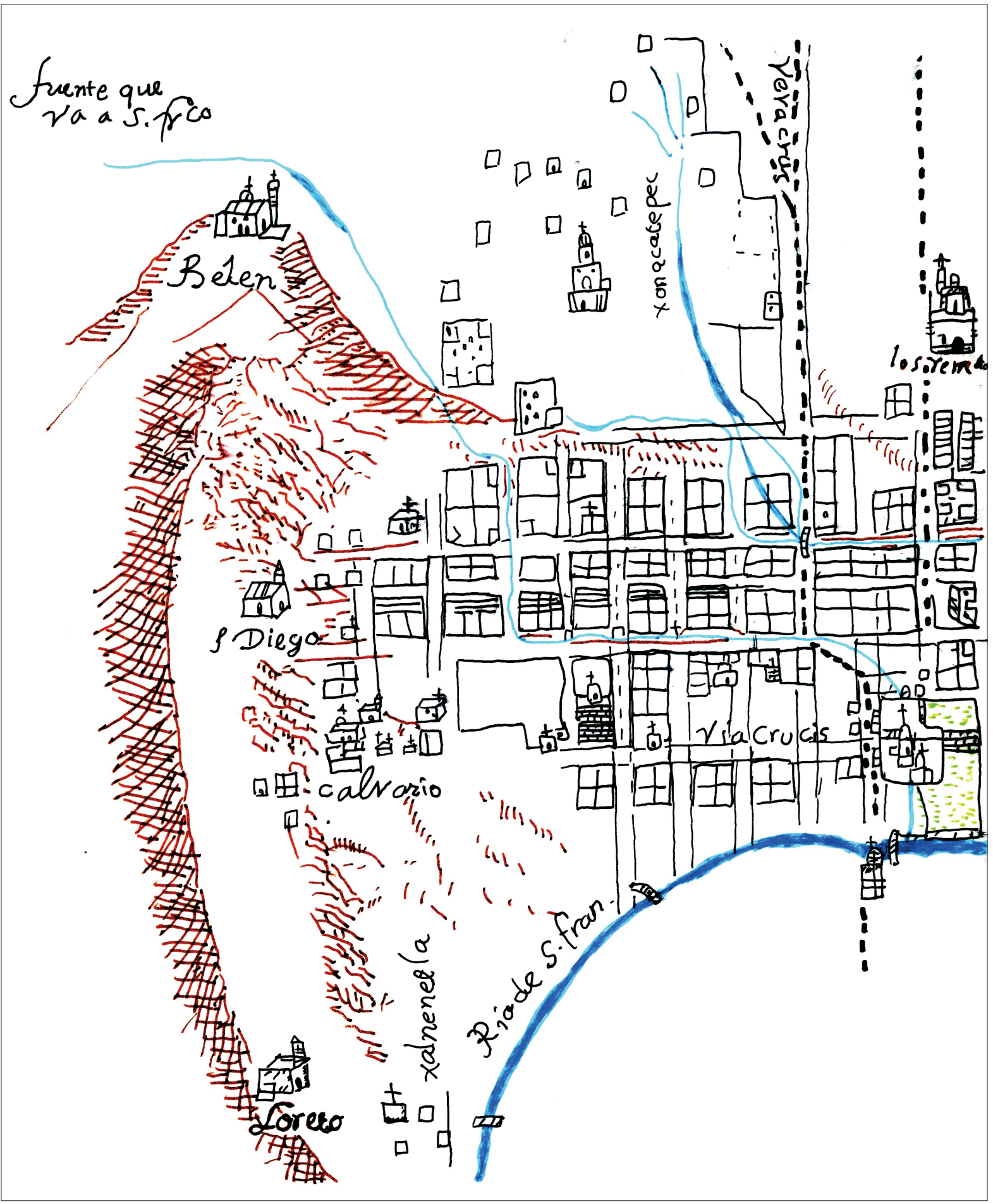




\section{Lectura urbana de la planta de la Ciudad de Los Ángeles 1698}

De modo idéntico que cualquier otra ciudad, viven de un control del espacio

que ejercitan gracias a las redes de rutas que de ellas arrancan, del encuentro con otras rutas, de su constante adaptación a condiciones nuevas

y de sus evoluciones lentas o bruscas

Fernand Braudel

El Mediterráneo y el mundo mediterráneo en la época de Felipe II (I)

\subsection{PRESENTACIÓN}

El plano resguardado en el Archivo General de Indias formó parte de un legajo, custodiado en el mismo repositorio que tiene el siguiente registro:

Legajo: México, 341, con el título: Simancas/Secular/Audiencia de Méjico. Expedientes relativos a la administración de alcabalas de la Puebla de Los Ángeles, año de 1698.'

En el Catálogo de mapas y planos de México en el AGI se registra como:

AGl: MP, México, 529.

Atribuido a Christobal de Guadalaxara²

1. La consulta de la documentación se puede realizar de dos maneras, la primera a través de una estancia en Sevilla para realizar la lectura y paleografía del legajo; la segunda, se realiza a través de la solicitud para que se realice la digitalización del legajo, el pago anticipado y la promesa de que el disco magnético o "CD" con todo el contenido requerido llegará al domicilio del investigador solicitante. Esta segunda opción fue por la que optamos y recibimos el material en tres meses contados a partir de los primeros días de diciembre. Es pertinente mencionar que cuando un expediente aún no ha sido digitalizado se debe a que ningún otro investigador ha solicitado una copia o reprografía del mismo, por lo menos en los últimos diez años, ya anteriormente al año 2000 se realizaban copias fotostáticas de los expedientes y no se utilizaba el scanner como herramienta de digitalización de los expedientes del Archivo General de Indias.

2. Plano custodiado en el Archivo General de Indias, Sevilla, España. Christóbal de Guadalaxara. Con este nombre aparece una persona con el cargo de alcalde de la ciudad de Puebla en el año 1659, y para el año 1698 en que se registra en la elaboración del Plano, estuvieron como alcaldes de la Ciudad de Los Ángeles Jerónimo de Salazar y Sebastián de Mora y Medrano, quienes, junto con otros funcionarios principales de las Reales Alcabalas de la ciudad, encargaron el Plano a Ch. de Guadalaxara por su condición de Maestro Mayor de Arquitectura y conocedor amplio de la entonces Ciudad de Los Ángeles y su entorno territorial inmediato. 
En una lectura superficial del expediente que hicimos en la Sala de Consulta del AGI, observamos que el legajo trata de los problemas que se tuvieron para la recaudación de impuestos en LCLA por la falta de puestos de vigilancia y registro de mercancías, también llamadas garitas; por la necesidad de trabajadores que hiciesen las rondas adecuadas entre garita y garita de la ciudad con el objeto de evitar el paso de mercancías sin el pago de alcabalas; así como los problemas de corrupción de funcionarios, religiosos, hacendados o comerciantes, que asociados con sigilo en grupos con intereses comunes obstaculizaban el envío completo de las cuotas correspondientes a la realeza española o bien, obtenían ganancias fraudulentas de beneficio exclusivo para ellos.

El expediente citado fue localizado por el autor de estas líneas quien seleccionó los legajos del AGı, y realizó la paleografía de los folios, que en sus partes determinantes han servido para corroborar, confirmar y añadir nuevos datos acerca de las condiciones para la selección del sitio como puerto de tierra, los acuerdos y negociaciones para lo que denominamos: intervención urbana comercial-militar; ${ }^{3}$ para nosotros ésta corresponde a la nueva organización de las entradas de la ciudad, los caminos periféricos y la disposición de inmuebles para el control, registro y salvaguarda de mercancías y personas en la ciudad como parte de la adaptación a las nuevas condiciones administrativas y de adecuación urbana estratégica de LCLA para cumplir con la recaudación.

Es importante aclarar que la identificación del expediente que acompañó al plano de 1698 fue posterior a la lectura urbanística de la imagen; el expediente con los legajos seleccionados fueron encargados el 29 de noviembre de 2012 en el AGı en Sevilla y el expediente digitalizado en un CD lo recibimos en la Ciudad de México a finales de marzo de 2013.

\subsection{LECTURA URBANA}

Se realizó tomando en cuenta dos aspectos:

i. La factura del plano responde al encargo de las autoridades de la Corona de España con la finalidad de llevar una administración de las alcabalas más funcional y realizar los edificios y la disposición de caminos adecuados para ese fin. Las peculiaridades de la información allí registrada, los temas tratados en el plano y las fronteras territoriales consideradas en el mismo fueron las nece-

3. Le denominamos intervención urbana comercial-militar pues consideramos la primera durante el período de fundación de la ciudad alrededor del Convento de San Francisco; la segunda en la traza realizada que tiene como centro la actual Plaza Mayor de la Ciudad. 
sarias para cumplir con el requerimiento fiscal de Carlos II. Es evidente que el responsable de la elaboración del documento Christobal de Guadalaxara y los dibujantes que realizaron el Plano tenían un conocimiento pormenorizado de la ciudad y su entorno, así como un dominio destacado en la expresión plástica de la información allí plasmada.

La complejidad evidente del documento nos hizo reflexionar sobre la necesidad de hacer una lectura de los temas que nos parecieron relevantes; por ello, el análisis de los temas del plano de 1698 es más amplio que la de los planos de 1700, 1724 y 1862.

ii. La aplicación del método para la lectura urbana.

\subsection{LOS MOTIVOS QUE LLEVARON A LA REALIZACIÓN DEL PLANO}

La realización del plano, hecha entre 1697 y 1698, planta de La Ciudad de Los Ángeles de la Nueva España tuvo como motivos particulares los siguientes:

i El registro de los puestos de garitas y guardas existentes en 1697 por el juez privativo superintendente, por nombramiento real de las alcabalas de La Ciudad de Los Ángeles: don Juan José de Veitia Linage, para proponer un mejor funcionamiento administrativo y de resguardo de la ciudad en su condición de puerto seco o de tierra en el tránsito de mercancías como el Gran Azogue del Reino de México con ultramar a través del Puerto de Veracruz o el de Acapulco, las mercaderías o géneros provenientes del propio Reino y los productos agrícolas, pecuarios y manufacturados del territorio de LCLA para el consumo interno y la exportación.

ii. Evaluar, proponer y disponer de los recursos para la edificación de las instalaciones de resguardo de la ciudad, que permitieran formar un círculo conformado por puestos de garitas alrededor de la ciudad y caminos que los unieran entre sí.

Con la finalidad de dar certeza a las afirmaciones de los párrafos anteriores, consideramos fundamental presentar el título del expediente consultado: AGı, México, 341, para, posteriormente, presentar los Autos relativos a la orden específica para la realización del plano de 1698.

TESTIMONIO DE AUTOS, QUE SE REMITE A EL REAL Y SUPREMO CONSEJO DE INDIAS. POR SER DON JUAN JOSEPH DE VEITIA LINAGE DEL ORDEN DE SANTIAGO, CONTADOR MAYOR DEL TRIBUNAL Y REAL AUDIENCIA DE CUENTAS DE LA NUEVA ESPAÑA. JUEZ PRIVATIVO SUPERINTENDENTE DE LAS REALES ALCABALAS DE ESTA CIUDAD Y SU JURISDICCIÓN, EN QUE SE CONTIENEN LOS EXPRESADOS, EN LAS FOJAS SIGUIENTES. 
AUTO EN QUE; SU MINISTRO; DA LA FORMA DE LAS GARITAS Y PUESTOS EN QUE SE HAN DE EDIFICAR Y MANDA SE FORME MAPA DE LA CIUDAD ${ }^{4}$

En la muy noble y leal Ciudad de los Ángeles en veinte y seis días del mes de noviembre de mil seiscientos noventa y siete años su merced el señor Juez privativo superintendente de las Reales Alcabalas de esta ciudad. Habiendo visto las diligencias y testimonios de susodichas por el presente escribano en orden al reconocimiento de las garitas de la ciudad para cuyo efecto salió con el teniente y escribano del cabildo y uno de sus porteros en virtud de lo expresado en su Recepta y respecto de que esta ciudad, no ha tenido ni poseído según parece más que tres garitas, que la una está en el camino Real que va a la Ciudad de México; a la parte norte otra en el Camino de Tlaxcala por el mismo viento donde llaman la Hacienda de Las Trancas y la que está a la parte del sur Camino Totomehuacan porque las demás que en circunvalación de la ciudad se muestran son de las guardas de la gentuza del pulque y porque es necesario edificar las más de ellas a competentes distancias para que los guardas puedan cómodamente vigilar los muchos caminos y veredas, que por todas partes hay ...

Mandaba y mando que Don Joseph Zurita vecino de esta Ciudad supla por ahora la cantidad que fuere necesaria para dicha obra que se le satisfará de las primeras condenaciones, que se causaren en dicha Real Aduana. Y para más clara inteligencia se ruegue y encargue a el licenciado Don Cristóbal de Guadalajara presbítero que como plástico e inteligente delinee la ciudad y sus ejidos, cuya figura y mapa se ponga con los Autos, para que con ciencia del susodicho; se reconozca y vea si los puestos mencionados, están en partes competentes, donde se cojan los caminos, más principales que vienen para la ciudad para su mejor custodia. Y así lo proveyó, y firmo. Don Juan Joseph de Veitia Linage. Ante mi Antonio Ximenez de Guzmán escribano.

\section{REQUERIMIENTO DE RUEGO Y ENCARGO A EL LICENCIADO DON CRISTÓBAL DE GUADALAXARA ${ }^{5}$}

En la muy noble y leal Ciudad de Los Ángeles a veinte y siete días del mes de noviembre de mil seiscientos y noventa y siete años hice notorio el dicho Auto del Brigadier Don Cristóbal de Guadalajara presbítero domiciliario de este obispado en la parte que le toca. A quien rogué y encargué haga y forme el mapa y figura de esta ciudad, y como platico en ella reconozca los lugares y puestos asignados en el 
dicho Auto, están en partes competentes y habiéndolo oído y entendido. Dijo que por las experiencias con que se halla, reconoce están muy conformes, a la custodia de los Caminos por ser los lugares más precisos y que está presto a hacer y formar la delineación y figura de la ciudad con pronta obediencia, por ser del servicio de Su Majestad, Y esto respondió de que doy fe y lo firmo. Brigadier Don Cristóbal de Guadalaxara. Ante mi Antonio Ximenez de Guzmán escribano.

En estos párrafos selectos se destacan las intenciones de Carlos II, rey de España, para La Ciudad de Los Ángeles; primero, con el designio de Veitia Linage como su representante directo para las alcabalas de LCLA, esto es, que todos los asuntos relacionados con esta alcaldía no serían atendidos por la Hacienda del virreinato sino directamente por el representante del rey; segundo, la transformación de LCLA para atender fiscal y administrativamente, con guardias y supervisores para evitar el contrabando de mercancías por el paso ilegal de las mismas burlando las garitas y aduanas; el establecimiento de un sistema de recaudación fiscal más eficiente, que evitara el contrabando de mercancías y evitara la coalición delictuosa de grupos económicos y autoridades locales para evadir el pago de alcabala; la elaboración de un plano que contuviera la propuesta estratégica para atender la construcción de garitas y caminos que las unieran; las garitas se establecerían en los caminos de entrada-salida de la ciudad por donde pasara el mayor número de mercancías.

\subsection{SISTEMA DE REPRESENTACIÓN PLÁSTICA Y GRÁFICA}

La expresión plástica del documento pictórico se realizó a través de diversos planos de composición:

1. En perspectiva, para dar la sensación de volumen en el plano, se presentan los cerros y vertientes alrededor de la ciudad; árboles y la mayoría de los edificios relevantes.

2. En planta se aprecian los ríos y barrancas, los caminos de diverso tipo, los canales de agua, la delimitación de manzanas y parcelas, las áreas agrícolas y los caseríos dispersos.

3. De frente o de perfil algunos edificios.

4. Los dibujos de los edificios en el plano se representan con la vista desde el poniente hacia el oriente.

5. Se utilizan dos sistemas de proporciones; el primero, que atiende a la mancha urbana tiene una escala definida que no sabemos cuál es, porque no tiene una representación de escala gráfica o numérica, sin embargo observamos que existe una concordancia en las medidas de manzanas, lotes, calles, edificios y en los ríos y canales que pasan por la ciudad; el segundo, que utiliza un sistema refe- 
rencia y se encuentra fuera de la ciudad, esto es, los ríos y cerros no guardan la misma proporción en medidas lineales, sólo son una referencia geográfica de lo que existe alrededor de la misma, siven también para ubicar molinos y batanes que se encuentran en las riveras del Alseseca, del San Francisco y del Atoyac. Los pueblos están representados por una iglesia, si ésta es más elaborada en sus grafías, el pueblo tiene una mayor categoría; estamos ante una representación simbólica de los pueblos alrededor de LCLA.

La representación gráfica está presentada de la siguiente manera:

1. Los caracteres latinos asociados a diversos elementos en el plano.

2. Signos para la identificación de pueblos y su categoría a través de edificios eclesiásticos de diverso orden. Cabe señalar que tienen una condición distinta de significación de aquellos en donde se está representando exclusivamente una iglesia con su ubicación y orientación precisa dentro de la traza urbana.

3. Símbolos para la identificación de caminos en diversas categorías, así como para indicar canales y cajas de agua.

La superposición de planos de composición en planta, de perfil o de frente y en perspectiva, permiten generar un sistema de representación complejo y flexible que da cuenta de la realidad espacial, temporal y temática de LCLA en 1698 que interesaba poner en evidencia en ese momento. La representación gráfica, por su parte, nos está mostrando un conjunto de códigos que es importante identificarlos para acceder a una lectura rigurosa de los mismos.

El plano de 1698 tiene un sistema de representación que utiliza artificios plásticos de tradición indígena y europea creando un documento expresivo, de un rico contenido de información de LCLA; tiene una proporción bien definida en la mancha urbana y en el uso de la perspectiva para los edificios y el paisaje natural, la multiplicidad de planos de composición: planta, perfiles y perspectivas, así también la variedad de proporciones: uno para la traza urbana con escala y proporciones definidas y otro para su entorno, los tamaños o dimensiones de los edificios fuera de la mancha urbana significan la importancia de los mismos y son los símbolos de pueblos, los más grandes en tamaño son de mayor importancia en el relato del territorio referido. 


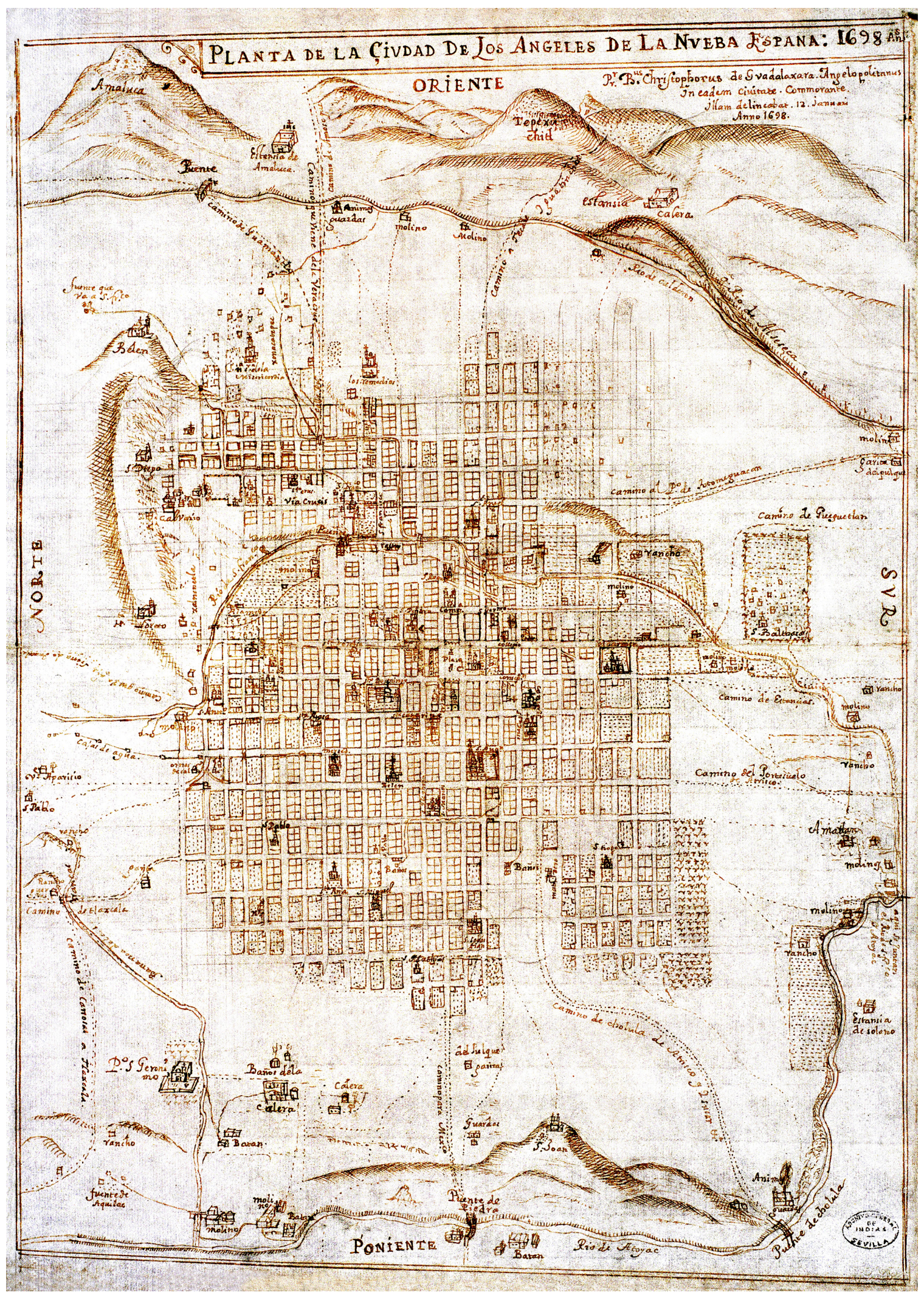

PLANO 5.1. Planta de La Ciudad de Los Ángeles de la Nueva España, 1698. AGI, MP, México, 529. 


\subsection{DIVISIÓN DE LA CIUDAD POR SECTORES URBANOS}

Se realizó el estudio minucioso del plano en cada uno de los temas seleccionados, se hizo la división virtual de la ciudad por sectores físicos en la que cada parte se identifica mediante una clave para comparar las características de cada una y del conjunto de la ciudad. Los sectores urbanos fueron delimitados tomando en cuenta:

a. El Río San Francisco como elemento divisorio de la ciudad,

b. La consideración de áreas que cuentan con 30 a 50 manzanas,

c. La delimitación en primera instancia del área central de la ciudad, esto es, las manzanas alrededor de la plaza mayor.

d. La homogeneidad en la morfología de las manzanas y el trazado de la ciudad.

e. En total se definieron nueve sectores urbanos para el área continua de la ciudad.

Es muy importante enfatizar que el uso de códigos en cada una de las partes de la ciudad es para tener siempre presente en que lugar se cuenta con determinadas características e identificarlas fácilmente.

\subsection{PAISAJE NATURAL}

El paisaje natural en el que se asentó LCLA se conserva para 1698 con los siguientes elementos:

1. La representación de cerros y vertientes se hace con líneas continuas en el contorno y dando volumen a éstos a través de líneas paralelas y entrecruzadas que dan la sensación de sombras en los cerros. Aparecen al oriente, el Cerro Tepoxuchitl en primer plano y la Serranía de Amozoc en segundo; los cerros de Loreto y Belén al noreste y el cerro de San Juan al poniente, así como algunas elevaciones terrestres menores.

2. Los ríos representados en planta por medio de dos líneas continuas más o menos paralelas, con las ondulaciones propias de la ruta de los mismos: Alseseca, San Francisco y Atoyac. Otros arroyos menores son los que vienen del Barrio denominado Xonacatepec que se encuentra en la parte baja del Cerro Belén, actualmente Cerro o Fuerte de Guadalupe. Estos elementos están representados por una sola línea continua.

3. La Barranca de las Trancas al noroeste de la ciudad con dirección oriente-poniente se representa por dos líneas continuas que culminan en el río Atoyac.

El paisaje natural en el que se asienta LCLA cuenta una riqueza excepcional: tiene el resguardo de cerros al oriente, poniente y norte. Tiene tres ríos de gran caudal: el Ato- 


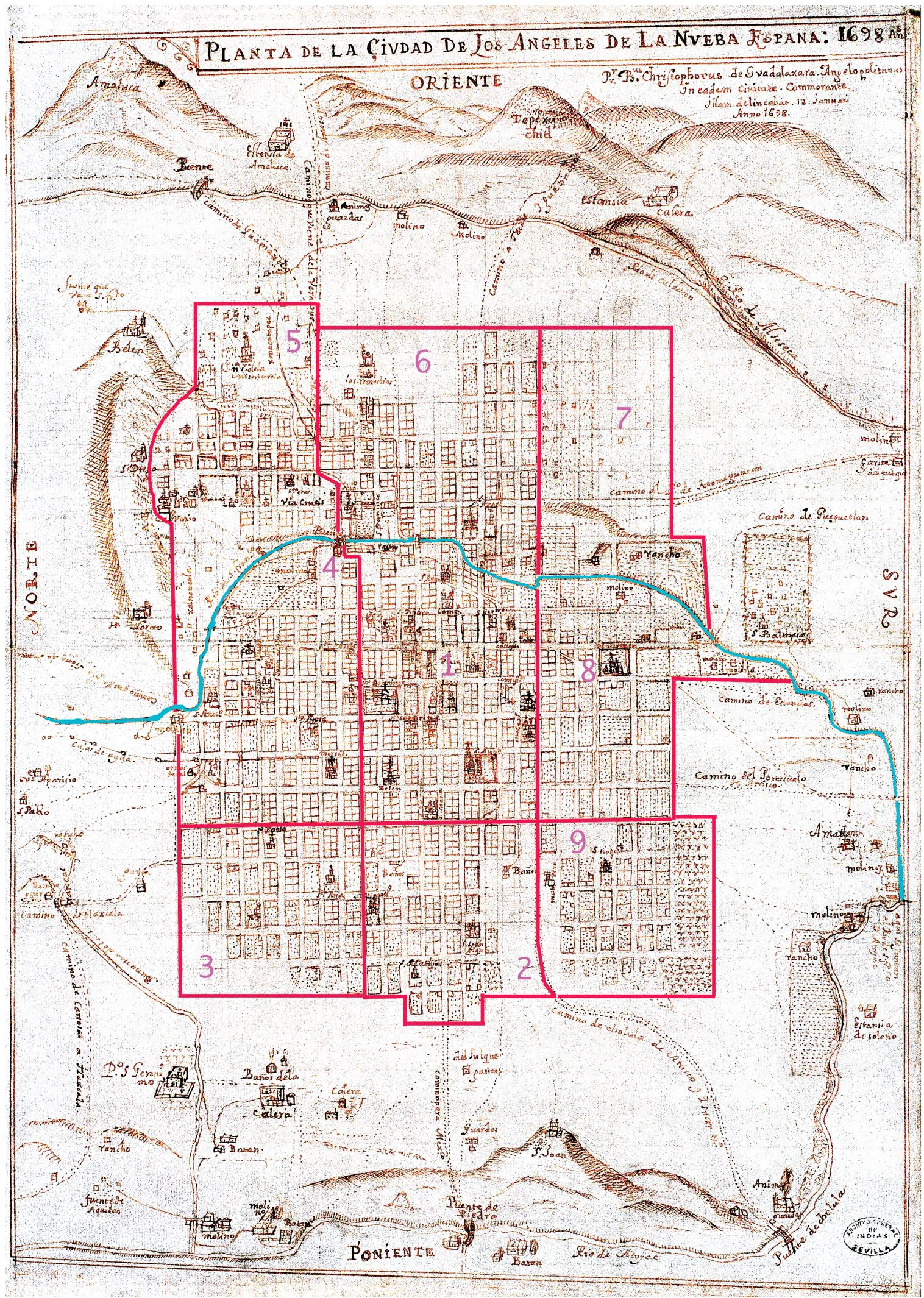

PLANO 5.2. Definición de sectores urbanos en la Planta de La Ciudad de Los Ángeles, 1698. 

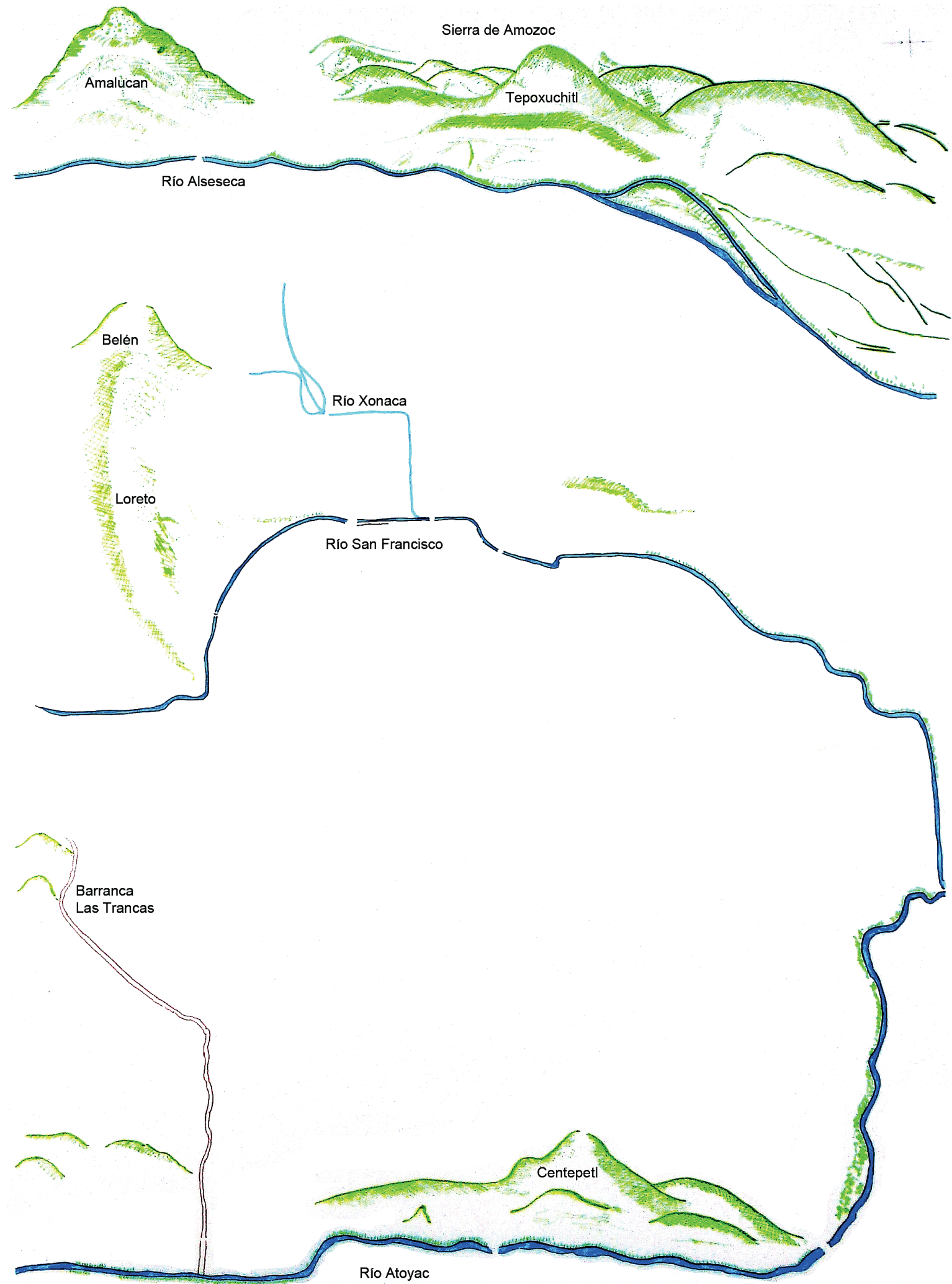

PLANO 5.3. Paisaje Natural en la Planta de La Ciudad de Los Ángeles, 1698. 


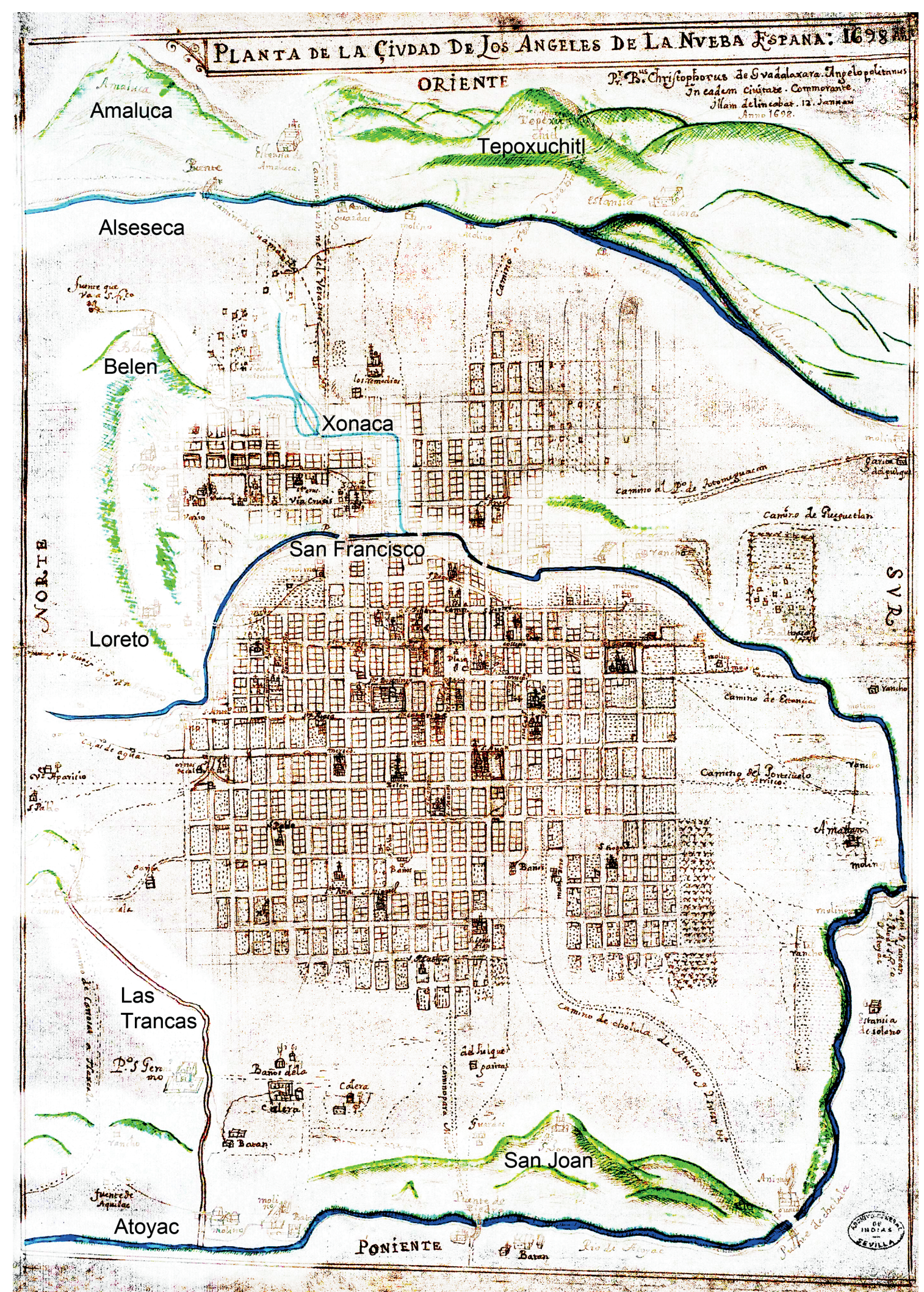

PLANO 5.4. Paisaje Natural en la Planta de La Ciudad de Los Ángeles, 1698. 
yac que se forma en la Sierra Nevada y se une a la desembocadura del río Balsas en Guerrero y que en su transcurso pasa por el lado poniente, por fuera de la traza urbana de LCLA; el Alseseca al oriente de la ciudad, fuera de la traza urbana, que se forma de los escurrimientos del volcán La Malinche y que desemboca en el Lago de Valsequillo; el San Francisco proveniente de La Malinche, que pasa por la traza urbana de LCLA y se une finalmente al Atoyac.

Es evidente que las condiciones geográficas del lugar en que se asentó la ciudad, contenía los recursos naturales en cuerpos de agua, tierras fértiles y un terreno sólido, apto para el desarrollo urbano.

Consideramos la hipótesis de que el sitio fue seleccionado por la nobleza indígena de la región de transmontaña o poblano-tlaxcalteca, quienes destacaron por una condición de gran fortaleza como guerreros y que no pudieron ser dominados por sus enemigos de la Triple Alianza: mexicas, acolhuas y tepanecas, durante la segunda mitad del siglo XV. Así el sitio elegido para la fundación de la ciudad tiene todas las condiciones para el resguardo del nuevo asentamiento: estaba rodeada de ríos, barrancas y cerros de diverso tamaño; se encontraba al centro de los principales pueblos aliados de guerreros, que se unieron al proceso conquistador del Imperio español: al norte, Tlaxcala; al sur-poniente Cholula; al poniente, Huejotzinco y Calpan; al sur-oriente, Totomehuacan, con la posterior inclusión, durante la segunda década del siglo XVI, de los pueblos de Tepeyacac (Tepeaca) y Cuautinchan al oriente.

\subsection{HIDROGRAFÍA}

Los ríos principales que cruzan la ciudad se representan en el plano de 1698, en orden de importancia, los siguientes:

1. Río Atoyac, nace de las vertientes de la Sierra Nevada, cruza LCLA, se une a la Cuenca del río Balsas y desagua en el océano Pacífico. En el plano aparece en la parte occidental de la ciudad, en un recorrido norte-sur.

2. Río Alseseca, nace de las vertientes del volcán La Malinche y se une al río Atoyac a la altura del Lago de Valsequillo. En el plano aparece en la parte oriental de la ciudad y corre de norte a sur.

3. Río San Francisco, aparece en la parte oriental de la ciudad y se une al Atoyac en el lugar denominado Amatlán, en las afueras de la ciudad, donde se localizaron los molinos de Enmedio; el trayecto del río inicia en las faldas de La Malinche, pasa por el lado poniente del Cerro de Loreto, cruza la ciudad de norte a sur $y$, en su trayecto final, se desvía hacia el sur-poniente para unirse al Atoyac. 
4. Barranca de Las Trancas, es una de las vertientes de La Malinche en la parte norte de la ciudad, corre en dirección oriente-poniente hasta encontrarse con el Atoyac; tiene dimensiones considerables y fue una corriente importante de agua en temporada de lluvias.

5. Arroyo Xonacatepec, proviene de las faldas de La Malinche, tiene un pequeño ramal que va hacia el río Alseseca al sur del camino a Veracruz; el cauce principal se dirige al río San Francisco y pasa por la parte sur del convento del mismo nombre; están dibujados dos pequeños cuadros en el transcurso del arroyo que pudieron tratarse de cajas para contener el agua.

6. Fuente que va a San Francisco, son un conjunto de manantiales ubicados al noreste del cerro de Belém, llegan al convento de San Francisco y en su trayecto recorren gran parte del sector primigenio de la ciudad.

7. Canalizaciones de agua, hay un conjunto de canalizaciones de agua que tienen los siguientes trayectos:

i. Del río San Francisco al convento de La Merced.

ii. De la parte norte del río San Francisco salen algunos breves canales hacia lo que pudieron ser tomas de agua.

iii. Del río San Francisco al molino frente al convento de San Francisco.

iv. Del río San Francisco corre sobre una calle paralela hasta llegar a la iglesia de San Roque.

v. Del río San Francisco al molino cercano a la Iglesia del Carmen.

vi. Dos baños de aguas sulfurosas conocidos desde el siglo XIX como baños del Paseo Bravo tienen canales que desembocan en el río San Francisco, pasan por la Iglesia del Carmen.

vii. Del río San Francisco al molino cerca de San Balthazar.

viii. Del río San Francisco a los molinos de Amatlán.

ix. De la barranca de Las Trancas a un Batán

x. De los Baños de La Calera, en el noroeste de la ciudad, al Batán.

xi. De La Fuente de Aguilar, en el noroeste de la ciudad, a un molino.

xii. Hay dos canales que surten de agua a un molino, uno que viene de la barranca de Las Trancas y el otro proveniente del río Atoyac.

xiii. Del río Atoyac a un Batán

8. Puentes, son las obras civiles asociadas a los ríos y barrancas de la ciudad que cumplen las siguientes funciones:

i. La conexión y paso de uno a otro lado del río.

ii. La identificación de puntos de acceso a la ciudad para su vigía 
iii. La creación de plazas o espacios abiertos antes o después de algunos de los puentes con fines de intercambio comercial y de convivencia.

iv. Los puentes registrados son los siguientes: un puente en el Alseseca en el camino de Guamantla: tres puentes en el San Francisco, el más importante, ubicado junto al convento de San Francisco; dos puentes en el Atoyac, uno en el camino a la Ciudad de México, otro camino a la ciudad de Cholula.

Después de esta descripción de los elementos hidrográficos que aparecen en el plano, observamos que hay un registro de los cuerpos de agua y de las obras realizadas para la dotación de los edificios significativos en las actividades religiosas y productivas; estos elementos dan cuenta de la obra civil que se había desarrollado en el amplio espacio geográfico delimitado por los ríos Alseseca, San Francisco y Atoyac para el beneficio de la industria y otras actividades productivas que ya estaban implantadas en la ciudad del siglo XVII. Desde la relevancia que representan los recursos y las obras hidráulicas LCLA tuvo todas las condiciones de gran ciudad. 


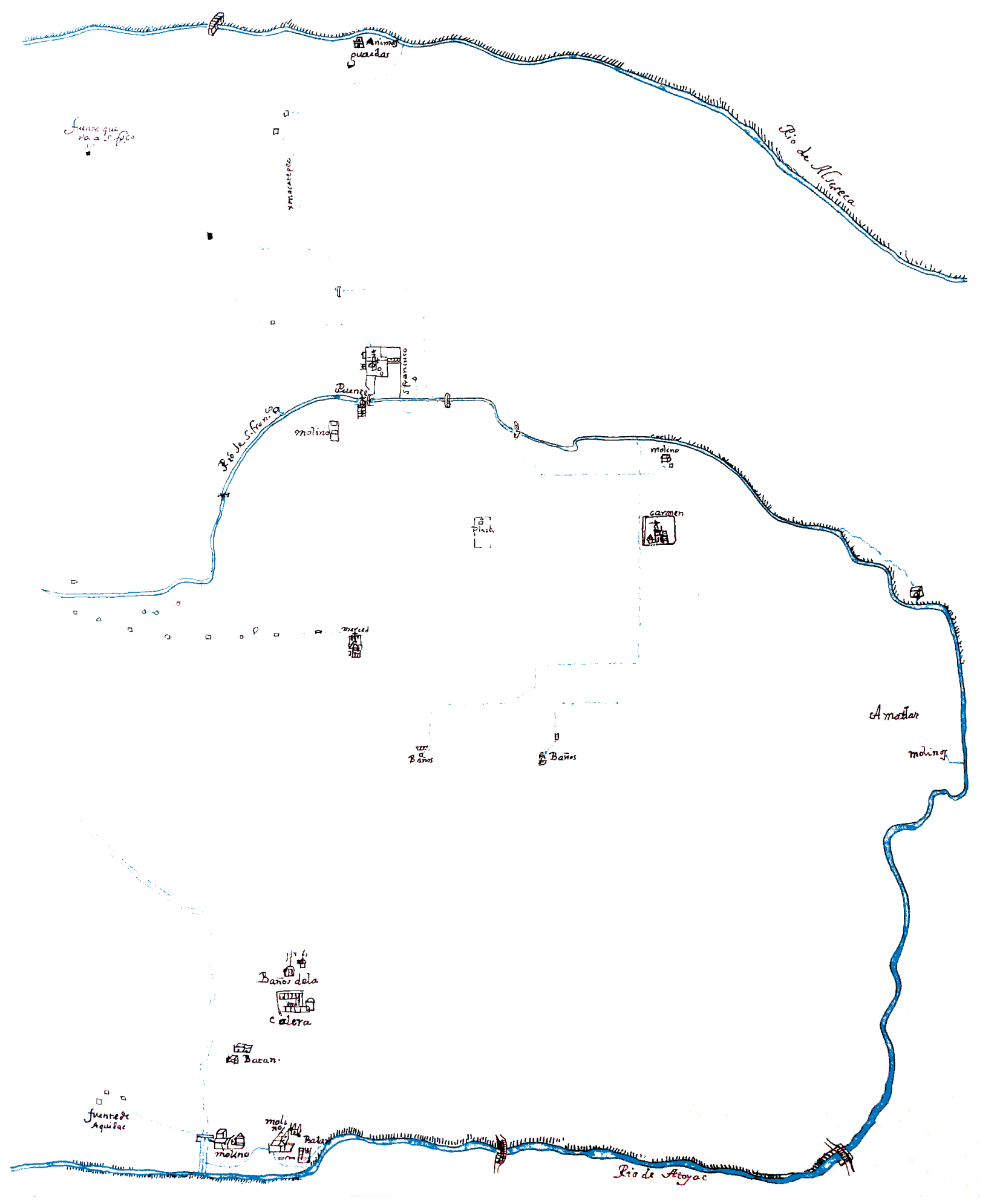

PLANO 5.5. Ríos, arroyos, manantiales y canales de agua en la Planta de La Ciudad de Los Ángeles. 


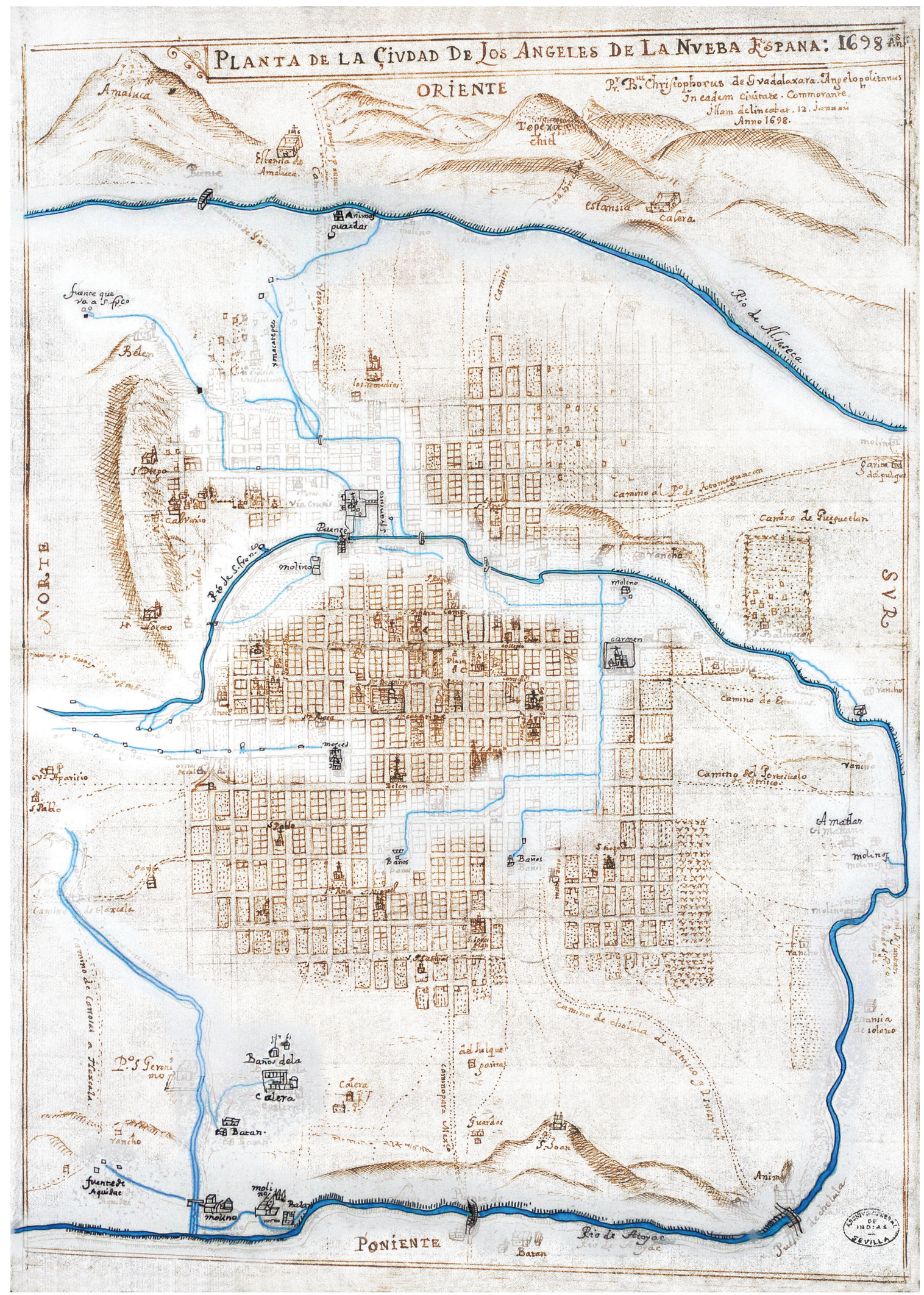

PLANO 5.6. Ríos, arroyos, manantiales y canales de agua en el plano de 1698. 


\subsection{LETREROS EN EL PLANO}

Los letreros que existen en el plano son de diverso orden y de gran utilidad para localizar con precisión elementos geográficos, edificios importantes con diversas funciones, parajes, pueblos y caminos, como a continuación clasificamos para obtener mayor beneficio de la información:

i. Título del Plano, año y autor:

Planta de la Ciudad de Los Ángeles de la Nueva España: 1698 Añs

Prv. Bus. Christophorus de Guadalaxara. Angelopolitanus

In cadem civitabe. Commorante.

Illam delineabar. 12. januari

anno 1698.

ii. Puntos cardinales:

Oriente, Norte, Sur, Poniente.

iii. Cerros principales:

Amaluca, Tepexuchitl, Belen, San Diego, Loreto, S. Joan.

iv. Ríos, barranca, cajas de agua y fuentes de agua:

Río de Calderón, Río Alseseca, Río de Atoyac, Barranca Las Trancas, Cajas de agua, Fuente que va a San Francisco, Fuente de Aguilar.

v. Destinos principales asociados a los caminos que se encuentran con la Ciudad: Camino de Guamantla, Camino de Amozoque, Camino que viene de la Veracruz, Camino a Tecali y Guatinchan, Camino al Pueblo de Totomeguacan, Camino de Gueguetlan, Camino de Estancias, Camino del Portezuelo de Atrisco, Camino de Cholula, de Atrisco y Isucar Villa, Camino para México, Camino de Carrozas a Tlaxcala, Camino de Tlaxcala, Camino que va a la Sierra de ...

vi. Pueblos en las cercanías:

Pueblo San Geronimo, San Pablo, San Balthazar.

vii. Ranchos y estancias:

Estancia de Amaluca, Estancia (junto al Camino a Cuauhtinchan), rancho (en El Carmen), Estancia de Solano, rancho (en el Camino de Estancias), rancho (en el Camino del Portezuelo de Atlixco), rancho (junto al Río Atoyac), rancho (junto al Pueblo San Geronimo), rancho (junto a guardas en el Camino de Tlaxcala), rancho (junto al Pueblo San Pablo).

viii. Caleras y hornos de cal:

Calera (junto al Río Alseseca), Calera (entre el Camino a México y la Barranca de Las Trancas), hornos de cal (al Norte de la ciudad junto a las cajas de agua). ix. Molinos y batanes:

Molino (tres letreros en la rivera del Alseseca), molino (seis letreros en la rivera del San Francisco), molino (junto a la Barranca Las Trancas), molino (dos letre- 
ros junto al Río Atoyac) molinos (en la intersección de los ríos San Francisco y Atoyac).

Batán (junto a la Barranca de Las Trancas), batán (dos letreros junto a la rivera del Atoyac).

x. Iglesias, conventos y ermitas por sectores urbanos (véase plano 6.2):

Sector 1: San Roque, Compañía, San Geronimo, San Pedro, Santo Domingo, Santa Catarina, Concepción, Santa Inés, Belén, San Agustín, San Marcos.

Sector 2: San Pablo, San Miguel, San Sebastián, San Mathias.

Sector 3: San Pablo, Santa Ana.

Sector 4: San José, San Juan de Dios, Santa Teresa, San Antonio, Santa Mónica, Santa Rosa, Merced.

Sector 5: Calvario, San Juan del Río, Santa Cruz, Via Crucis, Nuestra Señora de la Misericordia, Xalnenetla.

Sector 6. Los Remedios, San Francisco, Santo Ángel.

Sector 8: El Carmen, Al norte de la ciudad: Belén, San Diego, Loreto.

Al Sur de la ciudad: San Balthazar.

xi. Baños:

Sector 2: 2 Baños.

Fuera de la traza al norponiente de la ciudad: Baños de La Calera.

xii. Matadero. Uno en el Sector 9:

xiii. Guardas y garitas:

Camino para México: Del Pulque garita, Guardas.

Camino de Cholula, Atrisco y Isucar: Ánimas guardas.

Camino al Pueblo de Totomeguacan: Garita del Pulque.

Camino que viene de la Veracruz: Ánimas Guardas.

Camino a Tlaxcala: Garita, guardas.

xiv. Puentes:

Sobre el Río Atoyac: Puente de Piedra, Puente de Cholula.

Sobre el Río San Francisco: Puente.

Sobre el Río Alseseca: Puente. 


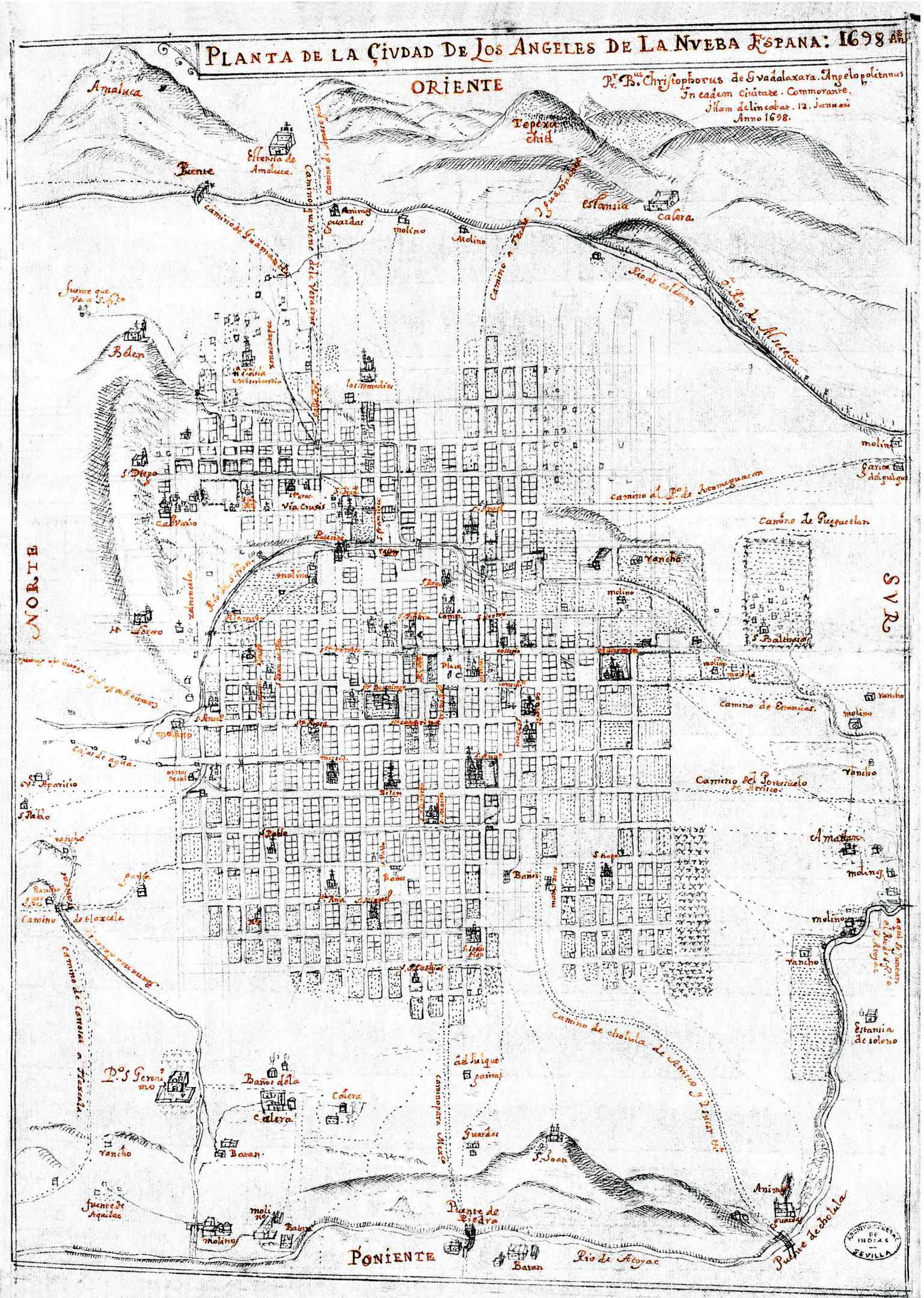

PLANO 5.7. Letreros que acompañan a la Planta de 1698 


\subsection{MORFOLOGÍA URBANA: CALLES, CAMINOS, PLAZAS, MANZANAS Y PARCELACIONES}

Las calles, manzanas y plazas de LCLA fueron inscritas dentro de un gran cuadrángulo que se implantó sobre la parte más llana, como si se tratara de una gran malla reticular que se dejara caer sobre el territorio y que se va adaptando a las características del sitio:

i. LA ORIENTACIÓN DE LAS CALLES están definidas en el eje virtual que marca la línea que va de las cumbres del Cerro San Joan (antes Centépetl) al Cerro de Tepoxuchitl con una desviación de la traza de $17^{\circ}$ del norte hacia el este.

ii. LA ADECUACIÓN DE LA MALLA URBANA con los cerros de Loreto y de Belén donde se localizan manzanas de mayor dimensión conforme se acercan a los lugares de mayor pendiente en los cerros.

iii. LA ADECUACIÓN O ALTERACIÓN de la forma ortogonal de la traza junto a la Rivera de San Francisco por su trayectoria sinuosa.

iv. LOS CAMINOS. En el trazado urbano se incorporan los caminos que son en orden de importancia:

a. Caminos Principales. Están señalados con dos líneas punteadas y paralelas en el documento original y, para mayor claridad en el plano que realizamos, están señaladas con una línea gruesa. Tienen los siguientes destinos, algunos de larga trayectoria: 1. México, 2. Tlaxcala, 3. Cholula-Atlixco-Izucar, 4. Totomeguacan, 5. Veracruz, 6. Portezuelo de Atlixco, 7. Estancias.

b Caminos a Pueblos Vecinos. Están señalados con una línea punteada y van para los pueblos vecinos de: 1. Huamantla, 2. Cuauhtinchan, 3. Huehuetlan, 4. A garita y guardas Camino a México, 5. San Jerónimo, 6. San Pablo, 7. San Aparicio y 8. La Sierra de Tlaxcala.

c. Caminos a la Periferia de la Ciudad. Están señalados con una línea punteada y van para: 1. Molinos, 2. Estancias, 3. Ranchos, 4. Batanes, 5. Baños y 6. Cerro de San Joan.

v. PLAZAS. En particular sorprende la concentración de las plazas que están junto al Convento de San Francisco con la mayor ocupación de superficie sobre las otras. Cumplieron varias funciones primordiales: la comercial, la de oficios religiosos y peregrinación del Convento de San Francisco a "El Calvario:", lugar de encuentro y convivencia de los ciudadanos y de recreación.

a. La amplia área como vestíbulo de la ciudad para la transacción de mercaderías y géneros provenientes de ultramar por Veracruz o Acapulco o del propio territorio de la Nueva España. 
b. La misma condición de su amplitud en superficie es con la finalidad de iniciar el peregrinaje desde el Convento de San Francisco a un conjunto de capillas que desembocan en el sitio denominado El Calvario, especialmente en la temporada de Semana Santa. Este corredor urbano de aproximadamente un kilómetro, tiene una riqueza estética singular por la amplitud de las calles y pequeñas plazas que articulan a las capillas y la enorme Iglesia de San Juan del Río memorable por su gran atrio que se integra en este "paseo" singular por su disposición dentro de la ciudad y en el escenario adecuado para la reproducción del mito y del rito católico.

Este conjunto de plazas de San Francisco se extiende y conecta por un puente al otro lado del río con la plaza actualmente denominada de "Dolores". Más adelante y con dirección hacia el Sur se observan dos plazas en lo que se conoce como "El Parián". La siguiente plaza en el centro de la ciudad tiene las diversas funciones de centro cívico, de recreación, religioso, de poder político, de plaza de toros, de registro administrativo de mercancías y otras actividades; los principales edificios que rodean la plaza son: la catedral al sur, el palacio de gobierno al norte, los portales al oriente y el poniente: es la Plaza Mayor de LCLA.

vi. MANZANAS son en su mayoría rectangulares con el ya sabido modelo de cien por doscientas varas y que suman 249 manzanas con forma y dimensión similares que representan el 73\% del total de las manzanas (342) de la Ciudad (véase Plano 6.10).

vii. PARCELACIÓN. Por lo que respecta a la parcelación de ocho predios de $50 \mathrm{x}$ 50 varas dispuestos en manzanas de 200 x 100 varas se cuenta con 96 y que equivale a 33\% del total (véase Plano 6.10).

viii. EL SECTOR URBANO 5, alrededor del Convento de San Francisco, tiene manzanas cuadradas; esta disposición en el trazado se debe a que esa era la tradición urbanística de los frailes franciscanos, ${ }^{6}$ los casos más próximos son la ciudad de Cholula, Huejotzingo, Calpan y Tlaxcala, en los tres últimos alrededor del convento se presenta la disposición de las manzanas ortogonales y lados del mismo tamaño. El sector 5 (véase Plano 6.2.) tiene como cualidad más evidente, la forma cuadrada de las manzanas, esto es, 25 de las 33 manzanas son cuadradas y equivalen al $76 \%$ del conjunto de manzanas pertenecientes a este sector urbano (véase Plano 6.10).

ix. EL TOTAL DE MANZANAS CUADRADAS en la mancha urbana son 54 y representan el 16\% del total (véase Plano 6.10). 
x. EL GRAN PREDIO. Llama la atención la existencia de un gran predio o supermanzana fuera de la traza urbana en el que se ubica un pequeño poblado llamado San Balthazar, con una pequeña iglesia y un conjunto de casas aisladas.

xi. MORFOLOGÍA DE MANZANAS. Para observar lo que se refiere a la morfología de las manzanas y su parcelación, el Plano 6.10. nos muestra que hubo en la ciudad una amplia y rica variedad de formas de manzanas y distribución de las parcelas, que nos remiten a una ciudad compleja y con más recursos desde la morfología urbana; sin duda, en este momento de registro, 1698, muestra el proceso culminante de crear ciudad en el sitio geográfico elegido por indígenas y europeos; adecuando las ideas europeas de morfología urbana y las preexistencias urbanísticas indígenas, a través de las adecuaciones en las formas de las manzanas y en la adaptación de las calles a esos requerimientos. Desde esos motivos, podemos considerar su morfología como una de las experiencias más valiosas en América. 


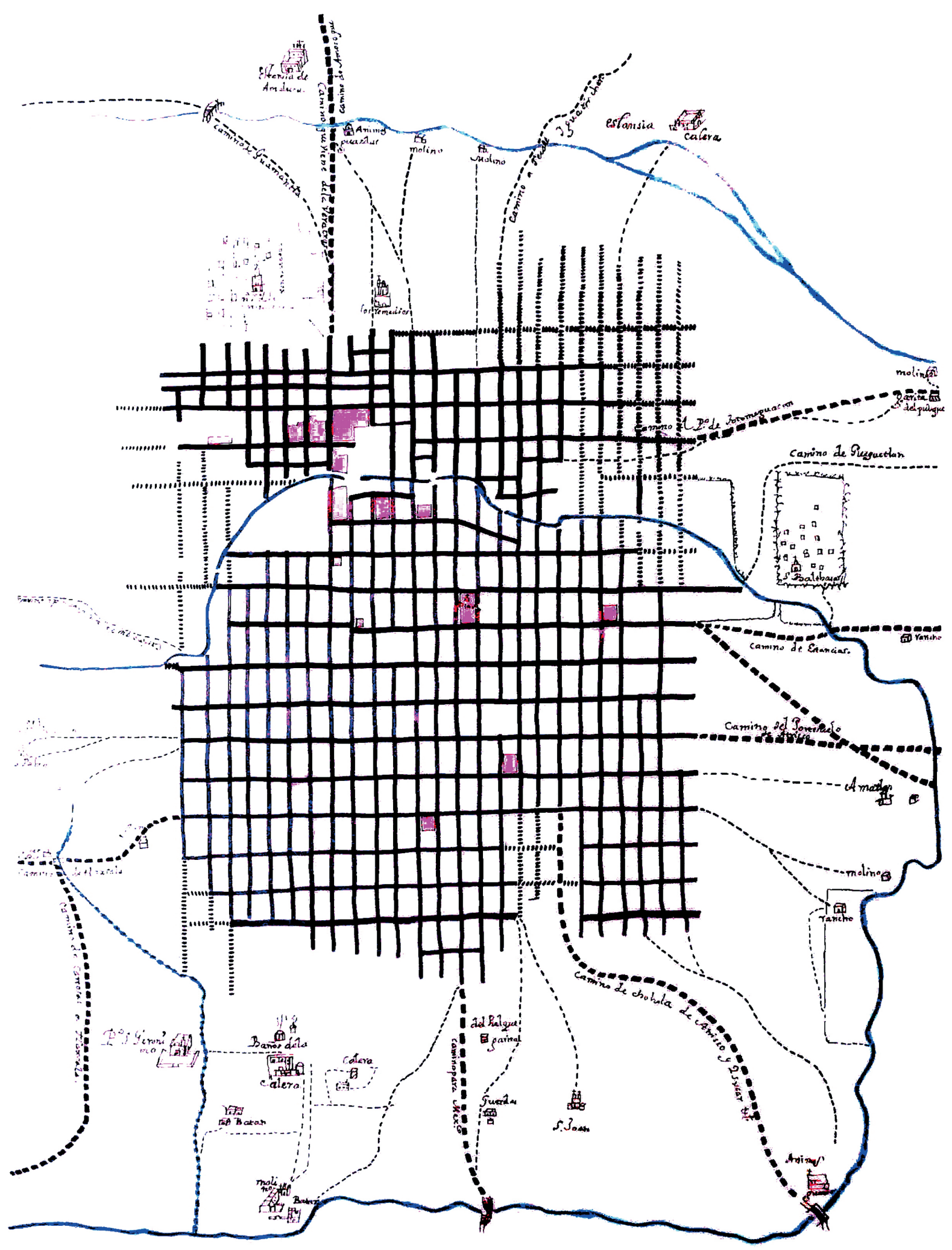

PLANO 5.8. Traza urbana, plazas y caminos de la ciudad en el plano de 1698. 


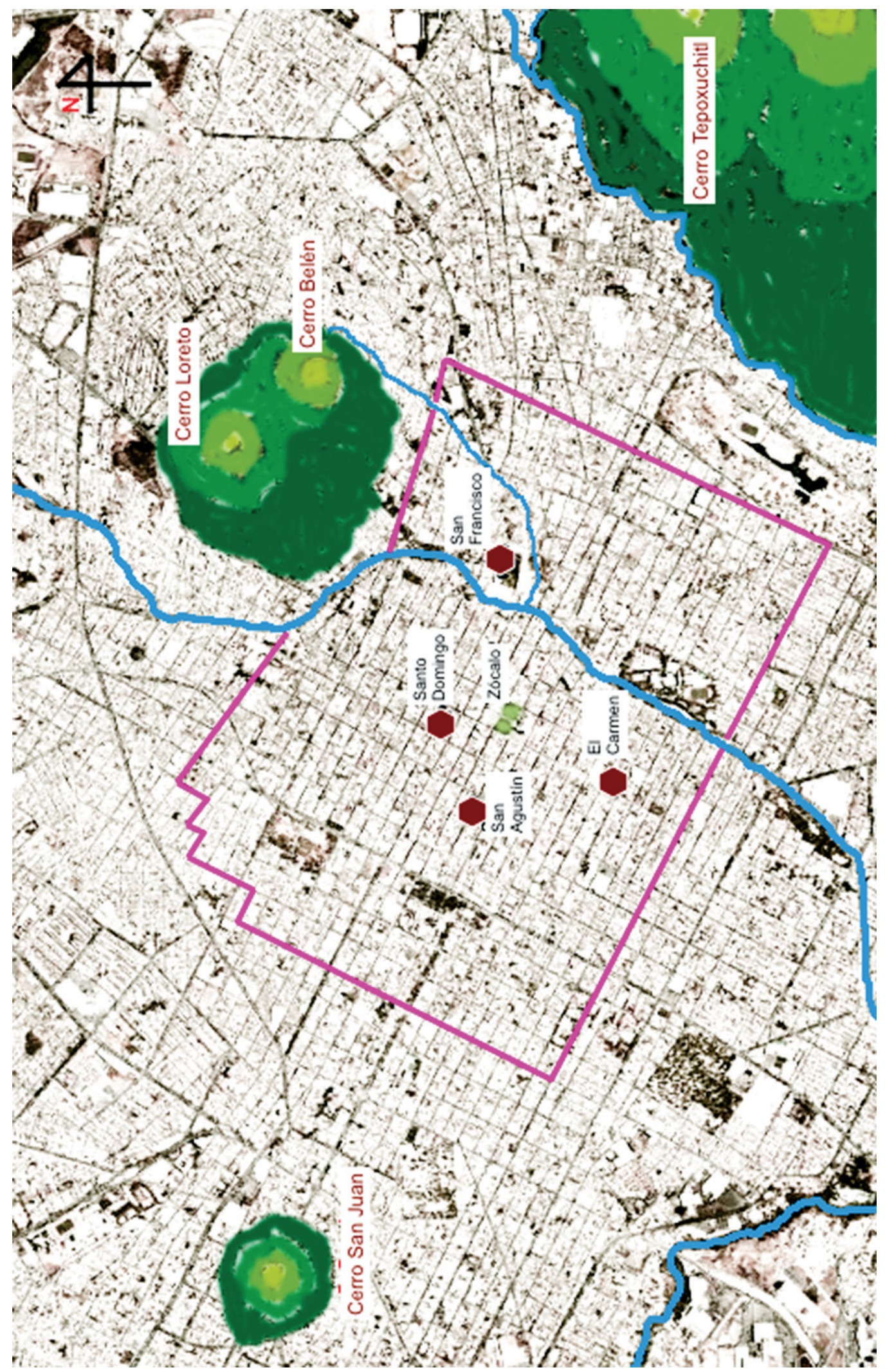

PLANO 5.9. Delimitación de la traza urbana del año 1698 con los ríos

y cerros principales en una fotografía urbana actual. 


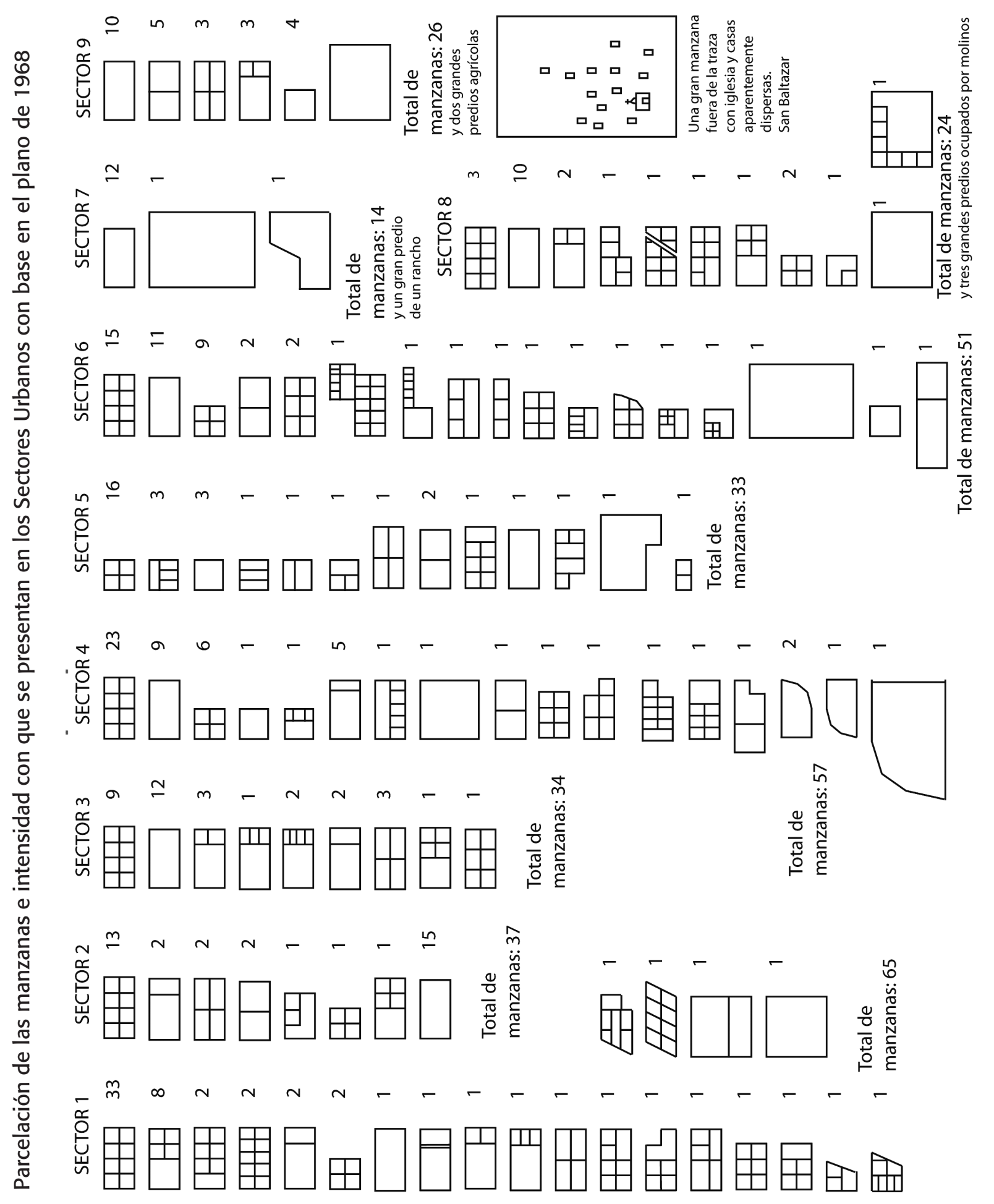




\subsection{PRINCIPALES EJES DE COMPOSICIÓN}

Desde el punto de vista comercial y de fiscalización regional y local, identificamos los ejes de composición a partir de la proveniencia de las rutas comerciales y caminos en su integración con las calles, plazas y conventos de LCLA.

1. CIUDAD DE MÉXICO-VERACRUZ. En primer término, la dirección más importantes y privilegiada de la ciudad en el plano corre de poniente a oriente; es la unión de los caminos por la traza urbana de LCLA. Este camino viene de la Ciudad de México, cruza el río Atoyac por el Puente de Piedra y antes de entrar a la traza urbana se bifurca. El primer ramal recorre nueve manzanas, pasa por la Plaza Mayor, dos cuadras más adelante da vuelta a la izquierda -hacia el norte- en la calle paralela al río hasta la plaza de Dolores, cruza el puente del río San Francisco y llega a la enorme plaza y Convento de San Francisco, dos cuadras adelante se incorpora al camino a Veracruz. El segundo ramal, entra de poniente-oriente, recorre cuatro manzanas pasa por la plaza y el convento de San Agustín, cuatro cuadras adelante da vuelta hacia el norte por una calle en diagonal durante tres más, se enlaza de nuevo al primer ramal en el trecho hacia la plaza de Dolores. Enfatizamos el hecho de que este recorrido de enlace entre los caminos a Ciudad de México y a Veracruz pasa por el 80\% de las plazas registradas en el plano, el corredor urbano más importante de LCLA por su contenido edilicio y su calidad urbanística presenta una trayectoria en forma de bayoneta.

ii. PUEBLA-ACAPULCO. Observamos en el plano el eje que va de la Plaza Mayor a la Iglesia del Carmen con un recorrido de seis cuadras en la dirección al Camino del Portezuelo de Atrixco, y al Camino de Estancias. En el primer ramal, el destino final es el Puerto de Acapulco en la ruta a Filipinas; el destino inmediato: Atlixco y su región, fueron sustanciales en la producción y en la industria de los molinos de trigo, con un intercambio comercial intenso con LCLA; el segundo ramal hacia las Estancias, donde estuvieron las unidades agropecuarias en las que se produjo forraje y cría de ganado.

iii. OAXACA-PUEBLA. El camino que llega a la LCLA proveniente a lo lejos de la región de Oaxaca, pasa por los pueblos emblemáticos por su predominio guerrero y económico antes del contacto con los europeos: Tepeaca, Cuauhtinchan y Totomehuacan; entra a la traza de la ciudad en la dirección sur-norte, recorre 14 cuadras y remata en el Convento de San Francisco y su plaza.

iv. TLAXCALA-PUEBLA. Del camino de Tlaxcala a LCLA se accede por la actual Calle 11 Sur, recorre 11 manzanas, pasa por la plaza que se ubica junto a los Baños, recorre otras 12 manzanas, sale de la traza y continúa hacia la industria de los molinos de trigo, al Atoyac y un Rancho. El caso de estos ejes tienen 
importancia por la relación política que tiene con los pueblos de Tlaxcala y sus aliados de Totomehuacan sobre todo durante el siglo XVI y posteriormente en la construcción de obras civiles.

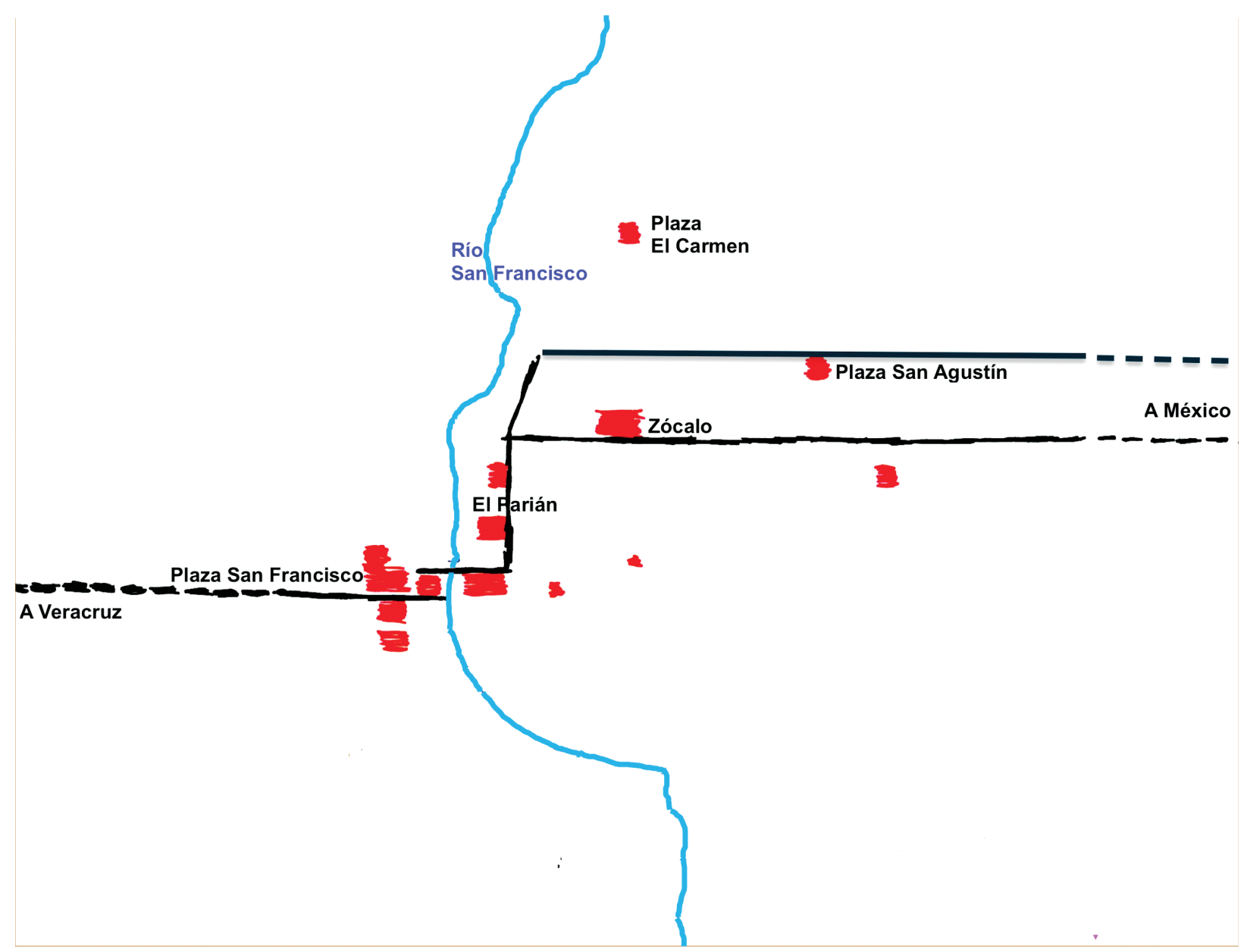

PLANO 5.11. Caminos de penetración-salida a LCLA y los ejes con los espacios de actividad comercial: guardas, garitas, plazas, aduanas y conventos según el Plano de 1698. 


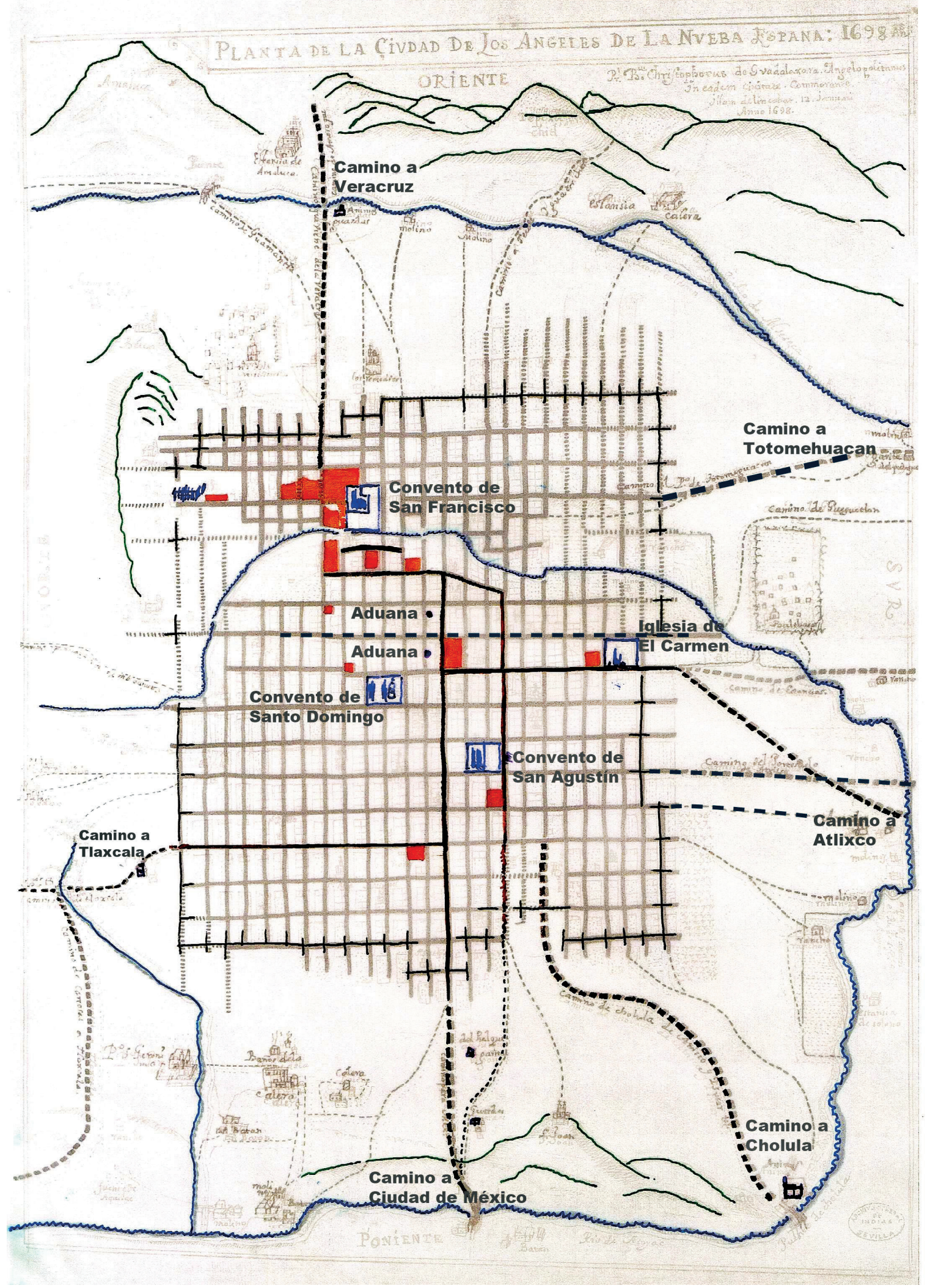




\subsection{FISCALIZACIÓN DE BIENES Y PERSONAS}

\section{GUARDAS}

Las guardas o lugares de salvaguarda para la ciudad se encuentran situadas estratégicamente, todas en la intersección entre caminos y ríos o barrancas, en los siguientes sitios:

1. En caracteres latinos junto a un edificio aparece el letrero: guardas Ánimas; el edificio está situado al oriente de la ciudad por fuera de la mancha urbana en la intersección del río Alseseca y el camino que va a Amozoc y al Puerto de Veracruz.

2. Otro edificio con el letrero: guardas, está situado al poniente de la ciudad antes de cruzar el río Atoyac cerca del llamado Puente de Piedra que cruza el río y que formó parte del camino a la Ciudad de México.

3. Con el nombre de guardas Ánimas está el edificio ubicado al suroeste de la ciudad junto al Puente de Cholula, que cruza el río Atoyac y que formó parte del camino, cuyos destinos fueron Cholula, Atlixco e Izucar.

4. Al norte de la ciudad, en la intersección del Camino a Tlaxcala, la Barranca de las Trancas y el Camino de Carretas se encuentra el edificio con el letrero guardas.

\section{GARITAS}

Las garitas o lugares de defensa y fiscalización de las mercancías y los transeúntes que entraban y salían a la ciudad se encuentran registradas en el plano como sigue:

1. Con el nombre de garita del pulque se observa un edificio situado al poniente entre la mancha urbana y el edificio guardas junto al camino para México.

2. Al sureste de la ciudad junto al camino al Pueblo de Totomeguacan se sitúa el edificio con el nombre de garita del pulque.

3. Fuera de la traza urbana de la ciudad por el lado Norte junto al Camino de Tlaxcala está situado un edificio con el nombre de garita.

En el primer y tercer casos las garitas son antecedidas por un edificio de guardas, en el segundo caso no aparece, pues la garita está en el extremo del plano y es probable que el edificio de guardas se encontrara después de ésta. Sin embargo, es prudente señalar la estrecha relación entre guardas y garitas, que, evidentemente, conformaban lo que podemos denominar el borde de defensa y fiscalización de bienes y personas que entraban y salían de la ciudad por los caminos. 


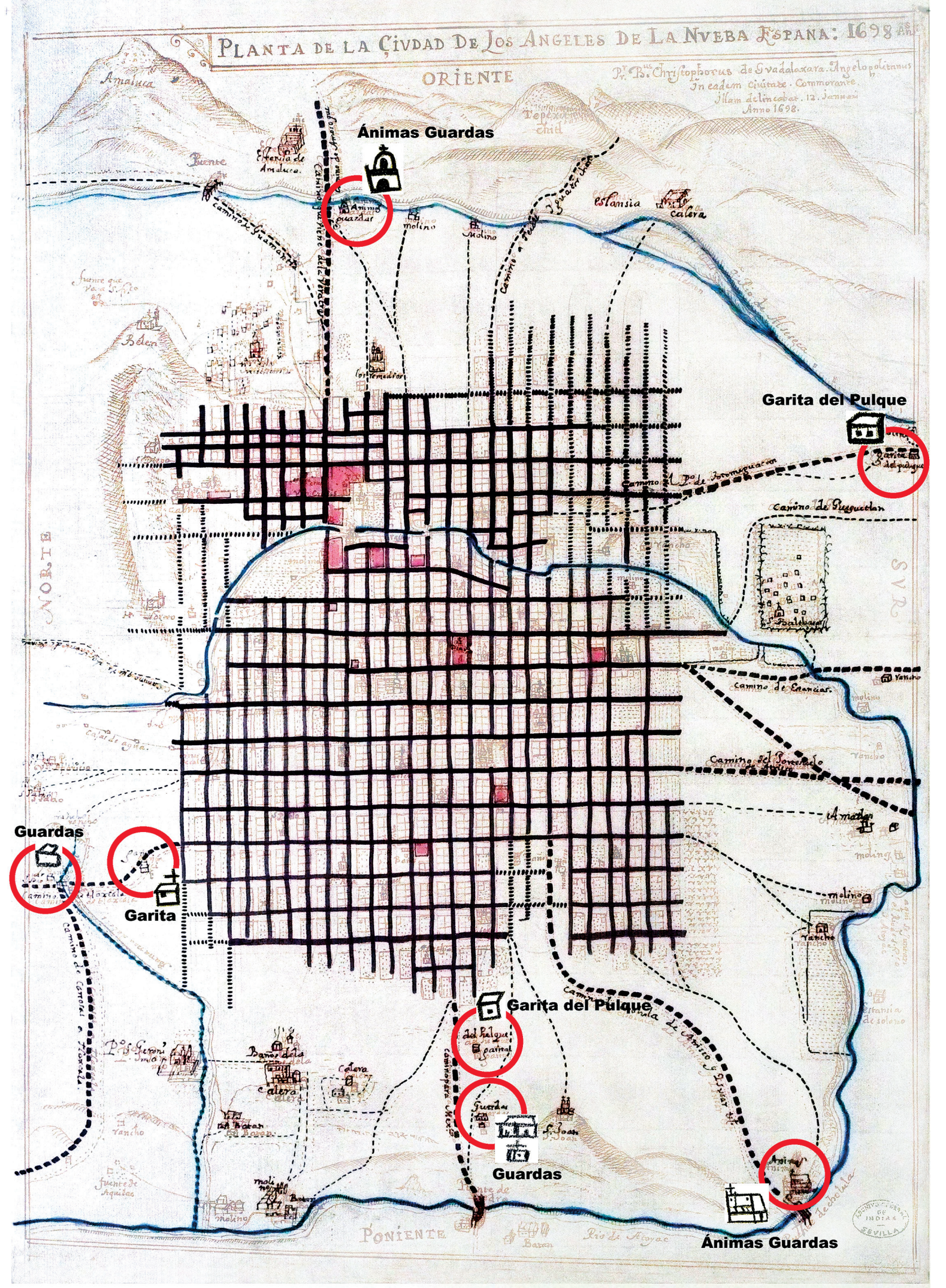


Entre los siglos XVII al XIX, las guardas y las garitas funcionaban en ciertos periodos de tiempo para la vigía de personas; en otros, para la fiscalización de mercancías en su paso por la ciudad; esto dependía de las condiciones para la recaudación fiscal o de la tensión social existente en un determinado momento. De cualquier manera, las guardas y garitas por tradición europea y por su disposición en el territorio de LCLA, definitivamente tuvieron una condición militar tanto en los diseños arquitectónicos como en la localización estratégica en el entorno de la ciudad. El comercio masivo de mercancías siempre ha estado asociado con la protección militar.

\subsection{SUPERVISIÓN DE GARITAS EN 1697}

De acuerdo con el Legajo del Archivo General de Indias, contamos con la siguiente descripción en torno a las garitas y guardas existentes hechas por el Juez privativo superintendente de las Reales Alcabalas de Puebla Don Joseph de Veitia Linage los días 24 y 25 de noviembre de 1697. En ese expediente se describen las garitas y guardas registradas en el plano de 1698 y en algunos casos, las distancias que separan a unos de otros; también en el Plano 6.14 plasmamos cómo, cuando y en dónde se realizaron estas visitas por el enviado real.

A continuación citamos en amplitud los autos que dan fe de la importancia fiscal de LCLA para la Corona, para lo cual, primero se procedió a la supervisión de los edificios fiscales existentes. Los citamos en amplitud para observar como se realizó este proceso que antecedió al proyecto del círculo de garitas.

Garitas y guardas existentes en LCLA hasta noviembre de 1697.

Autos del 25 de noviembre de 1697 con la clasificación: AGı, México, 341.7

Folio 15v-16

AUTO [GARITAS]

En la muy noble y leal Ciudad de Los Ángeles a veinte y tres días del mes de noviembre de mil seiscientos noventa y siete años su merced dicho señor Juez privativo superintendente de las Reales Alcabalas Haciendo dicho tanteo, Regulación y Vista de ojos de los ejidos, entradas y salidas de la ciudad, caminos Reales y veredas para la disposición de las Garitas donde los Guardas han de asistir. Respecto de no saberse entre las que sean reconocidas cuales son de la ciudad y cuales del asiento del pulque. Mandaba y Mando se despache Recepta para que esta nobilísima 
Ciudad ordene se muestren a el presidente escribano las que le pertenecen y así lo proveo y firmo. Don Juan Joseph de Veitia Linage. Ante mi Antonio Ximenez de Guzmán escribano.

Folio 16-16v.

AUTO [MOSTRAR GARITAS EXISTENTES]

En la muy noble y leal Ciudad de los Ángeles en Veinte y cuatro días del mes de noviembre de mil seiscientos noventa y siete años el Señor Juez privativo superintendente de las Reales Alcabalas de esta ciudad, Don Juan Joseph de Veitia Linage, Con vista de la Recepta de esta nobilísima ciudad, en que dispone salga el escribano de su ayuntamiento con un portero a mostrarle las garitas, que le pertenecen; a el presente escribano. Mandaba y mandó, ponga y asiente por testimonio las que por los susodichos se le mostraren con claridad y distinción para la disposición más conveniente de las que se han de edificar y fechas las diligencias dará cuenta y así lo proveo y firmo. Don Juan Joseph de Veitia Linage. Ante mi Antonio Ximenez de Guzmán escribano.

Folio 17-17v.

TESTIMONIO

En cumplimiento del Auto por su merced proveído y resuelto por la nobilísima Ciudad. Certifico y doy testimonio en la más bastante forma que puedo y debo, cómo habiendo salido en compañía de Francisco Herrera Calderón escribano público y teniente de cabildo y de Joseph, sumaba su portero para el camino del portezuelo que llaman de Amatlan y llegado al molino que está inmediato a la Barranca donde dijo dicho portero ser uno de los caminos principales que entran en la ciudad y que en tiempos de naos de Philipinas es más frecuentado y no haber en él garita porque el guarda que ha asistido en dicho camino ha estado en dicho molino inmediato a la ermita. Y continuando la diligencia se llegó al puente de Vigas Camino de Cholula donde dijeron no haber Garita y haber asistido siempre los Guardas en ermita de las Ánimas que está inmediata a el Río de Atoiaque; y de aquí se pasa al camino Real de esta a la Ciudad de México y llegando a la garita inmediata al cerro de San Juan, dijeron ser y pertenecer a la ciudad; y cruzando el llano para el poniente hasta coger el camino Real que va a Tlaxcala y continuando por él a la parte del norte donde como a tres cuartos de legua de la ciudad se mostró otra garita que dijeron ser también de ella, la cual esta a orillas de una barranca por frente de la Hacienda que llaman de Las Trancas, y por ser tarde se quedó esta diligencia en este estado para proseguirla mañana y para que conste en virtud de lo mandado doy el presente en la muy noble y leal Ciudad de los Ángeles, en veinte y cuatro días del mes de 
noviembre de mil seiscientos y noventa y siete siendo visto por Luis de Benavides Franco Bazan y Juan Silvestre, vecinos de esta ciudad. Ante mi y hago mi signo. Antonio Ximenez de Guzmán.

Folio $17 \mathrm{v}-18$

PROSIGUE

En continuación de lo mandado habiendo salido de la ciudad, en compañía de otro escribano y portero para el llano de Totomehuacan; se mostró la garita que está en el camino Real que va hacia dicho pueblo y otras partes que dijeron ser también y pertenecer a la ciudad y que no tiene otras ningunas, porque el guarda del camino de Amozoque tiene su asistencia en la ermita de las Ánimas y respecto de no haber otra diligencia que hacer, por Consta y a por la Vista de Ojos que su merced hizo las

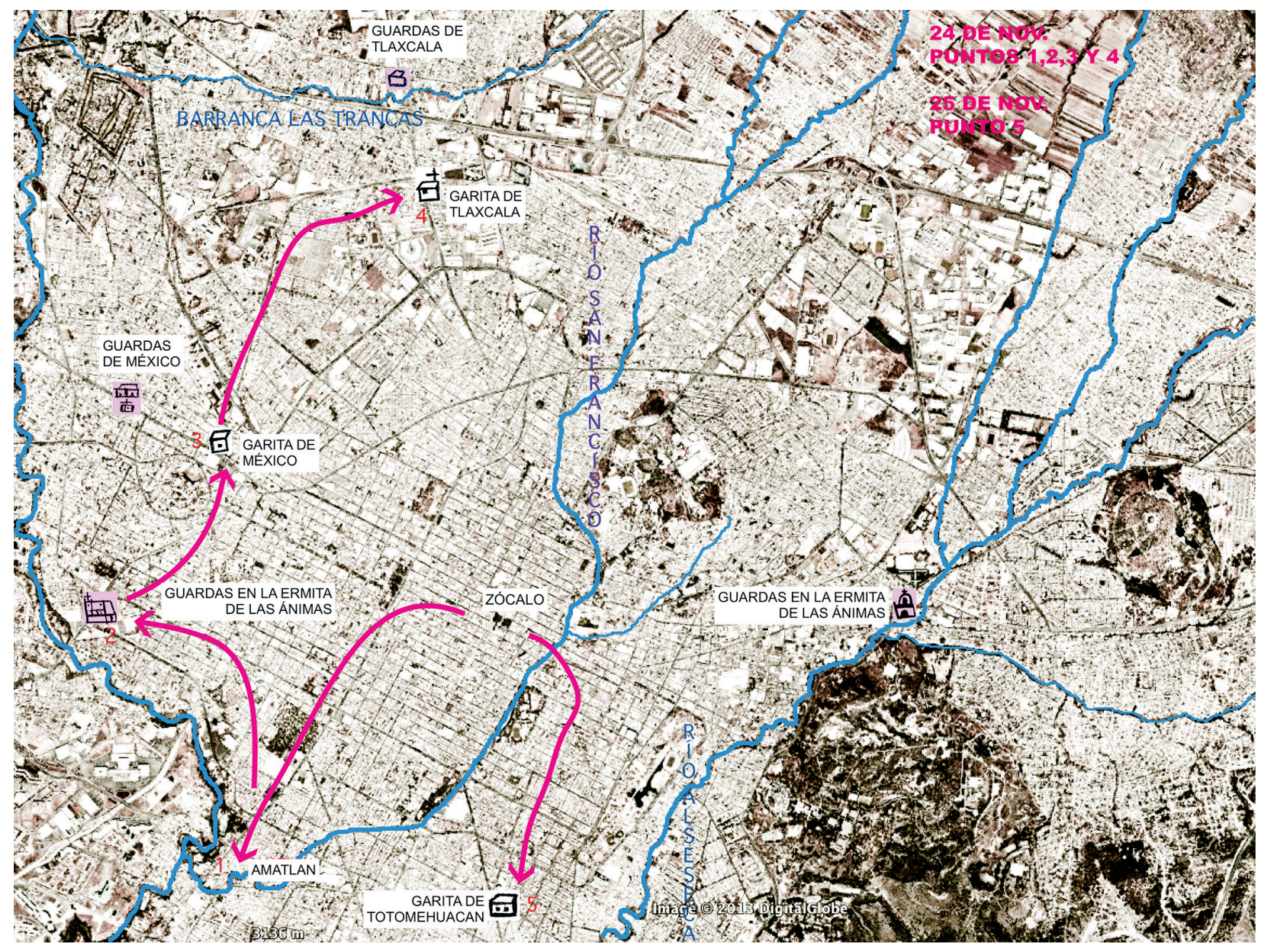

PLANO 5.14. Garitas y lugares visitados por el Juez Privativo Superintendente de las Reales Alcabalas de Puebla Don José Veitia Linage, el escribano público y su portero los días 24 y 25 de noviembre de 1697. Identificación por JGAc sobre fotografía aérea del año 2013 de la ciudad de Puebla. 
distancias que hay de unas a otras partes y constar asimismo cuáles sean las garitas de la ciudad en virtud de lo mandado doy el presente en ella a veinte y cinco días del mes de noviembre de mil seiscientos noventa y siete años, siendo testigos Luis de Benavides, Joseph, Antonio y Juan Camacho, vecinos de esta ciudad. Ante mi y hago mi signo Antonio Ximenez de Guzmán escribano.

\subsection{DISPOSICIÓN DE NUEVAS GARITAS EN 1698}

En el Auto del 26 de noviembre de 1697 encontramos la orden de la nueva localización de las nueve garitas propuestas para LCLA, después realizamos un plano con la identificación de los sitios, en donde se ubicó el nuevo círculo de garitas en una fotografía urbana actual para contar con una referencia más realista del manejo del espacio urbano y geográfico de la ciudad.

Localización de las nueve garitas propuestas en círculo para la fiscalización de mercaderías en LCLA

AGI, México, 341. Folio 18-19v.

AUTO EN QUE; SU MINISTRO; DA LA FORMA DE LAS GARITAS Y PUESTOS EN QUE SE HAN DE EDIFICAR Y MANDA SE FORME MAPA DE LA CIUDAD

En la muy noble y leal Ciudad de los Ángeles en veinte y seis días del mes de noviembre de mil seiscientos noventa y siete años su merced el señor Juez privativo superintendente de las Reales Alcabalas de esta ciudad. Habiendo visto las diligencias y testimonios de susodichas por el presente escribano en orden al reconocimiento de las garitas de la ciudad para cuyo efecto salió con el teniente y escribano del cabildo y uno de sus porteros en virtud de lo expresado en su Recepta y respecto de que esta ciudad, no ha tenido ni poseído según parece mas que tres garitas, que la una está en el camino Real que va a la Ciudad de México; a la parte norte otra en el Camino de Tlaxcala por el mismo viento donde llaman la Hacienda de Las Trancas y la que está a la parte del sur Camino Totomehuacan porque las demás que en circunvalación de la ciudad se muestran son de las guardas de la gentuza del pulque y porque es necesario edificar las más de ellas a competentes distancias para que los guardas puedan cómodamente vigilar los muchos caminos y veredas, que por todas partes hay, las cuales están en las puertas siguientes.

1. La garita que está en el camino de Totomehuacan se ha de retirar y fabricar más al centro en un altillo inmediato al Camino Real que sale de la Ciudad para esta parte porque desde allí podrán los guardas reconocer todos los caminos que por el llano pasan. 
2. En el camino que va al portezuelo que llaman de Amatlán después de pasada la Barranca, se ha de fabricar en lo más eminente de la subida otra garita porque aunque hay poco más de media legua de este puesto a él en que se ha de fabricar la antecedente, se divisan una a otra y reconocen los caminos que hay por todo el llano.

3. En el camino de Cholula a la subida más adentro se ha de fabricar otra porque además de los caminos mencionados en la Vista de ojos que vienen de Atlixco, Acapulco, Amilpas y otras muchas partes y los de Cholula que pasan por allí estará en parte proporcionada para cuidar la vereda que viene por tras el Cerro de San Juan orilla de Atoiaque [el río].

4. Otra garita antigua demolida y arruinada que está a distancia de media legua del puesto donde se ha de poner la antecedente Camino Real de México que ha sido del asiento del pulque, se ha de reedificar por estar en proporcionada distancia y más a el centro porque aunque la ciudad tiene Garita por esta parte, está más retirada y es menos a propósito.

5. Otra Garita se ha de edificar inmediata a una ermita que está Camino de Tlaxcala que llaman Santa Cruz por ser el lugar apropiado para reconocer el dicho Camino Real y el del paso del Atoiaque que llaman de Las Caleras y los muchos que por un lado y otro de dicha ermita pasan.

6. Asimismo se ha de edificar otra Garita sobre la loma de Belén inmediata a una que tiene allí el asiento del pulque por donde causan y salen de la ciudad muchos caminos que también van a Tlaxcala a la sierra y a las haciendas de Guamantla y ésta por estar en parte alta descubre todo el llano por una y otra parte.

7. Otra se ha de formar y edificar en el vacío inmediato al rancho de labor que está después del barrio de Xonacatepec, Camino Real que va a Guamantla y pasa por la puente de Amaluca.

8. La garita del camino de Amozoque se ha de conservar en la ermita de Las Ánimas porque aunque está retirada y distante de la ciudad, está en lugar y puesto donde los caminos que salen de la ciudad, se juntan y ser el principal de la nueva Veracruz.

9. Otra Garita se ha de fabricar pasada la barranca del Tepoxuchitl. Por donde tienen muchos Caminos Reales y veredas y entran por varias partes en la Ciudad, de manera que a la distancia referida que dan en igual proporción y más comodidad para la custodia de los Caminos y para que tenga efecto lo referido. 
Mandaba y mando que Don Joseph Zurita vecino de esta Ciudad supla por ahora la cantidad que fuere necesaria para dicha obra que se le satisfará de las primeras condenaciones, que se causaren en dicha Real Aduana. Y para más clara inteligencia se ruegue y encargue a el licenciado Don Cristóbal de Guadalajara presbítero que como plástico e inteligente delinee la ciudad y sus ejidos, cuya figura y mapa se ponga con los Autos, para que con ciencia del susodicho; se reconozca y vea si los puestos mencionados, están en partes competentes donde se cojan los caminos, más principales que vienen para la ciudad para su mejor custodia. Y así lo proveyó, y firmo. Don Juan Joseph de Veitia Linage. Ante mi Antonio Ximenez de Guzmán escribano. 


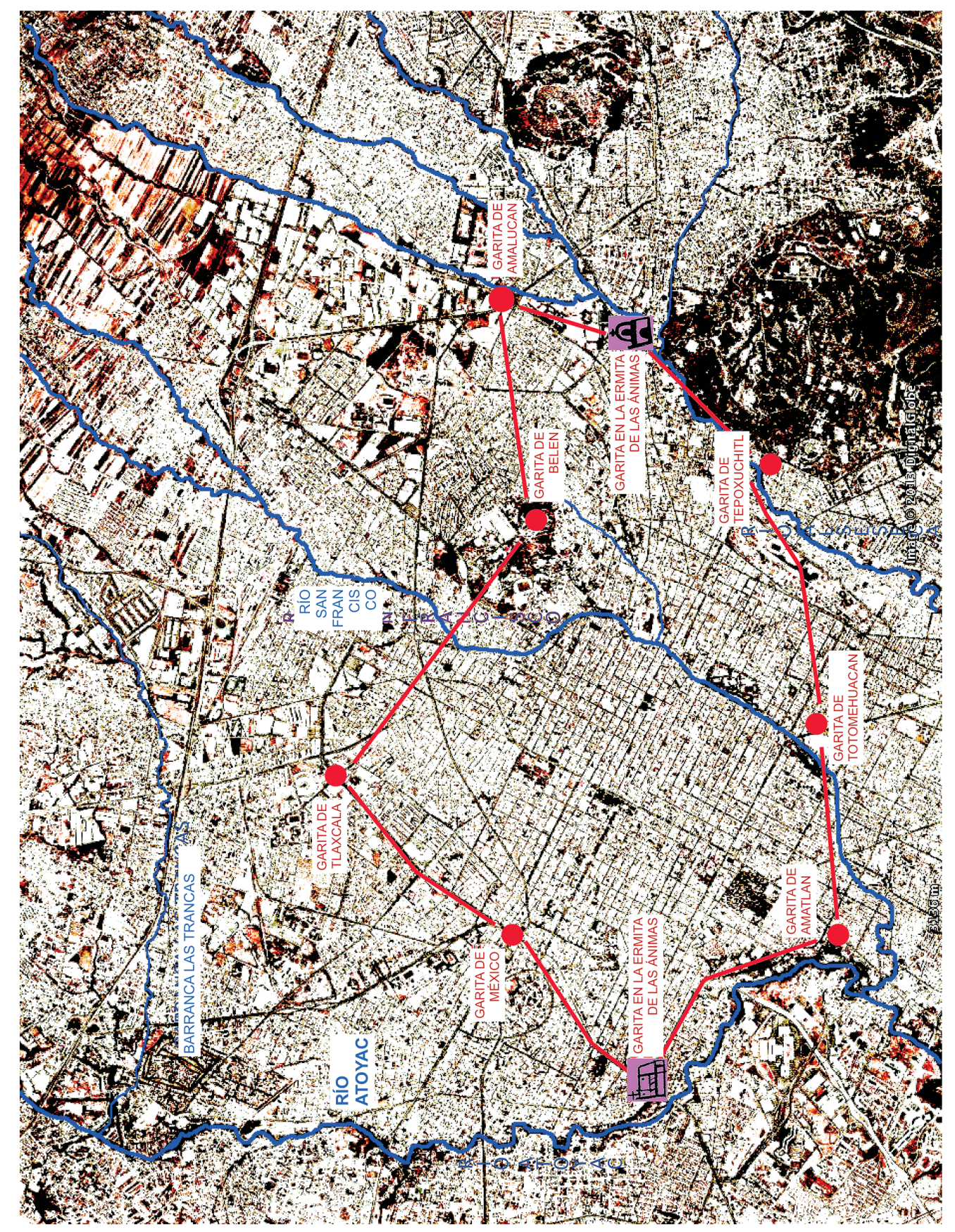

PLANO 5.15. Señala las Garitas propuestas por el Juez Privativo Superintendente de las Reales Alcabalas de Puebla Don Juan Joseph de Veitia Linage el 26 de Noviembre de 1697. Identificados y señalados por JGAC sobre una fotografía aérea del año 2013 de Google Earth. 
De los textos que aparecen en el expediente confirmamos la colocación de las garitas tomando en cuenta:

- LA UBICACIÓN de algunas de las garitas en sitios que dominan un paisaje amplio; colocadas, en su mayoría, en los caminos principales de acceso a la ciudad; en la intersección entre caminos con ríos o barrancas, junto a los puentes.

- EL CÍRCULO periférico a la ciudad. Hasta 1997 había 3 garitas existentes y dos guardas en lo que fueron ermitas; estuvieron bien ubicadas y por eso fueron consideradas en el proyecto de crear el círculo de 9 garitas que se implantaría a partir de 1698. Cada una de las garitas estaría unida a sus dos próximas vecinas por caminos para formar un cordón continuo alrededor de la ciudad.

- CAMINO DE RONDA. La idea de formar un cordón de caminos tendientes al círculo, se realizó para que haya la oportunidad de conectar las garitas entre si y evitar el paso de personas dedicadas al contrabando de mercancías sin pasar por las garitas o puertas fiscales de la ciudad.

- LA FORMACIÓN DEL MAPA de la ciudad. Los autos anteriores señalan la necesidad de realizar un mapa de la ciudad para la ubicación de las nueve garitas propuestas por Juan Joseph de Veitia Linaje, sin embargo, no aparecen las 9 garitas proyectadas, aunque sí están las existentes hasta 1697 en el mapa o plano de 1698.

\subsection{ADMINISTRACIÓN Y FUNCIÓN DE LAS REALES ALCABALAS}

Para completar el análisis de las garitas, es imprescindible contar con el registro de administración y funcionamiento de las Reales Alcabalas que encontramos y seleccionamos en el expediente y que a continuación presentamos; en estos testimonios reales, cédulas y autos vamos a constatar la importancia de la ciudad como puerto de tierra del imperio español y las características locales que debe adoptar para cumplir con la administración funcional en el amplio sistema de rutas comerciales.

AGI, México, $341^{8}$

Folio 1

TESTIMONIO DE LA REAL CÉDULA DE SU MAJESTAD.

En la muy noble y leal Ciudad de Los Ángeles a primero de noviembre de mil seiscientos noventa y siete años, el Señor Capitán de caballos coraza Don Juan Joseph

8. Identificación, selección y paleografía de Jorge GAC 
de Veitia Linaje caballero de la orden de Santiago contador mayor del tribunal y Real [...] de cuentas, de este Reino dijo que en ejecución y obedecimiento a Su Majestad que Dios guarde y por su real cédula su fecha, en Madrid a los veinte y seis de Junio del año pasado de mil seiscientos noventa y cinco firmada de su real Mano y Refrendada del señor Don Bernardino Antonio de Pardiñas Villar de Franco secretario en que le nombra por Juez privativo superintendente de las reales Alcabalas, de más servicios Reales, Unión de Armas, y armada de Varlovento de esta ciudad y lugares de su jurisdicción.

Por el tiempo de cinco años que han de correr y contarse desde el primero de enero del año próximo venidero de mil seiscientos noventa y ocho, para cuyo tiempo han de estar prevenidas las cosas conducentes y útiles, de esta administración y porque se ha de hacer reconocimiento de los Caminos Reales, entradas y salidas de esta ciudad y garitas donde los guardas han de tener su residencia y proceder a las disposiciones y ordenes que se han de observar para lo cual en virtud de la facultad que se le concede, nombrara su merced [...] por el tiempo de su voluntad y por el trabajo y ocupación le asignaba quinientos pesos de salario en cada un año pagado al fin del mismo y manda y mandó asiente y copie al pie de este auto la Real cédula de su Majestad con las demás diligencias de su presentación para que vaya por la vera de estos autos; y que para dar principio a las diligencias de su encargo le asista a el reconocimiento de los Caminos Reales de esta ciudad, entradas y salidas de ella y ponga por fe y diligencia la vista de estos; que su merced hiciere de los ejidos, distancia de Garitas para cuyo efecto asignara el día de mañana y demás consecutivos. Igual que en la manera que quede le hacía e hizo el alto nombramiento para que así los ministros de esta Real Aduana como todas las demás personas citantes y habitantes en esta ciudad y fuera de ella le hayan y tengan por tal escribano de esta Real Aduana guardándole las preeminencias y prerrogativas que como a tal le están concedidas, y así lo proveyó, mandó y firmó. Don Juan Joseph de Veitia Linage.

Ante mi Antonio Ximenes de Guzmán escribano de Su Majestad y de la Real Aduana de esta ciudad y su jurisdicción en cumplimiento del Auto de esta dicha parte hice sacar y saqué la Real Cédula de Su Majestad con las demás diligencias.

REAL CÉDULA

Presentación

Folio 11 Y 12

GUARDA MAYOR

...En la de Guarda Mayor a Don Joseph Méndez Hidalgo Azperiqueta quien ha de ser obligado por sí o en compañía de su ayudante que irán mencionados a cui- 
dar los caminos y contornos de la ciudad y que los referidos y Guardas menores, alternadamente conforme les cupiese, de noche compartidos en patrullas o en cuadras anden de unas en otras partes por toda la circunferencia de ésta; y en las partes caminos o veredas, donde amenazare riesgo, [designario] o fraude poner la prevención o guarda conveniente cuidando así mesmo que los guardas según su asignación estén y residan de día en sus garitas, puestos y caminos corriendo la sierra y campaña los pueblos circunvecinos y contornos para descubrir y saber las prevenciones que puede haber poniendo especial cuidado en el cumplimiento de su obligación.

FOLIO 12

AYUDANTE

En la de ayudante de dicho, Guarda mayor a Don Antonio de León Benet, quien en la misma conformidad se dedicará a la custodia de los caminos, de noche y de día conforme y cuando le cupiere distribuyendo una y otra entre los demás las órdenes que su merced diera y porque en el tiempo que por todas las entradas y ejidos ocurren partidas de ganado mayor han de tener especial vigilancia y cuidado así dicho, ayudante como dicho Guarda mayor de saber las cantidades que se vendieren trayendo razón de sus dueños con especificación para que por este medio se consiga el fin principal.

Folio 12-12v.

\section{RONDAS 4 personas}

En las de rondas de Juan Antonio Palomino. Francisco Mijares Ortiz, Don Gaspar Fernández de Viana y Don Agustín de Poussa quienes han de ser obligados según [...], a rondar de noche y de día la ciudad y sus contornos, visitar las garitas y así estar a su custodia y mandar que alguno de los guardas menores conducen a esta Real Aduana las cargas y recuas, visitando asimismo y rondando la campaña reconociendo los pueblos circunvecinos y demás partes mayormente con algún indicio o sospecha y patrullas que de noche se han de formar compartiéndose según el número que hubiere.

Folio 12v. - 13

GUARDAS (16)

$\mathrm{Y}$ porque el tanteo, y reconocimiento, vista de ojos y diligencias fechas a prevenid a su merced nombrar y con efecto exige y nombra diez y seis Guardas menores que estos han de estar de pie compartidos en las garitas conforme su asignación; más o menos según la frecuencia y entradas de los caminos. Los cuales son [se nombran catorce de los diez y seis]. Que éstos han de ser obligados a asistir en sus 
puestos según y como va referido en los días y horas y alternándose de veinte y cuatro horas a veinte y cuatro horas, y de noche de forma que sea igual el trabajo reconociendo las recuas, pasajeros y demás cosas, que sean conducentes, a la buena administración dando, las Guías de la cantidad de cargas, y Géneros que fueren conduciéndolos de esta Real Aduana; Guardando y observando las órdenes que se les ordenaren y distribuyeren por el Guardia mayor o su ayudante asistiendo de noche a la escuadra y patrullas, que se han de formar Rondando los ejidos y su circunvalación de la ciudad combinadamente conforme a quienes tocare guardando asimismo la forma e instrucción que se les diere.

Folio 13

MINISTRO

En la de ministro de Vara a Miguel de Sierra Alta Arroyo quien ejecutará los mandamientos y órdenes que se le dieren haciendo los llamamientos y diligencias que fueren de su obligación y anexas a su oficio y ministerio. Todos los cuales han de ser obligados a dar cuenta a su merced, de las diligencias que se ejecutaren para que dé las providencias convenientes.

Folio 13

ASESOR

En la de asesor. A el licenciado Don Diego de Alcorta Camacho abogado de la Real Audiencia de esta Nueva España con cuyo parecer se han de resolver los puntos y casos que se ofrecieron en este juzgado.

Folio 13

FISCAL

En la de Promotor fiscal a el Doctor Don Diego Joseph Conchoso asimismo abogado de ella para que por lo que tocare a Su Majestad y sus reales haberes deduzca su real arbitrio.

Folio 13-13v.

COMISIÓN DE GUÍAS DE LA VERA CRUZ

En la de Comisarios de Guías de la nueva Vera Cruz a el Capitán Juan Baptista de Solabuena vecino de ella, el cual ha de dar las guías a los arrieros, carreteros y traficantes de los Géneros fardos o piezas que de dicho puesto sacaren ora sean para esta ciudad o para otra cualquiera parte con distinción de sus números, y marcas, su consignación y en recua de que arriere para que en esta Real Aduana se ajusten y comprueben con sus Guías así de los Géneros de Castilla, Caracas, Guaira, Maracaibo, Campeche, Habana y de más partes de mar en fuera y de sus costas reco- 
nociendo las cosas y partes donde presumiere pueda haber fraude o extravío a el cual se le despache un libro foliado, empergaminado y rubricado por el presidente escribano en que tome razón de dichas Guías, el cual remitirá a esta Real Aduana a el fin de año para que se le despache otro y todos los susodichos arrieros, carreteros y traficantes andasen obligados a manifestar ante dicho comisario la carga que de dicho puerto sacaren.

Folio 13v.

ESCRIBANO

El presente escribano a quien su merced tiene nombrado en dicho ministerio para la formación y disposición de los Autos, Testimonios y demás instrumentos que de aquí emanaren y se ofrecieren en este tribunal.

Folio 14-14v.

A el presidente escribano les despache nombramientos en forma especificando puedan traer $y$ traigan armas ofensivas $y$ defensivas $y$ les hayan $y$ tengan por Ministros de este Juzgado y puedan entrar y entren en cualesquiera casas, de esta ciudad o fuera de ella, Ranchos, haciendas o molinos, huertas y demás casas, donde presumieren o tuvieren noticia o pueda haber extravíos o fraudes, en que no se les pondrá embarazo ni impedimento alguno por ninguna persona. Jueces y Justicias de Su Majestad; antes en su real nombre les den y hagan dar el favor y auxilio que necesitaren arreglándose todos y cada uno de por sí al cumplimiento de su obligación que para todo lo referido les da comisión cuan bastante en derecho se requiere y es necesario y así lo proveyó y firmó Don Juan Joseph de Veitia Linage. Ante mi Antonio Ximenez de Guzmán escribano.

La administración de alcabalas y las funciones de los trabajadores contratados para cubrir las actividades que hicieran más eficientes y eficaces el registro, recolección de impuesto y control mercantil fueron definidas en el último quinquenio del XVII para la gran plaza comercial de LCLA. Los párrafos seleccionados del expediente en el AGı así lo manifiestan. De allí destacamos los siguiente:

- La construcción de un cerco fiscal y defensa de la ciudad: el resguardo de la ciudad.

- La definición de una estructura de funcionarios para la administración eficiente y eficaz en la recolección de impuestos.

- La identificación de las principales rutas y destinos en la relación con LCLA. Destaca como principal a. la ruta LCLA-Veracruz y de allí a Campeche, Castilla, Caracas, Guaira, Maracaibo y otras; b. la ruta LCLA a Atlixco, Acapulco y de allí a 
las Filipinas; c. la ruta a Tlaxcala; d. la ruta: a la Ciudad de México; e. la ruta a Totomehuacan, Cuauhtinchan, Tepeaca y de allí a Oaxaca.

- La disposición de armas ofensivas y defensivas para aquellos funcionarios que se considerara pertinente en la labor de ataque al fraude y el contrabando.

- Nuevas disposiciones para la ciudad que permiten funcionarios seleccionados para intervenir o allanar propiedades particulares que se consideren estar en fraude o realizando contrabandos. Medidas que colocaron a la ciudad en condiciones de mayor opresión social para contar con mayores recursos fiscales para la Corona de España.

\subsection{EDIFICIOS PARA LA PRODUCCIÓN}

\section{MOLINOS}

Los molinos fueron los edificios construidos en la rivera de los tres principales cuerpos de agua corriente: San Francisco, Alseseca y Atoyac.

En este plano se identificaron los siguientes:

Tres molinos en las orillas del Río Alseseca que llevaban por nombre: ${ }^{9}$

1. El Cristo

2. Santa Bárbara

3. Guadalupe

Ocho molinos sobre el río San Francisco:

1. San Antonio

2. San Francisco

3. El Carmen

4. Dos molinos en Huexotitla

5. La Teja

6. Dos molinos en Amatlán, cerca de la intersección del río San Francisco con el río Atoyac.

Tres molinos sobre el Río Atoyac

1. De en medio, cerca de la intersección con el río San Francisco

2. Dos molinos en el paraje de Santo Domingo, uno junto a la Barranca de las Trancas y que se abastecía de agua de la Fuente de Aguilar, el otro cerca de la barranca pero junto al Atoyac, según se indica en el plano.

9. Los nombres fueron tomados de Hugo Leicht, 1986 [1934]. 
Batanes. ${ }^{10}$ Se localizaron dos batanes junto al Río Atoyac, el primero cerca de la Barranca Las Trancas y el otro cerca del Puente a México, al igual que los molinos requieren de la fuerza hidráulica para el movimiento de máquinas y también el agua para el lavado de los hilados que producían.

10. El batán es una máquina destinada a transformar unos tejidos abiertos en otros más tupidos. Son impulsadas por la fuerza de una corriente de agua que hace mover una rueda hidráulica, que activa los mazos que posteriormente golpearán los tejidos hasta compactarlos. Estas máquinas, de extendida utilización en España, estuvieron en funcionamiento hasta finales del siglo XIX.

Se cree que la difusión de los batanes fue posterior a la de los molinos. La primera referencia que se tiene en España de los batanes es del siglo XII, unos documentos con fecha de 1160 sitúan dos batanes cerca de Gerona. Los batanes se extendieron por España, siendo numerosos los existentes en Galicia y destacando la comunidad asturiana en la que, a mediados del siglo XVII, había cerca de 200. Hoy en día la mayoría de ellos se encuentran en estado ruinoso o incluso totalmente desaparecidos, siendo muy pocos los que se conservan y siempre destinados únicamente a museo.

Un ejemplo de batán-museo, en la provincia de A Coruña, está en la parroquia de Mezonzo en el ayuntamiento de Vilasantar. Se cree que fue construido por los monjes que habitaban el monasterio de Mezonzo, donde ahora se encuentra la iglesia parroquial que data del siglo XII. De ser cierta esta creencia popular, sería uno de los batanes más antiguos de España. Este batán estuvo en funcionamiento hasta el año 1954, momento en que se abandona hasta su restauración en el año 2001 pudiendo ser visitado en la actualidad por el público.

Mientras estuvo en activo, el batán funcionaba desde el mes de febrero hasta junio. Durante el verano permanecía cerrado porque el río no tenía suficiente agua para su accionamiento y en el invierno no se podía utilizar porque era muy difícil el secado de las mantas.

Otro ejemplo de batán-museo se puede encontrar en la provincia de Huesca, concretamente se ubica en la localidad de Fiscal en la comarca del Sobrarbe. Se le conoce como el Batán de Lacort.

El emplazamiento de los batanes siempre es en la orilla de los ríos para aprovechar su fuerza hidráulica. En el cauce del río se construía una pequeña presa, desde ella el agua era conducida por una canalización con fuerte pendiente hasta la rueda. Al impactar el agua contra las cucharas de la rueda, esta comenzaba a girar llevando solidario el eje y poniendo en funcionamiento todos los mecanismos del batán. Al moverse la rueda se accionaban los mazos que comenzaban a golpear las mantas.

Otro pequeño canal conducía un poco de agua hasta la cuba para mantener mojadas las mantas durante buena parte del proceso, evitando su desgaste por rozamiento. Este chorrito de agua, a la vez también servía para refrigerar los soportes del eje.

Composición

Se trata de una máquina constituida casi en su totalidad por piezas de madera de roble.

Las partes más importantes son:

* La rueda, con un diámetro de tres metros y una serie de cucharas (a menudo dieciséis) repartidas regularmente en el perímetro, sobre las que impacta el agua que baja por el canal, produciendo el movimiento de la máquina.

* El eje que gira solidario a la rueda y por medio de dos levas hace mover los mazos.

* Los mazos, son dos que al caer golpean los paños que están situadas en la cuba.

* La cuba es el lugar en el que se colocan los paños. Está constituido a partir de un tronco de $230 \mathrm{~cm}$ de largo y $95 \mathrm{~cm}$ de diámetro que se excava en el centro hasta conseguir el hueco necesario para los mazos y los paños.

Elaboración del paño abatanado

A partir de aproximadamente unos $10 \mathrm{~kg}$ de lana de oveja se seguía el siguiente proceso:

1. Se lavaba y se secaba bien la lana, a continuación se cardaba con una carda de púas de alambre.

2. Una vez cardada se hacían pequeños lotes de lana llamados madejas. Se colocaban estas madejas en una rueca y con un huso se iban transformando en un ovillo de hilo.

3. Obtenidos los ovillos, las hilanderas utilizaban telares para tejer las mantas y las colchas, después de hacer las mantas se llevaban al batán para realizar el proceso de acabado.

4. Estas mantas eran colocadas en la cuba del batán siendo su longitud el doble del tamaño final de la manta.

El proceso de abatanamiento, en el que se elaboraban tres mantas de forma simultánea, duraba entre 24 y 30 horas. Durante el mismo se detenía el batán unas tres veces para cambiar las mantas de posición, finalizado el proceso, la manta quedaba lista para ser secada. 
127
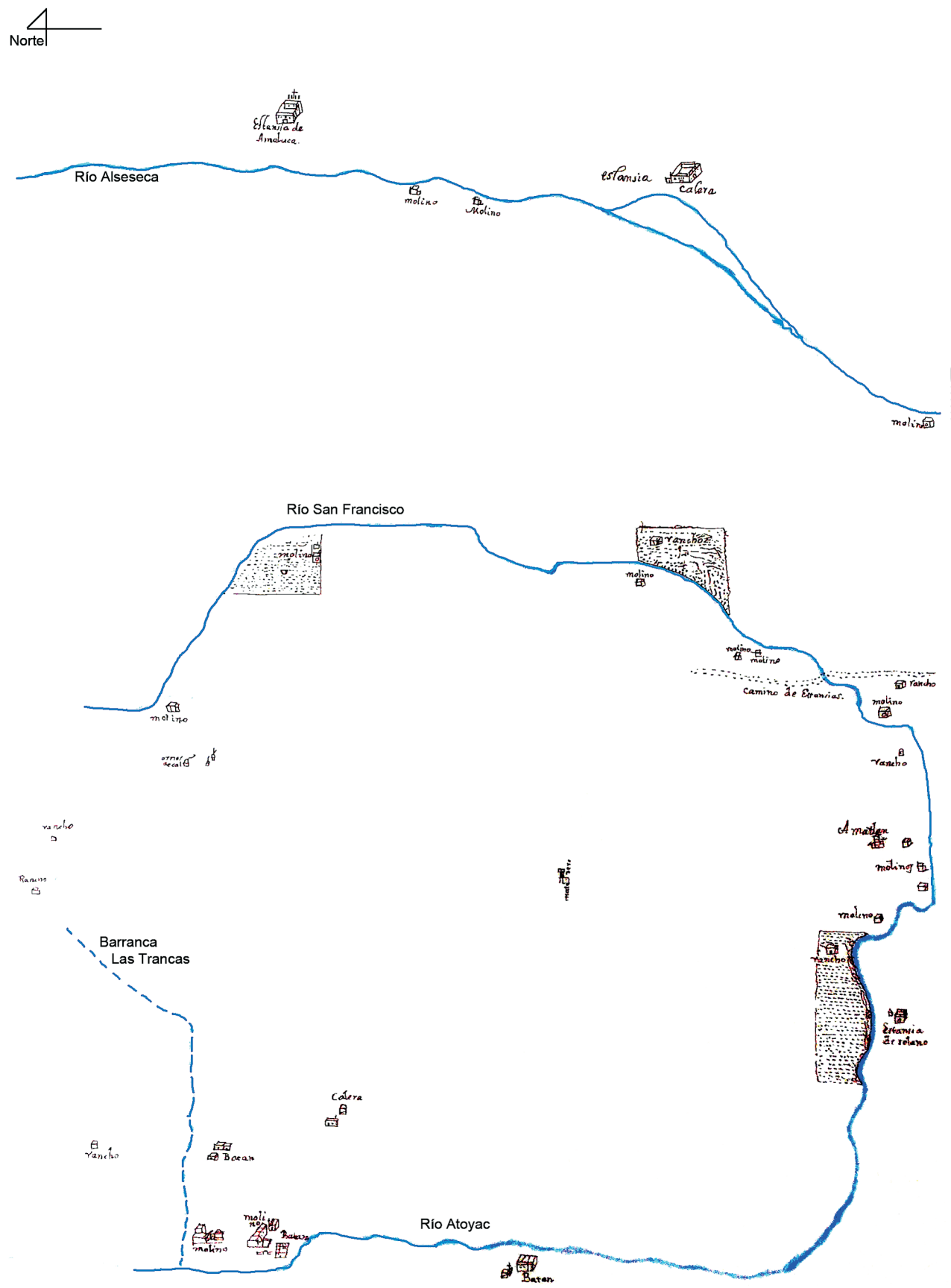

PLANO 5.16. Molinos y otros edificios productivos junto al agua en el Plano de 1698. 


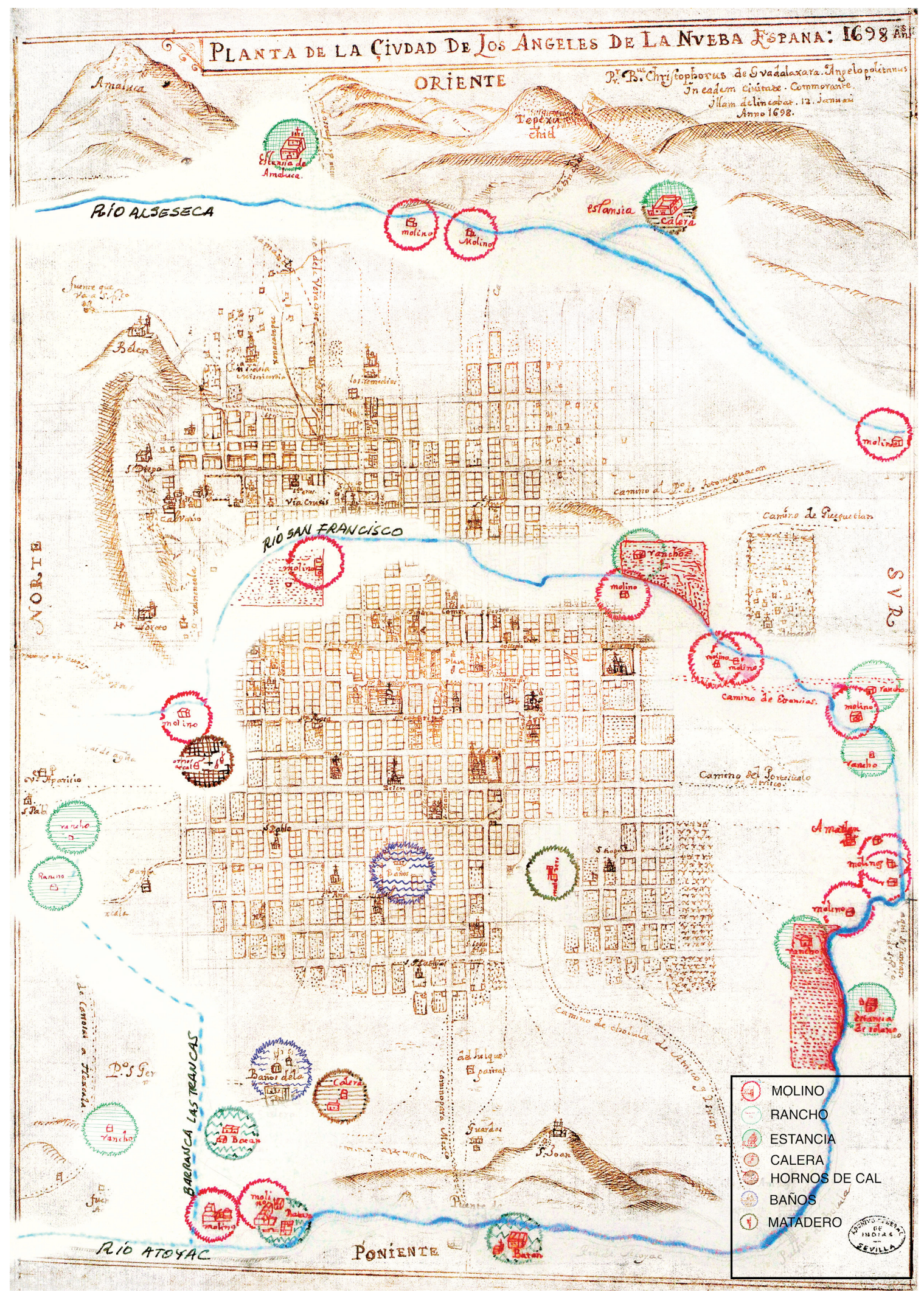

PLANO 5.17. Molinos y otros edificios productivos en el Plano de 1698. 


\subsection{TERRENOS DE CULTIVO}

Observamos que, en el plano de 1698 está definida la traza urbana como un gran cuadrángulo que tiene 342 manzanas de diversas formas y con variadas parcelaciones. De ese amplio conjunto de manzanas aproximadamente hay $40 \%$ que no aparece parcelado y que tiene algunos gráficos punteados o bien en apariencia de vegetales ordenados en hileras que son terrenos cultivados dentro de la misma traza.

Una vez determinada la traza urbana y las parcelaciones realizadas hasta ese momento, seguramente ocupadas en su mayoría para las actividades de la comunidad, quedan una gran cantidad de manzanas sin ocupar; como una política adecuada para la ciudad, esto es, que no queden como tierras ociosas o grandes predios baldíos; éstas fueron utilizadas para el cultivo de vegetales y frutos dentro de la traza sin alterar su funcionalidad en términos de la circulación adecuada de personas y carrozas. Estamos ante una urbanización que considera en su propio seno las actividades agrícolas, una condición que al menos se observó en la idea manifestada en el Plano en papel maguey ${ }^{11}$ para una porción de la ciudad de Tenochtitlan. El caso de LCLA registra la convivencia de actividades urbanas y agrícolas en la traza a la europea; algo muy peculiar y poco apreciado en ésta en particular; esta es una de las principales características de las nuevas ciudades que se implantaron en la región Puebla-Tlaxcala. ${ }^{12}$

Así también, en el interior del espacio formado por los ríos Alseseca y Atoyac en el entorno de la ciudad aparecen varios ranchos o fincas de labor:

i. Dos ranchos junto al Camino de Tlaxcala, al noroeste.

ii. Un rancho junto al Camino de Carrozas a Tlaxcala, al noroeste.

iii. Dos ranchos cerca de los molinos de Amatlán, al sur.

iv. Un rancho en la traza cerca del Camino al Pueblo de Totomeguacan y de San Balthasar, al sureste.

Fuera de la ciudad y al otro lado de los ríos Alseseca y Atoyac se encuentran otros edificios y superficies alrededor de ellos denominadas Estancias, lugares destinados al cultivo de granos y vegetales para el consumo del ganado; allí también se criaba al ganado para el abasto de la ciudad y la región. En el plano se encuentran registradas las siguientes:

\footnotetext{
11. Para una descripción amplia se puede consultar (J. González Aragón, 1993).

12. Tanto en el caso de las ciudades de Tlaxcala y LCLA fundadas en la primera mitad del Siglo XVI se presentan los casos en que la traza urbana contiene terrenos de cultivo y parece ser una constante de esquema de urbanización en la región Puebla-Tlaxcala; véase capítulo sobre Tlaxcala en Sáinz, Luis Ignacio y Jorge G. Aragón, 2015.
} 
i. Al oriente del río Alseseca, la Estancia de Amaluca y la Estancia Calera

ii. Al sur poniente de la ciudad, después del río Atoyac, se encuentra la Estancia de Solano.

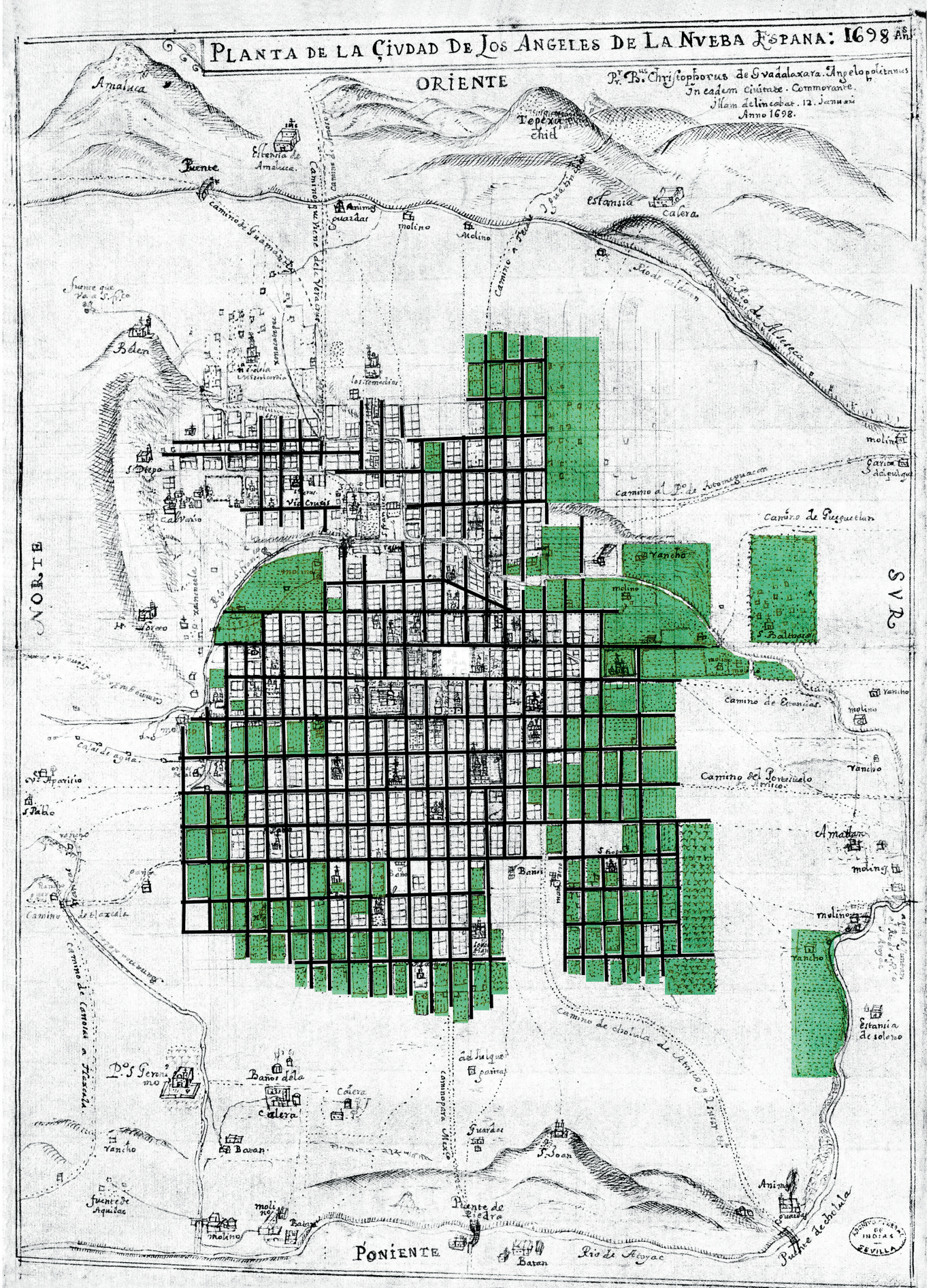

PLANO 5.18. Terrenos cultivados en la traza urbana y en el entorno en el Plano de 1698. 


\subsection{EDIFICIOS RELIGIOSOS}

Los edificios religiosos se presentan en el plano con diferentes gráficos y con localizaciones dentro de la ciudad o en los alrededores inmediatos, tienen funciones diferentes como: a) albergue de curas o frailes y de los oficios religiosos que allí se ofrecían; b) usos asociados a la vigía de la ciudad o sus partes; c) identificación de pueblos y barrios a partir del símbolo gráfico de un edificio religioso, por lo anterior los gráficos se clasifican con su localización en el sector urbano:

i. Conventos de las órdenes mendicantes y reclusos en el convento: San Francisco (S6), Santo Domingo (S1), San Agustín (S1), La Compañía de Jesús (S1), La Concepción(S1), San Jerónimo (S1), Santa Inés (S1), Santa Mónica (S4) y El Carmen (S8).

ii. Catedral, iglesias y parroquias del clero secular: Sector 1: Catedral junto al zócalo, San Pedro, San Cristobal, San Roque, El Hospitalito; Sector 4: Iglesia de Dolores, San Luis, Señor de las Maravillas, San Juan de Dios, San Antonio.

iii. Ermitas en dos entradas de la ciudad, utilizadas como edificio de guardas: una localizada en la salida de la ciudad junto al Camino de Veracruz y el río Alseseca; la otra junto al Camino a Cholula y el río Atoyac, ambas con el nombre de Guardas Ánimas y una cruz sobre la parte superior del edificio.

iv. Pueblos identificados con el gráfico de una amplia iglesia como es tradición en una parte de la cartografía europea de la época. El caso que registra el plano es el "Pueblo de San Gerónimo" ubicado al norte de la Barranca de Las Trancas.

v. Pequeños asentamientos o barrios de la ciudad identificados con el gráfico de una iglesia como San Pablo y San Aparicio ubicados fuera de la traza urbana al norte de ésta.

vi. Barrios de indios, Xonaca y Los Remedios al oriente de la ciudad.

vii. Corredores o caminos de peregrinaje, como el recorrido del Vía-Crucis en Semana Santa que tiene su inicio en el Convento de San Francisco y su culminación en la subida hacia los cerros de Loreto y Belén en el conjunto de capillas nombrado El Calvario.

viii. Iglesias sobre los cerros de San Juan al poniente, de Loreto, San Diego y Belén al norte, que además de lugares de oficios religiosos fueron de vigía y de actividad militar. 


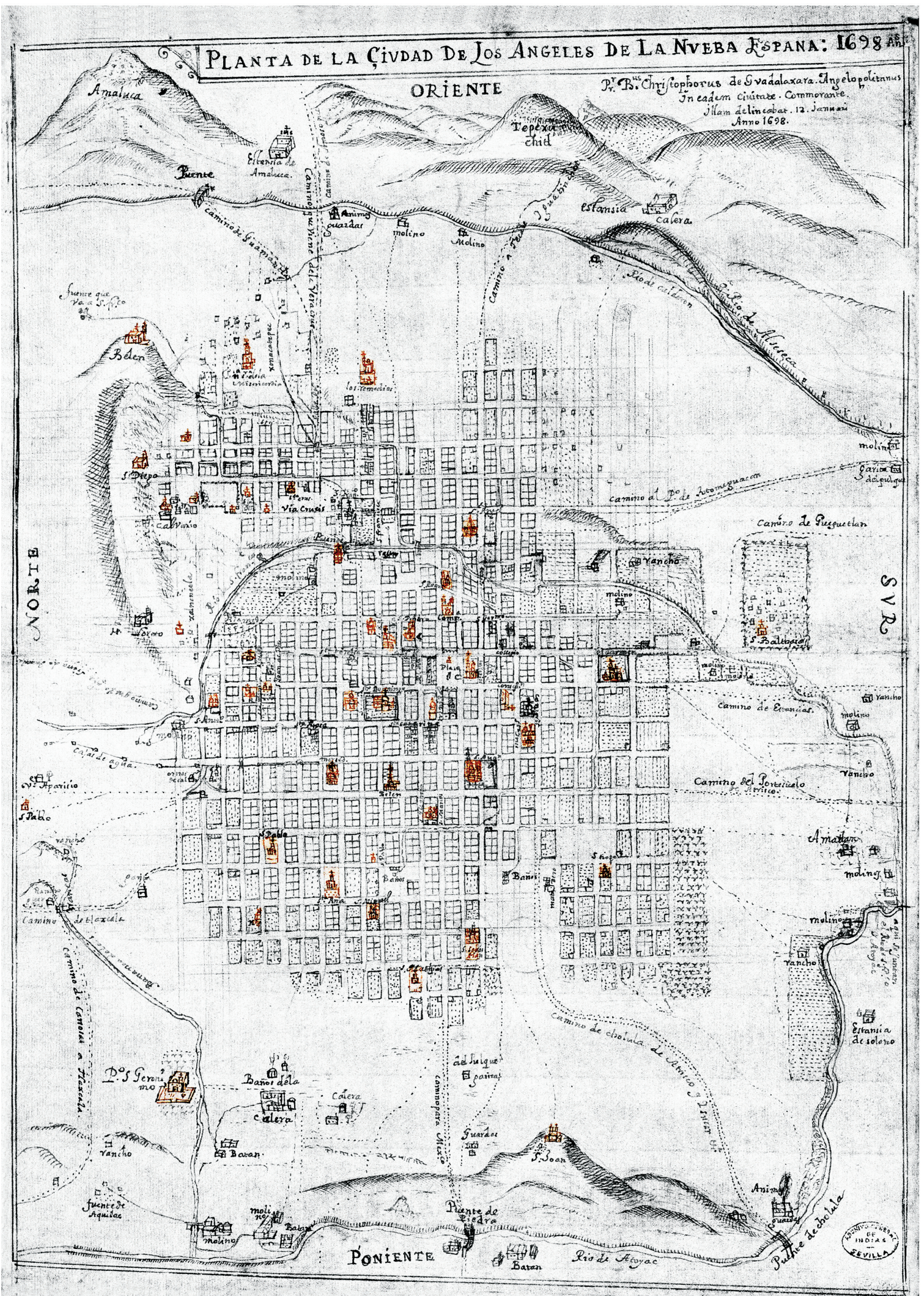

PLANO 5.19. Edificios religiosos en el Plano de 1698 


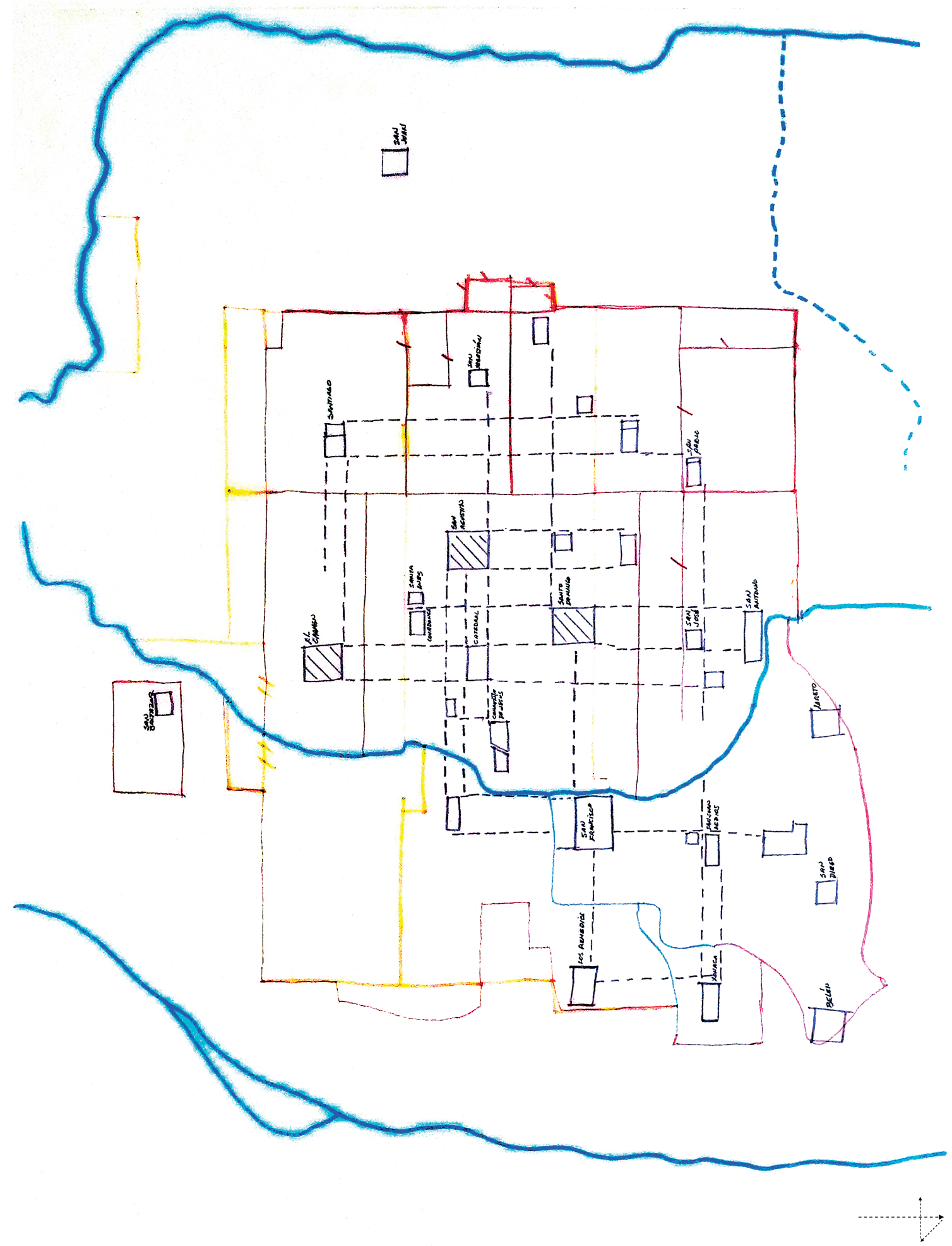

PLANO 5.20. Corredores que unen a los edificios religiosos en el Plano de 1698. 


\subsection{RESUMEN DE LA LECTURA URBANÍSTICA}

Podemos dar cuenta de lo siguiente:

\section{LA ELABORACIÓN DEL PLANO CON GRAN CANTIDAD DE INFORMACIÓN CODIFICADA.}

i. Los datos y la información referida a las guardas y garitas en la ciudad, así como los caminos y elementos geográficos asociados a ellas, se plasmaron y determinaron con mucha exactitud, porque eran los elementos que se requería contar con precisión para cumplir con la valoración de las garitas existentes y la propuesta para la implantación del círculo de garitas.

ii. La complejidad para realizar un plano tan preciso en información y tan esmerado en el manejo diferente de escalas y modos de representación requiere mucho más de dos meses; de acuerdo con el encargo hecho por el Juez privativo de acabalas Juan Joseph Veitia Linage, de noviembre a diciembre de 1697, para la planeación del nuevo círculo de garitas, que se implantaría en enero de 1698; requirió por tanto de un experto y conocedor de la ciudad, Christobal de Guadalaxara, de dibujantes con dominio de las formas de representación utilizadas en el documento pictórico y conocimiento profundo de las características de la ciudad.

iii. La información que contiene el plano es amplia, de buena calidad y para los fines de lectura urbanística que utilizamos fueron: 1. Paisaje natural, 2. Hidrografía, 3. Letreros clasificados en catorce temas, 4. Morfología urbana de caminos, calles, plazas, manzanas y parcelas, 5. Ejes principales de la ciudad, 6. Fiscalización con guardas y garitas de bienes y personas, 7. Edificios para la producción, 8. Terrenos de cultivo dentro y fuera de la traza, 9. Edificios religiosos.

\section{LA GEOGRAFÍA Y EL DISEÑO DE LA CIUDAD DE LOS ÁNGELES}

La orografía, los manantiales, la presencia de los ríos perennes y de temporal fueron atributos apropiados para las nuevas actividades en el territorio: agrícolas, pecuarias, industriales y de consumo para la población; también los cerros y los surcos naturales fueron barreras que se usaron y adaptaron para defender y controlar el paso a la ciudad.

En el plano, el trazado urbano tuvo las siguientes características:

i. La solución impecable entre la implantación de un asentamiento con los patrones europeos en manzanas y parcelas y una ordenación ortogonal o reticular.

ii. La adecuación de la misma con las rutas comerciales y productivas fuera de la mancha urbana. 
iii. La integración de pequeños asentamientos o barrios, algunos probablemente asentados allí desde antes de la fundación de la nueva ciudad.

iv. El trazado urbano sigue las condiciones de latitud del lugar y el azimuth de desviación de $17^{\circ}$ del norte hacia el oriente, que prevaleció en buena parte de los campos agrícolas, recintos sagrados y unidades habitacionales del centro de mesoamerica y que, coincide también con las líneas virtuales entre el Cerro de San Juan al poniente y el de Tepoxuchitl al oriente. ${ }^{13}$

v. La adaptación de la traza reticular con los accidentes del terreno y los cuerpos de agua, así como la amplia variedad de parcelaciones que se presenta en la ciudad hace más explícita la calidad del diseño urbano, la morfología urbana y sus transformaciones.

\section{EL CÍRCULO DE GARITAS Y EL BORDE DE CIUDAD}

La propuesta de la nueva ubicación de las garitas en el año de 1697 como un círculo de control comercial y defensivo, esto es, el primer límite o borde de ciudad en el que se suscribe la mancha urbana; tendrá breves adecuaciones en 1700 y mayores en 1724 para constreñir aún más el círculo de garitas y facilitar las rondas de caminos y el control cada vez más coercitivo para una mayor recaudación por concepto de la producción y el trasiego de mercancías en LCLA.

i. Observamos también que el círculo de garitas es la condición local de uno de los puertos de tierra más importantes de la Nueva España para la fiscalización de géneros y mercaderías de la región y del trasiego de las provenientes de ultramar en el Pacífico y en el Atlántico hasta la primera mitad del siglo XVIII.

ii. La relación de las rutas comerciales con la defensa militar es explícita en el territorio regional a través de los diversos fuertes y puestos militares sobre todo en el corredor Ciudad de México - Puebla - Veracruz y, desde luego en la amplia banda de costa del Golfo de México y de Honduras.

\section{LAS ÓRDENES MENDICANTES Y SU IMPRONTA URBANÍSTICA}

1. La preponderancia de los edificios de las órdenes mendicantes en la Ciudad: franciscanos, dominicos, carmelitas y agustinos durante los siglos XVI y XVII antes de las políticas de secularización ${ }^{14}$ impuestas por la realeza y la Iglesia para obtener mayores beneficios económicos del territorio conquistado, tuvieron una acción efectiva como: a. 
Edificios de defensa, algunos incluso amurallados y de gran altura; b. El diseño de una traza reticular con manzanas cuadradas por los franciscanos; c. La espiritualización católica de los indígenas y d. La función de Justicia que estuvo sustentada por la Inquisición durante un largo período virreinal. ${ }^{15}$

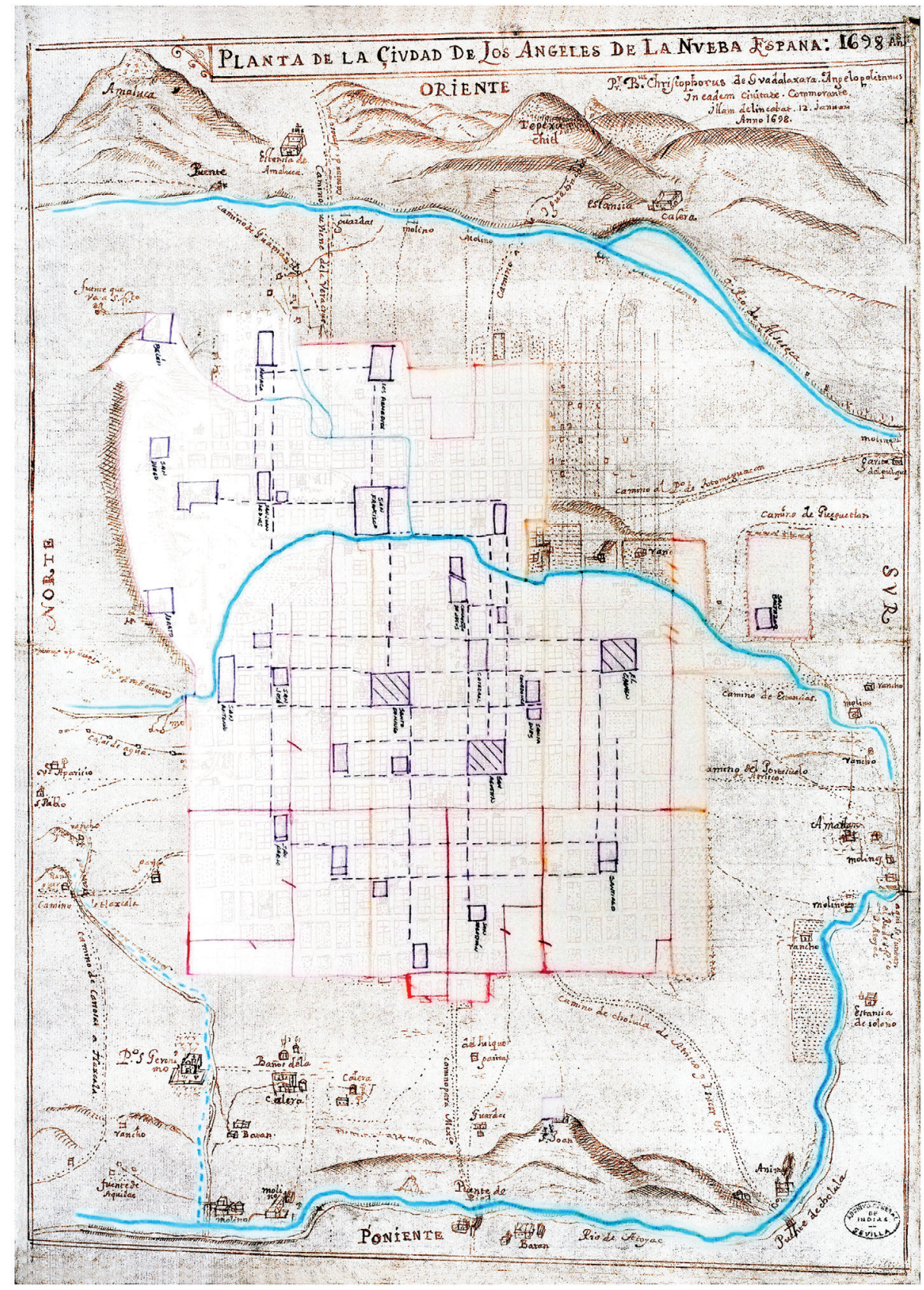

PLANO 5.21. Corredores que unen a los edificios

religiosos sobre el Plano de 1698 


\section{6 \\ Tres cortes en la ciudad de Los Ángeles I700, I724 y I862}

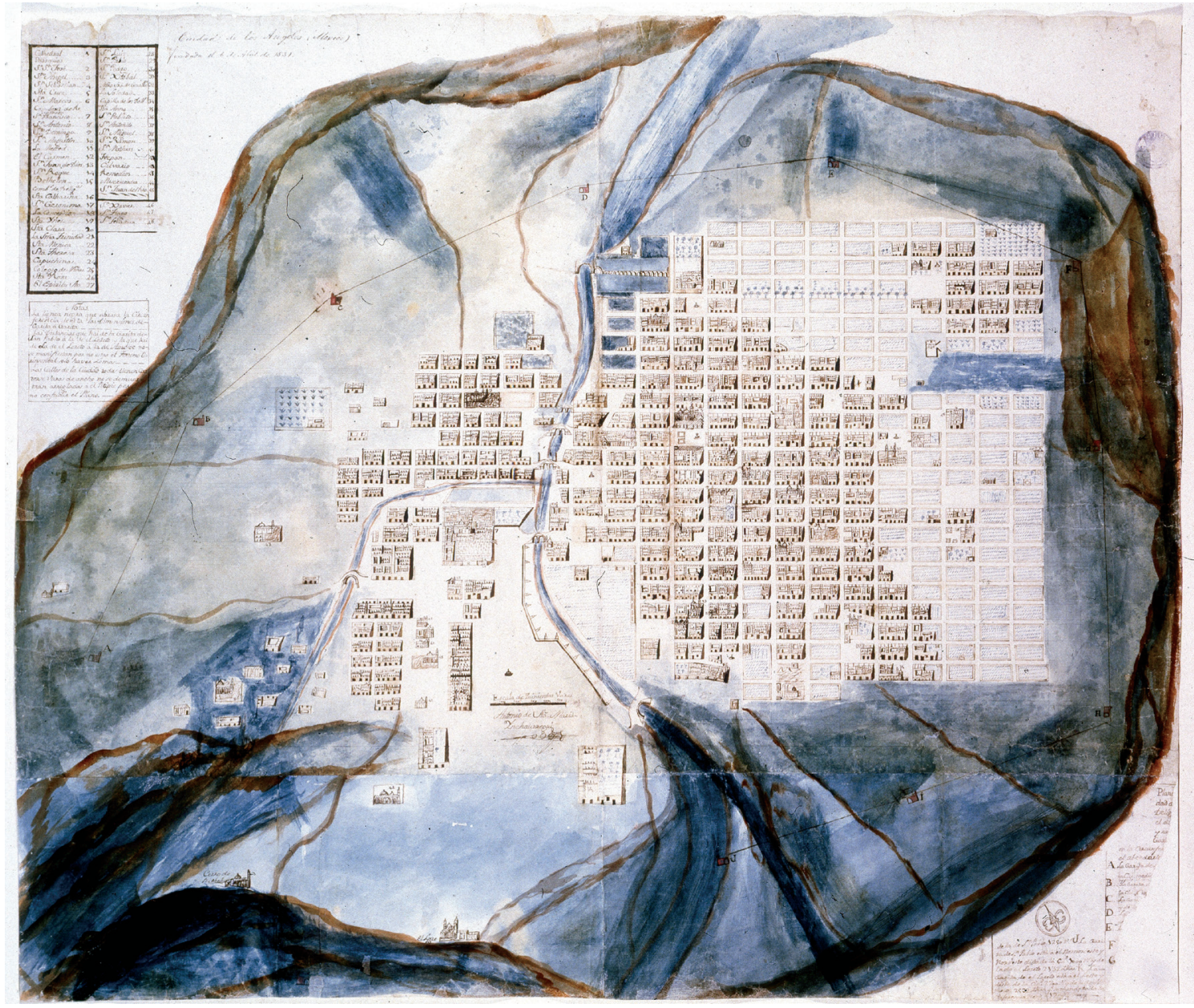

PLANO 6.1.1. Plano de la Ciudad de Los Ángeles (México). Fundada el 6 de abril de 1531. Año 1700. Museo Naval de Madrid. 


\subsection{LECTURA URBANÍSTICA DEL PLANO: CIUDAD DE LOS ÁNGELES (MÉXICO), AÑO DE 1700}

\subsubsection{FICHA BÁSICA DEL PLAN0:}

Título del plano: Ciudad de Los Ángeles (México).

Repositorio: Museo Naval de Madrid

Autor del plano según la firma: Antonio Santa María Ynchaustegui.

Año de elaboración: 1700.

Anotaciones: Tiene anotaciones alrededor de la pictografía de

1. El nombre del plano,

2. El autor,

3. La escala gráfica en varas, marcadas desde $0,100,200,300,400,500$.

4. Tabla de edificios religiosos con notas al pie,

5. Anotaciones sobre las garitas, textos incompletos por el deterioro sufrido por el documento.

6. La imagen de la ciudad se trabajó con tintas sepia, negra, roja y azul, acuarela de colores azul y marrón.

Representación plástica: La ciudad está representada como sigue:

1. En planta para los ríos, la traza urbana de las manzanas, calles y caminos;

2. En perspectiva, los edificios de todas las manzanas vistos desde el norte, mostrando las fachadas del sur, los espacios abiertos dentro de las manzanas y las fachadas internas que están en los patios.

3. De perfil se tiene el símbolo de cada garita en el círculo que forman alrededor de la ciudad, unidas por líneas negras que señalan la distancia en varas castellanas a escala.

\subsubsection{PRECEPTOS FISCALES DE LA CORONA ANTERIORES AL AÑO 1700}

La lectura urbanística de un Plano de la Ciudad de Los Ángeles (México) del año 1700 nos proporciona la comprensión de la estructura de la ciudad, sus orígenes, su relación con el contexto y, desde luego, la intervención oportuna e inteligente en la ciudad actual. En este análisis se realiza una lectura parcial, pues sólo atenderemos algunos aspectos de este complejo y bello plano realizado con una impecable calidad plástica, los temas son:

i. La geografía;

ii. El diseño reticular de la ciudad en sus orígenes y la implantación de otro circular en su perímetro; 

iii. Espacios públicos;
iv. la ciudad edificada;
v. Las obras de control fiscal y estratégico de la ciudad;
vi. Principales características urbanísticas.

Para comprender los motivos que llevaron a la realización de este plano, exponemos algunas de las políticas que impulsó la corona en la segunda mitad del siglo XVII para la mayor recaudación de dinero a través de un nuevo sistema de fiscalización y tasación de las mercancías más eficiente. El imperio aplicó estas políticas a todo el reino y en el caso particular de la Ciudad de Los Ángeles, una de las ciudades centrales, tuvo dos momentos importantes.

El primero fue con el envío de don Juan Palafox y Mendoza, quien fungió como obispo de Puebla y por breve tiempo como virrey de la Nueva España. Durante su estancia, alrededor de una década a partir de 1640, fue capaz de realizar impresionantes obras edilicias en la ciudad, pero también inició el proceso de secularización de la Nueva España, delegando funciones eclesiásticas y económicas más restrictivas a los frailes mendicantes, en especial a los franciscanos y a los jesuitas; tales medidas generaron mayores caudales de recaudación para la iglesia secular y la Corona; en particular, por la adjudicación de muchas de las propiedades acumuladas por el clero regular, la acotación de las actividades religiosas que pasan en ese momento al ejercicio y beneficio exclusivo de los seculares por los ingresos provenientes de bautismos, bodas y otros oficios de la iglesia, que, desde luego también reportaban mayores ingresos para la Corona. Con la presencia de Palafox y Mendoza en Nueva España, en Puebla en particular, da inicio la recaudación moderna de capital, que inicia con la apropiación de las rentas acumuladas por el clero regular a través de la secularización de Puebla en la segunda mitad del siglo XVII y después de la Nueva España durante el siglo XVIII.

El segundo, al final del poder ejercido por los austrias, fue la designación de José Echeverría Veitia Linaje, juez privativo del rey y responsable de las alcabalas de Puebla por designación real, para implantar un nuevo modelo de recaudación fiscal y vigía de los crímenes cometidos en contra de "Su Majestad Suprema" por el desvío de dineros, fraudes, contrabando, asociaciones de grupos de poder económico en la ciudad para evadir impuestos, por mencionar los más comunes que están ampliamente documentados en el expediente: México, 341 del año 1698 en el Archivo General de Indias. Existía esa necesidad en LCLA ya que su localización geográfica fue determinante en el flujo de mercancías que provenían de la Ciudad de México, el Puerto de Acapulco (en los caminos que siguen la Cuenca del Río Balsas, que inicia en las montañas de Puebla-Tlaxcala y en su desembocadura muy cerca de Acapulco, entre los estados 
de Guerrero y Michoacán). El tránsito continuo de recuas de mulas de puerto a puerto: Acapulco y Veracruz o con destinos hacia sus intersticios y otros lugares del extenso territorio, fue regulado en gran medida desde LCLA, acompañados por guardias que protegían y hacían llegar los cargamentos a buen destino. Hubo inspectores con amplio poder en la región para evitar contrabando. También aduanas, garitas y otros edificios que se propusieron realizar en la ciudad desde el año 1697 y que fueron modificados parcialmente y representados posteriormente en el plano de 1700 de la Ciudad de Los Ángeles (México).

La Nueva España y las ciudades centrales fueron en mayor medida el arca del imperio y desde allí se hicieron las transferencias de mercaderías y metales preciosos a la Corona pero también a las ciudades principales en el Gran Caribe y Asia a través de las Islas Filipinas, puertos y regiones para controlar el poder político y militar. Puebla fue una de las principales ciudades en este tipo de transacciones conocidas en la época como "situados". Su posición geográfica entre la Ciudad de México y Veracruz, como entre ésta y Acapulco. Fueron las rutas de tierra por las que circularon dinero, bastimentos y mercancías del puerto de Veracruz en el Atlántico al Puerto de Acapulco, que forman ejes o rutas de tierra, como parte de la economía global.

\subsubsection{RIOS, PUENTES Y CORREDORES URBANOS}

Los cuerpos de agua y cerros se aprecian junto con las calles y los bloques de las manzanas.

Los puentes sobre el río San Francisco, marcan la continuidad de las calles a uno y otro lado como se describe a continuación:

1. El primer corredor de poniente a oriente llega al centro del convento de San Agustín y por el oriente, al borde la ciudad.

2. El segundo corredor va desde el Río San Francisco hacia el poniente, pasa por la Plaza Mayor a un lado de la Catedral hacia el Camino a México.

3. El tercero va por el poniente hasta unirse con el camino a la Ciudad de México; por el oriente, hasta conectarse con el camino al cerro de Tepoxuchitl-y al pueblo de Cuauhtinchan.

4. El cuarto puente conecta el camino a Veracruz al oriente y a Ciudad de México y Tlaxcala al poniente.

5. El quinto conecta al norte con el Camino que va al Cerro de Loreto y a laSierra de Tlaxcala; al sur al zócalo de la ciudad.

Los corredores son importantes como tales porque forman vías directas y, en ocasiones, usos del suelo semejantes o complementarios; sin embargo una de las cualidades 


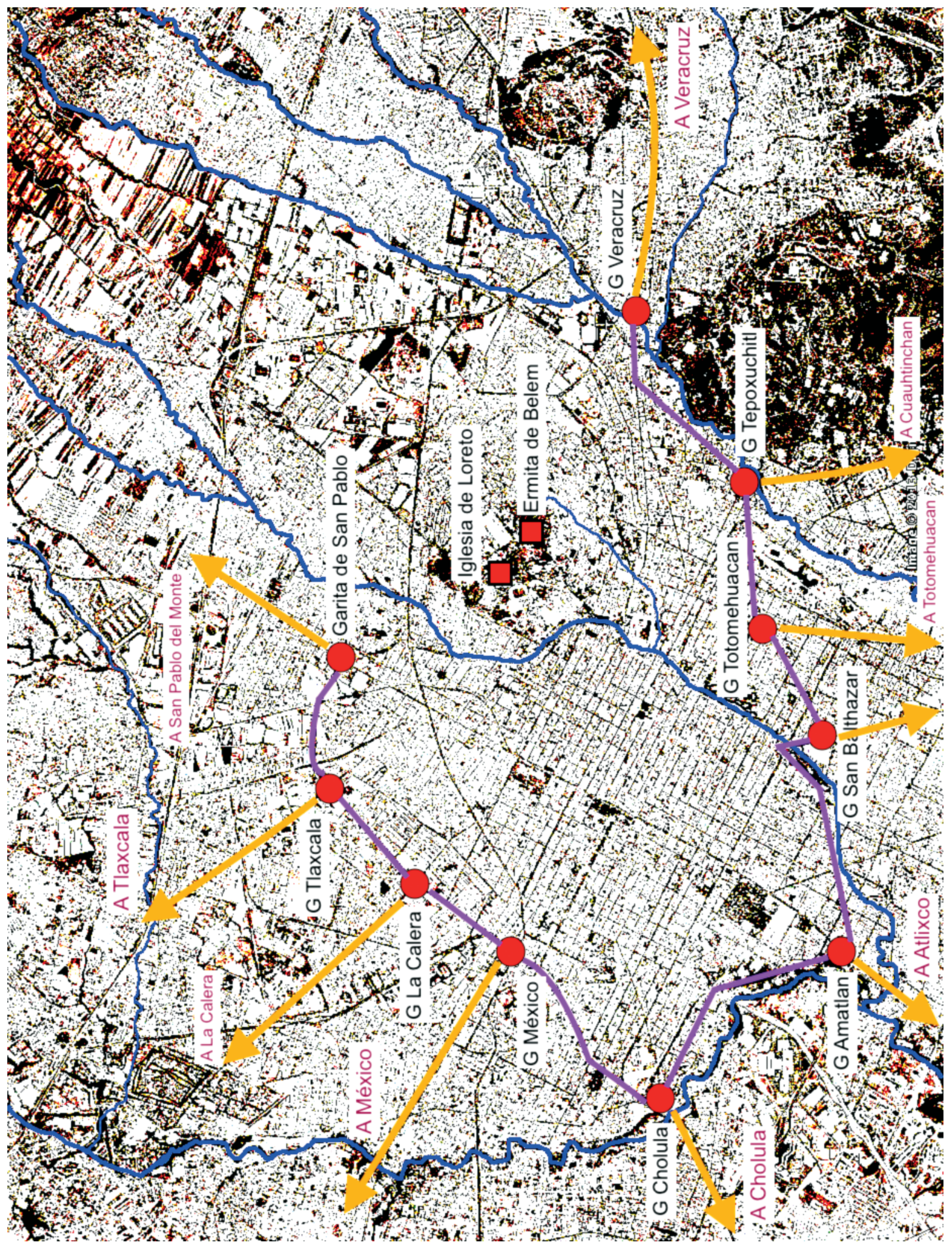

6.1.2. Plano de las garitas propuestas por el Juez Privativo Superintendente de las Reales Alcabalas de Puebla don Jose Veitia Linage el 26 de noviembre de 1697 en la Ciudad de Los Ángeles. Ubicadas por JGAC en una fotografía aérea (Google Earth, 2013) con base en el expediente registrado con la signatura: México, 341, AGI y el plano de 1698 de la Ciudad de Los Ángeles en el mismo repositorio. 
de la traza reticular ha sido precisamente su facilidad para alternar los recorridos por distintas rutas dentro de la ciudad.

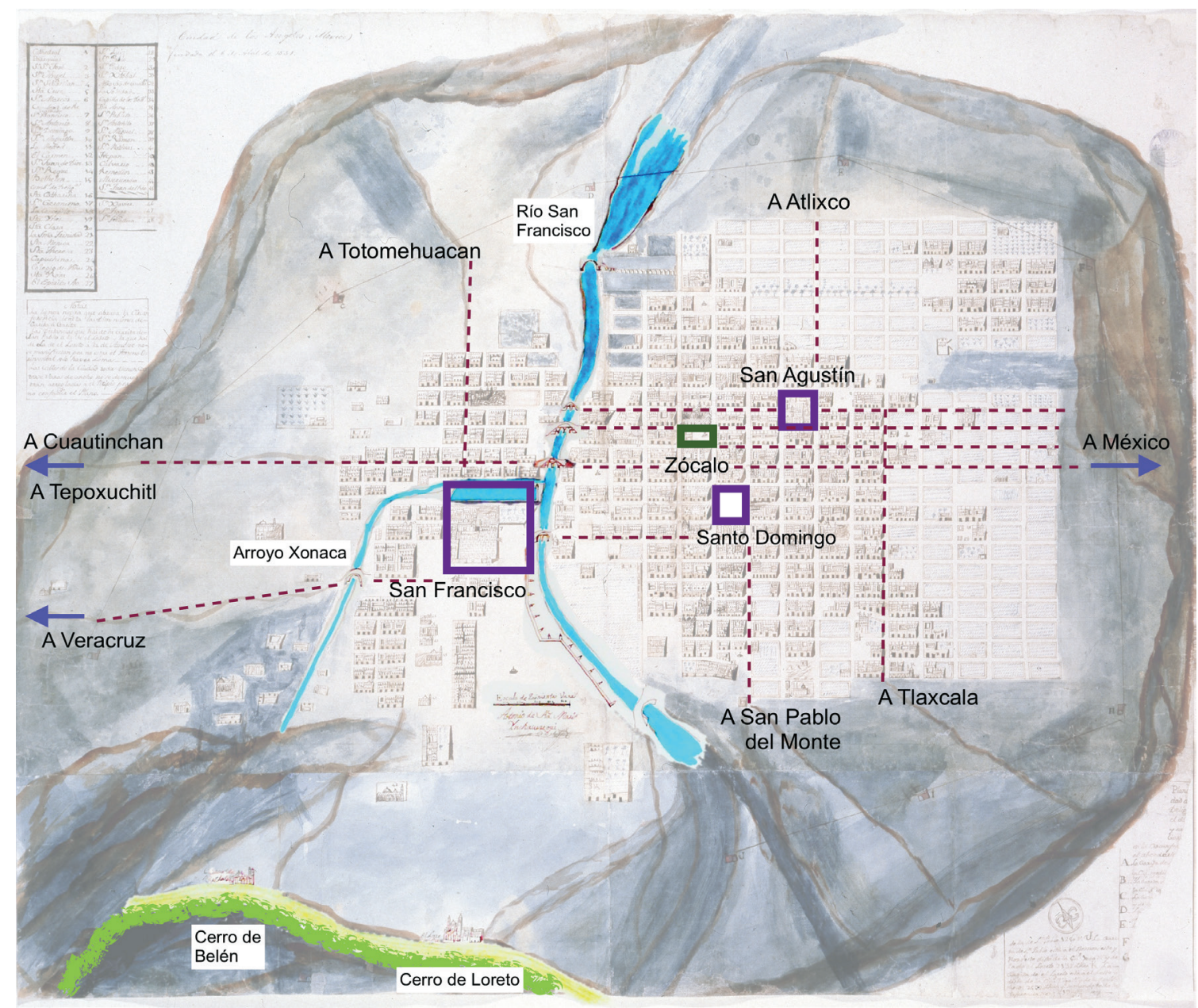

6.1.3. Plano de los cerros, ríos, puentes en su conexión con los corredores urbanos asociados a los principales edificios emblemáticos.

\subsubsection{PARTICIÓN DE LA CIUDAD Y MANZANAS EDIFICADAS}

De acuerdo con el plano de 1700, las manzanas edificadas en la ciudad ocuparon cerca del $60 \%$ y las no edificadas el $40 \%$.

La ciudad se divide en cuatro grandes sectores:

i. San Francisco, el primer enclave europeo en el sitio con el conjunto del Convento de San Francisco. Contaba con: 
1. La mayor cantidad de agua potable en el sector.

2. Los grandes espacios abiertos o plazas rituales y comerciales.

3. Un aljibe junto a San Francisco.

4. Con la mejor defensa formada por los ríos y los cerros de Loreto y Bethlem.

5. Trazo urbano con predominio de manzanas cuadradas, dispuestas alrededor del convento.

ii. El Centro con más de 100 manzanas edificadas al poniente del río San Francisco., con la Plaza Mayor, catedral y conventos en los principales ejes de la ciudad, con puentes sobre el río.

iii. Analco ubicado al oriente del río San Francisco. y al sur del Arroyo Xonaca, con predominio de manzanas cuadradas, con la parroquia con plaza anexa, situados al centro del barrio.

iv. Santiago es un barrio ubicado al suroeste y poco alejado del Centro tiene diecisiete manzanas edificadas y plaza, su conexión principal es por una calle arbolada hacia el oriente que remata en la Plaza del Carmen.

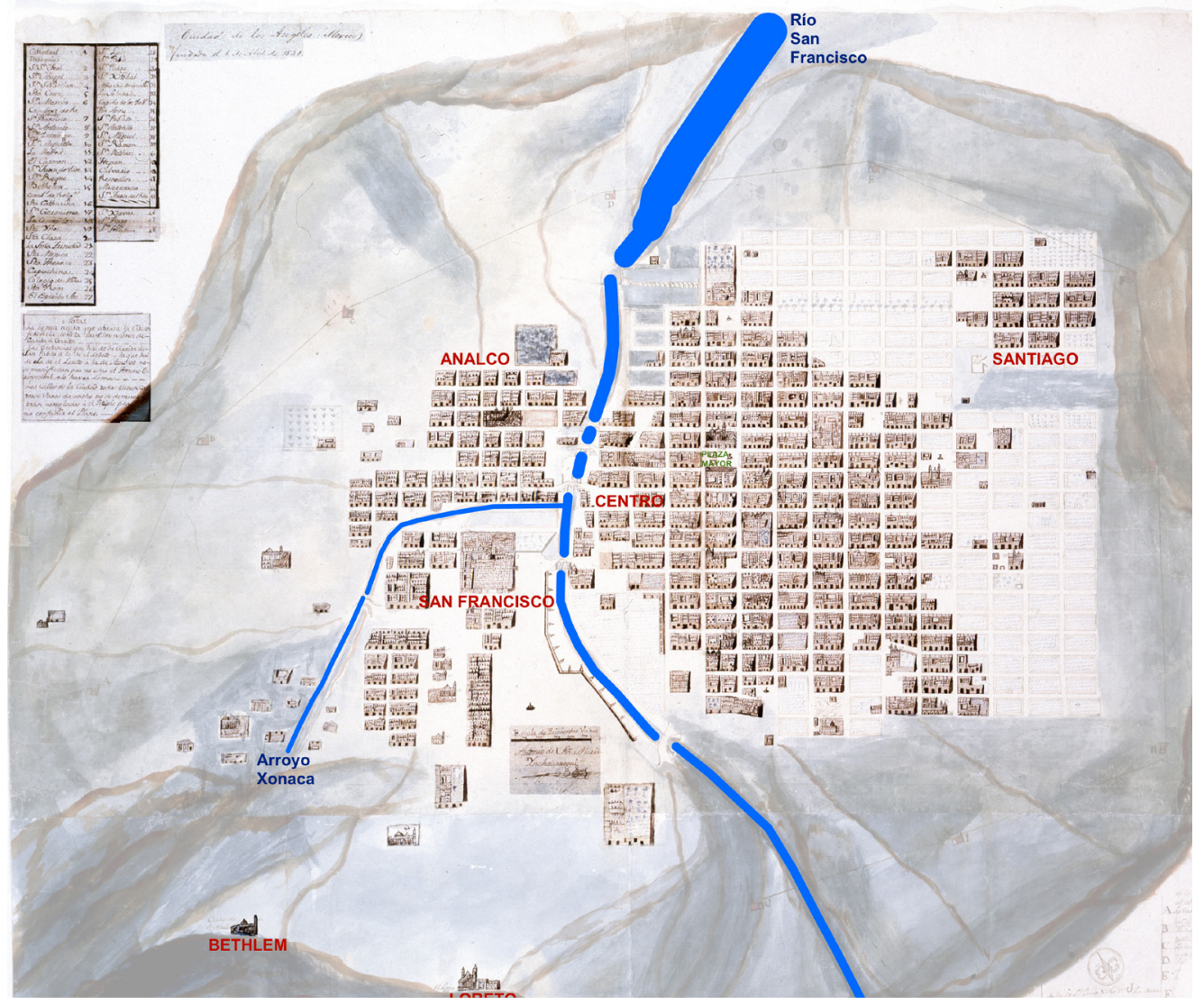

6.1.4. Plano con la partición de la ciudad en grandes sectores y manzanas edificadas 


\subsubsection{CONVENTO DE SAN FRANCISCO}

En este detalle del plano en el área de San Francisco observamos lo siguiente:

i. Al fondo (en la parte superior) el arroyo Xonaca

ii. Un gran estanque de agua

iii. El recinto amurallado de San Francisco con una superficie cercana a las 6 hectáreas.

iv. El perímetro amurallado tiene dos entradas francas al enorme atrio, una al poniente y la otra al norte.

v. Se tienen otras capillas que delimitan el atrio.
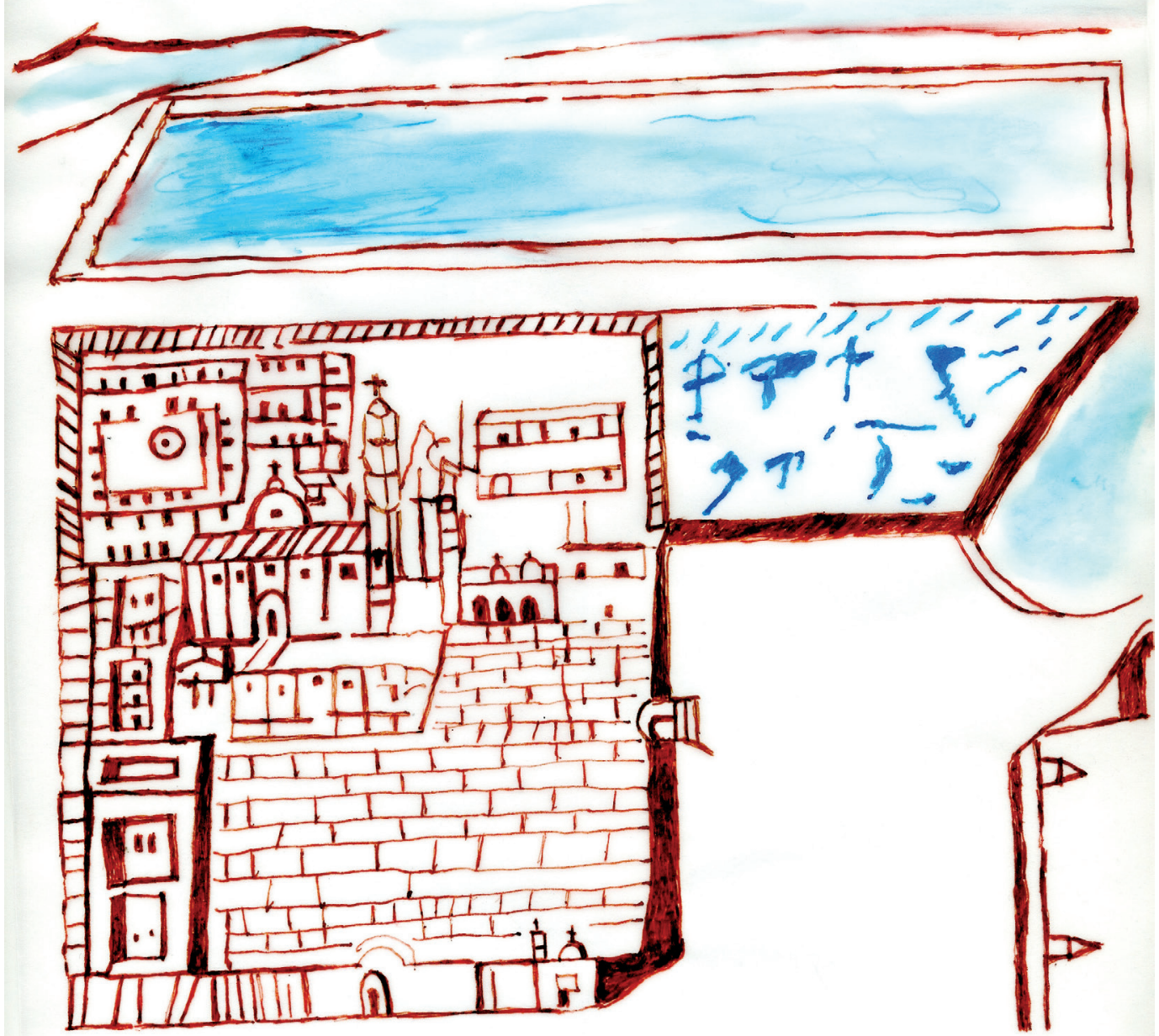
vi. Hay cinco o seis pequeños conjuntos de habitaciones dispuestos sobre el lado oriente y norte del recinto. Las habitaciones se encuentran dispuestas alrededor de un patio central y en algunos casos con crujías.

vii. Entre el recinto amurallado y el río está un predio delimitado que parece un huerto en la vega del río y por tanto con humedad abundante.

viii. La entrada principal al recinto amurallado da hacia el poniente y es el remate visual principal del puente que cruza el río San Francisco.

ix. Entre el puente y la muralla del convento se forma un gran espacio abierto: plaza y vestíbulo del convento, también de paso hacia el lado poniente de la ciudad en la ruta a Veracruz.

x. En la parte inferior derecha se tiene el gráfico de dos líneas con pináculos, que es un acueducto que se abastece del río y corre paralelo hacia el norte.

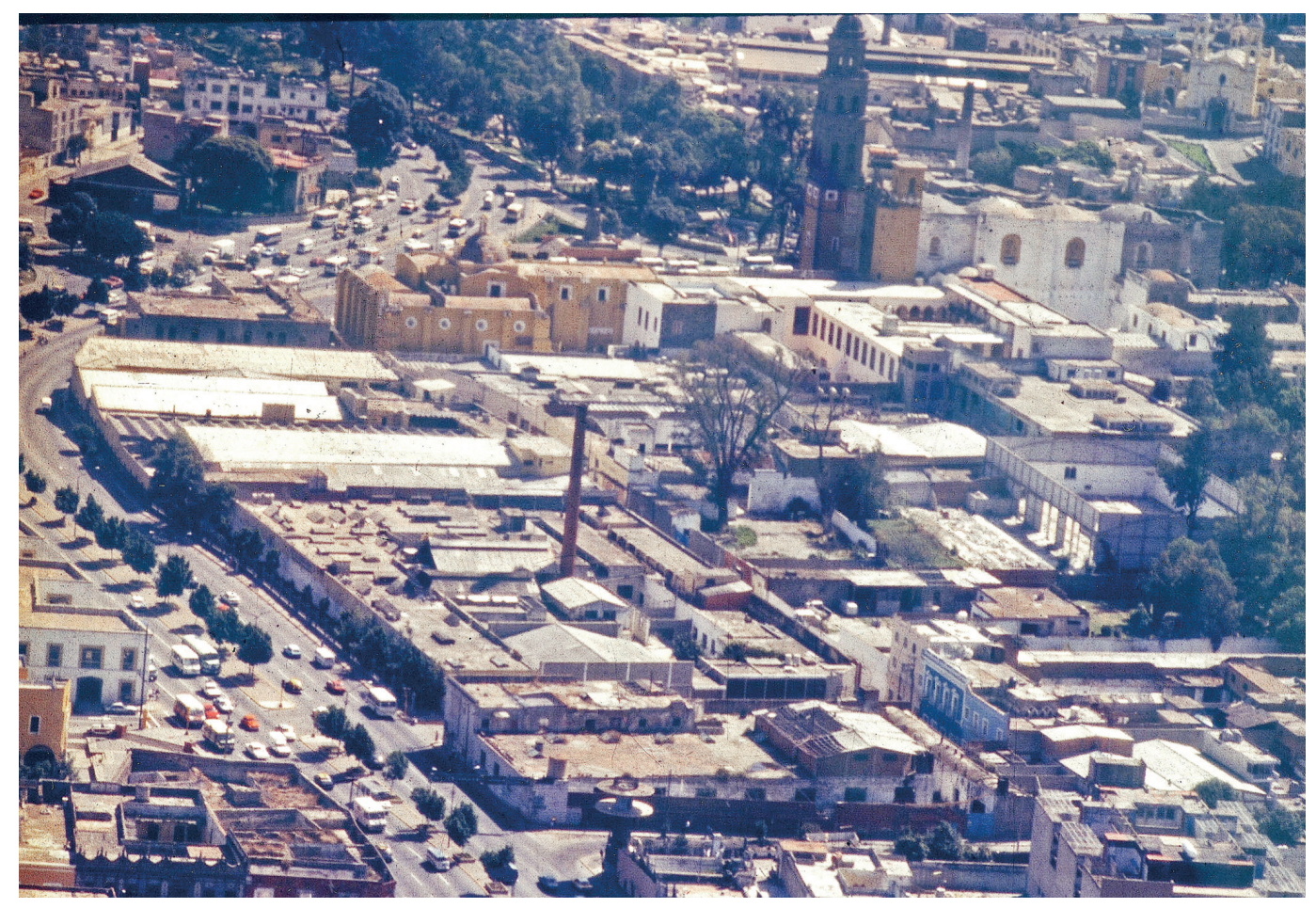

6.1.6. Fotografía de 1996 en el predio conventual de San Francisco.

\subsubsection{CAMINOS Y GARITAS}

A la disposición de las garitas en su conjunto se le llamó círculo o círculo de garitas.

En este plano aparecen las garitas desfasadas de los caminos, cuando en la realidad estaban junto a ellos, esto se debe a que las medidas entre garita y garita están a escala, en tanto que los caminos que salen de la ciudad tienen rumbo y dirección, aunque no 
la escala precisa de las líneas que unen las garitas y conservan medidas de distancia precisas. A eso se debe que las garitas no se encuentren pegadas a los caminos.

Los nombres que tienen cada una de las garitas se pusieron con los datos obtenidos del presente plano y con la lista que se encuentra en el expediente de 1697 (AGI, México, 341) en el que dice las nuevas garitas por construir.

En este plano se añadieron las garitas de San Balthazar, La Calera y Loreto, y se quitaron la de Belén y Amalucan con respecto al plano de 1698.

En el citado expediente de 1697 aparecen 9 garitas propuestas y en el plano de 1700 tenemos once.

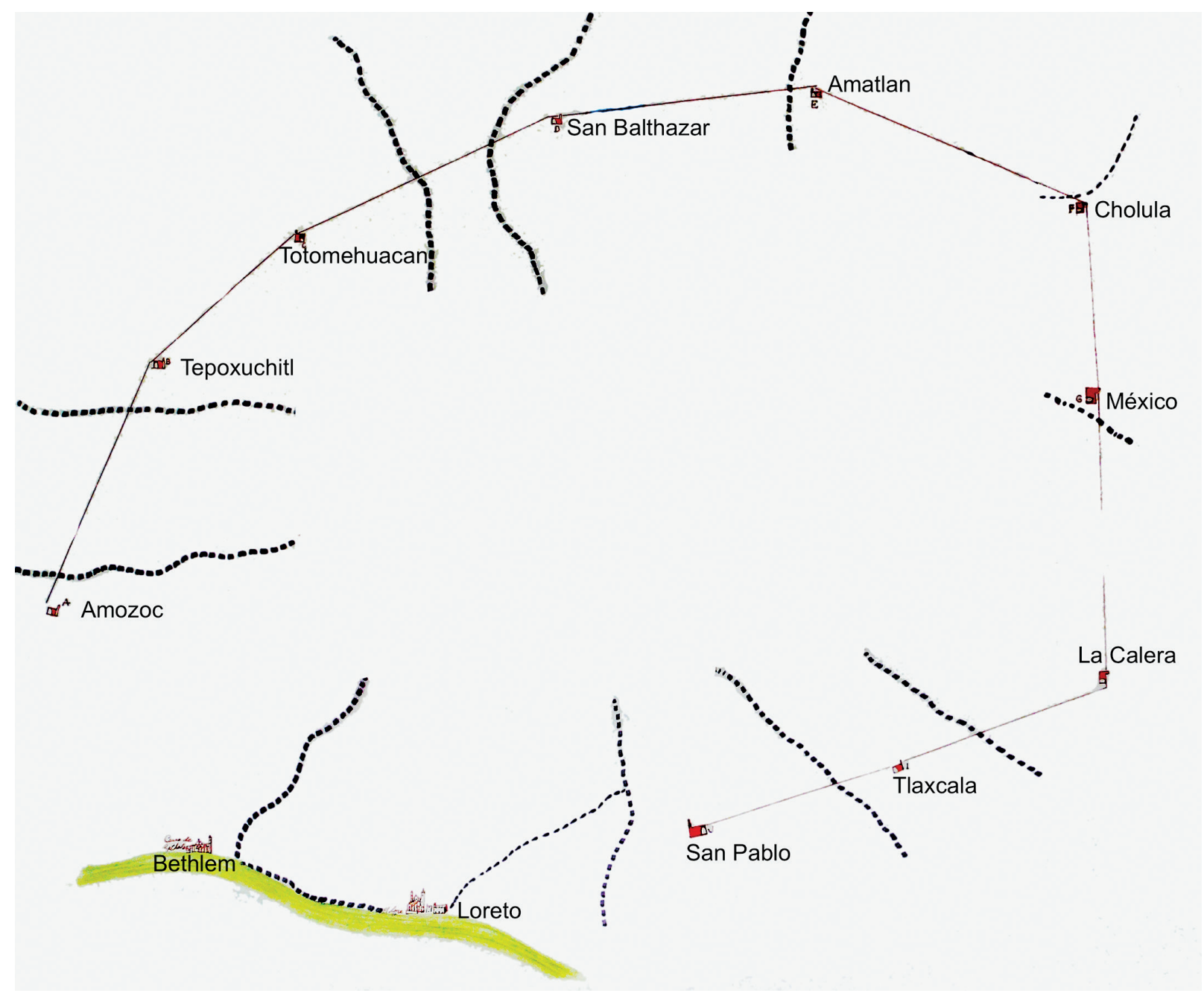




\subsubsection{CERROS, RÍOS, CÍRCULO EXTERIOR, CAMINOS, RETICULA Y PLAZAS}

En este plano conjugamos ríos, aljibe, cerros, garitas, caminos, calles, puentes y plazas, que nos permiten cualificar algunos de los atributos de LCLA:

1. Organización radial de los caminos de acceso a la ciudad y circular de conexión entre garitas; integración con el trazado reticular de la ciudad.

2. Presencia de plazas a uno u otro lado de los puentes sobre el río, que aglutinan cerca de $60 \%$ del total.

3. Diseño urbano de calidad en las riveras con conexión funcional oriente-poniente.

4. La plazas se dispusieron sobre los ejes de salida México-Veracruz y Tlaxcala.

5. El sector de San Francisco tuvo un lugar privilegiado por el recurso del agua, el cobijo de los ríos y cerros, amplios espacios abiertos entre los bloques de manzanas para el tránsito y la compra-venta de mercancías, así como para el rito religioso de "El Calvario de Jesucristo".

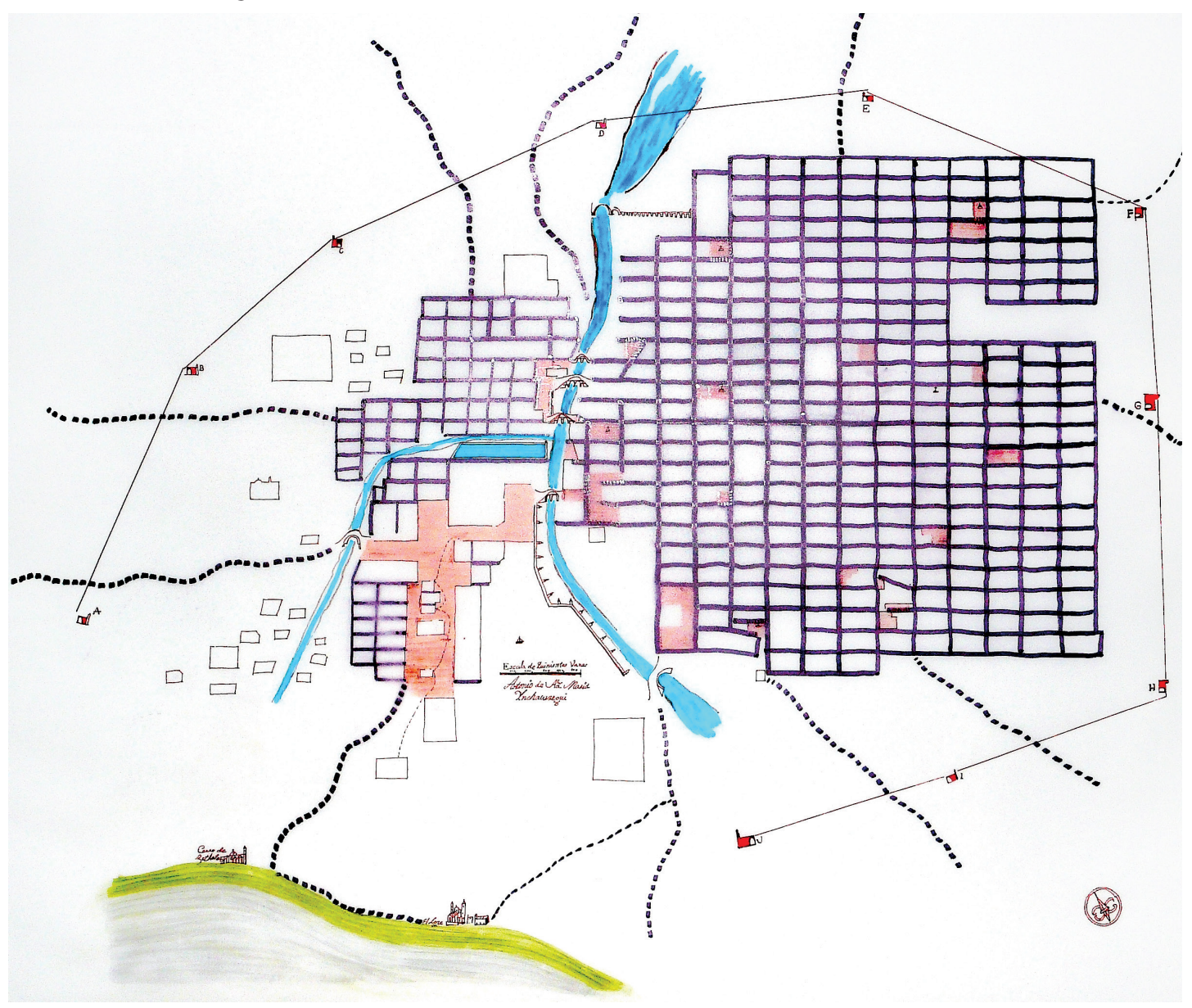

6.1.8. Plano con las diez garitas que circundan la ciudad. El diseño de calles, plazas y puentes son acordes con la condición de puerto de tierra. A uno y otro lado de los puentes había una plazoleta. 


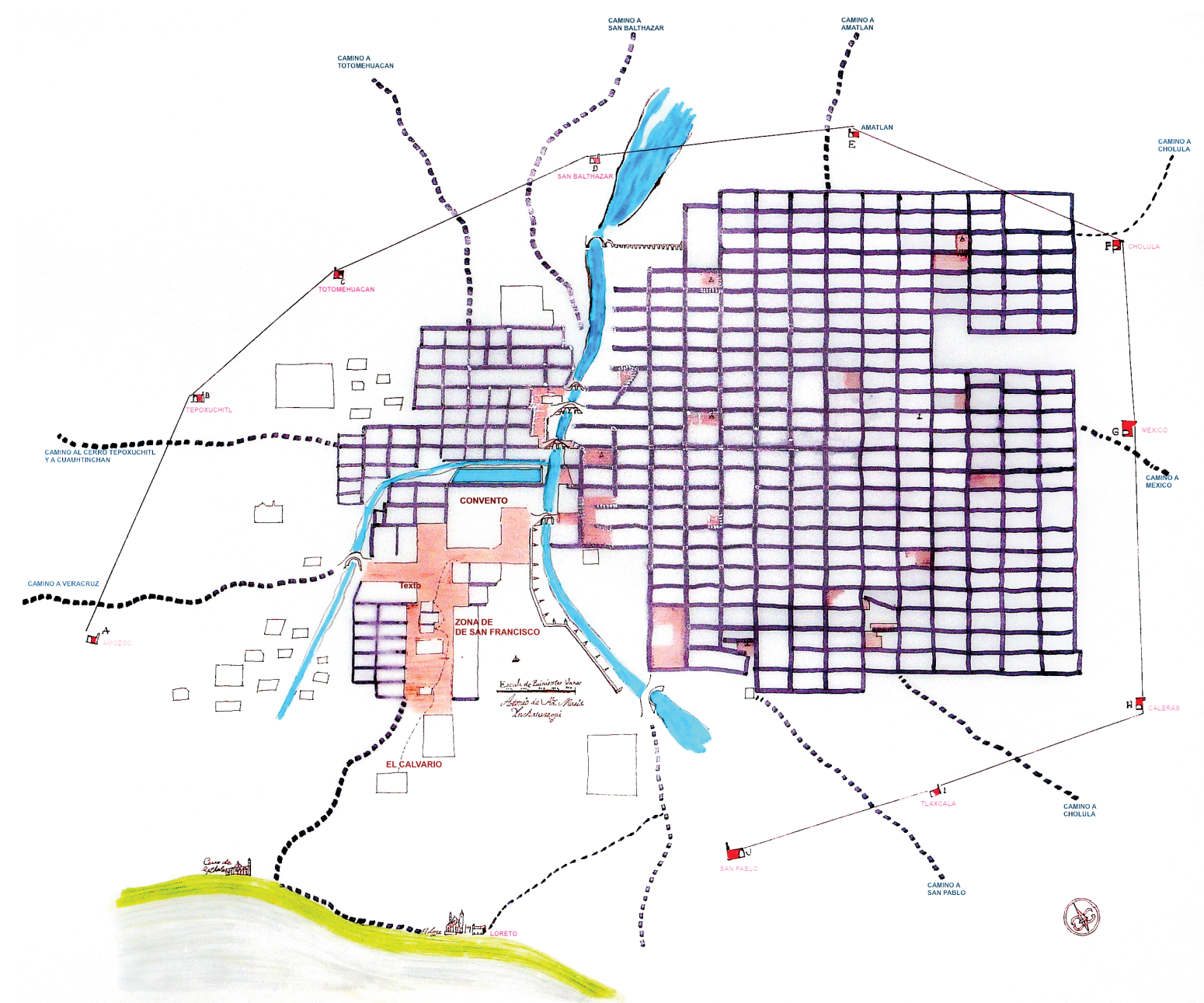

6.1.9. Plano con los ríos, cerros, círculo de garitas, caminos radiales,

calles en retícula, puentes y plazas.

\subsubsection{DIMENSIONES DEL SECTOR PONIENTE DE LA CIUDAD Y PLAZAS PÚBLICAS}

En el lado poniente del río San Francisco observamos un gran mosaico simétrico de 12 por 24 manzanas, que en conjunto forman un rectángulo de lados casi del mismo tamaño como se aprecia en el plano que sigue, las otras van variando su tamaño y forma porque se adaptaron al río y sus meandros. Se creó el gran sector de expansión de la ciudad al poniente del Río San Francisco con aproximadamente 100 manzanas con un diseño planeado e innovador para la gran ciudad en crecimiento y geográficamente estratégica, que formará parte de los puertos y ciudades de las principales rutas comerciales de la Nueva España. 
La mayoría de las manzanas están edificadas pero otras no; el símbolo que tienen las no construidas señala que las usaban para el cultivo agrícola en el interior de la ciudad, lo que permitió tener un uso, conservarlas y disponerlas en el futuro para su edificación.

En lo que respecta a las manzanas edificadas se tiene que en el conjunto de la ciudad hay ejes más largos que otros como sigue:

1. Los que van a las salidas a México y Veracruz.

2. Los otros caminos principales, por ejemplo, al barrio de Santiago, el camino a Cholula,

3. Todas las manzanas edificadas en el Camino a Tlaxcala y hacia Totomehuacan y a Tepoxuchitl-Cuauhtinchan.

La ciudad tiene una retícula de manzanas edificadas que se fue acomodando de acuerdo con la gravitación que ejercen los caminos hacia las ciudades y pueblos vecinos de relación, es por ello que se construye conforme a este patrón.

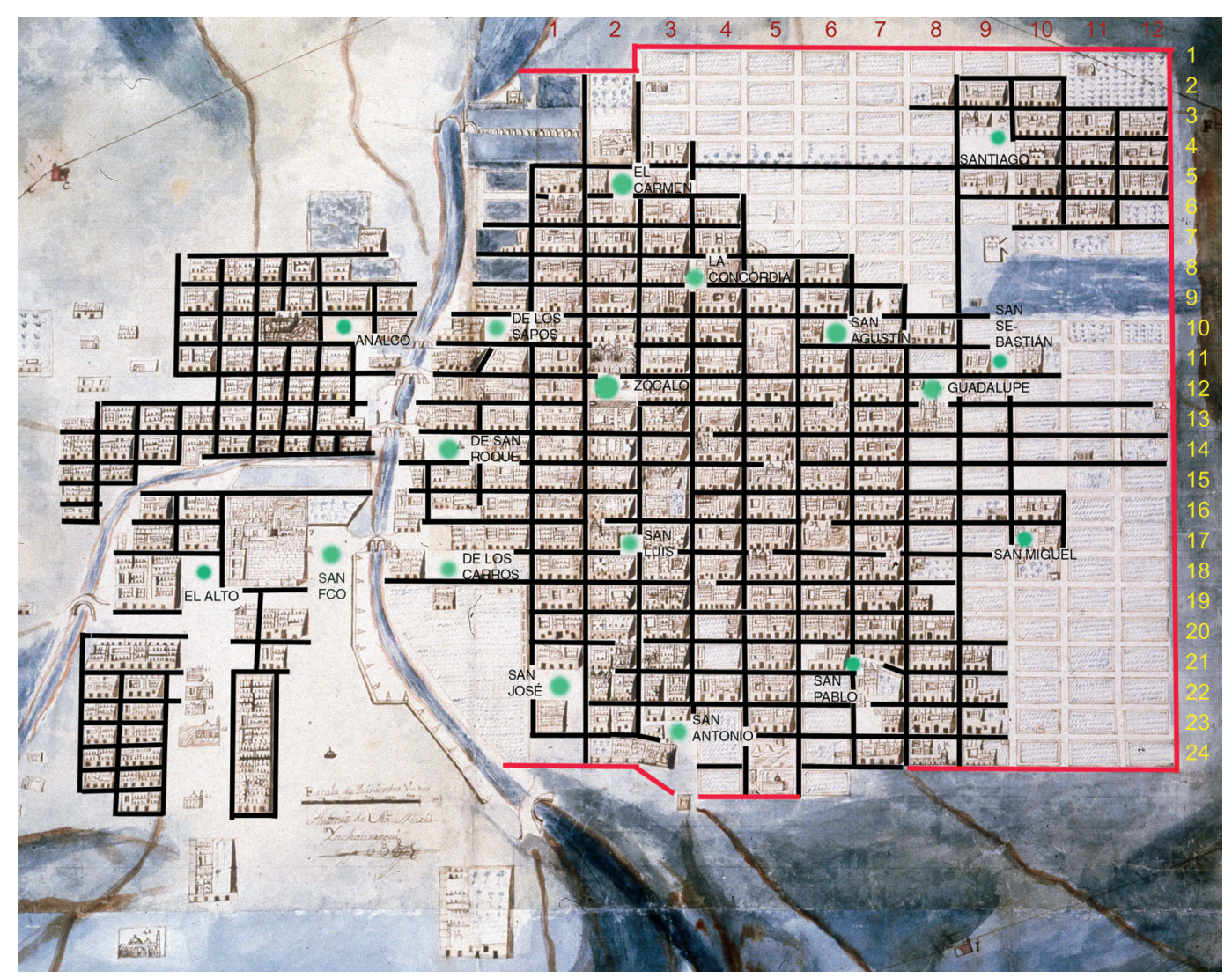

6.1.10. En este Plano se observa, después de las manzanas cercanas a la rivera por el lado poniente un gran mosaico de 12 manzanas en el eje oriente-poniente por 24 manzanas del eje norte-sur. Es una morfología de manzanas simétricas y del mismo tamaño y el gran mosaico en su conjunto forma un rectángulo con lados casi iguales. 


\subsubsection{INTEGRACIÓN FUNCIONAL DE LA CIUDAD CON EL EXTERIOR}

El río San Francisco en 1700 es el elemento geográfico que aglutina espacios emblemáticos de la ciudad: convento de San Francisco y Parroquia de Analco, entre otros.

Los puentes y las plazas para la transacción de mercaderías, los ritos religiosos y como espacios de recreación y convivencia de la comunidad.

Los acueductos al norte y al sur del río en la ciudad.

Los otras plazas públicas en el lado poniente del río están casi siempre asociadas con edificios de culto y sobre los ejes de salida más importantes de la ciudad.

Con estos elementos urbanos vemos un orden explícito de la ciudad en el acomodo del espacio público, la forma urbana de manzanas y los edificios fiscales con armonía y aprovechamiento de la topografía y los cuerpos de agua para la vida de la comunidad y la defensa del sitio..

En la traza reticular observamos el dominio de ejes de 2, 3 o hasta cinco calles paralelas destacadas de norte a sur y de oriente a poniente por su conexión con las rutas más socorridas.

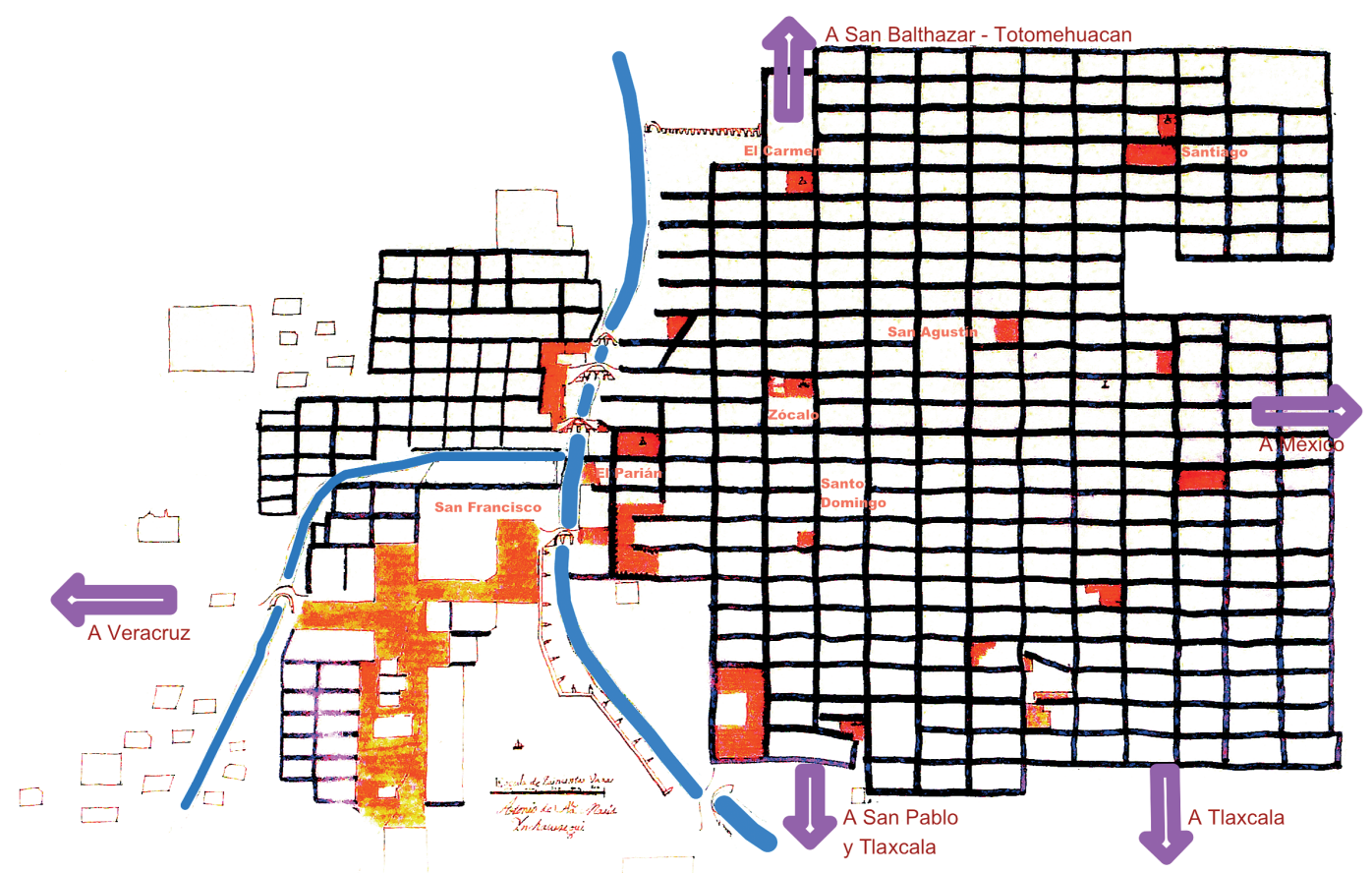

6.1.11. Plano con las plazas públicas, calles, puentes, acueductos y principales destinos. 


\subsubsection{LEYENDAS EN CARACTERES LATINOS}

Generalmente estamos acostumbrados a leer los letreros que acompañan a una imagen sin reparar en el amplio contenido de información que pueden mostrarnos. Una característica de los planos elaborados en el virreinato es la calidad de la información que nos ofrecen de la ciudad o de la entidad a la que hacen referencia; debido a ello nos interesa evidenciar esta información de letreros que cubren los siguientes aspectos:

i. En la parte superior central el título del plano y el año de fundación de la ciudad. ii. En la parte superior izquierda, una lista de edificios religiosos clasificados como sigue: Catedral, parroquias, conventos de religiosos, conventos de religiosas, iglesias e iglesias de barrio.

iii. En la parte inferior central, la escala y el autor del plano.

iv. En la parte media izquierda, las notas acerca de las garitas, las medidas entre una y otra y la de los anchos de las calles.

v. En la parte inferior derecha, la distancia entre cada una de las garitas respecto al centro de la ciudad.

Es un plano muy explícito de los temas relacionados con la nueva fiscalización, así como de la relación de estos elementos con los edificios religiosos de la ciudad y su clasificación como lo observamos en los letreros señalados a continuación.

La calidad de la información, incompleta por la pérdida de textos debido al deterioro, es sin duda, de una importancia sustancial para la recuperación del estrato de la ciudad en el año de 1700. Marca el inicio de un nuevo período morfológico de la Ciudad de Los Ángeles, ya que a partir de este año se configura una nueva ciudad por las nuevas implantaciones fiscales, de control y vigilancia de la ciudad a través del círculo de garitas externo a la mancha urbana con caminos que salen por cada una de ellas a las diferentes rutas. 


\begin{tabular}{|c|c|c|c|}
\hline Catedral & 1 & San Luis & 28 \\
\hline Parroquias & & San Pablo & 29 \\
\hline Señor San José & 2 & San Pedro & 30 \\
\hline Santo Ángel & 3 & San Cristóbal & 31 \\
\hline San Sebastián & 4 & $\begin{array}{l}\text { Nuestra Señora de } \\
\text { Guadalupe }\end{array}$ & 32 \\
\hline Santa Cruz & 5 & La Soledad & 33 \\
\hline San Marcos & 6 & Capilla de los XXXX & 34 \\
\hline Conventos de Religios & & Santa Ana & 35 \\
\hline San Francisco & 7 & San Pablito & 36 \\
\hline San Antonio & 8 & San Antoñito & 37 \\
\hline Santo Domingo & 9 & San Miguel & 38 \\
\hline San Agustín & 10 & San Ramón & 39 \\
\hline La Merced & 11 & San Matías & 40 \\
\hline El Carmen & 12 & Tecpan & 41 \\
\hline San Juan de Dios & 13 & Calvario & 42 \\
\hline San Roque & 14 & Remedios & 43 \\
\hline Bethelen & 15 & Misericordia & 44 \\
\hline Conventos de Religio & & San Juan del Río & 45 \\
\hline Santa Catarina & 16 & San Javier & 46 \\
\hline San Jerónimo & 17 & Santiago & 47 \\
\hline La Concepción & 18 & San Sebastián & 48 \\
\hline Santa Inés & 19 & & \\
\hline Santa Clara & 20 & & \\
\hline La Santísima Trinidad & 21 & & \\
\hline Santa Mónica & 22 & & \\
\hline Santa teresa & 23 & & \\
\hline Capuchinas & 24 & & \\
\hline Colegio de Niñas & 25 & & \\
\hline Santa Rosa & 26 & & \\
\hline El Espíritu Santo & 27 & & \\
\hline
\end{tabular}

Ciudad de los Ángeles (México)

Fundada el 6 de abril de 1531

\section{Notas}

La línea negra que abraza la circunferencia denota las dimensiones de Garita a Garita.

Las distancias que hay de la Garita de San Pablo a la de El Loreto y la que hay de la de El Loreto a la de Amoxoc no se manifiestan por no estar el terreno horizontal sólo haber Loma.

Las calles de la Ciudad toda tienen catorce varas de ancho no se demuestran

Escala de quinientas varas. Abajo: dibujo de una barra numerada de a cien varas desde 0 a 500 Antonio de Sta María Ynchaustegui.

Abajo: la rúbrica

De la de San Pablo 1250 varas J. La Garita de San Pablo está a el Nornordeste y Nordeste dista de la Ciudad 4000 varas y de lado al Loreto 2432 atrás.

K La Garita de el Loreto está al este y dista de la Ciudad 2700 varas. De la de Amozoc 2522 atrás. Que sumando toda la circunferencia [...]

\subsubsection{SUPERPOSICIÓN DEL PLANO DE 1700 EN UNA FOTOGRAFÍA AÉREA ACTUAL DE GOOGLE}

La traza urbana definida hasta 1700 tiene manzanas edificadas y no edificadas, estas últimas usadas mayormente para la agricultura. El plano es importante: 
1. Porque se constata la escala y la proporción del Plano en su coincidencia con la imagen de google.

2. Las diferentes partes de la ciudad edificada de 1700 cubren una superficie con cerca de $1.5 \mathrm{~km}^{2}$ y aprox. 260 manzanas edificadas de acuerdo con esta fuente de información planimétrica-urbanística.

3. Con el marco de latitud y longitud que agregamos ubicamos a la manera actual, La Ciudad de Los Ángeles con las referencias geográficas convencionales.

4. Comparativamente con la fotografía aérea, el Plano contiene una mejor representación de la información en cuanto a las edificaciones.

5. Es inherente su calidad plástica en el manejo de los planos "en planta" bidimensional y tridimensional de gran exactitud y belleza pictórica en el Plano de 1700.

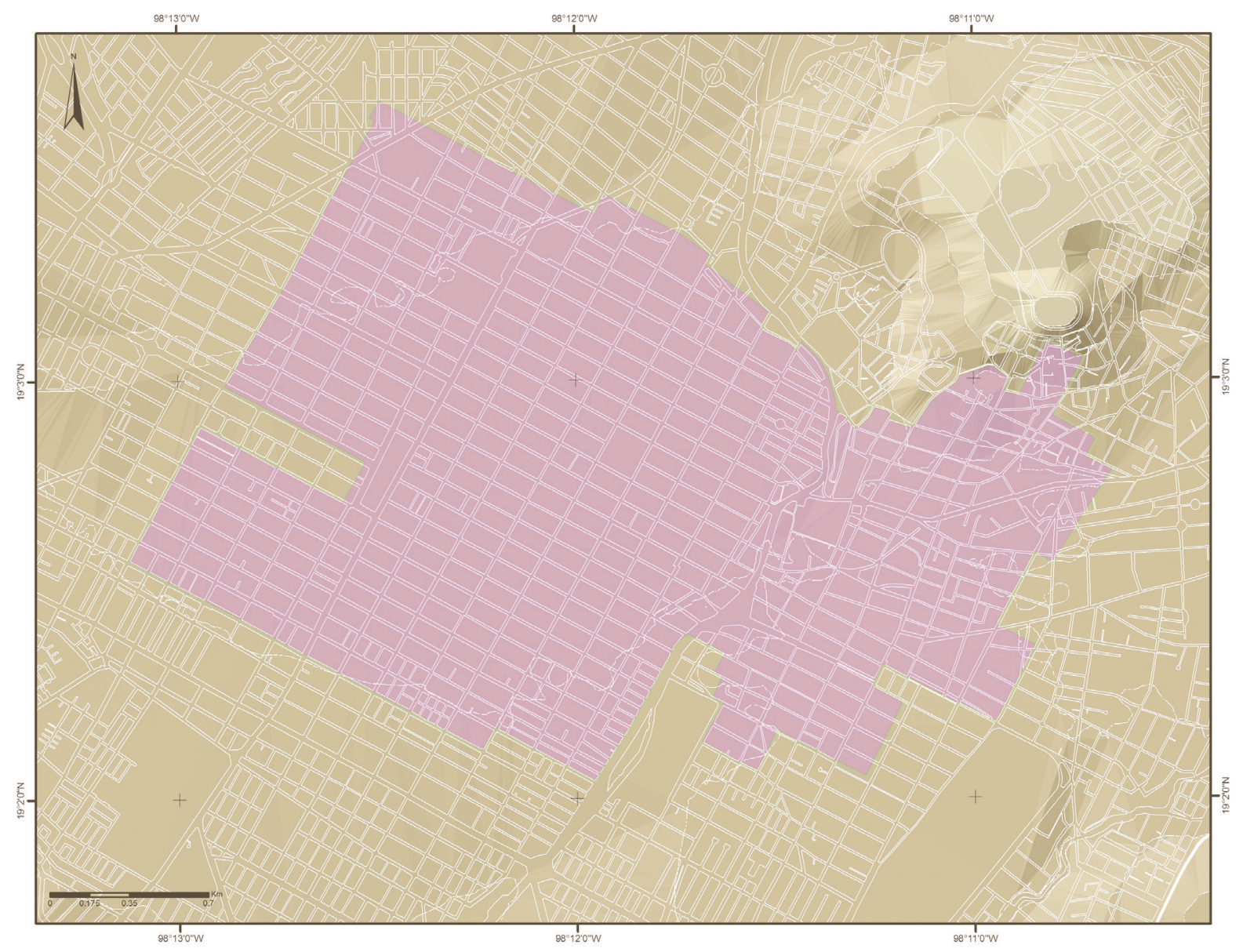




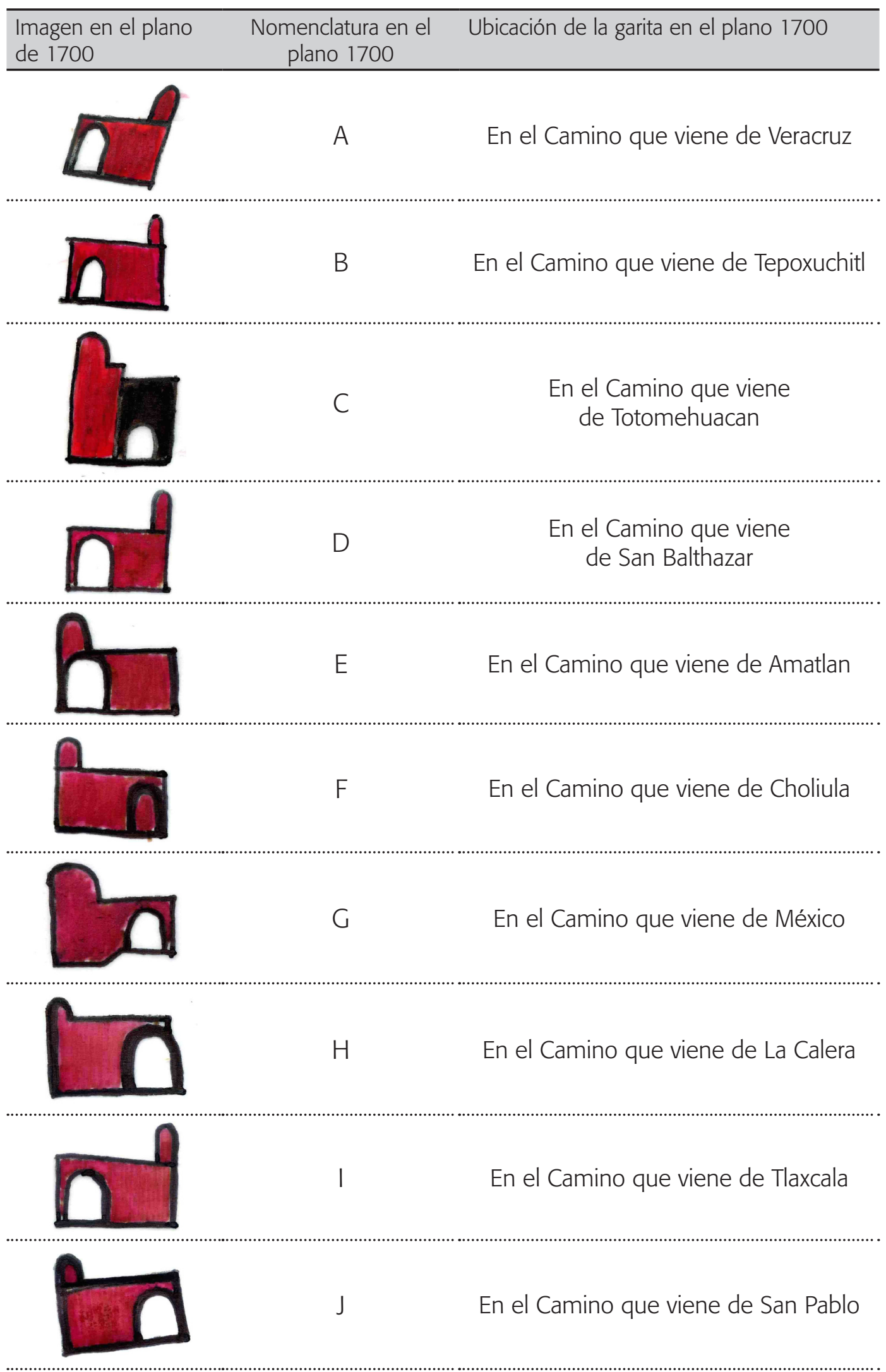



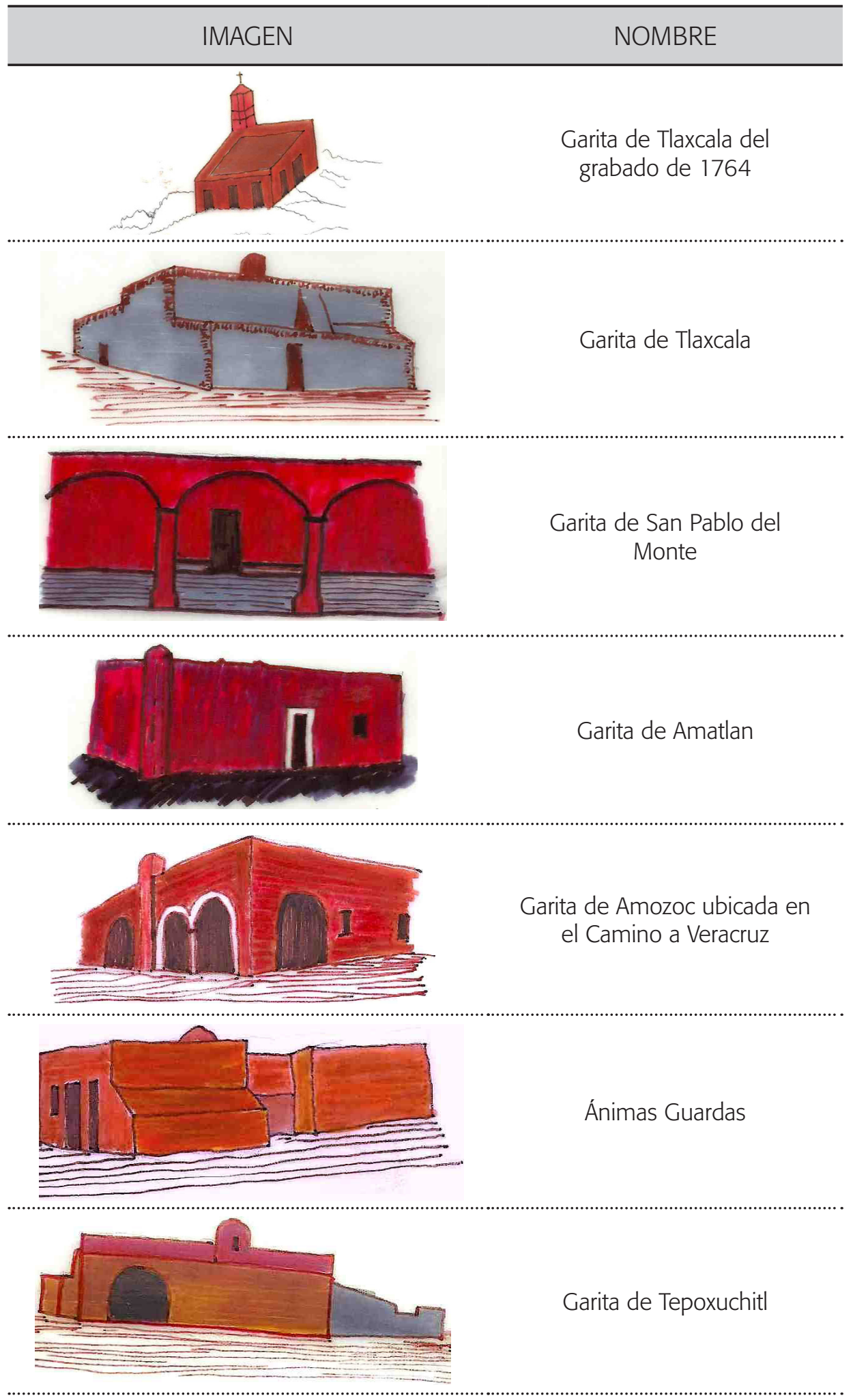

6.1.15. Garitas que aparecen en el libro de Hugo Leicht, 1934. Calcas de JGAC sobre fotografías blanco y negro de garitas en los años veinte y treinta del siglo xx en el libro Leicht. 


\subsubsection{PRINCIPALES CARACTERÍSTICAS URBANÍSTICAS EN 1700}

1. Topografía y cuerpos de agua. Hay una adaptación orgánica con la topografía, pues, en la zona de San Francisco y Analco, al oriente del río San Francisco, las calles y las manzanas se adaptan a la topografía del lugar, impidieron las inundaciones y evitaron riesgos por avenidas de agua. De igual manera sucede en la urbanización al poniente del mismo río.

2. Los puentes sobre el río están dispuestos funcionalmente, esto es, siguen los ejes de composición y tránsito más importantes del área urbanizada para pasar por el interior de la ciudad y conectarse con los caminos principales hacia el exterior.

3. El convento de San Francisco y el barrio primigenio se ubica en un sitio protegido por los ríos Xonaca y San Francisco y por los cerros de Bethlem y Loreto, además tiene una gran muralla que protege y delimita los edificios y el enorme atrio, también un gran receptáculo de agua conocido posteriormente como el "Estanque de los Pescaditos". Este emplazamiento y diseño dio protección estratégica a la fundación urbana.

4. La Ciudad de Los Ángeles de diseño reticular, tiene formas de manzanas que se pueden describir como sigue:

i. Rectangulares de $100 \times 200$ varas.

ii. Cuadradas de $100 \times 100$ varas alrededor del convento antes citado debido a que esa era la forma por tradición utilizada por los frailes franciscanos.

iii. Grandes predios destinados a conventos o asentamientos junto al perímetro de la ciudad como es el caso de: el barrio de Santiago, los conventos de dominicos, agustinos y carmelitas

iv. El gran conjunto urbano al poniente del Río San Francisco, denominada por algunos autores la segunda fundación, se forma por un rectángulo de $12 \times 24$ manzanas dispuesto para el crecimiento urbano de largo plazo, que en esa época apenas rebasaba el 50\% de ocupación edificada y el resto de cultivo agrícola en el seno de la ciudad.

v. Este gran mosaico nos induce a pensar en un trazado urbano de un sola vez, es decir, se diseña este gran rectángulo de 12 × 24 manzanas y junto, las manzanas cuidadosamente trabajadas funcional y formalmente a lo largo de la rivera. Es un diseño oportuno y previsor del crecimiento urbano de largo plazo.

5. Entonces, podemos apreciar como la ciudad reticular que se implanta durante los siglos XVI y XVII se le impone un perímetro formado por edificios llamados garitas para el control de paso de mercaderías y personas, unidas todas ellas por caminos que 
forman un polígono irregular alrededor de la ciudad establecida y que se le denominó círculo o circunferencia de garitas en los expedientes de la época. Esta obra urbanística, probablemente modesta en cuanto a la fábrica de sus edificios es una delimitación física resguardada en los puntos de ubicación de las mismas pero también con vigía en el círculo por los caminos de ronda las 24 horas del día, para evitar el contrabando de mercaderías, ya que, en ese período de tiempo, la Ciudad de Los Ángeles ocupó un papel sustantivo en el tránsito mercantil de la Nueva España.

Junto con el diseño circular alrededor de la ciudad se contó con 11 caminos dispuestos en forma radial, que son las conexiones hacia las principales ciudades y pueblos con los que, desde tiempos anteriores, ya se tenía una estrecha relación. Es importante este diseño por las siguientes particularidades:

i. La gran calidad del proyecto circular en el perímetro urbano con caminos perpendiculares que se integran a la ciudad pasando por las puertas de control, las garitas;

ii. Estos caminos de entrada se comunican, en lo general, a grandes vestíbulos urbanos: las plazas, que cumplen funciones diversas entre las que destacan, el uso comercial, ritual y de convivencia comunitaria, para posteriormente transitar y salir de la ciudad, en su caso, para dirigir a buen destino a los transeúntes y las mercaderías transportadas mayormente por recuas.

iii. La delimitación circular tuvo un papel a largo plazo de contención de la ciudad pues no fue rebasada sino hasta finales del siglo XIX, ya posterior a la construcción del ferrocarril y al crecimiento industrial de la contemporánea Puebla de Zaragoza.

Finalmente, la identificación de los elementos urbanísticos señalados en este capítulo y su estructuración en la actual ciudad de Puebla de Zaragoza es muy importante en términos de su conocimiento e investigación urbanística cabal, pero también para contar con mayores elementos de diseño, disposición urbana y edificatoria, identificación de edificios emblemáticos casi en el olvido, que nos permitan generar propuestas de intervención contemporánea en la ciudad, con base en el conocimiento de sus orígenes

1. Propuestas de este tipo las ha hecho Luis Ignacio Sáinz para el Puerto de Veracruz en lo que fueron las puertas de la antigua fortaleza, o bien el proyecto escultórico para el centro de Chihuahua acompañado de Agueda Lozano, Juan Álvarez del Castillo, Vicente Rojo, Federico Silva, Manuel Felguérez, Gilberto Aceves Navarro, Fernando González Gortazar, Luis López Loza, Brian Nilssen, José Luis Cuevas, Arnaldo Cohen, Gabriel Macotela y Manuel Hernández Suárez; experiencia única en México, para valorar y contribuir a la identidad de una comunidad a través de una planeación cuidadosa, que en México se ha denominado Plan Maestro, y 12 esculturas monumentales con criterios de volumen y alturas, realizadas por los mejores escultores del México contemporáneo. 
y transformaciones, es decir, la gran experiencia que ha tenido secularmente el paisaje cultural urbano en sus armonías y disrupciones con la geografía.

La recuperación del círculo de garitas y caminos de ronda que se implanta entre 1698 y 1724, y que se conserva en la ciudad hasta la primera mitad del siglo XX, se puede realizar a través de los artificios plásticos de grandes artistas mexicanos.' La finalidad de obras de este tipo son para poner en evidencia la memoria política y económica de la metrópoli americana y la comprensión urbanística de su origen y desarrollo.

\subsection{LECTURA URBANÍSTICA DEL PLANO: LAS GARITAS DE LA ADUANA DE PUEBLA DE LOS ÁNGELES}

\subsubsection{FICHA BÁSICA DEL PLANO}

Medidas del original: $75.5 \times 50 \mathrm{~cm}$.

Repositorio: Archivo General de Indias

Clave de catalogación: AGI, MP, México, 519.

Autores o signatarios: Juan José de Veitia, José Joaquín de Uribe y Castrejón.

Año de realización: 1724.

El Plano tiene dos hojas con leyendas, pegadas a la pintura de la ciudad, de $13 \mathrm{~cm}$ de ancho cada una, la primera colocada y pegada al plano en su lado izquierdo, la segunda pegada al lado derecho de Plano. Contienen los nombres de cada garita, las distancias que las separan una de otra y otros datos que se explican más adelante.

Orientación: Los cuatro puntos cardinales se señalan en caracteres latinos; también hay Rosa de los Vientos con flecha apuntando al sur.

La orientación dominante en el mapa es el oriente, ubicado en la parte superior. Todos los elementos del paisaje natural: cerros, vegetación y ríos, así como los del paisaje urbano y construido están representados de manera tridimensional. Da la impresión de una vista a vuelo de pájaro desde Cholula en el poniente al Teposuchil en el oriente.

Anotaciones: en caracteres latinos En el Plano se señalan:

1. Los cuatro puntos cardinales

2. Los barrios de la ciudad.

3. Los nombres de todas las garitas

4. Los nombres de los edificios y lugares emblemáticos. 
5. Al lado izquierdo del Plano hay una tabla con las medidas entre garitas y entre cada una y "los muros" de la ciudad, encabezada con el título de: "Cituación hasta el año de 1724. Del asiento en que hoy se hallan las garitas, hecha por el Señor Don Juan José de Veitia".

6. Al lado derecho del Plano hay una tabla con las medidas entre garitas y de éstas con "los muros" de la ciudad; lleva como título: "Nueva Cituación de las Garitas que se intentan recoger a extramuros de las entradas y salidas de la Ciudad por su Señoría el Señor Licenciado Don José Joaquín de Uribe y Castrejón Oidor de Canon de la Real Audiencia de este Reino, este año de 1724".

Representación plástica.

1. "En Planta" se dibujaron y pintaron las plantas de las manzanas de la ciudad: la zona centro, barrio de Analco y barrio de Santiago y en planta los caminos que unen las garitas,

"En volumen" o perspectiva, se dibujaron los edificios y caseríos emblemáticos de la ciudad, las, 10 garitas del círculo externo de garitas ("del asiento en el que hoy de hallan") y las 11 del círculo externo de garitas ("Nueva Cituación de las garitas")

2. La técnica usada es tinta sepia para contorno de edificios, manzanas, ríos y caminos, con aguada de diversos colores como relleno, sombras para volumen y vegetación.

Contenido

Al centro se encuentra la Puebla de los Ángeles, con su catedral en el núcleo y la traza reticular. Alrededor se distinguen los barrios y conjuntos religiosos importantes:, San Francisco, Analco, San Baltasar, Santiago, San José y San Antonio. Alrededor de esta gran ciudad y sus barrios periféricos se encuentran las 18 garitas; con líneas punteadas se representan los caminos con las medidas en cordeles de a 50 varas que unen unas con otras y penetran a la ciudad; también se señalan las distancias que hay en los diversos tramos de caminos. 


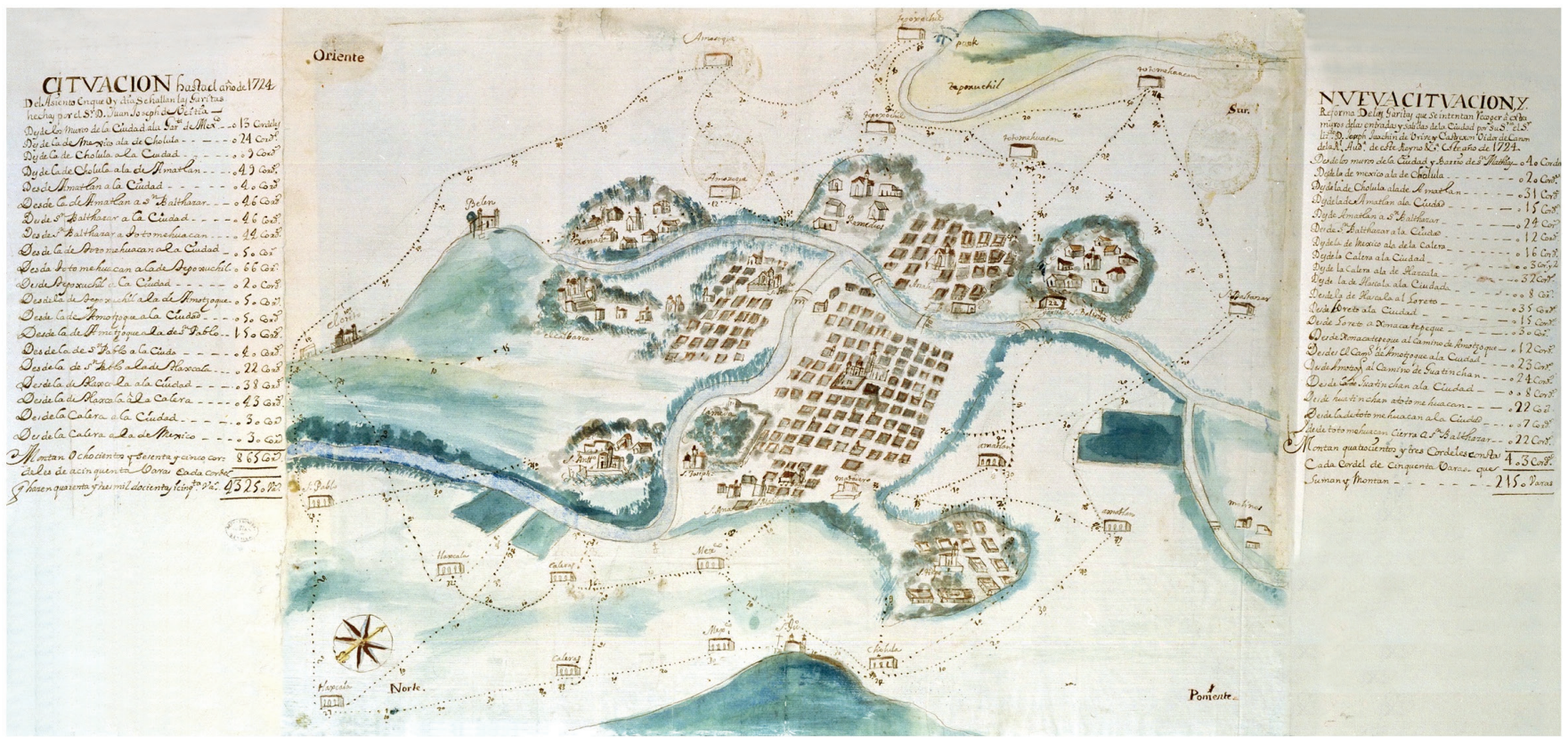

6.2.1. Plano de las garitas de la Aduana de Puebla de Los Ángeles

\subsubsection{PAISAJE DE CERROS Y BARRIOS}

En los extremos del mapa se tiene lo siguiente: en la parte superior, el oriente, el cerro del Teposuchil; en la izquierda, el norte, el cerro de Belén; en la inferior, el poniente, el cerro de San Juan. Está pintado con aguadas algunas áreas que indican los principales barrios de la ciudad: Xonaca, Remedios, Analco, San Baltazar, El Calvario, San Francisco, San Antonio Lameda (Alameda), Santiago y el Centro de la Ciudad.

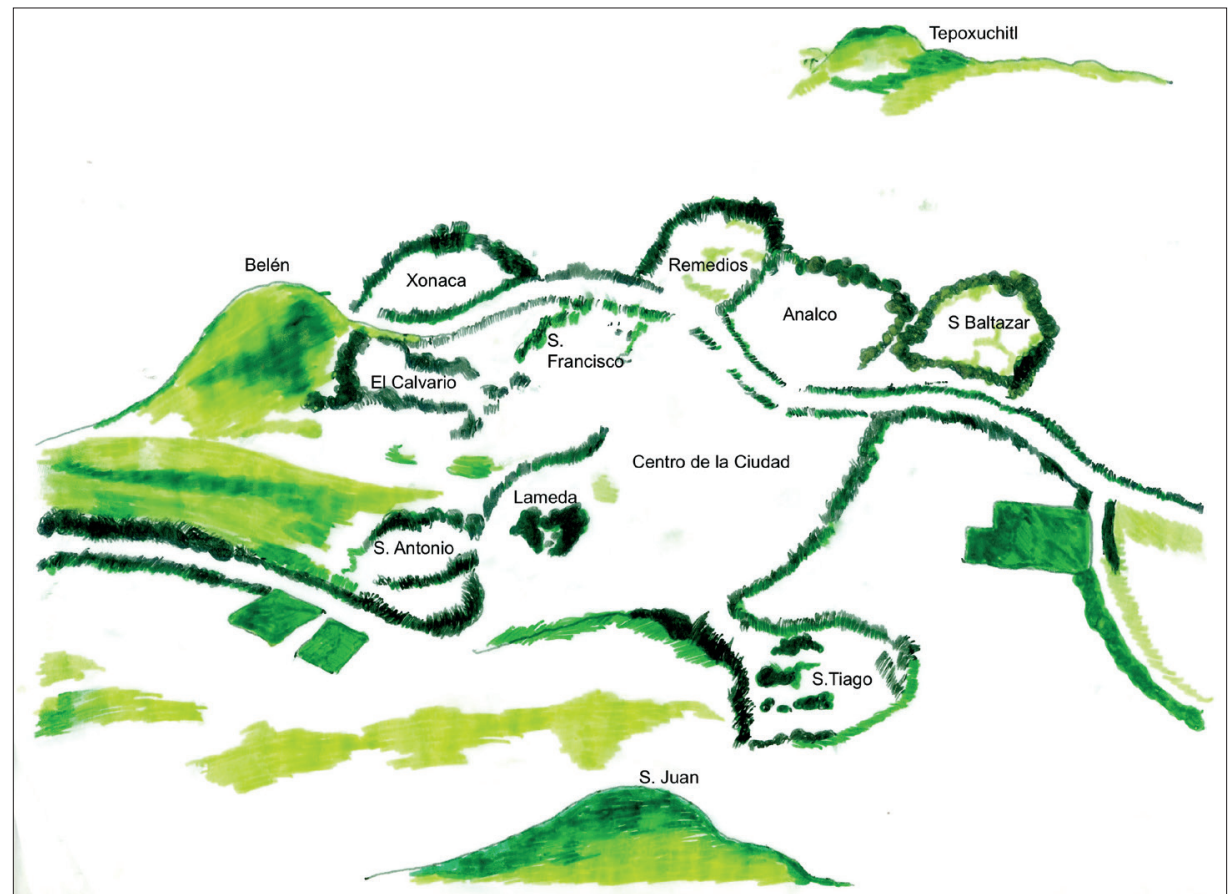

6.2.2. Plano con los cerros y barrios 


\subsubsection{CUERPOS DE AGUA}

Hay tres ríos en el espacio geográfico de la ciudad, dos que la cruzan la ciudad: el arroyo de Xonaca y el río San Francisco que se unen junto al Convento de San Francisco; el otro es el Río Alseseca, al oriente de la ciudad y en las faldas del Cerro de Tepoxuchitl.

Cerros, barrancas y ríos fueron y serán los contenedores de la ciudad.

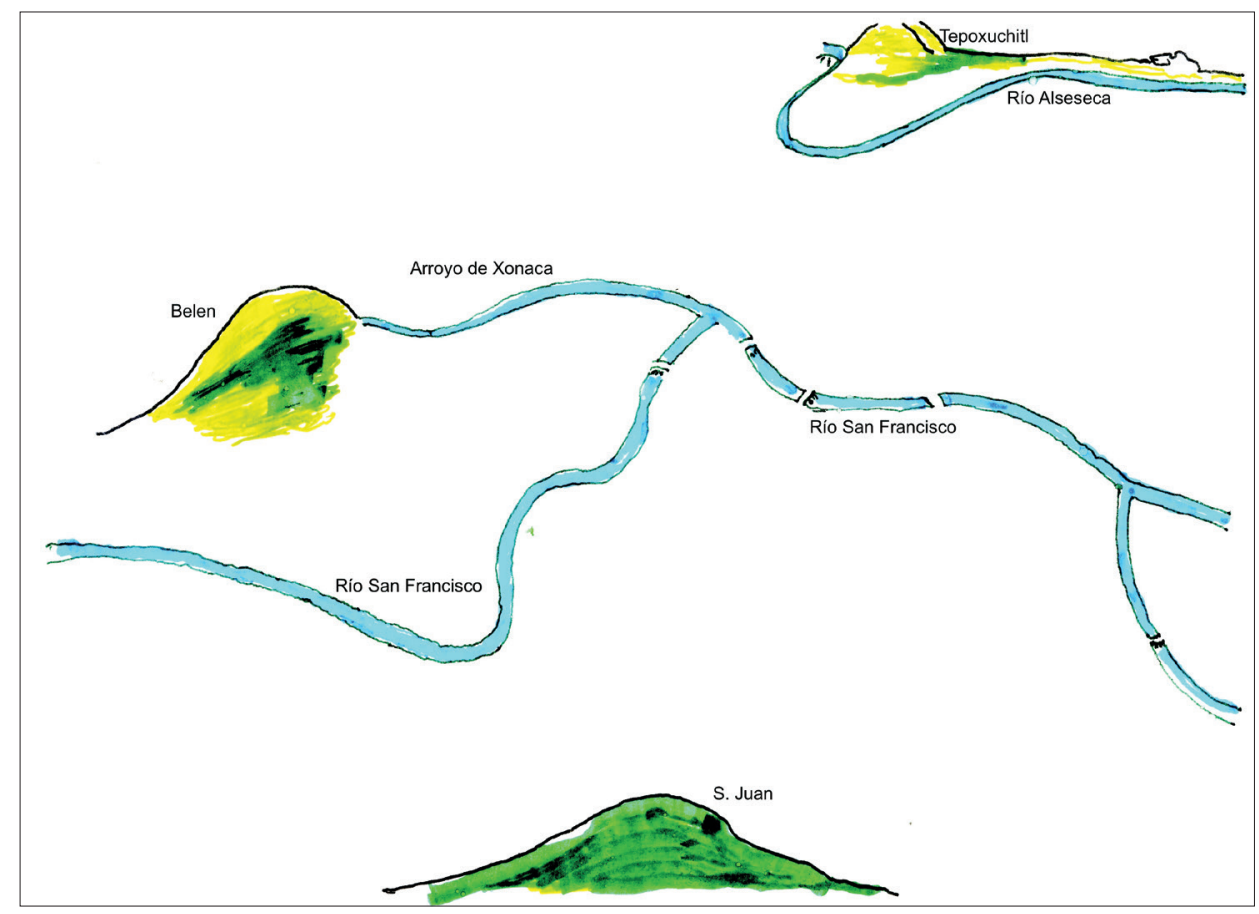

6.2.3. Plano con los ríos en la ciudad.

\subsubsection{TRAZA URBANA}

La traza de la ciudad en su primer momento, en 1531, fue alrededor del Convento de San Francisco, al modo de los campamentos militares ancestrales del Viejo Mundo. La morfología de las manzanas alrededor del Convento son en su mayoría cuadradas y dispuestas ortogonalmente, el Convento de San Francisco tiene su entrada mirando al poniente.

Lo que se conoce como "Segunda Fundación", hemos decidido llamarla el "ensanche de la ciudad" por los argumentos siguientes: 
1. El trazado y la disposición de las manzanas en San Francisco perduran hasta la actualidad con mínimas modificaciones. Esa fundación nunca fue abandonada totalmente, siempre ha sido parte de la ciudad; cambió su carácter al trasladar el espacio físico de poder de gobierno y ecleseástico a la Plaza Mayor en un entramado cercano a 300 manzanas ubicada al otro lado del río, al oriente de San Francisco. Allí se aplicaron las nuevas concepciones renacentistas de ciudad abierta, en particular las provenientes del tratado de León Baptiste Alberti en la segunda mitad del siglo XV en Italia.

2. El ensanche se realizó pues se tomo en cuenta que se requería un espacio físico mayor para implantar la traza con sus edificios para la habitación, el poder de gobierno, el de justicia y el religioso.

3. El ensanche, como ya se menciona en el subcapítulo 6.1, fue diseñado de una sola vez y ocupado poco a poco, según se requiriera, pero sin dejar superficies ociosas dentro de la nueva traza del ensanche, esto es, que fueron usadas como áreas de cultivo en tanto no se realizaran nuevas construcciones en ese espacio de crecimiento destinado a la urbanización.

4. El trazado es homogéneo en toda la ciudad, manteniendo la orientación de las manzanas implantadas en San Francisco; la ortogonalidad de las calles fue la constante, aunque con formas de manzanas diferentes, acordes con su tiempo, patrones de organización del espacio urbano y adaptación al medio físico.

5. La principal ruta hacia Veracruz permaneció atravesando el "barrio" de San Francisco en su trayecto de entrada-salida de la ciudad.

La traza urbana que se realza en el plano siguiente da cuenta de "la segunda fundación" o ensanche de la ciudad, San Francisco, Analco y Santiago. Son las mismas divisiones de la traza continua de la urbe, aunque separados por ríos o terrenos de cultivo dentro de la propia traza continua. Esta característica de Puebla de Los Ángeles ya la habíamos notado y registrado en el Plano 6.3 que se desprende del análisis del Plano del año 1700.

Ya para el año 1724 estamos ante una urbanización con un casco urbano central (la segunda fundación o ensanche) con los siguientes barrios principales: a. San Francisco, que pasa de ocupar el lugar central de la ciudad a principal barrio después de la "segunda fundación"; b. El barrio de Analco, separado de los anteriores ríos, y c. El barrio de Santiago, ubicado al suroeste del centro, en la entrada del camino que viene de Cholula y, separado del núcleo por manzanas sin urbanizar. 


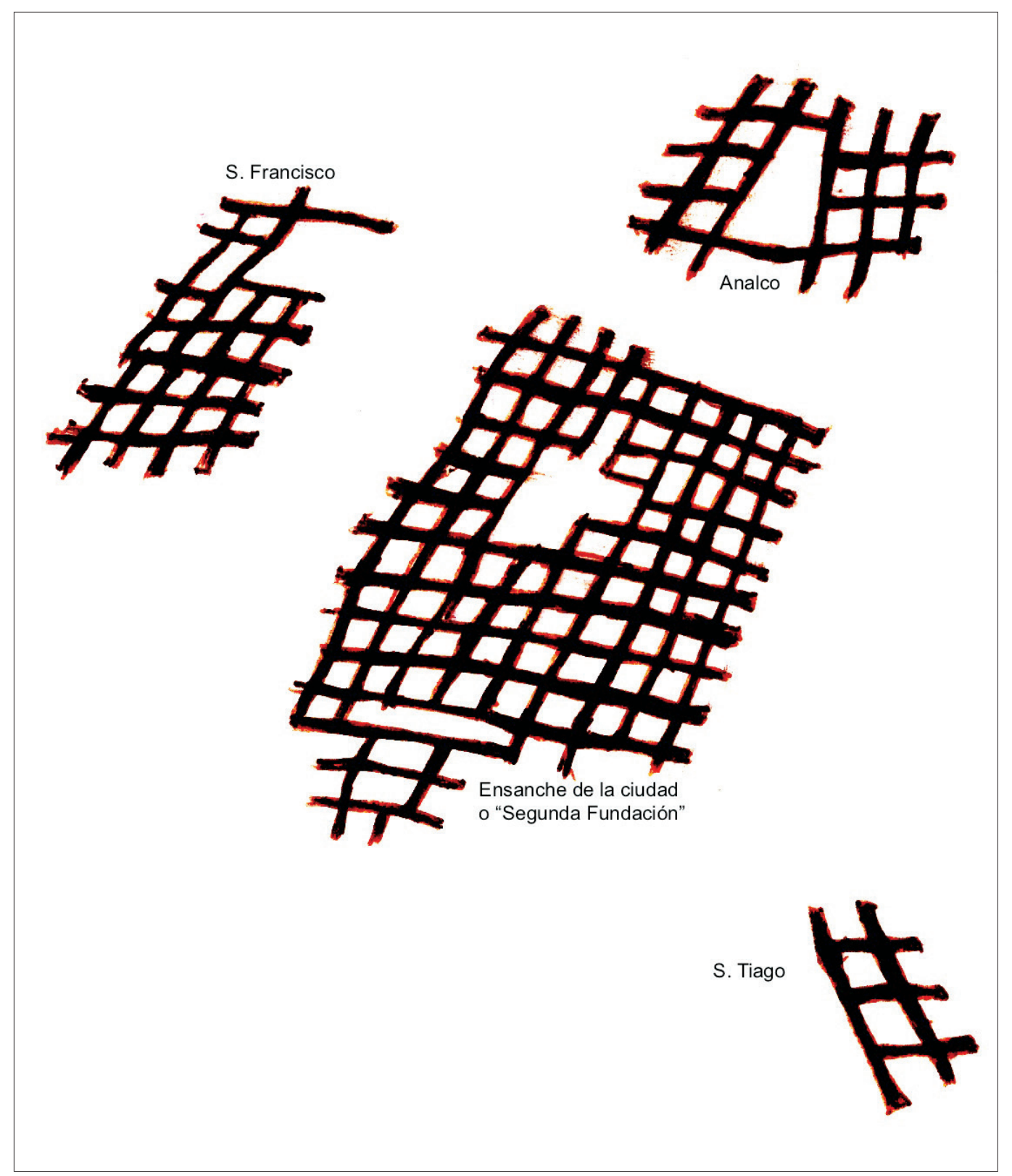

6.2.4. Plano del trazado de calles en San Francisco, Analco, el Ensanche y Santiago

\subsubsection{MANZANAS Y EDIFICIOS}

A través del Plano de manzanas y edificios, la ciudad no creció a través de la agregación continua, sino que fue creando agrupaciones por barrios que si bien, mantenían la misma orientación de las calles, su continuidad y proporciones, mantuvieron una separación en barrios, aunque integradas en una misma traza urbana. Esta descripción que nos muestra el Plano, nos confirma que la traza fue hecha de una sola vez en el área denominada centro o "segunda fundación". 
Destacan en el Plano, la capilla de Belén y la de San Juan que se encontraban sobre las cimas de los cerros del mismo nombre, el perímetro central con su catedral y los conjuntos de: El Calvario, Xonaca, San Francisco, Los Remedios, Analco, San Balthazar, Santiago, San José, San Antonio y Molinos. Sin duda, los principales barrios y edificios emblemáticos de la ciudad en 1724.

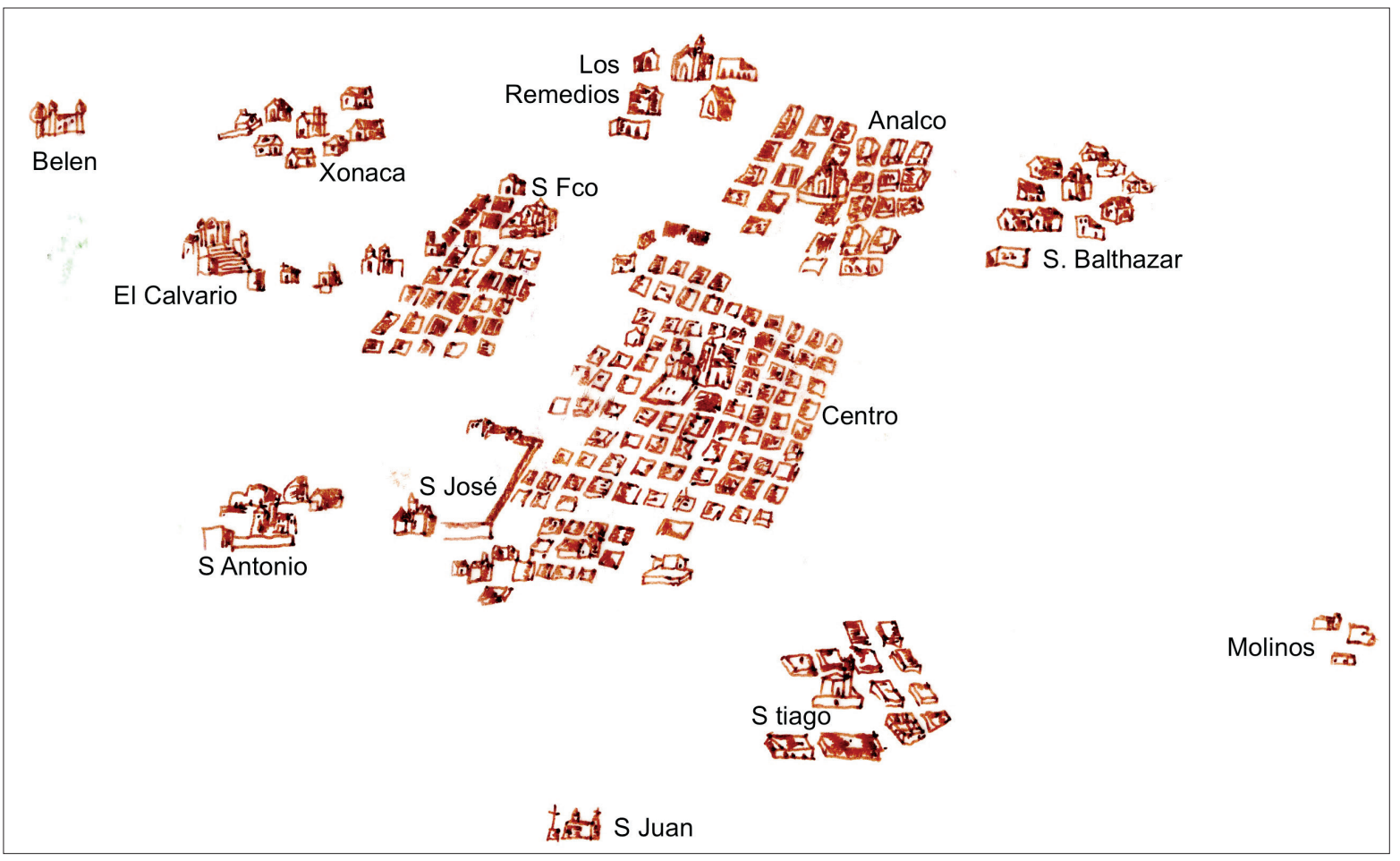

6.2.5. Plano con las manzanas y edificios principales de la ciudad en el año de 1724. Este plano destaca la subdivisión de barrios con el casco urbano.

\subsubsection{GARITAS}

Antes de 1724 las garitas estuvieron formando un círculo establecido en lugares seleccionados adecuadamente aunque alejado del área urbanizada de la ciudad. La lejanía de las garitas y los intereses de comerciantes por evadir la acabala en beneficio propio, llevó a la decisión Real, todavía con la participación de Joseph Veitia Linaje, responsable de las alcabalas reales en Puebla, fallecido en 1722 y con Joseph Joachin Uribe y Castrejón, nuevo encargado de las alcabalas en Puebla, a partir del deceso de Veitia, se consideró más oportuno acercarlas a la ciudad. Uno de los problemas mayores que se mencionan en el expediente que acompaña al Plano fue "la ocultación de los géneros más preciosos y llenos, de poco bulto", a través de la evasión de las garitas y los caminos de ronda. 
El acercamiento del círculo de garitas a la ciudad venía a resolver varios problemas: el primero 'por la facilidad y eficiencia que implica un menor recorrido de los guardas encargados de vigilar los caminos entre garita y garita durante las veinticuatro horas del día, producto del contrabando de mercancías, algunas de ellas de valor excesivo, como lo demuestra el folio 101 v. del expediente que acompaña a este Plano, que se muestra en el anexo

Había que recaudar los impuestos reales de Puebla en su magnitud total para de allí distribuir los dineros hacia el Gran Caribe, las Islas filipinas y España en la defensa y el mantenimiento de los territorios conquistados. Sin embargo después de esta gran intervención física en la gran ciudad de Puebla de Los Ángeles,vendrá un período de sustitución de funciones reales que se asignarán ahora a la capital de la Nueva España, la gran Ciudad de México y vendrán los auges mayores del Obispado de Michoacán y del Reino de Galicia, con sedes en Morelia y Guadalajara, respectivamente. Puebla y su ciudad capital pasarán a segundo término en la economía novohispana sobretodo después de 1740, año en que pierde el carácter de acabala real para depositarla en la Ciudad de México.

Las garitas establecidas hasta 1724 y el nuevo círculo de garitas propuesto en este mismo año, se presentan en el siguiente cuadro copiado de las tablas a uno y otro lado del Plano original de 1724.

\begin{tabular}{|c|c|c|c|}
\hline \multicolumn{4}{|c|}{ Leyendas en el plano: } \\
\hline \multicolumn{2}{|l|}{ Izquierda } & \multicolumn{2}{|l|}{ Derecha } \\
\hline \multicolumn{2}{|c|}{$\begin{array}{l}\text { Cituación hasta el año de 1724. Del asien- } \\
\text { to en que hoy se hallan las garitas, hecha } \\
\text { por el Señor Don Juan José de Veitia. }\end{array}$} & \multicolumn{2}{|c|}{$\begin{array}{l}\text { Nueva Cituación de las Garitas que se inten- } \\
\text { tan recoger a extramuros de las entradas y } \\
\text { salidas de la Ciudad por su Señoría el Señor } \\
\text { Licenciado Don José Joaquín de Uribe y Cas- } \\
\text { trejón Oidor deCanon de la Real Audiencia } \\
\text { de este Reino, este año de } 1724 \text {. }\end{array}$} \\
\hline $\begin{array}{l}\text { Desde los muros de la Ciu- } \\
\text { dad a la Garita de México }\end{array}$ & 13 cordeles & $\begin{array}{l}\text { Desde los muros de la Ciu- } \\
\text { dad y barrio de San Matías }\end{array}$ & 40 cordeles \\
\hline $\begin{array}{l}\text { Desde la de México a la de } \\
\text { Cholula }\end{array}$ & 24 cordeles & $\begin{array}{l}\text { Desde la de México a la de } \\
\text { Cholula }\end{array}$ & 20 cordeles \\
\hline $\begin{array}{l}\text { Desde la de Cholula a la } \\
\text { Ciudad }\end{array}$ & 9 cordeles & $\begin{array}{l}\text { Desde la de Cholula a la de } \\
\text { Amatlán }\end{array}$ & 31 cordeles \\
\hline $\begin{array}{l}\text { Desde la de Cholula a la de } \\
\text { Amatlán }\end{array}$ & 49 cordeles & $\begin{array}{l}\text { Desde la de Amatlán a la } \\
\text { Ciudad }\end{array}$ & 15 cordeles \\
\hline Desde Amatlán a la Ciudad & 20 cordeles & $\begin{array}{l}\text { Desde la de Amatlán a San } \\
\text { Baltasar }\end{array}$ & 24 cordeles \\
\hline
\end{tabular}




\begin{tabular}{|c|c|c|c|}
\hline $\begin{array}{l}\text { Desde la de Amatlán a San } \\
\text { Baltasar }\end{array}$ & 46 cordeles & $\begin{array}{l}\text { Desde San Baltasar a la } \\
\text { Ciudad }\end{array}$ & 12 cordeles \\
\hline $\begin{array}{l}\text { Desde San Baltasar a la } \\
\text { Ciudad }\end{array}$ & 46 cordeles & $\begin{array}{l}\text { Desde la de México a la de la } \\
\text { Calera }\end{array}$ & 16 cordeles \\
\hline $\begin{array}{l}\text { Desde San Baltasar a Toti- } \\
\text { mehuacan }\end{array}$ & 22 cordeles & Desde la Calera a la Ciudad & 08 cordeles \\
\hline $\begin{array}{l}\text { Desde la de Totimehuacan a } \\
\text { la Ciudad }\end{array}$ & 50 cordeles & $\begin{array}{l}\text { Desde la Calera a la de } \\
\text { Tlaxcala }\end{array}$ & 32 cordeles \\
\hline $\begin{array}{l}\text { Desde Totimehuacan a la de } \\
\text { Tepoxuchil }\end{array}$ & 66 cordeles & $\begin{array}{l}\text { Desde la de Tlaxcala a la } \\
\text { Ciudad }\end{array}$ & 08 cordeles \\
\hline $\begin{array}{l}\text { Desde Tepoxuchil a la } \\
\text { Ciudad }\end{array}$ & 20 cordeles & Desde la de Tlaxcala al Loreto & 35 cordeles \\
\hline $\begin{array}{l}\text { Desde la de Tepoxuchil a la } \\
\text { de Amozoc }\end{array}$ & 50 cordeles & Desde Loreto a la Ciudad & 15 cordeles \\
\hline $\begin{array}{l}\text { Desde la de Amozoc a la } \\
\text { Ciudad }\end{array}$ & 50 cordeles & Desde Loreto a Xonacatepec & 30 cordeles \\
\hline $\begin{array}{l}\text { Desde la de Amozoc a la de } \\
\text { San Pablo }\end{array}$ & 15 cordeles & $\begin{array}{l}\text { Desde Xonacatepec al cami- } \\
\text { no de Amozoc }\end{array}$ & 12 cordeles \\
\hline $\begin{array}{l}\text { Desde la de San Pablo a la } \\
\text { Ciudad }\end{array}$ & 20 cordeles & $\begin{array}{l}\text { Desde el camino de Amozoc } \\
\text { a la Ciudad }\end{array}$ & 23 cordeles \\
\hline $\begin{array}{l}\text { Desde la de San Pablo a la } \\
\text { de la Tlaxcala }\end{array}$ & 22 cordeles & $\begin{array}{l}\text { Desde Amozoc al camino de } \\
\text { Cuautinchan }\end{array}$ & 24 cordeles \\
\hline $\begin{array}{l}\text { Desde la de Tlaxcala a la } \\
\text { Ciudad }\end{array}$ & 38 cordeles & $\begin{array}{l}\text { Desde la de Cuautinchan a la } \\
\text { Ciudad }\end{array}$ & 08 cordeles \\
\hline $\begin{array}{l}\text { Desde la de Tlaxcala a la } \\
\text { Calera }\end{array}$ & 43 cordeles & $\begin{array}{l}\text { Desde Cuautinchan a Totime- } \\
\text { huacan }\end{array}$ & 22 cordeles \\
\hline Desde la Calera a la Ciudad & 30 cordeles & $\begin{array}{l}\text { Desde Totimehuacan a la } \\
\text { Ciudad }\end{array}$ & 07 cordeles \\
\hline $\begin{array}{l}\text { Desde la Calera a la de } \\
\text { México }\end{array}$ & 30 cordeles & $\begin{array}{l}\text { Y desde la de Totimehuacan } \\
\text { cierra a San Baltasar }\end{array}$ & 22 cordeles \\
\hline $\begin{array}{l}\text { Montan ochocientos sesenta } \\
\text { y cinco cordeles }\end{array}$ & $\begin{array}{l}865 \text { corde- } \\
\text { les }\end{array}$ & $\begin{array}{l}\text { Montan cuatrocientos y tres } \\
\text { cordeles que }\end{array}$ & 403 cordeles \\
\hline $\begin{array}{l}\text { De a cincuenta varas cada } \\
\text { cordel y hacen cuarenta y } \\
\text { tres mil doscientas treinta } \\
\text { varas }\end{array}$ & $\begin{array}{l}43250 \\
\text { varas }\end{array}$ & suman y montan & $\begin{array}{l}2[0] 150 \\
\text { varas }\end{array}$ \\
\hline
\end{tabular}

'Un cordel es igual a 50 varas y una vara castellana de $0.912 \mathrm{~m}$. 
167

6.2.6. Garitas externas e internas, con sus nombres asociados, tal como aparecen en el Plano de 1724.

Segunda columna: Situación hasta el año de 1724. Del asiento en que hoy se hallan las garitas, hecha por el Señor Don Juan José de Veitia.

Tercera columna: Nueva situación de las garitas.

Garita de México

Mexco Mexco

and

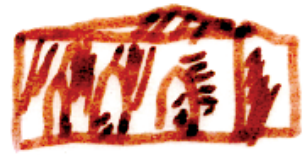

Garita de Cholula

cholula

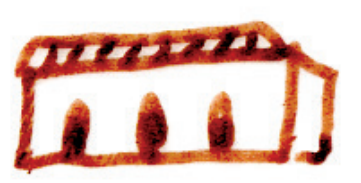

amatlan amatian
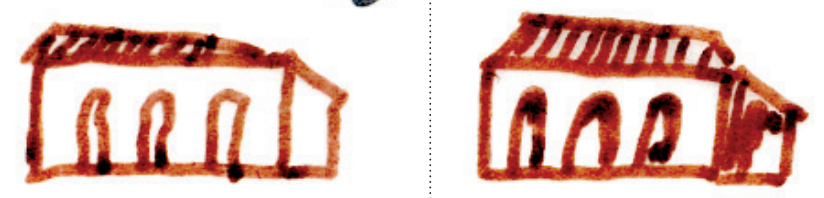

Garita de San Baltazar

Baltazat

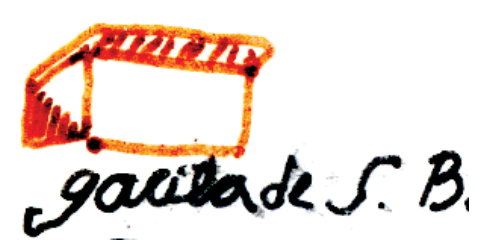

Garita de Totomehuacan Fo to me hearan zotome huacan
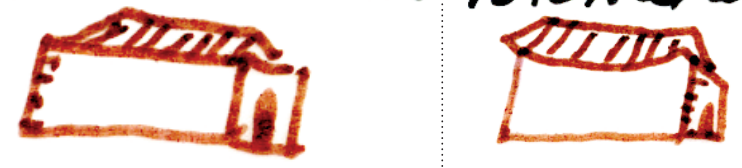

Garita de Tepoxochil

tepoxuchle 7opoxochil

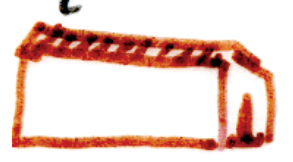

定

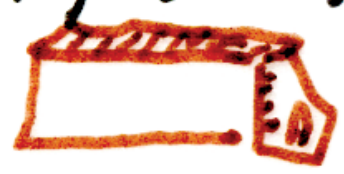




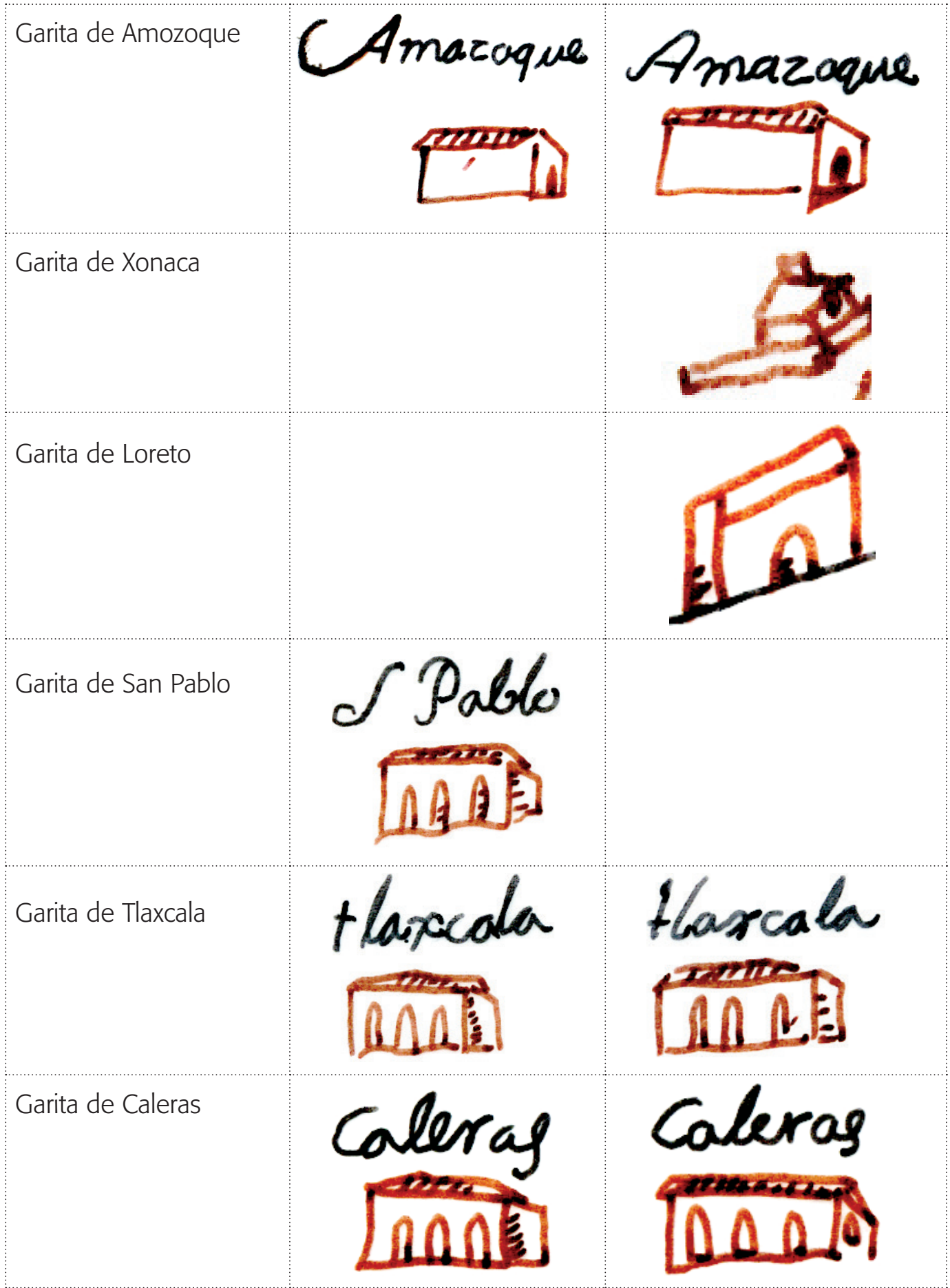

En el siguiente plano resaltamos en línea amarilla el círculo de garitas establecido hasta 1724 y en línea morada el círculo propuesto en 1724 para implantarse en lo inmediato e incorporar, como ya se anotó, un control más eficiente para la fiscalización de todos los bienes en trasiego. 


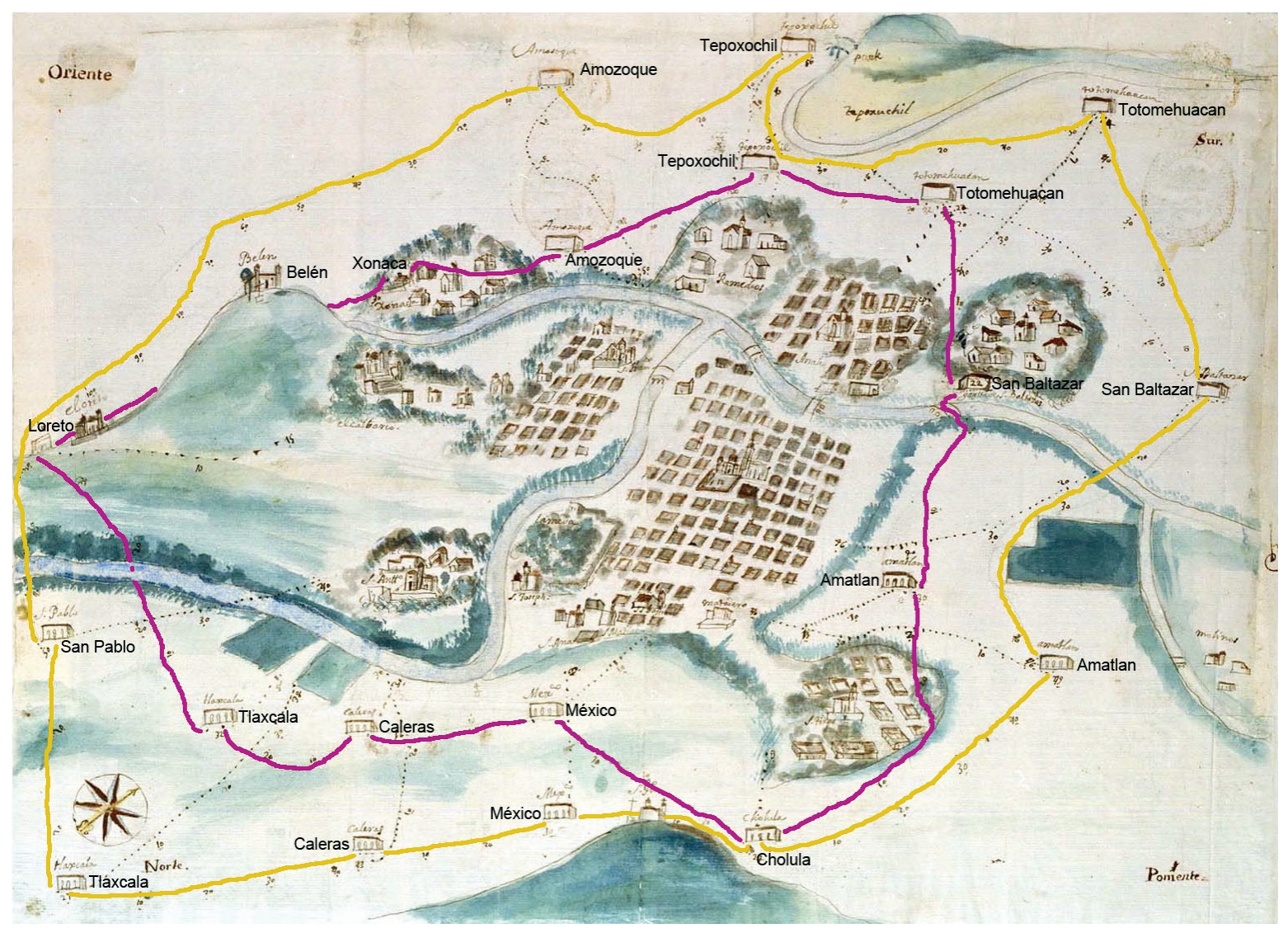

6.2.7. Plano de las Garitas en el que se marca en color amarillo el círculo de las garitas existentes en el año de 1724 y en color magenta el círculo de las nuevas garitas que se tienen que construir para el mejor control y vigía de la entrada y salida de mercancías para el pago de Alcabala Real y del paso de personas.

\subsubsection{PRINCIPALES CARACTERÍSTICAS URBANÍSTICAS EN 1724}

En el medio natural tiene los cerros Tepoxuchitl al oriente, Belén al norte y San Juan al oriente; los río Alseseca, Xonac y San Francisco. Geografía que contiene y divide a la ciudad.

Los barrios de la ciudad. Son marcadas las diferencias en este Plano en sus principales parcialidades; ${ }^{2}$ a. Al oriente del Río S. Francisco, San Francisco y Analco; al poniente el ensanche o centro de la ciudad y S. Tiago. En todas las partes señaladas apreciamos sus trazados reticulares, en los tres primeros hay predios mayores al común de la retícula, allí se asientan los edificios religiosos: el Convento de San Francisco (1535-1760), el Santo Ángel Custodio (1618-1632) y la Catedral de Puebla (1575-1678), consagrada en 1649 por Don Juan de Palafox y Mendoza.

2. Los denominamos barrios principales porque en este Plano aparecen con el dibujo de calles. En el Plano 6.14, resaltamos las calles o traza, lo que nos hace patente las parcialidades destacadas de la ciudad de La Puebla de Los Ángeles. 
La separación del Barrio de Santiago en los planos de 1700 y 1724, aunque se encuentra dentro del trazado del ensanche, se debe a que en su fundación fue destinado como Barrio de los Cholultecas, los que participaron en la construcción inicial de la ciudad; por ello el barrio se levanta a la entrada de la ciudad de Puebla de Los Ángeles que proviene del camino de la ciudad de Cholula.

El plano de 1724 tiene dos circuitos de garitas: el primero colocado en el exterior que corresponde a las garitas y caminos que las unen para la vigilancia continua entre estos elementos y, otro que es el proyecto de circuito interior de garitas para realizar en el futuro inmediato y que no se sabe con precisión cuántas de éstas se construyeron. Sin embargo, la nueva disposición del círculo de garitas proyectada en el año de 1724 tiene un recorrido de menos de la mitad del círculo que existió hasta ese momento: sin duda de una mayor funcionalidad en su recorrido periférico y hacia el centro de la ciudad, donde estaba la Aduana de la ciudad.

\subsection{CROQUIS DE LA CIUDAD DE PUEBLA Y SUS ALREDEDORES}

Año de realización: 1862

Repositorio: Biblioteca Nacional de Antropología e Historia

Catalogación: MID 47_20150706-120000:111, CAT 1084

Nota: Existe un ejemplar idéntico al original resguardado en la biblioteca citada, se trata del plano con el nombre de: Plan de la Puebla et de ses environs, elaborado en el año de $1854,{ }^{3}$ se encuentra bajo el resguardo del Centro Geográfico del Ejercito, en Madrid, bajo la signatura: SG.J-3a-2a-69. La diferencia con el Plano de 1862 se debe a que tanto el nombre del Plano como las leyendas asociadas a este documento cartográfico aparecen en lengua francesa.

Medidas: 39 X $53 \mathrm{~cm}$.

Orientación: Se señala con una flecha en la parte superior central Técnica usada en el Plano: Litografía de Decaen

Anotaciones y leyendas:

1. El nombre del plano, en la parte superior izquierda

2. La escala gráfica en varas, marcadas desde 0, 1000, 2000, 3000, 4000, 5000, en la parte inferior izquierda

3. Es errónea la fecha de elaboración del Plano, pues el ejército francés ocupó el Cerro de Amalucan y otras posiciones en los primeros días de mayo de 1862; estos registros del Plano no podían estar en el año de 1854. Además, durante el Segundo Sitio de los franceses en Puebla que inició el 16 de marzo de 1863, el general Ignacio Comonfort estuvo a cargo de la defensa mexicana entre los Pueblos de San Gerónimo ySan Pablo Xochimehuacan como lo asienta el Plano citado, después, el General fue asesinado el 13 de noviembre de 1863, Con estos datos inferimos que el plano original fue elaborado entre 1862 y 1863. 
3. Tablas de a. Fortificaciones, b. Iglesias y edificios principales, c. Plazas y plazuelas, y d. Altura de los principales cerros.

Representación plástica: La ciudad y sus alrededores se representan "en planta":

1. Los ríos en líneas ondulantes de color negro

2. Las manzanas edificadas con contorno negro y relleno en gris claro. Las manzanas no edificadas o con sólo uno o dos edificios están con contorno en línea punteada negra y las que tienen edificios se representan también en planta de color negro.

3. Las posiciones militares son líneas continuas en color café para los franceses y con el contorno de líneas para el ejército mexicano. Los parapetos franceses con líneas negras y cafés.

4. Las fortificaciones del ejército mexicano y bardas para cerrar calles en tinta negra con color rosa.

5. Una parte del centro de la ciudad, aproximadamente 37 manzanas con sus manzanas y edificios en tinta negra, tienen sobrepuesto el color verde; las calles están cerradas con bardas y una fortificación al sur de la Plaza de San Agustín, están representadas con tinta negra y con color rosa sobrepuesto.

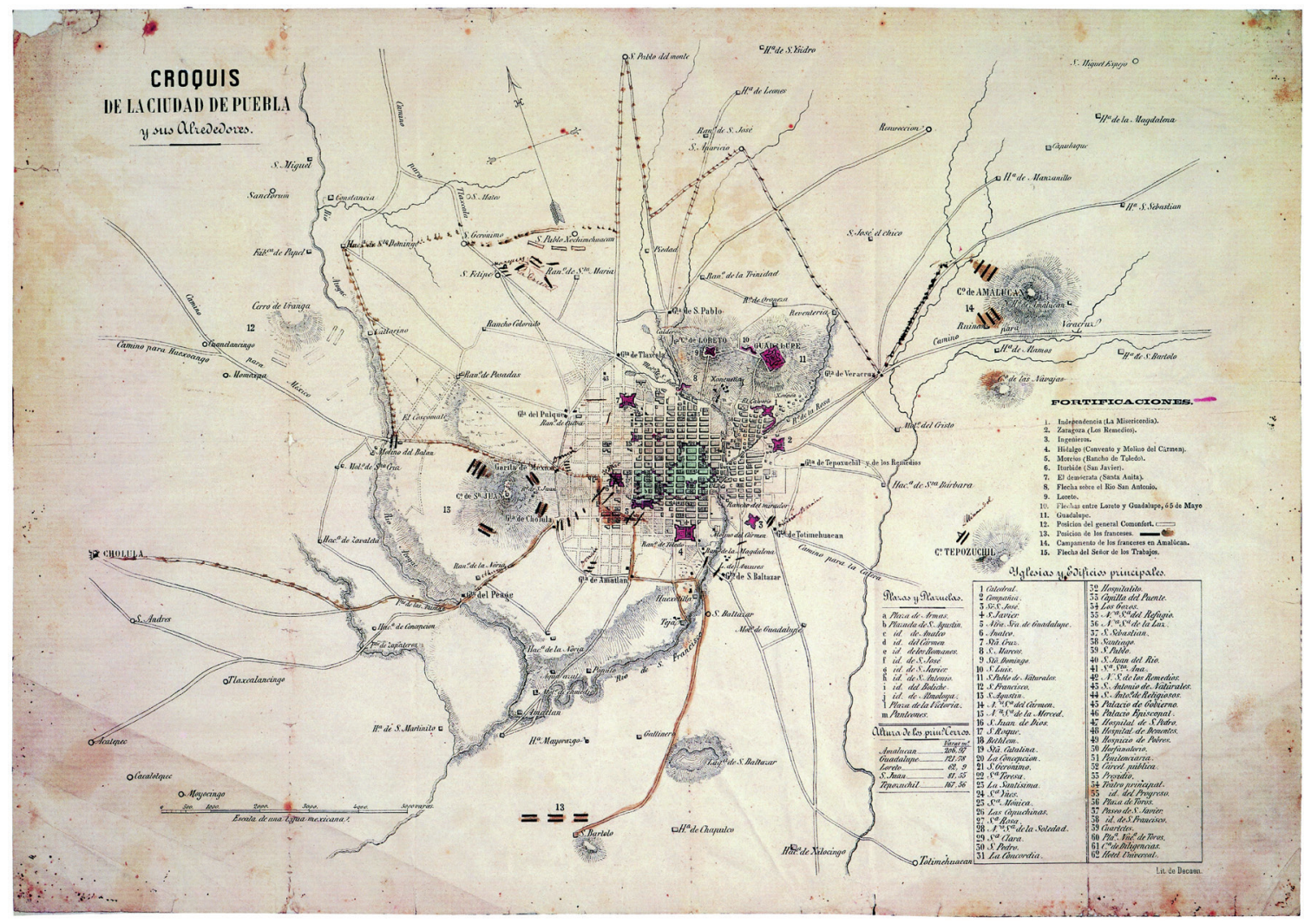


Este plano realizado el año de 1862 con motivo de la guerra propiciada por la intervención francesa en México y cuya batalla principal se realizó el Cinco de Mayo del mismo año, nos permite comprobar que el círculo de garitas propuesto en 1697 se transformó siguiendo los mismos principios comerciales y militares, para ese año las garitas construidas estaban dispuestas en el "círculo" cercano a la mancha urbana. Esta condición estratégica de diseño de la ciudad en ese lugar, ${ }^{4}$ asociada al círculo de garitas, fue un factor determinante en la victoria del ejército mexicano sobre el francés en la batalla del Cinco de Mayo de 1862.

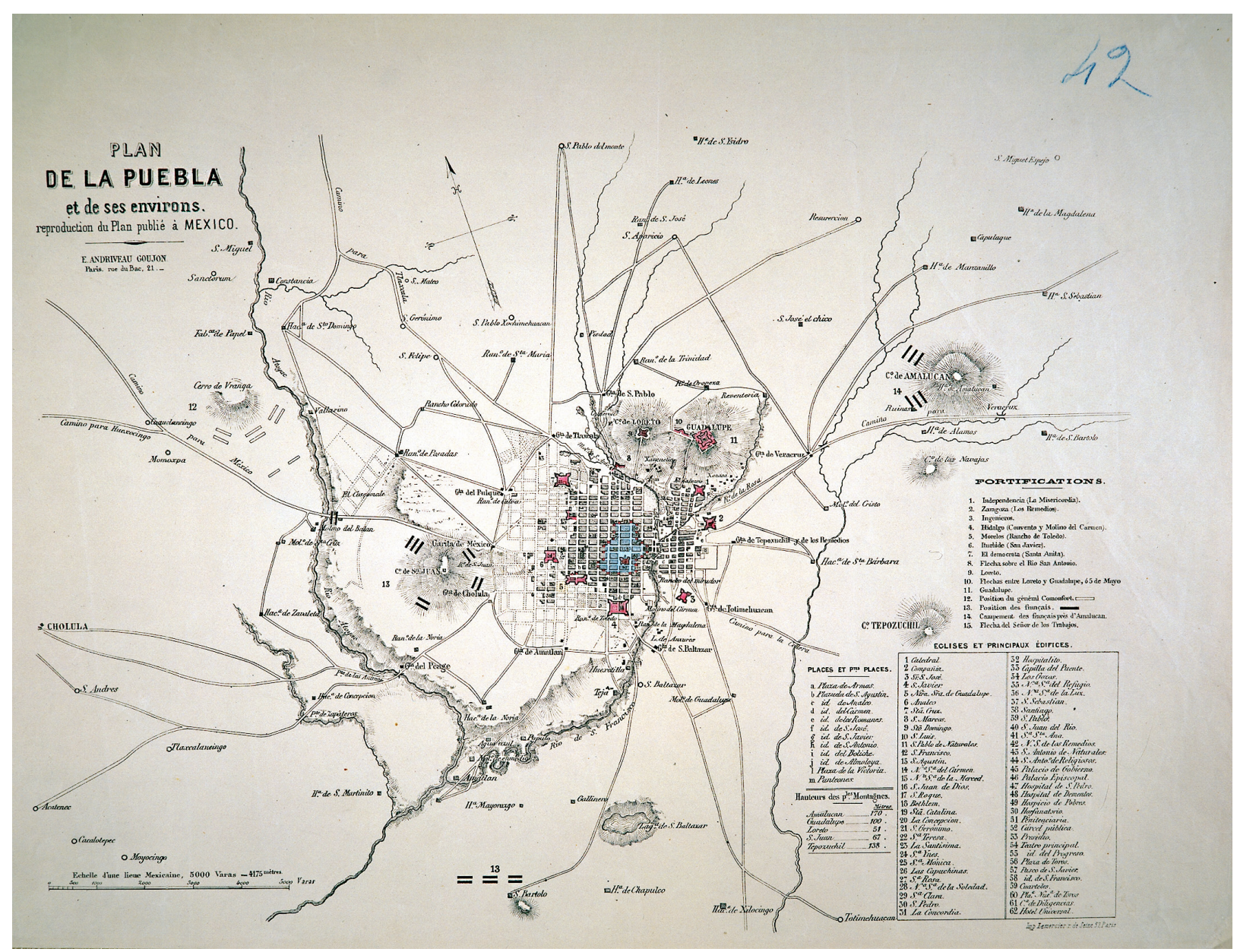

6.3.2. Plan de la Puebla et de ses environs, 1862, Centro Geográfico del Ejército, Madrid.

4. Cuando hablamos de condición estratégica de diseño, nos referimos desde la ubicación de la ciudad: rodeada de cerros al oriente, poniente y norte de la ciudad y ríos nacientes de las montañas que en conjunción con los primeros ya forman un lugar propicio para la futura misión defensiva de la ciudad. 
6.3.3. Leyendas que acompañan al Plano de 1862

\begin{tabular}{|c|c|}
\hline \multicolumn{2}{|c|}{ FORTIFICACIONES } \\
\hline 1. Independencia (La Misericordia) & 8. Loreto \\
\hline 2. Zaragoza (Los Remedios) & $\begin{array}{l}\text { 9. Flechas entre Loreto y Guadalupe, } \\
\text { o } 5 \text { de Mayo }\end{array}$ \\
\hline $\begin{array}{l}\text { 3. Hidalgo (Convento y Molino } \\
\text { del Carmen) }\end{array}$ & 10. Guadalupe \\
\hline 4. Morelos (Rancho de Toledo) & 11. Posición del General Comonfort \\
\hline 5. Iturbide (San Javier) & 12. Posición de los franceses \\
\hline 6. El demócrata (Santa Anita) & $\begin{array}{l}\text { 13. Campamento de los franceses en } \\
\text { Amalúcan }\end{array}$ \\
\hline 7. Flecha sobre el Rio San Antonio & 14. Flecha del Señor de los Trabajos \\
\hline
\end{tabular}

\begin{tabular}{|c|c|c|}
\hline \multicolumn{3}{|c|}{ IGLESIAS Y EDIFICIOS PRINCIPALES } \\
\hline 1. Catedral & 22. Sra. Teresa & 43. S. Antonio de Naturales \\
\hline 2. Compañía & 23. La Santísima & 44. San Antonio de Religiosos \\
\hline 3. Sr. S. José & 24. Sra. Ynes & 45. Palacio de Gobierno \\
\hline 4. S. Javier & 25 Sra. Mónica & 46. Palacio Episcopal \\
\hline 5. Ntra. Sra. de Guadalupe & 26. Las Capuchinas & 47. Hospital de S. Pedro \\
\hline 6. Analco & 27. Sra. Rosa & 48. Hospital de Dementes \\
\hline 7. Sta. Cruz & 28. Nta. Sra. de la Soledad & 49. Hospicio de Pobres \\
\hline 8. S. Marcos & 29. Sra. Clara & 50. Horfanatorio \\
\hline 9. Sto. Domingo & 30. S. Pedro & 51. Penitenciaria \\
\hline 10.S. Luis & 31. La Concordia & 52. Cárcel pública \\
\hline 11. S. Pablo de Naturales & 32. Hospitalito & 53. Presidio \\
\hline 12. S. Francisco & 33. Capilla del Puente & 54. Teatro principal \\
\hline 13. S. Agustín & 34. Los Gozos & 55. id. del Progreso \\
\hline 14. Ntra. Sra. del Cármen & 35. Nta. Sra. del Refugio & 56. Plaza de Toros \\
\hline 15. Ntra. Sra. de la Merced & 36. Nta. Sra. de la Luz & 57. Paseo de S. Javier \\
\hline 16. S. Juan de Dios & 37. S. Sebastián & 58. id. de S. Francisco \\
\hline 17. S. Roque & 38. Santiago & 59. Cuarteles \\
\hline 18. Bethlem & 39. S. Pablo & 60. Plaza Nueva de Toros \\
\hline 19. Sta. Catalina & 40. S. Juan del Rio & 61. Casa de Diligencias \\
\hline 20. La Concepción & 41. Sra. Sta. Ana & 62. Hotel Universal \\
\hline 21. S. Cerónimo & 42. N. S. de los Remedios & \\
\hline
\end{tabular}




$\frac{\text { PLAZAS Y PLAZUELAS }}{\text { Plaza de Armas }}$

Plazuela de S. Agustin

id. de Analco

id. del Cármen

id. de los Romanes

id. de S. José

id. de S. Javier

id. de S. Antonio

id. del Boliche

j. id. de Almoloya

Plaza de la Victoria.Panteones

\begin{tabular}{cc}
\hline \multicolumn{2}{c}{ ALTURA DE LOS } \\
PRINCIPALES CERROS \\
\hline \multicolumn{1}{c}{ Varas m } \\
\hline Amalucan & 206.97 \\
\hdashline Guadalupe & 121.78 \\
\hdashline Loreto & 62.9 \\
\hdashline S. Juan & 81.55 \\
\hdashline Tepozuchil & 167.56 \\
\hline
\end{tabular}

ALTURA DE LOS

Varas $\mathrm{m}$

Amalucan 206.97

21.78

oreto

67.56

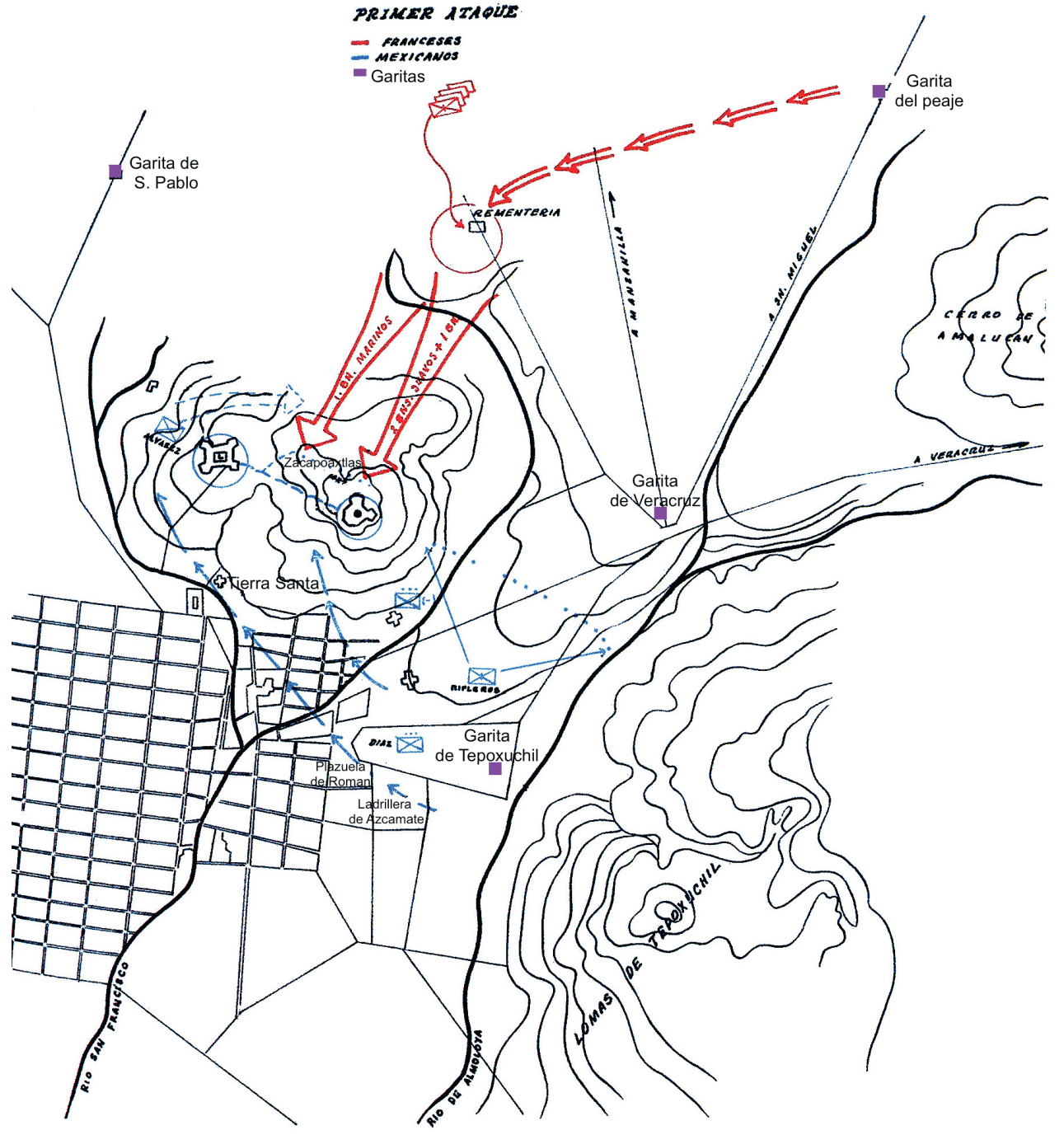

6.3.4. Ataque del Ejército francés (en color rojo) y defensa del Ejército mexicano (en color azul).

A cien años del 5 de mayo de 1862, Secretaría de Hacienda y Crédito Público, México,1962 en Palou, 2011, p. 47. 
El ejército francés tuvo el siguiente derrotero:

1. Provenía de las faldas del Cerro de Amalucan, donde se apostaron después del largo recorrido desde el Puerto de Veracruz.

2. Cruzaron el Río Alseseca hasta llegar a la Garita de Veracruz

3. Se trasladaron a la Garita del Peaje

4. Después al sitio denominado Rementería

5. Desde allí comenzaron el ataque con cañones hacia la iglesia-fuerte en el Cerro de Belén

6. Posteriormente avanzó el ejército francés para la batalla cuerpo a cuerpo con los mexicanos.

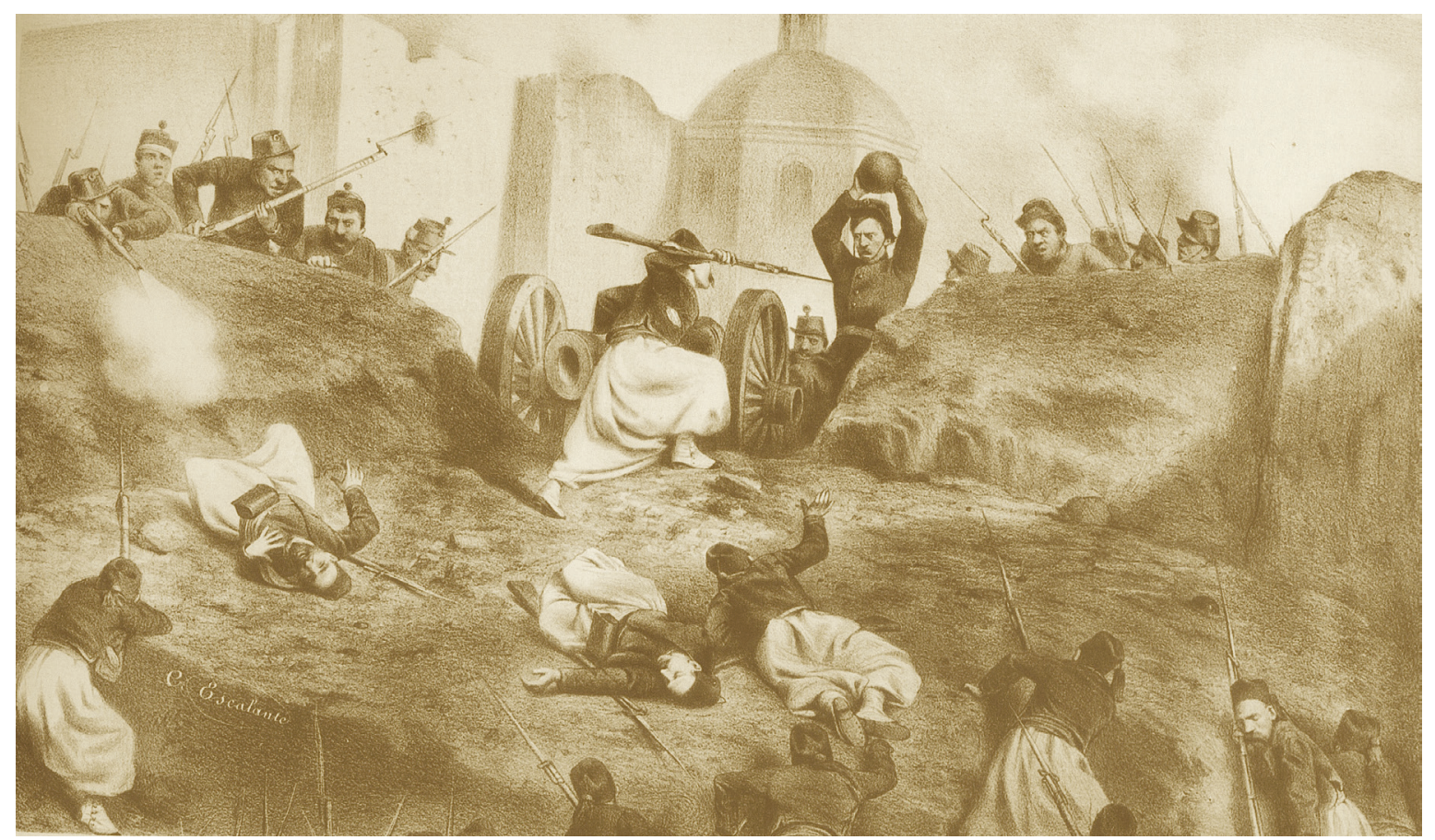

6.3.5. Una escena en el asalto del Cerro de Guadalupe el 5 de mayo de 1862.

Litografía de Iriarte y Ca., 1862.

De acuerdo con Pedro Ángel Palou (2011, p. 51):

5 de mayo de 1862.

El triunfo prohibido.

Lorencez y su gente estaban en la meseta de Puebla. El 4 de mayo hubo consejo de guerra y banquete para "celebrar anticipadamente" la segunda retirada de Zaragoza, ante las fuerzas unidas de Lorencez, Cobos y Márquez, repetirían lo de Acultzingo, forzarían la posición enemiga y el triunfo vendría solo. Los prácticos mexicanos -quién 
lo dijera- persistían en convencer a Lorencez del ataque por el sur de la ciudad. Pero él, su jefe de artilleros y el de ingenieros, consideraron insensato ir a estrellarse en los baluartes, fosos y parapetos, metiéndose como necios entre fuegos convergentes del enemigo. La solución era tomar las alturas. Y marcharon a las alturas.

Al final de la feroz batalla del 5 de mayo de 1862 entre los ejércitos contendientes, fueron dos los factores principales que favorecen el triunfo de las tropas mexicanas sobre el adversario; i. La primera, es la gran tormenta que se desata en el campo de batalla, lo que hace muy difícil la escalada para los franceses para tomar el Cerro de Guadalupe, lugar de mando y estratégico del ejercito mexicano; ii. La segunda es la toma del mando militar en su etapa final de la batalla por el general Porfirio Díaz quien decide atacar al ejercito francés por el flanco oriental del Cerro mencionado y doblegar al enemigo, Díaz celebra el éxito del Ejército mexicano con la frase $P a^{\prime}$ que sepan de que estamos hechos los mexicanos.

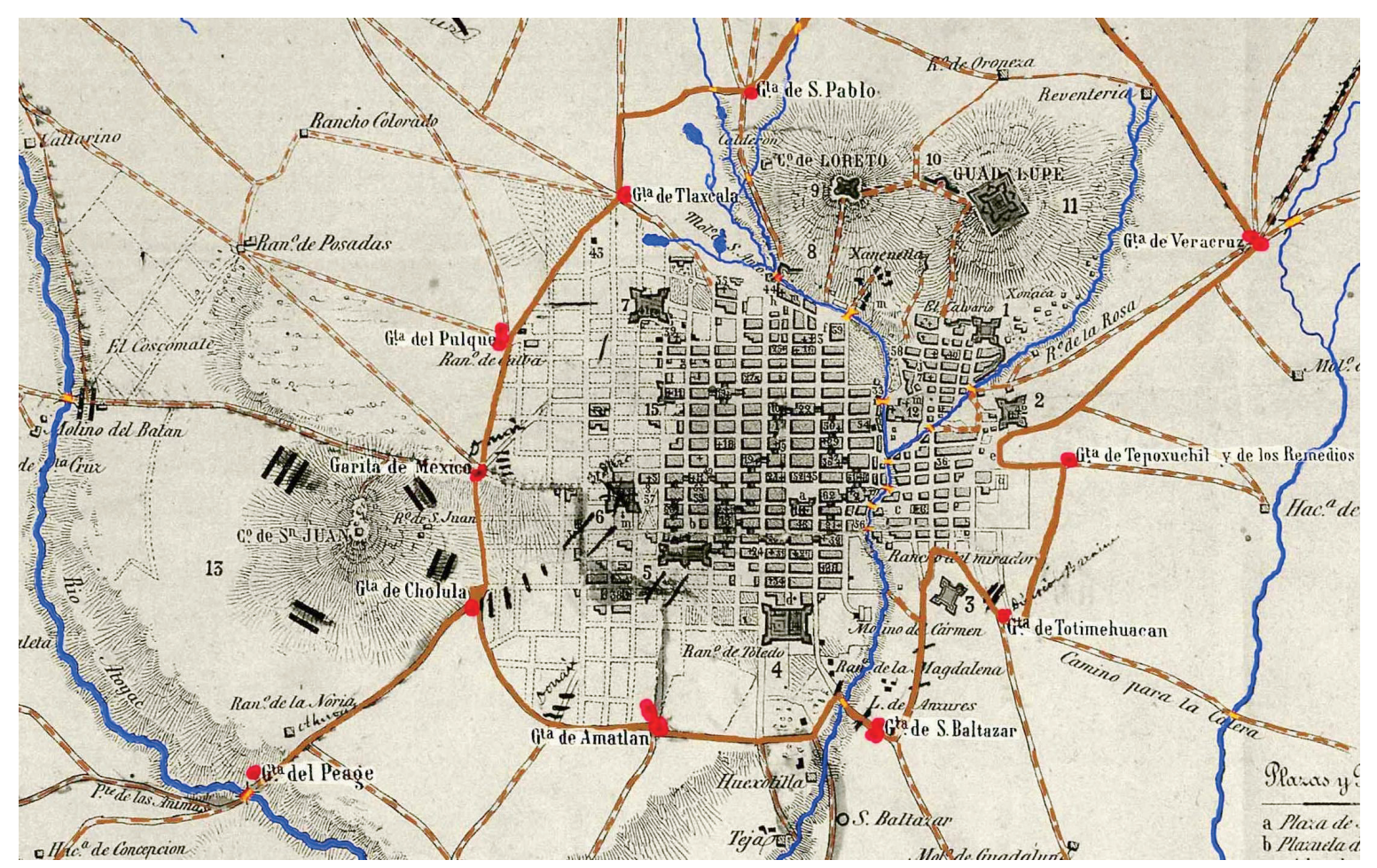

6.3.6. Detalle del Plano de 1862. Se enfatiza e polígono de garitas con los caminos que las unen; también se señalan todos los caminos o rutas que llegan a cada una de las garitas.

El círculo de garitas, tiene un sentido adicional: el de frontera y de contención del crecimiento de la ciudad; así podemos observar que la ciudad no rebasa los límites dispuestos por los caminos pintados de café, que unen los círculos rojos, las garitas. 


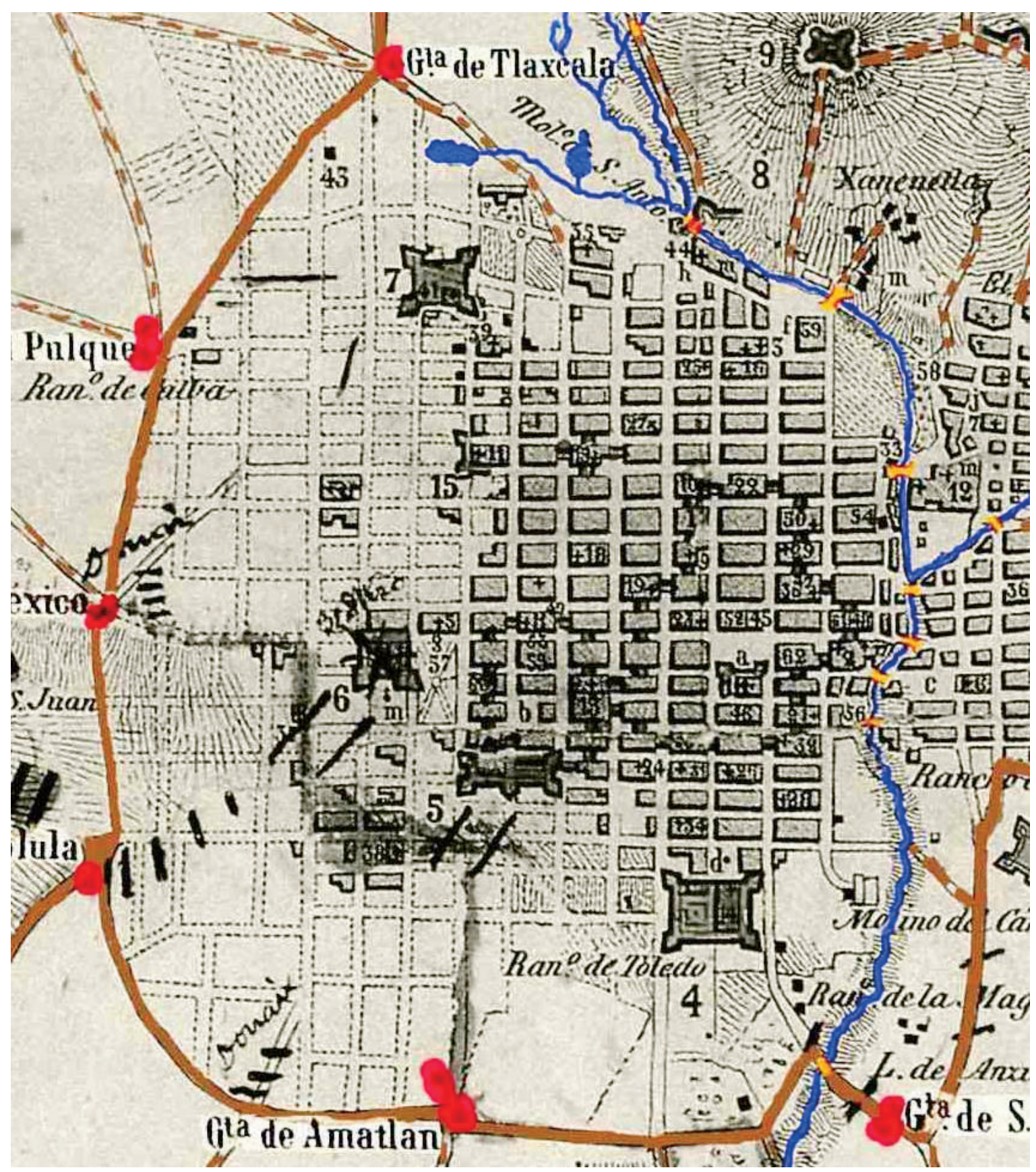

6.3.7. Detalle del Plano de 1862 en el que se destaca el sistema de garitas (en color rojo ) que eán comunicadas por "caminos de ronda" (en color marrón), con el borde oriental del Río San Francisco. A este conjunto que hemos denominado El ensanche de la Ciudad de Puebla, forma una almendra edilicia a la mexicana. 


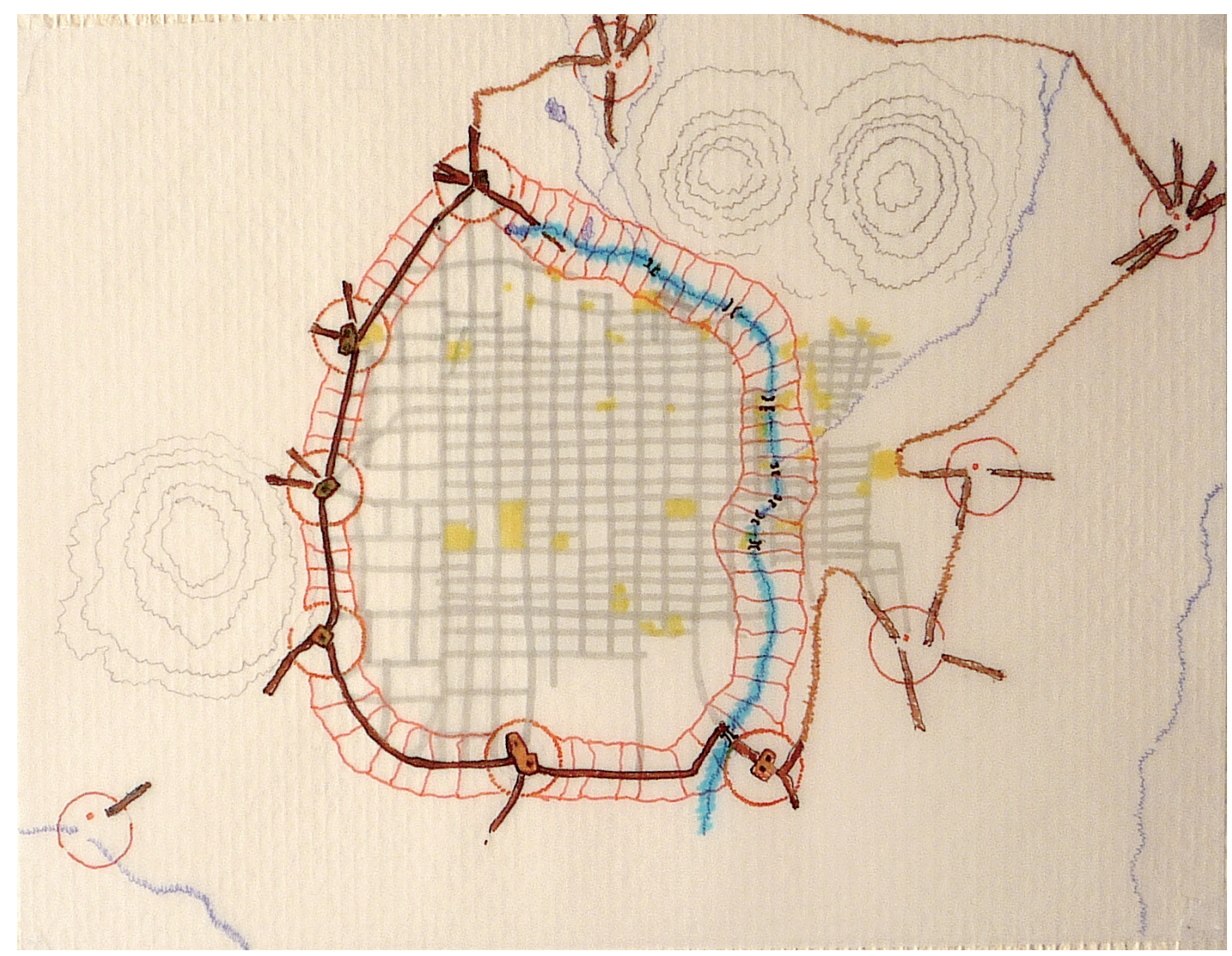

6.3.8. Boceto de lo que definimos conceptualmente como Almendra a la mexicana, que contiene a la parcialidad del ensanche de la ciudad Puebla, usualmente llamada "segunda fundación"

\subsection{PRINCIPALES CARACTERÍSTICAS URBANÍSTICAS}

El plano de 1862 está representado con la escala planimétrica con la que estamos más familiarizados se observa claramente el planteamiento de diseño urbano militar, estratégico para repeler ataques de grupos o ejércitos enemigos. El plano de 1862 también representa el cambio de una ciudad abierta hasta 1697 a una cerrada a partir de 1698 y con una permanencia de largo aliento hasta la segunda mitad del siglo XIX. Este segundo período fue relevante en la victoria del cinco de mayo de 1862 de las tropas mexicanas contra el ejército más poderoso del mundo de la época, el Ejército Francés.

Los elementos estratégicos que resguardaron la ciudad, en particular y como ejemplo emblemático durante la batalla que acabamos de mencionar, fueron:

I. El Río Alseseca y el puente de acceso a la ciudad, proveniente desde el camino de Veracruz. 
ii. El uso de las garitas de Veracruz o Amozoc y del Peaje por los franceses, como puntos de tránsito hacia el ataque

iii. La garita de Tepoxuchitl y la Iglesia de Los Remedios como puntos de defensa asignados a Porfirio Díaz.

iv. El Cerro de Belén y la iglesia-fuerte del mismo nombre comandado por el jefe militar del ejército mexicano, Ignacio Zaragoza.

Todos estos elementos geográficos y construidos fueron los que permitieron el control riguroso de la entrada de mercaderías y sus afiliados que las transportan y administran. Asimismo, el carácter eminentemente estratégico de los elementos señalados se manifiesta en la defensa y la intervención militar durante la segunda mitad del siglo XIX.

El conjunto urbano que denominamos almendra a la mexicana, es decir, el conjunto de garitas unidas por caminos y cerrando con el río San Francisco, se consolidó a través de los proyectos de 1698 y 1700, permaneció hasta finales del siglo XIX; La denominamos almendra mexicana por su forma evidente, también se debe a que, a diferencia de las almendras europeas y más particularmente de las españolas, no es'amurallada, en vez de murallas tiene caminos de ronda entre garita y garita que fueron recorridos de día y de noche por guardias designados a esa tarea.

Además de su carácter fiscal y defensivo fue un límite urbano de la ciudad que no fue rebasado, es decir, cumplió la función de borde o frontera de la ciudad que se mantuvo durante casi dos siglos en el lapso del virreinato y del siglo XIX.

Estos límites se mantuvieron hasta la aparición del ferrocarril y por ende el impulso de la actividad inmobiliaria, industrial y de traslado ferroviario de mercancías de la burguesía. Con ello se rebasaron abruptamente los límites de la ciudad que había impuesto la muralla virtual de garitas y caminos de vigía en los finales del siglo XIX y principios del XX. 


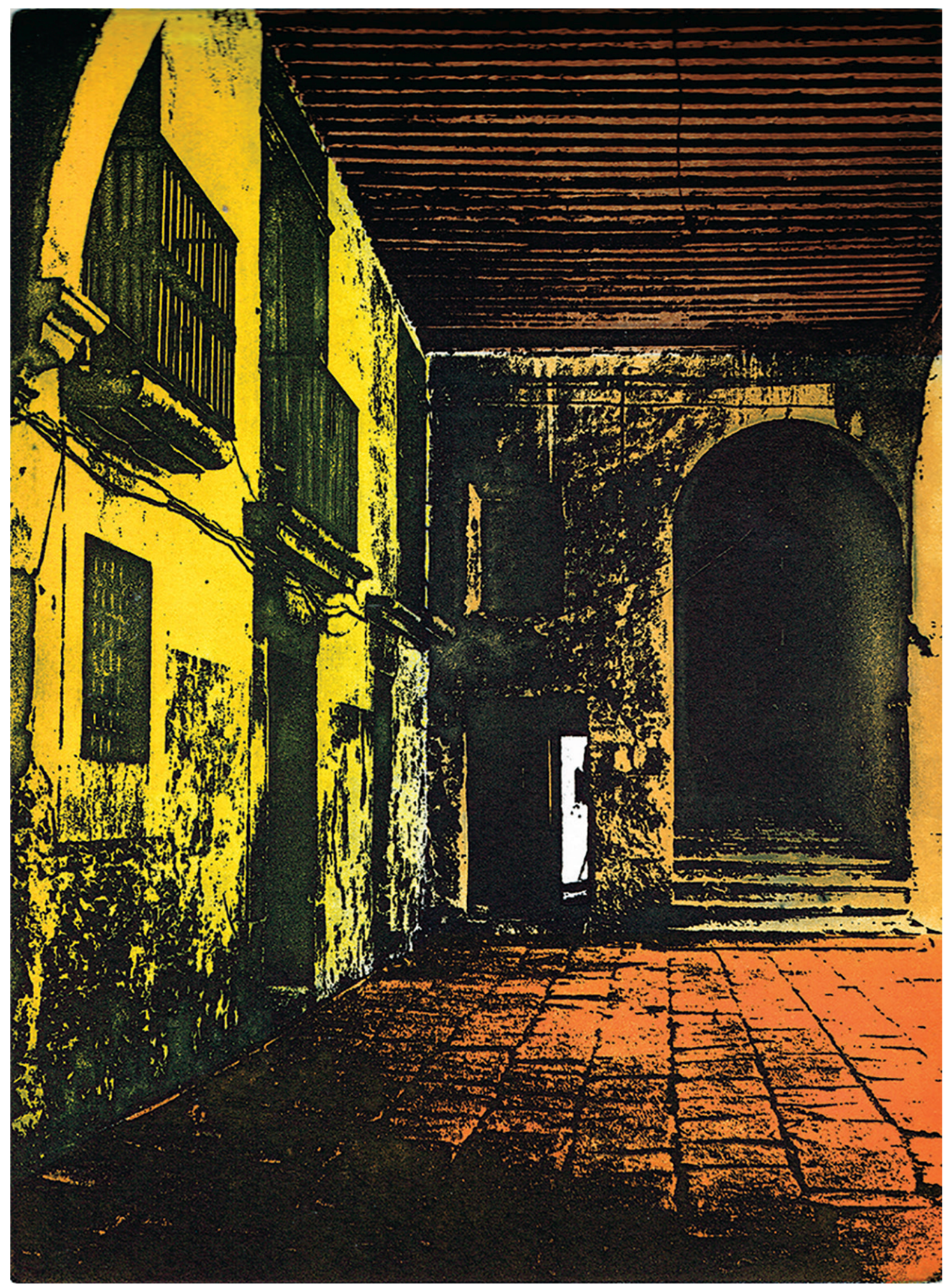




\section{El conjunto de garitas de $\mathrm{I} 698$ a la actualidad}

De acuerdo con las fuentes de información de mapas y planos antiguos de la ciudad de Puebla, existen los testimonios de su presencia desde el año 1698 en el Plano de la Ciudad de los Ángeles, atribuido a Christobal de Guadalaxara, que es el más antiguo del que se tenga conocimiento y dominio público.

Por su parte en el Archivo General de la Nación de México hemos localizado seis expedientes relativos a las garitas, alcabalas y rentas de los siglos XVII y XIX. También identificamos dos expedientes con la siguiente denominación:

Ordenanza tocante a la administración de alcabala de la Ciudad de Los Ángeles y su distrito. Correspondientes al año 1586, es decir apenas cincuenta años después de la fundación de la ciudad. Este expediente no lo consultamos, sin embargo, tenemos el dato de inicio de las alcabalas en la Ciudad de Los Ángeles.

Con relación al Plano de 1698 atribuido a Christobal de Guadalaxara (AGI, MP, México, 529) hemos encontrado en el Archivo General de Indias un expediente que acompañó al Plano mencionado; es un expediente de aproximadamente 900 fojas y cuya redacción se refiere fundamentalmente a las garitas, guardas y azogues de la ciudad de Puebla. Una cuestión similar pasa con el expediente en el que se encontraba originalmente el Plano de 1724 atribuido a Juan José de Veitia Linaje y José Joaquín de Uribe y Castrejón (AGI, MP, México, 519) cuya atención se centra al igual que el Plano de 1698 en las garitas, guardas y azogues de la ciudad. Este expediente es de aproximadamente 1600 fojas. 


\section{EL CONJUNTO DE GARITAS SEGÚN H. LEICHT}

Hugo Leicht, 1992 [1936] menciona que desde 1714 había 14 guardas de garita, es decir las personas encargadas de vigilar en cada uno de los puestos destinados a este al control de mercaderías y sus afiliados. Este autor es el único que se dedica a fotografiar algunas de las garitas que todavía existieron hacia los años 1930; están muy mal reproducidas en la publicación y por eso decidimos dibujarlas y añadirles color, como se presentan en el cuadro inferior

\section{Garita de Totomehuacan}

Las calles 12 Sur y 16 Sur a partir de la Calle 9 Oriente fueron calles que iban hacia la Garita de Totomehuacan. Antiguamente se nombraron como Calle de La Perita y Calle del Campo.'

La actual Calle 16 Sur a partir de la Calle 7 Oriente y de allí en su recorrido hacia el Sur se le conoció en buena parte del siglo XIX como Calle de la Garita de Totomehuacan o Calle de la Garita I. ${ }^{2}$ La Garita de Totomehuacan estuvo ubicada en ese momento en un promontorio natural al Sur-Oriente por fuera y en las cercanías de la traza urbana de la ciudad.

\section{Garita de Amatlán}

La Calle 11 Sur entre las Calles 17 y 19 Poniente se dirigía hacia el Molino de Amatlán de acuerdo con los registros del Padrón de 1728, posteriormente se denominó Calle de los Molinos, por estar situados un conjunto de éstos al final del camino, en el entronque de los ríos San Francisco y Atoyac. Hacia 1790 de citan tres molinos: Amatlán, de En Medio y del Batán; hacia 1810 tienen la denominación de San Juan Bautista El Grande de Amatlán, San Juan de En Medio y El Mayorazgo (éste último conocido hacia 1681 como San Cristóbal Amatlán)³.

La Calle 11 Sur durante el siglo XIX tuvo los nombres de Camino a los Molinos, Camino de la Garita de Amatlán, Calzada de Amatlán y Carril del Agua Azul. ${ }^{4}$

Frente a la Garita de Amatlán se edificó el Panteón Municipal.

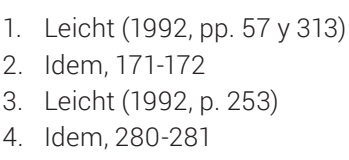




\section{Garita de Tlaxcala}

Por su parte la actual Calle 11 Norte desde la Calle 8 Poniente y siguiendo la primera en dirección Norte (donde antiguamente se encontraba la Garita de Tlaxcala) tenia la denominación de Calle Garita de Juárez en el año de 1872, desde luego haciendo referencia a la citada Garita de Tlaxcala donde desembocaba la Calle Garita de Juárez hoy Calle 11 Norte. ${ }^{5}$

Garita de Tlaxcala o del Pulque situada en la prolongación de la Calle 18 Poniente.

Garita de Tlaxcala la de la Aduana que sale de la Calle 7 Norte (la Iglesia del Refugio) para incorporarse luego a la 11 Norte y llegar a la Garita.

Garita de Amozoc

Según el Padrón de 1773 citado por Leicht la Garita de Amozoc o de Veracruz fue Ermita de Ánimas como otras que había cerca de los puentes de México y Cholula, de allí su nominación en el Plano de 1698 como Guardas Animas. Esta Garita se hallaba situada en lo que posteriormente se habilitó como Quinta de recreo de los seminaristas palafoxianos en 1903.

Garita de México

Garita de México en la continuación de la Calle 2 Poniente.

Garita de la Calera

Garita del Molino de Santo Domingo, de la Calera o de Rancho Colorado ubicada entre la Garita de Tlaxcala y la de México.

\section{Garita Las Cuartillas}

Garita de Las Cuartillas ubicada entre la Garita del Pulque y la de Tlaxcala, aproximadamente en la prolongación de la Calle 28 Poniente. 


\section{Garita de Las Pólvoras}

Hacia 1839 se tiene una Garita de las Pólvoras, tal vez por su relación con la Fábrica de Pólvora ubicada en la Calle 11 Norte y 12 Poniente. La Garita mencionada estuvo ubicada entre la Garita del Pulque y la Garita de la Calera.

\section{Garita de Xonaca}

Garita de Xonaca ubicada en la Calle 22 Oriente, frente a la Iglesia de Xonaca y que conserva actualmente el uso habitacional.

\section{Garita de Cholula}

Junto a la Garita de Cholula se edificó el Panteón de La Piedad.

Las Garitas de Santo Domingo, Las Cuartillas y de las Pólvoras no se tienen ubicadas con precisión. Desde nuestro punto de vista habría de hacer una revisión más exhaustiva en todos los planos del siglo XIX y considerar también la posibilidad de que hayan sido posteriores a las originales del siglo XVIII o bien algunas de las existentes pero con nomenclatura diferente en el siglo XIX.

El mismo Leicht menciona la Garita de la Calera como alias la del Pulque, que es la misma que es la "puerta" del camino a Rancho Colorado. 
7.1. Cuadro con las garitas identificadas por JGAC en los planos de 1698, 1700, 1724, 1862, fotografías de los años 1930 y fotografías del año 2010.

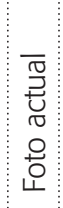

1

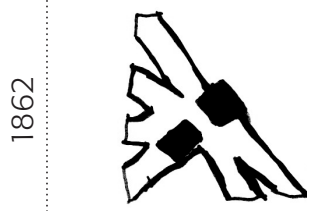

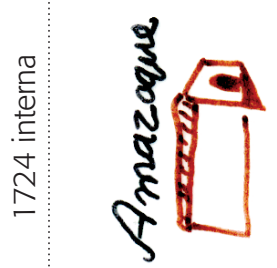

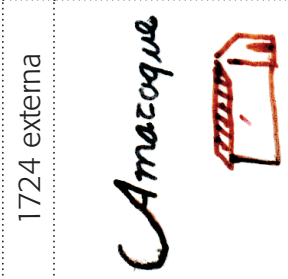

욤

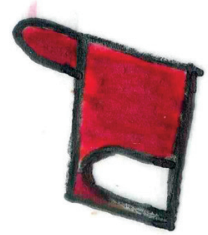

तD
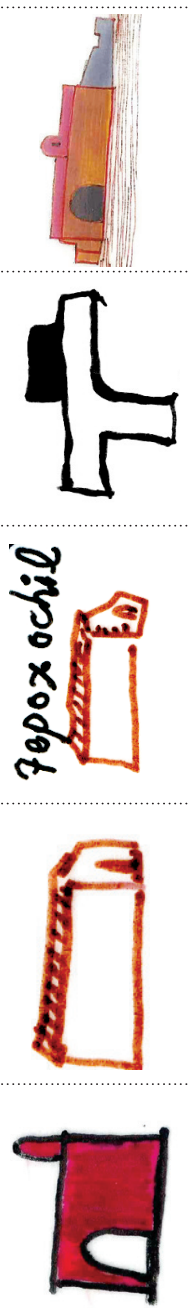

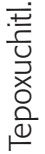
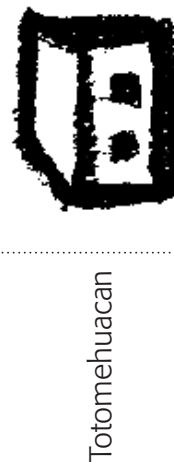
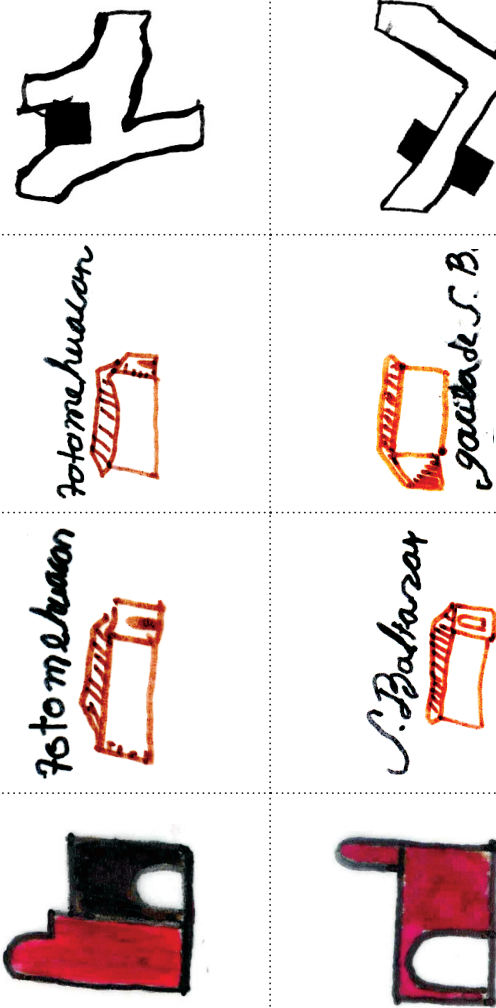

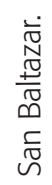



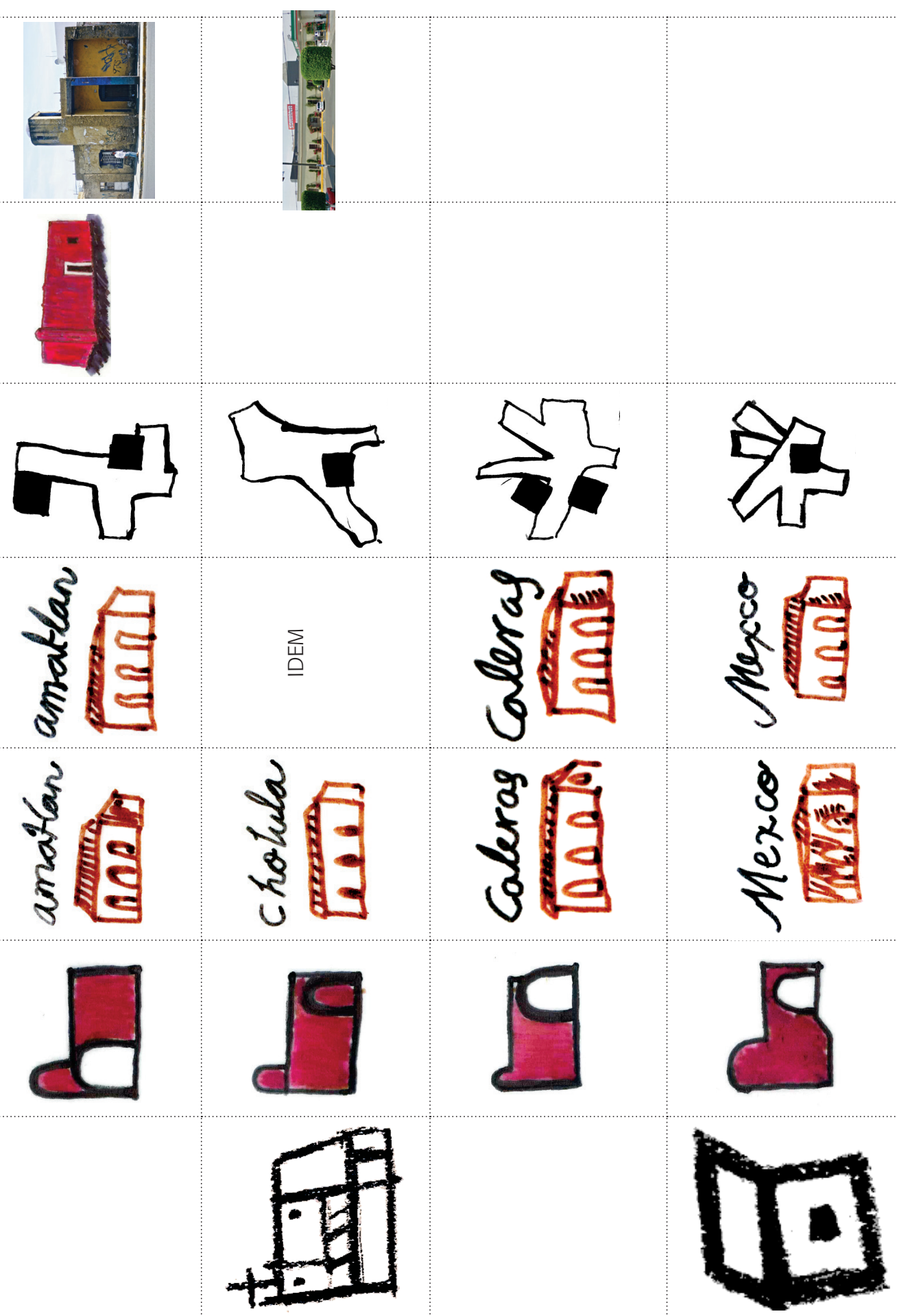

咅旁

量

? 


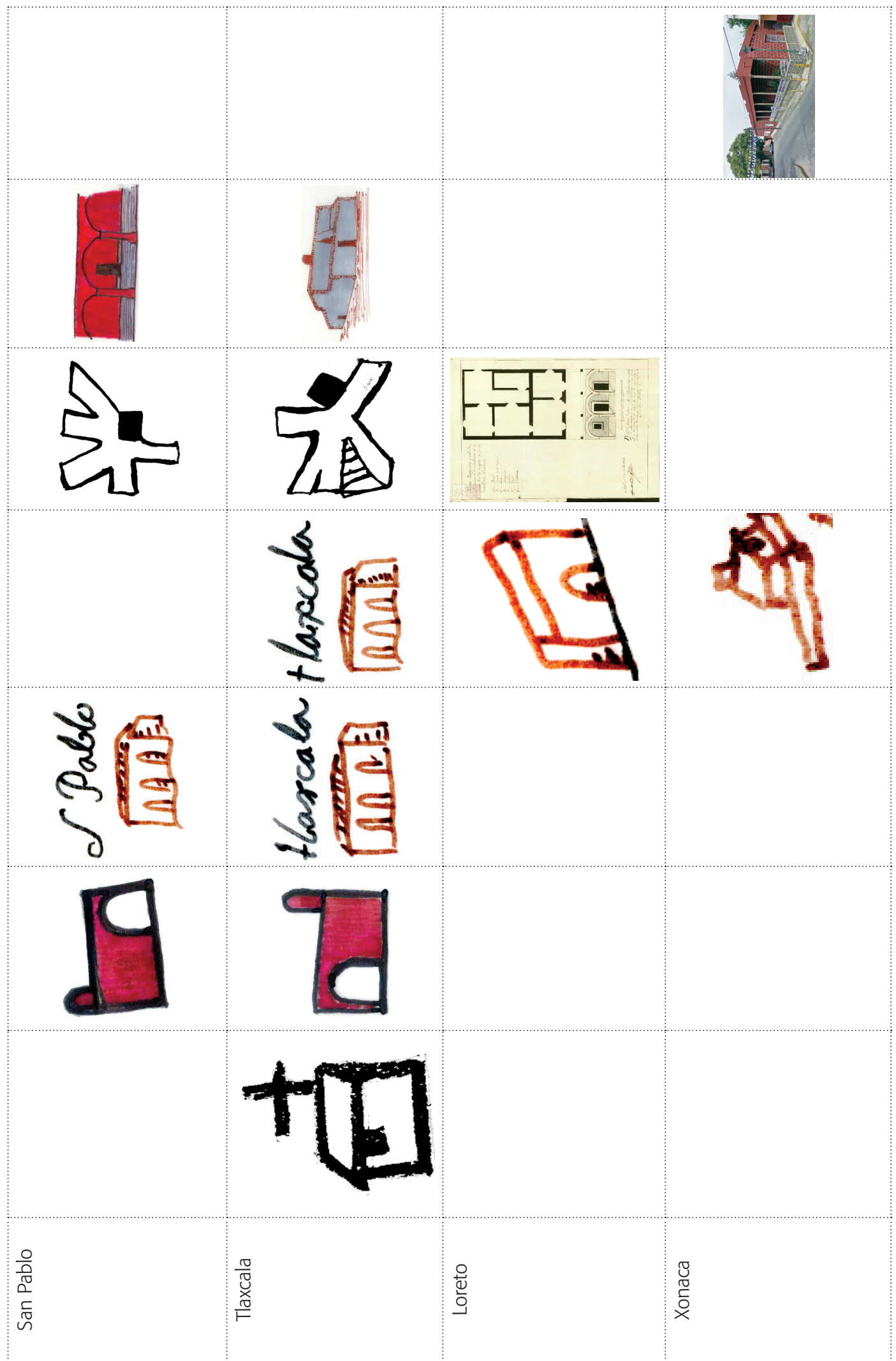




\section{Conclusiones}

Hemos probado que la información que nos brindaron los planos de los años 1698, 1700, 1724 y 1862, son de gran precisión en la localización de los diversos edificios de las garitas. En el caso de las garitas planeadas para construirse en el año de 1698, no aparecen registradas en el Plano; sin embargo en la fuente documental del AGI México, 341, sí aparecen especificadas cada una de las 9 garitas que van a formar el llamado "círculo de garitas" y que a partir de esa fuente, identificamos ese registro en el plano con la clave 5.15., con la traza actual y sobre él las garitas dispuestas por orden de José Veitia Linaje, responsable real de las alcabalas de Puebla el 26 de noviembre de 1698.

Para el año de 1700 se conservan las mismas garitas planeadas el 26 de noviembre de 1698 y se añade una nueva: la garita de San Pablo, ubicada entre la de Tlaxcala y la Iglesia de Loreto en el cerro del mismo nombre, para formar en este año de 1700 un círculo con 10 garitas.

En el año de 1724 hay una transformación radical del círculo de garitas pues se diseña otro círculo mas cercano la mancha urbana que facilita el recorrido entre las garitas pues todo el recorrido del "círculo de garitas" va de las 43,250 varas a 20,150 varas con el nuevo cordón de garitas; es decir menos de la mitad del recorrido, lo cual facilita la vigilancia y el resguardo de la ciudad.

También para este año se añaden dos garitas, la de Loreto y la de Xonaca y se elimina la de San Pablo, con lo cual forman un sistema de 11.

Para 1862 aparecen 11 garitas, 10 en los bordes de la ciudad edificada y una en la intersección entre el Camino a Cholula y el Río Atoyac llamada "Garita del Peage",

Es a partir de este plano de 1862 que nos damos cuenta que el círculo de garitas no fue rebasado y que por lo tanto confirmamos que se trata de un borde o frontera de la ciudad y que el sistema de garitas diseñado desde 1697 y transformado hasta el siglo XIX se comporta como una muralla virtual con sus puertas de entrada y delimitando la "Ciudad intramuros" o dicho con propiedad: La ciudad dentro de los caminos de ronda.

6. Una vara castellana es igual a $0.912 \mathrm{~m}$. 


\section{La Ciudad de los Ángeles, sus rutas en la Nueva España, el Gran Caribe y en Ultramar}

Este capítulo es una recopilación de los textos seleccionados por el autor de esta tesis con la finalidad de establecer las relaciones estrechas que existieron en el imperio español entre el dinero, la fiscalidad y la guerra sobre el territorio novohispano y europeo durante la Colonia. Esta tercia es significativa porque nos permite corroborar y confirmar nuestras hipótesis sobre la fiscalidad y defensa de La Ciudad de Los Ángeles, así como la relación temporal que adquirió dicha ciudad dentro de la economía global a través de las rutas del dinero, los bastimentos y las mercaderías en su tránsito desde el ultramar del Atlántico y del Pacífico.

Como los temas económicos y militares son de una gran complejidad, opté por la máxima de Umberto Eco. "si no tienes conocimiento del tema sube en los hombros de un gigante y desde allí aprecia el panorama de lo que te interesa". Los autores seleccionados son, sin duda alguna, gigantes en el conocimiento del tema que se expone a través de una selección de autores de libros científicos y textos relevantes en su interior que están estrechamente implicados con el tema que desarrollé en la presente tesis a través de las fuentes primarias denominadas planos históricos de La Ciudad de Los Ángeles y que presentan una lectura geográfica y urbanística del territorio de la ciudad y su región.

Estructuramos las lecturas de lo general a lo particular, primero con las bases de la economía, la fiscalización y las guerras del imperio, después de La Ciudad de Los Ángeles en particular. En la mayoría de las fichas agregamos algunos subtítulos para señalar con más precisión los temas que tenían más relación con nuestro tema de estudio. Por 
lo tanto. advertimos que no se trata de una traición a los autores citados, sino de una adecuación a nuestros propósitos.

Cierra el presente capítulo con el subcapítulo 8.7. Las rutas de ultramar relación con las internas. es un ejercicio de planos y bosquejos sintéticos y complementarios que es muy importante apuntar en la tesis.

\subsection{Carlos Marchal. y Johanna von Grafenstein coords. (2012, pp. 1-14 y pp. 54-63).}

\subsubsection{LOS SITUADOS COLONIALES EN EL SIGLO XVIII}

Que un imperio pueda sostenerse durante largo tiempo, incluso siglos, depende de varios factores, entre los cuales cuentan especialmente el dinero y las armas.

El sistema más complejo del mundo entre el siglo XVI y fines del XVIII reflejaba la multiplicidad de entidades administrativas y militares que constituían en conjunto, el imperio español, incluyendo los diversos reinos de la metrópolis, sus posesiones europeas, los 4 virreinatos americanos, así como 5 capitanías generales y numerosas guarniciones coloniales en América y en Filipinas.

Es importante contar con una visión de largo plazo, siendo preciso analizar en detalle no sólo la fiscalidad de cada región del imperio, sino el legado del complejo mecanismo de las transferencias financieras entre las propias colonias que eran conocidas como situados, término hoy poco familiar.

Las transacciones durante el siglo XVII se conocen gracias al excelente trabajo de Rafal Reichert. En esa centuria las transferencias de remesas fiscales de la Nueva España a las principales guarniciones y fortalezas españolas en el Gran Caribe, ascendieron a un total de más de 20 millones de pesos, una cantidad enorme para la época. Reichert estima que, esta suma representa cerca de $45 \%$ de los gastos propiamente militares registrados por la Real Hacienda Novohispana entre 1600 y 1700.

El caso del México borbónico, puede calcularse que los situados a las guarniciones militares en el Gran Caribe y a Filipinas, superaron los 150 millones de pesos entre 1700 y 1800 . Se trataba, en efecto, de flujos de capitales (fiscales) enormes para el antiguo régimen.

En el caso del imperio español en América, la naturaleza de las transferencias fiscales efectuadas desde las colonias fiscalmente más prosperas pasaron a las colonias más 
pobres para cubrir gastos militares y administrativos. Estas remesas sirvieron para apuntalar el conjunto de la maquinaria de la monarquía en ultramar, tanto en la América septentrional como en la meridional, así como en el Gran Caribe y en Filipinas. Los situados fueron, por consiguiente, uno de los secretos esenciales de la larga vida del imperio español en ultramar y ayudan a explicar porque su defensa militar no requirió casi nunca subvenciones de la metrópoli. Pero más allá de estas contribuciones de las colonias al sostenimiento del imperio, debe subrayarse que la propia Real Hacienda del gobierno de España también recibió cada año subsidios fiscales de sus colonias americanas en cantidades especialmente cuantiosas en épocas de guerras internacionales.

Basado en el análisis del caso de los situados novohispanos, Carlos Marichal demuestra como México se convirtió -a fines de 1700- en una especie de sub metrópoli que contribuía con el sostenimiento con la mayor parte de las plazas fuertes del Caribe mediante la remisión de ocho situados (La Habana, Santo Domingo, Puerto Rico, Cumaná, Trinidad, Louisiana, Panzacola y San Agustín de Florida), a los que habría que sumar el que anualmente se remitía a Filipinas en el galeón de Manila.

\subsubsection{FINANCIAMIENTO DEL IMPERIO ESPAÑOL EN AMÉRICA}

El hecho de disponer de excedentes monetarios, colocó al virreinato de la Nueva España -al igual que el del Perú- en un lugar especial dentro de la estructura global de las finanzas imperiales, ya que después de cubrir sus gastos internos imprescindibles, fue obligado desde la segunda mitad del siglo XVI a remitir un porcentaje de sus excedentes a la metrópoli y a determinadas guarniciones militares estratégicas del imperio que no tenían suficientes fondos para su sostenimiento.

Los datos indican que se produjeron ciertos picos en las remesas remitidas de la Nueva España que corresponden claramente a las coyunturas bélicas: La guerra de los Siete Años (1756-1763), la guerra contra Gran Bretaña (1779-1783), la guerra contra la Convención francesa (1793-1795).

\subsection{Alves Carrara, Angelo y Ernest Sánchez Santiró (2012, pp. 65-66)}

\subsubsection{GUERRA Y FISCALIDAD}

El estudio sobre los impactos provocados por los eventos bélicos en las finanzas públicas constituye uno de los tópicos principales de la historia fiscal. De hecho, la ecuación "guerra-fiscalidad" es una de las más empleadas a la hora de atender cuestiones como el incremento en la presión fiscal ejercida por los poderes públicos para atender a las necesidades financieras del conflicto armado, las alteraciones en el gasto fiscal, o las li- 


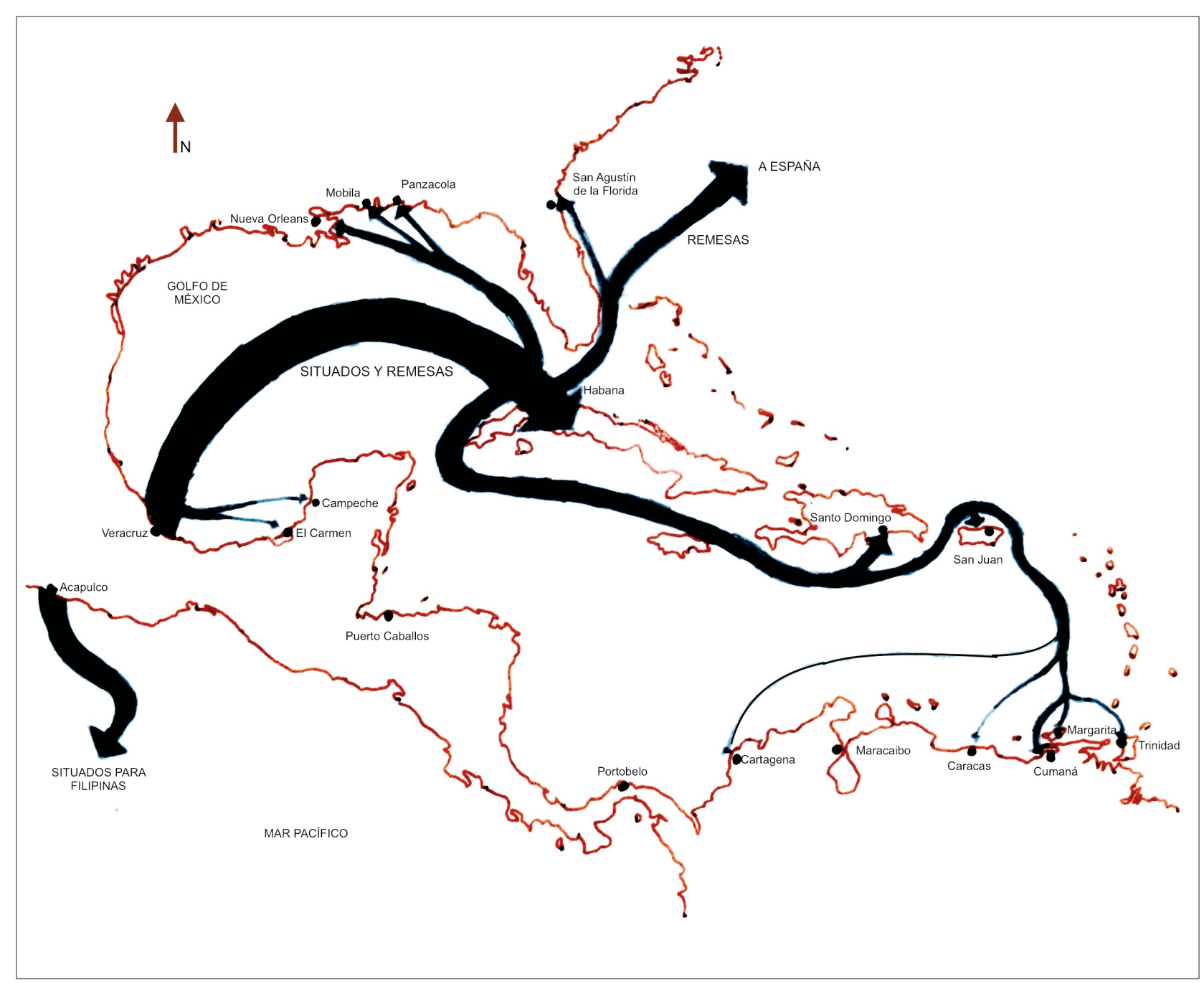

8.1. Trasferencias de recursos (Situados) a los puertos del Gran Caribe. En Marichal (2012). Copia de JGA

mitantes para poder enfrentar de manera solvente los requerimientos materiales de la guerra, por citar algunos de los rubros más destacables.

Los problemas fiscales se originaron con el proyecto de levantar una "Armada de Barlovento" que protegiese el tráfico marítimo de las Islas de Barlovento, el Seno Mexicano y las costas de la Tierra Firme, es decir, el espacio hoy denominado "Gran Caribe", que abarca desde la costa de Venezuela, pasando por Centroamérica, el Golfo de México y las Antillas Mayores y Menores y parte de las Bahamas.

El impulso que supuso dicha iniciativa para el reforzamiento de las contribuciones indirectas sobre el comercio interno y externo, en el marco de una Real Hacienda que hasta la primera mitad del siglo XVIII gravitó de forma mayoritaria sobre diversos impuestos directos sobre la minería, la producción agrícola o la capitación. 


\subsection{Reichert, Rafael (2013, pp. 7-33)}

\subsubsection{DESARROLLO Y FINANCIAMIENTO MILITAR DE LOS PRESIDIOS DEL GOLFO-CARI- BE DURANTE EL SIGLO XVII.}

Del gran número de comerciantes, militares y marineros que se dedicaron a estas empresas durante el régimen de los Habsburgo, los más conocidos fueron François Le Clerc, Jacques Soria, John Hawkings, Francis Drake, Henry Morgan, Laurens de Graaf (Lorencillo) y Bernard Desdjean (Barón de Pointis) quienes, mediante sus acciones, llevaron a la Corona española a plantear un sistema defensivo eficaz para proteger tanto a los habitantes como a las rutas marítimas por las cuales navegaban los buques cargados con tesoros americanos. Con este fin, en la década de 1540, Carlos I de España ordenó la organización de las primeras unidades de autodefensa compuestas por vecinos de los puertos americanos (milicias), y al mismo tiempo obligó a los comerciantes de Sevilla a realizar sus viajes a las colonias americanas en convoyes (Hoffman 1980: 19). Finalmente, en las Ordenanzas de 1564, quedó establecido el sistema de navegación segura en convoy con la división de los recorridos en dos flotas: la de Tierra Firme y la de la Nueva España (Haring 261).

Desde la década de 1540 las autoridades de la Corona tuvieron que enfrentar con otro problema: la falta de defensa contra saqueos y asaltos a los principales puertos americanos, como lo demostró Francis Drake en su viaje depredador por el Gran Caribe, cuando atacó sin grandes dificultades Santo Domingo, Cartagena de Indias y San Agustín de la Florida. Después de un golpe tan doloroso, el rey Felipe II dio comienzo al gran proyecto de amurallar los puertos en la región, dando prioridad a San Juan de Puerto Rico, Cartagena, Portobelo, La Habana y San Juan de Ulúa. Esos lugares se denominaron "llaves del Nuevo Mundo", debido a su importancia estratégica en la protección de las posesiones españolas y las rutas marítimas entre América y la metrópoli.

En la segunda mitad del siglo XVII, esos espacios se convirtieron en trampolines para acciones bélicas de piratas, corsarios, bucaneros y filibusteros, y en el siglo XVIII, fueron importantes núcleos mercantes, azucareros y bases navales estratégicas. Es importante recordar que, durante la época de los últimos Habsburgo, España mantenía sus defensas no sólo en Hispanoamérica, sino también en Asia (en Filipinas e islas Marianas). El norte de Nueva España, el Gran Caribe, Charcas, Chile, la costa pacífica del Perú y los archipiélagos asiáticos eran considerados fronteras imperiales donde el peligro de rebeliones de los nativos e invasiones extranjeras aún continuaba. Algunas de estas regiones tenían una economía local tan precaria que no se les permitía mantener sus plazas militares con recursos propios; por eso, para sustentar la maquinaria bélica de 
gran escala hubo que diseñar un sistema de financiamiento que llevó a la creación de socorros y situados'. Los subsidios estaban compuestos de plata, géneros, víveres y pólvora, que se enviaban desde los dos virreinatos, obligados por la Corona a suministrarlos. Este financiamiento comenzó a funcionar en la década de 1570 y se mantuvo en operación hasta las primeras décadas del siglo XIX.

\subsubsection{ECONOMÍA COLONIAL Y FINANCIAMIENTO MILITAR}

La historiografía del financiamiento militar se ha centrado sobre todo en los siglos XVI y XVIII, las épocas de gran esplendor de las armas españolas tanto en Europa como en América. Al revisar los trabajos sobre los gastos militares, destaca la segunda mitad del siglo XVI, cuando la Corona española planteó establecer un sistema defensivo en las Indias financiado por los virreinatos de Nueva España y del Perú.

Carlos Marichal y Matilde Souto demuestran que las remesas del situado superaron en varias ocasiones a las que se enviaban a la metrópoli: aparte de la agresiva política fiscal de los Borbones, la mayoría de la plata novohispana se empleaba en las empresas americanas y no en europeas. Estos aspectos son de gran interés, ya que marcan una diferencia importante con respecto a los siglos XVI y XVII, cuando los montos de los situados nunca superaron las remesas enviadas a España. Además demuestran el gran cambio de la política imperial española, que debía asegurar e invertir más dinero en las defensas americanas que las europeas debido a que la mayoría de los conflictos del XVIII se desarrollaron en las Indias.

Los ramos económicos más avanzados y lucrativos eran: la ganadería, practicada desde 1521 en todo territorio virreinal; la minería, con tres centros de extracción de plata importantes en Zacatecas (1564), Guanajuato (1554) y San Luis Potosí (1592); la agricultura, con sus principales núcleos en las ciudades de Chalco (1519), Toluca (1522), Puebla de los Ángeles (1531), Celaya (1551) y Atlixco (1579).

Estos sectores principales de la economía novohispana, junto con los tributos, alcabalas, derechos y almojarifazgo, entre otros impuestos, completaban los fondos mexicanos de arcas reales, de las cuales se mantenían las empresas expansionistas y defensivas que realizó la Nueva España a lo largo del siglo XVII.

1. El término "situado" se refiere a la asignación ("situación") a una plaza militar de una cantidad fija de dinero para su financiamiento. La cantidad otorgada era sufragada por otra caja real, ubicada en ocasiones en capitales de reinos distantes con excedentes fiscales, como sucedió en el caso de las islas del Gran Caribe, el cual administrativamente dependía del virreinato novohispano. En teoría, el situado tenía un carácter anual y constituía, junto con los propios recursos financieros de la caja receptora, el monto que se gastaba en las necesidades militares del presidio (Serrano Álvarez 2004:34) 
Jurídicamente, tanto Nueva España como el Perú eran gobernados por audiencias. En el caso del virreinato novohispano, había cuatro instituciones administrativas. La primera y más antigua fue la audiencia de Santo Domingo, establecida en 1511. La segunda, la audiencia de México, fue creada en 1528. La tercera audiencia, que se fundó bajo la autoridad novohispana, fue la de Guatemala, establecida en 1543. La última fue la audiencia de Guadalajara o de Nueva Galicia, que se instituyó en 1548.

Durante los reinados de Felipe III, Felipe IV y Carlos II, el sistema defensivo de las colonias españolas en el ámbito del Gran Caribe se dividía en dos partes generales. La primera, que era considerada de mayor importancia, se componía de los presidios de Florida, Cuba, La Española y Puerto Rico, junto con puertos de Tierra Firme y del Seno Mexicano.

El segundo segmento, estaba formado por las Pequeñas Antillas, Trinidad y Guayana, Nueva Andalucía, Venezuela, Maracaibo y, la Capitanía General de Guatemala.

Espacio geopolítico del Golfo Caribe:

- Florida: dependía de Santo Domingo. El puerto de San Agustín de la Florida cumplía el objetivo de protección y vigilancia del canal de las Bahamas, por donde atravesaba la ruta de las flotas que salían del Circuncaribe al Atlántico durante su tornaviaje a la metrópoli.

- Cuba: La Habana, Santiago de Cuba.

- La Española: Santo Domingo.

- Puerto Rico: San Germán y San Juan.

- Tierra Firme: Cartagena de Indias y Portobelo. Santa Marta y Río Hacha, formaban la primera y única defensa de la región sudamericana.

- Seno Mexicano: Cabo Catoche, Campeche, San Juan de Ulúa, Mérida, Sisal y Valladolid.

- La provincia de Trinidad y Guayana: Guayana, isla de Trinidad, Golfo de Paria, San José de Oruña y Puerto España.

- La provincia de Nueva Andalucía: Desde el Golfo de Paria hasta el de Cariaco, con capital en la ciudad de Cumaná y una fortaleza en Araya.

- La provincia de Venezuela: La Guaira, Caracas, Santa Ana de Coro, la isla de Margarita y la isla de Curazao.

- Las provincias de Coquibacoa, Mérida y La Grita: península de La Guajira, Mérida, Gibraltar, Pedraza y Barinas.

- Capitanía General de Guatemala: Santiago de los Caballeros de Guatemala, el castillo de la Inmaculada Concepción, ubicado cerca de la desembocadura del río de San Juan, la ciudad de Granada, San Carlos, Honduras y Trujillo. 
Durante el siglo XVI, los reyes españoles se ocuparon principalmente de trazar una política bélica contra Francia y los países protestantes, que los veían como guardianes de la fe católica y los grandes aliados del papado. A finales del XVI, la estrategia no cambió significativamente su dirección, pero, para conservar esa dinámica en Europa era necesario mantener un aparato militar capaz de sostener el control de diversos lugares del imperio en el Viejo Mundo. Por eso, a partir de la década de 1540, se produjo una enorme demanda de remesas para sustentar tropas desde Nápoles hasta Flandes. La solución del problema llegó de América, especialmente de los virreinatos de Nueva España y el Perú, cuya industria minera alimentaba con toneladas de oro y plata las arcas reales. Esos fondos permitieron el financiamiento de las empresas bélicas hispanas en el continente europeo.

\subsection{Piho, Virve 1(981, pp. 17-29 y 119-127)}

\subsubsection{LOS ANTECEDENTES POR MAYORES RENTAS DE LA NUEVA ESPAÑA PARA EL IMPERIO}

A mediados del siglo XVII estalla en la Nueva España, dentro del marco de la Iglesia Católica, un conflicto entre el clero secular y el clero regular cuyos orígenes se habían engendrado desde la llegada del primer obispo a este continente. El clero regular, que entró pocos años después de la conquista, había ocupado y dividido los territorios entre las principales órdenes religiosas: los franciscanos, dominicos y agustinos. En el transcurso del tiempo de habían asentado, afirmado en el poder y acumulando riquezas como consecuencias de un número creciente de curas seculares empezó a surgir a mediados del siglo XVI una tensión que se iba profundizando entre los dos sectores religiosos. Los curas seculares se encontraron en la miseria, sin puestos por ocupar ni campo de acción, porque las parroquias y el adoctrinamiento de almas estaban en manos del clero regular.

Un análisis de los acontecimientos de la historia eclesiástica de la Nueva España revela que la controversia entre ambos sectores del clero, llevada oficialmente bajo la apariencia de motivos religiosos, constituía en realidad una clara lucha por el poder económico y la dominación política y social.

Después de su llegada al nuevo mundo en 1640, el obispo Palafox arremete, sin pérdida de tiempo alguna en contra de las órdenes establecidas en el obispado de Puebla, que estaba a su cargo. Las medidas tomadas afectaban sobre todo a los frailes de San Francisco por el dominio de sus vastos territorios en esta región. Todos los religiosos que pretendían seguir en las parroquias de los indígenas tenían que someterse a un examen en el cual debían demostrar su capacidad para predicar en una lengua nativa. 
Como la gran mayoría de los frailes eran originarios de España y algunas otras partes de Europa, no podían cumplir con los requisitos puestos. En el curso de tres días, el obispo Palafox expropió las parroquias que se encontraban bajo la jurisdicción de las órdenes religiosas. Los frailes podían seguir ocupando las iglesias y los conventos, mientras los curatos entraron a formar parte de la jurisdicción del clero secular. Con esta medida el obispo Palafox solucionó, a la vez, el grave problema de desocupación que regía entre los clérigos seculares, que desde entonces se encargaron del adoctrinamiento de los indios en la diócesis de Puebla-Tlaxcala. A pesar del intento de extender esta medida en forma drástica a toda la Nueva España, la controversia sobre este asunto se prolongó hasta el siglo XVIII.

La primera diócesis en la Nueva España fue llamada la Carolense y fundada antes de la diócesis de México en 1519 por el papa León X. Fue trasladada de Yucatán a Tlaxcala, y confirmada en 1525 por Clemente VII. Sus límites se fijaron por Carlos I en una cédula dada en 19 de septiembre de 1526. Tenía esta diócesis de latitud cien leguas y de ancho sesenta. Los primeros frailes en llegar fueron los franciscanos en el año de 1523, entre ellos Tecto, Aora y Gante.

Después de los franciscanos llegaron a la Nueva España los dominicos en 1526. Los dos años que los franciscanos llevaban de delantera a los dominicos pudieron extenderse con toda libertad, sin que nadie les disputara el terreno. De ésta manera podían instalarse en la región del centro donde llegaron también hasta Huejotzingo y Calpan. Después de la ocupación de la parte central desbordaron sobre Michoacán y la Nueva Galicia para adelantarse hacia el norte. Mientras que los agustinos, últimos de las órdenes mendicantes en llegar, hasta el año de 1533, tenían que intercalarse en los huecos que les habían dejado las misiones franciscanas y dominicas. En los antiguos lugares de concentración política y religiosa de la época prehispánica fueron establecidos centros de evangelización así en Tlaxcala y Huejotzingo y en el Valle de México, además de México-Tenochtitlan en Tezongo y Churubusco. En los primeros años entre 1525 y 1531, fray Juan de Rivas fundó en el área de Tlaxcala el convento de Tepeaca.

En lo que se refiere al aspecto económico de las áreas ocupadas por el gobierno español en la Nueva España, existe ya con fecha 9 de noviembre de 1526, una Real Cédula dirigida a "Nuestro Gobernador o juez de residencia de la Nueva España" que demuestra el interés del Monarca con referencia a los ingresos de la Corona: "Oficiales envíen un tiento de cuenta de las rentas del rey cada año". Estas rentas del rey provenían de los diezmos. La costumbre de este pago al monarca por parte de grupos étnicos no españoles tenía su origen en los antecedentes históricos del siglo XIII, cuando en 1228 el concilio de Valladolid aplicó el pago del diezmo Real o predial a los moros y judíos. 


\subsubsection{EL DESARROLLO DE LA ECONOMÍA ECLESIÁSTICA HASTA 1640.}

La secularización de las parroquias.

Juan de Palafox y Mendoza, nació el 24 de junio del año de 1600 en Fitero, Navarra, como hijo natural del Marqués de Ariza, Don Jaime de Palafox y Mendoza. Por las circunstancias de su origen no tuvo ni el amparo de su madre ni la protección de su padre, fue abandonado en la rivera, recogido y criado por un pastor. A los diez años fue reconocido por el marqués, su padre, quien le proporcionó estudios que lo llevaron posteriormente a las universidades de Alcalá de Henares y Salamanca. Sentía una cierta inclinación hacia la carrera de las armas, lo que su padre no veía con buenos ojos. Se integró al estado eclesiástico a los 29 años sin abandonar su cargo en el Consejo de Indias, donde había ejercido el puesto de fiscal y hasta había llegado a ser el decano de este cuerpo.

El 24 de julio de 1640 llegó Juan de Palafox y Mendoza a su diócesis, a Puebla.

Palafox asumió el 10 de junio de 1642 el cargo de virrey, pero duro en él solo hasta el 23 de noviembre del mismo año.

Relacionado con la actuación del obispo Palafox, debe mencionarse también el conflicto que desató con la compañía de Jesús. Exigió a los miembros de esta orden que vivían dentro del obispado de Puebla, que no predicasen ni confesasen sin licencia suya y pagasen todos los diezmos sobre sus casas de campo. Como consecuencia de los litigios y pleitos que había originado el obispo Palafox tuvo que alejarse temporalmente de su diócesis y ocultarse para evitar atentados en contra de su persona.

Como consecuencia de las acciones de Palafox, llegó una ordenanza categórica del rey, dirigida al sucesor de Palafox en el virreinato, el Conde de Salvatierra, con fecha 25 de enero de 1648, que decía que los religiosos de la compañía de Jesús de su diócesis presentasen dentro de 24 horas las licencias que tenían para confesar y predicar, y que se les prohibía hacerlo mientras que no tuviesen la aprobación. La compañía de Jesús se opuso a las determinaciones originadas por el obispo y el asunto llegó a causar revuelo hasta en la corte española.

Con motivo de este pleito, en el que tuvieron que intervenir el papa y el rey Felipe IV, Palafox fue llamado a España para donde partió en el mes de mayo del año de 1649. 


\section{Antes de la secularización.}

Como resultado de la trayectoria del desarrollo de la historia económica de la Iglesia en la Nueva España, desde la conquista hasta el año de 1639, se desprende que la designación del obispo Palafox fue hecha por el rey Felipe IV. Con fines precisos de que este personaje resolviera el pleito pendiente desde los primeros tiempos. Este consistía en la urgencia del pago de los diezmos en territorios ocupados por el clero regular, que solamente se podía lograr por medio de la secularización de las parroquias que hasta entonces habían estado en manos de las órdenes religiosas, para poder entregarlas a la administración del clero secular.

Hasta entonces los beneficios económicos y el provecho del trabajo indígena ingresaban a los caudales de las órdenes religiosas, donde quedaban a la disposición de los superiores. Como consecuencia de esta situación, el rey tenía que complementar los gastos originados por el adoctrinamiento de los indios con fondos de la Real Hacienda, que fue la razón fundamental por la cual existe una gran necesidad de aliviar este peso económico.

Uno de los primeros pasos dados por el obispo fue que remitió una patente en la cual mandó a los frailes permanecer en los conventos encomendándose a Dios con letanías en lugar de salir a adoctrinar. Además no debían bautizar, ni asistir a los matrimonios, y no llevar el viático solemne. Otra orden dada por el obispo que abarcaba una cuestión económica, fue que las comunidades religiosas, en lugar de invertir en las fincas rústicas o urbanas que ellos juzgasen convenientes, pusiesen sus dineros por fuerza en las Cajas Reales de Madrid.

\section{Glosario.}

Clero secular: sacerdotes católicos que no viven en monasterios sujetos a una regla, sino en un mundo adscritos a una parroquia colegiata o catedral. En la Nueva España el clero secular estaba constituido por los obispos, que formaban también los concilios provinciales y abarcaban las diócesis y parroquias. (Pike en Piho: 1981).

Clero regular: se refiere al nombre dado a los sacerdotes, monjes y frailes católicos que pertenecen a cualquiera de las órdenes religiosas o congregaciones, han hecho votos monásticos y viven en comunidad (Pike en Piho, 1981). El clero regular se compone de las órdenes religiosas que constituyen organismos autónomos que siguen sus propias reglas, pero están directamente sujetas al Papa y solamente hasta cierto grado variable a los obispos. En la nueva España el clero regular está compuesto por tres nuevas órdenes que fueron: los franciscanos, dominicos y agustinos. A los que se juntaron posteriormente los jesuitas y otros. (Piho, 1981) 


\subsection{Celaya Nández, Yovana., Alcabalas y Situados. (2010).}

"Los aprietos de mi Hacienda y la necesidad de asistir a mis ejércitos, armadas y fronteras crece cada día, de suerte que obliga a emplear todo el cuidado y desvelo de mis ministros en atender al reparo de los daños que ellos (los enemigos) nos procuran y a engrosar las fuerzas con que conviene hacer oposición a sus designios y como el nervio principal que da calor a estos intentos es la Hacienda para suplir los gastos que son tan precisos en el reparo de tantos empeños públicos; he mandado emplear todo el cuidado y desvelo de mis ministros en procurar descubrir medios que aumenten el caudal para aplicarlos a la defensa comodidad y sosiego de mis reinos".

Real Cédula de beneficios de medios, Felipe IV, 1654.

\subsubsection{LA HACIENDA DE ANTIGUO RÉGIMEN.}

El control del comercio exterior en la entrada o salida de ciertos productos-oro, plata, granos- fue mediante el establecimiento de tasas. Además, el cobro de derechos sobre el tráfico de productos cuyo comercio estaba permitido, proporcionaba ingresos de cierta importancia para la Hacienda.

Los puertos de mar eran los puestos aduaneros con mayores ingresos y su organización en la época de los Austrias, prolongó el modelo medieval, caracterizado por la existencia de tramos litorales diferenciados por diferentes aranceles. Para el comercio con Indias se aplicaba el almojarifazgo, que grababa los géneros que se exportaban o se importaban de ahí.

El comportamiento de la Real Hacienda castellana y el sistema fiscal a lo largo de la primera mitad del siglo XVII da cuenta de la ausencia de una política de conjunto que permitiera sostener los proyectos internacionales de la monarquía. La guerra se convirtió de modo inmediato en una constante y creciente demanda de recursos. Es de tener en cuenta que por vía de los contratos de encabezonamiento de alcabalas, millones u otros gravámenes, la administración hacendística estimaba el monto total de ingresos anuales. Pero el monto final que efectivamente, y a sus debidos plazos, ingresaba en las arcas de cada una de las agencias recaudadoras, no siempre correspondía a lo esperado.

Durante la gestión del Conde de Olivares (1621) se reconocen sus empeños por aumentar el poder naval de España. En este rubro se preocupó no solo por tener una flota que hiciera frente a los ataques, sino recursos humanos y materiales, pertrechos, pólvora y alimentos, con carácter permanente. El proyecto de unión de armas, buscaba 
ante todo la unión del reino como una medida de defensa y proponía el sostenimiento de 140.000 hombres que debían estar en servicio y financiados de manera equitativa, por los reinos que integraban la monarquía, lo que representaba un ejército provisto de todo lo necesario para actuar donde y cuando se presentara una situación de emergencia. Los principios que animaban el proyecto eran sumamente razonables y sus perspectivas prometedoras, pues la cooperación militar y financiera podría ser un paso hacia la unificación política. La primera resistencia al proyecto fueron las Cortes de Cataluña; no obstante, el proyecto no se detuvo y se extendió a Flandes y América: los virreinatos del Perú y Nueva España contribuyeron con un incremento del 2\% en la alcabala. Un apoyo importante a las reformas del conde-duque, fue sin duda el Consejo de Hacienda, quizá el más profesional de todos los consejos de Felipe IV; su principal función era administrar las rentas reales, arrendándolas o controlándolas desde el gobierno. Los ingresos así conseguidos servían para pagar a los propietarios de los títulos de deuda del Estado, los Juros, y ofrecer garantías a los banqueros para sus asientos, contratos destinados al pago efectivo de los gastos en el interior o en el extranjero.

En materia fiscal y ante la situación heredada no se podían pronosticar grandes cambios en la política hacendística ni esperar el aumento de los recursos. El tejido de la vida española estaba demasiado exhausto para un súbito rejuvenecimiento. Una vez superados los conflictos generados por la nobleza en la llamada revuelta de los grandes y bajo el gobierno del duque de Medina Cheli, comienzan a observarse proyectos de reforma. El duque hizo gala de interés por la reforma comercial, algo no muy habitual entre la alta aristocracia y que no habían sentido sus predecesores, durante su administración se auxilió de José de Veitia Linaje, antiguo tesorero de la Casa de Contratación y secretario del Consejo de Indias. Desde su puesto de secretario del Despacho Universal, que asumió en Abril de 1682, José de Veitia funcionó como asesor especial del primer ministro en los planes para revitalizar el comercio colonial y sus rendimientos. Uno de sus proyectos más importantes fue atacar los abusos más flagrantes de la penetración comercial extranjera en Sevilla-Cádiz y dio mayor atención a las defensas del Imperio. Durante su gestión, Medina Cheli logró aportar esta habilidad política, incorporar nuevos talentos a las tareas de dirección y elevar el nivel del gobierno. Además de evitar el procedimiento de manipulación del sistema monetario como hicieron administraciones anteriores.

El mecanismo que la sostuvo la estructura fiscal-administrativa desde el siglo Xvı hasta el XVIII, fue la movilización de recursos fiscales y la capacidad negociadora de la corona para la obtención de recursos fuera y dentro del reino, la disponibilidad de hombres de negocio, banqueros y comerciantes, así como las ciudades para proporcionar recursos, hombres y armas, permitió que se conservara la política internacional desde Felipe II. 
Es un hecho que la carencia de una tesorería capaz de hacer frente a los pagos en los lugares y moneda convenidos por los contratos, mantuvo a la Corona en constante dependencia de los asentistas u hombres de negocio, capaces de cubrir de forma expedita estas necesidades. Pero el incremento de situar los gastos de guerra sobre los ingresos fiscales -es decir, el principio de transferencia de recursos en Castilla y en los virreinatos- permitió palear dicha carencia y, al mismo tiempo, mantuvo el interés de los banqueros por facilitar los recursos necesarios.

Es decir, proyectos como la Armada de Barlovento y situar los ingresos de determinadas rentas, funcionaron con un sistema de transferencia de recursos fiscales, provenientes de virreinatos como Nueva España o el Perú. Este sistema de transferencia debe tenerse en cuenta al pensar en la carga fiscal castellana y en los efectos de la política militar sobre los territorios americanos. Es necesario entender el uso de los recursos fiscales provenientes de Indias dentro del universo de las demandas de la Real Hacienda española del siglo XVII y primer reinado del siglo XVIII.

En lo que se refiere al régimen fiscal, el territorio novohispano seguía la misma línea del de Castilla. La Real Hacienda de Nueva España contribuía con los quintos y derechos de plata y oro, lo procedido de la venta de azogues, tributos de indios, alcabalas, cruzada, salinas, pólvora, media anata, papel sellado, pulques, nieve, lotería, aduanas de San Juan de Ulúa y Acapulco, almojarifazgo y algunos otros ingresos menores. De estos ingresos se sostenía la administración del virreinato y se costeaba la defensa y abastecimiento de tropas del Caribe y Filipinas, además de las flotas y el pago de la alimentación de los marineros de la armada de Barlovento. Del total recaudado y una vez descontados los costos de administración y defensa en el espacio americano, el producto líquido se enviaba a Castilla.

\subsubsection{ADMINISTRACIÓN DE LA ALCABALA EN PUEBLA.}

El sistema de transferencia de recursos puesto en operación desde la metrópoli era realizado entre las distintas cajas reales del virreinato y la caja matriz en recursos líquidos o en especie. Sin embargo, podía darse fuera de los canales administrativos de una caja real. Es decir, entre una instancia recaudadora del gravamen y la Hacienda virreinal. Los recursos de la alcabala en la ciudad de Puebla, formaron parte del sistema de transferencia, estableciéndose como renta situada a disposición de los oficiales de la Real Hacienda. El virrey, en su condición de autoridad máxima del virreinato -sobre el que descansaba la obligación de mantener la defensa del territorio y buscar todos los medios posibles para ésta- dispuso del principio básico del sistema de transferen- 
cias. Es decir, giró órdenes de compra y pago a los abastecedores de bizcocho y otros géneros para la travesía marítima que debían satisfacerse en Puebla.

En primer lugar, deben considerarse las condiciones de la ciudad y su región agrícola. La ciudad era centro de intercambios de la producción de cereales y manufacturas. El mercado de las flotas y presidios del Caribe demandaba, entre otros productos, bizcocho, tocino, jamón, garbanzo, frijol, habas, arroz y queso, elaborados en Puebla. En la lista de manufacturas producía jabón, piezas de vidrio, telas, sombreros, piezas de hierro, sillas de montar, entre otras. La disposición de la materia prima y su manufactura en la ciudad facilitaba el abasto de los pertrechos necesarios para la travesía marítima. Un segundo punto a considerar es la composición económica del cuerpo de regidores. Los capitulares tenían su base económica en la propiedad agraria o participando del comercio con Sevilla y Filipinas. Un ejemplo es la familia del regidor Carmona Tamariz, quien en su memorial dirigido al rey, daba cuenta de los múltiples servicios prestados a su familia a la Corona, en especial el abasto de bizcocho y otros géneros que demandaban las flotas. Por otra parte, si la relación no era directa, las redes de intereses implicaban, relaciones con el sector agrícola. El tercer punto es que la ciudad en su calidad de órgano de gobierno, controlaba la disposición y abasto de maíz, trigo y carne. De igual manera, en vista de que eran los regidores quienes satisfacían las órdenes de pago ellos decidían a quién compraban los géneros necesarios para las armadas, el nombre del abastecedor y el precio del insumo. Las tres condiciones anteriores otorgaban un terreno propicio para la formación de una red de intereses que tuviera bajo su cuidado el abasto a la gente del mar. La ciudad, al igual que regidores, hacendados y comerciantes, obtenían el beneficio exclusivo del abasto a las flotas de ambos mares mediante el control del ingreso fiscal que cubría dicho gasto.

La ciudad se obligaba a comprar bizcocho y demás géneros necesarios para el abasto de las flotas. Uno de los regidores asumía la responsabilidad de la compra a bizcocheros y tocineros de la ciudad y, una vez efectuada la compra, alquilar los arrieros necesarios para su envío a las costas. La adquisición de géneros ponía en operación un importante sistema de comercio y circulación que otorgaba beneficios a comerciantes, hacendados, panaderos, tocineros y arrieros, controlados por el cabildo. Los regidores se aseguraban que la Real Hacienda tuviera conocimiento de los costos realizados para satisfacer las órdenes del virrey y solicitaban una certificación del gasto efectuado, formula seguida año con año y en estrecha relación con el arribo de las flotas.

8.5.3. LOS BIZCOCHEROS.

Otro fenómeno importante en el periodo 1600-1683, en el contexto internacional fue el aumento de las necesidades defensivas en la última década del siglo XVII. Los 
proyectos de defensa se tradujeron en una mayor circulación de la Armada de Barlovento, aumento de soldados para las milicias y demanda de alimentos para sostener dicha población. En estas condiciones, después de 1670 se incrementó el gasto para las fuerzas militares y navales y la fortificación de los puertos remotos en el Caribe. Los temores de una invasión al territorio novohispano se hicieron efectivos con el ataque al puerto de Veracruz y Campeche en 1683. La presencia de Lorencillo evidenció la debilidad del sistema de defensa de tierra y la necesidad de fortificar ambas plazas. En este periodo el fenómeno de la transferencia de recursos desde la ciudad de Puebla cobra mayor significado ya que la demanda de pagos sobrepasará el pago anual de cabezón. Dentro del sistema de transferencia, el abasto de bizcocho y pago de las milicias para Filipinas presentaba mayor regularidad por las fechas más o menos exactas del arribo del nao. Por el contrario, la demanda de recursos para la armada de Barlovento estaba lejos de tal regularidad, lo que obligaba a contar con recursos todo el año.

El 3 de agosto de 1680, los regidores poblanos debían cubrir el pago de 2,000 quintales de bizcocho para la Armada de Barlovento, que se dirigía a Santa Marta. El costo del bizcocho y otras miniestras alcanzaba la suma de 8,000 pesos, y el Cabildo no tenía dinero para satisfacer la libranza. A pesar de la falta de recursos, los regidores aceptaron satisfacer el costo del abasto solicitando un préstamo a los vecinos de mayor caudal para cumplir con el pago. Al año siguiente y después de satisfechos los costos de abasto para las Filipinas, la ciudad tuvo que atender las demandas extraordinarias de bizcocho para La Habana y la Armada. El cabildo manifestó su queja por la excesiva demanda de alimentos, y el 29 de abril de 1681 envió un memorial al virrey explicándole que "con los despachos continuos de bastimentos y miniestras para los puertos de ambos mares" la ciudad tenía deudas con algunos vecinos de la ciudad y por lo tanto solicitaban un tiempo pertinente para pagar los préstamos. Los regidores sugerían al virrey delegar el pago del abasto en otros ingresos para disponer de recursos de la alcabala y cubrir los compromisos con los prestamistas.

Abasto a las flotas, 1685-1690.

Destinos: Campeche, Armada de Barlovento y Filipinas.

Con recursos provenientes de tributos, alcabala e impuesto del pulque.

\subsubsection{ACUERDOS DE ALCABALA.}

En el transcurso de 1692 y 1693 se expusieron los términos del conflicto entre autoridades de Hacienda y de gobierno con los comerciantes, la demanda de recursos por 
parte de la Hacienda aumentó la presión. La casa de Austria se enfrentaba a la inminente sucesión sin heredero directo y los conflictos bélicos presionaban a las Haciendas americanas. El virrey en curso, Gaspar de La Cerda y Sandoval y Mendoza, conde de Galve, era forzado para aumentar las remesas dirigidas a Castilla y al mismo tiempo, debía hacer frente a la defensa del Caribe ante los ataques piratas. En este escenario de escasez de recursos fiscales para el gasto en defensa, y condiciones locales adversas, se enfrentaron comerciantes y regidores poblanos.

\subsubsection{LA SITUACIÓN FISCAL EN LOS AÑOS NOVENTA Y LA SELECCIÓN DE VEITIA.}

El virrey proponía como opción que la renta se depositara en manos de un ministro "de la inteligencia, celo y desinterés que pide materia de tanta gravedad", los beneficios de un ministro al frente de las alcabalas se habían constatado en un crecimiento en la recaudación de la Ciudad de México, que había servido de parámetro para otorgar el nuevo asiento al consulado de comerciantes y sin los descuentos de falta de flotas y naos de Filipinas. En el tema de los descuentos por falta de flotas, el conde de Galve consideraba que su presencia o ausencia en las costas del virreinato no era determinante en el movimiento del ingreso fiscal, explicando que en caso de no arribar flota o nao a Nueva España, al año siguiente los envíos y tráfico de mercadería doblaban el volumen de intercambios por el año de atraso, produciendo un excedente del impuesto alcabalatorio. Por lo tanto, los recaudadores recuperaban el ingreso del año en que no se había presentado una flota, lo que hacía innecesario la concesión de rebajas por la interrupción del comercio interoceánico; sostenía también la importancia de cambiar el sistema de recaudación de la alcabala de puebla, en vista de que, lo practicado por el cabildo había producido daños a la Real Hacienda y aún no se liquidaban los atrasos (carta del virrey conde de Galve, 21 de junio de 1694).

El memorial del virrey fue remitido al fiscal del Consejo de Indias, quién emitió su parecer el 24 de mayo de 1695. El consejo coincidía con los argumentos del conde de Galve, por lo que una vez terminado el contrato en curso, la administración de las alcabalas de Puebla, debía ponerse en manos de un ministro de la mayor inteligencia. Al fiscal le parecía nombrar, para tan importante tarea a Juan Joseph de Veitia, contador mayor del tribunal, "así por la práctica y experiencia que tiene en la administración de este ramo de la Real Hacienda, como por el celo y desinterés con que ha manejado las de las alcabalas de México, que ha sido administrador" (Madrid 24 de mayo de 1695). El fiscal recomendaba que si se aprobaba su parecer fuera ratificado en Cédula Real lo más pronto posible. 
La opinión del virrey y del fiscal del consejo fue aprobada en 1695 por el rey mediante cédula real en la que se designaba a Juan Joseph de Veytia para el cargo de administrador de las alcabalas de la ciudad de Puebla. El ministro, al momento de nombramiento, se desempeñaba como contador mayor del tribunal de cuentas de la Ciudad de México. Carlos II sostenía que la administración se depositaba en el ministro por un tiempo de cinco años con el objetivo de "saber a punto fijo el valor de esta renta lo cual no se ha podido conseguir en más de noventa años que ha estado en arrendamiento". Joseph de veytia asumiría la administración una vez terminado el contrato de cabezón en curso, en 1698. Las atribuciones eran la recaudación del impuesto y de "todo cuanto procediera de esta renta". Al terminar su gestión de cinco años, el rey le otorgaba la comisión de poder admitir las posturas y pliegos que se hicieran por la ciudad y otras personas para la administración de la renta. En cuanto a los beneficios obtenidos por su cargo, Joseph de Veytia tendría autoridad en el espacio fiscal de la ciudad de Puebla, la cual no podría ser "coactada" por las autoridades virreinales "a mis Presidentes y Oidores de mi Audiencia Real de México que no se entrometan en el conocimiento de nada tocante a este ramo de Hacienda, por que vos solamente la habéis de tener a vuestro cargo sin dependencia de otro ningún ministro ni persona alguna".

En cuanto a méritos propios, la carrera profesional del funcionario se inició en Tehuacán como alcalde mayor. En 1683 adquirió por compra del cargo de contador mayor de cuentas y dos años después fue nombrado administrador de las alcabalas de México con el título de "Superintendente administrador privado de la Real Aduana de México y Real alcabala de la ciudad de México", desempeñándose como contador de la recaudación de la alcabala que al momento administraba la Real Hacienda. Otra razón personal pudo ser su relación consanguínea con un miembro del Consejo de Indias, su tío José de Veytia.

José de Veytia Caballero de la orden de Santiago, fue secretario del despacho universal y autor del texto, Norte y Contratación de las Indias Occidentales. Murió siendo miembro del Consejo de Cámara y Junta de Guerra de Indias y su sobrino, al momento establecido en Nueva España, fue nombrado heredero único (Michel Bertrand, comunicación directa).

Los acontecimientos de la última década del siglo demandaron un recurso fiscal destinado al gasto más sistemático. Los ministros de Carlos II buscaban evaluar sus ingresos fiscales para sostener su sistema de fiscalidad-defensa.

8.5.6. LA FISCALIZACIÓN MODERNA EN LOS ALBORES DEL XVIII. 
Joseph de Veytia desempeñó una comisión en Puebla con amplios poderes frente a autoridades políticas del virreinato, al mismo tiempo que contó con la complacencia de las autoridades metropolitanas. En lo que atañe el espacio físico de la gestión no existe límite alguno en vista de que la comisión determinaba los alcances, abarcando desde una provincia hasta un pueblo o dos sujetos en conflicto. En el caso de Joseph de Veytia, era una comisión de carácter fiscal de un gravamen por ventas y negocios realizados en la ciudad de Puebla y, por lo tanto, los alcances del cobro del gravamen eran los límites de su jurisdicción, definida a partir de la instalación de las garitas en la ciudad.

\section{1. Ámbito territorial de recaudación}

A las atribuciones concedidas por la cédula de 1695 siguieron las del tipo político, administrativo y justicia. El cargo de alcalde mayor de la ciudad de puebla le fue otorgado en 1699 y el mismo año sustituyó de justicia mayor. La solicitud es interesante porque el alcalde tenía justicia para impartir justicia de primera instancia.

En el control de los recursos alcabalatorios, desde 1699, obtuvo jurisdicción fiscal sobre las poblaciones circunvecinas: Tlaxcala, Tepeaca, Tecali, Atlixco, Tochimilco, Huejotzingo y Cholula. El nombramiento lo facultó para administrar o en su defecto arrendar la recaudación del impuesto. La jurisdicción sobre las poblaciones circunvecinas se convierte en un factor importante para extender su red política en la región y mediante el nombramiento de funcionarios y particulares subarrendando los distritos fiscales agregados.

\section{Juez superintendente de azogues}

La disposición de recursos fiscales de la región dificultó la relación con la ciudad virreinal y se acentuó con el cargo en 1709 obtuvo Veytia Linaje, juez superintendente de azogues a partir de la creación de la junta de azogues de 1708, el control del abasto dejó de estar en manos del virrey y la administración se trasladó a la ciudad de Puebla.

La gestión de Veytia Linaje iniciaba en enero de 1698, pero el comisario estimó necesario trasladarse a la ciudad de puebla desde octubre de 1697 para establecer las condiciones materiales y humanas que le permitían iniciar su tarea. Joseph de Veytia se había formado en el sistema burocrático y sostenía que el éxito de su administración dependería de un cuerpo de ministros que ejecutare y definiera sus proyectos.

Además de 20 ministros encargados de la vigilancia, 16 guardas y 4 rondas, era necesario incrementar el número de guardas y "tener espías secretas"; su función era intro- 
ducirse en lugares circunvecinos obteniendo información de almacenamiento clandestino de mercancías para imponer las penas necesarias. AGI México 342.

La continuidad le permitió financiar su proyecto de fortalecimiento y defensa del presidio de San Agustín de La Florida, que durante la gestión de Joseph de Veytia no se restringió a la demanda de un situado base sino que, conforme los recursos fiscales de la aduana poblana lo permitían, demandó recursos para el fortalecimiento del fuerte.

La figura del comisario permitió sin necesidad de una estructura jurídica, sentar las bases para una simbiosis entre la renta alcabalatoria de la ciudad de Puebla y el presidio de San Agustín de La Florida. El principio por el cual se estableció la figura del situado se cumplió en una relación directa entre el espacio fiscal que genera el recurso y el que lo demanda. Es la concentración de poderes fiscales que la figura del comisario otorgó en el manejo de recursos lo que permitió establecer dicha relación y a Felipe $\checkmark$ financiar su proyecto de convertir a San Agustín de La Florida no sólo en la frontera sino como avanzada frente a los establecimientos ingleses y franceses. El proyecto, sin bien fracasó, formó parte de una política fiscal en aras de racionalizar los recursos destinados a la defensa.

De 1698 a 1727 el sistema de administración por comisión fiscal se mantuvo en la ciudad de Puebla, según las necesidades imperiales necesitaron de un control de los recursos fiscales en la ciudad para atender las demandas del numerario en el Caribe.

\section{La administración por el arrendamiento, 1727-1742: recaudación y transferencia.}

En octubre de 1724, los diputados del comercio, mediante sus representantes en Madrid, presentaron a los ministros de Hacienda de Indias, el pliego de condiciones por el que la comunidad de mercaderes solicitaba la administración de las alcabalas de la ciudad de Puebla. Los representantes en Madrid solicitaron que dicho pliego fuese discutido por los ministros de Hacienda en la Corte, evitando así la injerencia de Joseph Joaquín de Uribe y del fiscal virreinal, quienes no mostraban un apoyo abierto a las aspiraciones de los comerciantes. Sin embargo, Felipe $V$, en su cédula de agosto de 1725 , consideró que debido a la importancia de la materia y a que los tribunales de Hacienda novohispana tenían mayor conocimiento del tema, el pliego de condiciones debía discutirse en la junta de hacienda, presidida por el virrey, miembros de la Audiencia y el fiscal. Por ello las cláusulas del contrato fueron discutidas en septiembre de 1726 en dicha junta. Los diputados del comercio sometieron a negociación 44 cláusulas en calidad de condiciones que, de ser aprobadas, les otorgarían el derecho de administración de la renta alcabalatoria de la ciudad de Puebla. 
La investigación del sistema de transferencias desde la ciudad de Puebla reveló la articulación entre recaudación fiscal y gasto en materia de defensa.

Un 4 por ciento de la alcabala fue aprobado por los cuerpos novohispanos para cubrir el costo de defensa por el Caribe. Destinado a satisfacer el gasto en alimentación, pertrechos y milicia.

La pregunta recurrente como un sistema de fiscalización financió la agitada actividad militar de la monarquía española desde el siglo XVı y hasta la primera mitad del siglo XVIII, el análisis de la recaudación y transferencia puede ayudar a entender la efectividad de la fiscalidad y la continuidad del sistema monárquico español.

\subsection{Fernández, Miguel Ángel (1988, pp. 159-164)}

\subsubsection{UNA HISTORIA QUE PERDURA. LA RUTA PUEBLA- ACAPULCO-FILIPINAS}

A pesar del intenso tráfico terrestre que durante algunas semanas al año unía a Acapulco con la Ciudad de México, a lo largo de los tres siglos de dominio colonial y aún una centuria después, el tendido vial entre los dos puntos apenas alcanzó el título de camino de herradura, con infinidad de obstáculos naturales -como ríos caudalosos, barrancas y abruptas pendientes- que dificultaron y encarecieron el traslado de las frágiles mercancías que provenían de Oriente. El camino, en sí, fue más que un itinerario teórico que una senda transitable por viajeros y recuas, y mucho menos por carretas.

Entre los primeros testimonios de las inconveniencias que se padecían en el trayecto, se encuentra el de Francesco Carletti, quien en 1595 partió de Acapulco con otros acompañantes: "... y fuimos por tierra con nuestra plata hacia la Ciudad de México. Por el camino pasamos un río que se puede nombrar entre los grandes, y así es nombrado Río Grande (Balsas o Mezcala) entre los españoles; y puesto que no hay comodidad ni de puentes ni de barcas para pasarlos, nos fue menester, tal como hacen los demás, ponernos encima de un montón de calabazas grandes y secas atadas a una rejilla de cañas puestas sobre ellas, sobre la cual se pone la silla del caballo, que se hace pasar a nado, y sobre la silla se sienta uno, y luego cuatro de aquellos indios, uno por esquina de la dicha rejilla con las calabazas nadando la empujan y conducen a la otra orilla del río, rompiendo la corriente del agua. Cosa menos peligrosa que aburrida, y máxime por las mercancías que se pasan cada año en tan gran cantidad y valor; y con todo no se pone remedio a ello, y pasan también con la misma dificultad y peligro el virrey 
cuando va desde México para embarcarse en dicho puerto de Acapulco para pasar al gobierno del Perú".

Quizá la explicación a este abandono radique en que, a diferencia del camino que unía a la Ciudad de México con Veracruz, el de Acapulco tan solo tenía utilidad durante la época de la feria. además, los asentamientos de españoles en el itinerario fueron escasos en los siglos XVI y XVII, no existiendo por ello, fuera de los comerciantes que año con año se aventuraban al puerto o que enviaban a sus representantes, personas pudientes interesadas en patrocinar cualquier mejoría. Por tal motivo, cuando en el año de 1679 Pedro Cubero emprendió la ruta, sus testimonios no riñeron con los que Carletti externara varias décadas atrás. Este religioso permaneció cinco meses en Acapulco, para luego emprender el viaje directamente a la ciudad de Puebla de los Ángeles por el mismo sendero que conducía a la capital de la Nueva España, y de cuyo derrotero tan sólo se desvió en el tramo final.

Según palabras de Cubero, "el camino (es) de los más ásperos que he andado en mi vida, porque no hay otra cosa que barrancos, montes, peñascos y despeñaderos de los más profundos que hay en el mundo... Salí de Acapulco, y pasando diversas montañas, al segundo día llegué a tan celebrada cuesta del Papagayo, que sobre su aspereza de subida y bajada, tiene más de tres leguas, en lo alto de la cumbre nos cogió una gran tempestad de truenos, relámpagos y agua, que entendimos que el cielo se venía abajo. En lo alto de la cuesta, apeándome para ponerme debajo de un árbol, porque los arroyos de agua que bajan eran tan grandes y con tanta furia que las cabalgaduras no podían de ninguna manera caminar, vi un árbol cuya corteza olía a bálsamo y reparé que entre aquella arboleada debía de haber muchos árboles aromáticos, porque era grande la fragancia que allí había. Luego bajamos para pasar el Río Papagayo, y lo que yo más me recelaba era, que no hubiese crecido, porque es de los Ríos más temidos de toda la Nueva España, por haberse tragado tantos hombres, su corriente es muy veloz y a treinta pasos del vado tiene un despeñadero, tan alto y profundo, que cayendo allí no tiene humano remedio".

Posteriormente atravesó "aquel tan profundo arroyo que llaman de la Imagen, por un peñasco muy alto donde hay una peña que parece de mármol blanco que desde el arroyo se ve y representa una Imagen muy grande como de Nuestra Señora de la Concepción, que la misma naturaleza labró ahí". Luego tocó algunos pueblos indígenas, deteniéndose en Tixtla y más tarde en Chilapa, "donde llegamos el día del Corpus y dije misa en el Convento de los padres agustinos". Finalmente, después de hacer pequeñas escalas en algunos poblados de indios y en varios ingenios, se detuvo en Atlixco, para de allí dirigir su marcha en forma directa hacia Puebla y Veracruz. 


\subsection{Las rutas de ultramar e internas en su paso por Puebla}

Los siguientes planos dan cuenta de las rutas están estrechamente relacionadas con la ciudad de Puebla, especialmente a partir de la modernización del sistema fiscal, cuando a partir de enero de 1698 la Corona designa a la entonces Ciudad de Los Ángeles como Plaza fiscal y comercial de primer orden se designó dependiente directamente de la Corona sin el intermedio de las autoridades del virreinato.

La designación del Juez privativo Real de confianza tuvo como motivo principal una mayor recaudación a través de dos factores; el primero a través de la modernización de la gestión del sistema fiscal, el segundo con la estrategia en el diseño físico de fiscalización y el tercero con el control estricto de los abusos de los poderosos en Puebla. Tanto los clérigos, funcionarios de alto y medios niveles, así como los principales empresarios en la producción distribución de granos y cerdos y sus derivados, evadieron el pago de alcabalas o inclusive extrajeron dineros de la bolsa destinada al rey.

Fueron esos los motivos por los que el nuevo responsable Real de las alcabalas, con un prestigio sólido en la administración de la Hacienda pública y de confianza para la élite política del reino español.

Dentro de esta estrategia se decidió implantar nuevas garitas, una de ellas fue la de Amatlán que se encontraba sobre el eje que actualmente es la Calle 11 Sur en su intersección con los ríos Atoyac y San Francisco y más tarde, en 1724, se ubicó en la misma calle, pero ahora más cercana a la traza urbana de la ciudad; todavía se puede observar en ruinas frente al Panteón municipal, esto es, en la Calle 11 Sur y 37 Poniente.

La Garita de Amatlan tiene un papel estratégico prioritario pues, como mencionan el expediente de 1698 del AGl, ya citado con anterioridad, porque se requería para el paso de productos de los molinos de harina provenientes de los molinos ubicados en las riveras cercanas, pero también de las mercancías que venían de Filipinas- Acapulco- La Cuenca del Balsas- Puebla "en tiempo de naos"2" y esa ruta accedía a la ciudad por el camino donde se ubicaron las 2 garitas de Amatlán.

Es por ese motivo que realizamos el ejercicio de identificación de las rutas en mar y tierra que se muestran a continuación.

2. Cuando mencionan "tiempo de naos" significa que había uno o dos viajes al año entre Acapulco- Fiipinas- Acapulco, pues eran los que permitían hacer viajes seguros, aprovechando las corrientes de viento que impulsaran a las naos. 


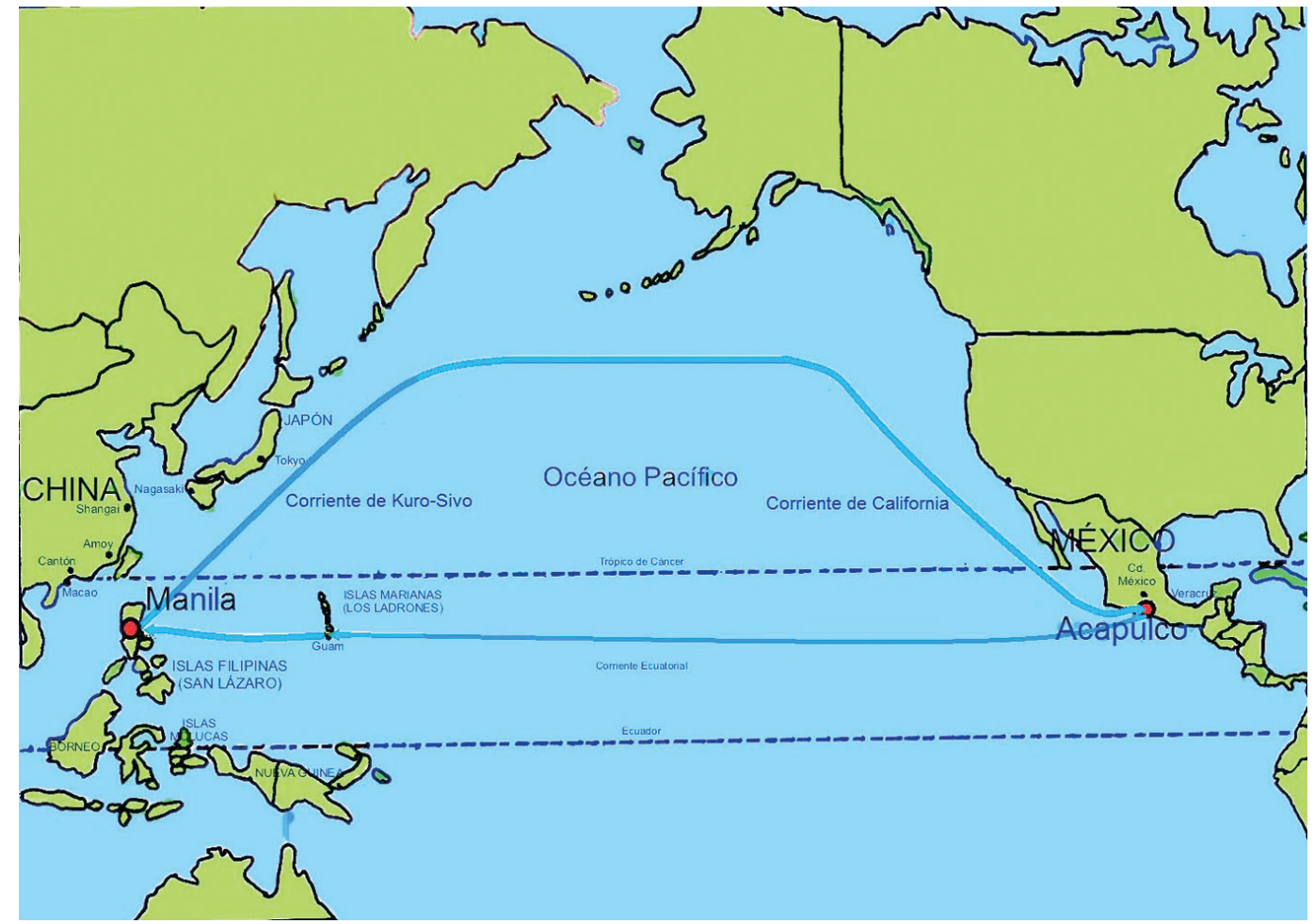

8.2. Ruta de transferencias entre Manila y Acapulco

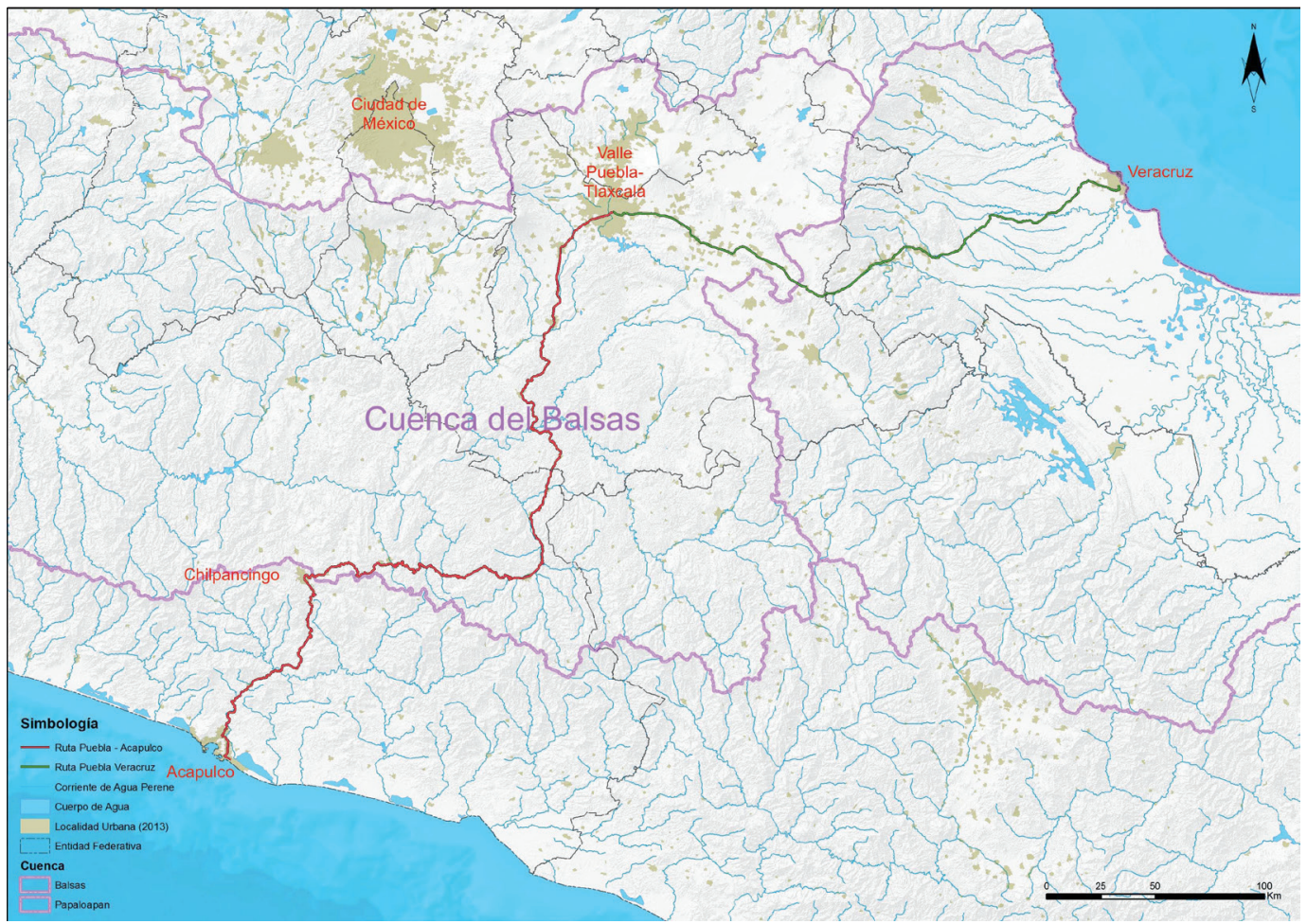

8.3. Plano que marca la Ruta Veracruz-Puebla- Acapulco. Sobretodo es fundamental señalar que el tramo entre Puebla y Acapulco fue muy recurrido para el traslado de bastimentos para la salida de la Armada de Filipinas y el traslado de mercaderías entre estos asentamientos.

La ruta Acapulco Veracruz fue la comunicación entre España y Filipinas hasta ya avanzado el siglo XVIII cuando el Imperio Español opta por la comunicación con Filipinas rodeando el Continente africano. 


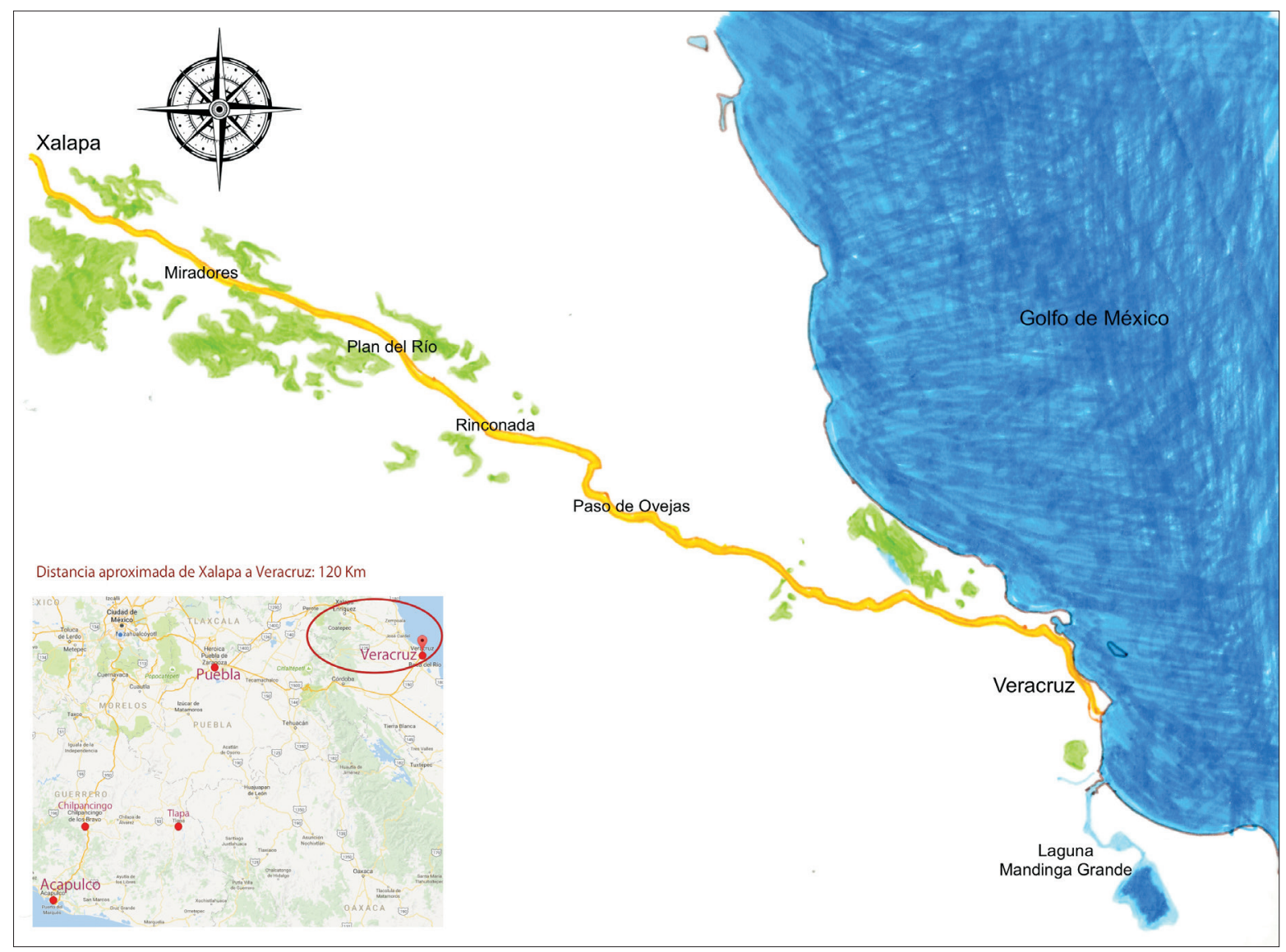

8.4. Tramo de Veracruz a Xalapa.

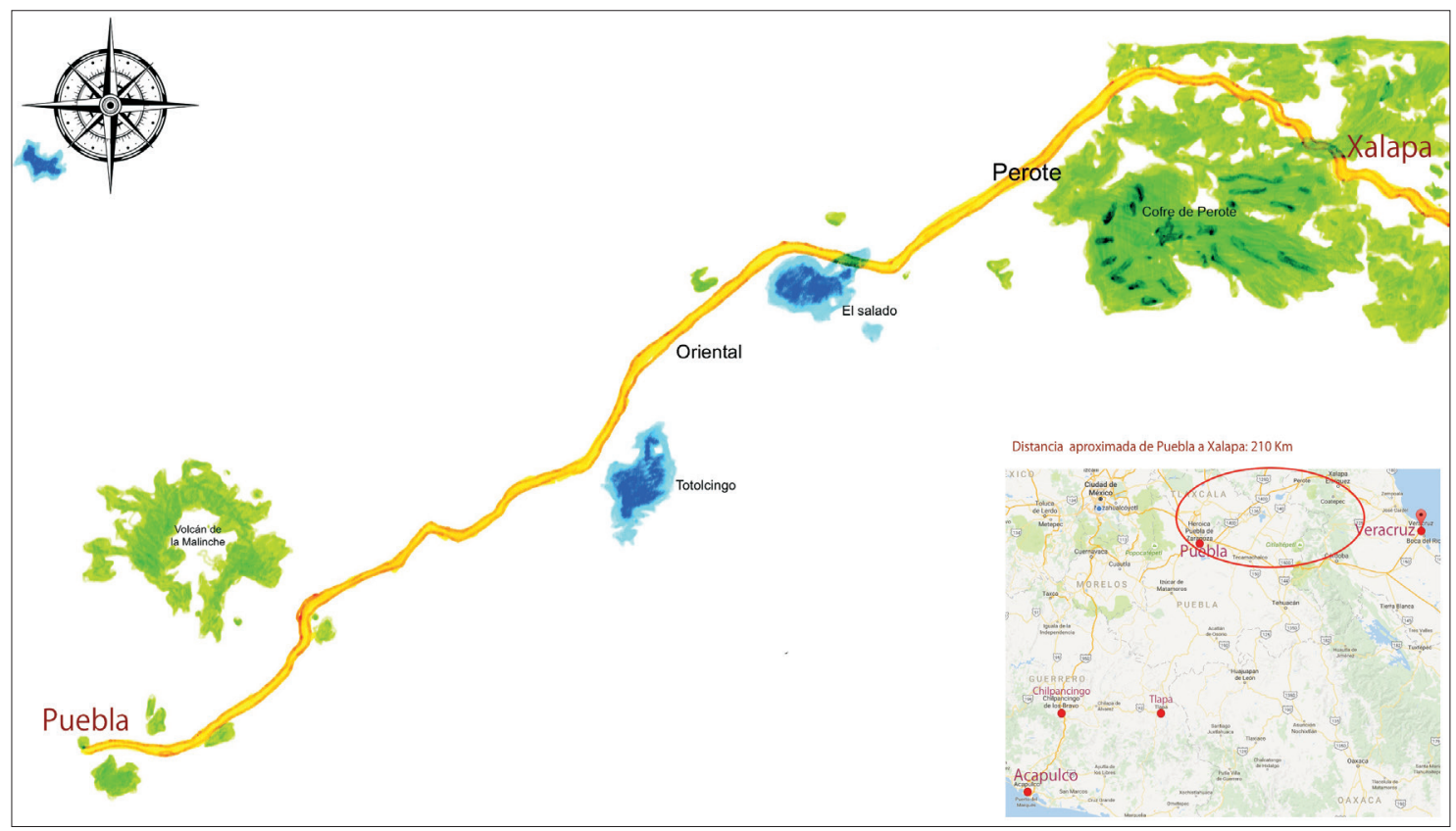

8.5. Tramo de Xalapa a Puebla. 


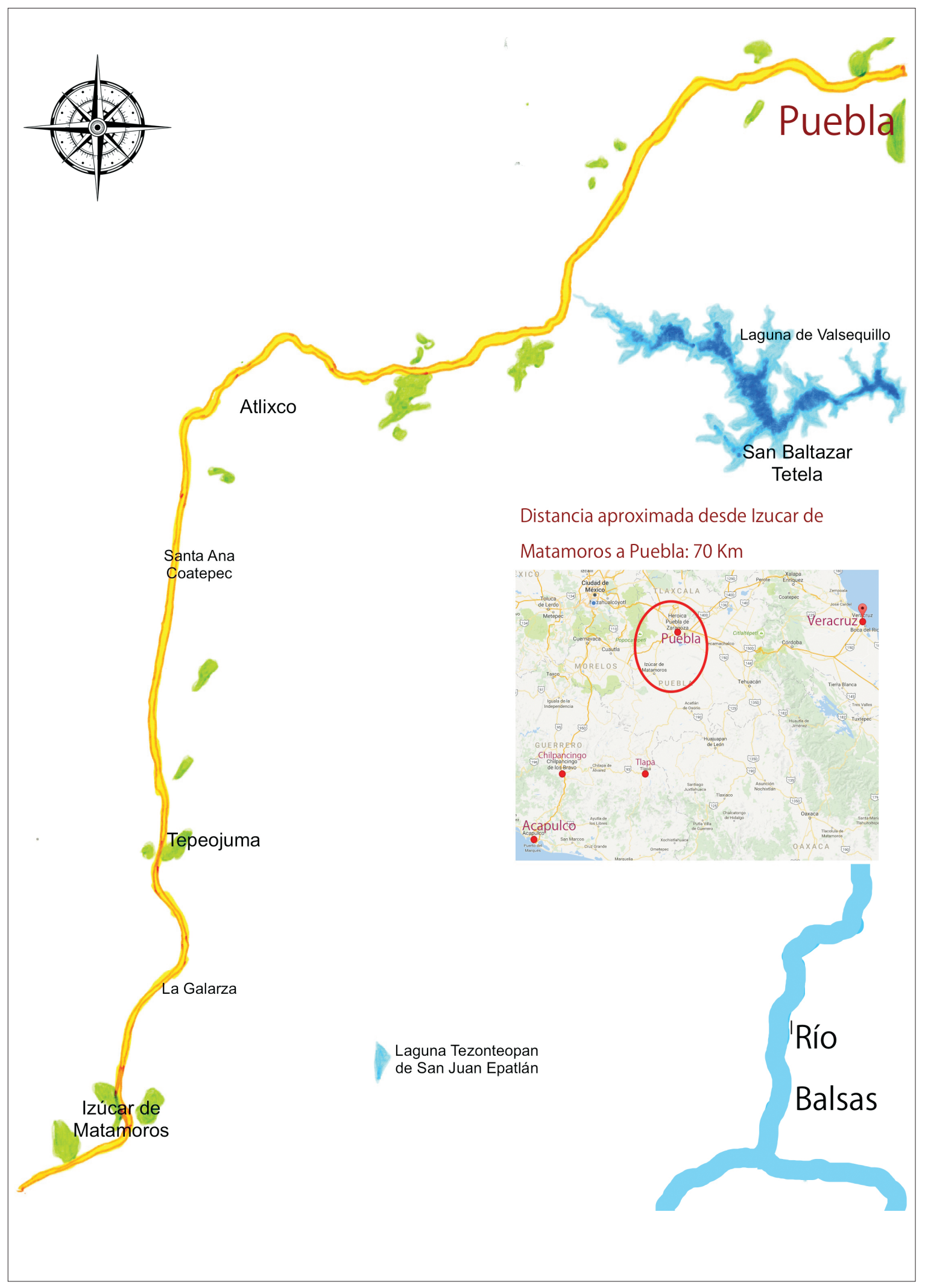

8.6. Tramo Puebla-Izucar de Matamoros. 


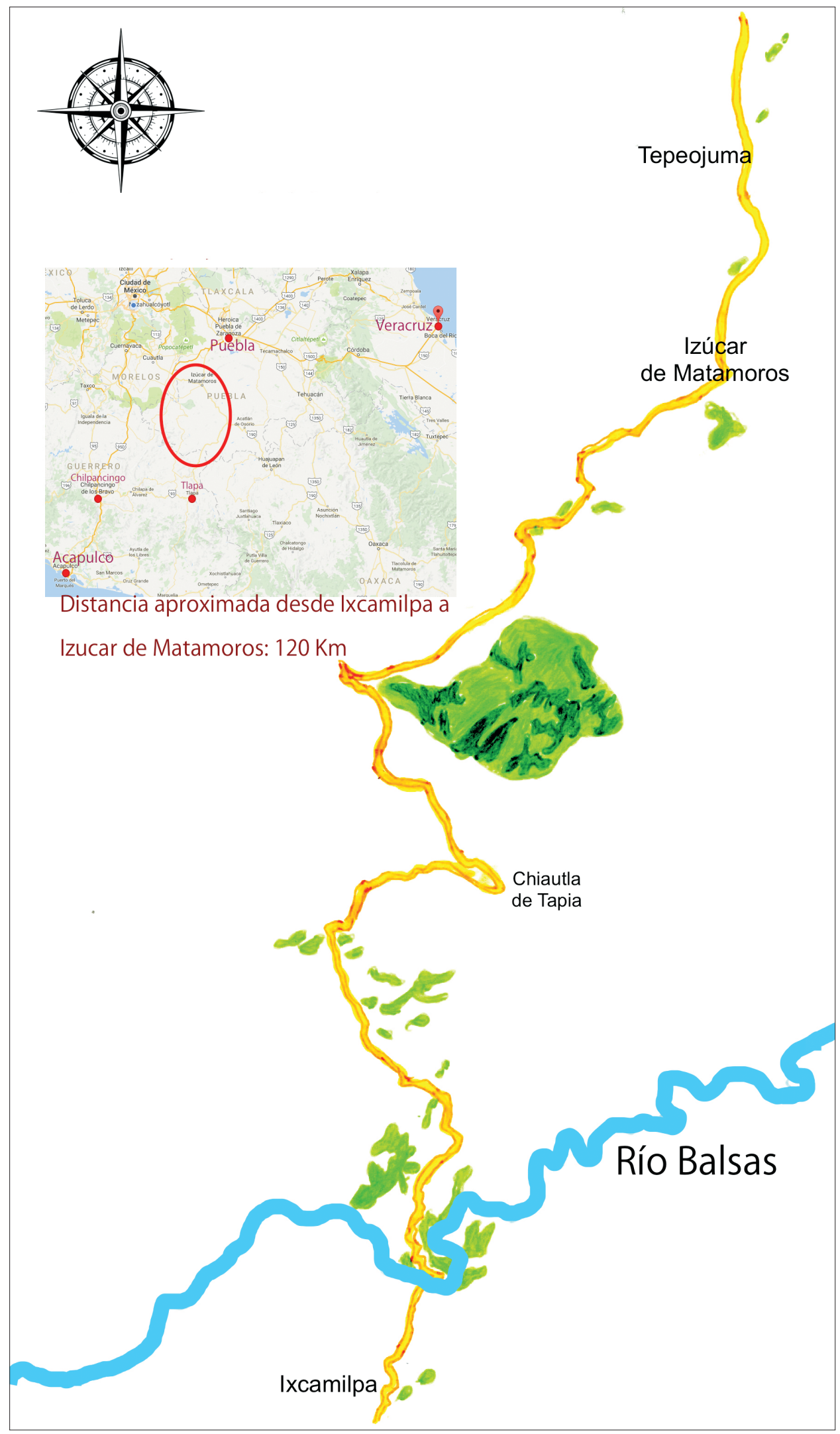

8.7. Tramo Izucar de Matamoros- Ixcamilpa. 


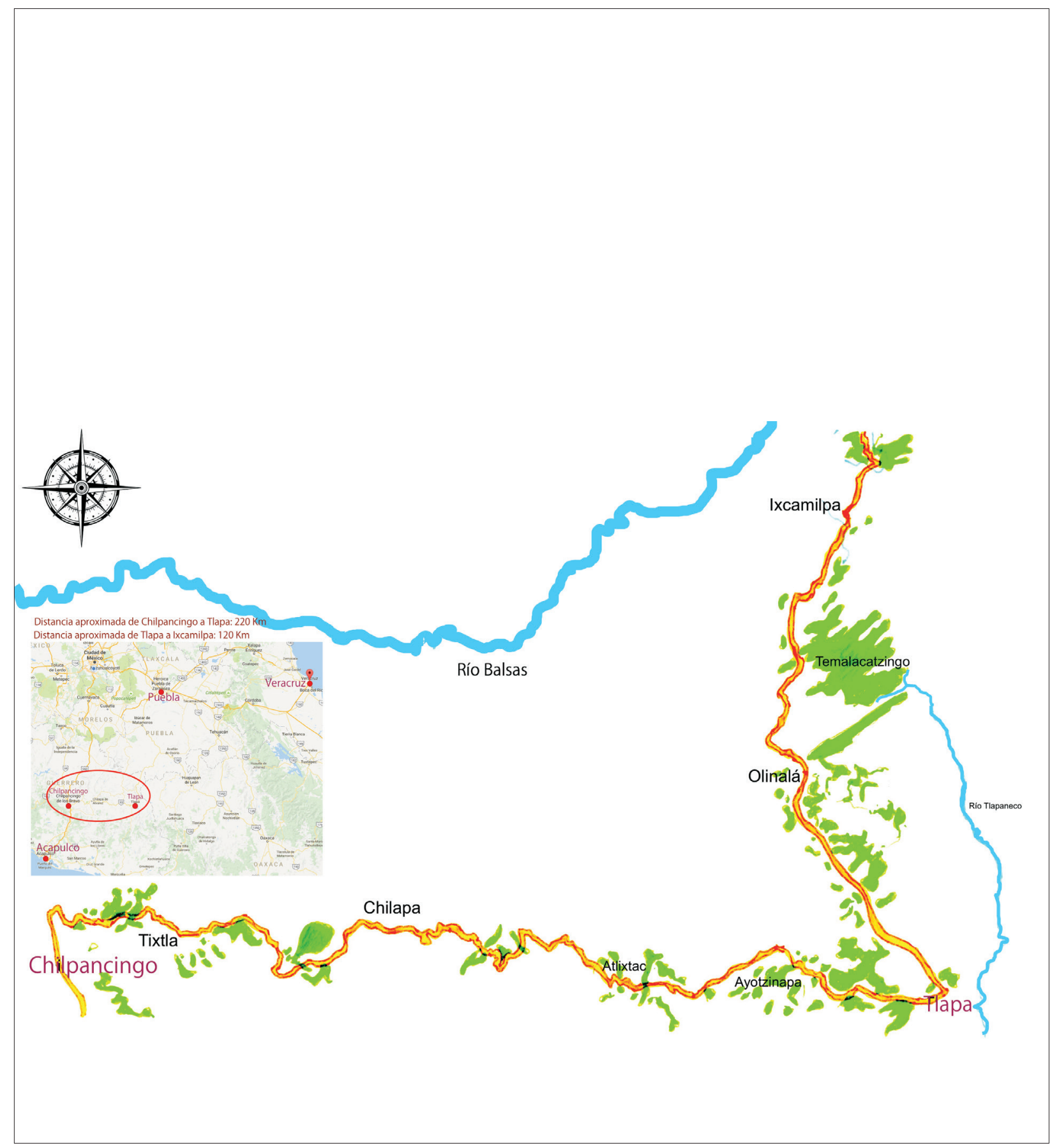

8.8. Tramo Ixcamilpa-Tlapa-Chilpancingo 


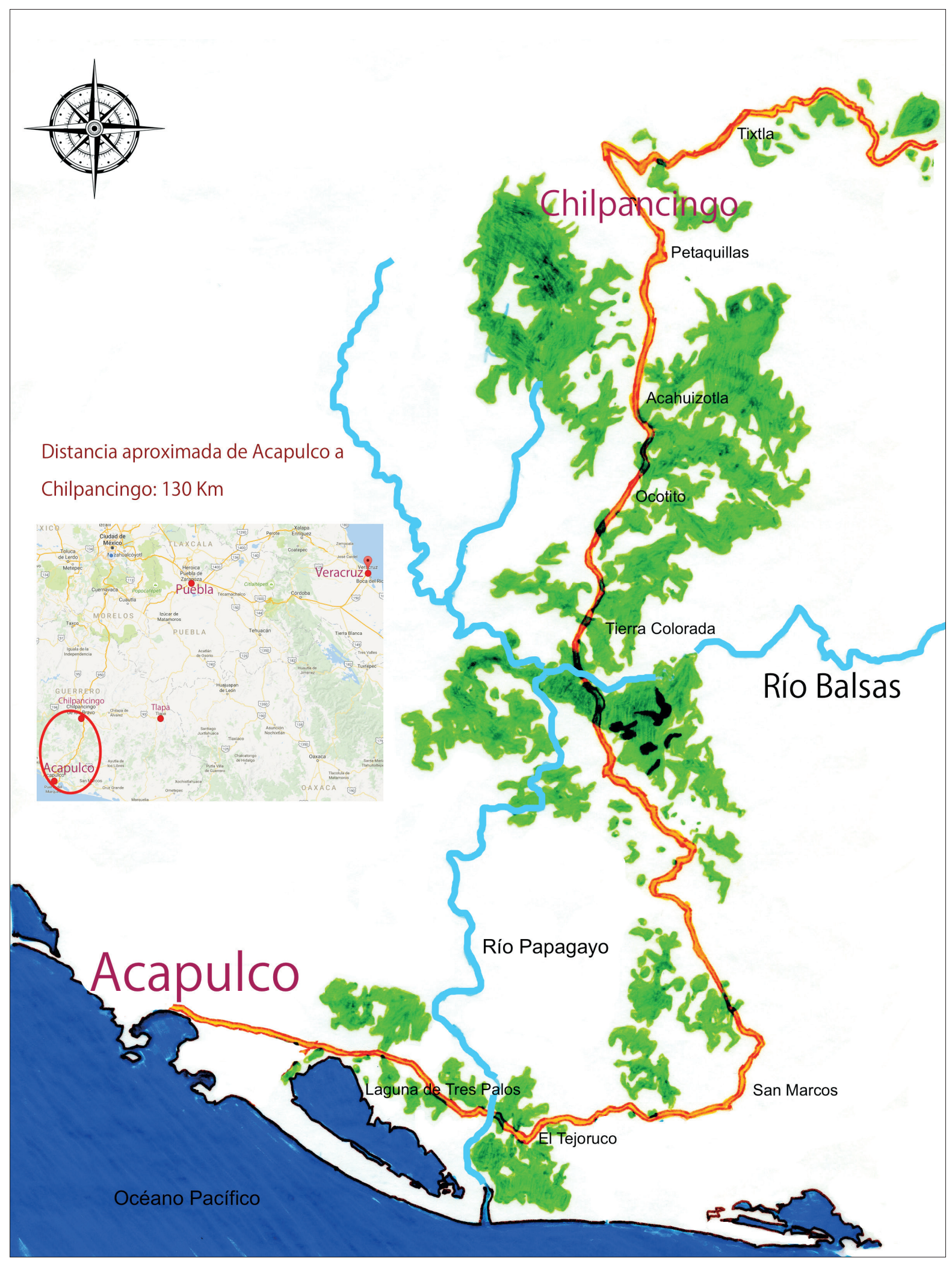

8.9. Tramo Chilpancingo-Acapulco. 


\section{CONCLUSION DEL CAPÍTULO}

Desde el nivel global de estrategia militar en los recorridos de ultramar y la selección de puertos y lugares mejor fortificados como un sistema de defensa para la entrada y salida de las embarcaciones hacia ultramar o dentro del Gran Caribe, así como para la edificación de fuertes y puertos de tierra, como es el caso de la ciudad de Puebla. La moderna intervención del sistema de garitas y su disposición en el territorio de la ciudad de Puebla, es sin lugar a dudas, parte y complemento final del Gran sistema defensivo del imperio español, como adecuadamente lo define Sánchez Santiró (2012, p. 65). La ecuación guerra-fiscalidad; añadimos nosotros: Aplicada desde el sistema global a la disposición y diseño estratégico de los inmuebles en la ciudad y, finalmente, el diseño arquitectónico de cada uno de los mismos. Aspectos que hemos demostrado en el análisis urbanístico y arquitectónico de los planos históricos estudiados.

Esquema de recaudación de bienes, servicios y alcabalas para la Corona Española, por JGA.

1. Corona española y fortificaciones de puertos en el Gran Caribe. PRINCIPALES BENEFICIARIOS.

2. Obispo de Puebla Juan de Palafox y Mendoza. RECAUDACIÓN DE BIENES Y SERVICIOS A TRAVÉS DE LA SECULARIZACIÓN LA IGLESIA DE 1640 A 1648.

3. Recaudador Juan José Veytia Linaje. RECAUDACIÓN DE ALCABALAS DE 1640 A 1648.

4. Real Hacienda + José Veytia Linaje (alcalde mayor) para una gestión y administración estructurada RECAUDACIÓN FISCAL MODERNA A PARTIR DE 1698.

5. Grandes capitales e intereses de comerciantes, clero y funcionarios afectaron la bolsa real. CONFLICTOS, ACUERDOS Y SOLUCIONES AL CONTRABANDO Y LA EVASIÓN DE IMPUESTOS DESDE 1698. 


\section{Conclusiones}

\section{LA CIUDAD DE PUEBLA EN EL CONTEXTO MUNDIAL}

Antes de la implantación de muchas de las garitas en las principales ciudades de la Nueva España, se realizaron en Puebla una serie de hechos que dieron como resultado un mayor control económico de los bienes y del tránsito de las mercaderías, se realizó una ciudad de carácter mundial en los flujos de ida y vuelta hacia Filipinas en el Pacífico, de México a diversas ciudades y puertos del Gran Caribe; y hacia Europa. El año de 1698 es el parteaguas, de este fenómeno dan cuenta:

La inclusión de la ciudad y el amplio territorio de la Puebla dentro de las alcabalas reales, esto es, que Puebla iba a depender directamente de la Corona Real sin el intermedio de las autoridades virreinales en todo lo que se refiere a la recaudación de impuestos y su distribución hacia Europa, el Gran Caribe y Filipinas.

Tiene una enorme producción de trigo, 14 molinos del mismo cereal y una dilatada producción de toneladas de biscocho o pan ázimo destinado al consumo de los marinos que partían a ultramar por el Seno mexicano y el litoral del Pacífico. Fue sustancial la participación de la ciudad de Puebla, porque surtía de pan y otras miniestras: manteca, tocino y maiz, a la Armada de Barlovento en el Golfo de México y a la Armada de Filipinas en el Pacífico. Fenómeno relevante por la enorme cantidad de tocinerías y panaderías, así como la producción mayúscula de maíz, que sólo pudo ser explicable por la enorme cantidad de bastimentos que requerían las Armadas en los principales puertos, dotación, que por otro lado requirió el trayecto entre 300 y 600 km, a uno y otro puerto de mar, con recuas de mulas para llevar los víveres en la larga travesía a ultramar. 
El auge de las rutas entre la ciudad de Puebla y los principales destinos: Veracruz, Ciudad de México y Acapulco inicia hacia 1640 y hasta 1649 con la llegada de Juan de Palafox y Mendoza como obispo de Puebla y breve virrey de la Nueva España, para apropiarse, en principio, de las rentas percibidas por la orden de los franciscanos y jesuitas en el Obispado de Puebla, con la expectativa de la secularización de la iglesia de la Nueva España para la mayor recaudación bienes para la Corona. En los años 1690 va a iniciar un gran aumento de la recaudación con las políticas reales que imponen un sistema de gestión, defensa y ofensiva militar desde lo global hasta lo local, en el período de finales del siglo XVII hasta 1740. La ciudad de Puebla con el respaldo Real y su dependencia directa fue una metrópoli central en los flujos de bienes, servicios y metales preciosos. Los principales destinos comerciales de Puebla fueron, el Puerto de Veracruz-Gran Caribe-Europa, Ciudad de México, Acapulco-Islas Filipinas-Asia y, las otras rutas provenientes de otros puntos cardinales del territorio novohispano. Puebla formó parte de los suministros económicos de la Nueva España cercanos al 50\% para la guerra hacia una gran parte del Gran Caribe y de las Filipinas.

El carácter global que ocupó la ciudad de Puebla en el primer cuarto del siglo XVIII es indudable, también transformó y consolidó elementos de urbanización en la ciudad como en las rutas y pueblos de paso de mercancías y personas que marcaron y dejaron improntas edificatorias, étnicas y culturales que perduran hasta la actualidad.

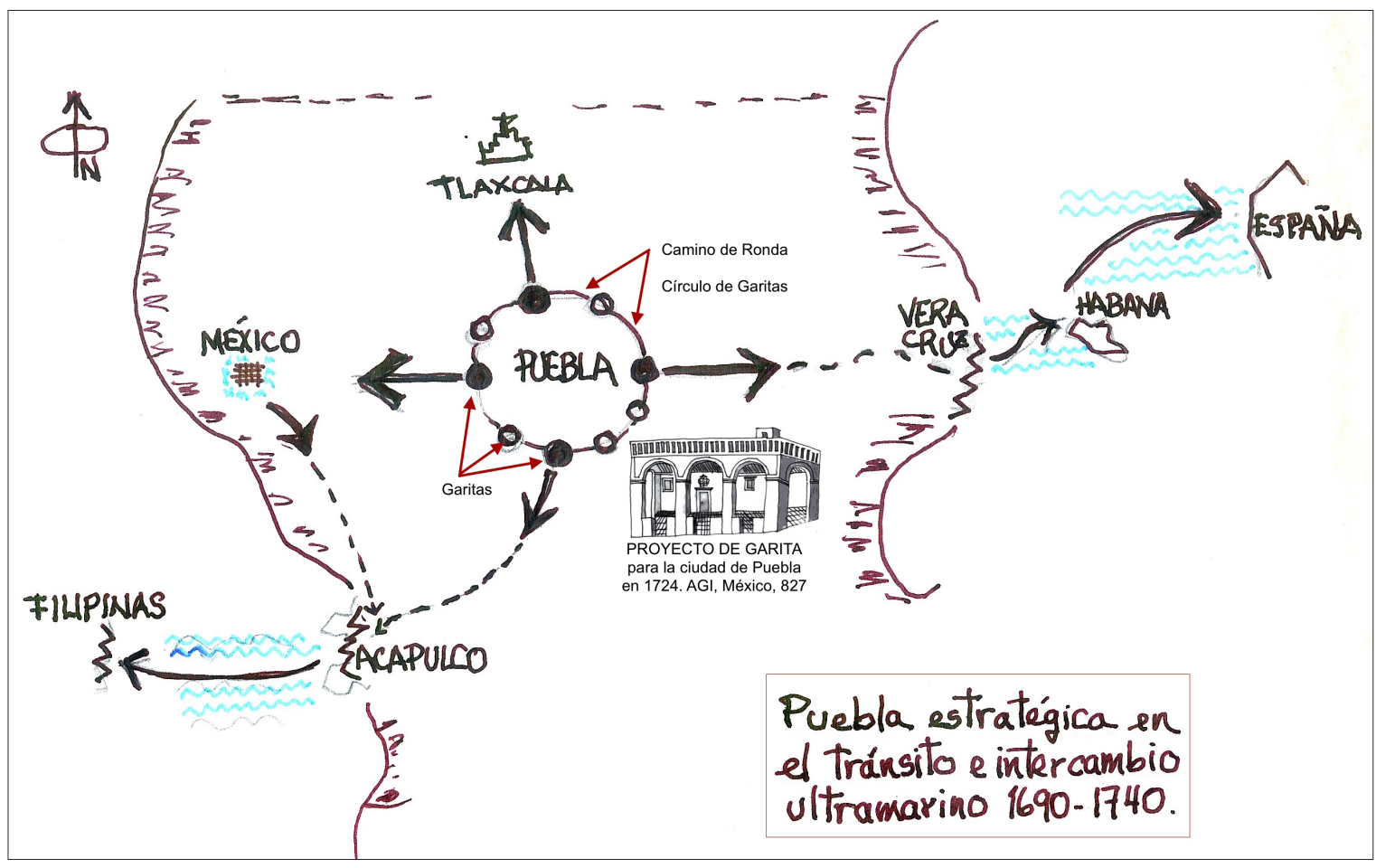

Bosquejo que manifiesta el riguroso control estratégico de lo global a lo local, la ciudad de Puebla, con su Círculo de Garitas y edificios respectivos. Todos formando parte de la política imperial de defensa y fiscalización del territorio 


\section{LOS HALLAZGOS SOBRE LA CIUDAD DE PUEBLA}

Cada uno de los planos históricos de la ciudad de Puebla que seleccionamos fueron realizados con técnicas de representación diversas y contenidos de información particulares. Tales características plantearon retos para la lectura estructurada y ordenada, sin embargo, los temas principales de análisis fueron aquellos relacionados con la urbanización y los edificios generados por el comercio, la fiscalización y la seguridad, defensa y control de la ciudad. Es allí donde encontramos nuevos conocimientos o lecturas de la ciudad histórica que permanecen o han dejado huella en la actual Puebla de Zaragoza:

El proyecto de La Ciudad de Los Ángeles establecido por la Segunda Audiencia de la Nueva España y el Obispo de Tlaxcala mantiene un carácter que podría denominarse "progresista" porque mantiene los preceptos de la utopía de una ciudad renacentista abierta, higiénica por la amplitud de sus calles, la ventilación y el asoleamiento adecuado; ciudad abierta porque no tenía obstáculos que impidieran el paso libre de la comunidad que allí habitaba y de sus visitantes. Pero, sobretodo, porque era elemental, mantener el pacto de alianza entre ibéricos e indígenas tlaxcaltecas en la política, la economía y las prebendas de los poderosos aliados, quienes fueron los que asignaron el lugar para la fundación de La Ciudad de Los Ángeles. Más adelante, desde mediados del siglo XVII comienza la pugna por mayores beneficios económicos para la Corona; en 1698, inicia un proceso de fiscalización de mercaderías mas eficiente para la recaudación Real ${ }_{1}$. Las manifestaciones en la forma y disposición de los nuevos elementos urbanos van imponiendo artificios edificatorios que regulan, controlan, imponen un pago o impiden el paso libre de bienes y personas por la ciudad.

A partir de la Fundación de la Real Aduana de la Ciudad de Los Ángeles, evento aunado a la autorización Real para que corriere la entrada de los géneros de la Nao de Filipinas en el año de 1698 dará como resultado un sistema de garitas y construcción de caminos entre ellas, formando un círculo alrededor de la ciudad que serviría para la vigía constante de mercancías y personas.

Los primeros tres planos analizados sobre la ciudad de Puebla: el de 1698, el de 1700 y el de 1724 dan cuenta, entre otras cosas, de la rápida y profunda intención por el resguardo de la ciudad establecido en principio con un sistema preliminar de edificios

1. Alrededor de 1575 se dictan desde la Corona, en particular el rey Felipe II, las ordenanzas para la recaudación de impuestos a través del cobro por el trasiego de mercancías. A mediados del siglo XVII inicia la secularización de la iglesia con grandes beneficios económicos. A finales del XVII se impone un sistema fiscal más elaborado y eficiente. 
de Guardas y Garitas antes del año de $1698^{2}$, año en que se define y comienza la construcción de un "círculo de garitas", evento que se comprueba en el Plano de 1700; 24 años después, apreciamos en el plano de 1724 otro círculo de garitas más cercano a la mancha urbana de la ciudad como proyecto para realizar en el futuro inmediato y tener un mejor control de la fiscalización.

La ciudad de Puebla en el período del siglo XVI al XIX se forma y consolida a partir de un complejo de relaciones. El medio geográfico y su apropiación para la satisfacción de las necesidades de la población. La orografía y los cuerpos de agua como parte de la defensa de la ciudad. La preexistencia de caminos y rutas que pasaban por el sitio de la nueva ciudad.

La primera fundación cuyo edificio emblemático es el convento de San Francisco y el castro franciscano en su entorno. Un diseño eminentemente defensivo. Después, la edificación del ensanche de la ciudad, con manzanas rectangulares. Aquí señalamos que la llamada "segunda fundación" de la ciudad fue trazada de una sola vez con 12 x 24 manzanas rectangulares y el resto acomodadas a la ruta sinuosa del río San Francisco y las pendientes más pronunciadas provenientes de los cerros de Belem y de Loreto. Desde luego el conjunto de manzanas no fue ocupado en su totalidad por edificios, sino poco a poco; en tanto, fueron manzanas dedicadas al cultivo agrícola.

Las rutas de los caminos preexistentes fueron importantes en el trazado de ciudad con ejes de composición en forma de bayoneta, de oriente a poniente y de norte a sur. Las rutas hacia los destinos principales se siguieron conservando en el período virreinal. También la utilización del trazado reticular como espacio flexible en la movilidad de personas, bienes y servicios. Los corredores o calles primarias aglutinan casi la totalidad de plazas y edificios emblemáticos. Los puentes sobre los ríos funcionaron como elementos de conexión, control y defensa de la ciudad.

La orientación geográfica de la ciudad proveniente de las orientaciones de los terrenos agrícolas para su mayor productividad fueron usados en gran parte de mesoamerica por la sociedad agrícola prehispánica; para el caso del trazo de La Ciudad de Los Ángeles mantiene la desviación azimutal de $17^{\circ}$. Esta desviación geométrica está relacionada con la latitud del lugar de fundación y trazo de terrenos de cultivo y un mejor aprovechamiento del movimiento solar para la producción agrícola; asimismo la mayoría de los centros ceremoniales prehispánicos la mantienen.

2. De acuerdo con el expediente AGI, México 341. 
La ciudad reticular a base de cuadros en la "primera fundación" franciscana entre los ríos San Francisco, Xonaca y los cerros de Belem y Loreto. Trazos a la manera de los franciscanos. provienen de raíces bíblicas: judeocristianas o romanas, sin embargo, todas coinciden con el trazo reticular de castro o campamento militar para la defensa del recinto urbano o sagrado de una ciudad. El caso de San Francisco en Puebla, además de su trazado reticular, está custodiado por los dos ríos de gran caudal y los promontorios antes señalados; es la modalidad defensiva de los "pueblos de indios" desde antes del contacto europeo.

La gran transformación de La Ciudad de Los Ángeles de una ciudad abierta, sin bordes urbanos que no fueran la propia traza, a una ciudad delimitada por un "círculo de garitas" y los caminos de ronda que las unen para la protección, la he definido como fortificación virtual porque no existe ninguna muralla alrededor de la ciudad, sin embargo hay una delimitación o demarcación precisa, establecida por las nueve garitas proyectadas en 1697, construidas en 1698, transformadas en 1700 y 1724. En todos esos años se realizaron los caminos que unieron cada una de las garitas con sus dos vecinas cercanas, una a la derecha y la otra a la izquierda, esos caminos fueron caminos de ronda. Los caminos de ronda fueron construidos para el tránsito de los guardias durante el día y la noche. En ese sentido la lectura urbana que realizamos contiene todos los elementos para proteger la ciudad y sometimiento al control fiscal.

Los resultados confirman que los planos de 1698, 1700 y 1724 corresponden al período más intenso de transformación en la recaudación hacendaría de la ciudad y también del virreinato en su conjunto, formaron parte de las regulaciones y las políticas predecesoras de las reformas borbónicas aplicadas en el último cuarto del siglo XVIII. El plano de 1862 es un plano militar que, asociado a la confrontación del 5 de mayo del mismo año entre las tropas mexicanas y francesas, da cuenta, entre otros factores, del lugar estratégico que ocupa la ciudad en la geografía inmediata: ríos, puentes, caminos y cerros, que fueron un factor determinante en el éxito mexicano en la batalla con el ejército más poderoso del mundo. Algunas de las garitas fueron usadas también como lugares defensivos en las batallas contra los franceses, por su ubicación en el intersticio de los caminos de acceso a la ciudad. El plano, también registra que la ciudad y sus edificios se enmarcan y no rebasan el círculo de garitas que persistía hasta 1862, 40 años después de la independencia consolidada de México. Fue un borde o perímetro de la ciudad o intramuros de larga duración por un período aproximado de 200 años. 


\section{MÉTODO PARA LECTURA URBANA DE PLANOS HISTÓRICOS DE MÉXICO}

Con relación con las transformaciones urbanísticas de la ciudad intra y extramuros, considerando el círculo de garitas como la "muralla virtual" de la ciudad. Esta ciudad, tema de nuestra tesis, experimenta un nuevo período morfológico que reconocimos a través de tres planos históricos de suma importancia y enorme calidad estética: 1698, 1700 y 1724 . Decidimos elaborar un método que nos permitió desentrañar lo que denominamos lectura urbana o urbanística de cada uno de los documentos planimétricos citados.

Es un método que iniciamos en el año de 1985 como parte del Seminario de escritura indígena tradicional azteca-náhuatl dirigido por Joaquín Galarza en el Centro de Investigaciones y Estudios Superiores en Antropología Social. Realizamos con ese método las tesis de grado y de maestría en arquitectura y ahora, con mayor profundidad, en el estudio de los planos históricos de la ciudad de Puebla.

Cada uno de los planos históricos de la ciudad de Puebla que seleccionamos fueron realizados con técnicas de representación diversas y contenidos de información particulares. Tales características plantearon retos para la lectura estructurada y ordenada, sin embargo, los temas principales de análisis fueron aquellos relacionados con la urbanización y los edificios generados por el comercio, la fiscalización y la seguridad, defensa y control de la ciudad. Es allí donde encontramos nuevos conocimientos o lecturas de la ciudad histórica que permanecen en la actual Puebla de Zaragoza:

El método inicia con la observación, la identificación de temas que se pueden trabajar en el plano histórico, esto es, la taxonomía o clasificación de los elementos que constituyen la ciudad representada en el plano histórico. Nos permitió formular, si el plano histórico lo permite, que deberá contener al menos, diez temas urbano-arquitectónicos:

- La topografía y la orografía. Es el continente geográfico del pueblo o ciudad que se comience a leer y va a condicionar la traza y la morfología de la ciudad.

- La hidrografía, que son los cuerpos de agua que describe el plano, o bien que se pueden inferir a partir de la información topográfica u ortográfica. Nos permite también apreciar la implantación de la ciudad en relación con la hidrografía y la topografía,

- Los caminos o rutas a la ciudad. Los caminos y las rutas representan la complejidad de la ciudad, pues dispone su relación con otros asentamientos humanos cercanos y lejanos. para todo tipo de intercambios; una ciudad que tiene más rutas y caminos de destino es también una ciudad más compleja. 
- Las calles y las plazas. Que permiten el tránsito y remanso de personas, carruajes, bestias y mercaderías para el comercio, el trabajo, la convivencia, el esparcimiento, los rituales y la fiesta. Son también los elementos esenciales para valorar la funcionalidad, la estética y la cultura urbanística del lugar irrepetible y único.

- La morfología de manzanas, que junto con las calles definen el trazado y las fachadas de los edificios, también las formas preconcebidas para las manzanas o bien, su ajuste a las pendientes, cuerpos de agua o accidentes en el espacio físico.

- La morfología de manzanas + lotes o parcelas. En la cultura europea es predominante que las manzanas sean el contenedor de varios lotes, no así para algunas ciudades mexicanas prehispánicas (p.e. el plano en papel maguey de la Ciudad de México), en las que hay un trazado reticular homogéneo pero cada parcela es aislada y forma una unidad habitacional. La morfología dominante en las ciudades de la Nueva España van a ser trazadas con los patrones europeos aunque mixturadas con persistencias y patrones urbanísticos oriundos del territorio conquistado.

- La morfología de manzanas + parcelas + edificios. La implantación de los edificios en las parcelas dan unidad, consistencia y seguridad a sus moradores La mayoría de los edificios se construyen al borde de la acera, formando una banda continua de fachadas a la calle, también con alturas homogéneas.

- Los usos del suelo. Generalmente vienen expresados los principales usos del suelo, ya sea en cuadros con números, letras, iconos o gráficos. También el propio plano es un texto que a través de líneas, puntos y colores nos está representando algunos de los usos del suelo, o en ocasiones con letreros sobre el plano. El estudioso del territorio y del espacio físico de la ciudad y su entorno puede identificar ciertos usos del suelo y clasificarlos para realizar una parte muy importante de la lectura urbanística del plano histórico.

- Los edificios religiosos. Fueron los artificios urbano-arquitectónicos iniciales para la conquista física y espiritual, pero también en el nuevo orden del virreinato, muchas de ellas fueron sede de la impartición de justicia, pero también una atribución a la iglesia como institución de Estado. La mayoría de los edificios religiosos están en ubicaciones importantes para la viga, el comercio, junto a plazas públicas y formando entre sí corredores urbanos que las relacionan físicamente. Fueron lugares rituales, de defensa, de justicia, de actividad económica y, en algunos casos de hospitales y orfanato.

- Los lugares, barrios y edificios emblemáticos. En muchas de las ciudades mexicanas hubo elementos geográficos emblemáticos, como montañas, cerros, cuevas, cuerpos de agua; también edificios o recintos sagrados y, en algunos 
casos, barrios o pequeños asentamientos en los alrededores de la ciudad "central" o "consolidada". Son emblemáticos porque son referentes para el trazado original de la ciudad o más tarde, ya instalada, adquieren esa condición en un nuevo periodo morfológico de la misma. Como emblemas de la ciudad está relacionada con tres aspectos fundamentales: la defensa del sitio, los caminos y las rutas y la sacralización del espacio físico. Son emblemas compartidos o propios de las culturas que allí estuvieron presentes, por lo que su mezcla convulsiva o dócil marca lo que Christian Norberg-Shulz denomina el genius loci o el espíritu del lugar, la habitabilidad del lugar desde la vivienda a los caminos, el paisaje en sus diversas acepciones y los artificios urbanos para la satisfacción de las necesidades humanas en una determinada época o período morfológico.

Observamos la importancia prioritaria que tienen estas fuentes de información cartográfica e histórica para el estudio y conocimiento más profundo de la ciudad y para la implantación de políticas para la conservación amplia, integral y razonada en beneficio de la sociedad.

El análisis del Plano de 1698 es mi mejor aportación. Permite la comprensión de la morfogénesis (el origen de la forma urbana), de la ciudad de Puebla, sus transformaciones y los motivos por los que ocurrieron; en particular, resaltando las garitas y su disposición defensiva y fiscal, asociada a las rutas con destinos de la micro-región y la región del imperio.

El método aplicado se ha validado y su eficiencia incorpora los conceptos de análisis aplicados por Jorge GAC a un corpus de planos históricos mexicanos: 1 plano parcial de la Ciudad de México con pictografía azteca (1988-1992), 33 planos de casas de la Ciudad de México con pictografía azteca (1985-1994), 1 plano de la ciudad de Tlaxcala (2014-2015), 2 planos de la Ciudad de Los Ángeles del siglo xVII 2010-2017), 1 plano de la ciudad de Puebla del siglo XVIII (2010-2017), 1 plano de la ciudad de Puebla del siglo xIX (2010-2017). Algunos han sido publicados, otros presentados en congresos internacionales y seminarios nacionales.

También la lectura urbanística a través de la dirección de 1 tesis de maestría de Marisol Gutiérrez e Iván Sanchez sobre Miahuatlan, Veracruz en Conservación y Restauración de Bienes Culturales Inmuebles, ENCRyM, INAH (2012-2015). Otra tesis de maestría de Misael Chavez sobre Tlaxiaco, Oaxaca en Ciencias y Artes para el Diseño, UAM-X (2014-2016). De servicio social he estimulado a los alumnos a que estudien planos históricos de su lugar de origen o bien de aquel que consideren de su interés personal; así, hemos trabajado: a. Lectura urbana de 1 plano de la ciudad de Oaxaca del siglo 
XIX por dos estudiantes de servicio social (2015), Lectura urbana del códice de Yuririapundaro, hoy Yuriria, Guanajuato del siglo XVI, por Jessica Rojas, estudiante de servicio social (2015-2017), En la docencia, he realizado ejercicios de lectura urbanística de planos históricos de las ciudades de Veracruz, Pachuca, Tlaxcala y Toluca, en el Taller de Planeación de la Carrera de Planeación Territorial de la Universidad Autónoma Metropolitana (2008-2017).

Las conclusiones son el resultado de una investigación de largo aliento que culmina en esta tesis de doctorado. Mis primeras publicaciones científicas fueron en 1989 usando un método para la lectura arquitectónica de 15 planos de tradición azteca del siglo XVI. En la presente, el método que utilicé está estructurado para la lectura urbanística de planos con predominio de pictografía europea renacentista: es una aplicación a otro tipo de planos y cortes de tiempo de la antigua Ciudad de Los Ángeles.

La reciente publicación El territorio y sus representaciones. Lecturas filosóficas, geográficas y urbanísticas de Luis Ignacio Sáinz y Jorge González Aragón, 2015, UAM da cuenta también del método, sus aplicaciones y los hallazgos en cinco ciudades mexicanas. Publicación que fue reconocida con el Premio UAM 2016 a la mejor investigación publicada en el año anterior del área Ciencias y Artes para el Diseño.

Jorge González Aragón Castellanos Coyoacán, México, mayo 5 de 2017. 


\section{FUENTES PRIMARIAS}

Plano: Planta de la Ciudad de Los Ángeles de Nueva España

Signatario: Christobal de Guadalaxara, 1698

Archivo General de Indias: AGI, MP, México, 529

Plano: Ciudad de Los Ángeles (México)

Signatario: Antonio de Santa María Inchauztegui, 1700

Museo Naval de Madrid: X. MN-p13-3

Plano de Las Garitas de la Aduana de Puebla de Los Ángeles

Signatarios: Juan José de Veitia y José Joaquín de Uribe y Castrejón, 1724

Archivo General de Indias: AGl, MP, México, 519

Plano: Croquis de la Ciudad de Puebla y sus alrededores

Inédito, 1862, Archivo Municipal de Puebla

LEGAJO: MÉXICO, 341, AGI. Simancas/ Secular / Audiencia de Mejico. Expedientes relativos a la administración de alcabalas de la Puebla de Los Ángeles, año de 1698. LEGAJO: MÉXICO, 827, AGI. Testimonio del año de 1724 de los autos y providencias dadas por el juez administrador de las reales alcabalas de esta ciudad y jurisdicciones de su agregación.sobre la nueva situación de las garitas de esta la aduana por hallarse las antiguas fabricadas en parajes muy distantes e incómodos. 


\section{BIBLIOGRAFÍA}

ALFARO Ramirez, G. R. (2004). La crisis política de la Puebla de los Ángeles. Autoritarismo y oligarquía en el gobierno de Don Juan José de Veytia y Linaje, 16971722. Relaciones: Estudios de Historia Y Sociedad (Zamora). 25, 213-256.

ALBI Romero, Guadalupe (2000). La Sociedad de Puebla de los Ángeles (1965)", en Contreras C., Carlos y Miguel Ángel Cuenya. Ángeles y constructores, México, BUAP-CONACyT-H. Ayuntamiento de Puebla, pp. 127-206.

ALVES Carrara Angelo y Ernesto Sánchez Santiró, Coords. (2012) Guerra y fiscalidad en la Iberoamérica colonial (siglos XVII-XIX), México, Editora UFJF.

ARCHIVO General de la Nación (1979). Catálogo de llustraciones. Centro de Información Gráfica, México, AGN, 13 vols.

BERTRAND, Michel. (1995). La contaduría de las alcabalas de Puebla: un episodio reformador al principio del siglo XVIII. Jahrbuch Für Geschichte Von Staat, Wirtschaft Und Gesellschaft Lateinamerikas. 32, 321.

BRAUDEL, Fernand. (1953). El mediterráneo y el mundo mediterráneo en la época de Felipe II. México, Fondo de Cultura Económica.

CELAYA Nández, Yovana. (2010). Alcabalas y situados. Puebla en el sistema fiscal imperial 1638-1742. México, D. F. El Colegio de México, Fideicomiso Historia de las Américas.

CHEVALIER, Francois (2000). Significación social de la fundación de la Puebla de los Ángeles (1957), en Contreras C., Carlos y Miguel Ángel Cuenya. Ángeles y constructores, México, BUAP-CONACyT-H. Ayuntamiento de Puebla.

COLEGIO de México. (1981). Historia general de México. México, D.F., Colegio de México.

CONTRERAS Cruz, C., y Cuenya, M. A. (2000). Ángeles y constructores: mitos y realidades en la historia colonial de Puebla, siglos XVI-XVII. Puebla, Benemérita Uni- 
versidad Autónoma de Puebla, Vicerrectoría de Investigación y Estudios de Posgrado, Dirección General de Fomento Editorial.

CONTRERAS Martínez, José Eduardo, (1995) En torno al concepto de guerra florida entre tlaxcaltecas y mexicas, en Dimensión Antropológica, vol. 3, enero- abril, 1995, pp. 7-26. Disponible en: http://www.dimensionantropologica.inah.gob.mx/?p=1537.

CUENYA Mateos, Miguel Ángel, Gabriel Luna y Julio César Romero (1999). Inventario de bandos, leyes, decretos y ordenanzas del ayuntamiento de Puebla, 1531 1910, México, BUAP-CONACyT-H. Ayuntamiento de Puebla.

DE LA TORRE Villalpando, Guadalupe (1999). Los muros de agua. El resguardo de la Ciudad de México, conaCulta, INAH, México, Consejo del Centro Histórico de la Ciudad de México, 152 pp.

DYCKERHOFF, Ursula (1988). La Época Prehispánica. En Milpa y Hacienda, editado por H. Prem, pp: 18-34, México, Fondo de Cultura Económica.

FERNÁNDEZ, Miguel Ángel (1988) La Nao de China, Monterrey, México, Grupo Vitro.

GALARZA, Joaquín y Keiko Yoneda. (1979). Mapa de Cuauhtinchan no. 3. MéxiCo, Archivo General de la Nación.

GALARZA, Joaquín. (1980). Estudios de escritura indígena tradicional (azteca-nahuatl). México, Archivo General de la Nación.

GALARZA, Joaquín. (1992). In amoxtli, in tlacatl. El libro, el hombre: códices y vivencias. México, Editorial TAVA.

GALARZA, Joaquín \& Becquelin, A. M. (1980). Doctrina christiana: méthode pour I'analyse d'un manuscrit pictographique mexicain du 18 e siècle avec application à la première prière: le Pater Noster. Paris, Soc. d Ethnographie.

GANTES Tréllez, M. (1983). Aspectos socio económicos de Puebla de los Ángeles: 1624 1650. México, UAP.

GARAVAGLIA, Juan Carlos., y Grosso, Juan Carlos. (1988). Las alcabalas novohispanas, 1776-1821. México, D.F., Archivo General de la Nación, Dirección del Archivo Histórico Central.

GLASS, John B. (1964). Catálogo de la colección de códices del Museo Nacional de Antropología. México, Museo Nacional de Antropología, Instituto Nacional de Antropología e Historia.

GONZÁLEZ Angulo, Jorge y Yolanda Terán Trillo. (1976). Planos de la Ciudad de México 1785, 1853 y 1896 con un directorio de calles con nombres antiguos y modernos. México. INAH, Departamento de investigaciones históricas, Seminario de Historia Urbana, 50 Colección científica.

GONZÁleZZ Aragón, J. (1989). Planos aztecas de la Ciudad de México. Aspectos arquitectónicos, en Galarza Joaquín y otros. Descifre de las escrituras mesoamericanas, Oxford, Great Britain, B.A.R. 
GONZÁLEZ Aragón, J. (1992). Tenochtitlan. Conjunto urbano azteca, en Federación Panamericana de Asociaciones de Arquitectos, Chile, Arquitectura Panamericana. Ciudades de América FPAA.

GONZÁLEZ Aragón, J. (1993). La urbanización indígena de la ciudad de México: el caso del Plano en papel maguey. México, D.F., Universidad Autónoma Metropolitana, Unidad Xochimilco.

GONZÁLEZ Aragón, J. (1997). Códice plano en papel maguey. México, Consejo Nacional para la Cultura y las Artes: Instituto Nacional de Antropología e Historia.

GONZÁLEZ Aragón, J., \& Cortés, J. L. (2001). Corpus urbanístico de Puebla y Oaxaca en España. Ciudad de México, Universidad Autónoma Metropolitana.

GONZÁLEZ Aragón, J. \& Cortés, J. L., (2003). Corpus urbanístico de la ciudad de México en el Archivo General de Indias. Ciudad de México, Universidad Autónoma Metropolitana.

GONZÁLEZ Aragón, J., \& Cortés, J. L. (2004). Corpus urbanístico de México en España. Ciudad de México, Universidad Autónoma Metropolitana.

GONZÁLEZ Aragón, J. (2008). Corpus urbanístico de Michoacán en los archivos españoles. México, D.F., Consejo Nacional para la Cultura y las Artes.

GONZÁLEZ Aragón, J., Carballo Cruz, Everardo. (2011). Arquitectura y urbanismo militar en Iberoamérica. Ciudad de México, Universidad Autónoma Metropolitana. Inédito.

GONZÁLEZ Aragón, J., Rodríguez Viqueira, M., \& Rodrigo Cervantes, N. E. (2009). Corpus urbanístico: fortificaciones costeras de México en los archivos españoles: arquitectura militar. Ciudad de México, Instituto Nacional de Antropología e Historia.

GONZÁLEZ Aragón, J., Sáinz, L. I., \& Rodrigo Cervantes, N. E. (2010). Corpus urbanístico de Campeche en los archivos españoles. Campeche, Gobierno del Estado de Campeche.

GONZÁLEZ Aragón, Jorge y Margarita García Cornejo (1988). México en el siglo XIX, en Covarrubias Gaitán, Francisco, La vivienda comunitaria en México, México, INFONAVIT, Pp.159-237.

GONZÁLEZ Lobo, Carlos L. A.. (2014). La traza urbana de la Ciudad de México-Tenochtitlan, en Rodrigo Cervantes, N. y otros (coords), Urbanismo y arquitectura militar en Iberoamérica. México, D. F., Universidad Autónoma Metropolitana

HIRSCHBERG, Julia (2000). La fundación de Puebla de los Ángeles. Mito y Realidad (1978), en Contreras C., Carlos y Miguel Ángel Cuenya. Ángeles y constructores, México, BUAP-CONACyT-H. Ayuntamiento de Puebla, pp. 53-89.

KIRCHHOFF, P. (1967). Mesoamérica, sus límites geográficos, composición étnica y caracteres culturales. Acta Americana 1:92-107

KIRCHHOFF, Paul; Lina Odena Güemes y Luis Reyes García. (1976). Historia Tolteca-Chichimeca. México, CISINAH, INAH-SEP 
LEICHT, Hugo (1992) [1936]. Las calles de Puebla, México, Junta de Mejoramiento Moral, Cívico y Material del Municipio de Puebla, 5a. ed, Puebla, 539 pp.

MARICHAL, Carlos. La Historiografía económica reciente sobre el México Borbónico: Los estudios del comercio y las finanzas virreinales, 1760-1820. Boletín del Instituto de Historia Argentina y Americana "Dr. E. Ravignani", Tercera Serie, núm. 2, 1er semestre de 1990, pp. 161.181.

MARICHAL, Carlos y Johanna Von Grafenstein, Coordinadores. (2012). El secreto del Imperio Español: Los situados coloniales en el siglo XVIII. México, El Colegio de México, Instituto de Investigaciones Dr. José María Luis Mora.

MARÍN-TAMAYO, Fausto (2000). La división racial en Puebla de los Ángeles bajo el régimen colonial (1960), en Contreras Cruz, Carlos y Miguel Ángel Cuenya (eds.).Ángeles y Constructores, México, BUAP-CONACyT-H. Ayuntamiento de Puebla, pp. 91-126

MARÍN-TAMAYO, Fausto (coord.) (1962) Puebla a través de los siglos. Panorama histórico de la ciudad, México, El Sol de Puebla, 240 pp.

MARTíNEZ Suárez, Xose Lois. (2014). La construcción la Galicia urbana: los campos como fringe-belt, en Rodrigo Cervantes, N. y otros (oords), Urbanismo y arquitectura militar en Iberoamérica. México, D. F., Universidad Autónoma Metropolitana

MORENO Toscano, A. (1976). El siglo de la conquista. Historia General de México, México, Tomo 2, 3-81.

MUNDY, Bárbara E. (1996). The mapping of New Spain. Indigenous Cartography and the Maps of the Relaciones Geográficas, USA, The University of Chicago Press. Chicago \& London

OROZCO y Berra, M. (1871). Materiales para una cartografía mexicana. México, Imprenta del Gobierno a cargo de José María Sandoval. http://galenet.galegroup.com/ servlet/Sabin?af=RN\&ae $=\mathrm{CY} 101385038 \&$ srchtp $=\mathrm{a} \& \mathrm{ste}=14$.

PALERM, Ángel, Carmen Viqueira, Editora. (1990). México prehispánico. Evolución ecológica del Valle de México. México, D. F. Consejo Nacional para la Cultura y las Artes.

PIHO, Virve. (1981). La secularización de las parroquias en la Nueva España y su repercusión en San Andrés Calpan, México, INAH.

PREM, H. J. (1989). Milpa y hacienda: tenencia de la tierra indígena y española en la cuenca del Alto Atoyac, Puebla, México, 1520-1650. México, D.F., CIESAS.

RECILLAS Gonzáles, Miguel Ángel y Joaquín Galarza. El científico y el hombre: su legado a México y a la humanidad Desacatos, núm. 22, septiembre-diciembre, 2006, pp. 181-190, Centro de Investigaciones y Estudios Superiores en Antropología Social México. http://www.redalyc.org/pdf/139/13902210.pdf

REICHERT, Rafal. (2013). Sobre las olas de un mar plateado. La política defensiva española y el financiamiento militar novohispano en la región del Gran Caribe, 1598-1700, Mérida, UNAM 
REYES García, L. (1996). Documentos nahuas de la Ciudad de México del siglo XVI, México, D.F., CIESAS, AGN.

RIVAS, Juan Luis De Las. (1992). El espacio como lugar. Sobre la naturaleza de la forma urbana. Valladolid, Universidad de Valladolid.

RODRIGO Cervantes, Norma Elisabethe. (2012). Estrategias de conservación urbana y manejo para los centros históricos de México: el caso de Morelia. México, INAH

RODRIGO Cervantes, Norma Elisabethe. (2014). Producción cartográfica durante los tres períodos morfológicos del urbanismo novohispano en México, en Rodrigo Cervantes, N. y otros (ooords), Urbanismo y arquitectura militar en Iberoamérica. México, D. F., Universidad Autónoma Metropolitana

RODRÍGUEZ Viqueira, Manuel. (2009). Arquitectura militar. Génesis y tipología. México, LIMUSA.

RODRÍGUEZ Viqueira, Manuel. (2014). Las fortificaciones de Portobelo en la costa del Caribe panameño durante el período colonial, en Rodrigo Cervantes, N. y otros (ooords), Urbanismo y arquitectura militar en Iberoamérica. México, D. F., Universidad Autónoma Metropolitana

RUIZ Medrano, E. (1991). Gobierno y sociedad en Nueva España: segunda audiencia y Antonio de Mendoza. Zamora, Mich, El Colegio de Michoacán.

SÁINZ, Luis. Ignacio y Jorge González Aragón, (2015), El territorio y sus representaciones. Lecturas filosóficas, geográficas y urbanísticas, México, Universidad Autónoma Metropolitana.

TEIXEIRA, Manuel C: (2004). A Construçao da Cidade Brasileira, Lisboa, Livros Horizonte.

TERÁN, Fernando De y otros. (1989). La Ciudad Hispanoamericana. El Sueño de un Orden. España, CEHOPU, MOPU.

TICHY, F. (1976). Orientación de las pirámides e iglesias en el altiplano mexicano. Puebla, México, Fundación Alemana para la Investigación Científica.

TOVAR de Teresa, G. (1987). La ciudad de México y la utopía en el siglo XVI. México, D.F., México, Fondo de Cultura Económica. México, Seguros de México.

VELASCO, José Luis (1982) El apogeo del realismo. Historia de la pintura. BarceIona, España. Ediciones CEAC, S. A.

WHITEHAND, J. W. R., editor (1981) The urban landscape: historical development and management. Papers by M. R. G. Conzen., London, Academic Press.

YANEZ Díaz, G. (1994). Desarrollo urbano virreinal en la región Puebla-Tlaxcala. Puebla, Pue, División de Estudios de Posgrado e Investigación de la Facultad de Arquitectura, Universidad Nacional Autónoma de México.

YONEDA Keiko. (1991). Los mapas de Cuahtinchan y la historia cartográfica prehispánica. México, CIESAS, Gobierno del Estado de Puebla, FCE. 


\section{AC-1 PREEXISTENCIAS URBANÍSTICAS}

1.Plano de los pueblos existentes en la Región Puebla-Tlaxcala en el momento del encuentro con los europeos

2. Valle Puebla-Tlaxcala en la actualidad

3. Las Rutas Comerciales de Veracruz, Tlaxcala, Puebla, Ciudad de México y Acapulco

4. Orientación de la Traza Urbana de la Ciudad de Los Ángeles y otros lugares del territorio circundante. (Basado en el original elaborado por Tichy, 1974)

5. Barrios indígenas en la Ciudad de Los Ángeles, según Fausto Marín Tamayo, 1960 

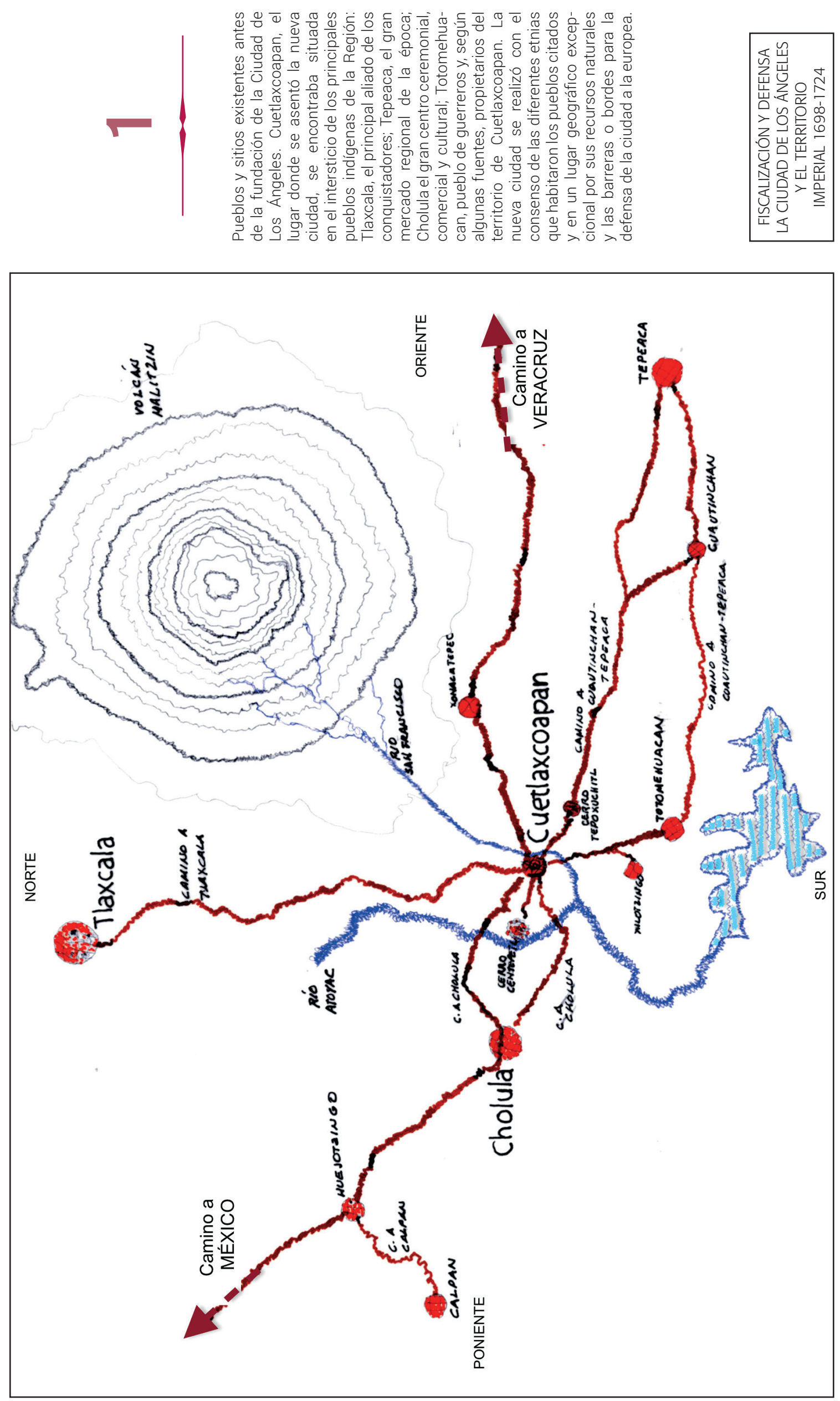

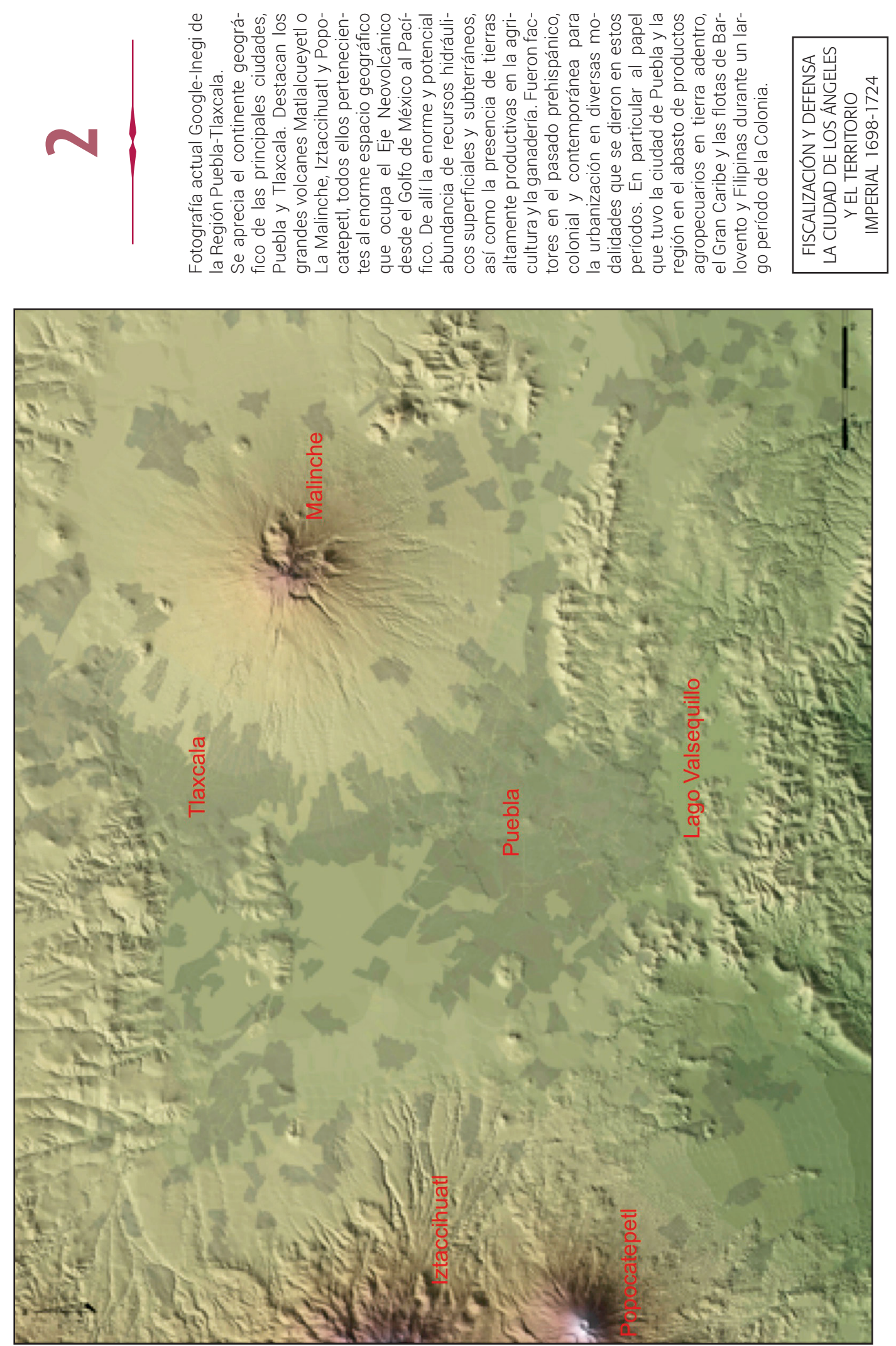

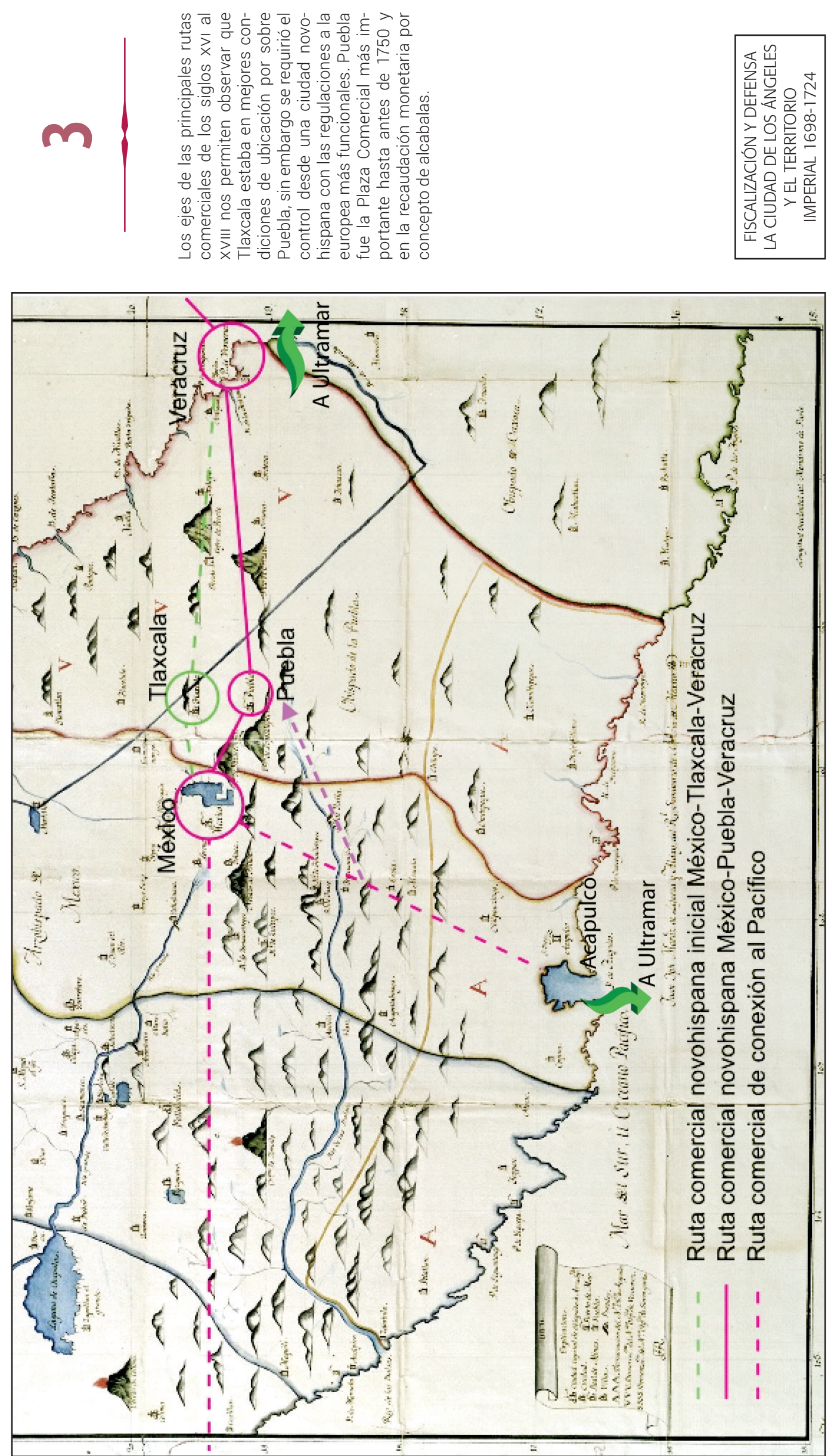

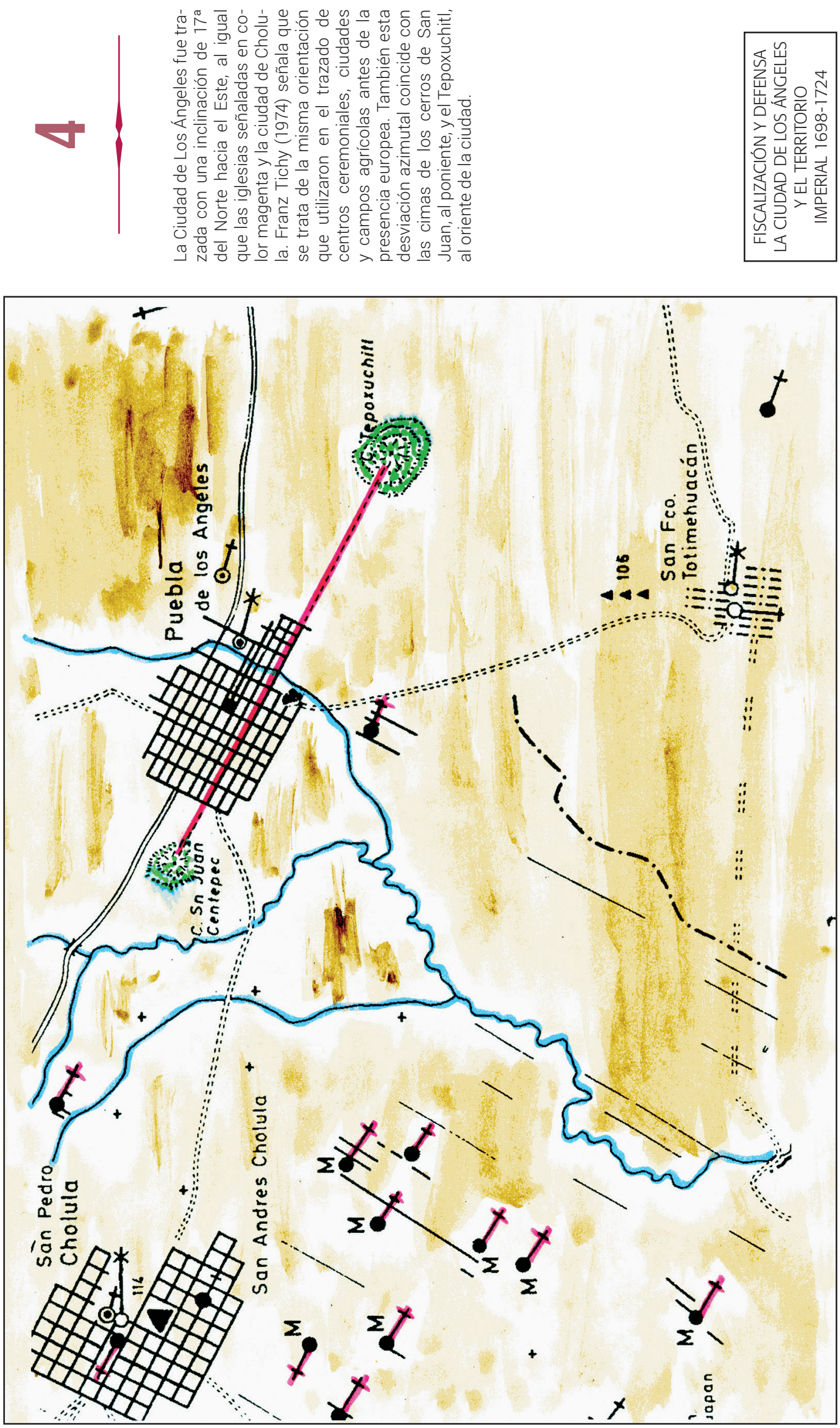

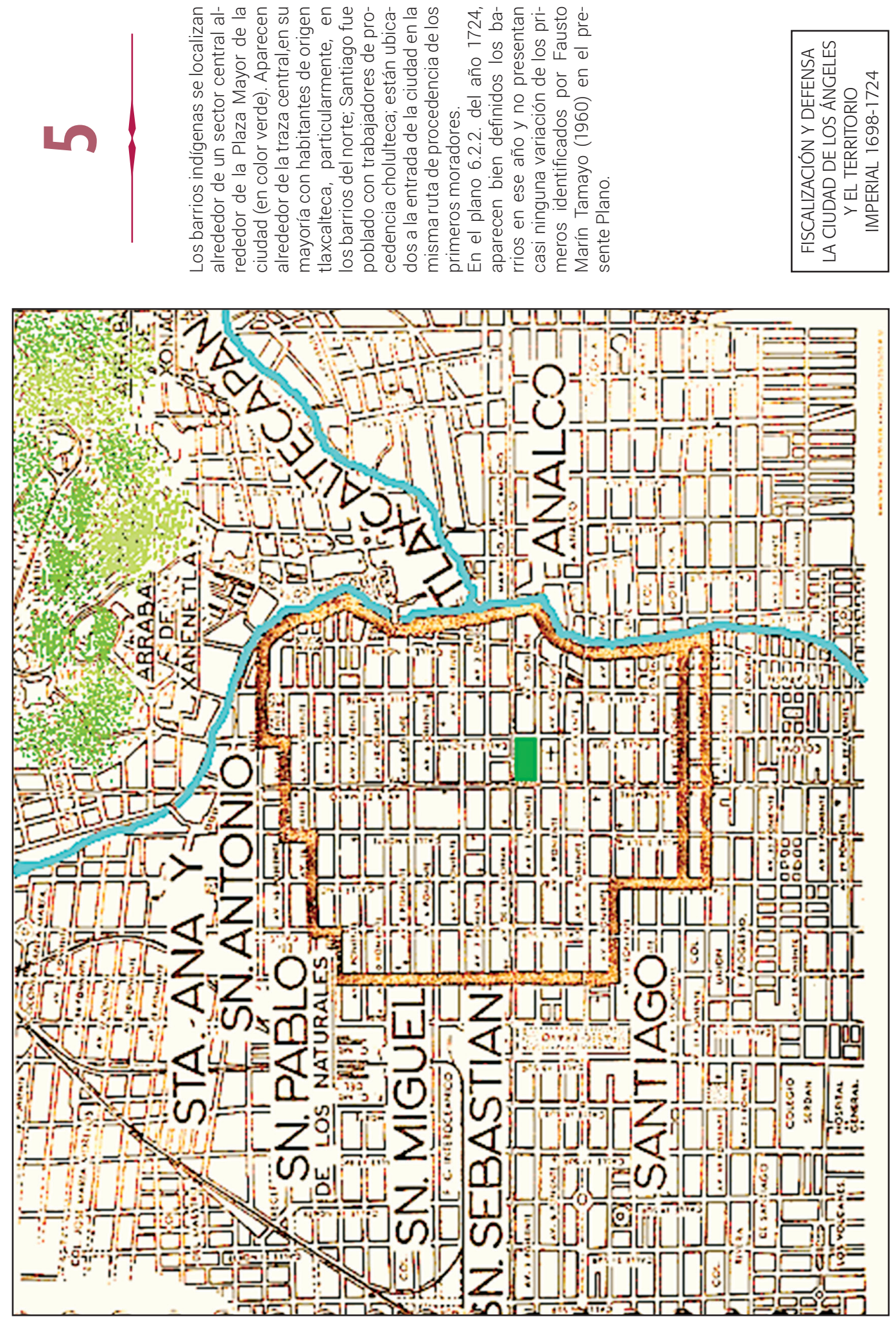


\section{$\mathrm{AC}-2$ LECTURA DEL PLANO DE 1698}

1. Planta de la Ciudad de Los Ángeles de La Nueva España, 1698. AGI, MP, México, 529

2. Definición de Sectores Urbanos de la Ciudad de Los Ángeles

3.Paisaje Natural de la Ciudad de Los Ángeles

4. Paisaje Natural de la Ciudad de los Ángeles y su relación con el espacio construido

5.Hidrografía de la Ciudad de Los Ángeles en el Plano de 1698

6. Hdrografía de la Ciudad de Los Ángeles y su relación con el espacio construido en el Plano de 1698

7. Letreros que aparecen asociados al espacio geográfico y la Ciudad de Los Ángeles en el Plano de 1698

8. Traza Urbana, Plazas y Caminos de la Ciudad de Los Ángeles en el Plano de 1698

9. Delimitación en una fotografía contemporánea (Google Earth, 2013) de la superficie que abarca la traza urbana delineada en la Ciudad de Los Ángeles en el Plano de 1698

10. Parcelación de las manzanas que aparecen en el Plano de 1698 clasificadas por Sectores Urbanos (ver Plano 2)

11. Caminos de Penetración y Salida de la Ciudad de Los Ángeles; los ejes aglutinantes de los espacios dedicados a la Actividad Comercial y fiscal: Guardas, Garitas, Plazas, Aduanas y la ubicación de los Conventos de frailes mendicantes: franciscanos, dominicos, agustinos y carmelitas en el Plano de 1698

12. Principales calles que cruzan la Ciudad de Los Ángeles para unir los caminos de México y Veracruz en el Plano de 1698

13. Garitas y guardas en el espacio público de la Ciudad de Los Ángeles en el Plano de 1698 
14. Garitas y lugares visitados por el Juez Privativo Superintendente de las Reales Alcabalas de Puebla Don José Veitia Linaje, el escribano público y su portero los días 24 y 25 de noviembre de 1697 en la Ciudad de los Ángeles. Identificación hecha por JGAC sobre una fotografía aérea (Google Earth, 2013) con base en el expediente con la signatura: México, 341, AGl y el Plano de 1698

15. Garitas propuestas por el Juez Privativo Superintendente de las Reales Alcabalas de Puebla Don Jose Veitia Linage el 26 de noviembre de 1697 en la Ciudad de Los ÁngelesUbicados por JGAC en una fotografía aérea (Google Earth, 2013) con base en el expediente con la signatura: México, 341, AGl y el Plano de 1698

16. Edificios y terrenos productivos en la Ciudad de Los Ángeles y cercanías con los principales cuerpos de agua en el Plano de 1698

17. Clasificación de los edificios y terrenos productivos en la Ciudad de Los Ángeles y su cercanía con los principales cuerpos de agua en el Plano de 1698

18. Terrenos cultivados dentro de la traza urbana y alrededor de la Ciudad de Los Ángeles en el Plano de 1698

19. Edificios religiosos en la Ciudad de Los Ángeles en el Plano de 1698

20. Corredores que unen los edificios religiosos en la Ciudad de Los Ángeles en el Plano de 1698 


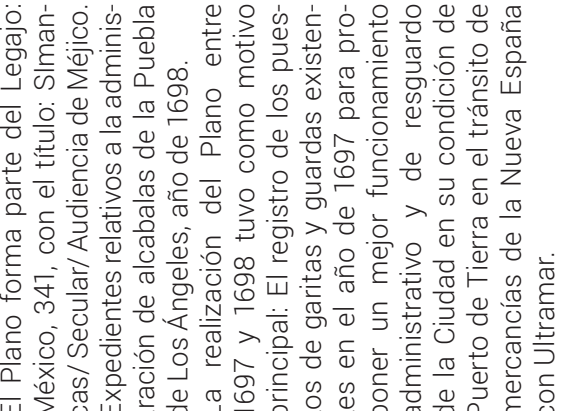

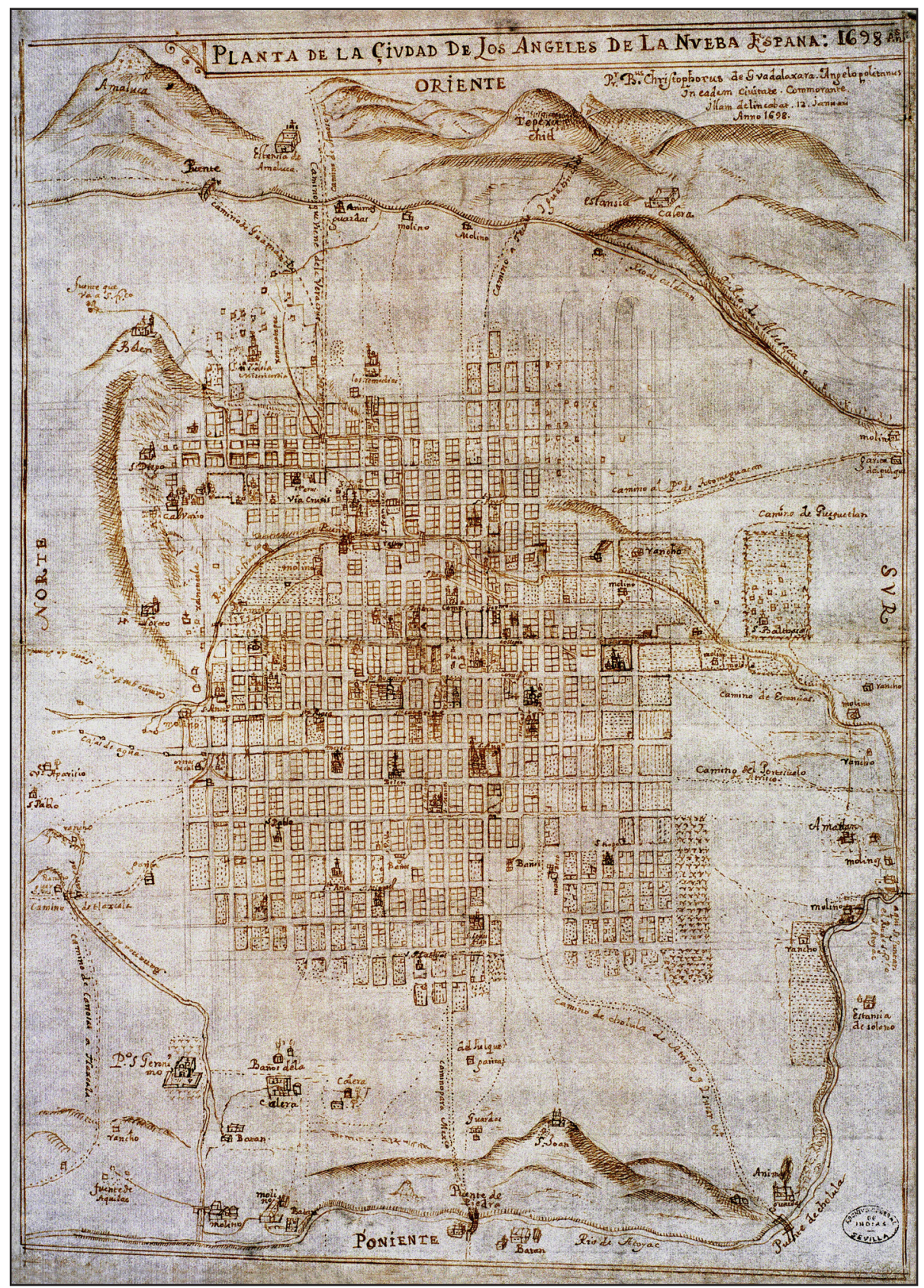




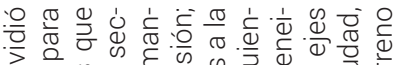

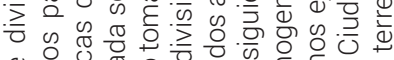

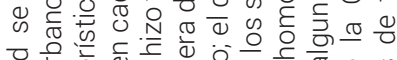

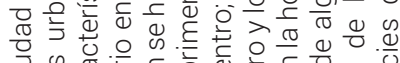

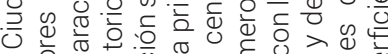

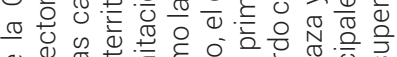

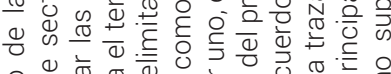

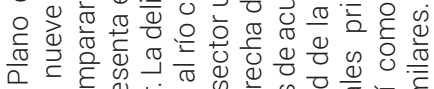

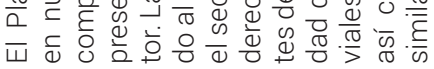

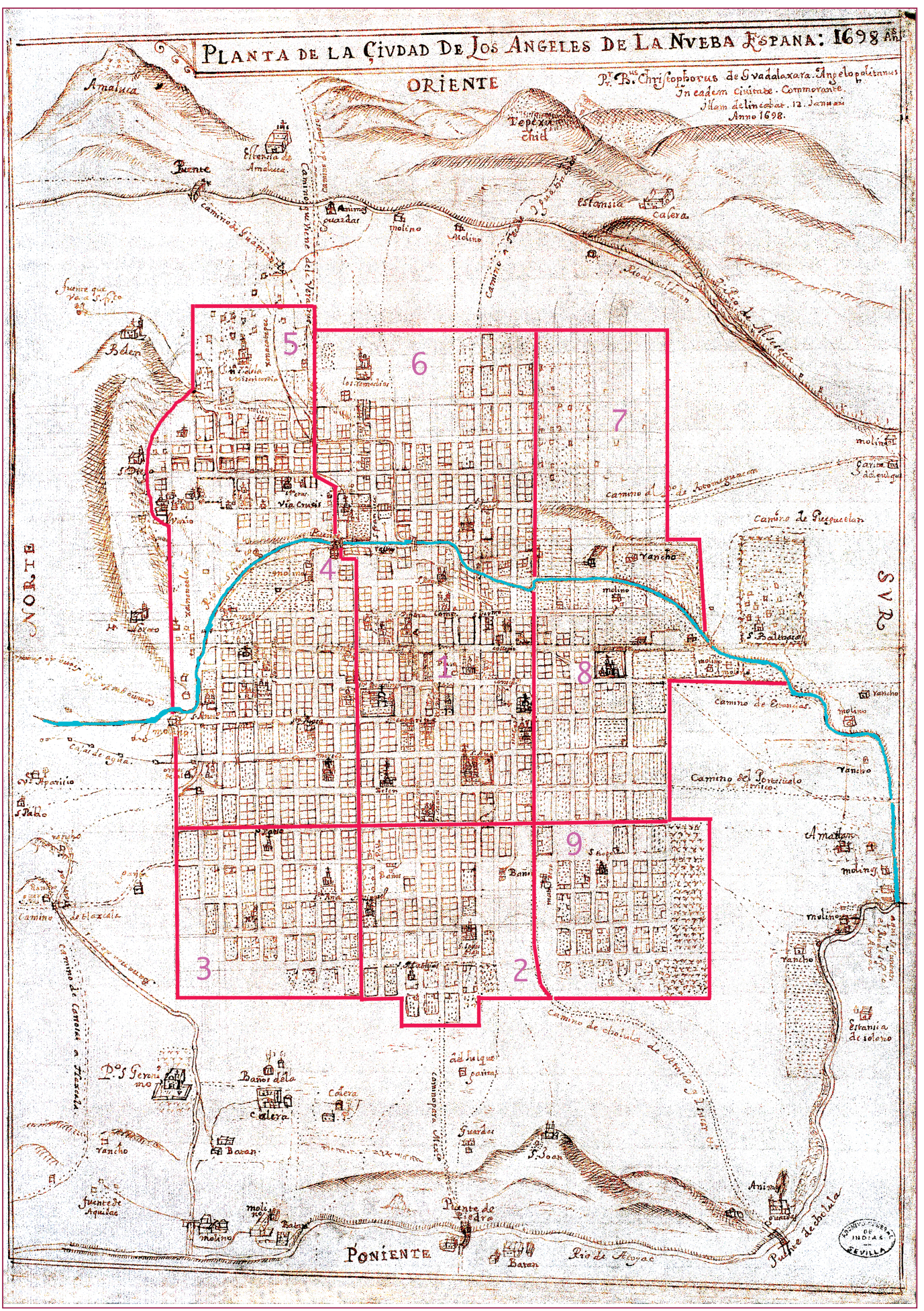



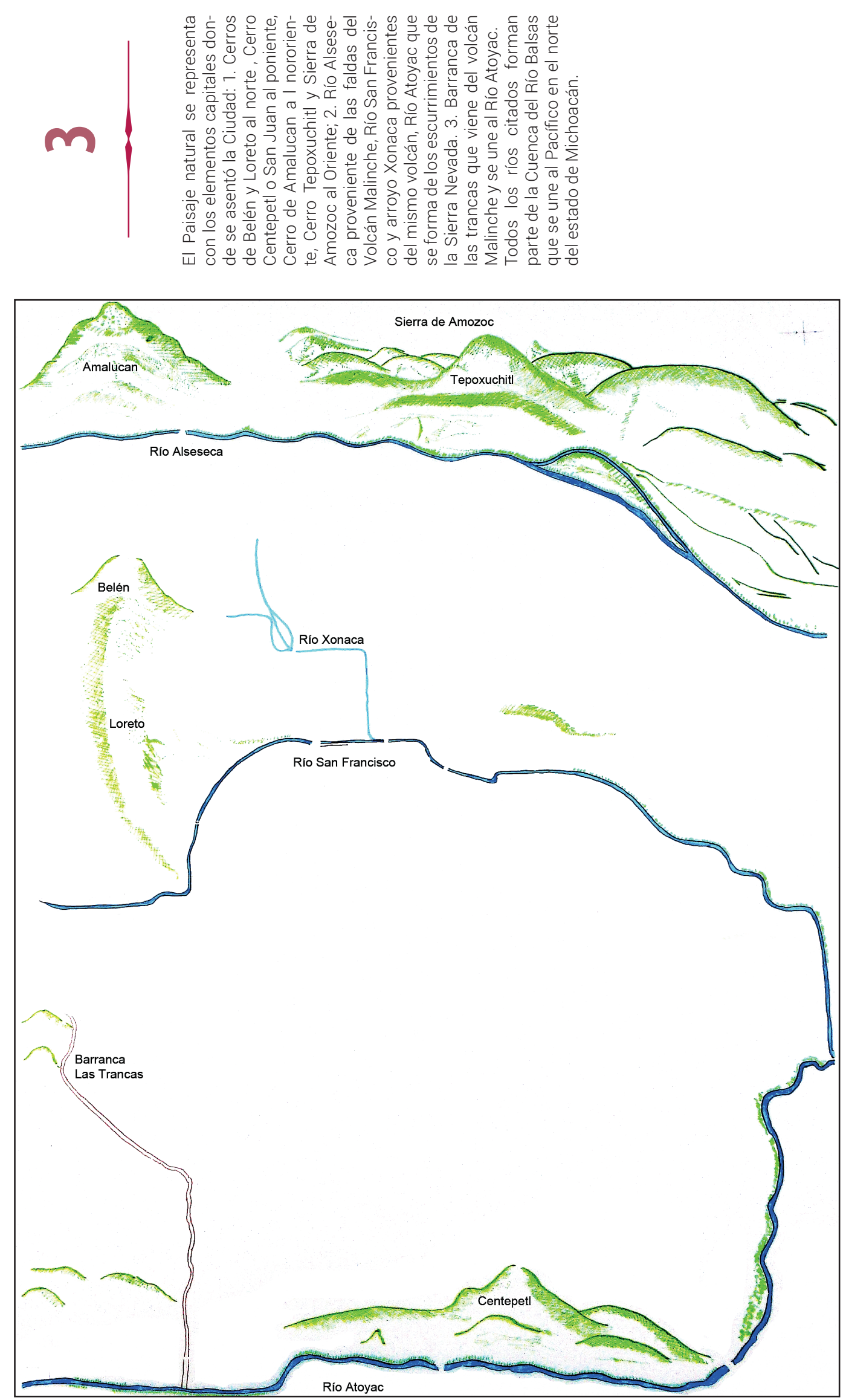

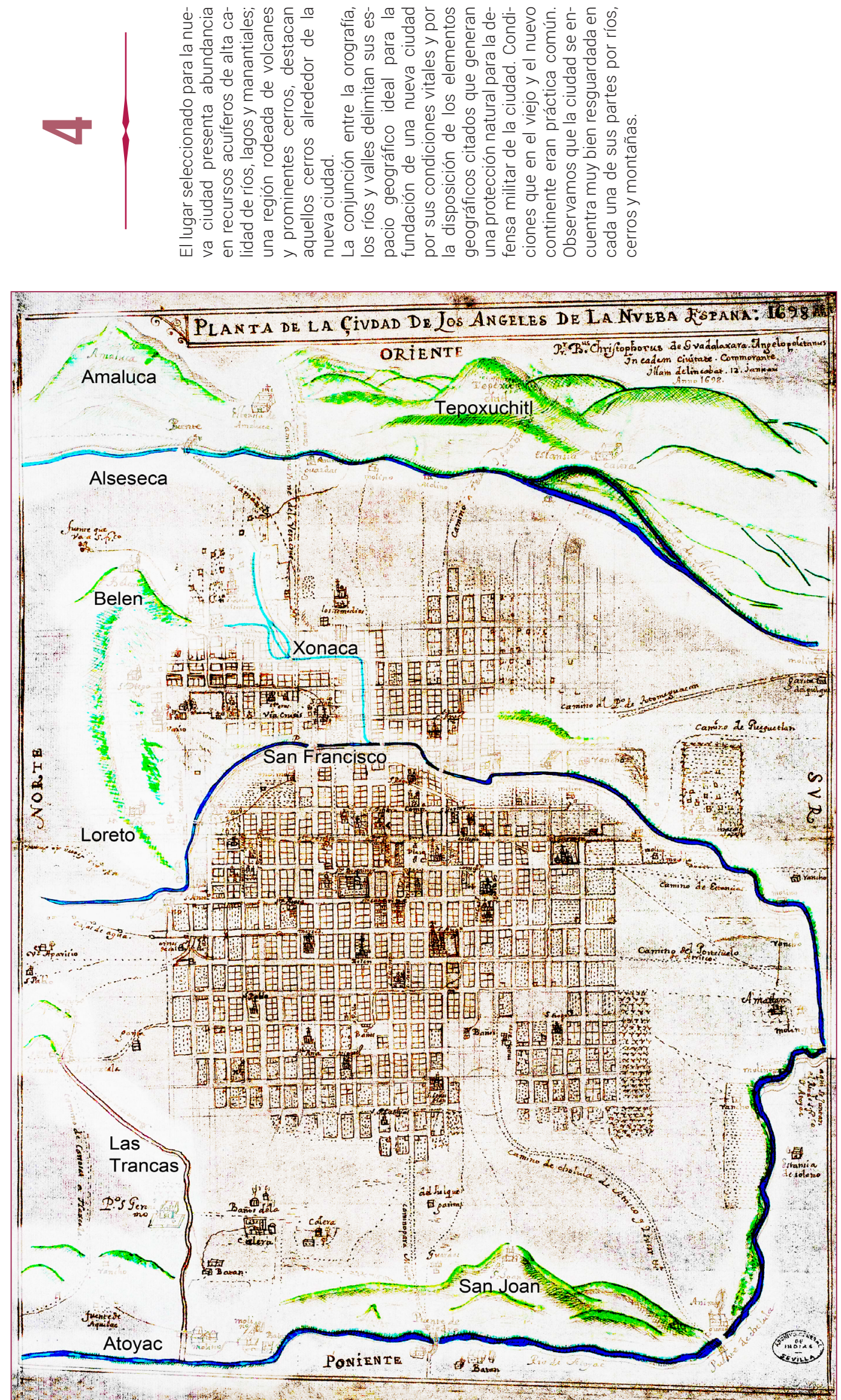

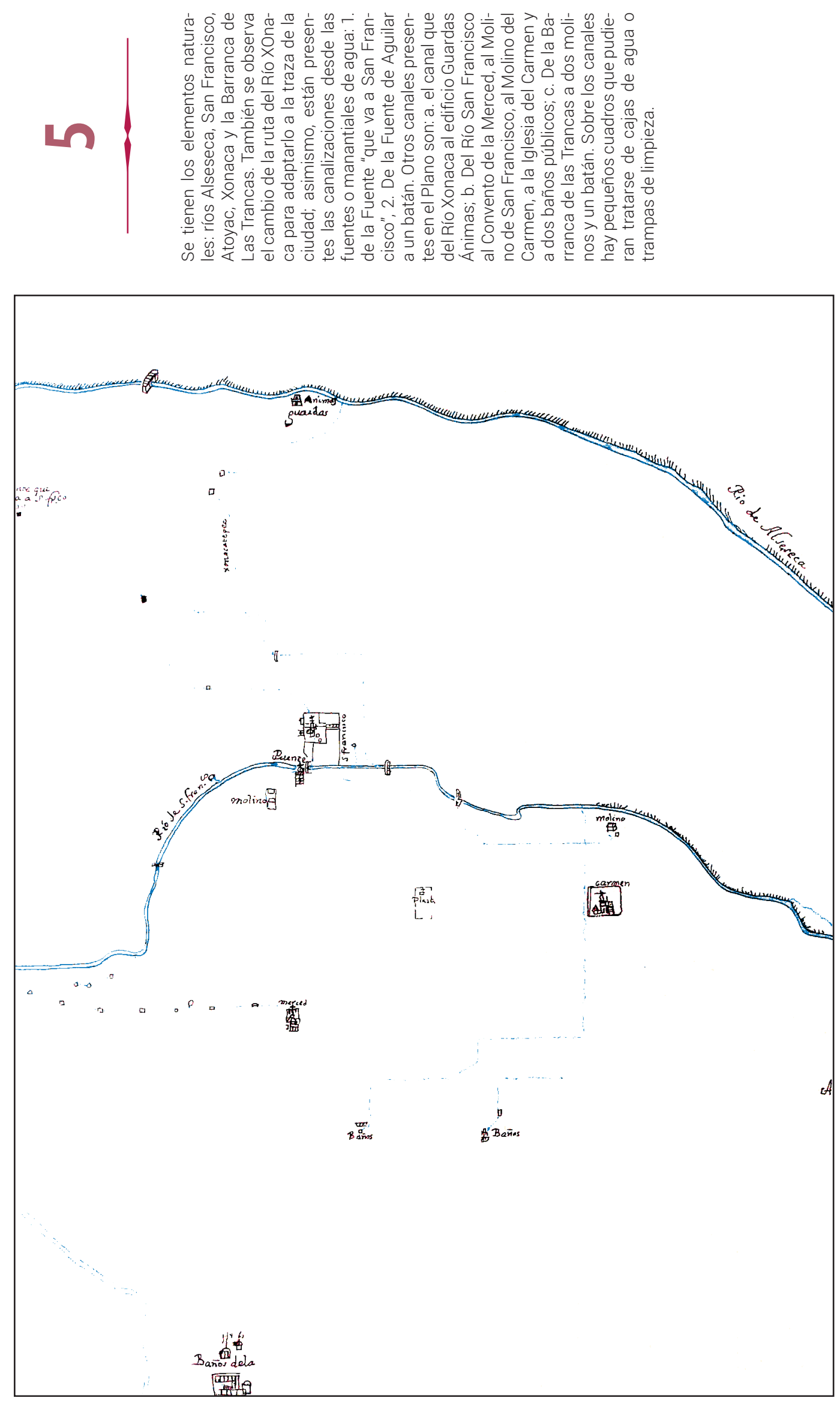

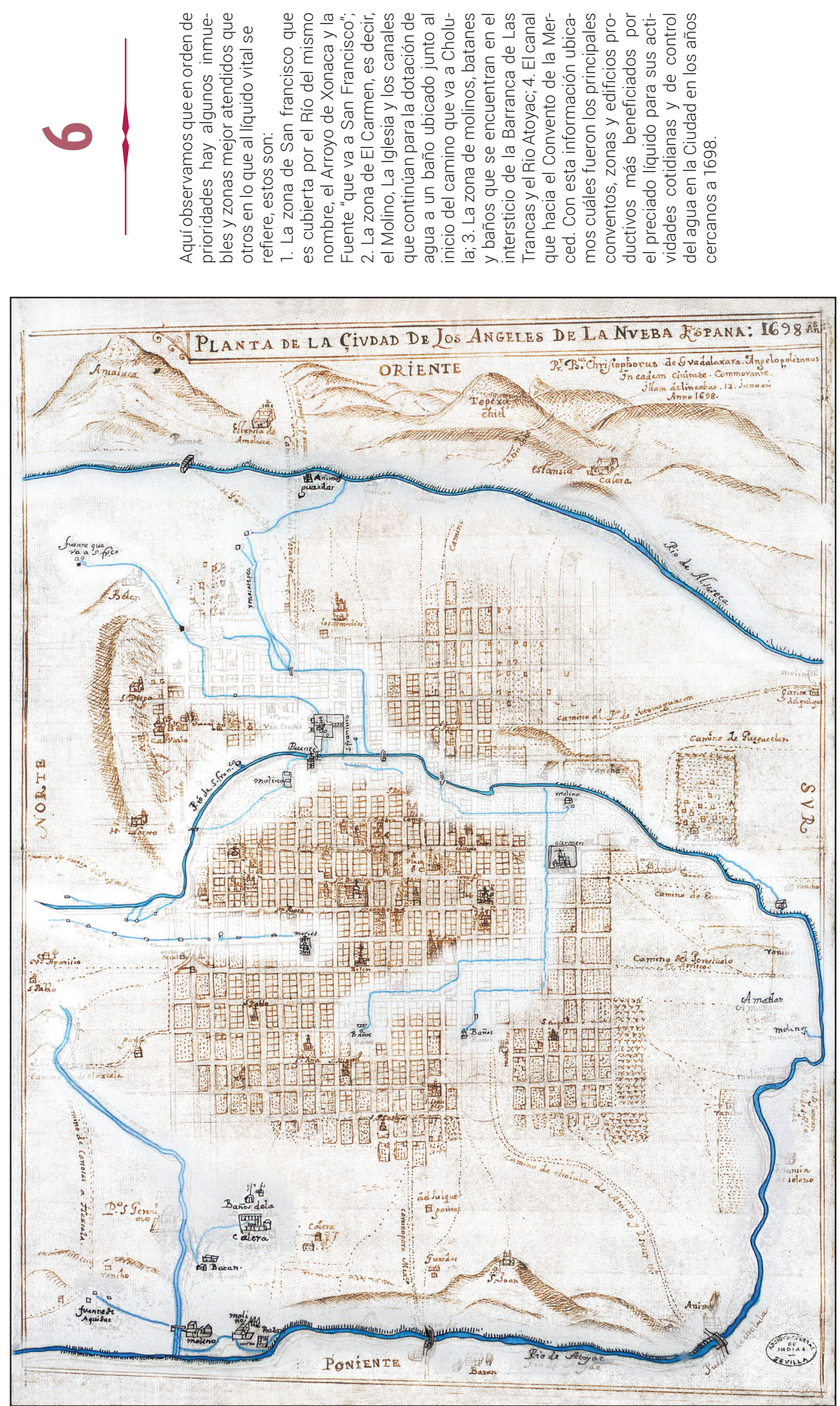

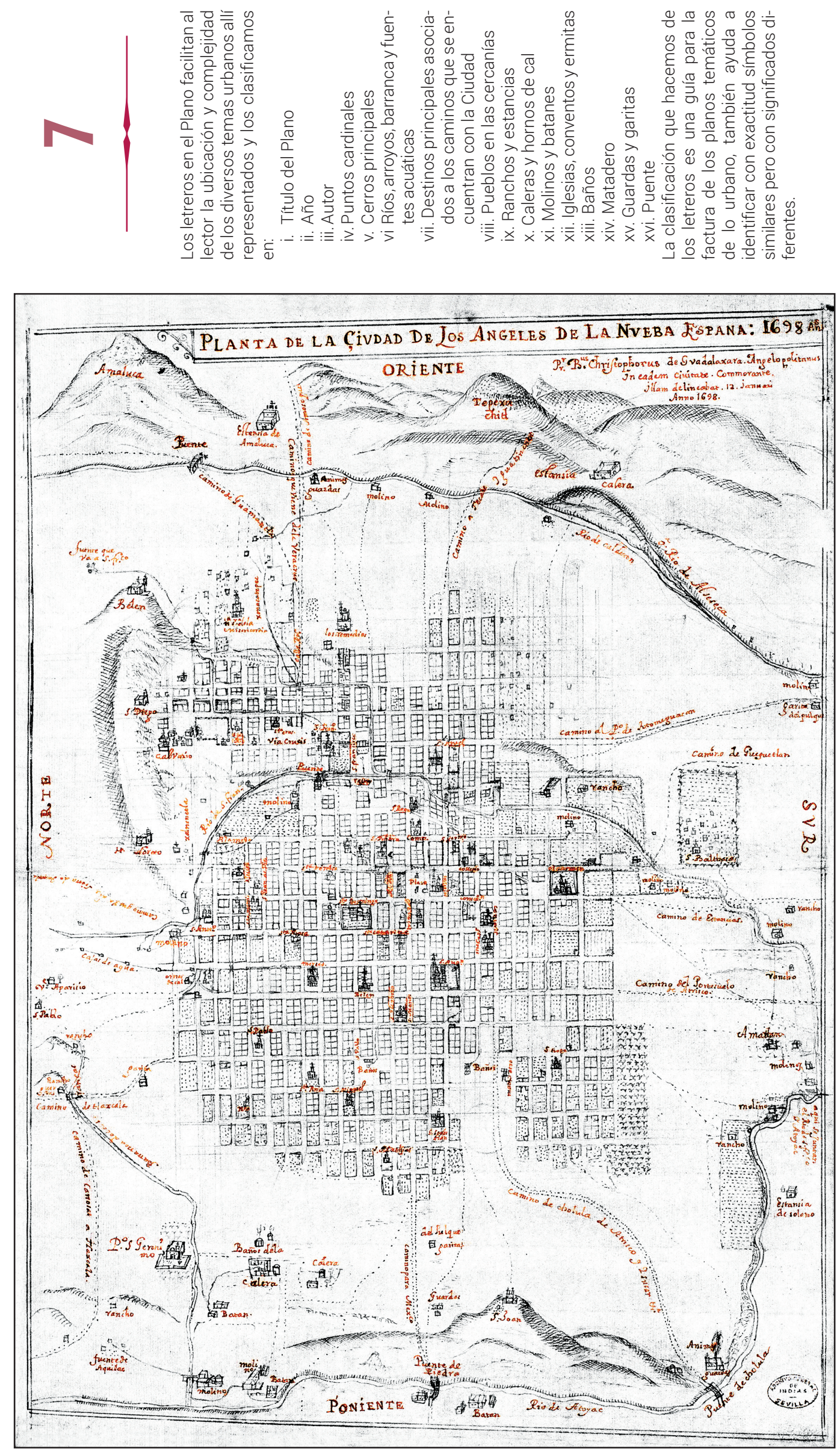

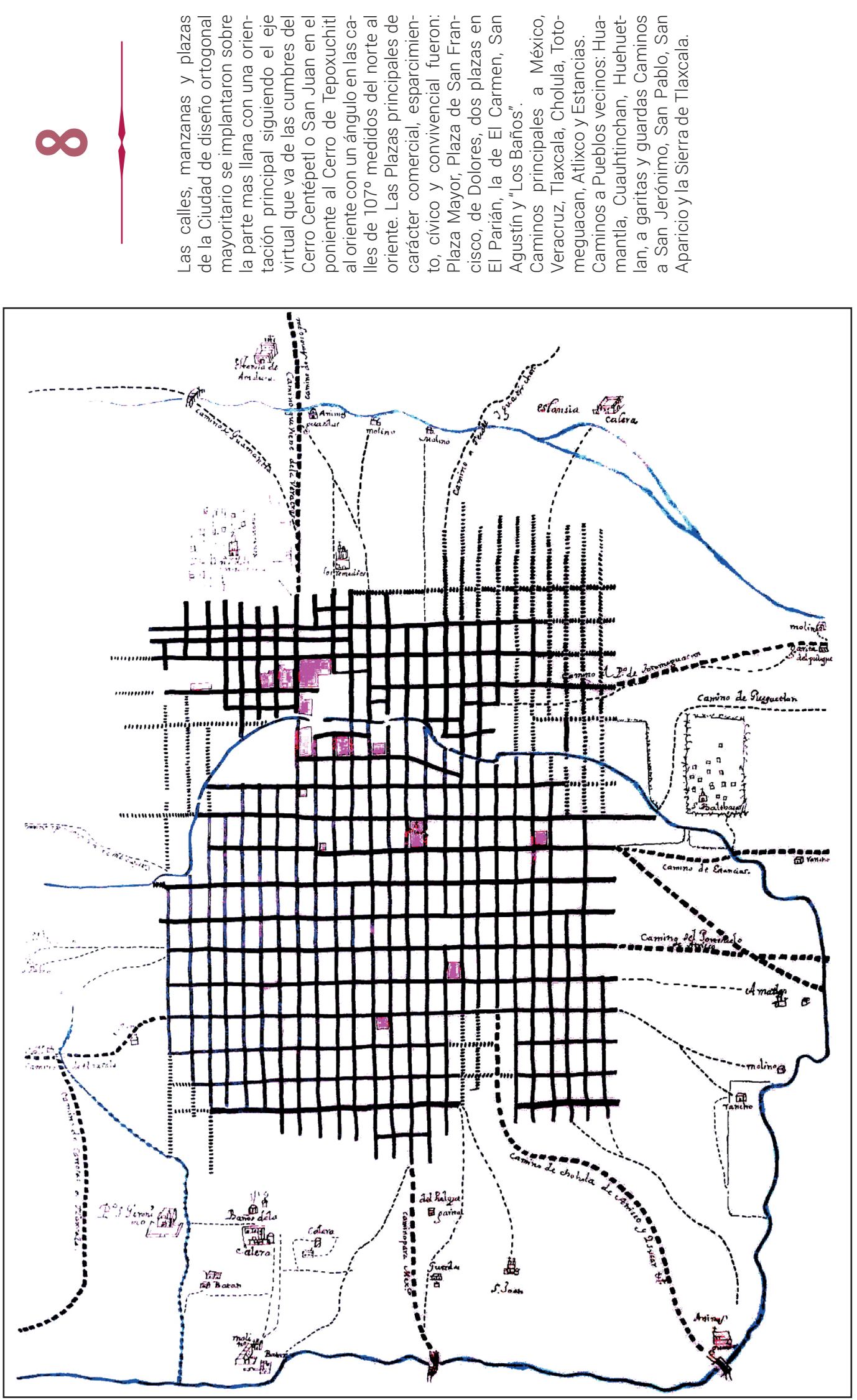


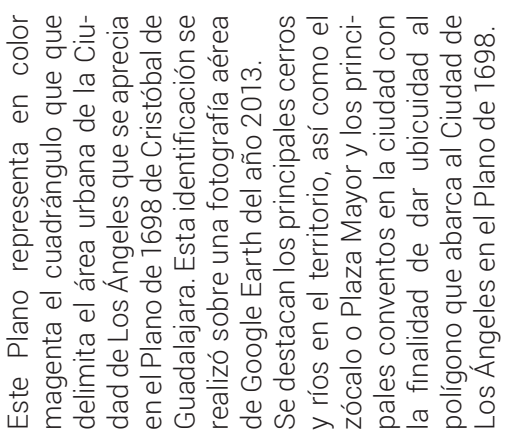

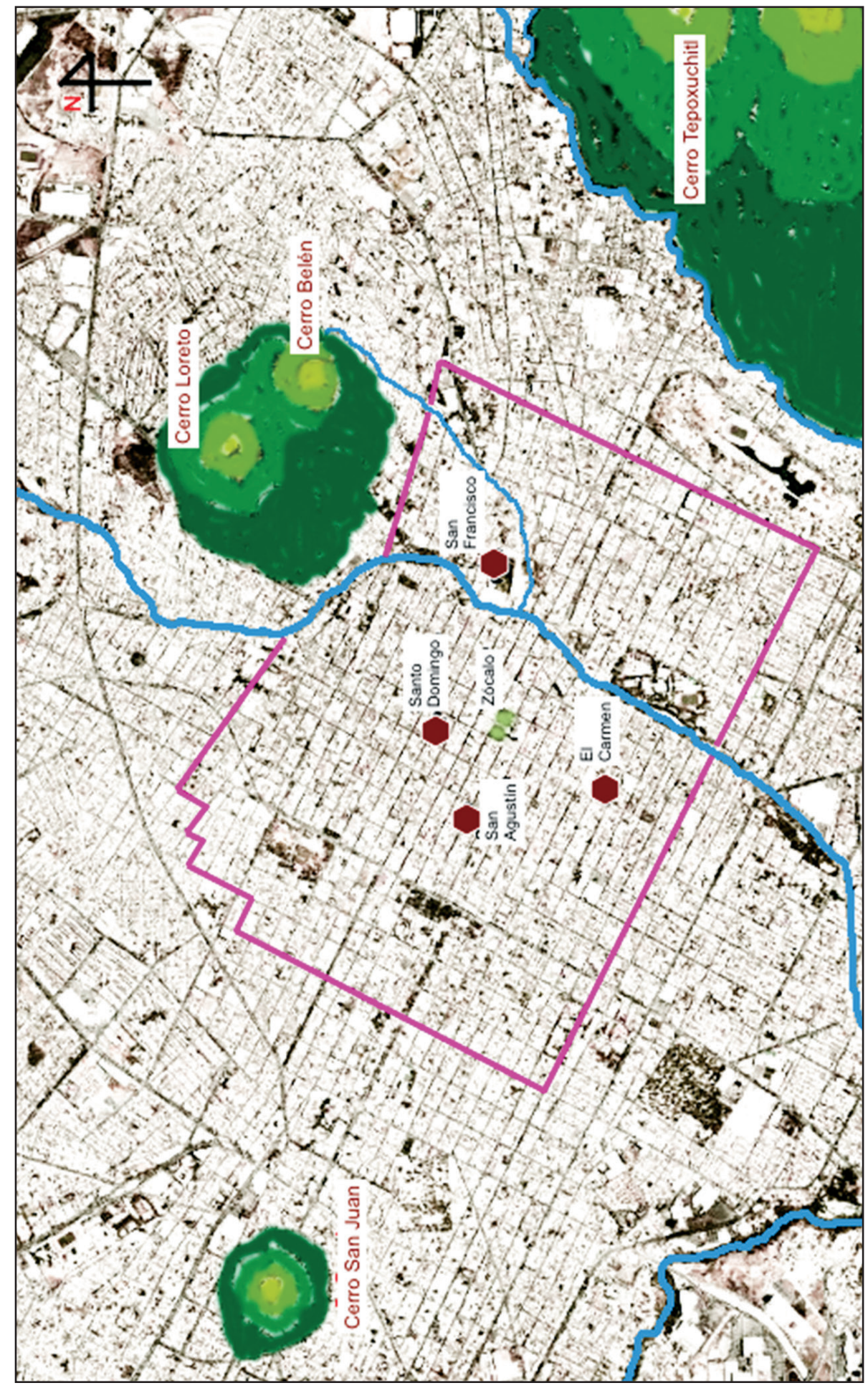



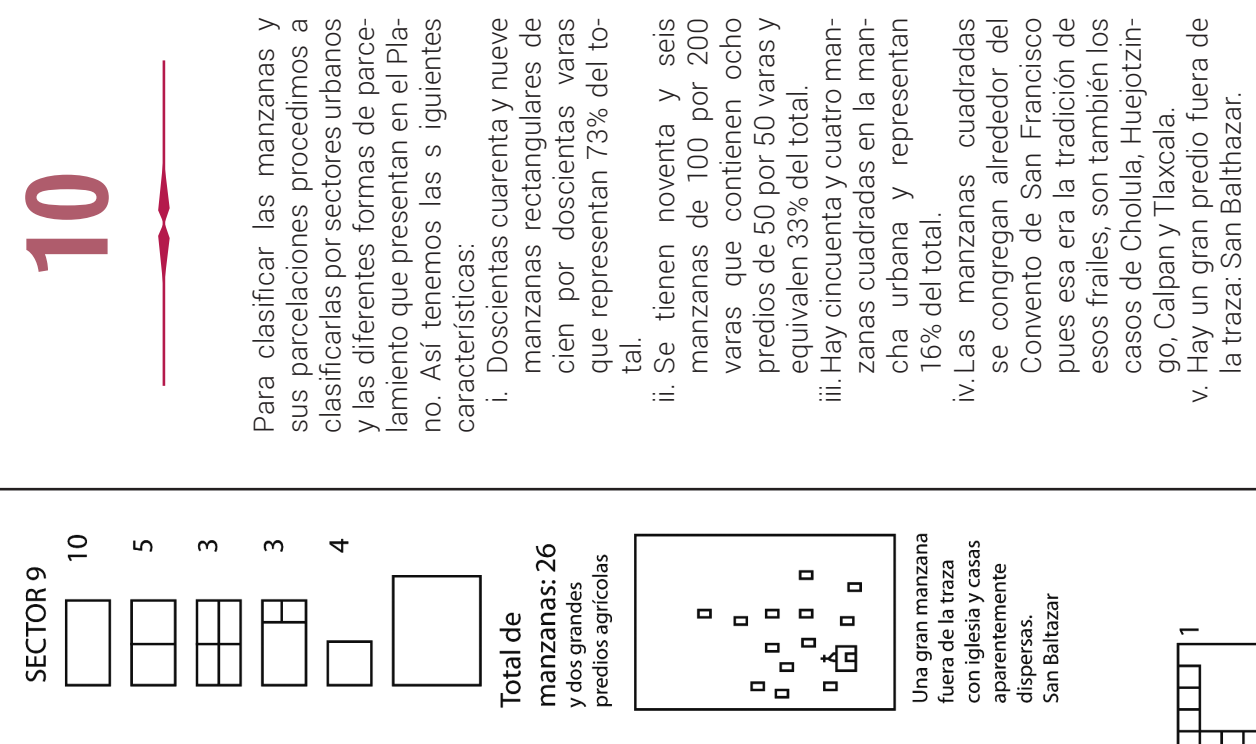

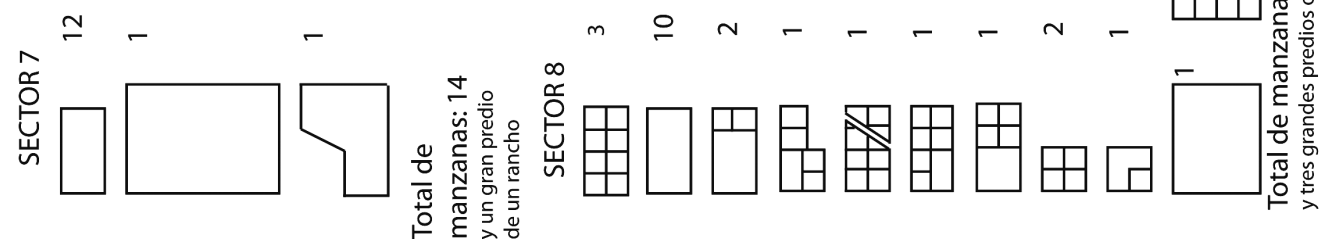

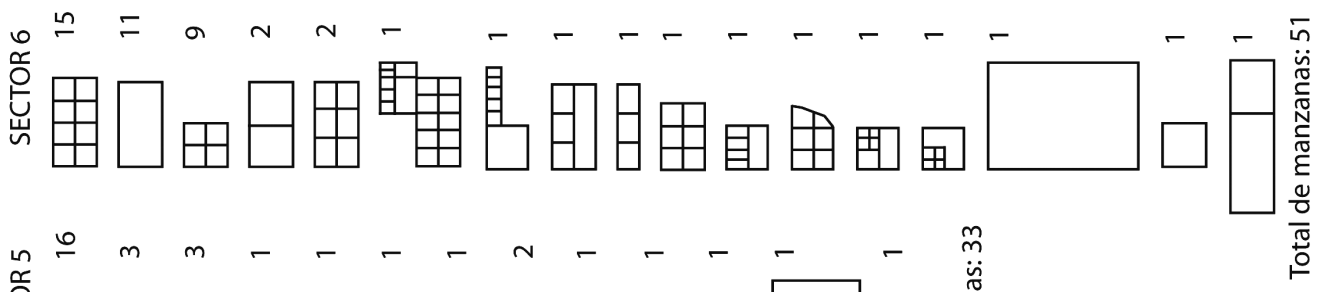

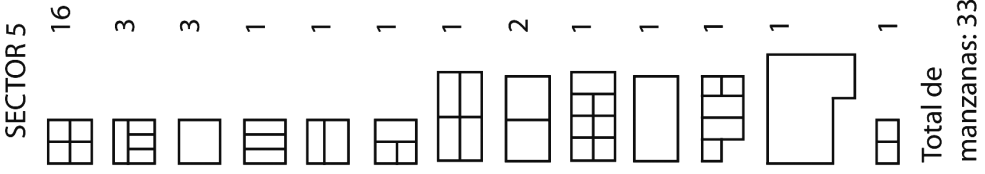

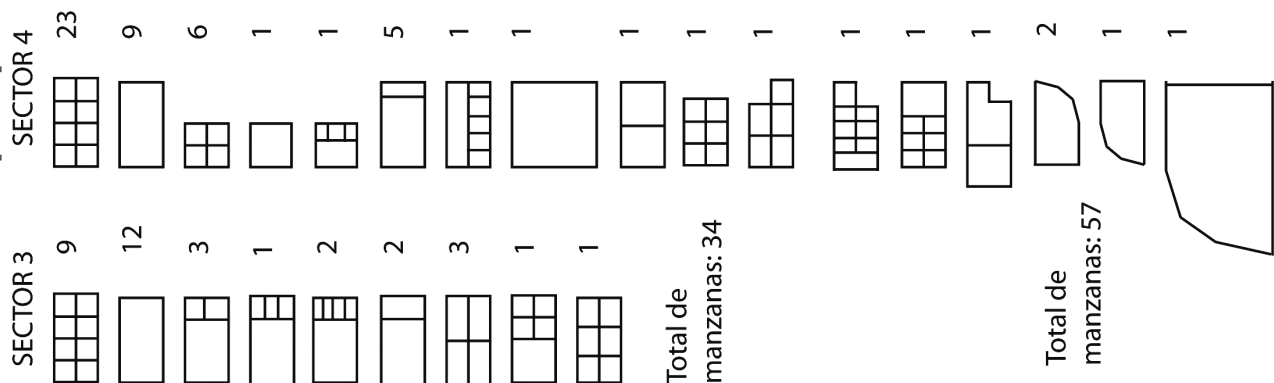

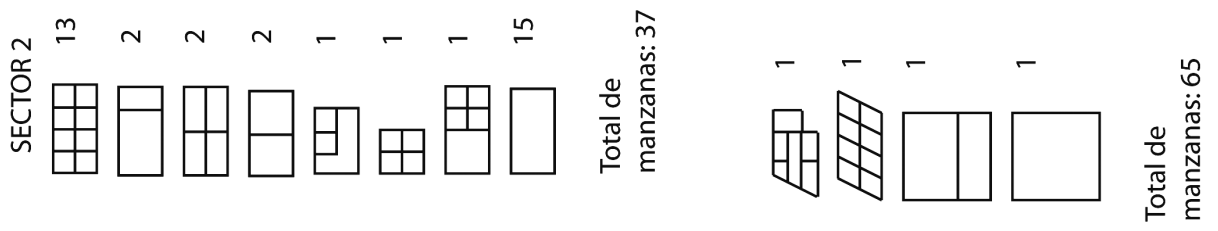

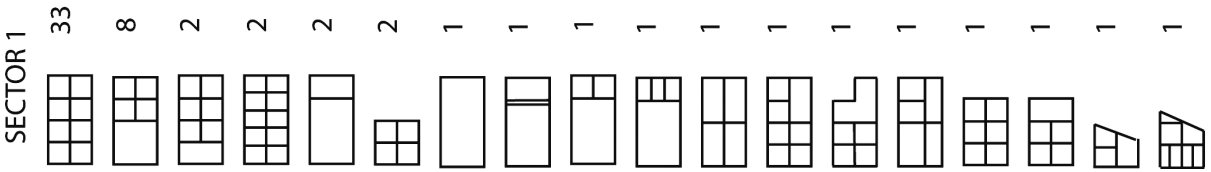



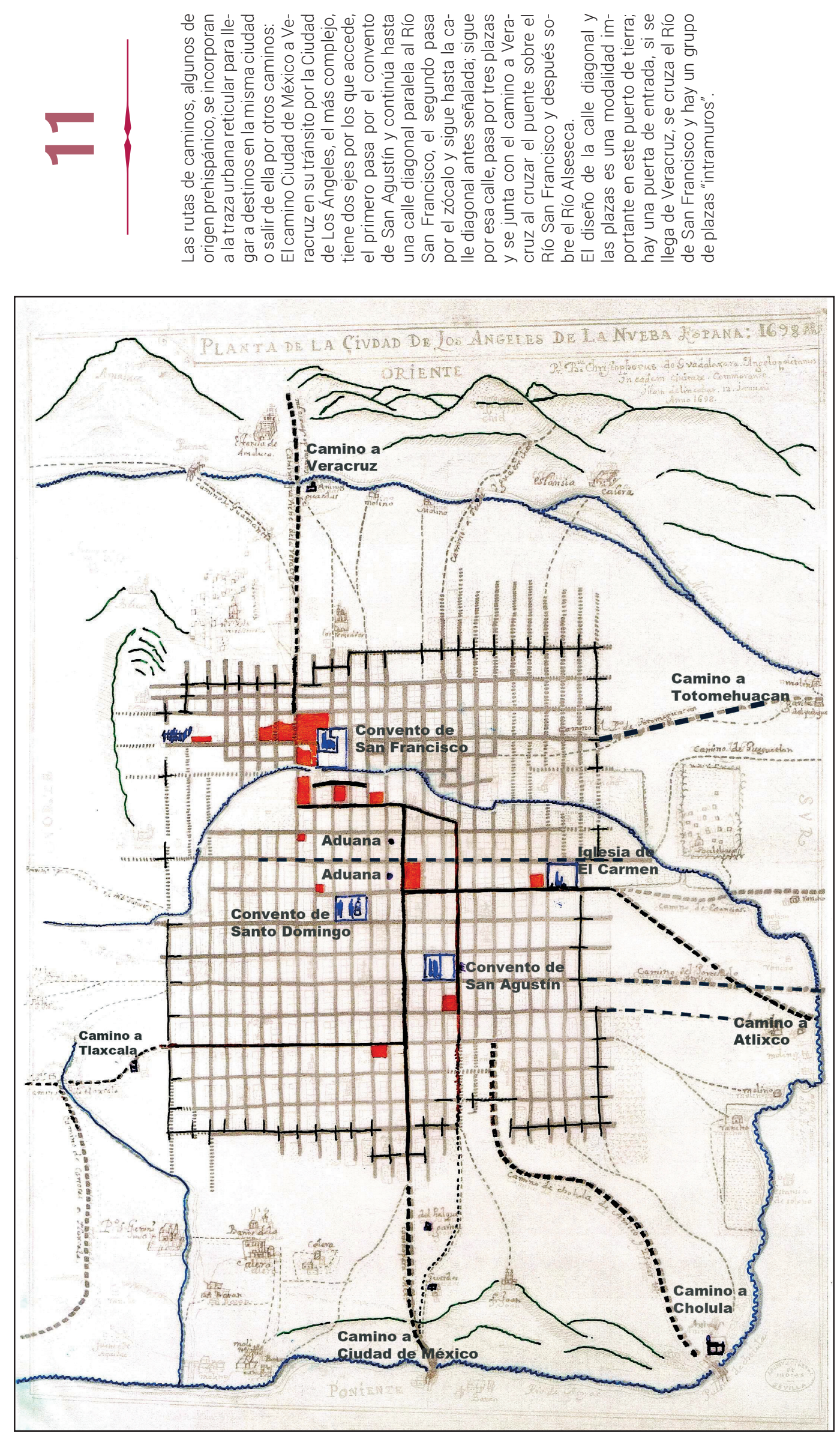

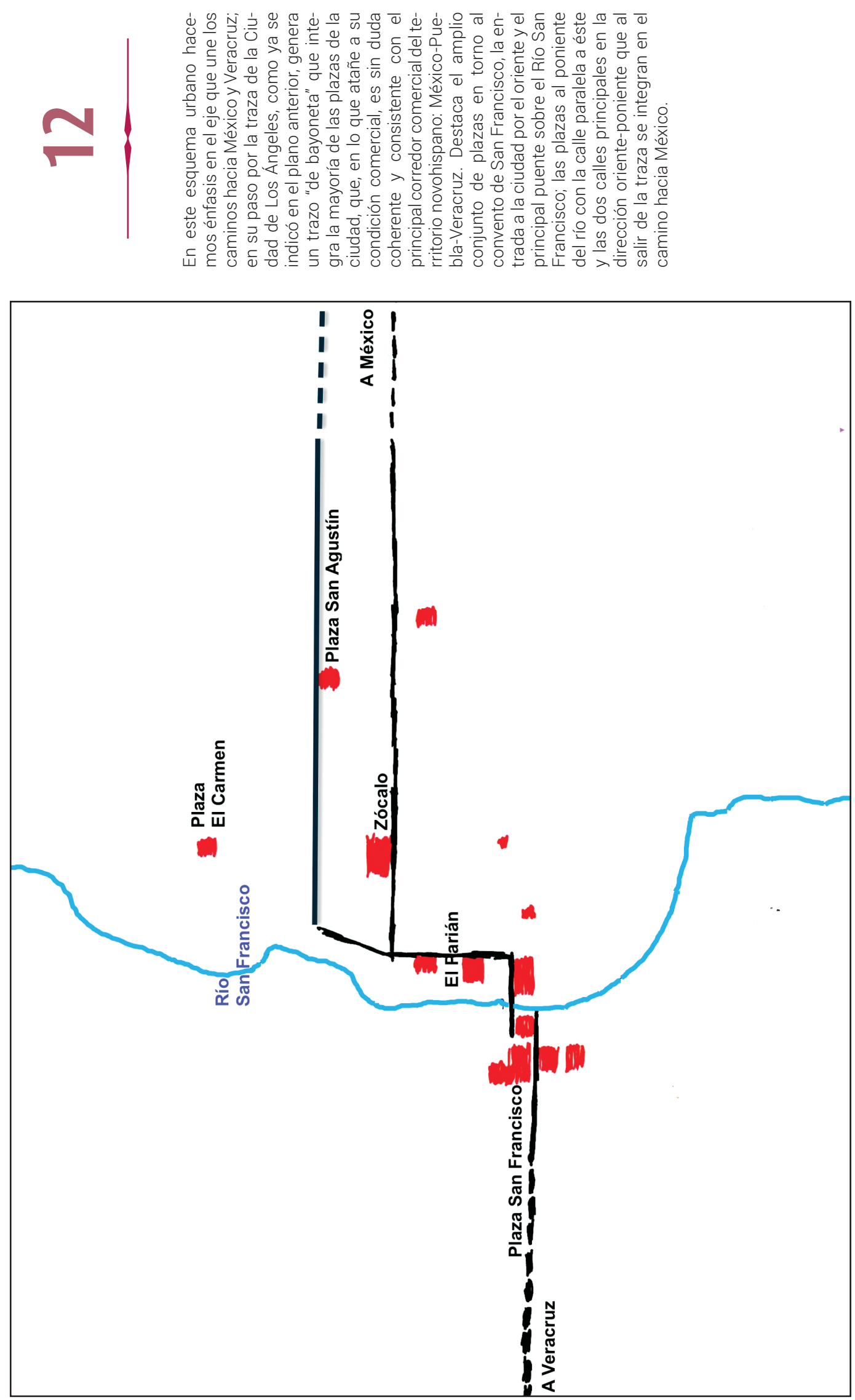

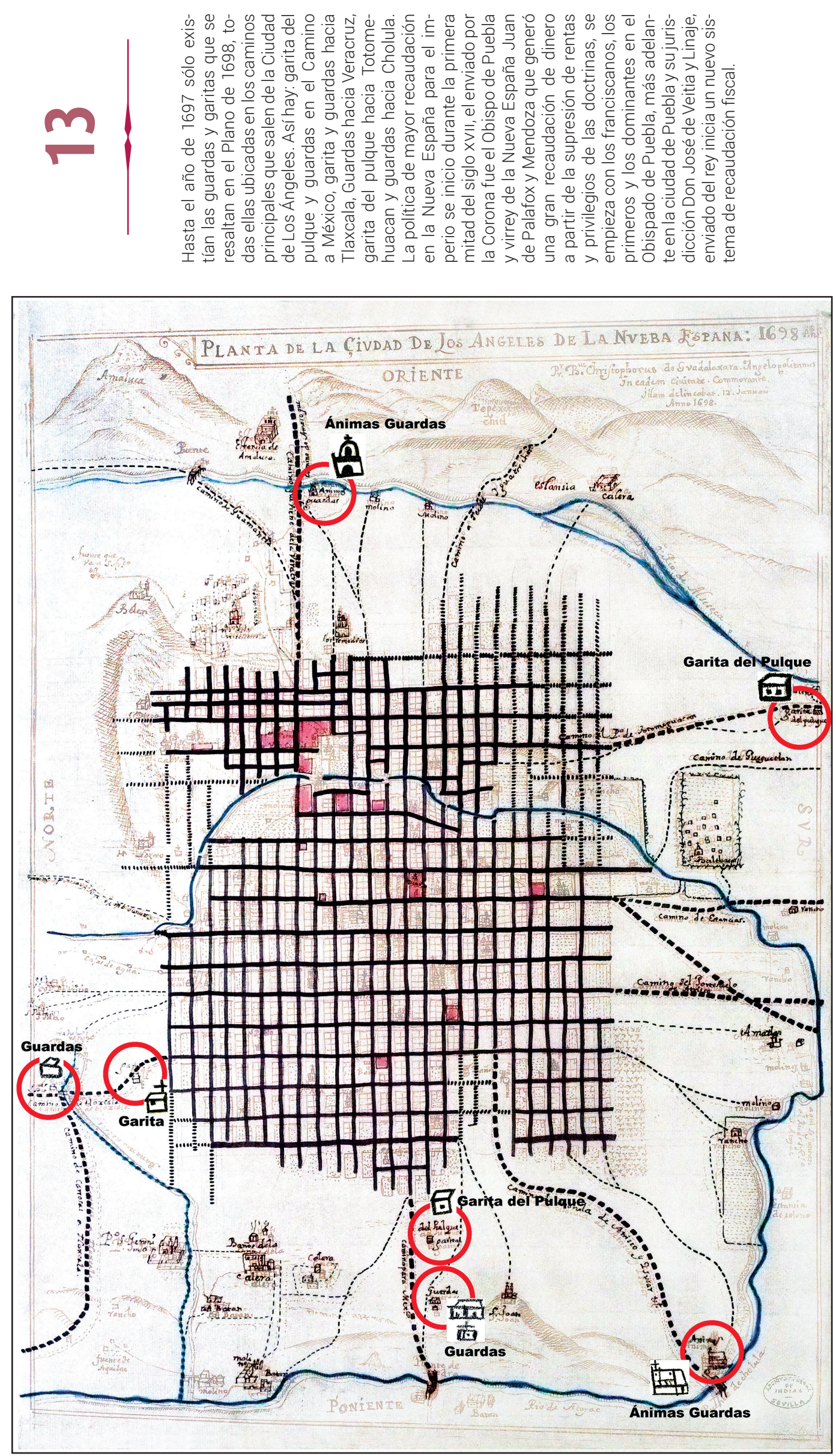

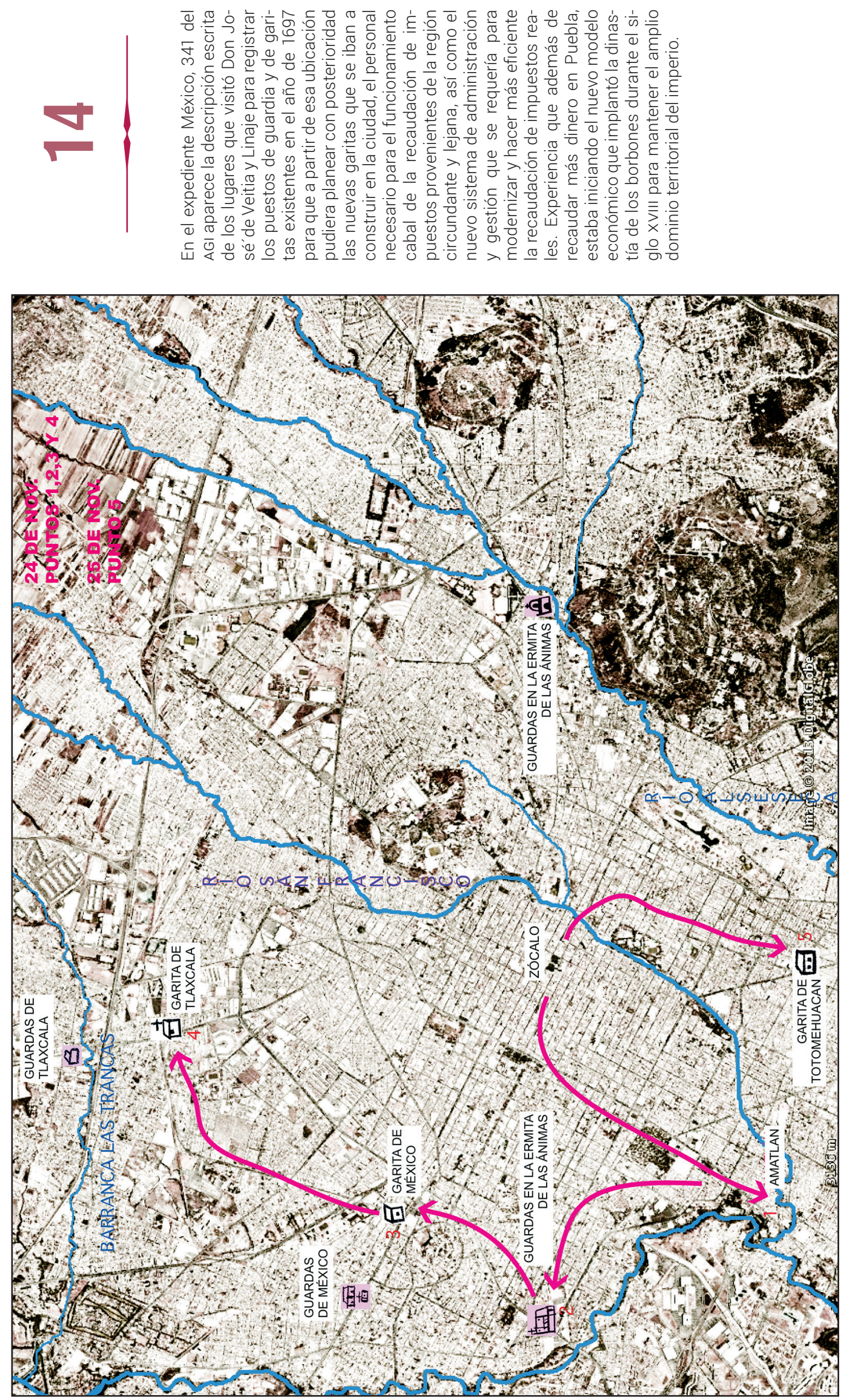

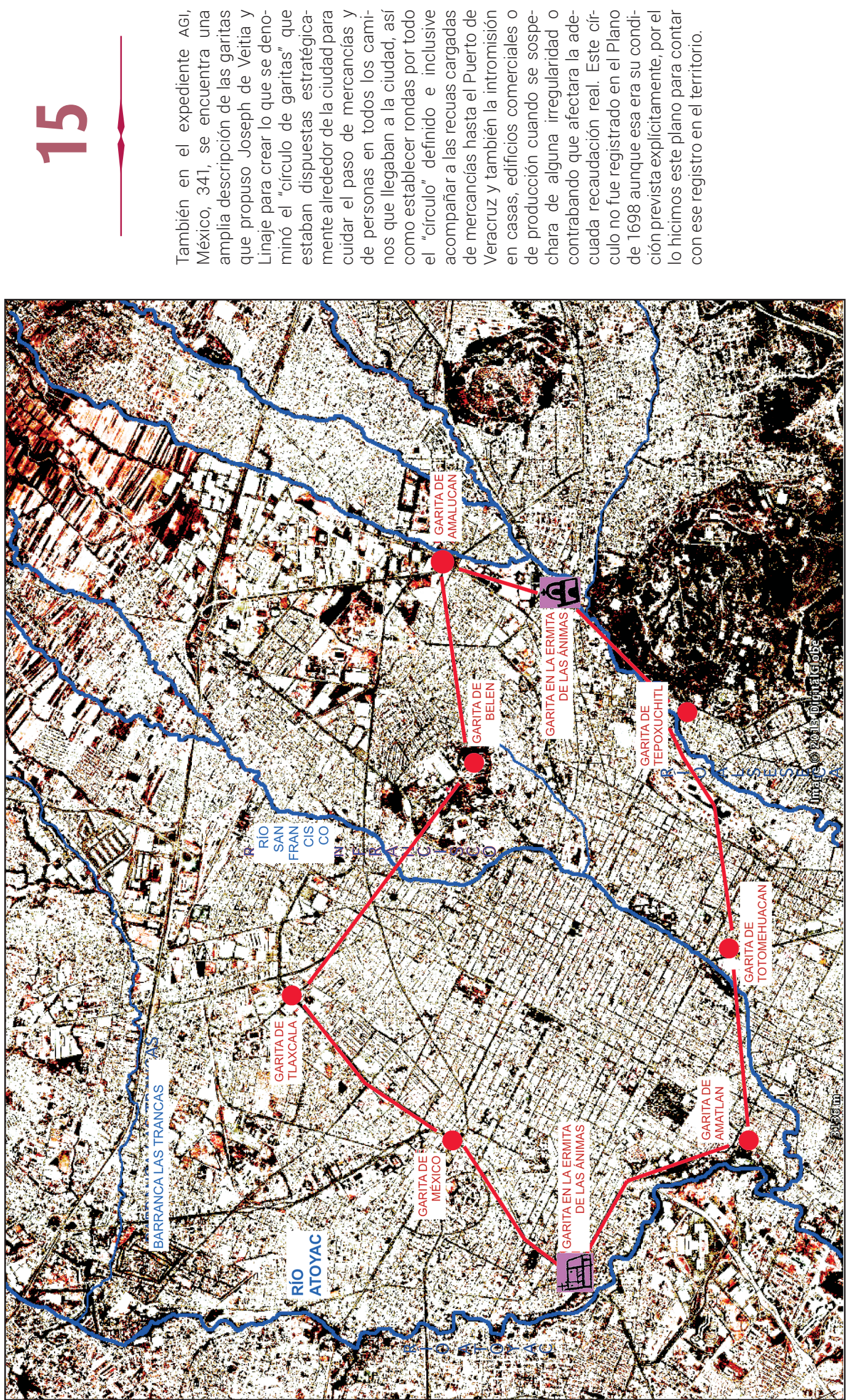


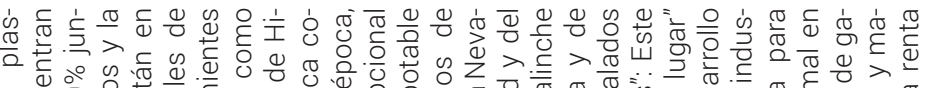

œ

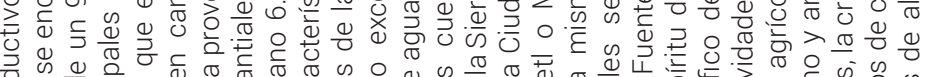

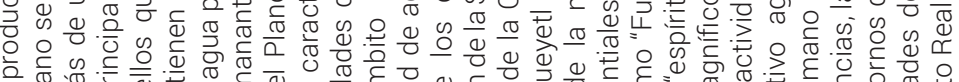

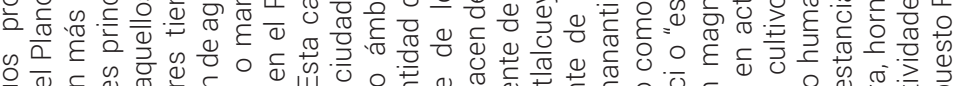

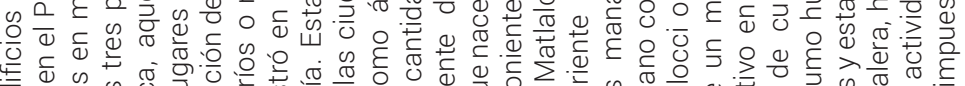

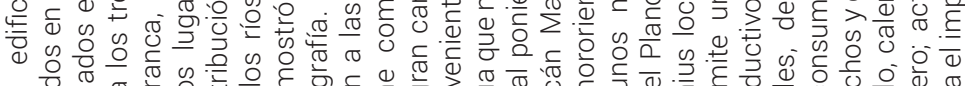

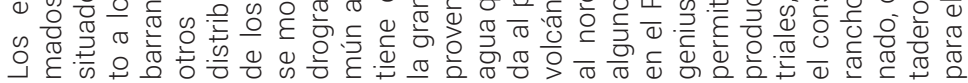

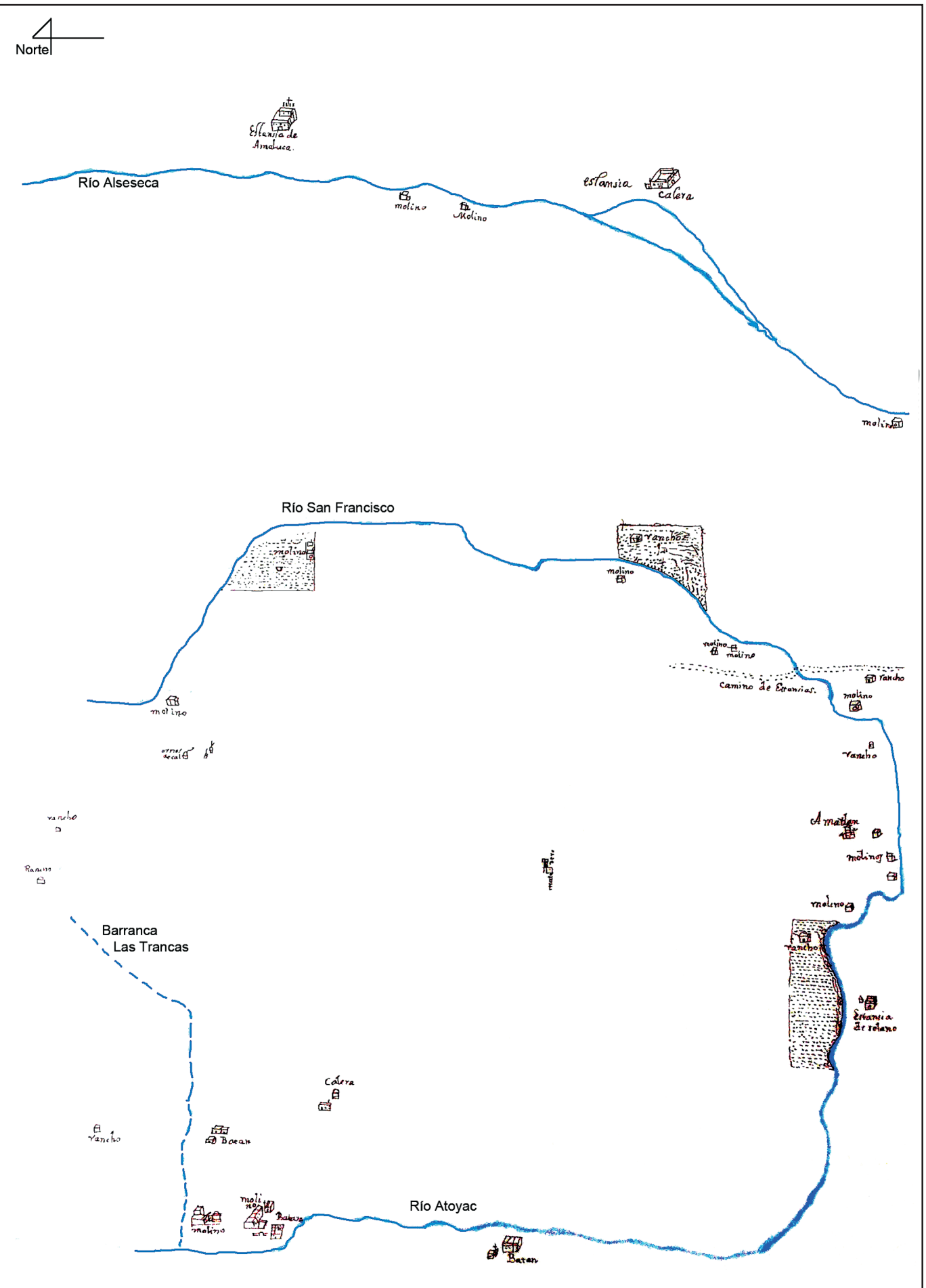



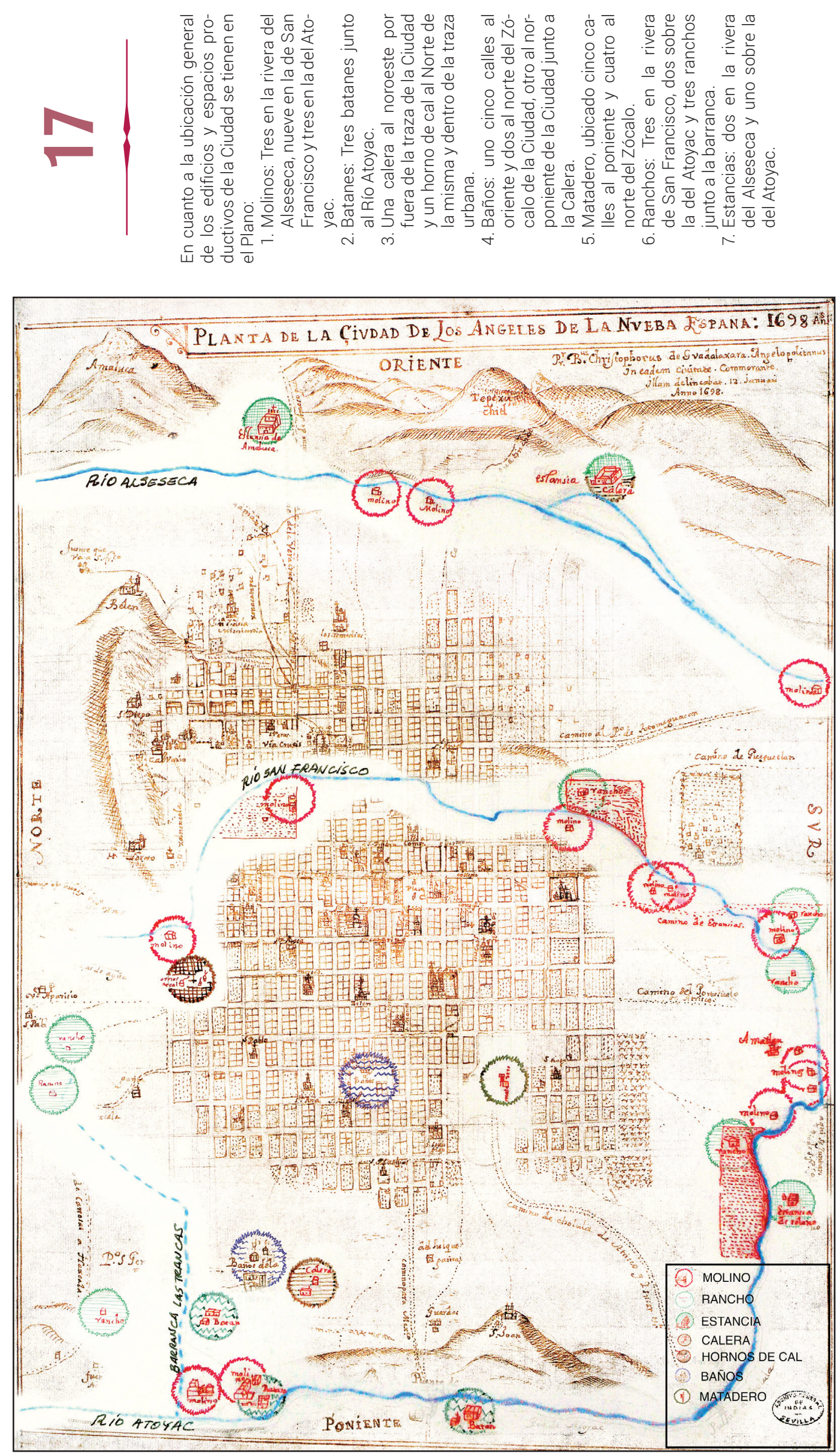

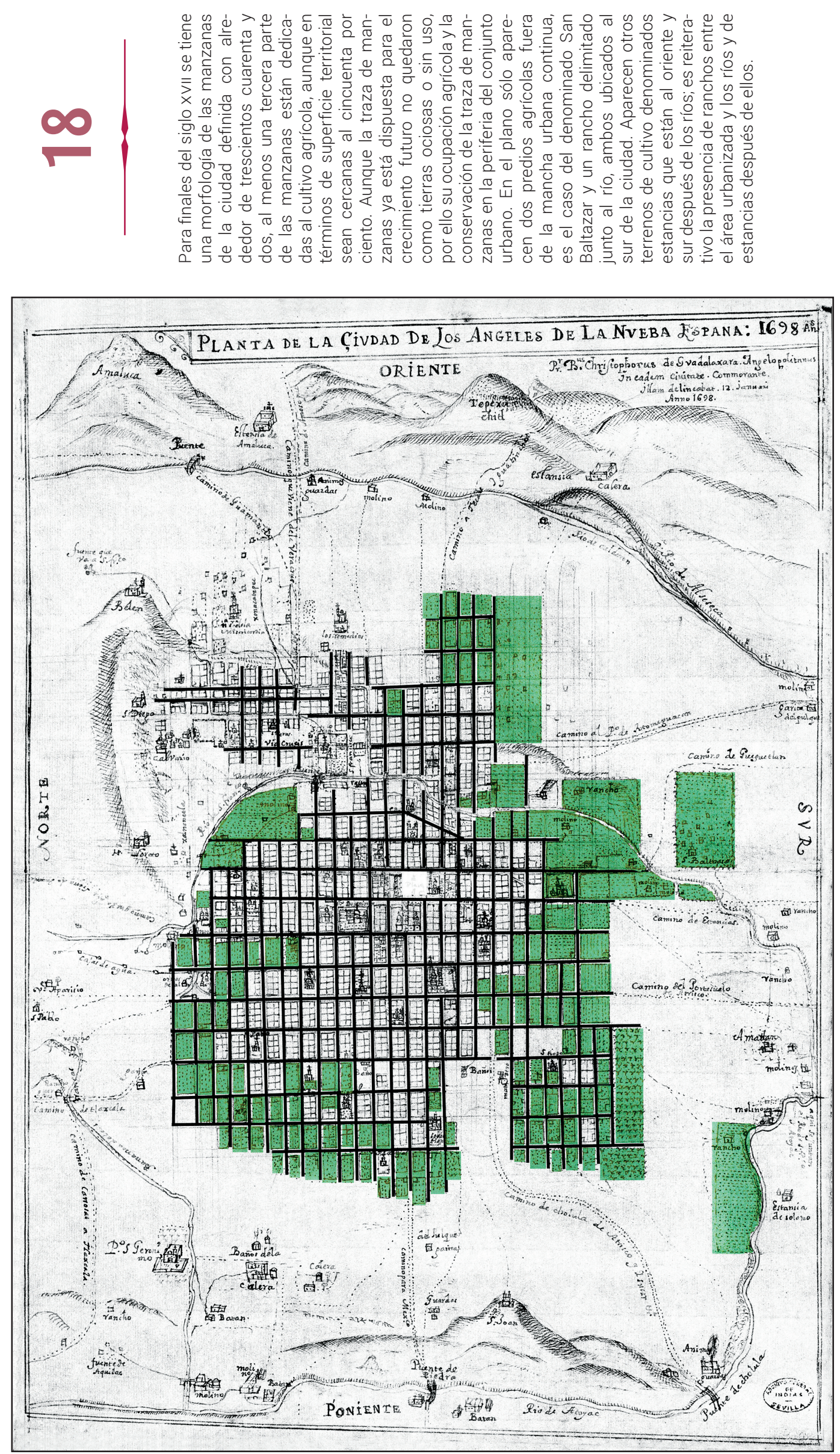

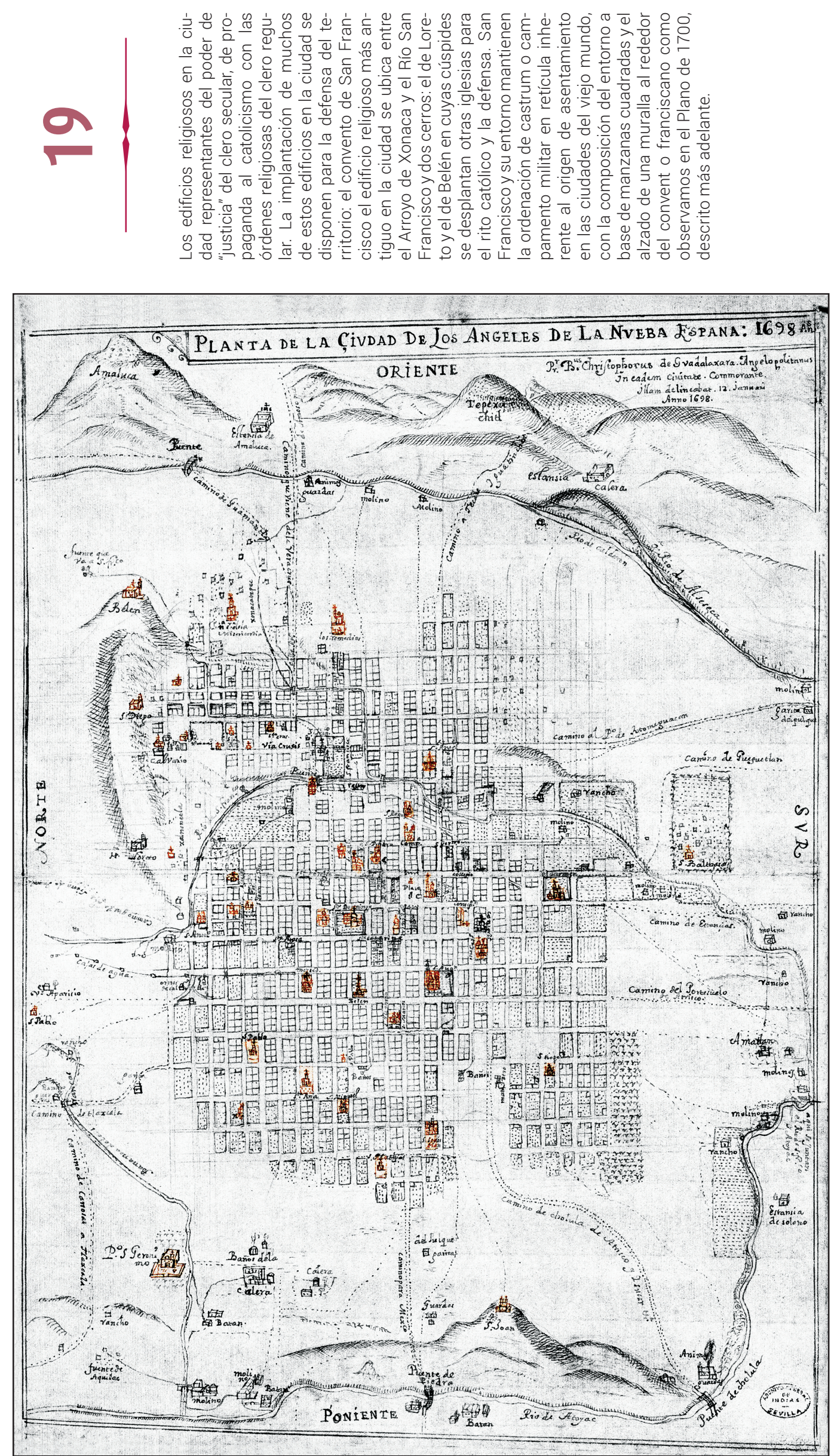

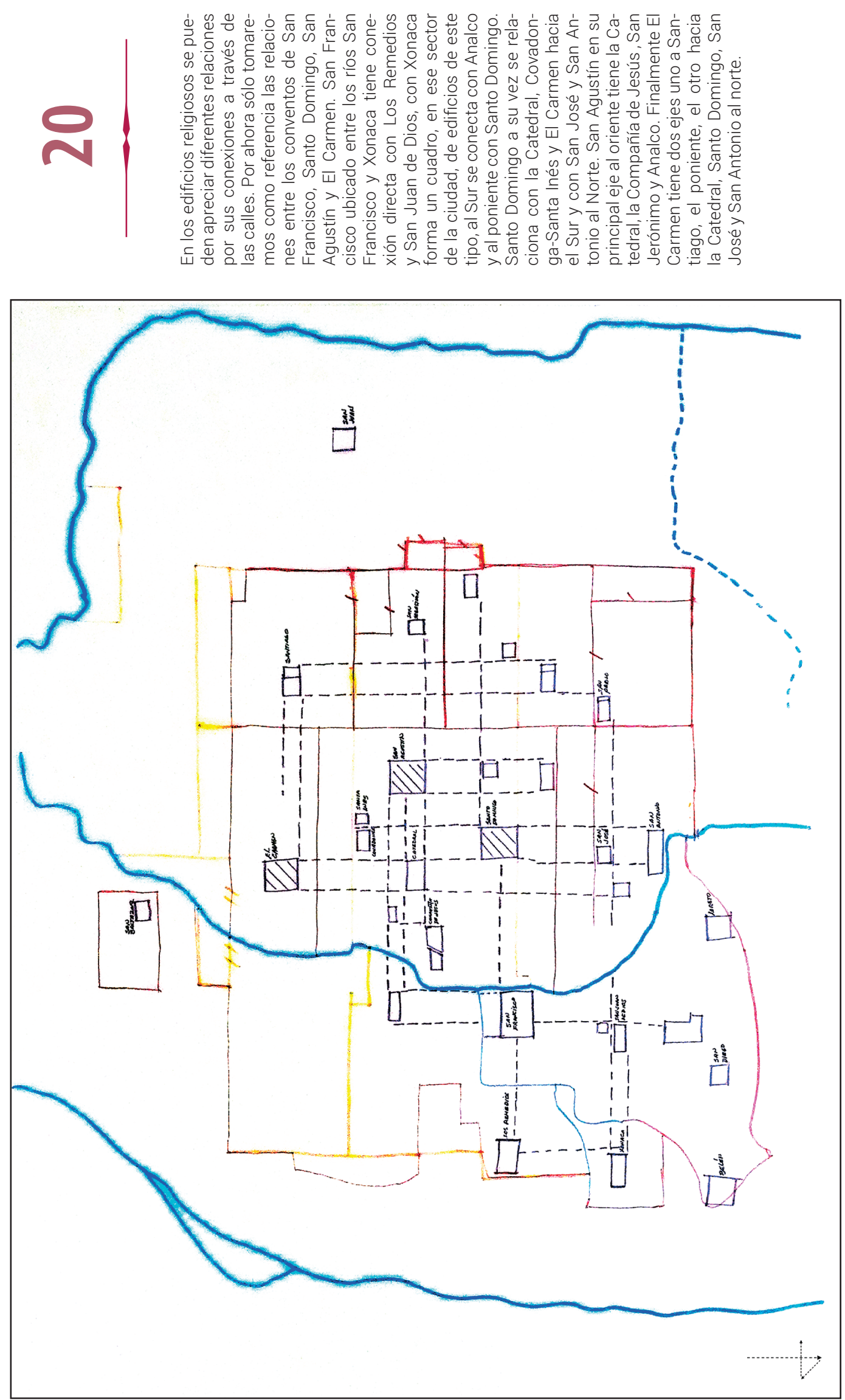


\section{$A C-3$ LECTURA DEL PLANO DE 1700}

1.Ciudad de Los Ángeles (México)

2. Plano de cerros y ríos con el paisaje urbano en el Plano de 1700

3. Plano Reconstructivo de las garitas del Plano 1700.

4. Plano de caminos y garitas en el Plano de 1700

5. Caminos y garitas con el paisaje urbano en el Plano de 1700

6. Circunferencia de garitas y espacio público: caminos y calles

7. Plano con ríos, cerros, círculo de garitas, caminos radiales, calles en retícula, puentes, plazas y acueductos

8. Plano con las principales plazas públicas, calles, puentes y acueductos que aparecen en el Plano de 1700

9. Plano con las principales Plazas en el espacio físico de La Ciudad de Los Ángeles

10. Plano de 1700 con las manzanas edificadas y la partición de la ciudad en grandes sectores

11. Principales edificios religiosos en el Plano de 1700

12. Plano con ríos, cerros, círculo de garitas, caminos radiales, calles en retícula, puentes, plazas, acueductos y los edificios 

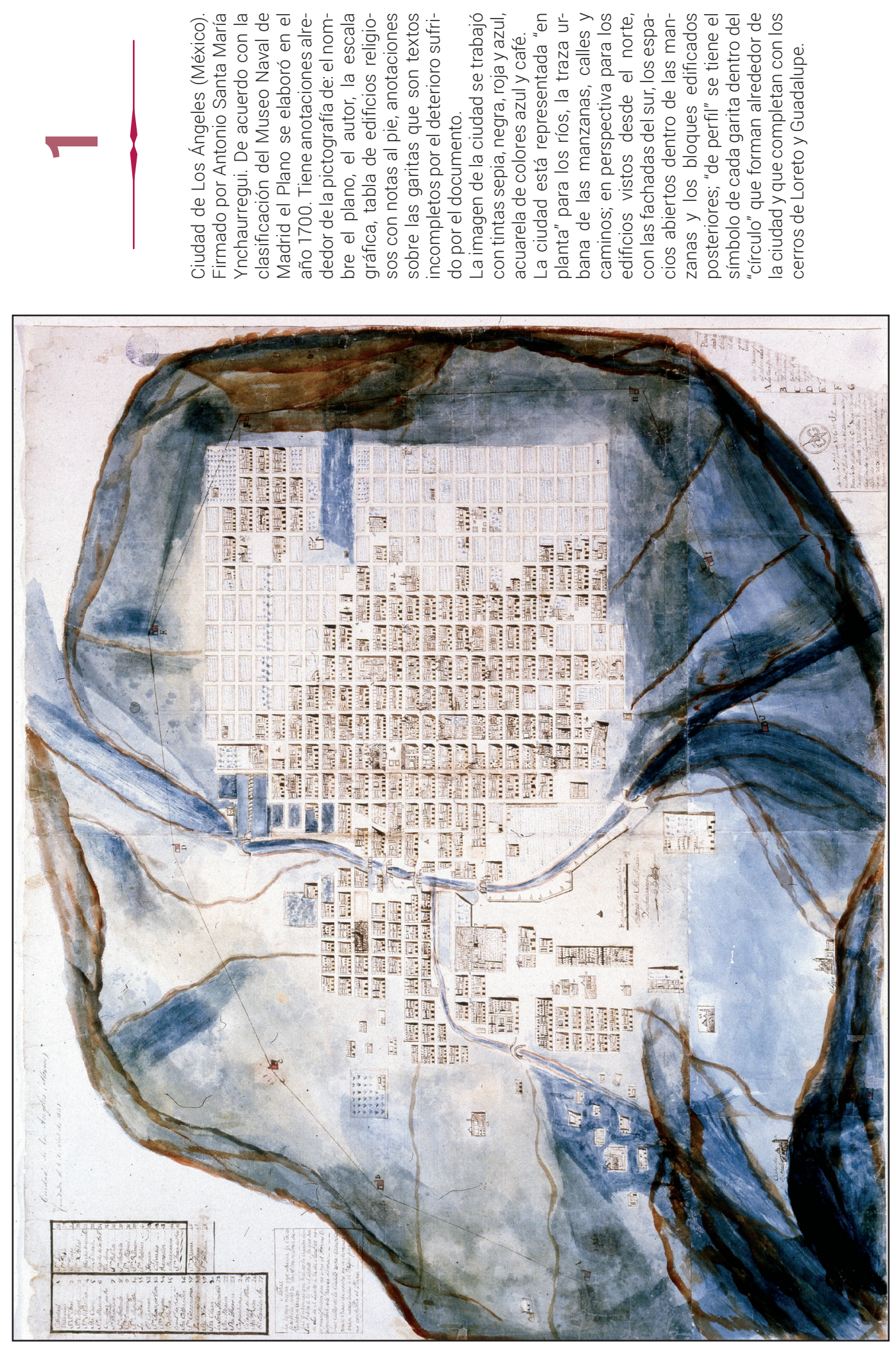

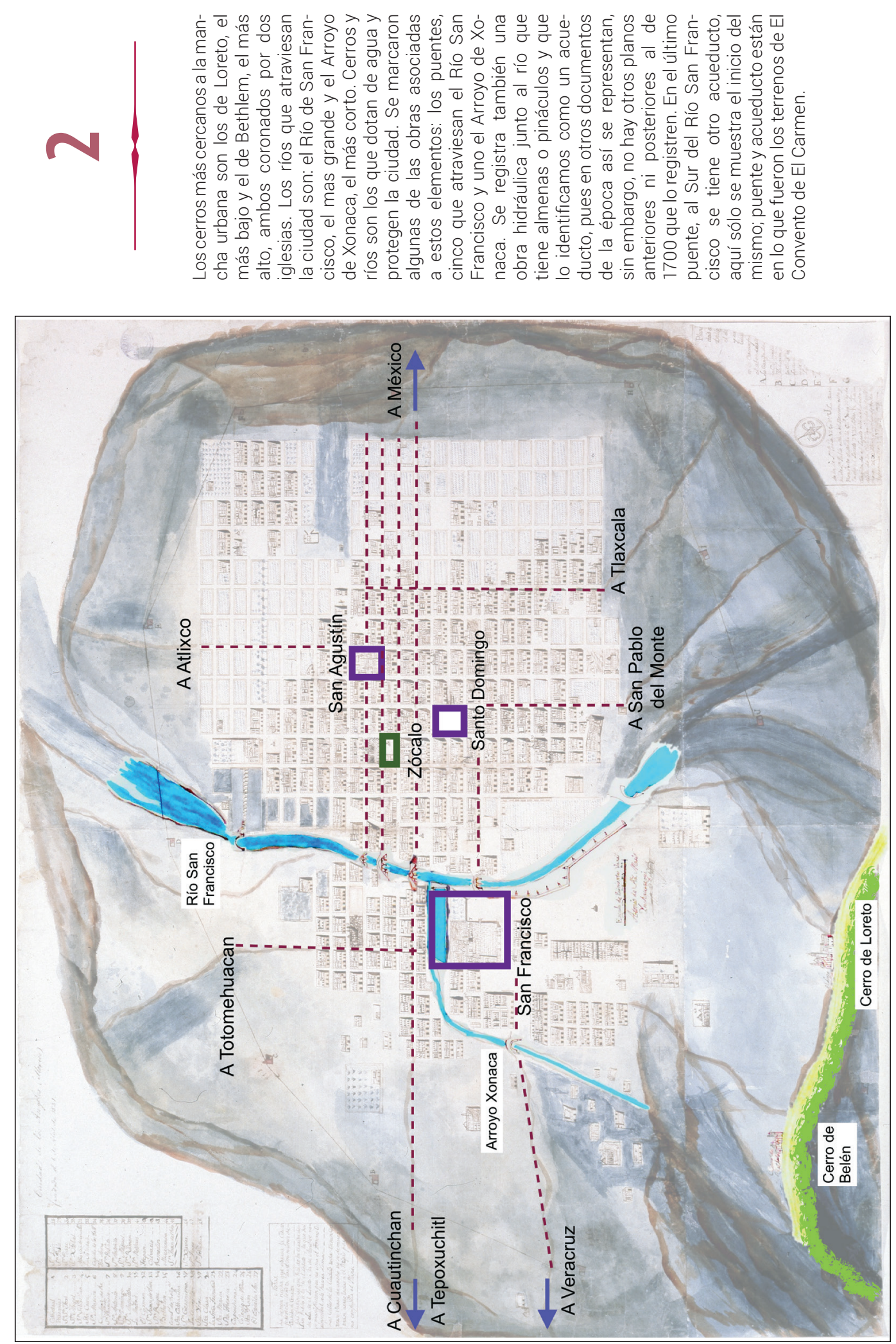

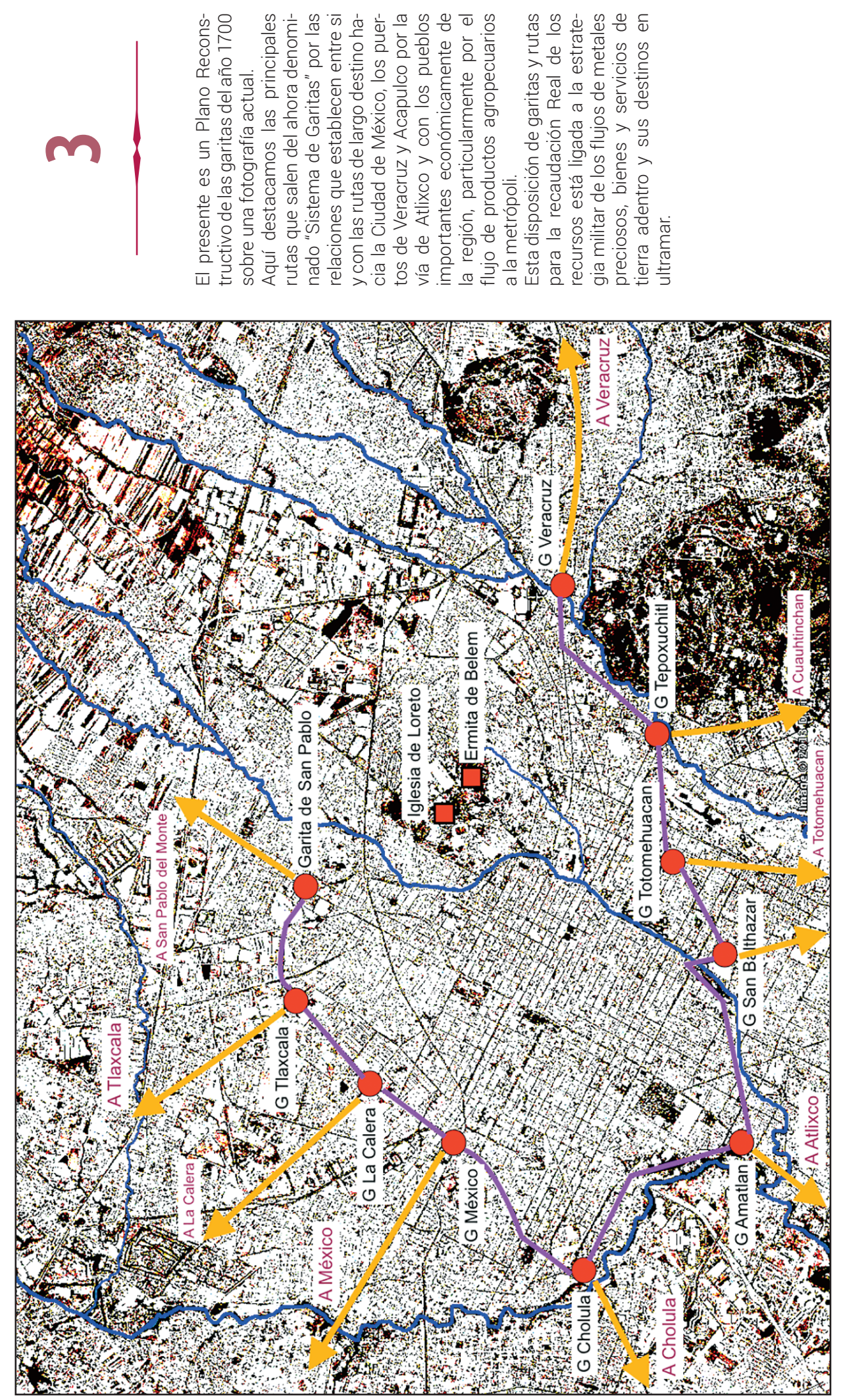

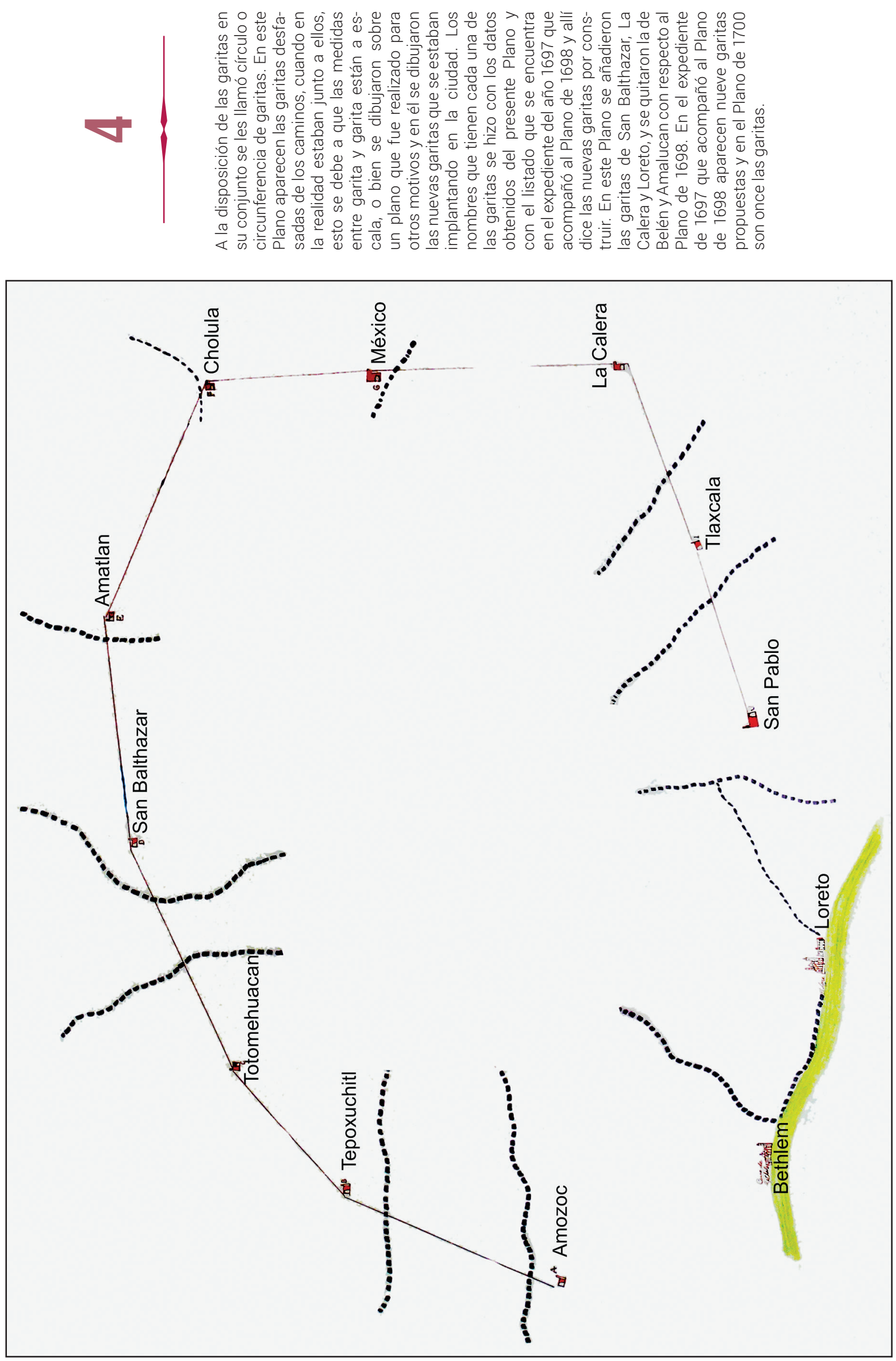

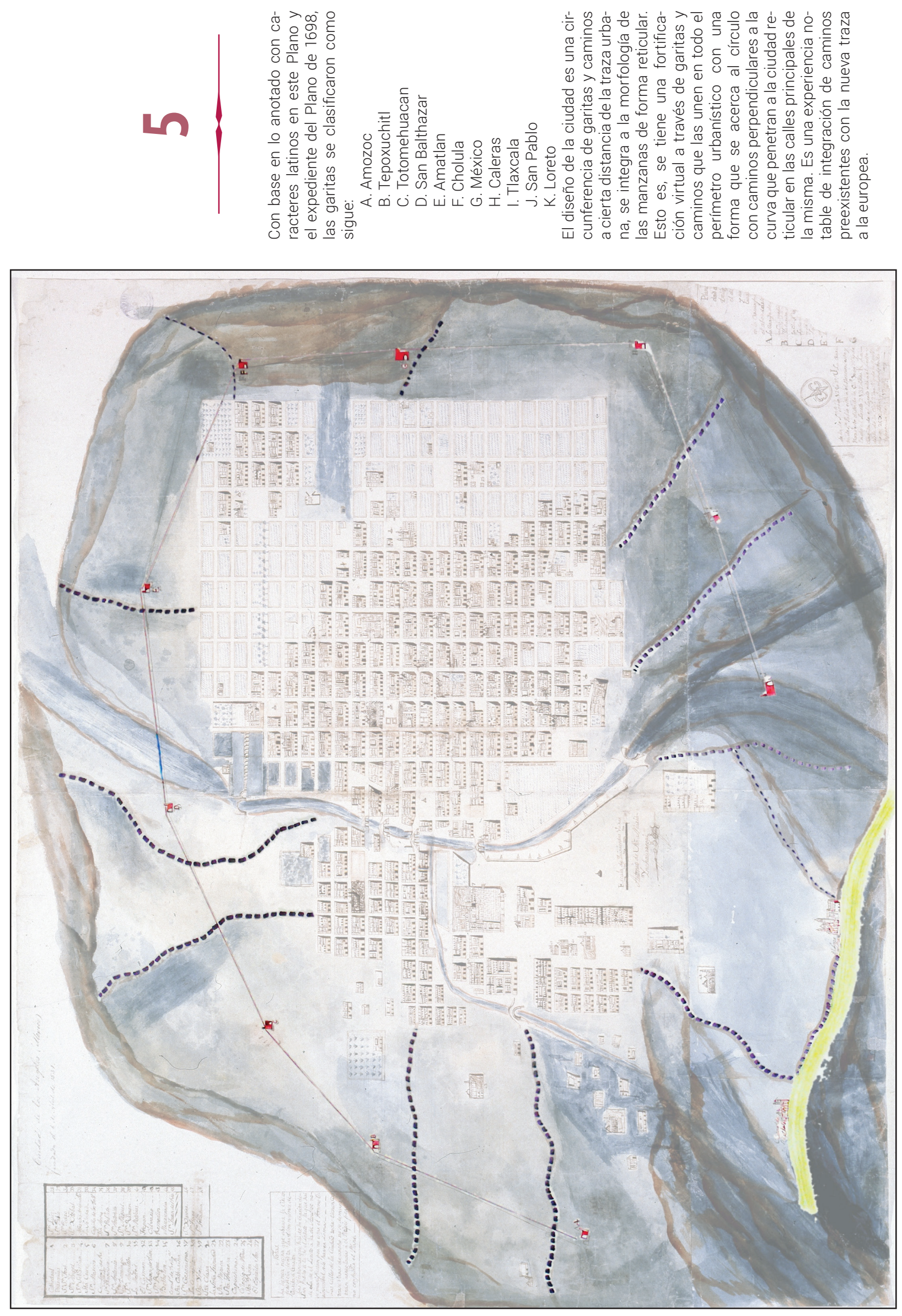

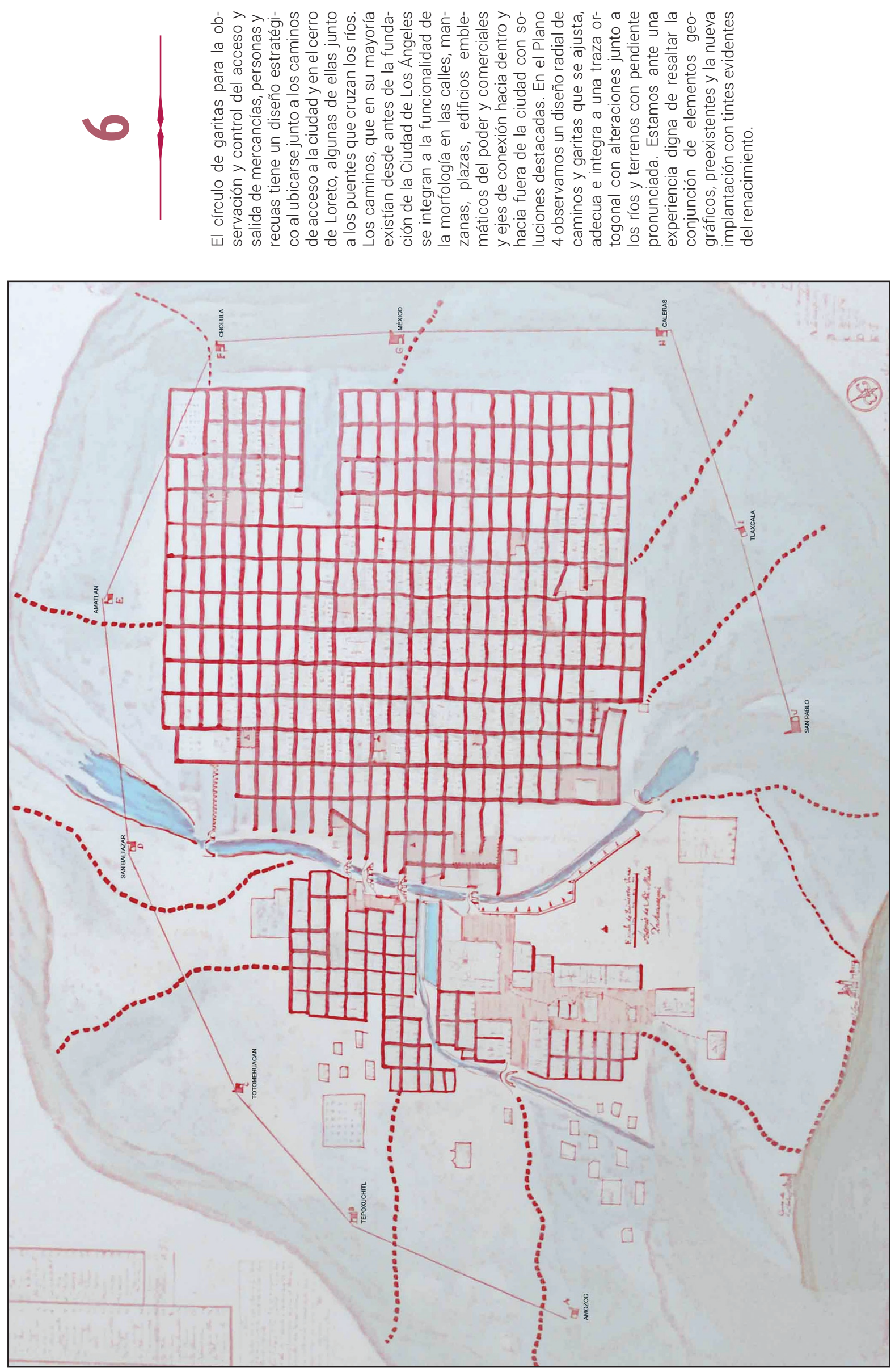

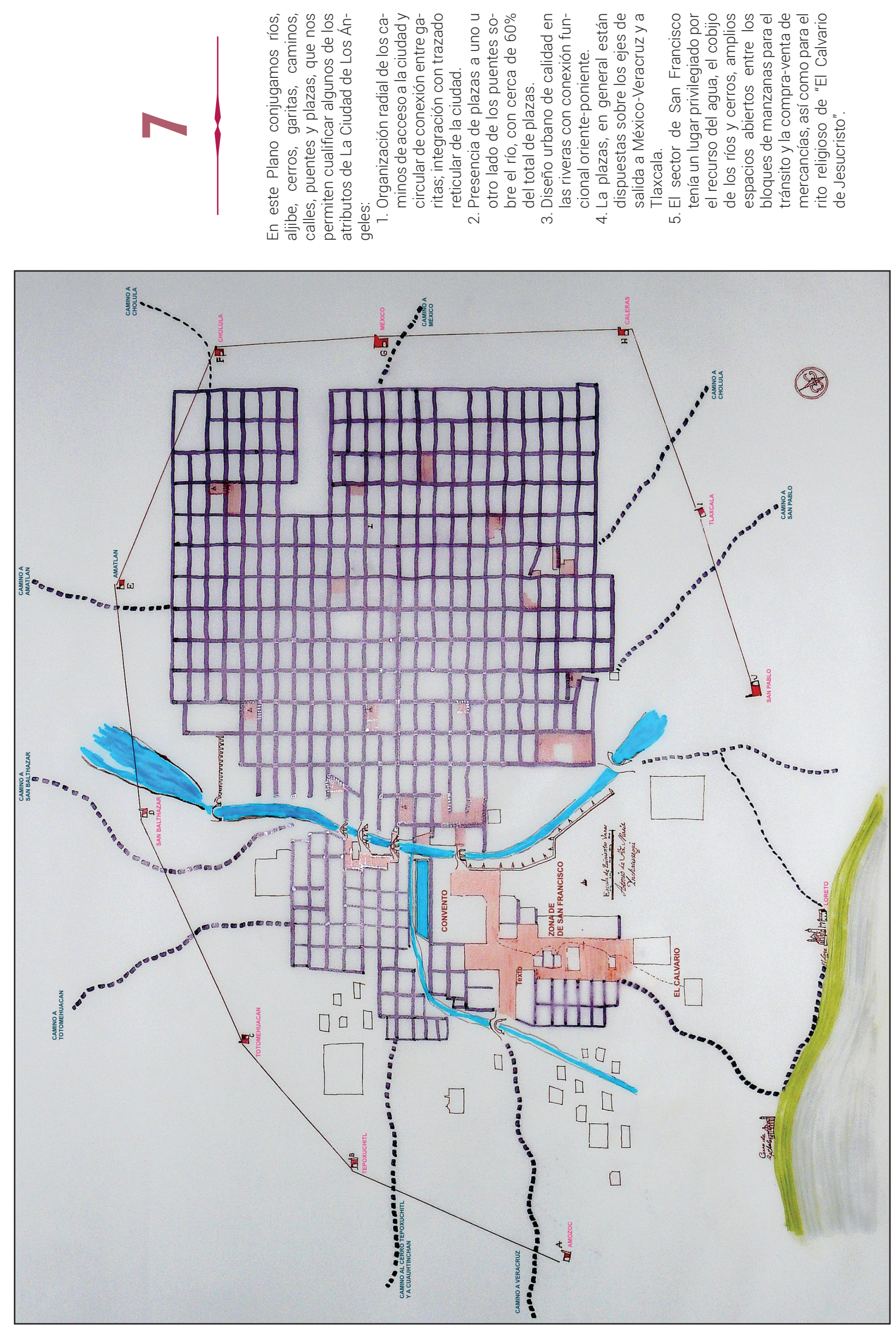

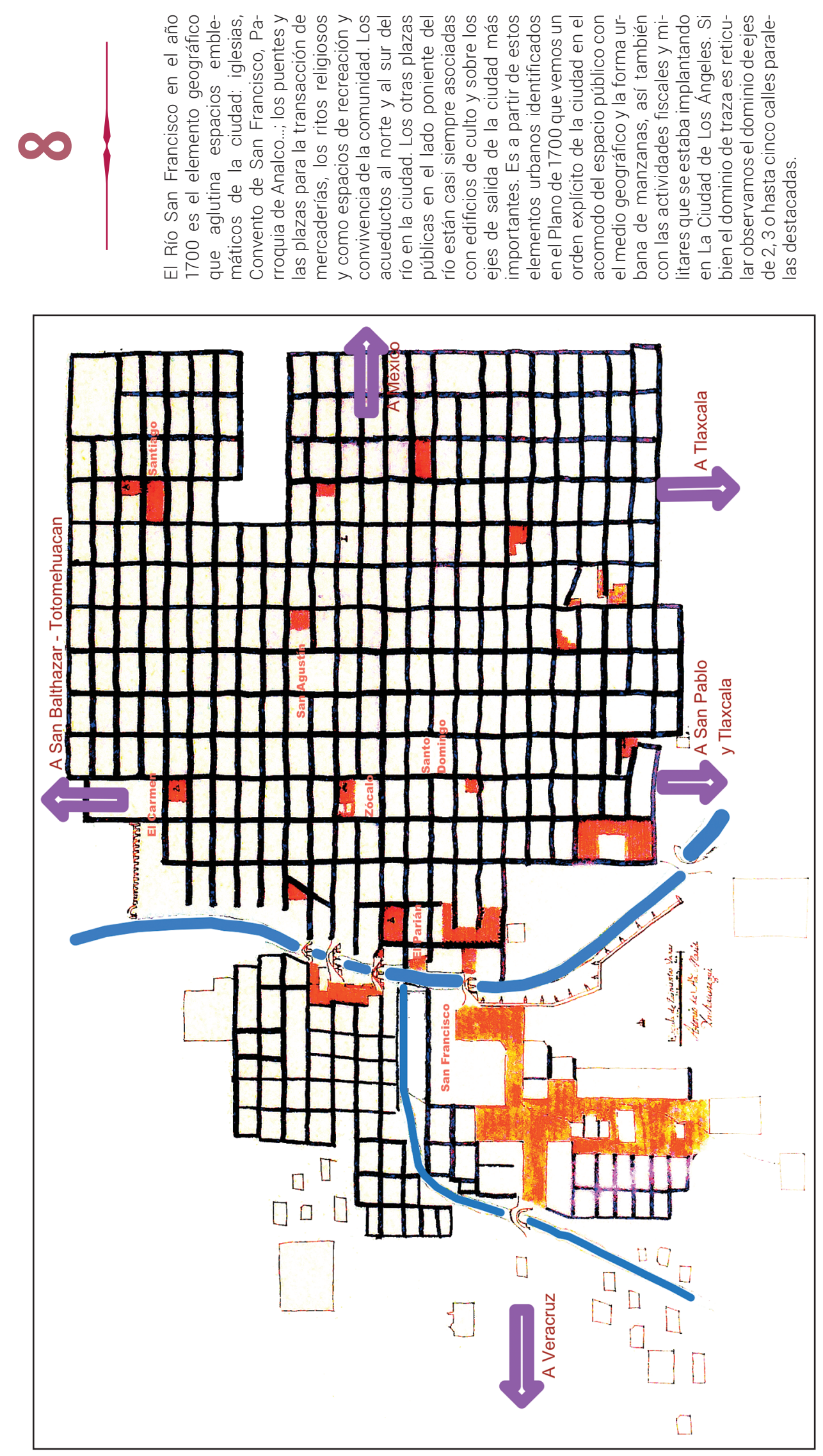

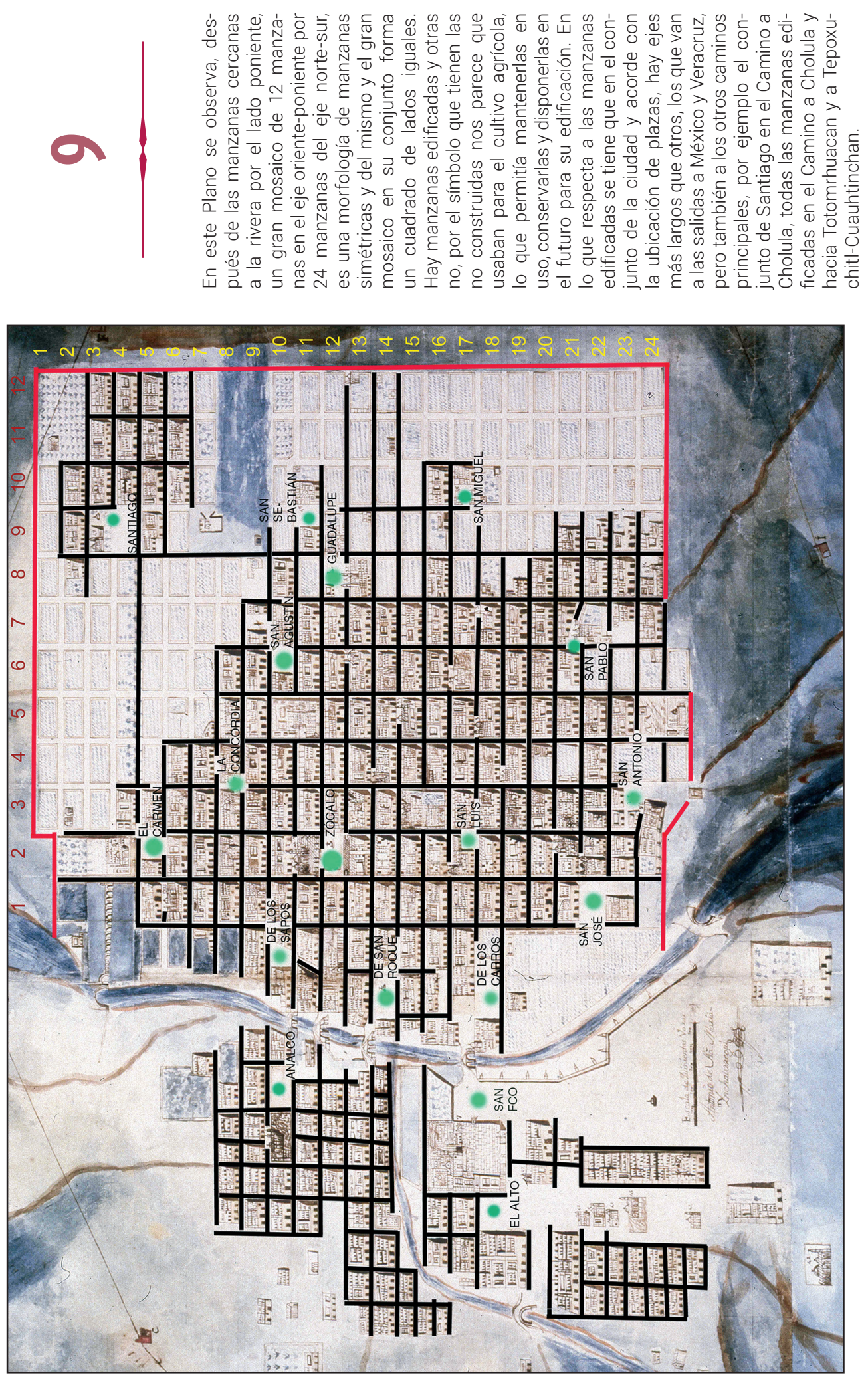

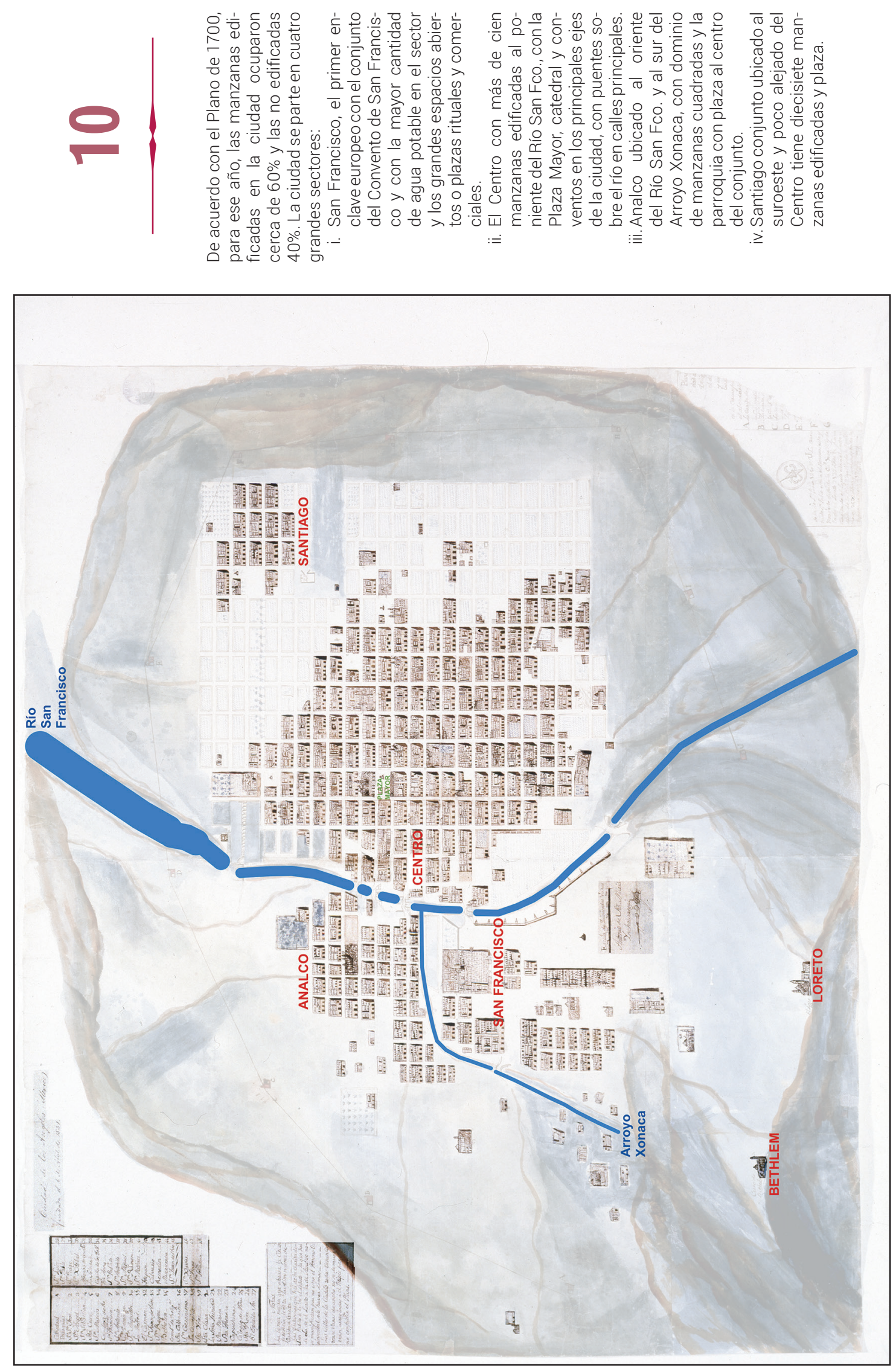

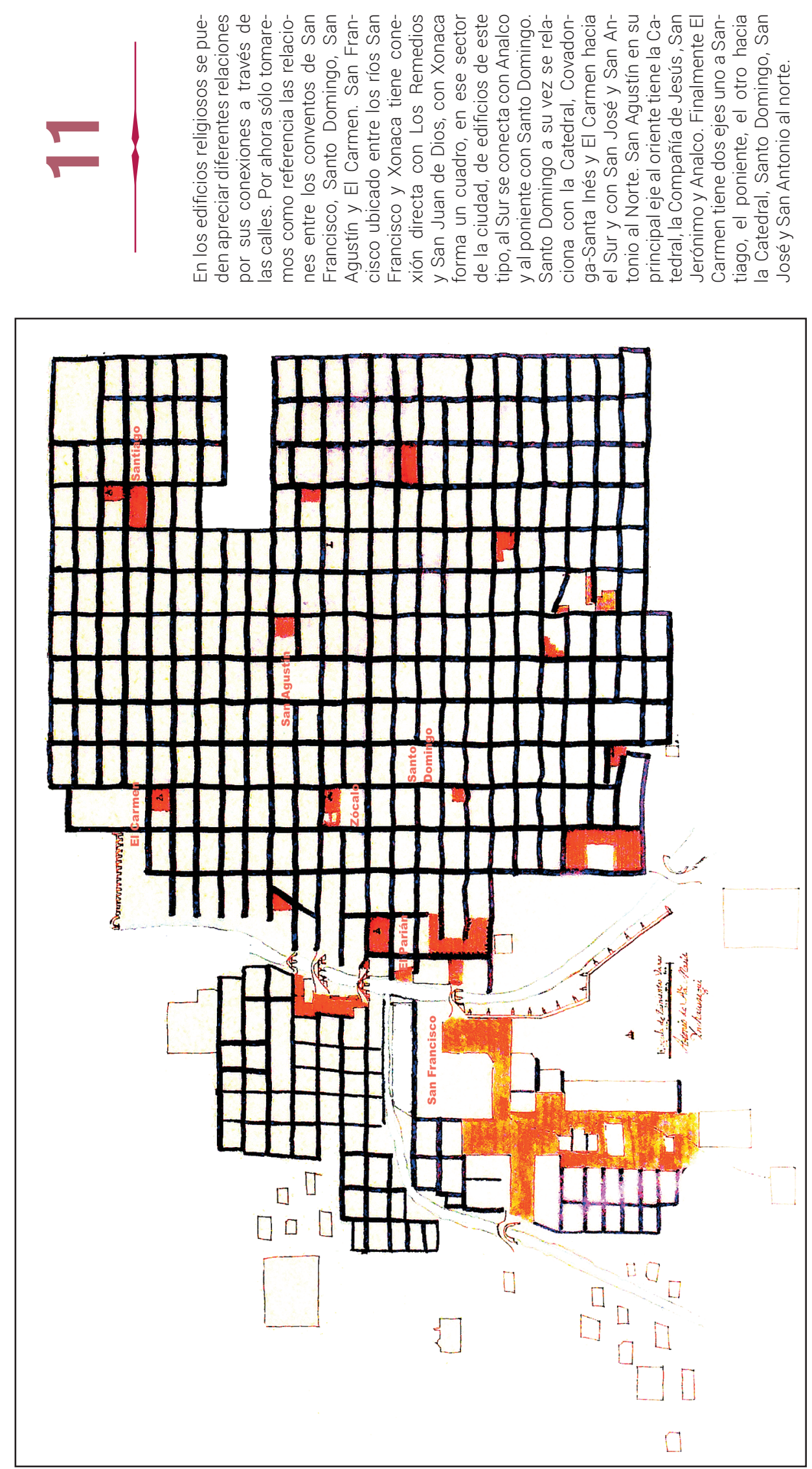

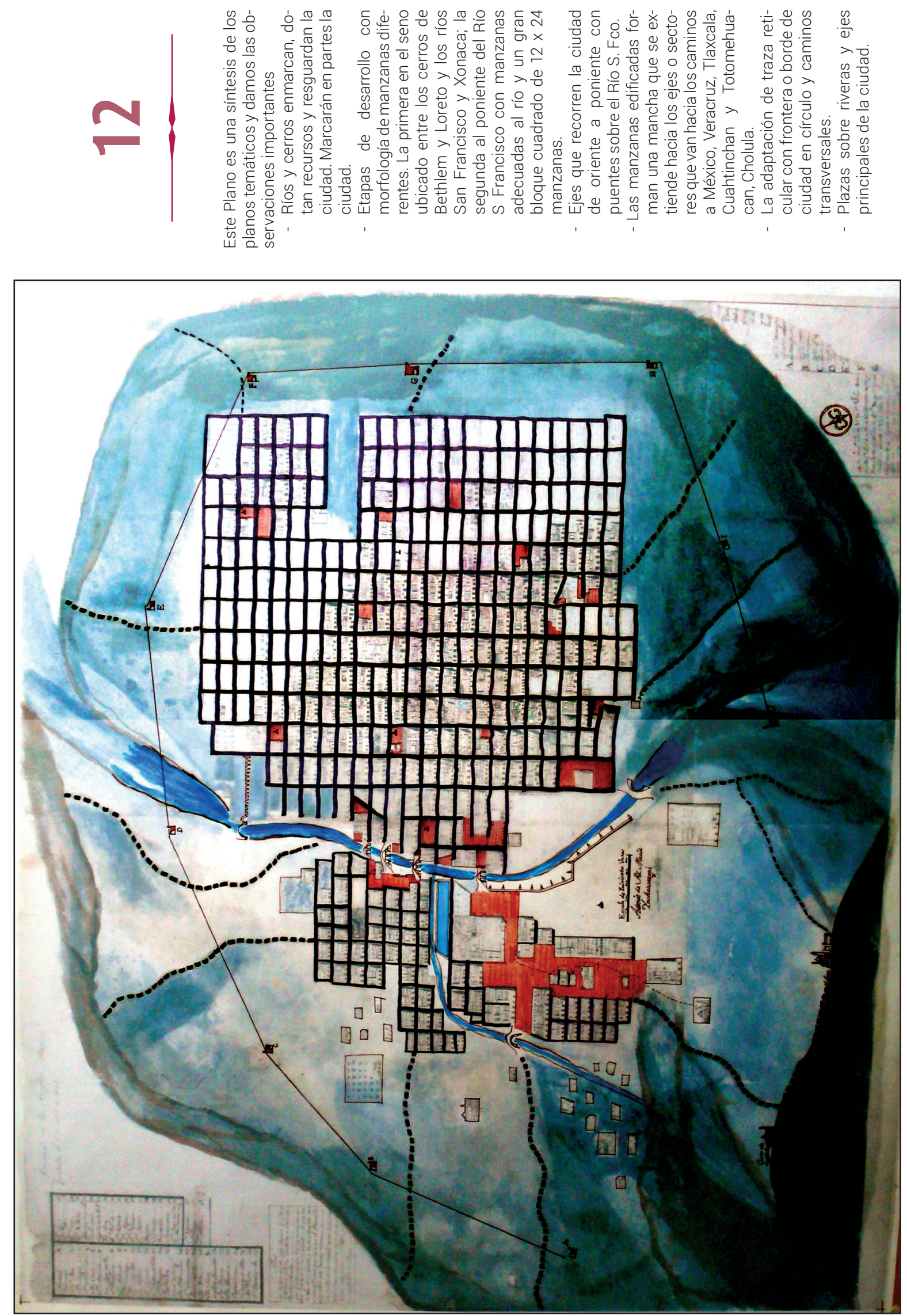


\section{$A C-4$ LECTURA DEL PLANO DE 1724}

1. Plano de las Garitas de la Aduana de Puebla de Los Ángeles por Juan José de Veitia y José Joaquín Uribe y Castrejón, 1724. AGI, MP, MÉXICO, 519

2. Cerros y ríos en el Plano de 1724

3. Caminos entre garitas en el Plano de 1724

4. Manzanas edificadas, edificios emblemáticos y garitas en el Plano de 1724

5. Caminos y círculo de garitas construidas hasta 1724 y el nuevo círculo previsto para el futuro inmediato, con el paisaje urbano y geográfico asociado

6. Originales del modelo de garita a construir en 1724

7. Diseño de garita para construirse en el nuevo círculo de garitas dispuesto en el Plano de 1724 


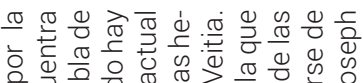

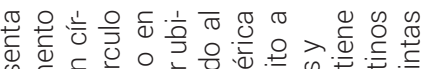

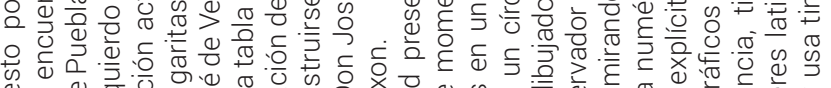

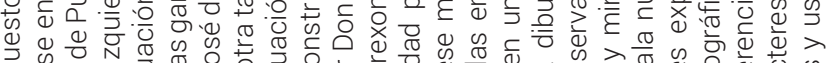

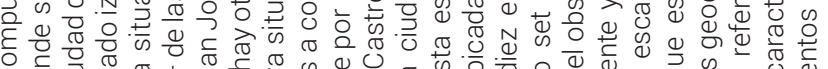

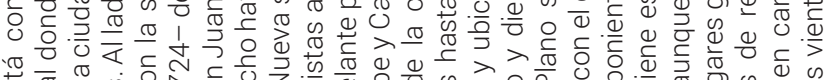

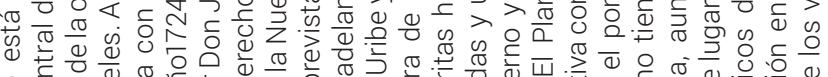

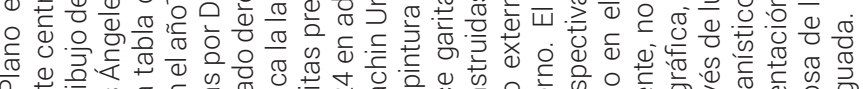

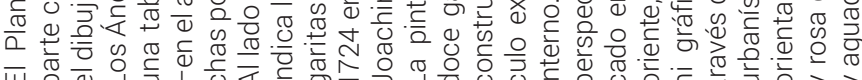

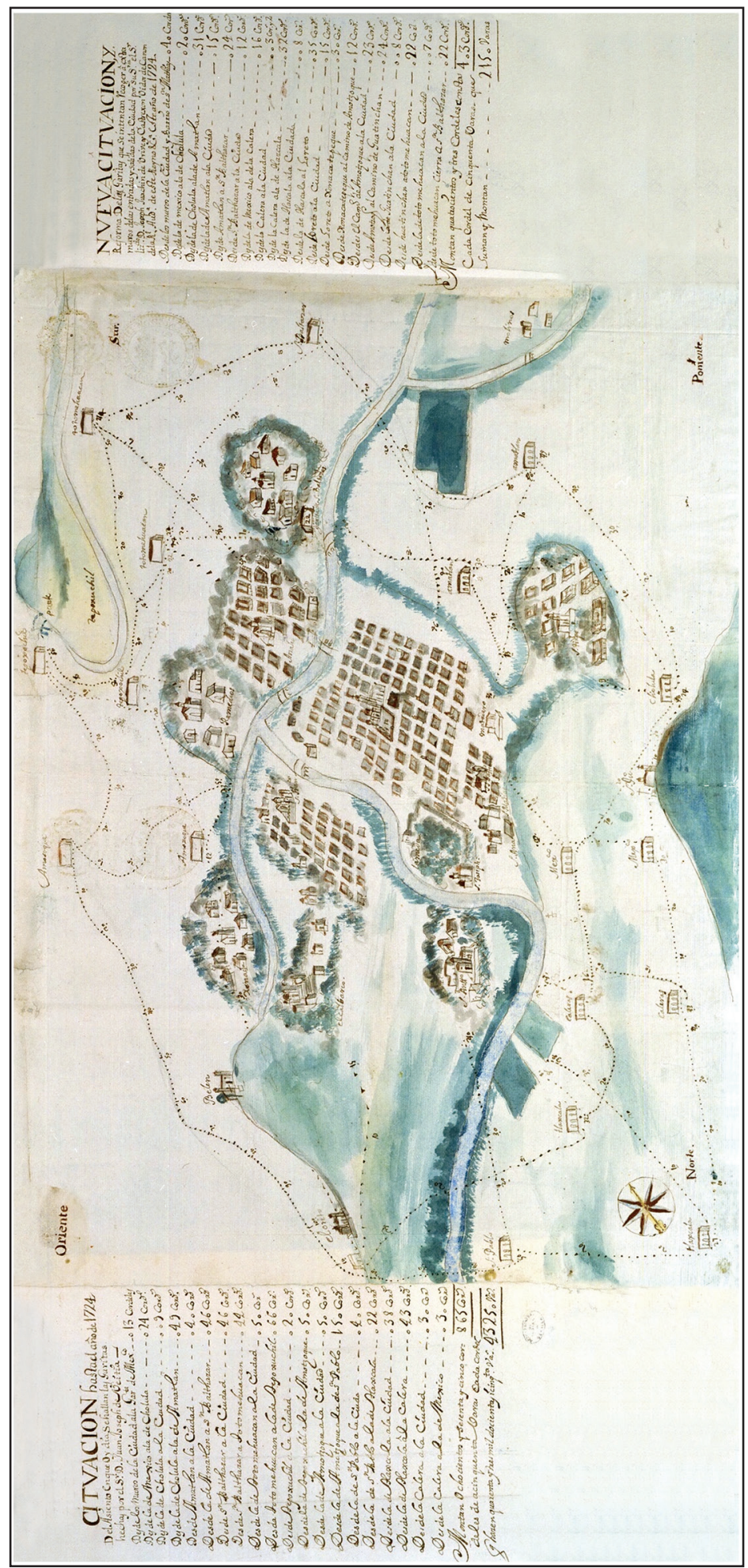



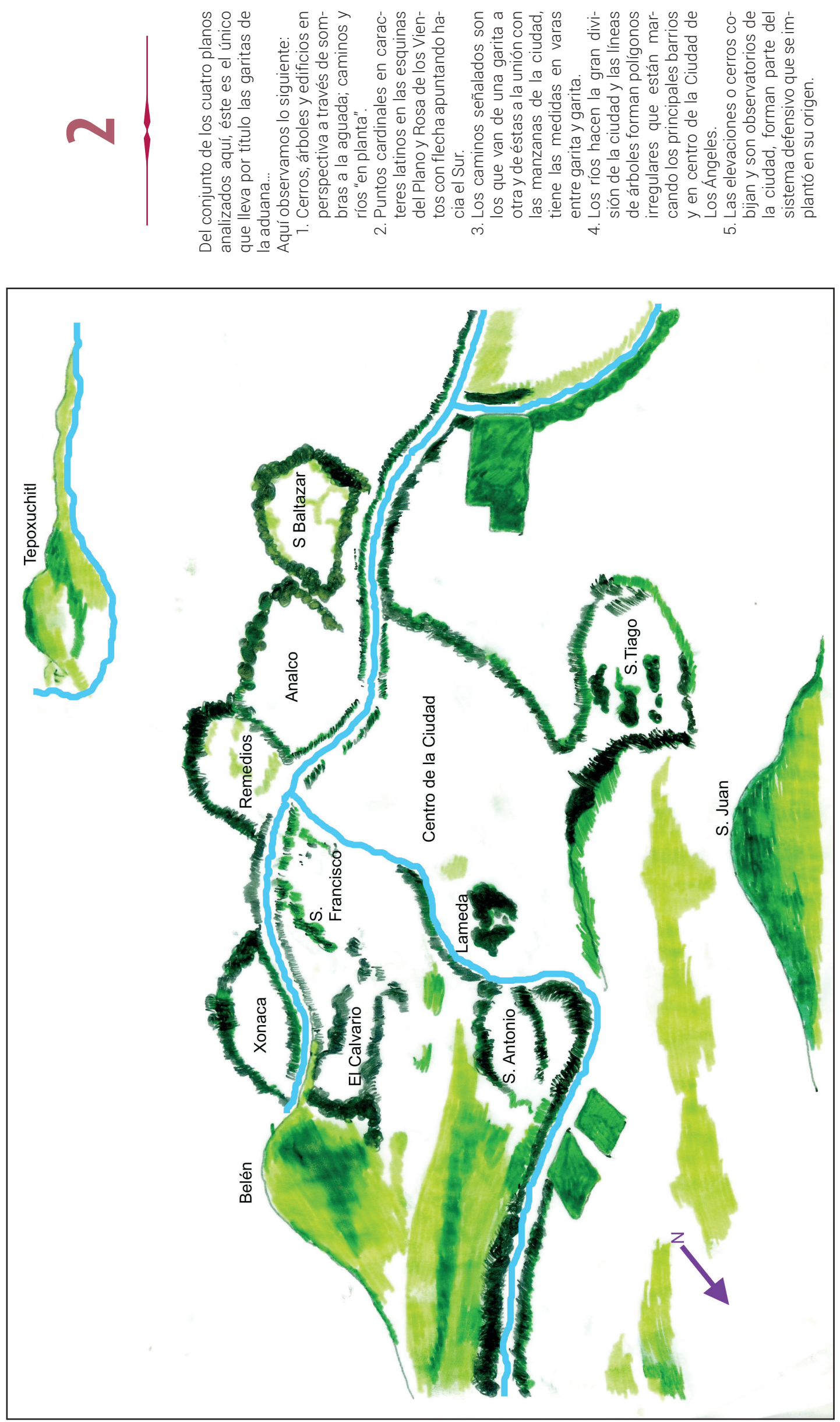

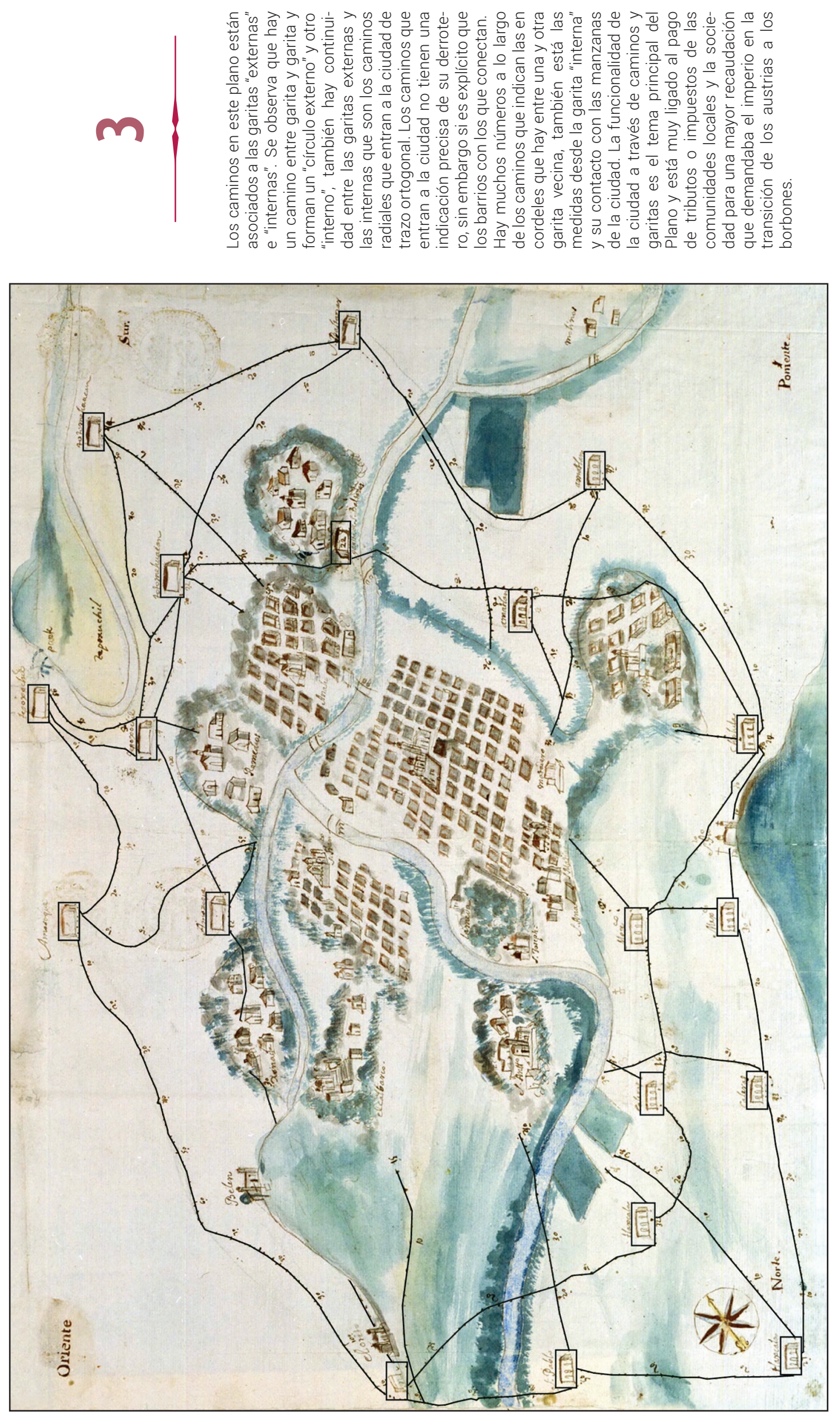

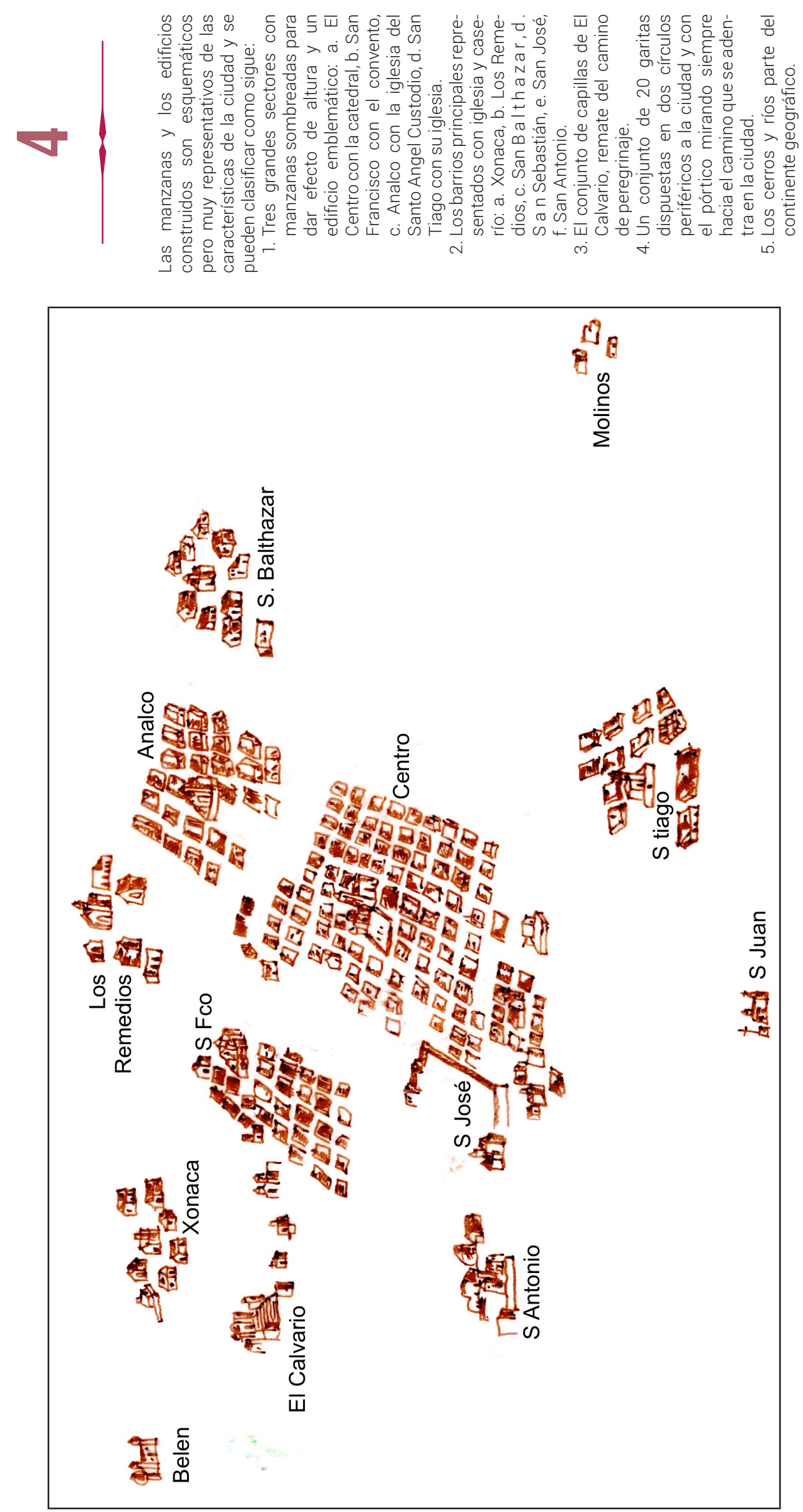

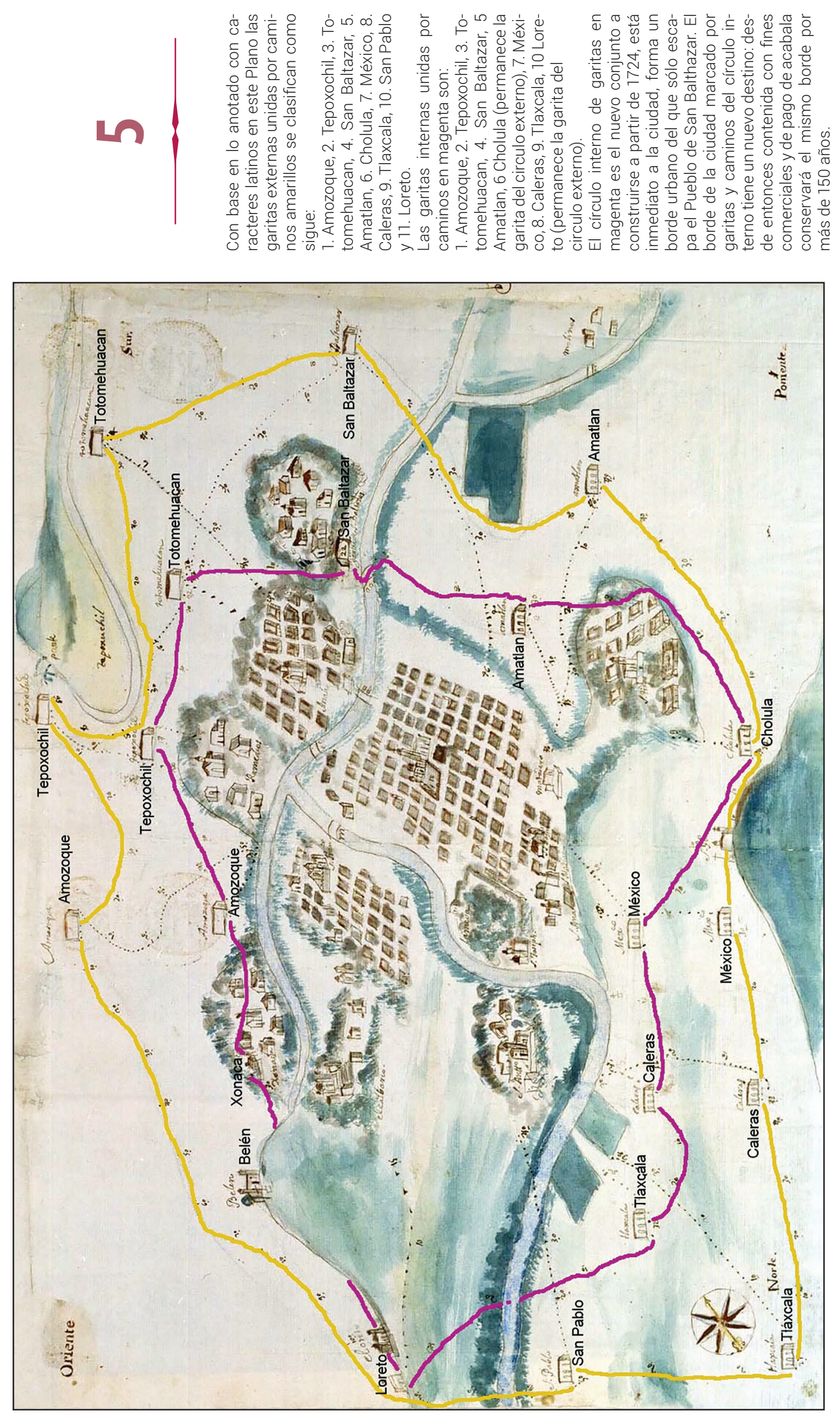

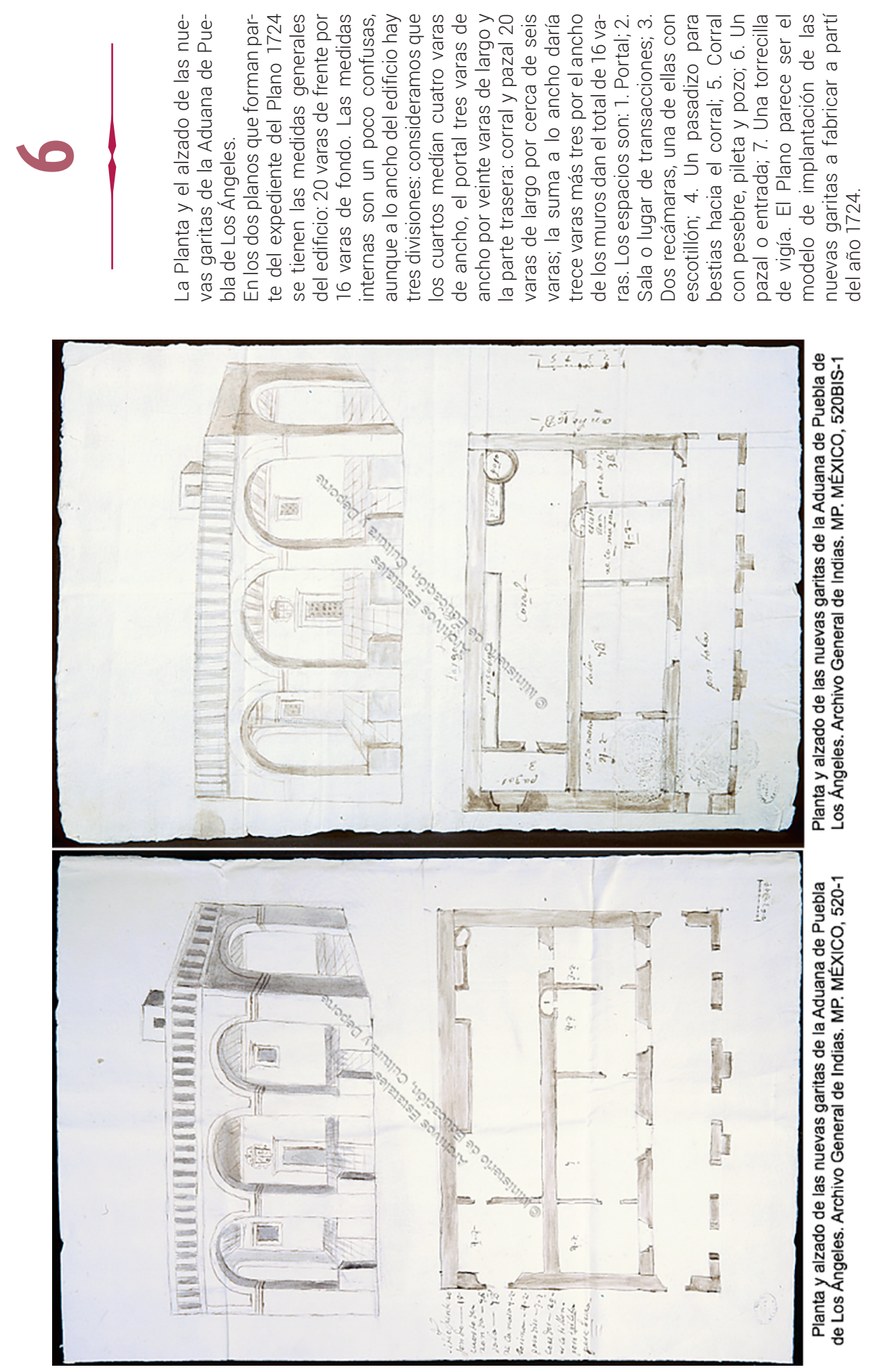

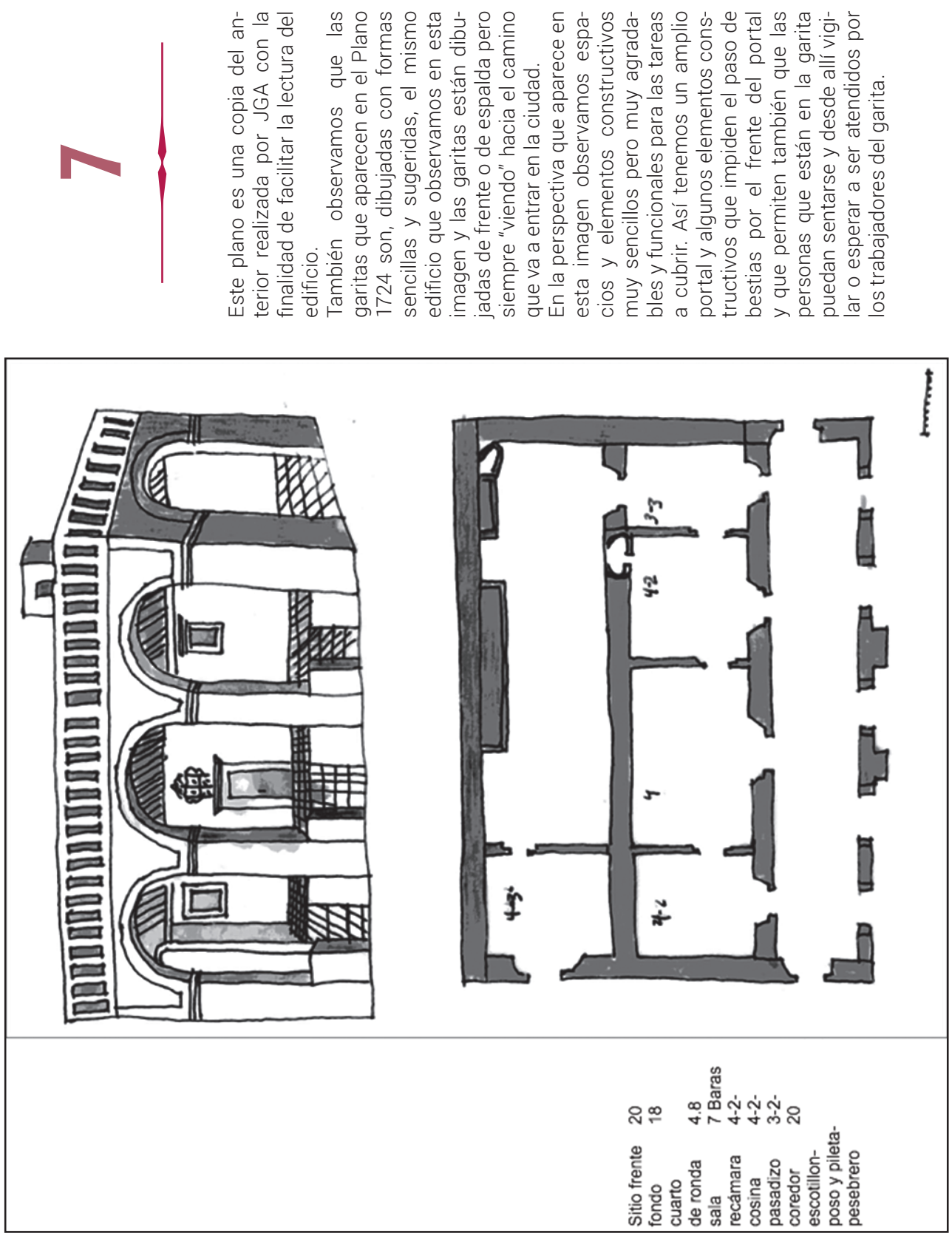


\section{$A C-5$ LECTURA DEL PLANO 1862}

1. Croquis de la Ciudad de Puebla y sus alrededores. 1862. Archivo del Ayuntamiento del Municipio de Puebla

2. Cerros y ríos, caminos y círculo de garitas, traza urbana y plazas públicas

3. Círculo de garitas que con el río forman la almendra a la mexicana en la Ciudad de Puebla

4. Persistencia del patrón defensivo-comercial del círculo de garitas en el año de 1862 a partir de la primera propuesta en 1697 y con algunas transformaciones en los años 1700 y 1724 

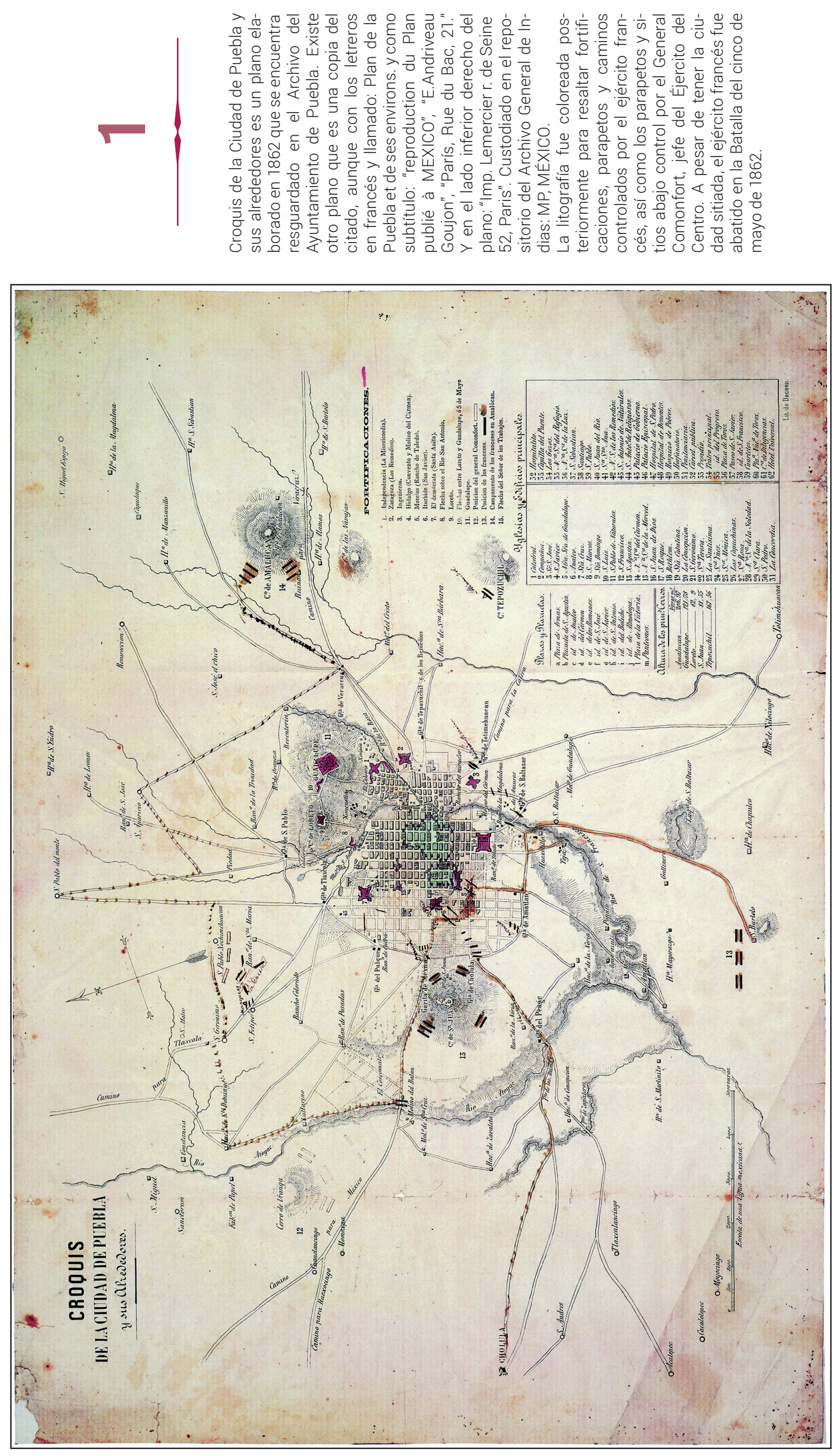

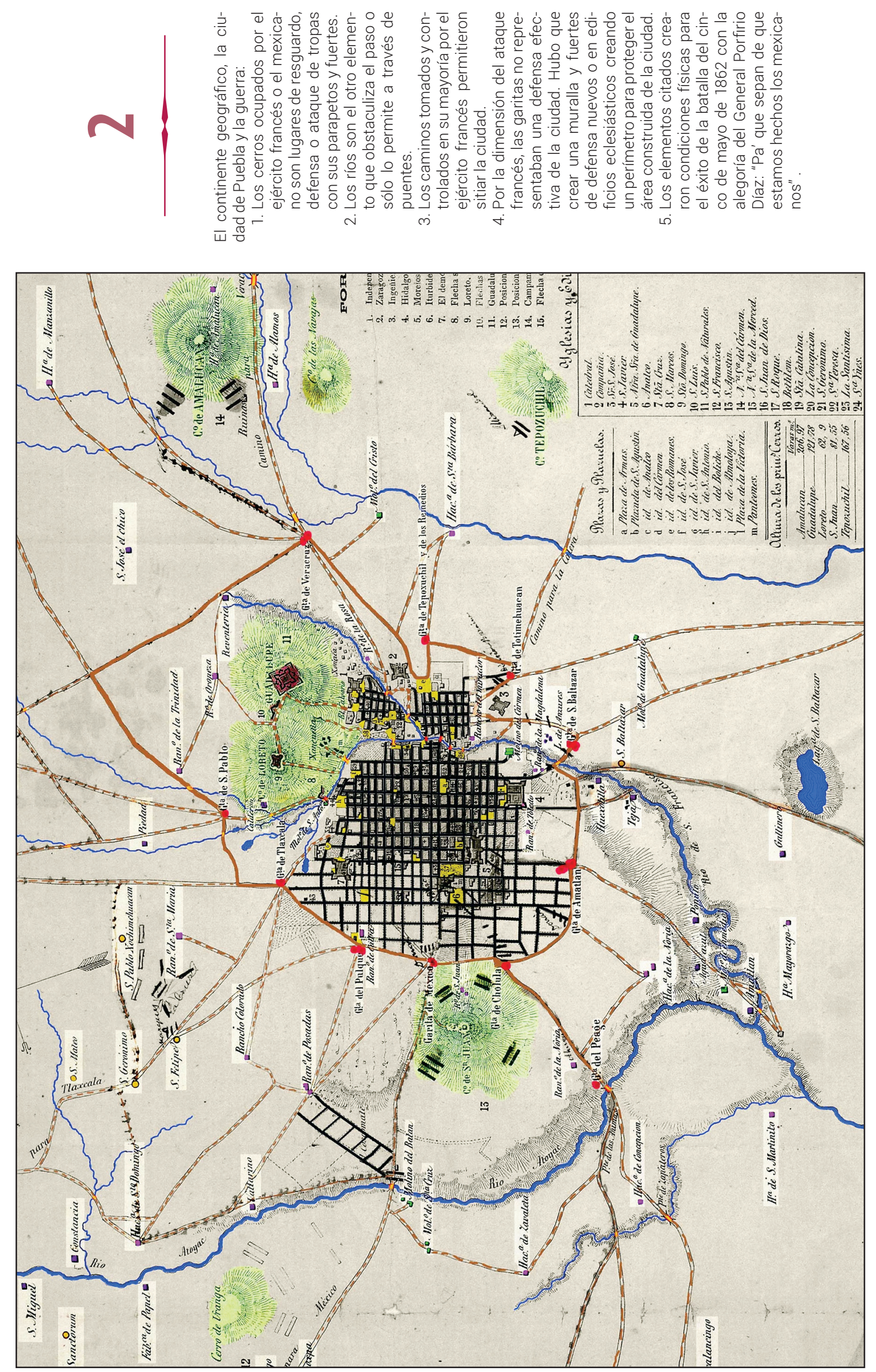

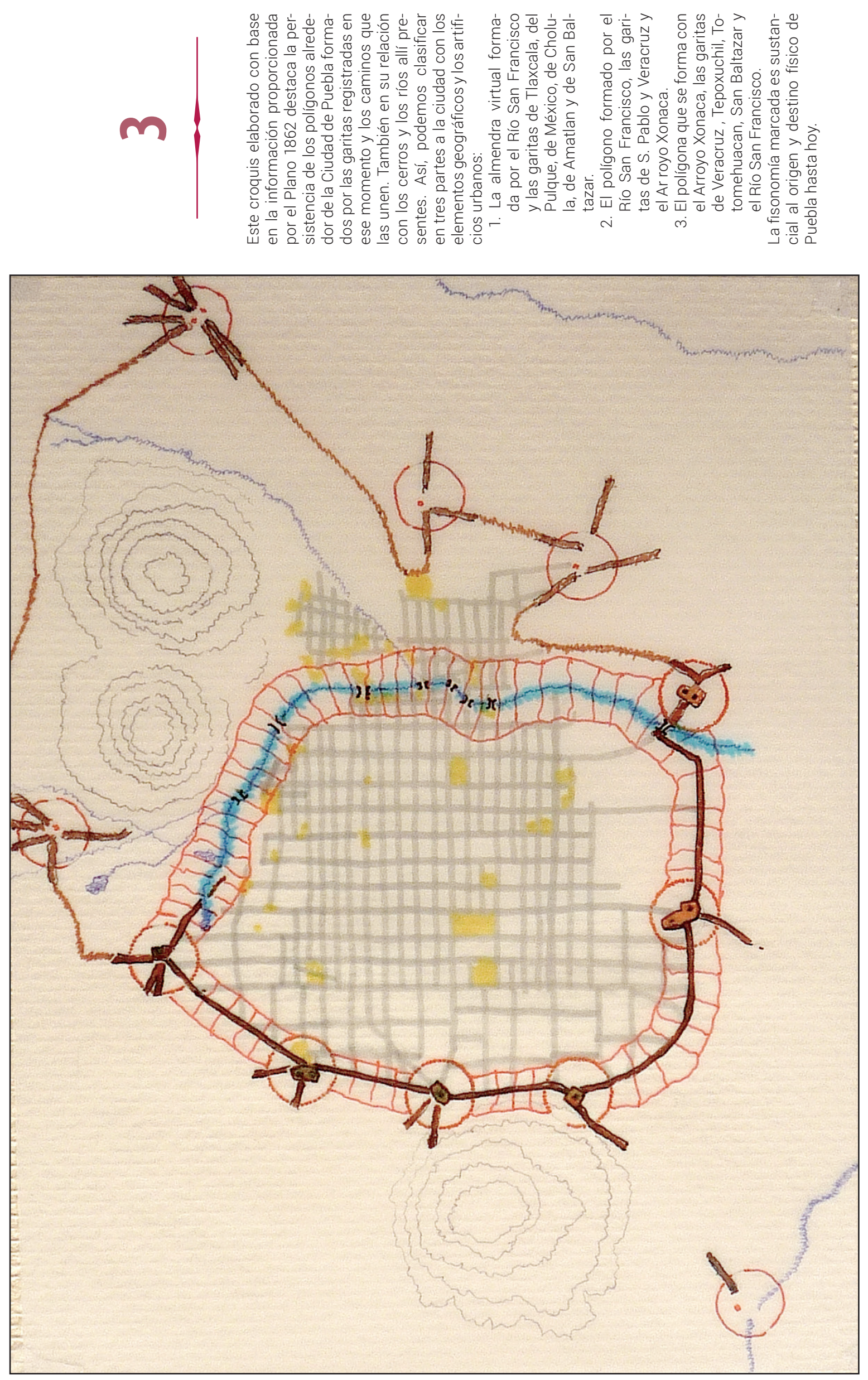

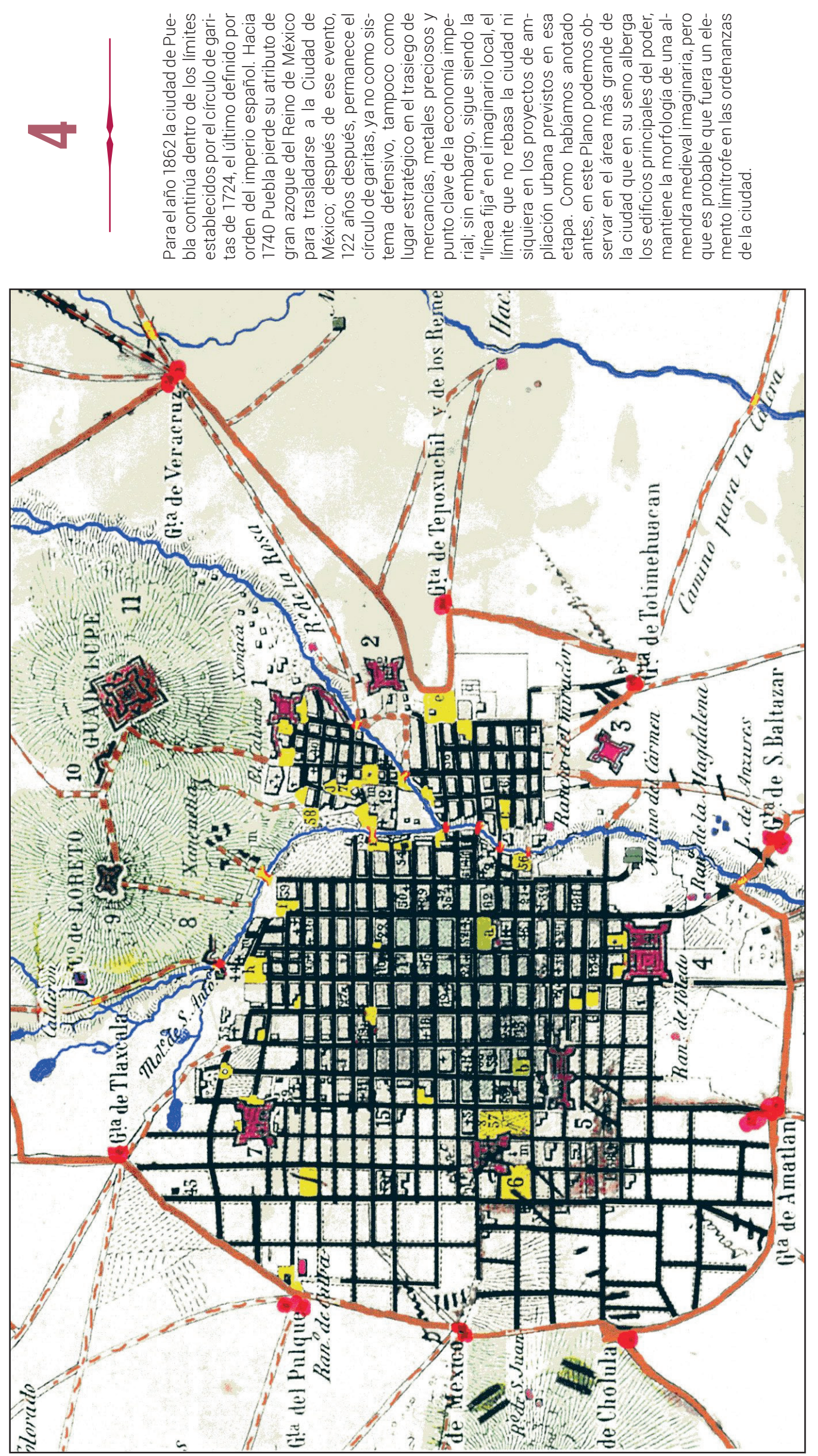


\section{AD-1 PALEOGRAFÍA PARCIAL: TESTIMONIO DE AUTOS. AÑO 1698}



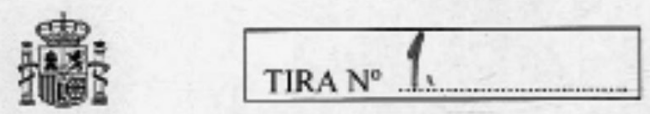

Archivo General de Indias

Ministerio de Educación, Cultura y Deporte

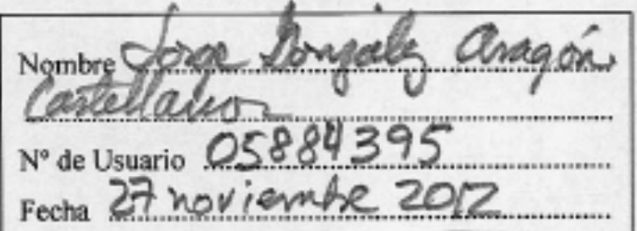

\section{SIGNATURA}

Sección / Unidad instalación (legajo)

MEXICO, 341 año 1698

Documento Centas del Capitán Juen de Cantajal.... / Testimoxio yautos que se remít del Real sumen consedo des 7 rediar

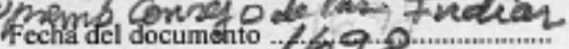

109.

\section{REPRODUCCIÓN}

Copia $\mathrm{B} / \mathrm{N}$ en papel

ㅁ

Copia B/N en soporte digital

Total reproducciones .... 625

Observaciones:

1. Las "Contos ó autos del

caption vian de Cartajol... "son:

16 epioducciones

2.- El "Fstimovio y ductor que se pemite del Real Conso de las Indias..." son:

a. PorTada : 1 foja

c. 1Toja en blanco is lio 0278

- Las tiras ge numeraran de forma correlativa a partî́ del número $1, \sin$ empezar nueva numeración al cambiar de signatura.

- Si se solicitan diferentes tipos de reproducciones, se rellenará una hoja petición por cada una de ellas. 
TESTIMONIO DE AUTOS, QUE SE REMITE A EL REAL Y SUPREMO CONSEJO DE INDIAS. POR SER DON JUAN JOSEPH DE VEITIA LINAGE DEL ORDEN DE SANTIAGO, CONTADOR MAYOR DEL TRIBUNAL Y REAL AUDIENCIA DE CUENTAS DE LA NUEVA ESPAÑA. JUEZ PRIVATIVO SUPERINTENDENTE DE LAS REALES ALCABALAS DE ESTA CIUDAD Y SU JURISDICCIÓN, EN QUE SE CONTIENEN LOS EXPRESADOS, EN LAS FOJAS SIGUIENTES.

Antes de la fundación de la Real Aduana de la Ciudad de Los Ángeles con todas las diligencias que se han ofrecido desde sus principios, vista de ojos, planta y formación de las garitas, nombramiento de ministros, certificación de lo que produjeron las Reales Alcabalas en los meses de enero y febrero. Orden de su Excelencia a pedimento de la Ciudad para que corriese la entrada de los géneros de la Nao de Filipinas de este año de 1698 de cargo del señor Juez privativo.

Sumaria de diligencias fechas en orden al exceso cometido por el regidor Don Domingo de la Edeza contra esta Real Administración. Consulta sobre este particular a el Real Acuerdo de Resolución que tomó su Excelencia dando su autoridad a el señor obispo de esta ciudad- Autos sobre los excesos de los eclesiásticos por los cuales consta perturbar el estilo que se debe observar en grave daño del Real Haber. Consultas fechas a su llustrísima y embarazos que se han ofrecido que motivaron ocurrir al el Real Acuerdo de notificación fechas a su Majestad por medio del señor provisor. Con todos los demás autos que en esta razón se hicieron que están a lo último según sus fechas de tiempo en que acaecieron. Pedimento fecho por los labradores de esta y de las jurisdicciones circunvecinas intentando no pagar Alcabala de los granos y frutos que introducen en esta Ciudad. Con lo resuelto por su merced, Diligencias fechas sobre no haber pagado Renta Alcabala que causó Don Pedro de Santillán Alcalde mayor de esta Ciudad con lo demás que se precisa en el auto que va por principio...

Folio 1

TESTIMONIO DE LA REAL CÉDULA DE SU MAJESTAD.

En la muy noble y leal Ciudad de Los Ángeles a primero de noviembre de mil seiscientos noventa y siete años, el Señor Capitán de caballos coraza Don Juan Joseph de Veitia Linaje caballero de la orden de Santiago contador mayor del tribunal y Real [...] de cuentas, de este Reino dijo que en ejecución y obedecimiento a Su Majestad que Dios guarde y por su real cédula su fecha, en Madrid a los veinte y seis de Junio del año pasado de mil seiscientos noventa y cinco firmada de su real Mano y Refrendada del señor Don Bernardino Antonio de Pardiñas Villar de Franco secretario en que le nombra por Juez privativo superintendente de las reales Alcabalas, de más servicios Reales, Unión de Armas, y armada de Varlovento de esta ciudad y lugares de su jurisdicción. 
Por el tiempo de cinco años que han de correr y contarse desde el primero de enero del año próximo venidero de mil seiscientos noventa y ocho, para cuyo tiempo han de estar prevenidas las cosas conducentes y útiles, de esta administración y porque se ha de hacer reconocimiento de los Caminos Reales, entradas y salidas de esta ciudad y garitas donde los guardas han de tener su residencia y proceder a las disposiciones y ordenes que se han de observar para lo cual en virtud de la facultad que se le concede, nombrara su merced [...] por el tiempo de su voluntad y por el trabajo y ocupación le asignaba quinientos pesos de salario en cada un año pagado al fin del mismo y manda y mandó asiente y copie al pie de este auto la Real cédula de su Majestad con las demás diligencias de su presentación para que vaya por la vera de estos autos; y que para dar principio a las diligencias de su encargo le asista a el reconocimiento de los Caminos Reales de esta ciudad, entradas y salidas de ella y ponga por fe y diligencia la vista de estos; que su merced hiciere de los ejidos, distancia de Garitas para cuyo efecto asignara el día de mañana y demás consecutivos. Igual que en la manera que quede le hacía e hizo el alto nombramiento para que así los ministros de esta Real Aduana como todas las demás personas citantes y habitantes en esta ciudad y fuera de ella le hayan y tengan por tal escribano de esta Real Aduana guardándole las preeminencias y prerrogativas que como a tal le están concedidas, y así lo proveyó, mandó y firmó. Don Juan Joseph de Veitia Linage.

Ante mi Antonio Ximenes de Guzmán escribano de Su Majestad y de la Real Aduana de esta ciudad y su jurisdicción en cumplimiento del Auto de esta dicha parte hice sacar y saqué la Real Cédula de Su Majestad con las demás diligencias.

\section{REAL CÉDULA}

Presentación

Folio 11 Y 12

\section{GUARDA MAYOR}

...En la de Guarda Mayor a Don Joseph Méndez Hidalgo Azperiqueta quien ha de ser obligado por sí o en compañía de su ayudante que irán mencionados a cuidar los caminos y contornos de la ciudad y que los referidos y Guardas menores, alternadamente conforme les cupiese, de noche compartidos en patrullas o en cuadras anden de unas en otras partes por toda la circunferencia de ésta; y en las partes caminos o veredas, donde amenazare riesgo, [designario] o fraude poner la prevención o guarda conveniente cuidando así mesmo que los guardas según su asignación estén y residan de día en sus garitas, puestos y caminos corriendo la sierra y campaña los pueblos circunvecinos y contornos para descubrir y saber las prevenciones que puede haber poniendo especial cuidado en el cumplimiento de su obligación. 
FOLIO 12

\section{AYUDANTE}

En la de ayudante de dicho, Guarda mayor a Don Antonio de León Benet, quien en la misma conformidad se dedicará a la custodia de los caminos, de noche y de día conforme y cuando le cupiere distribuyendo una y otra entre los demás las órdenes que su merced diera y porque en el tiempo que por todas las entradas y ejidos ocurren partidas de ganado mayor han de tener especial vigilancia y cuidado así dicho, ayudante como dicho Guarda mayor de saber las cantidades que se vendieren trayendo razón de sus dueños con especificación para que por este medio se consiga el fin principal.

Folio 12-12v.

RONDAS

En las de rondas de Juan Antonio Palomino. Francisco Mijares Ortiz, Don Gaspar Fernández de Viana y Don Agustín de Poussa quienes han de ser obligados según [...], a rondar de noche y de día la ciudad y sus contornos, visitar las garitas y así estar a su custodia y mandar que alguno de los guardas menores conducen a esta Real Aduana las cargas y recuas, visitando asimismo y rondando la campaña reconociendo los pueblos circunvecinos y demás partes mayormente con algún indicio o sospecha y patrullas que de noche se han de formar compartiéndose según el número que hubiere.

Folio 12v. - 13

GUARDAS

Y porque el tanteo, y reconocimiento, vista de ojos y diligencias fechas a prevenid a su merced nombrar y con efecto exige y nombra diez y seis Guardas menores que estos han de estar de pie compartidos en las garitas conforme su asignación; más o menos según la frecuencia y entradas de los caminos. Los cuales son [se nombran catorce de los diez y seis]. Que éstos han de ser obligados a asistir en sus puestos según y como va referido en los días y horas y alternándose de veinte y cuatro horas a veinte y cuatro hora, y de noche de forma que sea igual el trabajo reconociendo las recuas, pasajeros y demás cosas, que sean conducentes, a la buena administración dando, las Guías de la cantidad de cargas, y Géneros que fueren conduciéndolos de esta Real Aduana; Guardando y observando las órdenes que se les ordenaren y distribuyeren por el Guardia mayor o su ayudante asistiendo de noche a la escuadra y patrullas, que se han de formar Rondando los ejidos y su circunvalación de la ciudad combinadamente conforme a quienes tocare guardando asimismo la forma e instrucción que se les diere.

Folio 13

MINISTRO

En la de ministro de Vara a Miguel de Sierra Alta Arroyo quien ejecutará los mandamientos y órdenes que se le dieren haciendo los llamamientos y diligencias que fueren de su obliga- 
ción y anexas a su oficio y ministerio. Todos los cuales han de ser obligados a dar cuenta a su merced, de las diligencias que se ejecutaren para que dé las providencias convenientes.

Folio 13

Asesor

En la de asesor. A el licenciado DonDiego de Alcorta Camacho abogado de la Real Audiencia de esta Nieva España con cuyo parecer se han de resolver los puntos y casos que se ofrecieron en este juzgado.

Folio 13

Fiscal

En la de Promotor fiscal a el Doctor Don Diego Joseph Conchoso asimismo abogado de ella para que por lo que tocarea Su Majestad y sus reales haberes deduzca su real arbitrio.

Folio 13-13v.

\section{COMISIÓN DE GUÍAS DE LA VERA CRUZ}

En la de Comisarios de Guías de la nueva Vera Cruz a el Capitán Juan Baptista de Solabuena vecinp de ella, el cual ha de dar las guías a los arrieros, carreteros y traficantes de los Géneros fardos o piezas que de dicho puesto sacaren ora sean para esta ciudad o para otra cualquiera parte con distinción de sus números, y marcas, su consignación y en recua de que arriere para que en esta Real Aduana se ajusten y comprueben con sus Guías así de los Géneros de Castilla, Caracas, Guaira, Maracaibo, Campeche, Habana y de más partes de mar en fuera y de sus costas reconociendo las cosas y partes donde presumiere pueda haber fraude o extravío a el cual se le despache un libro foliado, empergaminado y rubricado por el presidente escribano en que tome razón de dichas Guías, el cual remitirá a esta Real Aduana a el fin de año para que se le despache otro y todos los susodichos arrieros, carreteros y traficantes andasen obligados a manifestar ante dicho comisario la carga que de dicho puerto sacaren.

Folio 13v.

ESCRIBANO

El presente escribano a quien su merced tiene nombrado en dicho ministerio para la formación y disposición de los Autos, Testimonios y demás instrumentos que de aquí emanaren y se ofrecieren en este tribunal.

Folio 14-14v

A el presidente escribano les despache nombramientos en forma especificando puedan traer y traigan armas ofensivas y defensivas y les hayan y tengan por Ministros de este Juzgado y puedan entrar y entren en cualesquiera casas, de esta ciudad o fuera de ella, Ranchos, haciendas o molinos, huertas y demás casas, donde presumieren o tuvieren no- 
ticia o pueda haber extravíos o fraudes, en que no se les pondrá embarazo ni impedimento alguno por ninguna persona. Jueces y Justicias de Su Majestad; antes en su real nombre les den y hagan dar el favor y auxilio que necesitaren arreglándose todos y cada uno de por sí al cumplimiento de su obligación que para todo lo referido les da comisión cuan bastante en derecho se requiere y es necesario y así lo proveyó y firmó Don Juan Joseph de Veitia Linage. Ante mi Antonio Ximenez de Guzmán escribano.

Folio 15v.-16

AUTO [GARITAS]

En la muy noble y leal Ciudad de Los Ángeles a veinte y tres días del mes de noviembre de mil seiscientos noventa y siete años su merced dicho señor Juez privativo superintendente de las Reales Alcabalas Haciendo dicho tanteo, Regulación y Vista de ojos de los ejidos, entradas y salidas de la ciudad, caminos Reales y veredas para la disposición de las Garitas donde los Guardas han de asistir. Respecto de no saberse entre las que sean reconocidas cuales son de la ciudad y cuales del asiento del pulque. Mandaba y Mando se despache Recepta para que esta nobilísima Ciudad ordene se muestren a el presidente escribano las que le pertenecen y así lo proveo y firmo. Don Juan Joseph de Veitia Linage. Ante mi Antonio Ximenez de Guzmán escribano.

Folio 16-16v.

AUTO [MOSTRAR GARITAS EXISTENTES]

En la muy noble y leal Ciudad de los Ángeles en Veinte y cuatro días del mes de noviembre de mil seiscientos noventa y siete años el Señor Juez privativo superintendente de las Reales Alcabalas de esta ciudad, Don Juan Joseph de Veitia Linage , Con vista de la Recepta de esta nobilísima ciudad, en que dispone salga el escribano de su ayuntamiento con un portero a mostrarle las garitas, que le pertenecen; a el presente escribano. Mandaba y mandó, ponga y asiente por testimonio las que por los susodichos se le mostraren con claridad y distinción para la disposición más conveniente de las que se han de edificar y fechas las diligencias dará cuenta y así lo proveo y firmo. Don Juan Joseph de Veitia Linage. Ante mi Antonio Ximenez de Guzmán escribano.

Folio 17-17v.

TESTIMONIO

En cumplimiento del Auto por su merced proveído y resuelto por la nobilísima Ciudad. Certifico y doy testimonio en la más bastante forma que puedo y debo, cómo habiendo salido en compañía de Francisco Herrera Calderón escribano público y teniente de cabildo y de Joseph, sumaba su portero para el camino del portezuelo que llaman de Amatlan y llegado al molino que está inmediato a la Barranca donde dijo dicho portero ser uno de los caminos principales que entran en la ciudad y que en tiempos de naos de Philipinas es más frecuentado y no haber en él garita porque el guarda que ha asistido en dicho camino 
ha estado en dicho molino inmediato a la ermita. Y continuando la diligencia se llegó al puente de Vigas Camino de Cholula donde dijeron no haber Garita y haber asistido siempre los Guardas en ermita de las Ánimas que está inmediata a el Río de Atoiaque; y de aquí se pasa al camino Real de esta a la Ciudad de México y llegando a la garita inmediata al cerro de San Juan, dijeron ser y pertenecer a la ciudad; y cruzando el llano para el poniente hasta coger el camino Real que va a Tlaxcala y continuando por él a la parte del norte donde como a tres cuartos de legua de la ciudad se mostró otra garita que dijeron ser también de ella, la cual esta a orillas de una barranca por frente de la Hacienda que llaman de Las Trancas, y por ser tarde se quedó esta diligencia en este estado para proseguirla mañana y para que conste en virtud de lo mandado doy el presente en la muy noble y leal Ciudad de los Ángeles, en veinte y cuatro días del mes de noviembre de mil seiscientos y noventa y siete siendo visto por Luis de Benavides Franco Bazan y Juan Silvestre, vecinos de esta ciudad. Ante mi y hago mi signo. Antonio Ximenez de Guzmán.

Folio 17v-18

PROSIGUE

En continuación de lo mandado habiendo salido de la ciudad, en compañía de otro escribano y portero para el llano de Totomehuacan; se mostró la garita que está en el camino Real que va hacia dicho pueblo y otras partes que dijeron ser también y pertenecer a la ciudad y que no tiene otras ningunas, porque el guarda del camino de Amozoque tiene su asistencia en la ermita de las Ánimas y respecto de no haber otra diligencia que hacer, por Consta y a por la Vista de Ojos que su merced hizo las distancias que hay de unas a otras partes y constar asimismo cuáles sean las garitas de la ciudad en virtud de lo mandado doy el presente en ella a veinte y cinco días del mes de noviembre de mil seiscientos noventa y siete años, siendo testigos Luis de Benavides, Joseph, Antonio y Juan Camacho, vecinos de esta ciudad. Ante mi y hago mi signo Antonio Ximenez de Guzmán escribano.

Folio 18-19v.

AUTO EN QUE; SU MINISTRO; DA LA FORMA DE LAS GARITAS Y PUESTOS EN QUE SE HAN DE EDIFICAR Y MANDA SE FORME MAPA DE LA CIUDAD

En la muy noble y leal Ciudad de los Ángeles en veinte y seis días del mes de noviembre de mil seiscientos noventa y siete años su merced el señor Juez privativo superintendente de las Reales Alcabalas de esta ciudad. Habiendo visto las diligencias y testimonios de susodichas por el presente escribano en orden al reconocimiento de las garitas de la ciudad para cuyo efecto salió con el teniente y escribano del cabildo y uno de sus porteros en virtud de lo expresado en su Recepta y respecto de que esta ciudad, no ha tenido ni poseído según parece mas que tres garitas, que la una está en el camino Real que va a la Ciudad de México; a la parte norte otra en el Camino de Tlaxcala por el mismo viento donde llaman la Hacienda de Las Trancas y la que está a la parte del sur Camino Totomehuacan porque las 
demás que en circunvalación de la ciudad se muestran son de las guardas de la gentuza del pulque y porque es necesario edificar las más de ellas a competentes distancias para que los guardas puedan cómodamente vigilar los muchos caminos y veredas, que por todas partes hay, las cuales están en las puertas siguientes.

1. La garita que está en el camino de Totomehuacan se ha de retirar y fabricar más al centro en un altillo inmediato al Camino Real que sale de la Ciudad para esta parte porque desde allí podrán los guardas reconocer todos los caminos que por el llano pasan.

2. En el camino que va al portezuelo que llaman de Amatlán después de pasada la Barranca, se ha de fabricar en lo más eminente de la subida otra garita porque aunque hay poco más de media legua de este puesto a él en que se ha de fabricar la antecedente, se divisan una a otra y reconocen los caminos que hay por todo el llano.

3. En el camino de Cholula a la subida más adentro se ha de fabricar otra porque además de los caminos mencionados en la Vista de ojos que vienen de Atlixco, Acapulco, Amilpas y otras muchas partes y los de Cholula que pasan por allí estará en parte proporcionada para cuidar la vereda que viene por tras el Cerro de San Juan orilla de Atoiaque [el río].

4. Otra garita antigua demolida y arruinada que está a distancia de media legua del puesto donde se ha de poner la antecedente Camino Real de México que ha sido del asiento del pulque, se ha de reedificar por estar en proporcionada distancia y más a el centro porque aunque la ciudad tiene Garita por esta parte, está más retirada y es menos a propósito.

5. Otra Garita se ha de edificar inmediata a una ermita que está Camino de Tlaxcala que llaman Santa Cruz por ser el lugar apropiado para reconocer el dicho Camino Real y el del paso del Atoiaque que llaman de Las Caleras y los muchos que por un lado y otro de dicha ermita pasan.

6. Asimismo se ha de edificar otra Garita sobre la loma de Belén inmediata a una que tiene allí el asiento del pulque por donde causan y salen de la ciudad muchos caminos que también van a Tlaxcala a la sierra y a las haciendas de Guamantla y ésta por estar en parte alta descubre todo el llano por una y otra parte.

7. Otra se ha de formar y edificar en el vacío inmediato al rancho de labor que está después del barrio de Xonacatepec, Camino Real que va a Guamantla y pasa por la puente de Amaluca.

8. La garita del camino de Amozoque se ha de conservar en la ermita de Las Ánimas porque aunque está retirada y distante de la ciudad, está en lugar y puesto donde los caminos que salen de la ciudad, se juntan y ser el principal de la nueva Veracruz. 
9. Otra Garita se ha de fabricar pasada la barranca del Tepoxuchitl. Por donde tienen muchos Caminos Reales y veredas y entran por varias partes en la Ciudad, de manera que a la distancia referida que dan en igual proporción y más comodidad para la custodia de los Caminos y para que tenga efecto lo referido.

Mandaba y mando que Don Joseph Zurita vecino de esta Ciudad supla por ahora la cantidad que fuere necesaria para dicha obra que se le satisfará de las primeras condenaciones, que se causaren en dicha Real Aduana. Y para más clara inteligencia se ruegue y encargue a el licenciado Don Cristóbal de Guadalajara presbítero que como plástico e inteligente delinee la ciudad y sus ejidos, cuya figura y mapa se ponga con los Autos, para que con ciencia del susodicho; se reconozca y vea si los puestos mencionados, están en partes competentes donde se cojan los caminos, más principales que vienen para la ciudad para su mejor custodia. Y así lo proveyó, y firmo. Don Juan Joseph de Veitia Linage. Ante mi Antonio Ximenez de Guzmán escribano.

Folio 19v.

NOMBRAMIENTO A DON JOSEPH ZURITA

En veinte y seis de noviembre de mil seiscientos y noventa y siete años notifique que el Auto del usos, a Don Joseph Zurita vecino de esta Ciudad, en la parte que le toca el cual dijo cumplirá con lo que se le manda y esto respondió de que doy fe y lo firmo. Don Joseph de Zurita. Ante mi Antonio Ximenez de Guzmán escribano.

Folio 19v.-20

REQUERIMIENTO DE RUEGO Y ENCARGO A EL LICENCIADO DON CRISTÓBAL DE GUADALAXARA

En la muy noble y leal Ciudad de Los Ángeles a veinte y siete días del mes de noviembre de mil seiscientos y noventa y siete años hice notorio el dicho Auto del Brigadier Don Cristóbal de Guadalajara presbítero domiciliario de este obispado en la parte que le toca. A quien rogué y encargué haga y forme el mapa y figura de esta ciudad, y como platico en ella reconozca los lugares y puestos asignados en el dicho Auto, están en partes competentes y habiéndolo oído y entendido. Dijo que por las experiencias con que se halla, reconoce están muy conformes, a la custodia de los Caminos por ser los lugares más precisos y que está presto a hacer y formar la delineación y figura de la ciudad con pronta obediencia, por ser del servicio de Su Majestad, Y esto respondió de que doy fe y lo firmo. Brigadier Don Cristóbal de Guadalaxara. Ante mi Antonio Ximenez de Guzmán escribano.

Folio 20-20v.

AUTO PARA QUE DON JOSEPH ZURITA COSTEE Y COMPRE LAS COSAS QUE FUEREN NECESARIAS PARA LA REAL ADUANA 
En la muy noble y leal Ciudad de Los Ángeles a veinte y ocho días del mes de noviembre de mil seiscientos noventa y siete el señor Juez privativo superintendente de las Reales Alcabalas de esta ciudad y su jurisdicción en virtud de Real orden de Su Majestad. Dijo que por cuanto son precisas diferentes cosas, para en llegando el tiempo dar principio a su administración que será el día primero de enero del año próximo venidero para cuando han de estar dispuestas y prevenidas. Mandaba y mando que Don Joseph de Zurita vecino de esta ciudad, compre la cantidad de terciopelo carmesí, forro y guarnición para el dosel que se ha de disponer en la Real Contaduría; y que se hagan mesas, escaños y un cajón de tres llaves, donde se recojan los efectos que se fueren causando y haga formar y encuadernar un libro General del papel del sello cuarto de marca mayor y todos los demás, que sean necesarios así para la Real Contaduría como para los comisarios de Guías y los borradores en papel común, hacer y fabricar una romana de caja y un peso de cruz con sus balanzas, pesas y demás cosas que sean necesarias procurando sea con la mayor conveniencia y [...] que se pudiere y fechos dichos gastos dará cuenta a su merced con relación Jurada, y así lo proveo, mando y firmo. Don Juan Joseph de Veitia y Linage. Ante mi Antonio Ximenez de Guzmán escribano.

Folio 20v.

NOMBRAMIENTO A DON JOSEPH ZURITA

En la muy noble y leal Ciudad de Los Ángeles en veinte y ocho días del mes de noviembre de mil seiscientos noventa y siete; notifique el Auto del uso según y como en él se contiene a Don Joseph Zurita vecino de esta ciudad, quien habiéndolo oído y entendido. Dijo que está presto a cumplir con lo mandado por su merced y esto respondió de que doy fe y lo firmo. Don Joseph Zurita. Ante mi, Antonio Ximenez de Guzmán escribano.

Folio 20v.

AUTO PARA QUE EL MAPA HECHO POR EL LICENCIADO DON CRISTÓBAL DE GUADALAJARA SE PONGA CON LOS AUTOS

En la muy noble y leal Ciudad de Los Ángeles a ocho días del mes de diciembre de mil seiscientos y noventa y siete años el señor Juez privativo superintendente de las Reales Alcabalas. Habiendo visto la delineación y figura de esta ciudad fecha por el licenciado Don Cristóbal de Guadalaxara mandaba y mando le ponga con los Autos y así lo proveo y firmo. Don Juan Joseph de Veitia Linage. Ante mi Antonio Ximenez de Guzmán escribano.

Folio 43v.-44

En la muy noble y leal Ciudad de Los Ángeles en siete días del mes de febrero de mil seiscientos y noventa y ocho años, el señor Capitán de Caballos Corazas Don Juan Joseph de Veitia Linage del orden de Santiago Contador mayor del Tribunal y Real Audiencia de cuentas de esta Nueva España, Juez privativo, Superintendente de las Reales Alcabalas 
de esta ciudad y su jurisdicción, en virtud de Real Cédula de Su Majestad. Dijo que por cuanto se ha experimentado, la multiplicidad de partidas, Cartas que se causan de debito en esta Aduana de los que contraen el Alcabala y que esto ocasiona notable atraso y embarazo, ocupando el tiempo no sólo en haber de sacar hijuelas, a el cabo del mes para que con ellas vaya a recaudar su monto (de los deudores) el cobrador, si no están bien la contingencia a que exponen algunas dependerse y que para esto sólo se necesita de un contador que estuviese empleado para este fin además del mucho papel de oficio que se consumiría y también porque es necesario haya dinero de contado para socorrer los guardas todos los meses, para su sustento por ser sujetos sumamente pobres, y que los más de ellos comen de fiado, lo cual no se conseguiría si no se cobrasen de contado las partidas menudas por todo lo cual. Mandaba y mando que las que no pasaren de doce pesos se cobren de todo aunque sean estas de personas, abonadas y conocidas mediante a las razones expresadas pues siendo así se evitara, los inconvenientes y atrasos en esta administración que van preponderados, y de este auto se sacará Testimonio y se fijará en la puerta de la Contaduría de esta Real Aduana para que a todos conste y así lo proveyó y firmó. Don Juan Joseph de Veitia Linage. Ante mi Antonio Ximenez de Guzmán escribano.

\section{Folio 44v.-45}

En la muy noble y leal Ciudad de Los Ángeles, en siete días del mes de febrero del mil seiscientos noventa y ocho años, el señor Capitán de caballos corazas Don Juan Joseph de Veitia Linage del orden de Santiago, Juez privativo, superintendente de las Reales Alcabalas de esta Ciudad, dijo que en atención a haberse reconocido los muchos fraudes y extravíos que se cometen en los mesones de esta ciudad, y en especial en los de San Miguel en el de Sosa y los que están en el Barrio de Analco y Alto de San Francisco, de los tratos y ventas que en ellos se efectúan por los forasteros que en ellos pasan, donde ocurren muchos comerciantes, de esta ciudad, y se usurpan a Su Majestad; sus Reales Alcabalas. Mandaba su merced y mando se notifique a todos los dueños de los dichos mesones o arrendatarios que de aquí en adelante con pena de quinientos pesos y del interés de Su Majestad y de cuatro años de servicio en las islas Philipinas que de las Compras Ventas, tratos y cambios que en ellos se efectuaron y efectuaren así de mulas, caballos, como de otros cualesquiera géneros y cosas de que se den a la Real Alcabala Reconociendo que los que en ellos intervinieren y concurrieren en dichos mesones sin pagar este Real [impuesto] a Su Majestad, de que darán cuenta a su merced, a cualquiera de sus ministros, para que se apliquen los medios convenientes para su cobranza con apercibimiento que se efectuará, en sus personas, las penas que van expresadas, más o menos conforme a delito o exceso que se cometieren y así lo proveyó y firmó. Don Juan Joseph de Veitia Linage. Ante mi Antonio Ximenez Guzmán escribano. 


\section{AD-2 PALEOGRAFÍA: TESTIMONIO DEL AÑO DE 1724}


Archivo General de Indias

Ministerio de Educación, Cultura y Deporte

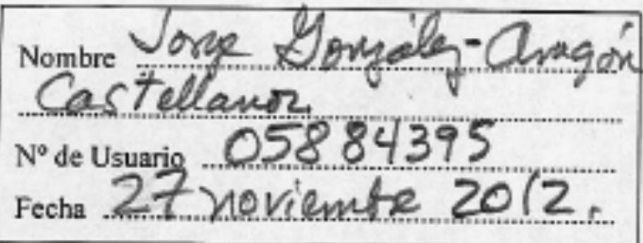

\section{SIGNATURA}

Sección / Unidad instalación (legajo) MEXico, 827

Documento kestimovio año $172 \%$

De los avios a Provieloncias dados porels sobre La Nueva Situación de las Gar'tas Real Adiana por ollarne Fecha del documento .172 .4

\section{REPRODUCCIÓN}

Copia B/N en papel $\square$

Copia $\mathrm{B} / \mathrm{N}$ en soporte digital (8)

Total reproducciones ...190

Observaciones:

Sondor legajor.

El pimero temina con eto nodefolio 1364 el otro comierya en el falio 138.

for follios no non rubreventew por ello el total son: 190 kproduscioner.

- Las tiras se mumerarán de forma correlativa a partir del número 1, sin empezar nueva numeración al cambiar de signatura.

- Si se solicitan diferentes tipos de reproducciones, se rellenará una hoja petición por cada una de ellas. 


\section{TESTIMONIO DEL AÑO DE 1724}

DE LOS AUTOS Y PROVIDENCIAS DADAS POR EL JUEZ ADMINISTRADOR DE LAS REALES ALCABALAS DE ESTA CIUDAD Y JURISDICCIONES DE SU AGREGACIÓN.

SOBRE

LA NUEVA SITUACIÓN DE LAS GARITAS DE ESTA LA ADUANA POR HALLARSE LAS ANTIGUAS FABRICADAS EN PARAJES MUY DISTANTES E INCÓMODOS.

En la ciudad de los Ángeles a catorce días del mes de febrero de mil setecientos veinte y cuatro años

Folio 101v.

AUTO PARA QUE SE PUBLIQUE BANDO LLAMANDO A DENUNCIA DE LOS EXTRAVÍOS Y GÉNEROS DE CONTRABANDO

En la Ciudad de Los Ángeles a veintiocho días del mes de febrero de mil setecientes veinte y cuatro años el señor Don Joseph Joachin de Uribe y Castrejón Caballero de la Orden de Santiago del Consejo de Su Majestad su oidor decano de la Real Audiencia de este Reino, Juez Superintendente y administrador de las Reales Alcabalas de esta Ciudad y Jurisdicciones de su Agregación. Dijo que por cuanto por el informe de la Contaduría de esta Real Aduana y certificación del escribano de ella dada por orden de su Señoría se tiene reconocido de la grave sospecha de ocultación de los géneros más preciosos y llenos de poco bulto y mucho precio respecto a que hallándose la presente flota descrita en el Puerto de la Veracruz y con ....

Folios 103v., 104, 104V., 105, 105V., 106

MEDIDA PRIMERA

Yo el infraescrito escribano identifico y doy testimonio de verdad que hoy día de la data de este el señor Don Joseph Joachin de Uribe y Castrejon Caballero del orden de Santiago del Consejo de Su Majestad su oidor decano de la Real Audiencia de este Reino, Juez Superintendente y Administrador de las Reales Alcabalas de esta Ciudad y jurisdicciones de su Agegación. Para proceder a las medidas de la circunferencia de las Garitas de esta Real 
Aduana y la del sentido de ellas a esta Ciudad. Salió de ella en compañía de el esscribano y el Guarda Mayor de esta Real Aduana y otros de ella. Asimismo de Justicia y de Christobal de Ortigoza Maestro Mayor de Arquitectura nombrado por su Señoría para dichas medidas a hora de las siete de la mañana poco más o menos y habiendo llegado a la salida del camino que va a la Ciudad de México el dicho Maestro Mayor tiró un cordel de cincuenta varas con que dio principio a dicha medida por lo que mira al centro corriendo a la garita que está en dicho camino y se halló haber trece cordeles y desde la referida garita Corrió la medida a la que está en el Camino que va a la Ciudad de Cholula y consta de Veinte y Cuatro Cordeles, y desde ella se cogió al centro de la Ciudad y parece haber nueve Cordeles, y desde la referida garita de Cholula corrió la Medida a la que está en el Camino que sale a los Molinos de Amatlán y con esta en Distancia de Cuarenta y nueve Cordeles. Y desde ella se tiró la medida a dicho Centro de la Ciudad y este parecen de Cuarenta Cordeles; y desde la referida garita de Amatlán Se tomó la medida a la que está en el Camino del Pueblo de san Baltazar y parece ser en distancia de Cuarenta y seis cordeles. Y desde ella a dicho centro de la Ciudad de otros Cuarenta y seis, y desde la referida garita de San Baltazar Corrió la medida hasta la que está en el Camino del Pueblo de Totomehuacan y parece ser la distancia de cuarenta y Cuatro Cordeles y la del Centro desde ella a la Ciudad de Cincuenta Cordeles; y corriendo la medida desde la referida garita de Totomehuacan a la de Teposuchil consta la distancia de una a otra de sesenta y seis cordeles; Y la del Centro desde ella a la Ciudad de Veinte Cordeles; Y por ser dadas las Doce horas del medio día sin embargo de no haberse parado en dicha medida y corrido con ella a toda prisa desde la referida hora sin pasar por no haberse fenecido el Mandato de su señoría le suspendió para proseguirle a la tarde de este día. Y para que conste doy el presente en la Ciudad de Los Ángeles a Veinte y ocho días del mes de febrero de Mil Setecientos y Veinte y Cuatro años y lo firmó su señoría con dicho Maestro Mayor siendo testigos Joseph de [Revillas], Juan Gonzáles y Diego de Cárdenas vecinos de esta Ciudad. Don Joseph Joaquín de Uribe y Castrejon. Cristóbal de Herrera Camacho y Ortigoza, ante mí Nicolás de Guzmán escribano de Aduana.

Folios 106, 106v., 107

\section{MEDIDA SEGUNDA}

En la Ciudad de Los Ángeles dicho día Veinte y ocho de febrero del mil Setecientos y Veinte y Cuatro años. Su señoría Juez Superintendente de las Reales Alcabalas de esta Ciudad para la prosecución de dichas Medidas a hora de las tres de la tarde poco más o menos salí, en compañía de mi, el escribano, Maestro Mayor de Arquitectura, Guarda Mayor y burros de esta Real Aduana y Ministros de su Asistencia y hubieron llevado a la garita que 
llaman de Tepoxuchitl donde se suspendió la medida la mañana de este día. El dicho Maestro Mayor tiró el cordel de cincuenta varas cogiendo a la garita que está en el Camino Real del Pueblo de Amozoque y consta la distancia de una a otra de Cincuenta Cordeles y de ahí se corrió con la medida al Centro de la Ciudad y consta de a unos Cincuenta Cordeles. Y desde la referida garita de Amozoque se corrió con la Medida para la garita que está en el Camino del Pueblo de San Pablo del Monte y parece ser la distancia de una a otra de Ciento y Cincuenta Cordeles; y desde ella se prosiguió al Centro de la Ciudad y consta ser la distancia de Cuarenta Cordeles y por ser tarde y quasi oscuro de mandato de su Señoría se suspendió la dicha medida para proseguirla cuando convenga y lo firmo con el dicho Maestro Mayor siendo testigos Joseph de Rivillas, Juan González y Diego de Cárdenas Vecinos de esta Ciudad. Don Joseph Joachin de Uribe y Castrejon, Christobal de Herrera Camacho y Ortigosa. Ante mí Nicolás de Guzmán escribano de Aduana.

Folios 107, 107v., 108, 108v., 109

\section{MEDIDA TERCERA}

Yo el infraescrito escribano Certifico y doy testimonio de Verdad que hoy día de la Data de éste a hora de las siete de la mañana poco más o menos Su señoría en prosecusión de las Medidas contenidas en estos autos en compañía de mí, el escribano, Maestro Mayor de Arquitectura y demás ministros, pasó a la garita que está en el Camino del Pueblo de San Pablo del Monte hasta donde llegó el día de ayer la dicha Medida y habiéndose tirado el cordel de Cincuenta Varas por dicho Maestro Mayor para la garita que sale para la Ciudad de Tlaxcala medida en distancia Consta de Veinte y siete cordeles y desde ella al Centro de la Ciudad parece haber treinta y ocho cordeles. Y desde la Referida garita de Tlaxcala se tomó la medida pa la garita que está en el Camino que llaman de la Calera y con ésta su distancia de Cuarenta y tres Cordeles y la del Centro desde ella a la Ciudad de treinta Cordeles. Y corriendo la medida desde la referida garita de la Calera a la del Camino de México parece tuvo de distancia Treinta Cordeles conque se cerró la circunferencia de las distancias que hay de unas a otras garitas. Y con esto se feneció la dicha Medida y el dicho Maestro Mayor dijo que por el resumen de cordeles que tiene hecho parece haber en la circunferencia de dichas garitas Quinientos y Veinte y nueve Cordeles que al respecto de dichas Cincuenta varas cada una Componen Veinte y seis milCuatrocientas y cincuenta Varas; y el centro de dichas garitas a la ciudad, trescientos y treinta y seis cordeles que hacen diez y seis mil y ochocientas varas salvando error formal o material. Y que la dicha la ha fecho Bien y Fielmente a su leal saber y entender debajo del juramento que tiene hecho ante su señoría y todo su leal saber y entender. Y para que así conste de mandato de su señoría dicho señor Juez Superintendente doy el presente en la Ciudad de Los Ángeles a Veinte 
y nueve días del mes de febrero de mil Setecientos y Veinte y Cuatro años y lo firmó su señoría con dicho Maestro Mayor siendo testigos Joseph de Rivillas, Juan González y Diego de Cárdenas Vecinos de esta Ciudad, Don Joseph Joachin de Uribe y Castrejon, Christobal de Herrera Camacho y Ortigoza. Y hago mi signo en testimonio de Verdad, Nicolás de Guzmán escribano de Aduanas.

Folios 109, 109v., 110, 110 v., 111

\section{DILIGENCIA SOBRE LA NUEVA SITUACIÓN DE LAS GARITAS Y MEDIDAS}

Yo el infraescrito escribano certifico y doy testimonio de Verdad cuyo día de la fecha a hora de las tres de la tarde poco más o menos, el Señor Don Joseph Joachin de Uribe y Castrejón Caballero del orden de Santiago del Consejo de su Majestad, Mayor decano de la real Audiencia de este Reino, Juez Superintendente y Administrador de las Reales Alcabalas de esta Ciudad y Jurisdicciones de su agregación. Para la prosecusión de las diligencias contenidas en estos autos y nueva Situación de las garitas de estaReal Aduana en compañía de mí el escribano y del Maestro Mayor de Arquitectura Christobal de Ortigoza , guarda Mayor y otros de esta Real Aduana, salió al campo a reconocer los parajes más cómodos y apropiados para la situación de dichas garitas y fábrica de ellas en partes que puedan darse la mano y ayudarse los unos guardas a los otros en los frangentes que se les ofrecieren y puedan acaecer con los pasajeros y para hallar los extravíos grandes que hasta aquí se imaginan, se hacen y habiéndose hecho reflexión por su señoría de dichos parajes por la vuelta que fue dando a toda la circunferencia de la medición que pareció más proporcionada al Centro de la Ciudad conferíolo su señoría con dicho Maestro Mayor y guardas que vinieron todos en un mismo Dictamen como prácticos y experimentados en su ministerio y en esta conformidad para reconocer la circunferencia de la nueva Planta y sentar de ella a la Ciudad se tiró el cordel de Cincuenta Varas desde los muros de esta Ciudad y Barrio de San Matías hasta el lugar asignado para la garita que sale por el camino de la Ciudad de México, cuya distancia consta de cuatro Cordeles y desde allí Corrió la medida al paraje donde se ha de fabricar la garita del camino de la Ciudad de Cholula por arriba del Barrio de Santiago que consta de la misma mediación de centro y la distancia de uno a otro de Veinte Cordeles. Y desde allí el dicho paraje del Camino de Cholula se pasó a la situación donde se ha de fabricarla garita de Amatlán y consta de uno a otro de treinta y un cordeles y, desde el referido paraje de Amatlán corriendo al centro de la Ciudad consta de quince cordeles y desde el dicho Paraje de Amatlán corrió la medida al asignado paraje para el camino de San Baltazar, y es la distancia de Veinte y ocho Cordeles. Y desde el referido Paraje al centro de la Ciudad consta de Doce Cordeles. Y por ser tarde no prosiguió la dicha medida suspendiéndose de mandato de su señoría para proseguirla cuando convenga y para 
que conste doy el presente en la Ciudad de los Ángeles a primero día del mes de Marzo de mil setecientos y Veinte y Cuatro años, y lo firmó su señoría con dicho Maestro Maestro Mayor siendo testigos Joseph de Rivillas, Gabriel de Navarro y Juan González, vecinos de esta Ciudad. Don Joseph Joachin de Uribe y Castrejón, Christobal de Herrera Camacho y Ortigoza. Ante mí, Nicolás de Guzmán, escribano de Aduana.

Folios 111, $111 \mathrm{v} ., 112,112 \mathrm{v} .113,113 \mathrm{v}$.

\section{SEGUNDA DILIGENCIA Y MEDIDA}

Yo el infrraescrito escribano certifico y doy testimonio de Verdad que hoy día de la fecha a hora de las siete de la mañana poco más o menos el señor Juez administrador de las Reales Alcabalas de esta Ciudad salió en compañía de mi, el escribano y del Maestro de Arquitectura, guarda mayor y otros de esta Real Aduana para la prosecusión de las diligencias contenidas en estos autos, y habiendo llegado al paraje de la garita del Camino Real a México, el dicho Maestro Mayor tiró el cordel de cincuenta varas cogiendo al paraje asignado pa la garita de La Calera en cuya distancia hubo diez y seis cordeles, y desde allí al centro de la Ciudad y desde allí al centro de la Ciudad tres cordeles y Veinte varas. Y desde el Referido paraje de la Calera corrió la medida al asignado para la garita del Camino Real de Tlaxcala en cuya distancia hubo treinta y dos Cordeles. Y desde allí al centro de la Ciudad se midieron ocho Cordeles. Y desde dicho paraje de Tlaxcala se tiró la medida al señalado en el Cerro de Loreto y consta la distancia de uno a otro de treinta y cinco cordeles, y desde allí al centro de la Ciudad se midieron quince Cordeles. Y desde el Referido paraje de Loreto se tiró la medida al Barrio de Xonacatepeque y lugar asignado y consta de treinta Cordeles y desde allí se pasó con la medida a los Caminos de Amozoque y parece ser la distancia de Doce cordeles, y corriendo desde dichos Caminos al centro y calle Real de la Ciudad consta la distancia de Veinte y tres cordeles. Y volviendo a dicho Paraje y camino de Amozoque se tiró la medida al paraje del camino de Guatinchany tuvo Veinte y Cuatro Cordeles, y desde allí al centro de la Ciudad se midieron ocho Cordeles. Y desde el Referido paraje de Guatinchan corrió la medida al paraje asignado en el Camino de Totomeguacan en cuya distancia hubo Veinte y dos Cordeles, y de allí al centro de la Ciudad siete cordeles. Y desde el Referido paraje de Totomeguacan al del Camino del Pueblo de San Balthazar se midieron Veinte y dos cordeles conlo cual se cerró la circunferencia, regulación y tanteo hecho por su señoría para la nueva situación de dichas garitas y resumado el número de cordeles de dicha circunferencia por dicho Maestro Mayor parece ser el todo de ellos de Docientos y cinccuenta y cinco, que reducidos a varas suman Doce mil y ochocientas que al respecto décimo mil por legua componen Dos leguas dos mil y ochocientas varas. Y tod el Referido centro que consta de ciento y nueve cordeles hacen cinco mil cuatrocientas y 
cincuenta varas que compone una legua y cuatrocientas y cincuenta varas con que resulta de diferencia en la Cercanía de la nueva Planta de garitas de esta Ciudad trece mil y setecientas varas. Y el centro de ellas a la Ciudad once trescientas y cincuenta varas según se percibede la circunferencia y centro de las medidas de las primeras diligencias hechas por su señoría y el dicho Maestro dijo que la dicha medida nuevamente hecha está a todo su leal saber y entender. Y para que conste el mandato de su Señoría, dicho Juez doy el presente en la muy nobley muy leal Ciudad de la Puebla de Los Ángeles a dos días del mes de Marzo de mil setecientos y Veinte y Cuatro y lo firmó su señoría con dicho Maestro Mayor siendo testigos Joseph de Rivillas, Don Ángel del Campo Viscarra, Juan González y Diego deCárdenas, Vecinos de esta Ciudad, Don Joseph Joachin Uribe y Castrejón, Christobal de Herrera y Ortigoza. Ante mí Nicolás de Guzmán escribano de Alcabala.

Folios $113 \mathrm{v}$

AUTO PARA QUE EL MAESTRO MAYOR RECONOZCA EL REPARO DE QUE NECESITAN LAS GARITAS

En la Ciudad de Los Ángeles a tres días del mes de Marzo de mil setecientos y Veinte y Cuatro años el señor Don Joseph Joachin de Uribe y Castrejón Caballero del Orden de Santiago del Consejo de Su Majestad, su oidor decano 


\section{AD-3 GLOSARIO}


Alcabala: La alcabala constituye una de las figuras fiscales más antiguas e importantes de la Hacienda del antiguo régimen español. La interpretación clásica remonta a su origen a la concesión temporal realizada por las cortes de Burgos en 1342 a favor de Alfonso XI. Desde entonces se perpetuó en cabeza de la corona castellana hasta que 1813, las cortes de Cádiz la suprimieron, reemplazándola por una contribución directa.

En América se le instauró desde temprano, ya que si bien Carlos V había otorgado en 1522 una franquicia eximiendo de alcabalas a sus súbditos novohispanos, muy pronto las necesidades de las Arcas Reales llevaron a la Corona a derogar esa merced temporal. En efecto, en 1568 Felipe II expidió una carta real, reafirmada por la Real Cédula del 1 de noviembre de 1571, por la que ordenó el cobro del real derecho de alcabala en sus dominios de Las Indias. Grosso y Garvaglia, 1996: p.19

Alcalde mayor: Juez de letras que ejercía la jurisdicción ordinaria en algún pueblo. En Nueva España gobernaba en nombre del rey (Celaya Nández, 2010).

Almojarifazgo: Derecho que se pagaba por los géneros o mercaderías que salían del reino, por los que se introducían en él, o por aquellos con que se comerciaba de un puerto a otro dentro de España.

Armada de Barlovento: Flota que se formó desde 1935 de manera esporódica con la finalidad de proteger la navegación de los barcos españoles por el Caribe durante el periodo colonial.

Azogue: Plaza de algún pueblo, donde se tiene el trato y comercio público.

Bizcocho: Pan sin levadura, que se cocía por segunda vez para que perdiese la humedad y durase mucho tiempo.

Cabezón: Lo mismo que encabezamiento. Padrón o lista de contribuyentes y contribuciones. La escritura de obligación de la cantidad que se debía pagar de alcabala y otros derechos reales.

Caminos de ronda: camino exterior e inmediato a la muralla de una plaza o contiguo al borde de ella.

Estancia: Hacienda de campo destinada al cultivo, y más especialmente a la ganadería.

Garita: Entrada a la ciudad, edificio de fábrica que se coloca en los puntos salientes de la ciudad para abrigo y defensa de los centinelas y para el registro de mercaderías. 
Guardas: Edificios para la protección y defensa.

Miniestras: La frase "cantidad de miniestras necesarias" indicaba que por la cantidad de bizcocho se debía enviar el correspondiente a tocino, manteca, queso, arroz, habas, frijol, garbanzo y vino. (Celaya Nández 2010).

Nao: Embarcación antigua.

Peso líquido: Es el peso neto más la humedad del producto.

Puerto de tierra: Paso entre montañas donde se halla una aduana.

Quintales: Peso de 100 libras equivalente en Castilla a 46 kg aproximadamente.

Situado: aparte del participio pasivo del verbo situar, esta palabra poseía la acepción fiscal de salario, sueldo o renta señalado sobre algún efecto. Asignar o determinar fondo para que se cobrara alguna cosa. Designó el destino de ciertas cantidades (sueldos y otros recursos) enviados a un territorio para cubrir determinados gastos, generalmente de tipo militar. Pero no solo se refería al destino de las cantidades, si no a las cantidades mismas, en cuanto a factores de la contabilidad enviados y guardados en determinados sitios para diferentes gastos. (Celaya Nández 2010) 